\title{
Lithospheric shortening and ductile deformation in a back-arc setting: South Wanganui Basin, New Zealand
}

\author{
by \\ Erik Ewig
}

\author{
A thesis \\ submitted to the Victoria University of Wellington \\ in fulfilment of the \\ requirements for the degree of \\ Doctor of Philosophy \\ in Geophysics. \\ Institute of Geophysics \\ Victoria University of Wellington \\ Te Whare Wānanga o te Upoko o te Ika a Māui \\ Wellington \\ Aotearoa
}

July 15, 2009 



\section{Abstract}

South Wanganui Basin (SWB), New Zealand, is located behind the southern end of the Hikurangi subduction system. One of the most marked geophysical characteristics of the basin is the $-150 \mathrm{mGal}$ Bouguer/isostatic gravity anomaly. Sediment fill can only partly explain this anomaly. 3-D gravity models show that the gravity anomaly associated with the basin is generally consistent with a downwarp model of the entire crust. However, the downwarp of the Moho has to be 3-4 times larger than the downwarp of the sediment-basement interface to fit the observed gravity anomaly. Hence a model of lithospheric shortening where ductile thickening of the crust increases with depth is proposed.

Finite element modelling demonstrates that the crust, in order to produce the ductile downwarp, is best modelled with at least two distinct different layers. The model requires the top $15-20 \mathrm{~km}$ of the crust to behave purely elastic and the lower part ( $10 \mathrm{~km}$ thick) to be viscoelastic with a viscosity of $10^{21} \mathrm{~Pa} \cdot \mathrm{s}$. The existence of this ductile lower continental crust can be explained due to fluids released from the subducting slab accumulating in the lower crust. This is supported by receiver function analysis results. These results propose a $10 \pm 2 \mathrm{~km}$ thick low S-wave velocity layer in the lower crust.

The vertical loading necessary to create the basin is high (up to $200 \mathrm{MPa}$ ) and is difficult to explain by slab pull forces transmitted via a strongly coupled subduction interface alone. An additional driving mechanism proposed is a thickened mantle lithosphere inducing normal forces on the base of the crust. However, the exact origin of the basin remains a puzzling aspect.

Receiver function analysis shows that the crust of the subducting Pacific plate underneath the mainland in the lower North Island is abnormally thick $(\sim 10 \mathrm{~km})$ for oceanic crust. This matches with results from the 3-D gravity modelling. Further features discovered with the receiver function analysis are an up to $6 \mathrm{~km}$ thick low-velocity layer on top of the slab, which is interpreted as a zone of crushed crustal material with subducted sediments. Furthermore, a deep Moho $(39.5 \pm 1.5 \mathrm{~km})$ is proposed underneath the northern tip of the Marlborough sounds.

Shallow seismic and gravity investigations of the southeastern corner of the SWB reveal a complex faulting regime with high-angle normal and reverse faults 
as well as a component of strike slip. The overall style of faulting in the SWB changes from the west to the east. There are the low-angle thrust faults of the Taranaki Fault zone in the west, the high-angle mostly reverse faults in the eastern part of the basin and the strike slip faults, with a component of vertical movement, at the eastern boundary within the Tararua Ranges. 


\section{Acknowledgement}

First of all I would like to thanks my supervisor, Tim Stern, for his excellent guidance and great support during this project. Thank you also to Euan Smith and Martha Savage for the review and discussion of some of the chapter of this thesis and Karen Brown for editing the main chapters.

At Victoria University there are many people I would like to thank: There is Anya the best office mate for the last three years, Adrian, Wanda, Suz, Michelle, Sandra, Yannik, Jan, Nicholas, Dan, Mark and many more who made my time in the department instructive and enjoyable. A special thank goes to all the people who helped me in the field. But also to fellow students who gave me the chance to join their fieldwork and see so much of the stunning New Zealand country.

Thanks to the Wellington Regional Council for their financial support and permission for the seismic fieldwork in the Waikanae area. Further financial support was provided by the Victoria University PhD scholarship and the FRST grant (VICX0705, Tectonic framework and dynamics of the New Zealand continent).

Thanks also to Simon Lamb for the discussion of a possible additional driving mechanism of the South Wanganui Basin; H. Green Energy Ltd. and an Ian R Brown Associates Ltd. for seismic data and a little insight into the industry view of the South Wanganui Basin; Swift Energy and Austral Pacific Ltd. for the work on the on- and offshore seismic project; and Jonathan Ravens and Guy Maslen (GNS Science)for answering some of my seismic processing questions.

Of course, a special thanks to my parents who always supported me in whatever I did or wanted to do. Also, thanks to my friends here (for having a good time) and overseas (for trying to stay in touch over the last years and especially in the last 6 months).

Last but not least, many thanks to my partner Sonja Greve for her love, support, fun, good times... and of course, for proofreading my thesis. 



\section{Contents}

Abstract I

\begin{tabular}{ll|l} 
Acknowledgement & III
\end{tabular}

List of Figures $\quad$ VII

$\begin{array}{ll}\text { List of Tables } & \text { XI }\end{array}$

1 Introduction 1

1.1 Thesis outline ....................... 2

2 Tectonic setting 5

2.1 New Zealand plate tectonic setting . . . . . . . . . . . . . 5

2.1.1 South Wanganui Basin . . . . . . . . . . . . . . . . . 10

2.1.2 Southeastern onshore area of the SWB . . . . . . . . . . . 12

2.2 Further geophysical and geological observations important for the SWB ............................... 12

2.3 Slab pull force and corresponding surface deformation . . . . . . . 17

3 Shallow seismic and gravity methods 21

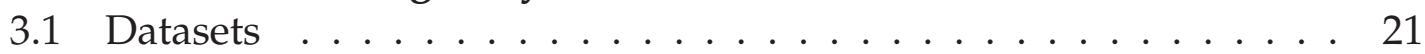

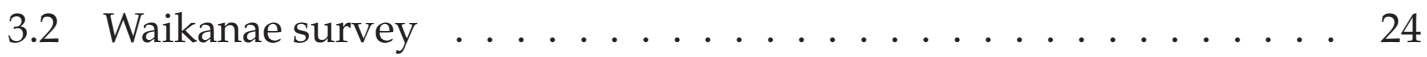

3.2 .1 Gravity method .................. 24

3.2.1.1 Peka Peka profile . . . . . . . . . . . 26

3.2.1.2 Greenhill Road profile . . . . . . . . . . . . . 29

3.2.1.3 Moana Road profile . . . . . . . . . . . . . 30

3.2.1.4 Paetawa Road profile . . . . . . . . . . . . 31

3.2.2 Seismic reflection survey along Peka Peka Road . . . . . . . 32

3.2.2.1 Interpretation . . . . . . . . . . . . 33

3.2.3 Seismic tomography method .............. 36

3.2.4 Seismic refraction method: East-west profile . . . . . . . . 38

3.2.4.1 Intercept-time analysis . . . . . . . . . . 40

Near surface velocity model . . . . . . . . . . . . . 40

Refraction data intercept-time analysis . . . . . . 41 
3.2.4.2 Raytracing . . . . . . . . . . . . . 45

3.2.5 Seismic refraction method: North-south profile . . . . . . . . 45

3.2.5.1 Intercept-time analysis . . . . . . . . . . . . 47

Refraction data intercept-time analysis . . . . . . . 47

3.2.5.2 Raytracing . . . . . . . . . . . . . . . . 51

3.2.6 Summary of results for the Waikanae survey . . . . . . . . 53

3.3 Waikawa Beach survey . . . . . . . . . . . . . . . 57

3.3 .1 Gravity method . . . . . . . . . . . . . . . . 57

3.3.2 Seismic reflection method . . . . . . . . . . . . . . 60

3.3.2.1 Interpretation . . . . . . . . . . . . . . . . 60

3.3.3 Summary of results for Waikawa Beach Road survey . . . . 61

3.4 Levin survey . . . . . . . . . . . . . . . . . 63

3.4 .1 Gravity method . . . . . . . . . . . . . . 65

3.4 .2 Seismic reflection data . . . . . . . . . . . . . . . . . 65

3.4.2.1 Interpretation . . . . . . . . . . . . . 68

Levin $301 \& 302 \ldots \ldots \ldots \ldots$

Levin $303 \ldots \ldots \ldots \ldots$. . . . . . . . . . . 70

3.4.3 Summary results Levin survey . . . . . . . . . . . . . . 72

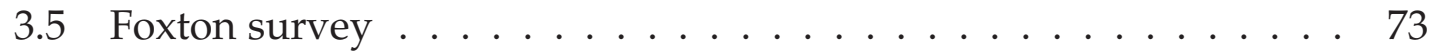

3.5.1 Gravity method . . . . . . . . . . . . . . . 73

3.5.2 Seismic reflection method . . . . . . . . . . . . 75

3.5.2.1 Interpretation . . . . . . . . . . . . . . 77

3.5.3 Discussion and summary of results from the Foxton survey 79

3.6 Intra-basement reflections . . . . . . . . . . . . . . . . 81

3.7 Summary onshore surveys in the South Wanganui Basin . . . . . 84

4 3-D modelling of the gravity anomaly of the South Wanganui Basin $\quad 87$

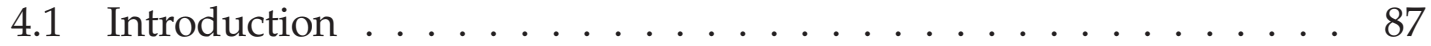

4.2 Model setup . . . . . . . . . . . . . . . . . . . . . . 89

$4.3 \quad$ 2.5-D gravity model of the subducting slab . . . . . . . . . 91

4.4 3-D gravity model of the basin and thickened crust . . . . . . . . 96

4.4 .1 Sediment densities . . . . . . . . . . . . . . . . . . 97

4.4 .2 Modelling theory . . . . . . . . . . . . . . . . . . . 98

4.4 .3 Modelling results . . . . . . . . . . . . . . . 100

4.5 Combined gravity effect . . . . . . . . . . . . . . 100

4.6 Isostasy and mass balance . . . . . . . . . . . . . . . . . . 103

4.7 Summary . . . . . . . . . . . . . . . . . . . . . . . . . 109

5 Receiver functions 111

5.1 Dataset and methods used . . . . . . . . . . . . . . . . . 111

5.2 Observed receiver functions . . . . . . . . . . . . . . . . . . 113

5.2 .1 Station DUWZ . . . . . . . . . . . . . . . . . . . . . . 114

5.2 .2 Station KIW . . . . . . . . . . . . . . . . . . . . . . . 116

5.2 .3 Tararua deployment . . . . . . . . . . . . . . . . 118 
5.3 Interpretation . . . . . . . . . . . . . . . 120

5.3.1 Forward modelling . . . . . . . . . . . . . . . 121

$5.3 .2 \mathrm{H}-\kappa$ stacking . . . . . . . . . . . . . . . . . . 127

5.3.3 Common conversion point (CCP) stacking . . . . . . . . . 130

5.4 Summary . . . . . . . . . . . . . . . . . . . . . 134

6 3-D finite element modelling of deformation in the North Island 135

6.1 Model Setup . . . . . . . . . . . . . . . . . . . . 135

6.1.1 Why a viscoelastic layer? . . . . . . . . . . . . . 137

6.1.2 Boundary conditions and grid definition . . . . . . . 138

6.1 .3 Forces, gravity and buoyancy . . . . . . . . . . . . . 138

6.1.4 Definition of material properties . . . . . . . . . . . . 139

6.1.5 Meshing of the model . . . . . . . . . . . . . . . 141

6.2 Modelling . . . . . . . . . . . . . . . . . . . . 142

6.2.1 Different viscosities . . . . . . . . . . . . . . . . . . 148

6.2.2 Different thicknesses . . . . . . . . . . . . . . . . 152

6.2.3 Different Young's moduli . . . . . . . . . . . . . . . . . . 152

6.2 .4 Load distributions . . . . . . . . . . . . . . . . . . . 154

6.3 Predicted faulting styles . . . . . . . . . . . . . . . . 160

6.4 Discussion . . . . . . . . . . . . . . . . . . . . 163

6.5 Summary . . . . . . . . . . . . . . . . . . 169

7 Summary and conclusions $\quad \mathbf{1 7 1}$

7.1 Shallow structures in the southeastern offshore corner of the SWB . 171

7.2 Deeper structures of the SWB . . . . . . . . . . . . . . 172

$\begin{array}{ll}\text { A Seismic Method } & \mathbf{1 7 5}\end{array}$

A.1 Seismic reflection method . . . . . . . . . . . . . . 175

A.1.1 Seismic reflection data acquisition . . . . . . . . . 175

A.1.1.1 Spread geometry . . . . . . . . . . . . 175

A.1.1.2 Seismic Sources . . . . . . . . . . . . . . 176

A.1.1.3 Receivers ..................... 176

A.1.2 Seismic reflection processing . . . . . . . . . . 177

A.1.2.1 Debiasing . . . . . . . . . . . . 177

A.1.2.2 Header information . . . . . . . . . . . . 177

A.1.2.3 Quality control . . . . . . . . . . . . . . . 179

A.1.2.4 Filtering ................... 180

A.1.2.5 Compensation for attenuation . . . . . . . . . 180

A.1.2.6 Deconvolution . . . . . . . . . . . . 181

A.1.2.7 Static correction . . . . . . . . . . . . . . . 182

A.1.2.8 Velocity analysis . . . . . . . . . . . . . 183

A.1.2.9 Dip moveout $(\mathrm{DMO})$ correction . . . . . . . . . . . . 184

A.1.2.10 Migration . . . . . . . . . . . . . . . . . 184

A.1.2.11 Stacking ................. 185 
A.1.2.12 Post-stack enhancement . . . . . . . . . . . . 185

A.1.3 Processing parameters . . . . . . . . . . . . . . 186

A.1.3.1 Waikanae survey . . . . . . . . . . . . 186

Peka-main . . . . . . . . . . . . 186

Peka-west . . . . . . . . . . . . . . 188

Peka-east . . . . . . . . . . . . . . 190

A.1.3.2 Waikawa survey ... . . . . . . . . . . 191

A.1.3.3 Levin survey . . . . . . . . . . . . . . . . 193

Levin $301 \& 302 \ldots \ldots$. . . . . . . . . . . . . . . . . . . . . . . . . . . . .

Levin 303 . . . . . . . . . . . . . . . . . 195

A.1.3.4 Foxton survey . . . . . . . . . . . . . 196

A.2 Seismic refraction method . . . . . . . . . . . . . . . . 198

A.2.1 Theory . . . . . . . . . . . . . . . . . . 198

A.2.2 Intercept time analysis . . . . . . . . . . . . . . . 199

A.2.3 Raytracing ... . . . . . . . . . . . 203

B Gravity Methods 205

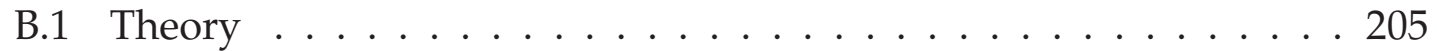

B.2 Gravity data processing and reduction . . . . . . . . . . . 206

B.2.1 Drift correction . . . . . . . . . . . . 206

B.2.2 Latitude correction . . . . . . . . . . . . . . . . . . 207

B.2.3 Free-air correction . . . . . . . . . . . . . 207

B.2.4 Terrain correction . . . . . . . . . . . . . . 207

B.2.5 Bouguer correction . . . . . . . . . . . . . . 208

B.3 Regional gravity field and residual gravity values . . . . . . . . . . 208

B.4 Uncertainties in gravity measurements . . . . . . . . . . . . . . . . 210

B.5 Gravity data . . . . . . . . . . . . . . . . . . . . 212

C Receiver function theory $\quad 221$

C.1 Analysing receiver functions . . . . . . . . . . . . . . . . 223

C.2 H- $\kappa$ stacking technique . . . . . . . . . . . . . . . . . . . . 225

C.3 Common conversion point (CCP) stacking . . . . . . . . . 226

D Finite element modelling (FEM) theory 229

E Three-component refraction data from the northwestern edge of the $\begin{array}{ll}\text { SWB } & 235\end{array}$

E.1 Introduction . . . . . . . . . . . . . . . . . 235

E.2 Dataset . . . . . . . . . . . . . . . . . . 235

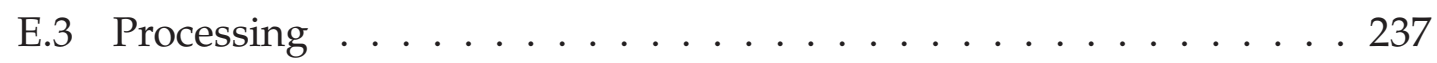

E.4 Interpretation . . . . . . . . . . . . . . . . 242

E.4.1 Intercept time method for vertical component data . . . . . 242

E.4.2 Raytracing of vertical component data . . . . . . . . . . . . 246

E.4.3 Three-component nature of the data . . . . . . . . . . . . 247

E.4.4 Conclusions . . . . . . . . . . . . . . . . . . . . . . 249 
Contents

F Geometry information about the conducted surveys 253

G Enlarged seismic sections from chapter 3 255

References 257 



\section{List of Figures}

2.1 Tectonic setting of New Zealand . . . . . . . . . . . . . . . 6

2.2 Major faults in the SWB . . . . . . . . . . . . 7

2.3 Free-air/isostatic gravity anomaly of the North Island . . . . . . . . 9

2.4 Cross-section sketch of the SWB . . . . . . . . . . . . . . . . . . 11

2.5 Kapiti Manawatu Fault System . . . . . . . . . . . . . . . . . . . . . 13

2.6 Seismic section across the Taranaki Fault Zone . . . . . . . . . . . . 14

2.7 Seismicity cross-section across the SWB . . . . . . . . . . . . . . 15

2.8 Surface displacement and deviatoric stressfield of a subducted slab 18

2.9 Surface displacement of a subducted slab [Stern, 1982] . . . . . . . 19

3.1 Active onshore seismic lines and the Kapiti Manawatu Fault System 22

3.2 Detailed map of conducted active seismic lines . . . . . . . . . . 23

3.3 Location map of the Waikanae gravity survey . . . . . . . . . . . . . . . 25

3.4 Residual gravity map of the greater Waikanae area . . . . . . . . . . 27

3.5 Peka Peka Road residual gravity models . . . . . . . . . . . . . . . . . . 28

3.6 Greenhill Road residual gravity model . . . . . . . . . . . . . . . . . 29

3.7 Moana Road residual gravity model . . . . . . . . . . . . . . . . . . 30

3.8 Paetawa Road residual gravity model . . . . . . . . . . . . . . . . 31

3.9 Location map of the Peka Peka seismic reflection survey . . . . . . 32

3.10 Time-migrated seismic section - Peka Peka Road profile . . . . . . . 34

3.11 Detailed view of Hadfield Fault in seismic section . . . . . . . . . 36

3.12 Tomography velocity model along Peka Peka Road . . . . . . . . . 37

3.13 Geometry for Peka Peka refraction survey (east-west) . . . . . . . . . 38

3.14 Raw refraction shotgathers (Peka Peka, east-west) . . . . . . . . . . 39

3.15 Raw reflection shotgathers (Peka Peka, east-west) . . . . . . . . . . 41

3.16 Velocity model sketch of Peka Peka refraction survey . . . . . . . . 42

3.17 Time-distance plot (refraction, east-west) . . . . . . . . . . . . . . 43

3.18 Forward raytracing velocity model (east-west) . . . . . . . . . . . . 46

3.19 Geometry for Peka Peka refraction survey (north-south) . . . . . . . 47

3.20 Raw refraction shotgathers (Peka Peka, north-south) . . . . . . . . . 48

3.21 Refraction time-distance plot (north-south) . . . . . . . . . . . . 50

3.22 Forward raytracing velocity model (north-south) . . . . . . . . . . . 52

3.23 Summary maps of the result from the Waikanae area survey . . . . 55

3.24 Location map of the Waikawa gravity survey . . . . . . . . . . 58 
3.25 Waikawa survey residual gravity model . . . . . . . . . . . . . 59

3.26 Location map of the Waikawa seismic reflection survey . . . . . . . 60

3.27 Time-migrated seismic section - Waikawa Road profile . . . . . . . 62

3.28 Location map of the Levin gravity survey . . . . . . . . . . . . . . . 64

3.29 Levin residual gravity models . . . . . . . . . . . . . . . . . . . . 66

3.30 Map of the Levin seismic reflection survey . . . . . . . . . . . . . . 67

3.31 Time-migrated seismic section - Levin 301\&302 . . . . . . . . . . . . 69

3.32 Time-migrated seismic section - Levin 303 . . . . . . . . . . . . . 71

3.33 Location map of the Foxton gravity survey . . . . . . . . . . . . . . 74

3.34 Foxton area residual gravity models . . . . . . . . . . . . . 76

3.35 Location map of the Foxton seismic reflection survey . . . . . . . 77

3.36 Time-migrated seismic section - Foxton survey . . . . . . . . . . 78

3.37 Shotgather (shotid \# 24) of Foxton survey . . . . . . . . . . . 80

3.38 Illustration of phaseshift on zero-phase wavelet . . . . . . . . . 81

3.39 Examples for intra-basement reflector in the SWB - I . . . . . . . . . 82

3.40 Examples for intra-basement reflector in the SWB - II . . . . . . . . 84

3.41 Example for intra-basement reflector in the Taranaki Basin . . . . 85

4.1 Free-air/isostatic gravity anomaly of the North Island . . . . . . . . 88

4.2 Elastic versus viscoelastic deformation of a plate . . . . . . . . . 89

4.3 Bathymetry map of the southwestern North Island . . . . . . . . . . . 90

4.4 Slab depth and gravity profile lines . . . . . . . . . . . . . . . . . . . . 91

4.5 2-D gravity models of the subducting slab . . . . . . . . . . . . 93

4.6 Gravity anomalies for different slab thicknesses . . . . . . . . . . . 94

4.7 Gravity anomaly map of the subducting slab . . . . . . . . . . . . 95

4.8 Cross-section of the sediment basin and the Moho deformation . . 96

4.9 Nafe-Drake curve . . . . . . . . . . . . . . . . . . . . 97

4.10 Sediment and Moho depth isopachs . . . . . . . . . . . . . . . . 99

4.11 Gravity anomalies of different contributing features . . . . . . . . . 101

4.12 Cross-sections of final models . . . . . . . . . . . . . . . . . 102

4.13 Density cross-section through the SWB . . . . . . . . . . . . . . 103

4.14 Gravity anomaly maps for different models and real data . . . . . . 104

4.15 Cross-sections of final models . . . . . . . . . . . . . . . . . 105

4.16 Zones of the subduction system for the mass balance calculations . 106

5.1 Station locations - Receiver function study . . . . . . . . . . . . . . . 112

5.2 Teleseismic events for DUWZ station . . . . . . . . . . . . . . . . 114

5.3 DUWZ binned receiver functions . . . . . . . . . . . . . . . . . . . 115

5.4 DUWZ stacked receiver functions . . . . . . . . . . . . . . . . . 115

5.5 Teleseismic events for KIW station . . . . . . . . . . . . . . . . . . . . . . . . . . . . . . . .

5.6 KIW binned receiver functions . . . . . . . . . . . . . . . . . . . . . . . . . 117

5.7 KIW stacked receiver functions . . . . . . . . . . . . . . . . . 117

5.8 Tararua array stacked receiver functions . . . . . . . . . . . . . . . 119

5.9 Stacked radial receiver functions and gravity anomaly . . . . . . . 120 
5.10 Velocity models established by forward modelling . . . . . . . . . . 122

5.11 Synthetic and real receiver functions for KIW . . . . . . . . . . . . . 123

5.12 Synthetic and real receiver functions for DUWZ . . . . . . . . . . . 125

$5.13 \mathrm{H}-\kappa$ stack synthetic data for stations KIW . . . . . . . . . . . . 128

$5.14 \mathrm{H}-\kappa$ stack for stations KIW, W1, W2 and N6 . . . . . . . . . . . . . 129

$5.15 \mathrm{H}-\kappa$ stack for stations DUWZ . . . . . . . . . . . . . . . . . . . . . 130

5.16 CCP stack . . . . . . . . . . . . . . . . . 133

6.1 Illustration of basic model setup . . . . . . . . . . . . . . . . . . 137

6.2 Maxwell model . . . . . . . . . . . . . . . . . . . . . . 140

6.3 Illustration of the mesh used for the modelling . . . . . . . . . . . . 142

6.4 Rock uplift and subsidence of the North Island since the Miocene . 143

6.5 Illustration of basic model setup - Loads . . . . . . . . . . . . . . . . . 145

6.6 Basic load distribution . . . . . . . . . . . . . . . . . . . 146

6.7 Chronology of deformation - Model 100 . . . . . . . . . . . . . . 147

6.8 Cross section of vertical deformation - Model 100 . . . . . . . . . . . 149

6.9 Cross section of vertical deformation - Model 100, 109, 110,111 . . . 150

6.10 Cross section of vertical deformation - Model 100, 104, 105 . . . . . 151

6.11 Cross section of vertical deformation - Model 100, 112, 113 . . . . . 153

6.12 Cross section of vertical deformation - Model 100, 125, 126 . . . . . 155

6.13 Cross section of vertical deformation - Model 100, 103 . . . . . . . . 156

6.14 2-D map of surface deformation - Model 100 . . . . . . . . . . . 157

6.15 2-D map of surface deformation - Model FINAL3 . . . . . . . . . . . 158

6.16 2-D map of surface deformation - Model FINAL6 . . . . . . . . . . . 159

6.17 Comparison of observed rock uplift and modelled uplift . . . . . . 161

6.18 Predicted favoured faulting in the SWB . . . . . . . . . . . . . . 162

6.19 Comparison of observed and predicted faulting in the SWB . . . . . 163

6.20 Illustration of the proposed driving force of the basin . . . . . . . . 166

6.21 Interseismic slip deficit map and slow slip earthquakes . . . . . . 168

A.1 Hydraulic thumper . . . . . . . . . . . . . . . . . . . . 177

A.2 Seismic processing sequence . . . . . . . . . . . . . 178

A.10 Snell's law . . . . . . . . . . . . . . . . . . . . . . 199

A.11 Illustration refraction for flat two-layer model . . . . . . . . . . . 200

A.12 Illustration refraction for flat three-layer model . . . . . . . . . . . . 201

A.13 Illustration refraction for flat two-layer dipping model . . . . . . . 202

A.14 Illustration refraction interface with step . . . . . . . . . . . . 203

B.1 Regional gravity anomaly in the Kapiti-Horowhenua region . . . . 209

B.2 Gravity anomaly corresponding to different faulting structures . . 211

C.1 Schematic illustration of receiver functions principle . . . . . . . . 222

D.1 Single truss as example for FEM . . . . . . . . . . . . . . . . . 230

D.2 Combined truss example for FEM . . . . . . . . . . . 231 
E.1 Map of the study area . . . . . . . . . . . . . . . . 236

E.2 Receiver-gathers 915F . . . . . . . . . . . . . . . . . . . . 239

E.3 Subsection of receiver-gather $915 \mathrm{~F}$ with different timebases . . . . . 240

E.4 Receiver-gather 915F, 915C . . . . . . . . . . . . . . . . . . 241

E.5 Receiver-gather OLD, 915B, 915E . . . . . . . . . . . . . 243

E.6 Refraction analysis of gather 915C and 915F . . . . . . . . . 245

E.7 Raytracing model . . . . . . . . . . . . . . . . . . . . 246

E.8 Reflection analysis of gather 915F . . . . . . . . . . . . 247

E.9 Three-components of receiver gather 915F . . . . . . . . . . 248

E.10 Schematic geological cross-section . . . . . . . . . . . . 250

E.11 Seismic reflection image across the Taranaki Fault Zone . . . . . . 251 


\section{List of Tables}

3.1 Field parameter Peka Peka Road survey . . . . . . . . . . . . . . . 32

3.2 Near surface velocity model (east-west) . . . . . . . . . . . . . 42

3.3 Intercept-time analysis (east-west, dipping layers) . . . . . . . . 44

3.4 Near surface velocity model (north-south) . . . . . . . . . . . . . 49

3.5 Intercept-time analysis (north-south, horizontal layers) . . . . . . 51

3.6 Intercept-time analysis (north-south, dipping layers) . . . . . . . . 51

3.7 Field parameter Waikawa Beach survey . . . . . . . . . . . . . 61

3.8 Field parameter Levin survey . . . . . . . . . . . . . . . . . 67

3.9 Field parameter Foxton survey $\ldots \ldots \ldots \ldots$

4.1 Sediment interval velocities and corresponding densities . . . . . 98

4.2 Mass balance for gravity modelling . . . . . . . . . . . . . 108

5.1 Station locations - Receiver function study . . . . . . . . . . . . 113

5.2 New Zealand velocity models . . . . . . . . . . . . . . . . . 131

5.3 Parameters for CCP stack . . . . . . . . . . . . . . . . . . 131

6.1 Material parameters for model $100 \ldots \ldots$. . . . . . . . . . 141

6.2 Model parameter and deformation values - Model 100, 109, 110 . 150

6.3 Model parameter and deformation values - Model 100, 104, 105 . . 151

6.4 Model parameter and deformation values - Model 100, 112, 113 . . 153

6.5 Model parameter and deformation values - Model 100, 125, 126 . 155

B.1 Waikanae gravity data . . . . . . . . . . . . . . . . . 212

B.2 Waikawa gravity profile data . . . . . . . . . . . . 215

B.3 Levin gravity profile data . . . . . . . . . . . . . . 216

B.4 Foxton gravity profile data . . . . . . . . . . . . . . 218

E.1 Field Parameters . . . . . . . . . . . . . . . . . . . . . . . 237

E.2 Intercept-time analysis P-wave arrivals $\ldots \ldots \ldots \ldots . \ldots .244$

E.3 Intercept-time analysis S-wave arrivals . . . . . . . . . . . . . 249 



\section{Chapter 1}

\section{Introduction}

At active continental margins, oceanic crust gets recycled into the mantle. The oceanic lithosphere generally descends under less dense continental lithosphere and initiates numerous processes in the earth due to the cold and hydrated nature of the subducting slab. Back-arc basins form an integral but often neglected part of such "subduction factories" and can vary in style from extensional with thin lithosphere (Mariana-type) to compressive tectonics with a thickened lithosphere (Chilean-type) [Uyeda, 1981; Uyeda \& Kanamori, 1979].

The negative buoyancy of the subducting slab is assumed to be one of the main driving forces of plate tectonics [Conrad \& Lithgow-Bertelloni, 2002; Harper, 1989] and of surface subsidence in the fore-arc and back-arc regions [Bott, 1993; Davies, 1981]. The coupling of the slab with the overriding plate is assumed to have a strong influence on the deformation style observed above subduction zones. Strong coupling is more likely to produce a compressional back-arc setting, and weak coupling results in a well developed extensional back-arc basin [Bott, 1993; Whittaker et al., 1992].

The North Island of New Zealand presents an opportunity to study the two different types of back-arc basins in continental lithosphere. In the central North Island, an extensional regime dominates with high heat flow, volcanism and active doming [Cole et al., 1995; Pulford \& Stern, 2004; Stern \& Davey, 1985; Stratford \& Stern, 2006]. This rapidly switches to mild compression, reverse faulting, low heat flow and thickened lithosphere in the southwestern part of the North Island (South Wanganui basin (SWB)) [Funnell et al., 1996; Lamarche et al., 2005; Stern et al., 1992; Wallace et al., 2004].

The SWB is located around $200 \mathrm{~km}$ west of the subduction margin of the obliquely convergent Pacific-Australia plate boundary. Because it is located at the same distance to the margin as the extensional back-arc basin to the north, the SWB is described as a back-arc basin, despite the lack of volcanic arc magmatism at these latitudes [Davey \& Stern, 1990; Katz \& Leask, 1990]. One of 
the most marked geophysical characteristics of the SWB is the $-150 \mathrm{mGal}$ gravity anomaly [Hunt, 1980]. The sediment infill of the basin can only partly account for this anomaly [Smith et al., 1989; Stern et al., 1992]. The origin of the strong anomaly and the driving mechanism for the development of the basin are still under debate [Lamarche et al., 2005; Stagpoole \& Nicol, 2008; Stern et al., 2006, 1992]. A flexural downwarp of the crust underneath the SWB due to strong coupling on the plate interfaces is proposed as a possible driving mechanism [Stern et al., 1992].

The main objective of this thesis is to further investigate this subsidence and what is causing it. The scale of investigations addressed with this thesis range from imaging shallow structure in the southeastern corner of the SWB, to broader, deeper crustal/lithospheric structures. In particular, the following questions are addressed:

- How thick is the crust underneath the SWB?

- How large are the forces responsible for creating the crustal structure underneath the SWB and what is the possible origin of these forces?

- Which rheology has to be assumed for the overriding Australian plate to explain the deformation?

- How thick is the crust of the subducting Pacific slab, and what influence does it have on the observed gravity anomaly of the basin?

- What happened to the thickened mantle lithosphere in the lower North Island?

- What are the styles of shallow tectonic structures in the region and how do they reflect the large scale driving force of the basin?

\subsection{Thesis outline}

In the first chapter, the tectonic setting of New Zealand, and particularly for the western side of the lower North Island, is introduced. The two different types of back-arc regimes existing in the North Island of New Zealand are illustrated and the different geophysical observations in these areas are highlighted. Furthermore, possible explanations for these different zones are discussed and open questions for the study area are introduced. This chapter also presents an overview of shallow structures identified mainly on the eastern side of the SWB.

Chapter 3 is dedicated to a shallow seismic and gravity investigation of the southeastern corner of the SWB. It presents results from newly acquired and reprocessed seismic and gravity data. A detailed study is carried out in the 
Waikanae area, between the foothills of the Tararua Ranges and the coastline, including a 2-D residual gravity and seismic reflection, refraction and tomography data analysis. The aim of this chapter is to help with the seismic risk assessment of the area and seek to understand the shallow structure in the context of the tectonic behaviour of the southern part of the North Island.

In chapters 4-6 the deeper structure of the SWB is investigated. Chapter 4 presents results from the 3-D modelling of the strong gravity anomaly associated with the SWB. All previous studies have modelled the gravity anomaly of the basin as a 2-D structure perpendicular to the strike of the slab. However, the anomaly is almost circular in shape, suggesting a strong 3-D nature of the origin of the anomaly. Furthermore, the gravity effect for slabs of different overall crustal thickness, as well as slabs with changing thicknesses in downdip direction, is investigated.

Chapter 5 contains results from a receiver function profile for stations at the southern end of the SWB. The profile starts in the Tararua Ranges and runs almost perpendicular to the subduction trench. The main motivation for this study was to acquire more information about the thickness of the crust underneath the SWB and to further investigate the crustal thickness of the subducting slab.

To explore the driving mechanism of the basin, a finite element model of the deformation at the surface and within the crust for the lower North Island is constructed (chapter 6). It investigates the forces needed to create a crustal deformation as predicted with the previous methods and discusses their possible origin. A qualitative statement about the rheology of the lithosphere of the Australian plate is proposed. Additionally to the basin subsidence, the model includes the uplift to the east and north of the basin to incorporate this influence in the development of the basin. The last chapter (chapter 7) summarises all results and concludes the main section of the thesis.

Appendix E presents results of a seismic experiment within the Taranaki Fault Zone at the northwestern corner of the SWB. In the experiment, offshore shots recorded with a 'classical' seismic reflection survey were recorded with three component short period seismographs. The project was mostly of experimental nature. The main aims were to acquire a sediment velocity model and possible use S-wave arrivals to establish $\mathrm{Vp} / \mathrm{Vs}$ values for the sedimentary sequence. 



\section{Chapter 2}

\section{Tectonic setting}

\subsection{New Zealand plate tectonic setting}

The New Zealand mainland is situated at the boundary between the Pacific plate in the east and Australian plate in the west (see figure 2.1). Along this boundary the subducting system changes polarity. At the southern tip of the South Island the Australian plate subducts under the Pacific plate, along the Puyesgur trench, at a rate of $38 \mathrm{~mm} / \mathrm{a}$ [DeMets et al., 1990]. East of the North Island the thickened oceanic crust of the Hikurangi Plateau, as part of the Pacific plate, subducts under the continental crust of the Australian plate with rates of $48 \mathrm{~mm} / \mathrm{a}$ in the north and about $42 \mathrm{~mm} / \mathrm{a}$ in the south [DeMets et al., 1990]. In the central South Island, between the two opposing subduction regimes, the plate motion is accommodated by continental collision and a component of strike-slip motion along the Alpine fault [Walcott, 1998]. The Marlborough Fault System links this transpressive strike-slip setting with the subduction setting to the north [Little \& Jones, 1998].

Around $30 \mathrm{Ma}$ the Tonga-Kermadec-Hikurangi subduction system was still located north of New Zealand. The development of a plate boundary through New Zealand started about $45 \mathrm{Ma}$ and the basic features of the present plate boundary were established around 21 Ma [King, 2000; Sutherland, 1995; Walcott, 1987]. Since then compression and tectonic shortening of the overriding Australian plate progressed southward. In the zones of compression basins developed whose depocenters migrated southwards with time as well. The youngest representative of these basins is the South Wanganui Basin (figure 2.1), which is filled with sediment of Plio-Pleistocene age [Anderton, 1981]. Additionally, around $70 \pm 30 \mathrm{~km}$ of Miocene shortening in the western North Island [Nicol et al., 2007; Stern et al., 2006] resulted in the development of a broad compressional foreland basin to the west of the Taranaki Fault Zone (figure 2.2), the Taranaki Basin [Stern \& Davey, 1990]. 


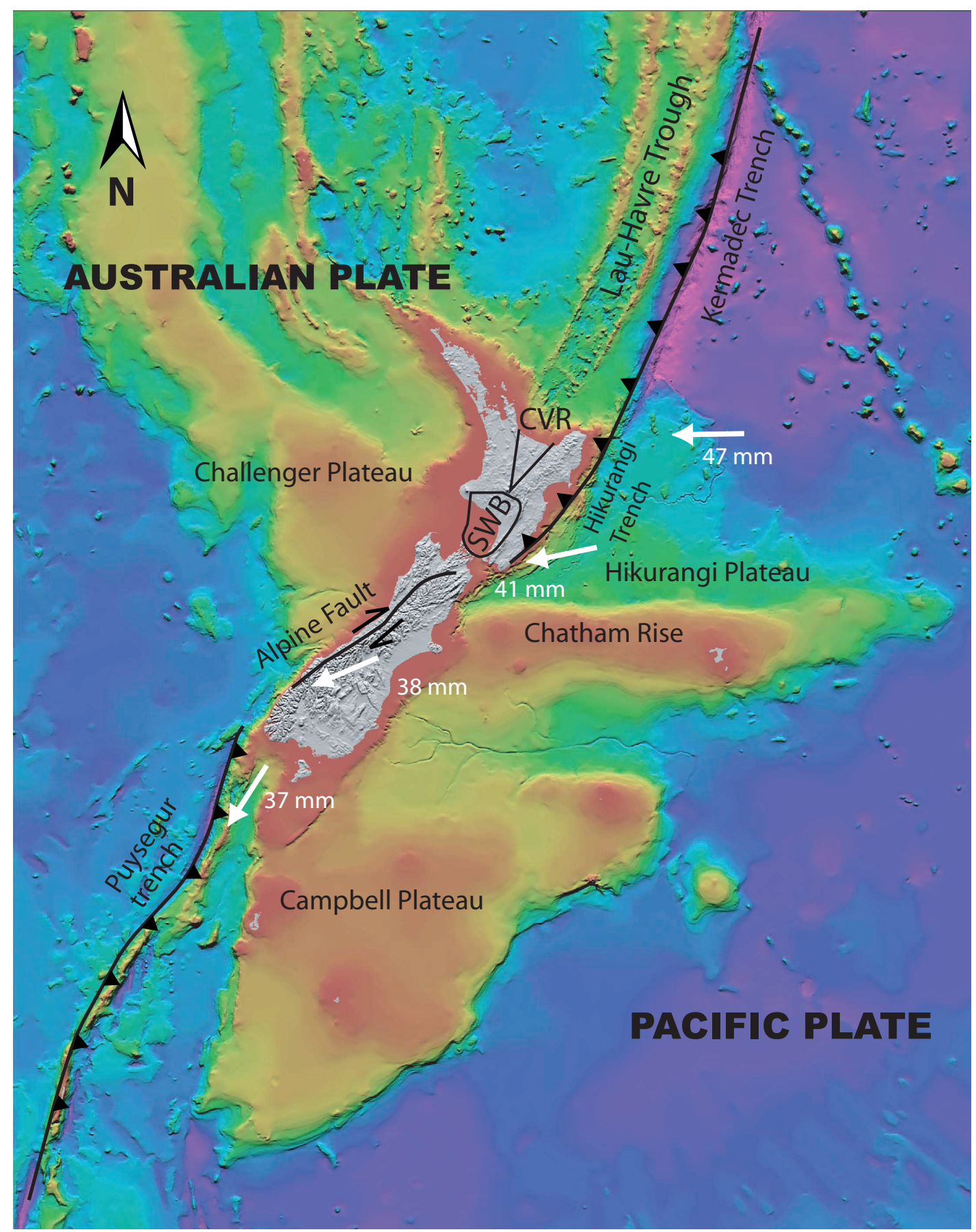

Figure 2.1: Principal tectonic setting of New Zealand. Black lines illustrate the plate boundary and the triangles indicate the direction of subduction. White arrows represent convergence rates of the Pacific plate relative to a fixed Australian Plate [DeMets et al., 1990]. The back-arc system continues for $\sim 2000 \mathrm{~km}$ north of New Zealand along the Lau-Havre Trough. Background colours represent the bathymetry (taken from [CANZ (Charting Around New Zealand), 1997]). 
2.1 New Zealand plate tectonic setting

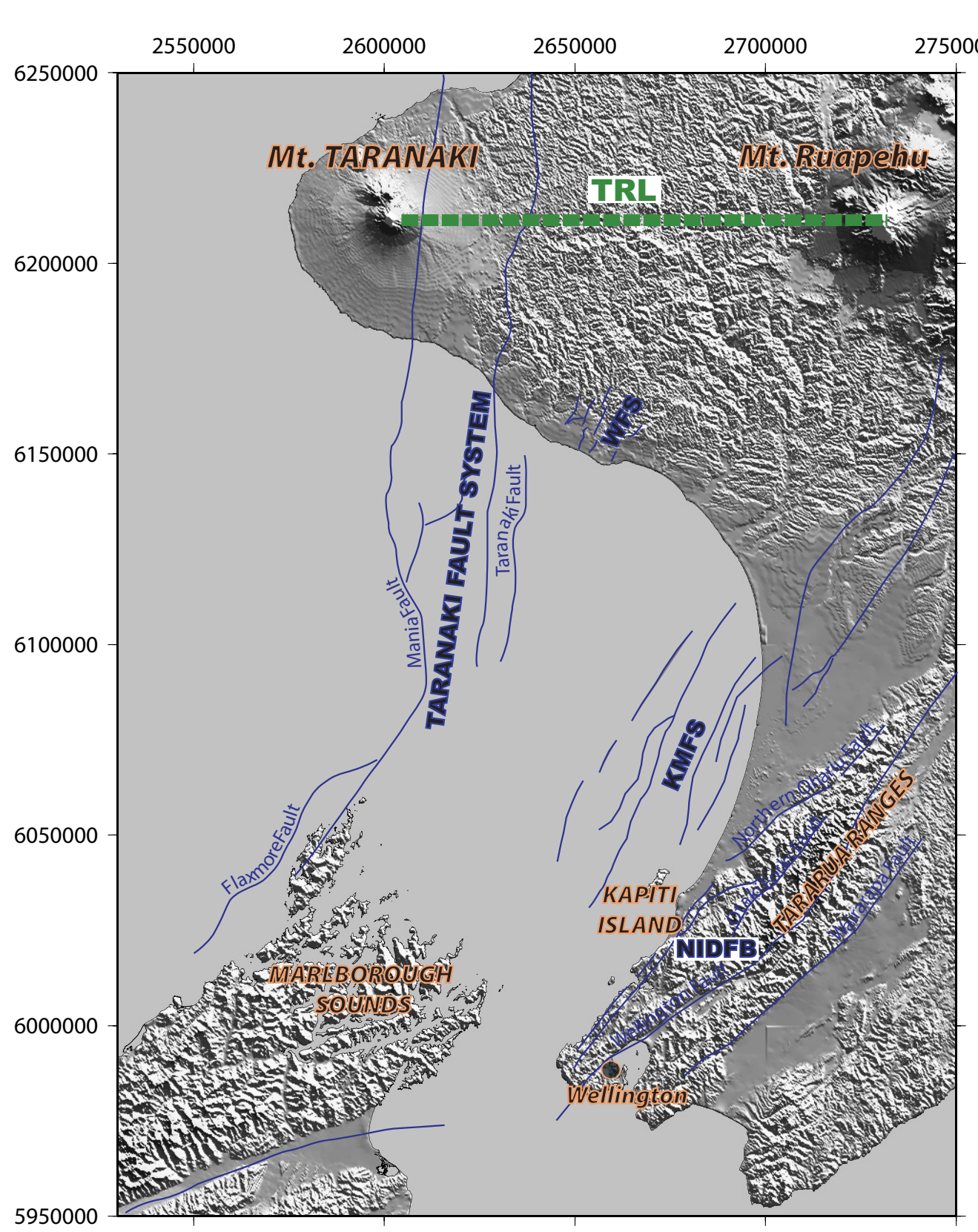

Figure 2.2: Major faults in the SWB. Green line indicates the location of the Taranaki-Ruapehu line (TRL) [Salmon, 2008]. In the west the Taranaki Fault System is shown, consisting of the Taranaki, Mania, and Flaxmore thrust faults. Along the Kapiti coast the main faults of the reverse Kapiti-Manawatu Fault System (KMFS) [Lamarche et al., 2005] are marked. The faults shown within or at the edge of the Tararua Ranges are part of the North Island dextral fault belt (NIDFB) [Beanland, 1995]. Furthermore, the Waverly Fault System (WFS) in the northwestern corner of the SWB is shown. The projection of this map is in New Zealand Map Grid (NZMG).This is a conformal projection with a metric scale system [Hannah, 1984]. The origin is placed at latitude 41 degrees south and longitude 173 degrees east. The coordinates of this point in the NZMG system are $2510000 \mathrm{~m}$ east, $6023150 \mathrm{~m}$ north. All maps within this thesis are displayed with the NZMG coordinate system. 
In the late Miocene the compressional regime of the Taranaki Basin switched to extension north of the Taranaki-Ruapehu line [Walcott, 1987], significant reverse throw on the Taranaki Fault stopped [King, 2000], and rapid rock uplift started in the central North Island in the early Pliocene [Pulford \& Stern, 2004]. The still ongoing compression in the south of the North Island and the extension in the north is consistent with a clockwise rotation of the Hikurangi margin relative to the Australian plate of around 6-7 ${ }^{\circ}$ per Ma for the last 4-5 Ma [Walcott, 1987] and the roll back of the slab [Walcott, 1984, 1987]. However, it is not established if extension causes rotation or if the rotation causes extension.

The coupling at the subduction interface in the North Island changes along the margin. In the south, the interface is locked and the locking weakens towards the north [Reyners, 1998; Wallace \& Beavan, 2006]. This is associated with an increasing crustal thickness of the Hikurangi Plateau to the south [King, 2000]. Furthermore, the thickness of sediments within the trench changes from up to $4 \mathrm{~km}$ in the south of the North Island to less than $1.5 \mathrm{~km}$ in the far north [Smith et al., 1989].

Due to the oblique subduction in the lower North Island the deformation in the upper plate is partitioned between strike-slip and compression. The strikeslip motion mainly occurs along the North Island dextral fault belt (NIDFB) (figure 2.2), which is around $450 \mathrm{~km}$ long and contains numerous individual faults [Beanland, 1995]. The compressive deformation produces a well developed accretionary prism [Collot et al., 1996; Lewis \& Pettinga, 1993] east of the North Island and a fore-arc basin in the southeastern North Island [Beanland \& Haines, 1998; Lamarche et al., 1995].

The North Island is here being separated into four tectonic provinces (figure 2.3): (1) the eastern North Island, (2) the Central Volcanic Region (CVR), (3) the northwestern North Island, and (4) the South Wanganui Basin (SWB) (section 2.1.1).

The eastern North Island (figure 2.3) is bordered to the west by the Axial Ranges. The uplift of the Tararua Ranges is a result of a northwest tilting of basement blocks due to ramping of the Australian plate over the unlocked portion of the Pacific Plate [Ghani, 1978; Neef, 1999; Nicol \& Beavan, 2003; Wells, 1989]. The uplift occurred in the Pleistocene [Lamb \& Vella, 1987; Wells, 1989]. The forearc region is also uplifted, possibly due to the high buoyancy of the thick oceanic crust or/and the underplating of the Australian plate with sediments [Neef, 1999; Walcott, 1987]. The geology of the region is dominated by the sediments of the East Coast Basin.

The Central Volcanic Region is the continuation of the back-arc extension of the Lau-Havre Trough into continental New Zealand (figure 2.3) [Karig, 1970]. Presently, the Central Volcanic Region undergoes northwest-southeast extension of 5-15 mm/a [Cole, 1990; Lamarche et al., 2005; Wallace et al., 2004]. This re- 


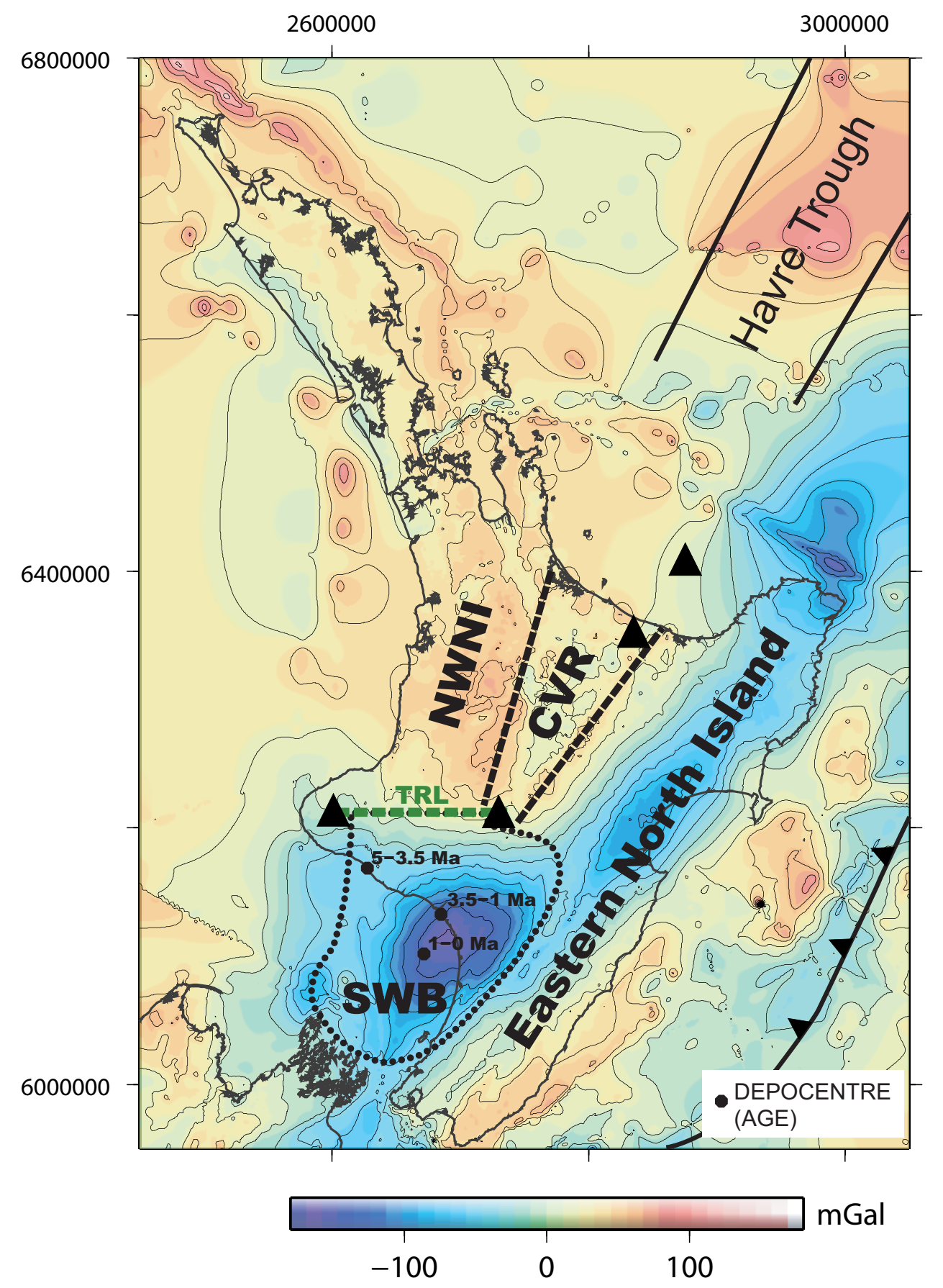

Figure 2.3: Free-air/isostatic gravity anomaly of the North Island [Reilly et al., 1977]. The boundary of the Central Volcanic Region (CVR) is indicated by a dashed line. Black dotted line shows the boundary of the SWB basin. The locations of the depocenter for different time-stages are marked by a black circle. Furthermore, the locations of the northwestern North Island (NWNI) and of the fore-arc region are shown. Active andesite volcanoes are shown as black triangles. 
sults in a wedge-shaped region of thinned continental crust $(\sim 20 \mathrm{~km})$ [Stratford \& Stern, 2004], which is strongly defined by a low in the residual gravity anomaly [Stern, 1979]. Mt. Ruapehu volcano defines the southern-most point of the Central Volcanic Region and is the location of the slowest extension. The surface geology of the Central Volcanic Region is dominated by volcano clastic deposits which are $2-3 \mathrm{~km}$ thick [Stern, 1987]. High heat flow $\left(\sim 800 \mathrm{~mW} / \mathrm{m}^{2}\right)$ [Bibby et al., 1995], active volcanism, high seismic attenuation [Mooney, 1970; Satake \& Hashida, 1989] and pervasive normal faulting [Villamor \& Berryman, 2001] also characterise the Central Volcanic Region.

Located in the far back-arc, the northwestern North Island (figure 2.3) is bounded by the Central Volcanic Region to the east and by the Taranaki-Ruapehu lines to the south (figure 2.3). This region currently shows no deformation [Wallace et al., 2004] but underwent shortening in the Miocene [Stagpoole \& Nicol, 2008]. This region is further characterised by uplifted sedimentary basins [Kamp, 1999] and by the northern part of the crustal Taranaki Fault System [King \& Thrasher, 1996]. Like the Central Volcanic Region, the northwestern North Island is associated with thinned crust (25-28 km) [Horspool et al., 2006; Stern, 1987], high heat flow $\left(\sim 86 \mathrm{~mW} / \mathrm{m}^{2}\right)$ and high seismic attenuation [Mooney, 1970; Satake \& Hashida, 1989].

The Taranaki-Ruapehu line which connects the volcanoes Mt. Taranaki and Mt. Ruapehu (figure 2.3 and figure 2.2), describes a significant boundary from north to south in several geophysical observations. Observations include changes in crustal thickness (stepping from a thin $25 \mathrm{~km}$ in the north to a minimum of $32 \mathrm{~km}$ in the south), seismic attenuation and electrical resistivity [Salmon, 2008]. Gravity data (figure 2.3) show a steep gradient across the line, also indicating a strong contrast in crustal thickness. Stern et al. [2006] proposed that the Taranaki-Ruapehu line is a dynamic phenomenon, which represents the southern-most extent for the time-progressive, convective removal of mantle lithosphere and parts of the crust. The hypothesis of a development and viscous removal of Rayleigh Taylor instabilities underneath the North Island can account for many observations in the North Island, such as the migration of the depocenter of the sedimentary basins, surface uplift and deep earthquakes $(\sim 600 \mathrm{~km})$ [Stern et al., 2006]. Lithospheric thickening of the northwestern North Island during the Miocene provides the initial conditions required for the development of Rayleigh Taylor instabilities [Houseman \& Molnar, 1997].

\subsubsection{South Wanganui Basin}

In the late Miocene the region covered by the SWB was emergent and deposition occurred to the northwest and southeast [Fleming, 1975]. The present SWB is a region of broad crustal downwarp [Stern et al., 1992] with predominantly reverse faulting [Lamarche et al., 2005]. The basin is one of the largest sedimentary basins 


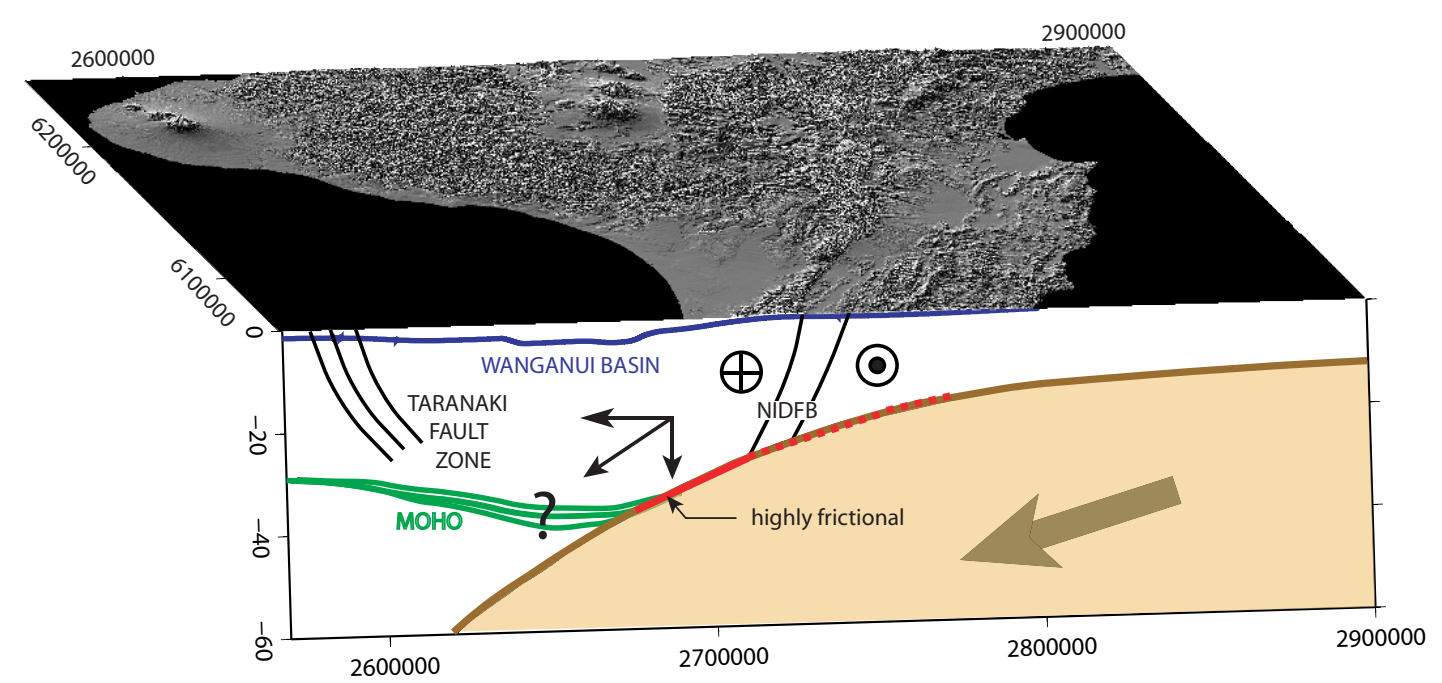

Figure 2.4: Cross-section sketch of the southern part of the SWB illustrating the proposed driving force of the basin. The shear force at the highly coupled interface creates a vertical pull as well as in-plane stress in the overriding plate. Blue line shows the depth of the sediment basin. The location of the Australian Moho is only sketched is only sketched in this figure and it's exact location is subject of this study. Also shown are the approximate locations of the Taranaki Fault Zone in the west and North Island dextral fault belt (NIDFB) in the east. The dashed red line shows the region of slip deficit at the plate interface [Wallace et al., 2004]. The solid red line shows the approximate location of the loading zone of Stern et al. [1992] flexural modelling.

in New Zealand and was formed in the Pliocene-Pleistocene [Anderton, 1981], with subsidence rates of about $1 \mathrm{~mm} / \mathrm{yr}$. It is located around $200 \mathrm{~km}$ landward of the Hikurangi subduction margin (see figure 2.3). Boundaries of the basin are the recently uplifted greywacke ( $<2 \mathrm{Ma}$ ) of the Tararua and Ruahine mountain ranges to the east [Lamb \& Vella, 1987] and the submerged Patea-Tongaparutu high to the west [Katz \& Leask, 1990; Wilson \& McGuire, 1995]. Northwards, the extent of the basin is limited by the Taranaki-Ruapehu line, and the southern boundary is described by the submerging Marlborough Sounds. The top of the subducting plate lies at a depths of 25 to $200 \mathrm{~km}$ beneath the basin [Ansell \& Bannister, 1996]. At the eastern, offshore side of the SWB a reverse fault system called the Kapiti Manawatu Fault System (Kapiti Manawatu Fault System) (figure 2.2), controls the subsidence of the basin [Lamarche et al., 2005].

The basin cannot easily be explained by classic models for orogenic belts. The driving mechanism of the basin is still unclear, but the preferred explanation is a broad-scale lithospheric flexure due to high frictional coupling at the plate interface (see figure 2.4) [Stern et al., 1992].

A seismic stratigraphic interpretation shows that the subsidence of the SWB 
basin happened in two phases [Proust et al., 2005].First, in a pregrowth phase, between 3.8 and $1.35 \mathrm{Ma}$, in which the deformation was probably initially homogeneous across the basin. Afterwards, in the second, syngrowth phase (1.35 Ma to present) basinward thickening happened during which the deformation was localised [Proust et al., 2005].

The marine connections of the basin changed during its evolution [Anderton, 1981]. The connection to the northwest became progressively limited until cut off in the late Pleistocene. A marine connection to the east existed during Pliocene across the trend of the Axial Ranges. It is not completely clear if a connection to the eastern basin existed through Cook Strait during the early Pliocene.

\subsubsection{Southeastern onshore area of the SWB}

In the onshore part of the SWB, between the Axial Ranges and the coast, the surface expression of the faulting is masked beneath the coastal floodplain. Seismic reflection data, however, show a series of north-northeast trending half grabens which are bounded by high-angle faults with offsets of up to $500 \mathrm{~m}$ [Aharoni, 1991; Bekesi, 1989]. Above some faults, sediments have been draped, producing anticlines and synclines, some of which appear to be still growing at the surface [Te Punga, 1957]. In the Horowhenua region, two major anticlines can be found close to Levin and Shannon (figure 2.5). The area is undergoing slight uplift at around $0.3 \mathrm{~mm} / \mathrm{a}$ [Shepherd, 1987]. Sea-level changes during interglacial and glacial periods had the biggest influence on sedimentation of shallow marine and terrestrial sediments [Hughes, 2005].

On the western side of the Tararua Ranges (figure 2.4 and 2.5) is a zone of strikeslip faults which runs subparallel to the west coast of the lower North Island and possibly extends offshore (see figure 2.5). Horizontal slip rates on these faults are between 1-3 mm/a [Heron et al., 1998; Litchfield et al., 2004, 2006; Van Dissen et al., 1999]

\subsection{Further geophysical and geological observations important for the SWB}

Associated with the SWB is an unusually deep Moho ( $>40 \mathrm{~km}$ ) (figure 2.6) [Stern \& Davey, 1989], a strong negative gravity anomaly $(-150 \mathrm{mGal})$ (figure 2.3) [Hunt, 1980; Reilly et al., 1977], mild compression (4 mm/yr) [Wallace et al., 2004], swarm-like earthquake activity [Garrick \& Gibowicz, 1983], low heat flow [Funnell et al., 1996] and low seismic attenuation [Salmon et al., 2005]. The following section lists and describes the main observations and studies within the SWB. 


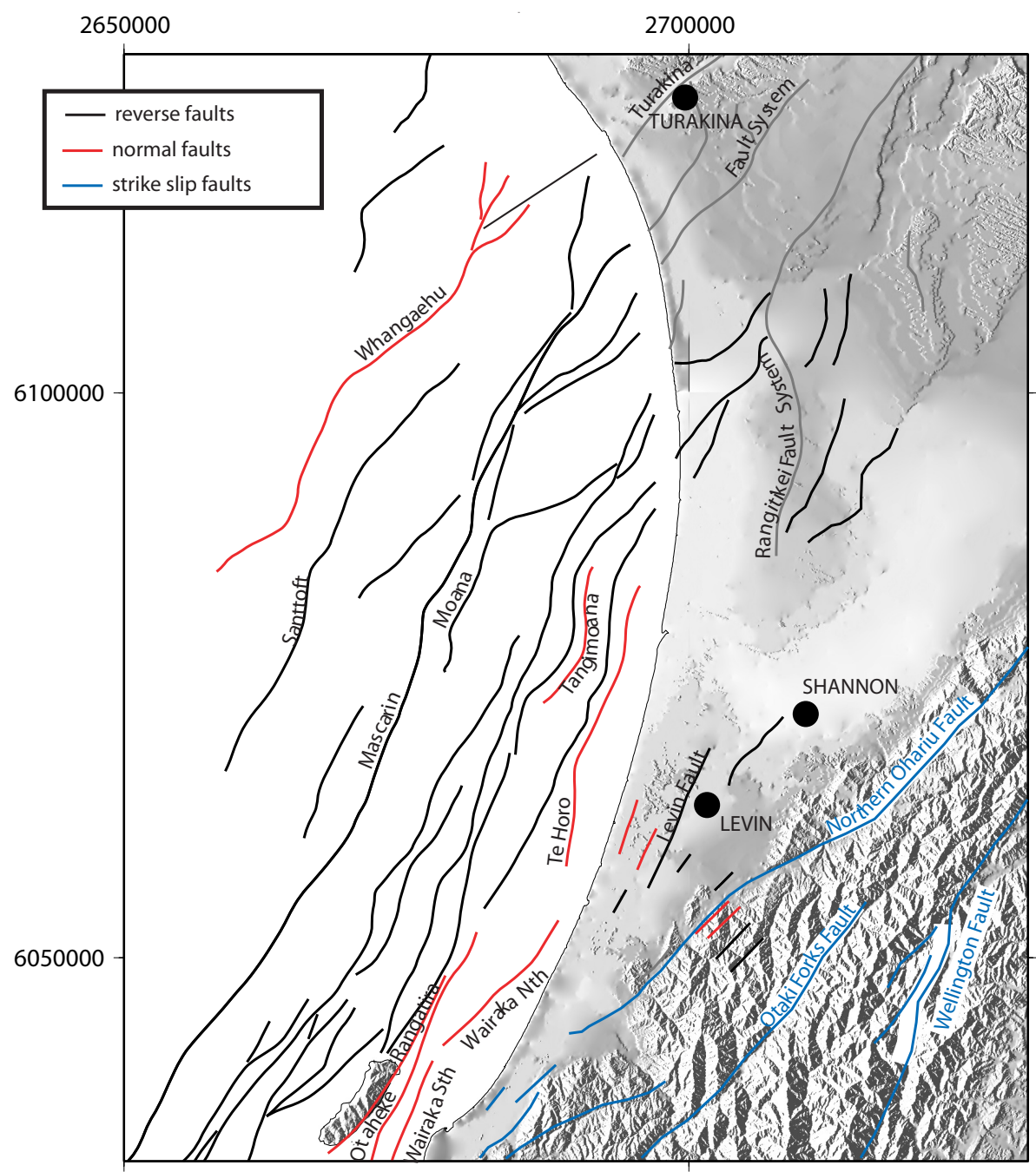

Figure 2.5: Map of the mapped faults in the southeastern corner of the SWB. Different colours represent the different sense of the faults. The offshore part of the faults can be summarised as the Kapiti Manawatu Fault System (Kapiti Manawatu Fault System) [Lamarche et al., 2005].

Seismicity The basin seismicity is dominated by events within the Benioff zone [Ansell \& Bannister, 1996; Reyners, 1998]. However, crustal seismicity in the overriding plate occurs throughout the crust down to $40 \mathrm{~km}$ (figure 2.7). This unusually deep seismicity for continental crust [Maggi et al., 2000] could be explained by a relatively cold crust due to low heat flux [Stern et al., 1992], because temperature is the main control mechanism for the strength of the lithosphere [Chen \& Molnar, 1983; Watts et al., 1980].

The Wanganui-Manawatu-Kapiti region experiences swarm-like earthquake activity $\left(\mathrm{M}_{W}<5\right)$ located mostly offshore close to the present depocenter [Garrick \& Gibowicz, 1983]. A possible cause of earthquake 


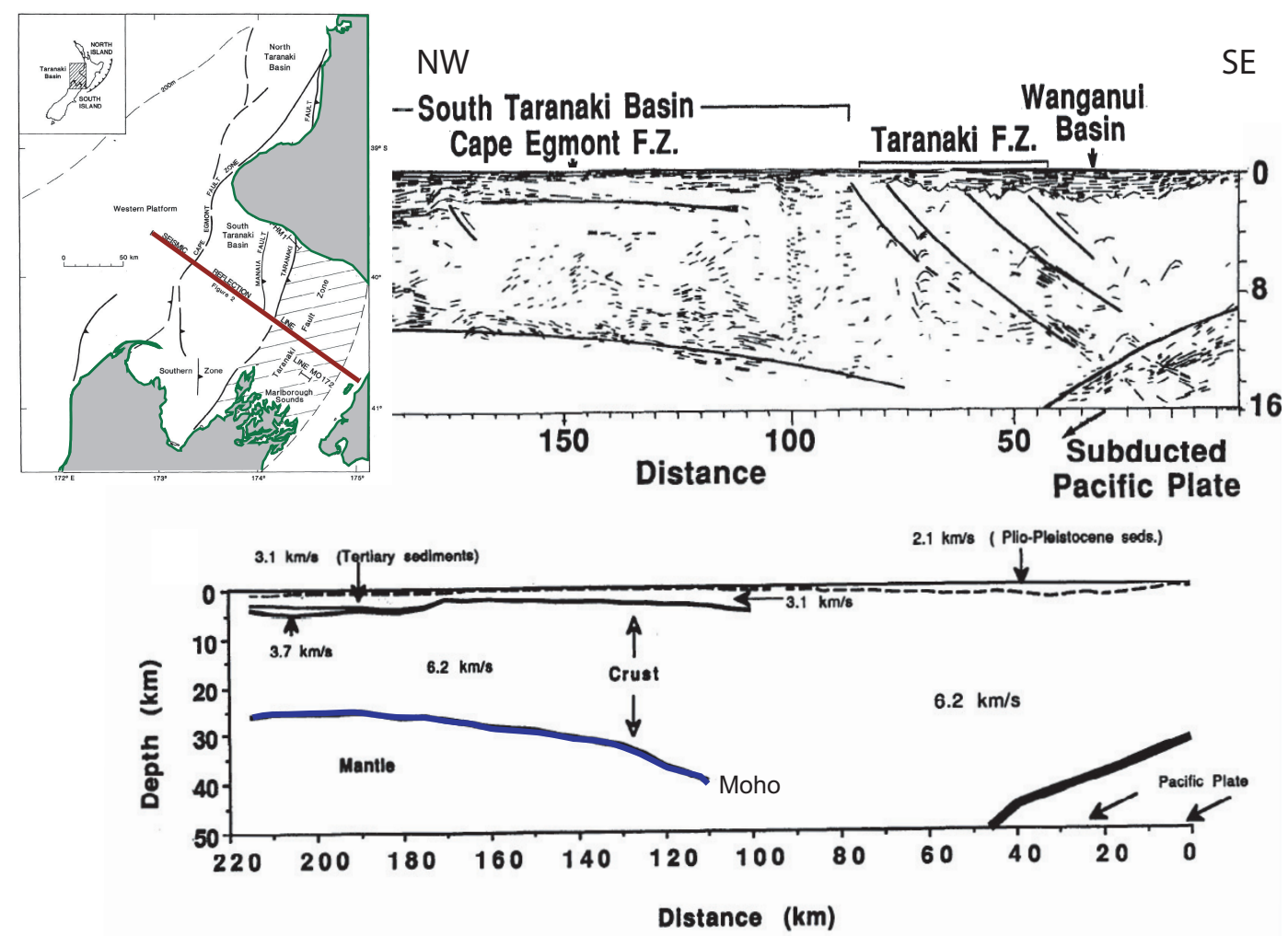

Figure 2.6: Unmigrated section and interpretation of a deep crustal seismic line across the Taranaki Boundary fault [modified from Holt \& Stern, 1994]. The interpretation shows at least $10 \mathrm{~km}$ of crustal thickening at the eastern margin of the South Taranaki Basin into the SWB. However, the Moho reflector (blue line) cannot be identified underneath the SWB itself. The inset on the top left corner shows the location of the seismic profile (red line).

swarms could be fluids driven off the subducted plate into cold and thickened mantle lithosphere [Reyners et al., 2006; Stern et al., 2006].

Fault-plane solutions for shallow crustal earthquakes indicate mostly normal faulting, whereas lower crustal earthquakes show mostly reverse faulting [Garrick \& Gibowicz, 1983]. Similar mixed faulting behaviour can be seen in the upper crust [Lamarche et al., 2005]. Historically, this region experienced at least one large earthquake near Wanganui city in 1897 ( M 7) [Eiby, 1968]

Taranaki Fault Zone The Taranaki back-thrust system is approximately $600 \mathrm{~km}$ long and is located entirely in the continental crust of New Zealand [Stagpoole \& Nicol, 2008]. It forms the eastern boundary of the Taranaki Basin. The fault system consists of the Waimea-Flaxmore Fault in the northern South Island and the Mania Fault, the Tarata and the Taranaki Fault to the north (see figure 2.2). The displacement of the fault system is linked to the 


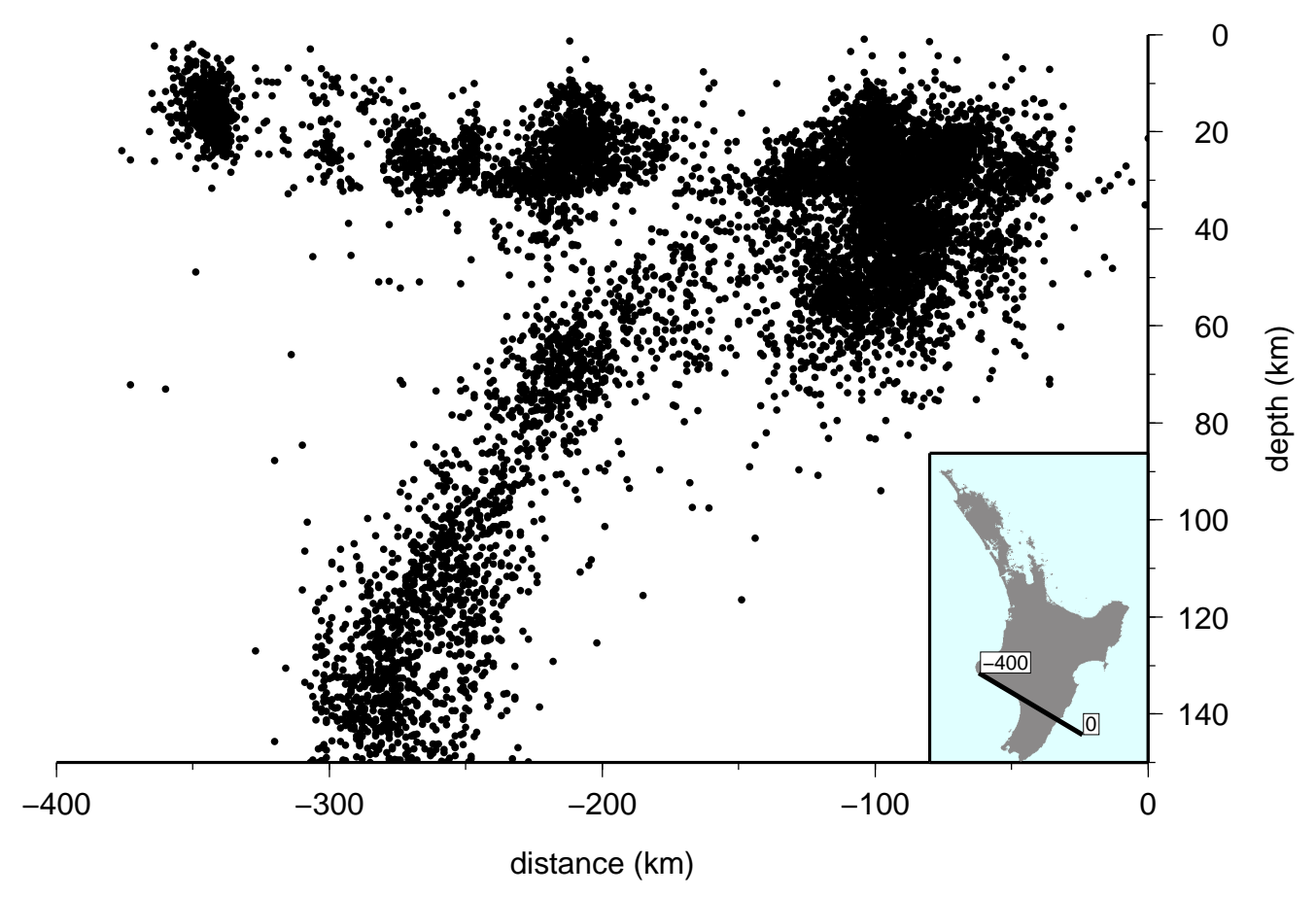

Figure 2.7: Seismicity along profile A-A' of inset map. This profile runs through the Wanganui Basin and crosses the Taranaki-Ruapehu line at the western end. Events with $M>2$, between 1990 and 2006 and a swath width of $50 \mathrm{~km}$ to the south are used. Crustal seismicity can be seen throughout the whole crust. Benioff zone becomes almost vertical at $300 \mathrm{~km}$ along the profile line. Numbers in inset map mark the start and end point of the profile line.

subduction interface with the fault accommodating a few percent of the relative plate motion [Holt \& Stern, 1994]. The fault can be described as a back thrust antithetic to the subduction thrust (figure 2.6).

Sedimentation of the SWB is thought to have started when uplift, basement erosion and displacement on the Taranaki and Mania faults ceased at $\sim 5 \mathrm{Ma}$ [Anderton, 1981]. It is argued that this is consistent with a southward stepping of the fault and a migration of the depocenter in the same direction [Stagpoole \& Nicol, 2008]. The southward stepping of the fault (400-450 km during the Tertiary), in turn, is a result of slab-roll back/clockwise rotation of the subducting Pacific plate, which isolates the fault from the downgoing plate [Stagpoole \& Nicol, 2008].

The Taranaki Basin, located west of the Taranaki Fault, is the most western element of plate tectonics in the North Island. Its early history is dominated by Cretaceous rifting. However, most of the more than $7 \mathrm{~km}$ of sedimentation [Palmer, 1993] within the basin happened during a compressional phase in the Oligocene to late Miocene [Hunt, 1980]. Deep seismic data re- 
veal at least $10 \mathrm{~km}$ of crustal thickening underneath the basin during the Miocene, and it is therefore described as classical retroarc foreland basin [Stern \& Davey, 1990] during this period rather than a rift basin [Kamp, 1986].

Kapiti Manawatu Fault System The Kapiti Manawatu Fault System is located $200 \mathrm{~km}$ to the west of the Hikurangi subduction margin at the eastern corner of the SWB [Lamarche et al., 2005; Nodder et al., 2007]. It is a compressional low-strain fault system (strain rates two to five times smaller than in the fore-arc basin to the east), which runs north-northeast parallel to the Axial ranges. Lamarche et al. [2005] proposes that the steep reverse faults $\left(>60^{\circ}\right)$ within the system are a reactivation of extensional structures and that the compression of this area started $\sim 1800 \mathrm{ka}$ ago. The extension period which originally created the normal faults cannot be dated but most likely happened during a widespread extensional phase in New Zealand during the late Cretaceous to early Eocene [Lamarche et al., 2005].

Furthermore, two faults of the Kapiti Manawatu Fault System (the Mascarin and the Rangitikei faults) are possibly linked to the plate interface [Lamarche et al., 2005]. The system can potentially generate high-moment magnitude earthquakes ( $\mathrm{M}_{W}$ between 5.5 and 7.5), but the long recurrence intervals (>10000 a) keep the seismic hazard of the Kapiti Manawatu Fault System low [Nodder et al., 2007].

Sediments Most of the 4-4.5 km sediments are shallow marine mudstones which show a gentle dip towards the depocenter [Hunt, 1980]. The supply for the sediment infill initially originated from the uplifted areas to the southwest but an increasing supply came from the northeast, as the North Wanganui Basin emerged. During the Pleistocene, an additional sediment source was provided by the uplift of the Axial Ranges to the east [Anderton, 1981].

The present day depocenter of the basin migrates to the south, causing offlap of older sediments in the north and onlap of younger sediments to the south [Anderton, 1981]. The migration is at least partly driven by the Quaternary uplift and doming of the central North Island [Stern et al., 1992]. This migration of the depocenter southward with time has been described as a "geological standing wave" with a wavelength of $300 \mathrm{~km}$ [Stern et al., 1992].

Surface deformation modelling Flexural deformation modelling for the SWB showed that high vertical loads are needed to create the basin [Stern et al., 1992]. The loading is explained as a component of shear stress, which developed along the subduction thrust (figure 2.4). The thrust in the lower North Island is assumed to be strongly coupled [Reyners, 1998; Wallace \& Beavan, 2006]. Estimations for the effective elastic thickness (Te) of the SWB show values around $10 \pm 5 \mathrm{~km}$ [Stern et al., 1992]. Further results from this 
modelling show that compressional and extensional stresses created within the basin have sufficient amplitudes to cause normal and reverse faulting respectively, and their location is in partial agreement with the observed faulting within the SWB [Stern et al., 1992].

\subsection{Slab pull force and corresponding surface defor- mation}

The gravitational pull of subducted slabs is thought to be one of the main driving mechanism of the Earth's tectonic plates [Conrad \& Lithgow-Bertelloni, 2002; McKenzie, 1969; Moores \& Twiss, 1995]. The magnitude of this force depends on the length of the slab and on the density contrast between the slab and the surrounding material, and is generally larger for older lithosphere. Additional forces controlling the subduction of the slab and the movement of the plates are the ridge push force (originating from the topographic slope at a spreading centre), the slab-drag (arises from resistance of mantle to the sinking slab) and the trench-suction force (a force which draws the overriding plate towards the trench) [Moores \& Twiss, 1995]. It is not possible to calculate the magnitudes of all components of the force model of the subduction system.

The subducting slab represents a density anomaly in the mantle underneath the overriding plate. To keep the system in isostatic equilibrium surface subsidence has to occur. Proposed mechanisms to compensate for this mass deficit are the tension between the slab and the overriding plate, or a negative pressure perturbation in the mantle wedge [Davies, 1981]. The coupling of the plates at the subduction interface is crucial for the kind of surface deformation predicted [Bott, 1993; Bott et al., 1989; Whittaker et al., 1992].

The stress regime resulting from a subducting slab has been modelled by Whittaker et al. [1992] and Bott [1993] for a locked and an unlocked subduction interface. They showed that a locked interface results in vertical surface deformation as well as deviatoric compressional stresses in the overriding plate. The slab pull is ineffective in such a situation. In the case of a complete unlocked interface, the compressive stress vanishes almost completely and the deviatoric stress extends to the boundaries of the model indicating an active slab pull force. Furthermore, the plate displacement vectors of such models show a component of moveout towards the trench, called trench-suction force [Moores \& Twiss, 1995].

Figure 2.8 shows modelling results for a slab extending to a depth of $300 \mathrm{~km}$ with a dip of $45^{\circ}$ and a $30 \mathrm{~km}$ thick crust for the subducting and overriding plate [Whittaker et al., 1992]. In the model with a locked interface a horizontal deviatoric stress of up to $70 \mathrm{MPa}$ above the subduction slab in the overriding plate can be achieved. The surface above the slab shows a broad downwarp with a 


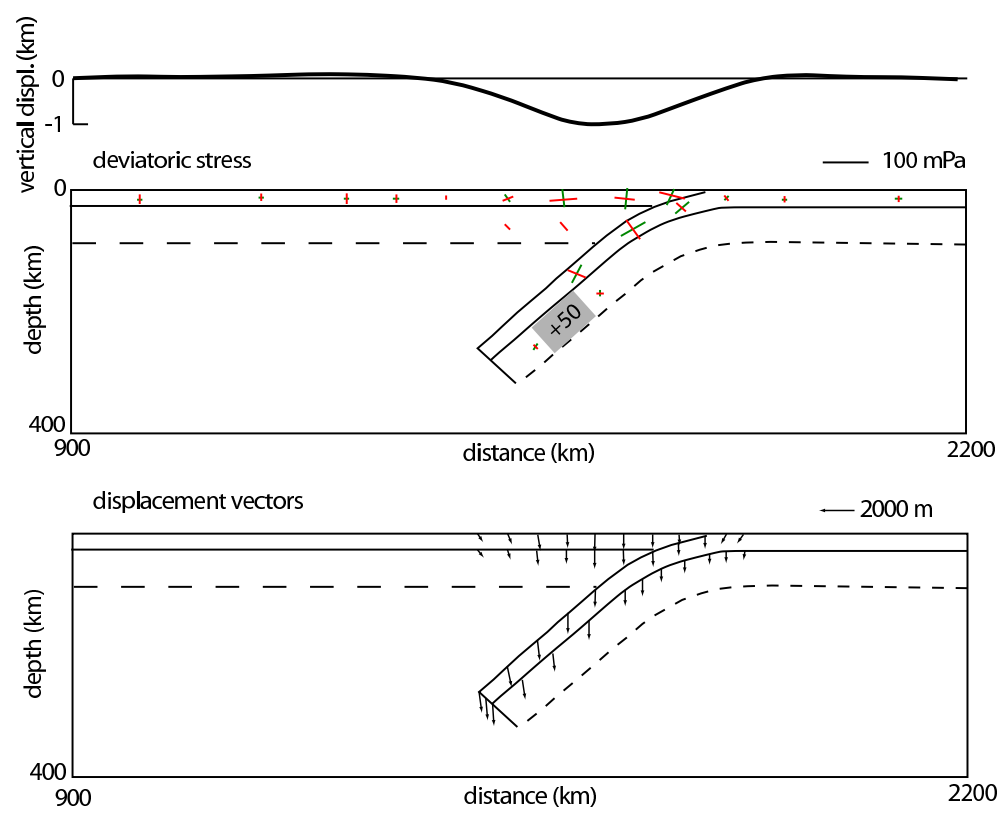

(a) locked subduction interface

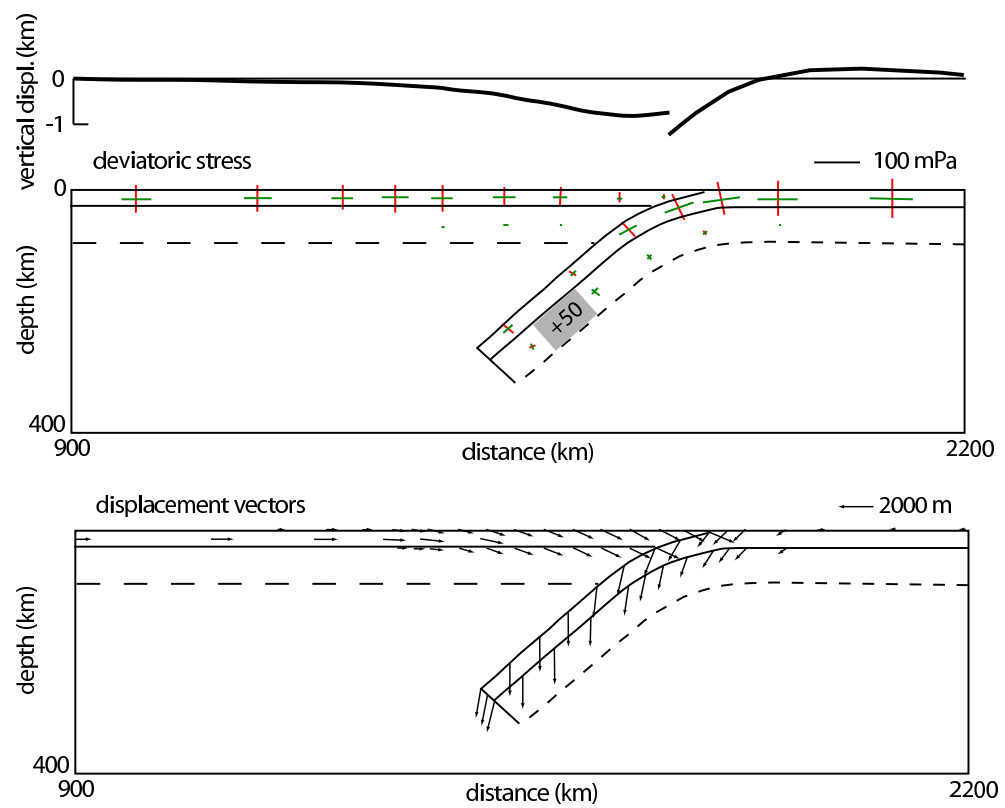

(b) free subduction interface

Figure 2.8: Deviatoric stress distributions (middle figure in (a) and (b)) and displacement fields (bottom figure in (a) and (b)) produced by models of a subducting slab with excess density of $50 \mathrm{~kg} / \mathrm{m}^{3}$ dipping at $45^{\circ}$ and extending to about $300 \mathrm{~km}$ depth [after Bott, 1993; Whittaker et al., 1992]. The base of the lithosphere is marked by a dashed line and the upper elastic part of the lithosphere is marked by the solid lines. The vertical surface displacement due to the downpull of the lithospheric root is shown in the top figure of (a) and (b). Both of the in-plane stresses are shown (red:compressional stress; green:tensional stress). Models also include excess continental surface loading relative to oceanic regions. Vertical exaggeration is 3.7 . 


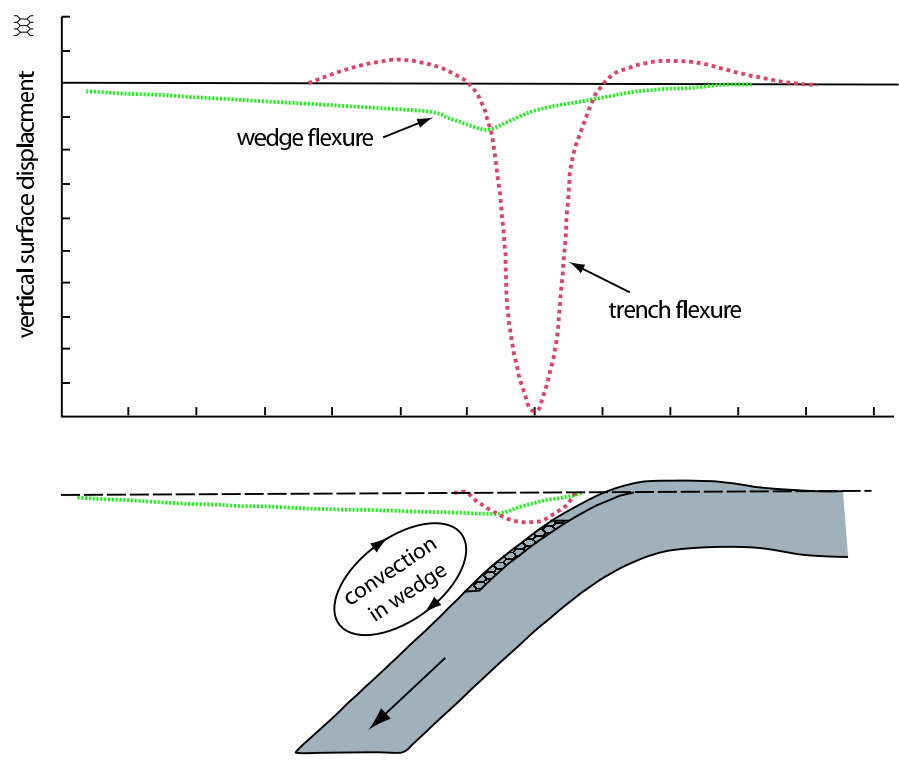

Figure 2.9: Calculated surface displacement of a subducted slab (modified from Stern [1982]). The model and the results are only schematic and show different displacement patterns possible. For explanation about mechanisms see text.

maximum magnitude of $\sim 1 \mathrm{~km}$. Additionally, the sinking slab shows a substantial component of rollback. For a deeper reaching slab the resulting stresses are higher and the corresponding flexure larger. However, for deeper slabs different processes are starting to take place, such as the penetration of the slab into the mantle transition zone, with a significantly higher viscosity and therefore a stronger resistance. The major difference is a narrower surface deformation with similar stress magnitudes in the surface plate. This modelling illustrates the importance of coupling between the plates for the observed stress regime at the surface of the overriding plate.

In a different modelling approach, Davies [1983] investigates the observed surface deformation with different compensation mechanisms. He observes two different types of deformation, a so called wedge-flexure due to suction forces created by mantle convection and trench-flexure due to stresses transmitted through the plate interface (see figure 2.9). Both phenomena compensate the same mass deficit at which wedge-flexure is shallow with a large wavelength compared to trend flexure which is deeper and narrower. The efficiency of the wedge-flexure mechanism depends on the viscosity of the asthenosphere, the subduction velocity of the slab and the density contrast between the asthenosphere and the material that overlies the depressed lithosphere [McKenzie, 1969]. The wedgeflexure is similar to the trench suction and can only take place on unlocked plate interfaces.

"Real" subduction zones will represent neither a completely locked nor a completely unlocked case, but an intermediate case due to some friction on the in- 
terface. To summarise, the mass anomaly compensation mechanism depends strongly on the coupling between the plates. However, other factors such as the viscosity of the asthenosphere, the velocity of the subducting plate, and the depth of the slab also define the compensation mechanism. 


\section{Chapter 3}

\section{Shallow seismic and gravity methods}

This chapter describes the exploration of shallow structures at the south-eastern boundary between the South Wanganui Basin (SWB) and the Tararua Ranges using different geophysical methods. The onshore part of the SWB is known only from scattered geophysical surveys and a few exploration wells. The need for more detailed information arises as active structures are often hidden under young sand dunes and recent sedimentation. Therefore, the new data presented in this chapter can help with the risk assessment for the Kapiti Coast area. Furthermore, understanding the shallow structure in this transition zone between the subsidence of the SWB and the uplift of the Tararua Ranges can help to understand the tectonic behaviour of the southern part of North Island. This includes the question: is subsidence in the eastern part of the SWB mainly driven by a) thrust sheet loading or b) vertical forces acting on or within the crust?

Studies from the National Institute of Water and Atmospheric Research (NIWA) and the oil exploration companies show high-angle reverse faults in the east of the SWB. This is consistent with GPS data, which indicate that the whole basin, at least for the last decade, is under minor compression. Nevertheless, high resolution seismic reflection data [Lamarche et al., 2005] also document a zone of near-vertical, low-strain, normal faults in the western most offshore part of the basin (figure 3.1).

\subsection{Datasets}

The geophysical methods used here to acquire new information about the shallow structure include seismic reflection and refraction, seismic tomography and gravity. Three new seismic reflection lines and two refraction lines were con- 


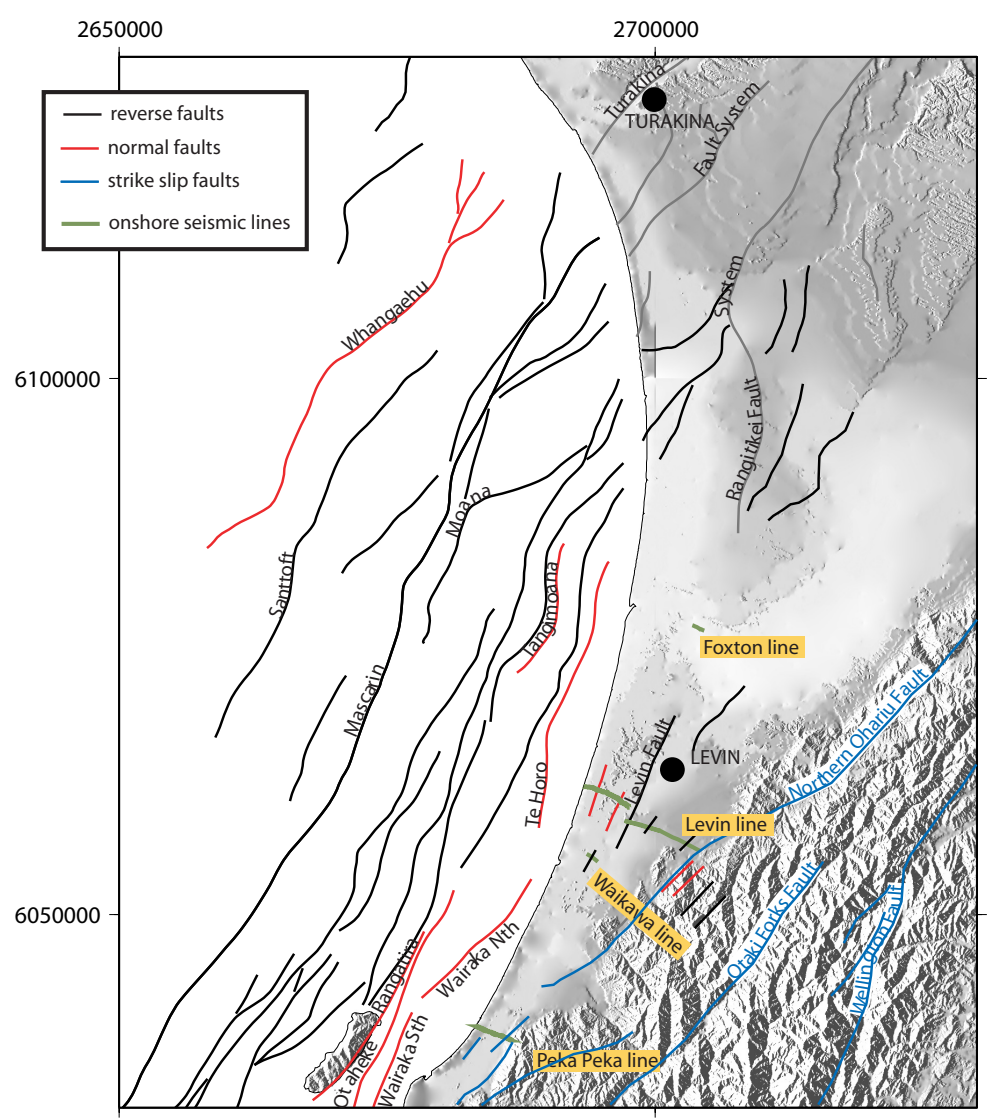

Figure 3.1: Overview of the existing onshore seismic lines and the Kapiti Manawatu Fault System [modified from Lamarche et al., 2005] and other faults in the study area.

ducted and three existing seismic lines were reprocessed (figure 3.2). The analysed gravity surveys consist of 162 new gravity points and 173 points taken from the Geological and Nuclear Sciences (GNS Sciences) and Victoria University Wellington (VUW) database. All profiles, apart from one in the Waikanae area, are running in east-west direction, perpendicular, and if possible, across the boundary between the Tararua Ranges and the SWB.

The first step in a new field experiment is to choose good field site locations. Crucial factors are accessibility of the area, safety for the field crew, and absence of potential noise sources. Preliminary gravity studies were carried out to acquire initial information and to plan further aspects of the project. In the case of the Foxton profile line, gravity data from the GNS Sciences database were used for initial modelling, and more detailed gravity surveying along the profile line was complete during the seismic reflection profiling. The initial gravity models are later refined by using results from seismic data interpretation. However, results from gravity modelling (section 3.2.1, 3.3.1, 3.4.1, 3.5.1) are presented first, because they often range over a wider area and were collected first. 


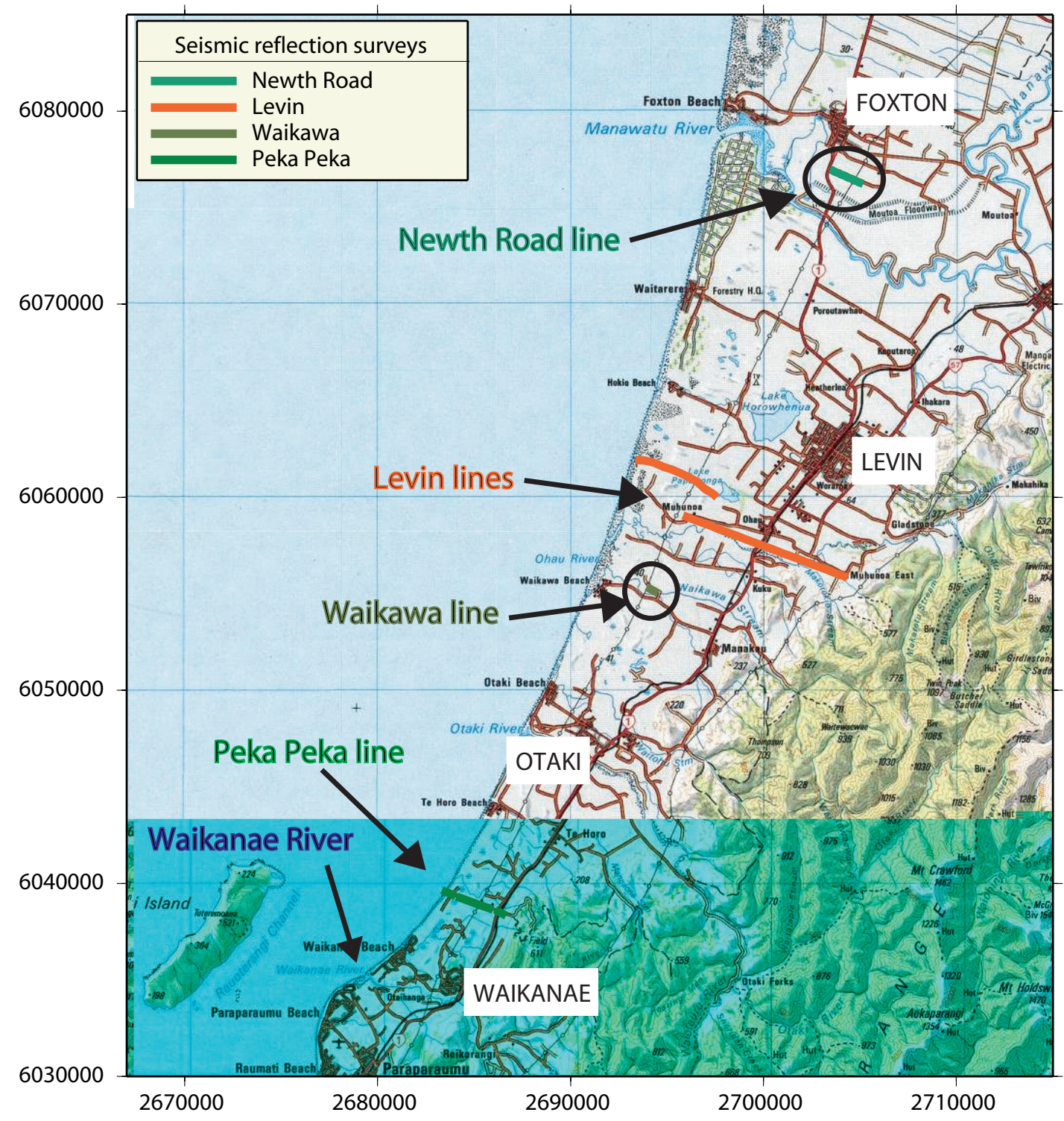

Figure 3.2: Location of the seismic lines discussed in this chapter. Most of these lines are combined with at least one gravity survey. For exact details see individual sections.

Seismic reflection profiling (section 3.2.2, 3.3.2, 3.4.2, 3.5.2) is used to create a more detailed picture of the subsurface with lateral and vertical changes in seismic velocity. It is only used on specific pre-investigated targets because of the high costs. All three newly acquired seismic datasets are collected in different field seasons and run along or parallel to the gravity lines.

Seismic refraction data were collected along the Peka Peka profile (section 3.2.4 and 3.2.5) and can be used to refine and confirm results from gravity and seismic reflection analysis. Compared to seismic reflection, seismic refraction has several advantages such as the better determination of seismic velocities and the need for 
fewer explosion sources. On the other hand, larger offsets are necessary and the method only works for increasing velocity with depth.

During seismic reflection shooting along Peka Peka Road additional seismic data were recorded, which is used to make a smooth 2-D velocity model of the subsurface (see section 3.2.3). This seismic tomography modelling is typically used for deeper crustal structure and is here implemented to test what can be achieved with such a small scale geometry setup.

\subsection{Waikanae survey}

The Waikanae survey consists of two parts. The first part is a regional gravity study of the area between the Waikanae River in the south, Peka Peka Road in the north and the foothills of the Tararuas in the east. The second part is a detailed study of the northern end of this area including gravity modelling and different seismic methods (reflection, refraction and tomography). The main fieldwork for this survey was undertaken in the summer of 2004/2005 and some smaller trips subsequently completed the dataset.

\subsubsection{Gravity method}

The used gravity dataset contains 45 newly acquired measurements, 14 measurements from the GNS Sciences gravity database and 21 from the VUW gravity database. Tables B.1 to B.4 in appendix B provide the grid reference and other information for all stations.

The datapoints are arranged in four profile lines with randomly spaced points between them (see figure 3.3). Three lines run approximately east-west, perpendicular to the Tararua foothills (Peka Peka Road profile (orange line), Greenhill Road profile (green line), Moana Road profile (blue line)), and one line (Paetawa Road profile (purple line)) runs perpendicular to the other three lines, along the coast.

The raw gravity measurements are first reduced to Bouguer gravity values, followed by the calculation of the regional field, which is then used to reduce the data to residual gravity values. A detailed discussion of the estimation of the regional gravity field as well as other aspects of gravity data analysis can be found in appendix B.

Figure 3.4 shows the residual gravity map of the greater Waikanae area. It is produced by contouring all collected residual gravity values within the region. 


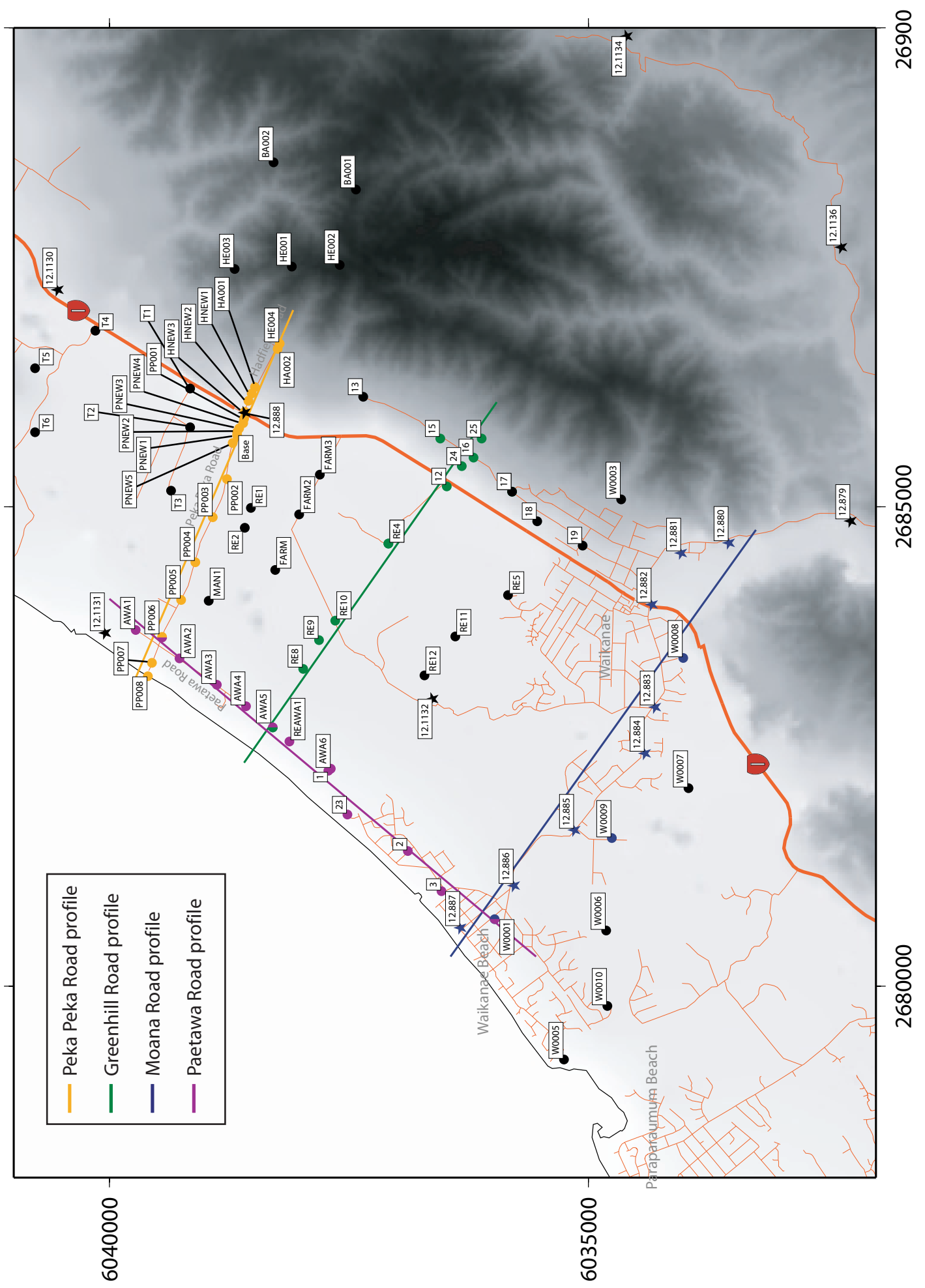

Figure 3.3: Location map of the data points used for the Waikanae gravity survey. The 80 datapoints originate from different sources; stars indicate data taken from the GNS Sciences database, circles represent points collected by VUW. The lines show the different profiles for the gravity modelling. Coloured points indicate the affiliation to the respective profile line. Black points are not included in any profile. 
The white area in the map indicates the surface exposure of basement (residual gravity values close to zero). The blue colour indicates the lowest gravity values, corresponding with the largest basement depth. Residual gravity values also depend on factors like the density contrast and the lateral extent of basement highs and lows. However, a basement high which extends and widens from Waikanae township (see figure 3.4)to the north can be extracted. The east-east gradient of the resdiual gravity value indicates a deepening of the basement to the west, where the very strong gradient underneath state highway 1 (SH1) in the north of the study area indicates a steep drop of the basement.

\subsubsection{Peka Peka profile}

The Peka Peka profile (yellow line figure 3.3) consists of 24 datapoints and runs approximately east-west, from the coastline along Peka Peka Road (west of SH1) and Hadfield Road (east of SH1) into the foothills of the Tararua Ranges (length $\sim 6 \mathrm{~km}$ ). It crosses SH1 between point PP001 and HNEW3.

The initial model (figure 3.5(a)) considers a three-layer case with a thin top layer consisting of mainly sand and gravels. This layer has a high density contrast $\left(\Delta \rho=-770 \mathrm{~kg} / \mathrm{m}^{3}\right.$, Carmichael [1989]) to the surrounding Mesozoic greywacke (density of $2670 \mathrm{~kg} / \mathrm{m}^{3}$, after Cope [1967]; Whiteford [1974]). The second layer represents Pleistocene sediments with an average density of $2000 \mathrm{~kg} / \mathrm{m}^{3}$ [Hunt, 1980].

Results show an average basement depth of around $200 \mathrm{~m}$ west of SH1 with a basement high between kilometre 1.3 and 2.1 (figure 3.5(a)). Underneath SH1 the basement vertically offsets by around $220 \mathrm{~m}$. With gravity modelling it is not possible to distinguish between a high-angle normal, and high-angle reverse fault. Therefore, this offset is modelled as a vertical fault.

To the east of SH1 (underneath Hadfield Road) a shallow basement is inferred $(<100 \mathrm{~m})$ with an outcrop of basement around station HE004 (figure 3.3). The basement high in the middle of Peka Peka Road is asymmetric with a $20^{\circ}$ flank on its western side and a lower dipping side on the east (figure 3.5(a)). Seismic data, to be described in section 3.2.2 and 3.2.4, show a significantly deeper basement horizon. Therefore, the density contrast between the lower layer and the surrounding material is decreased to $\Delta \rho=-400 \mathrm{~kg} / \mathrm{m}^{3}$ in order to achieve a consistent result. An explanation for this relative high density for shallow Pleistocene sediments could be a high content of well graded gravels [Kokusho et al., 2004]. The inferred layer densities cannot be correlated against drillhole data because available data logs are only qualitative and the deepest drillhole in the area reaches only $90 \mathrm{~m}$.

Changes in the shape of the basement between the two models are minor. But an overall deeper basement horizon and steeper flanks on the basement high 


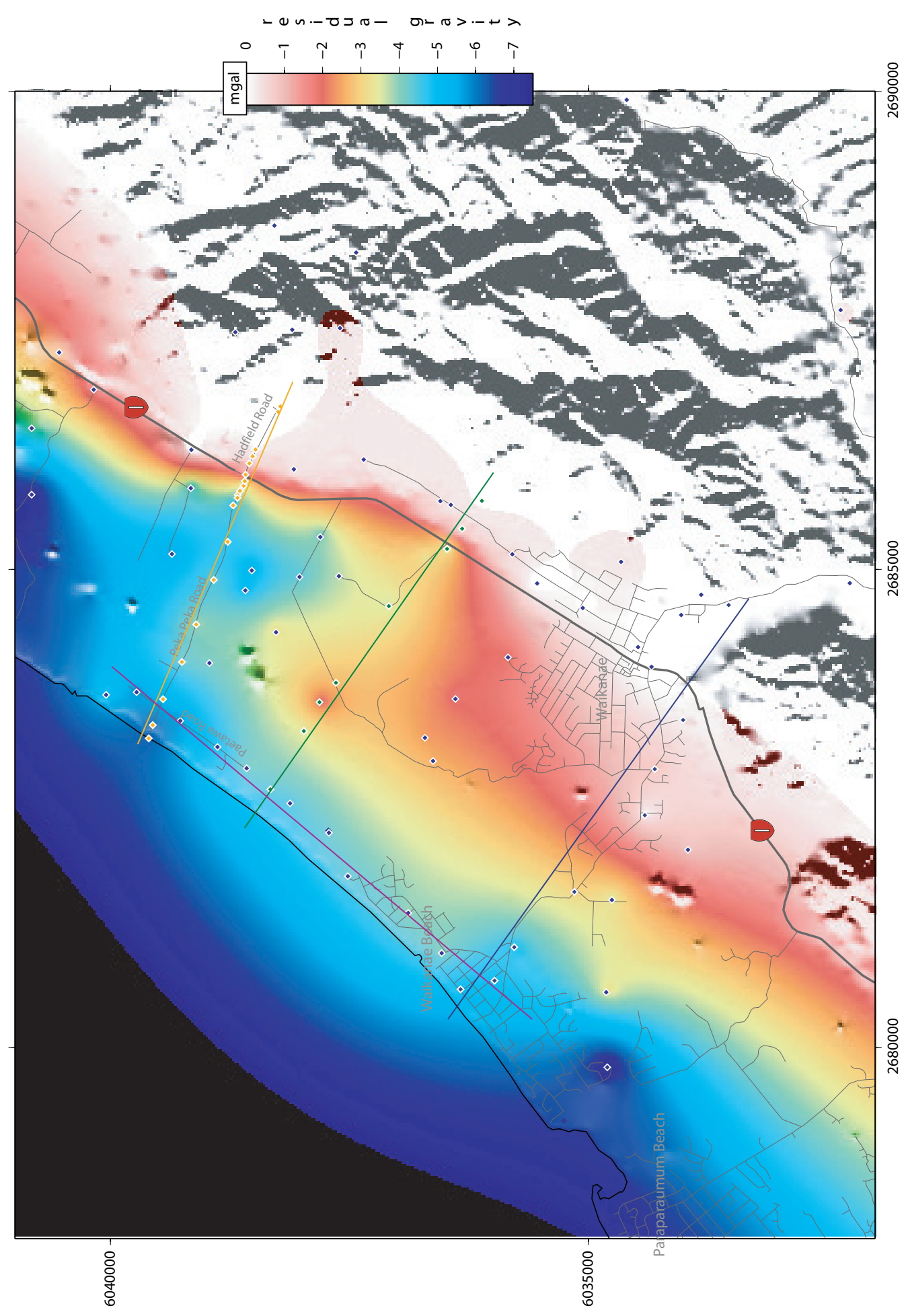

Figure 3.4: Residual gravity map of the greater Waikanae area. Blue dots indicate the data points used for creating this residual gravity map. SH1 is marked by the thick grey line and SH1 sign. The shading indicates topography. Note the drop in gravity values across $\mathrm{SH} 1$ in the north of the study area. Furthermore, data imply a basement high underneath Waikanae township. The lines show the different profiles for the gravity modelling. Coloured points indicate the affiliation to the respective profile line. 


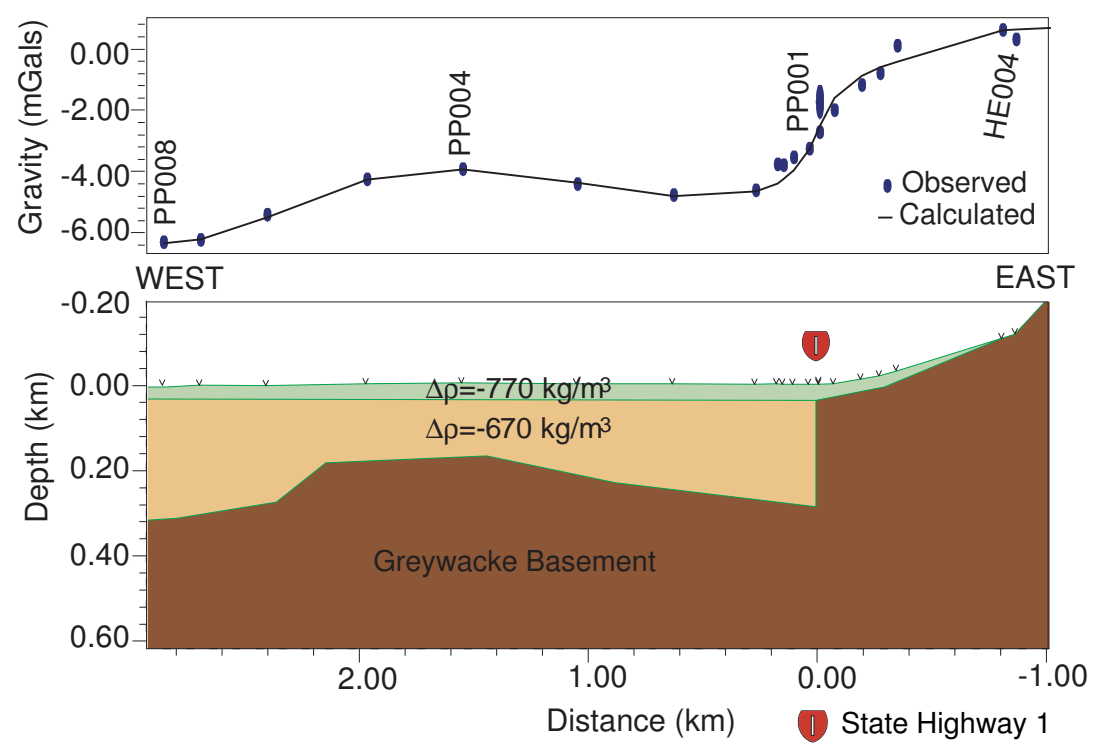

(a) High density contrast

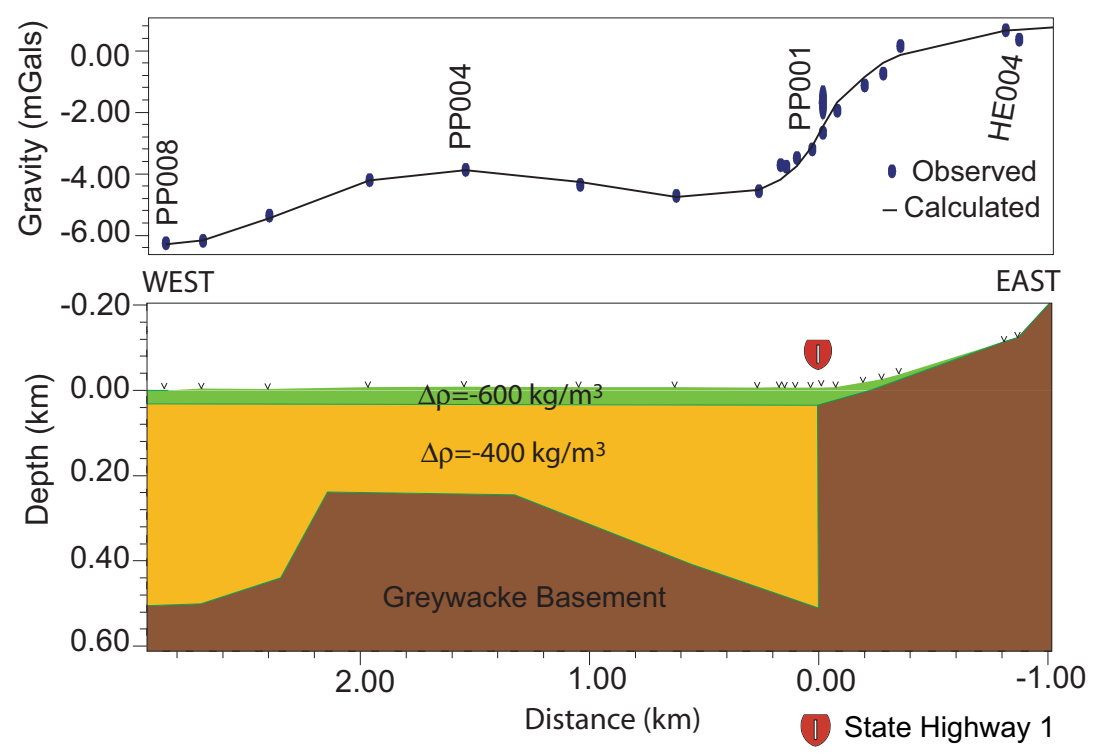

(b) Low density contrast

Figure 3.5: Peka Peka Road residual gravity models: top figures show the residual gravity measurements (blue dots) and the calculated values (black lines). Bottom figures represent the corresponding density models. (a) Model 1 assumes a standard Pleistocene sediment density for the second layer of $2000 \mathrm{~kg} / \mathrm{m}^{3}$. (b) Model 2 assumes a higher density (smaller density contrast) for the second layer in order to make the basement depth consistent with the seismic data. The surrounding material is assumed to be greywacke with a density of $2670 \mathrm{~kg} / \mathrm{m}^{3}$. The vertical size of the datapoints represents error bars. The zero position on the $x-$ axis is equivalent to the location of SH1. Depth is relative to sea level, and there is a vertical exaggeration of 1.8 


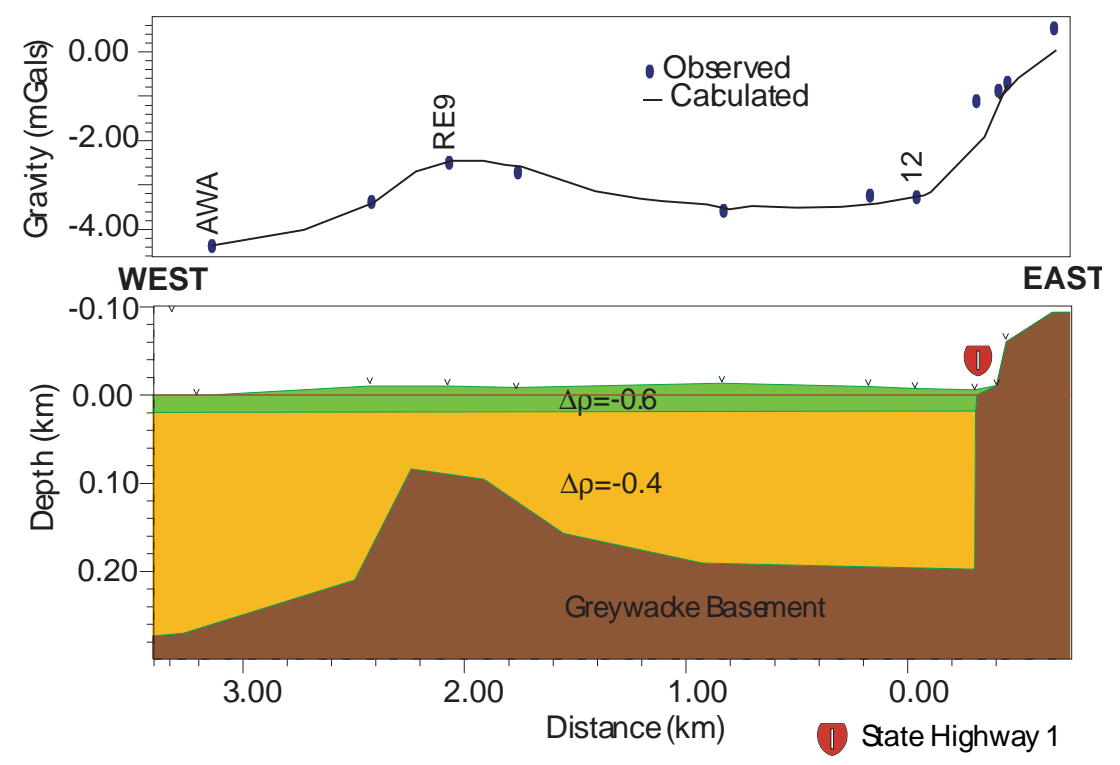

Figure 3.6: Greenhill Road residual gravity model: top figure shows the residual gravity measurements (blue dots) and the calculated values (black line). Bottom figure represents the corresponding density model. Used densities are identical to densities used for model 2 of the Peka Peka profile (figure 3.5). The surrounding material is inferred to be greywacke with a density of $2670 \mathrm{~kg} / \mathrm{m}^{3}$. The zero position on the $\mathrm{x}$-axis is equivalent to the location of SH1. The vertical size of the datapoints represents error bars. Depth is relative to sea level, and there is a vertical exaggeration of 4 .

is observed for the models with the lower density contrast (figure 3.5(b)). The offset underneath $\mathrm{SH} 1$ is again modelled as a vertical offset but with a magnitude of around $520 \mathrm{~m}$. Between kilometre 1.4 and 2.2 the basement high reaches a depth of around $230 \mathrm{~m}$ and its eastern flanks dip with an angle of $\sim 45^{\circ}$ (figure 3.5(b)).

\subsubsection{Greenhill Road profile}

The Greenhill Road profile (green line figure 3.3) runs roughly parallel to the Peka Peka profile in a distance of about $1.6 \mathrm{~km}$ to the south. It consists of ten datapoints and has a length of about $4 \mathrm{~km}$.

Modelling of the observed residual gravity anomaly is consistent with the low density model from the Peka Peka profile (see section 3.2.1.1). Thus, the final model in figure 3.6 consists of three layers with the following densities: top layer $\rho=1900 \mathrm{~kg} / \mathrm{m}^{3}$, second layer $\rho=2270 \mathrm{~kg} / \mathrm{m}^{3}$, surrounding greywacke $\rho=2670 \mathrm{~kg} / \mathrm{m}^{3}$.

Results from this profile show, like in the Peka Peka profile (section 3.2.1.1), 


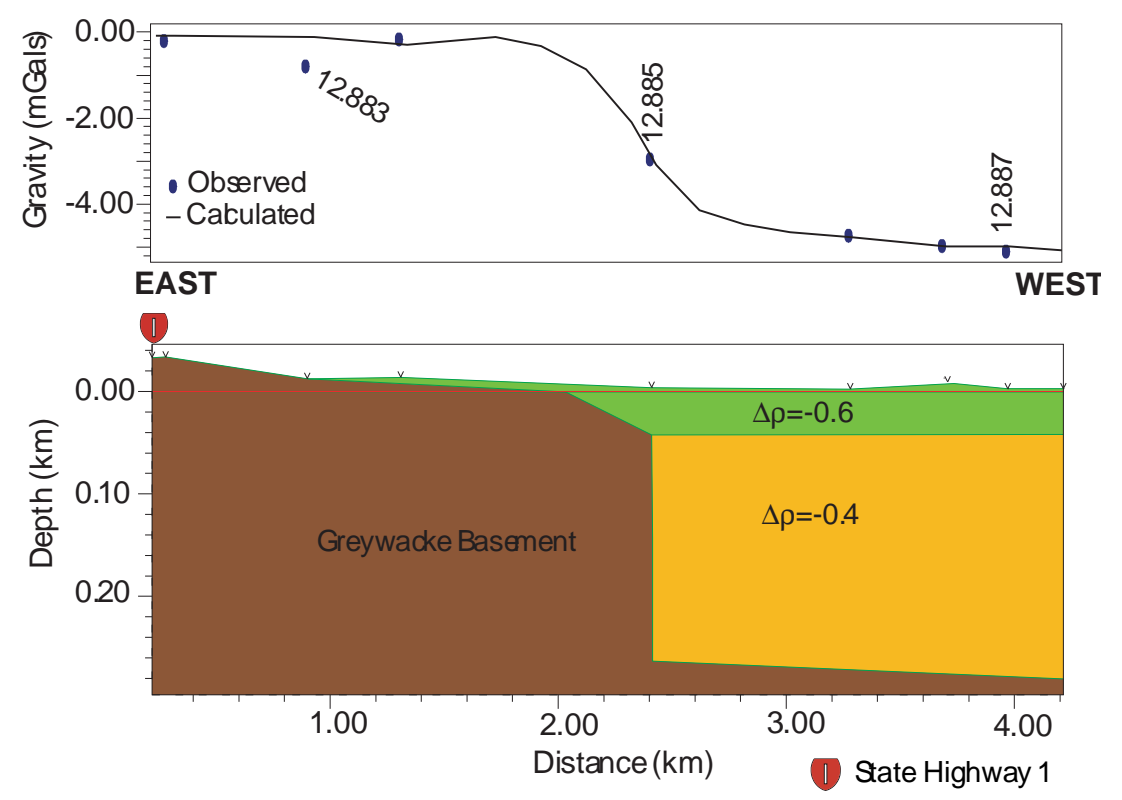

Figure 3.7: Moana Road residual gravity model: top figure shows the residual gravity measurements (blue dots) and the calculated values (black line). Bottom figure represents the corresponding density model. However, this model is poorly constrained due to a lack of data points. Used densities are identical to densities used for model 2 of the Peka Peka profile (figure 3.5). The surrounding material is inferred to be greywacke with a density of $2670 \mathrm{~kg} / \mathrm{m}^{3}$. The zero position on the $\mathrm{x}$-axis is equivalent to the location of SH1. The vertical size of the datapoints represents error bars. Depth is relative to sea level, and there is a vertical exaggeration of 4.7 .

a high-angle structure underneath SH1, but with only around $200 \mathrm{~m}$ of vertical offset. Furthermore, a basement high (depth around $100 \mathrm{~m}$ ) can be seen further to the west, with much smaller lateral extent $(400 \mathrm{~m})$ than in the Peka Peka profile but comparable dips on its flanks. The western flank is slightly steeper $\left(27^{\circ}\right)$ and the eastern flank shows a similar dip.

\subsubsection{Moana Road profile}

The Moana Road profile (blue line, figure 3.3) is the third line perpendicular to the coastline and located around $3.2 \mathrm{~km}$ to the south of the Greenhill Road profile. It consists of 11 datapoints and has an approximate length of $4 \mathrm{~km}$.

To keep the models consistent, the same model parameters are used as for the Peka Peka Road and Greenhill Road profile (see section 3.2.1.1 and 3.2.1.2). Again a high-angle structure is modelled, but this time $2 \mathrm{~km}$ west of SH1. However, this is poorly constrained due to the lack of data between kilometre 1.5 and 3.0. The vertical offset across this feature is approximately $260 \mathrm{~m}$ and the basement to the 


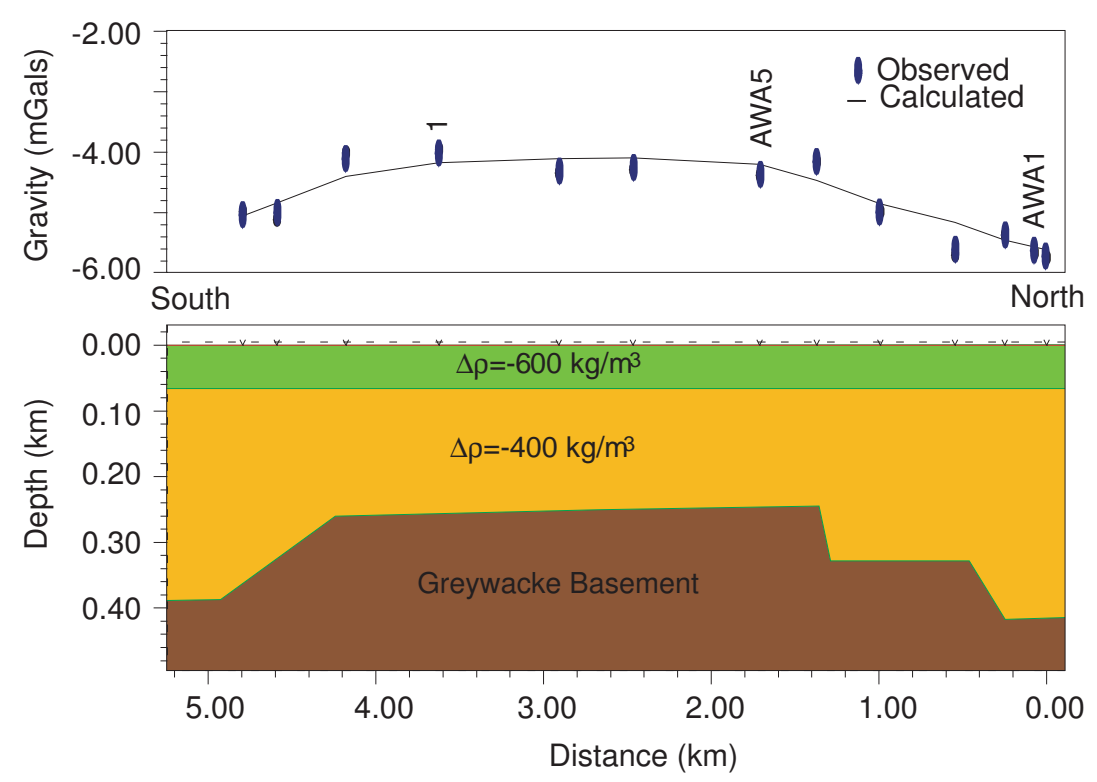

Figure 3.8: Paetawa Road residual gravity model: top figure shows the residual gravity measurements (blue dots) and the calculated values (black line). Bottom figure represents the corresponding density model. Used densities are identical to densities used for model 2 of the Peka Peka profile (figure 3.5). The surrounding material is inferred to be greywacke with a density of $2670 \mathrm{~kg} / \mathrm{m}^{3}$. The zero position on the $\mathrm{x}$-axis is equivalent to the location of the northern-most point of the survey (AWA1). The vertical size of the datapoints represents error bars. Depth is relative to sea level, and there is a vertical exaggeration of 3.8.

west is almost flat with a dip of less than $1^{\circ}$. There is no basement high as seen in the profile lines to the north. East of the high-angle offset the basement is shallow $(<100 \mathrm{~m})$ and it outcrops $600 \mathrm{~m}$ west of SH1.

\subsubsection{Paetawa Road profile}

The Paetawa Road profile (purple line, figure 3.3) runs parallel to the coastline and cuts the other three profile lines perpendicular at their western end. It consists of 13 datapoints, with one point in common with each of the east-west lines. The total length is about $5.6 \mathrm{~km}$.

Again the same model parameters are used as for the three east-west lines (see section 3.2.1.1, 3.2.1.2 and 3.2.1.3). The resulting model shows a flat basement at a depth of $\sim 400 \mathrm{~m}$ on the northern and southern side of the profile. In between it rises to a depth of $\sim 270 \mathrm{~m}$. The northern flank is modelled as a vertical offset $(\sim 120 \mathrm{~m})$ close to the intersection (AWA5) with the Greenhill Road profile. This is done because seismic refraction (section 3.2.5) shows a flat basement at a depth of $400 \mathrm{~m}$ north of AWA5. 


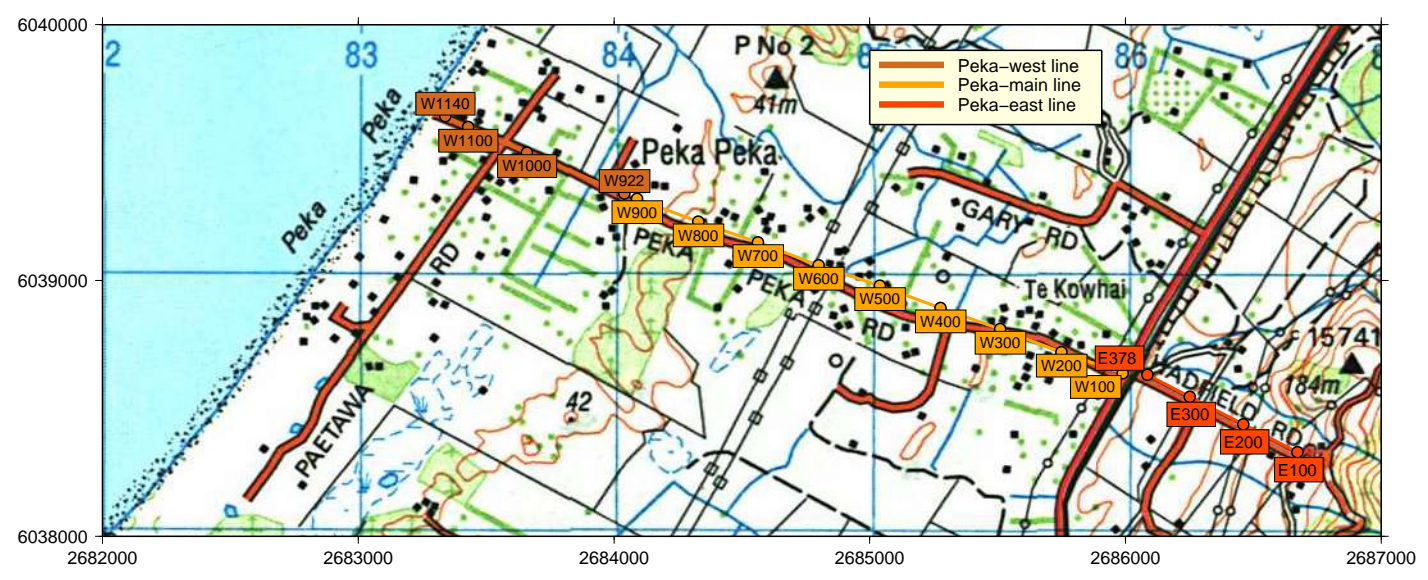

Figure 3.9: Overview of the Peka Peka seismic reflection survey. The experiment was conducted in three parts: Peka-main (gold line), Peka-west (brown line) and Peka-east (orange line). The numbers represent locations of CDP-bins.

\begin{tabular}{|c|c|c|c|}
\hline LINE ID: & Peka-west & Peka-east & Peka-main \\
\hline Source & EG\&G Thumper & Powergel $^{T M} 500 \mathrm{~g}$ & Powergel $^{T M} 500 \mathrm{~g}$ \\
Shot interval & $5 \mathrm{~m}$ & $20 \mathrm{~m}$ & $10 \mathrm{~m}$ \\
Shot depth & $0 \mathrm{~m}$ & $3 \mathrm{~m}$ & $3 \mathrm{~m}$ \\
Geophone spacing & $5 \mathrm{~m}$ & $5 \mathrm{~m}$ & $5 \mathrm{~m}$ \\
Number of geophones & 48 & 48 & 48 \\
Spread & end shots & end shots \& split spread & end shots \\
Min offset & $5 \mathrm{~m}$ & $3 \mathrm{~m} \mathrm{\&} 0 \mathrm{~m}$ & $30 \mathrm{~m}$ \\
Max offset & $26 \mathrm{~m}$ & $265 \mathrm{~m}$ & $265 \mathrm{~m}$ \\
Sampling interval & $1 \mathrm{~ms}$ & $1 \mathrm{~s}$ & $1 \mathrm{~ms}$ \\
Recording length & $2048 \mathrm{~ms}$ & $2048 \mathrm{~ms}$ & $2048 \mathrm{~ms}$ \\
Fold (maximum) & mostly constant (36) & mostly constant (12) & mostly constant (24) \\
\hline
\end{tabular}

Table 3.1: Field parameters for the Peka Peka seismic reflection survey

\subsubsection{Seismic reflection survey along Peka Peka Road}

A $2.4 \mathrm{~km}$ long seismic reflection survey was conducted in the summer of 2004/2005, running east-west along Hadfield and Peka Peka Road (see map in figure 3.9). The seismic line is split in three different sections: Peka-main (yellow line), Peka-west (brown line) and Peka-east (orange line). The eastern-most section (Peka-east) of the survebathymetryy runs from the top of Hadfield Road westwards to SH1. It consists of 37 explosive shots, fired in a distance of $20 \mathrm{~m}$. For Peka-main, which had 182 explosive shots, the shot spacing is decreased to $10 \mathrm{~m}$ and it runs from SH1 westwards for around $2 \mathrm{~km}$. The third section (Peka-west) is an extension of the Peka-main with a small overlap of $100 \mathrm{~m}$ close to CDP 920. An EG\&G hydraulic thumper (see appendix A) was used as a seismic signal generator for the third section and 150 shots were fired. Due to the smaller seismic 
energy of the source and much lower cost per shot, the shot spacing was further decreased to $5 \mathrm{~m}$. Along the whole length of the line the geophone spacing was $5 \mathrm{~m}$ and for most shots in Peka-main and Peka-east the minimum offset is $30 \mathrm{~m}$. Because of logistical problems it was not possible to shoot Peka-west with a constant minimum offset and most shots were done with a split-spread geometry. An overview of the field parameters can be found in table 3.1.

\subsubsection{Interpretation}

The interpretation of the seismic section is done by correlating the main reflection events across the profile. Information obtained by gravity modelling (section 3.2.1.1) and seismic refraction analysis (section 3.2.4) is used to give additional control to the seismic interpretation and vice versa.

Due to the different seismic signal sources used, each segment is interpreted individually and the individual parts are joined afterwards. The final section and its interpretation are presented in figure 3.10. A timeshift is applied to align Peka-east on the eastern side of SH1, due to a different processing datum. The joining point of sections Peka-main and Peka-west is around CDP W910. Pekawest is shot with a smaller minimum offset, and therefore shallower events are visible.

The different seismic horizons are defined by the reflection characteristics, amplitude, continuity and frequency. A termination of such a reflector could indicate a fault location. However, faults can also be indicated by diffractions that arise from subsurface edges and dip divergences not related to stratigraphy.

The seismic section (figure 3.10) has an overall low signal-to-noise ratio and a minor penetration of the seismic signal. A thick layer of dune sands at the surface could produce this high seismic attenuation. SH1, a road with a high traffic load, could be partly responsible for the low signal-to-noise ratio, especially for CDPs east of CDP W300. However, this part of the section is shot with a split-spread geometry, so that the shotgathers are contaminated by ground-roll. Contrary to expectations, the section using the hydraulic thumper as a source (Peka-west) shows a higher signal-to-noise ratio and deeper reflectors than the section shot with explosives (Peka-main). This is most likely because of a much higher fold of the seismic data (shot spacing $5 \mathrm{~m}$ compared to a shot spacing of $20 \mathrm{~m}$ for line Peka-main). Also the frequency characteristic of the hydraulic thumper could be more suitable for the present case.

In the section westwards of CDPW300 continuous reflectivity is observed down to $300 \mathrm{~ms}$ and down to $500 \mathrm{~ms}$ at the Peka-west section at the western end of this line. For the CDPs east of CDP W200 there is almost no continuous reflectivity visible. 


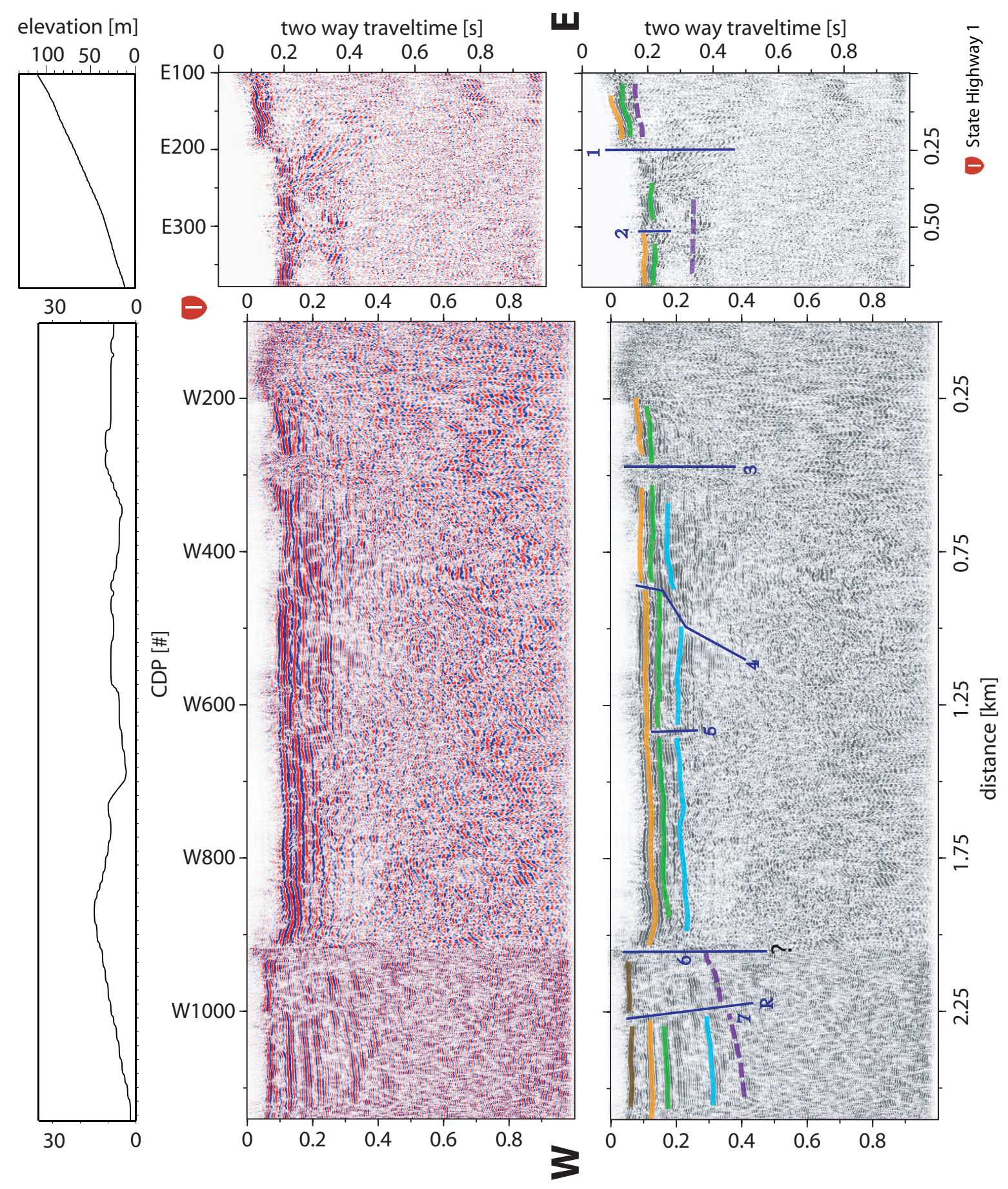

Figure 3.10: Final time-migrated section of the Peka Peka line. The panel in the middle shows the uninterpreted section and the bottom panel shows the interpreted section. CDP spacing is $2.5 \mathrm{~m}$. The eastern section is along Hadfield Road, the long western section runs along Peka Peka Road. It has to be noted that at around CDP 920 the seismic signal source changes. The top panel displays the elevation along the profile. Note the correlation of some of the fault location with surface elevation features. 
At the section on the eastern side of SH1, between CDPE100-E200, there is only a thin band of reflectivity from 100-150 ms TWTT. For CDP E200-E370 there are two bands of high reflectivity visible, one $50 \mathrm{~ms}$ wide between $180-230 \mathrm{~ms}$ and another one between 300 and $400 \mathrm{~ms}$.

Identifying the observed reflectors is done qualitatively by using the reflector characteristics, because no drillhole data are available. Five main seismic reflectors are picked, correlated and labelled from top to bottom. A description of the different events follows:

Reflector-1 (brown) is the top reflector for CDPs west of W1010. It is only traceable at this section of the profile because of the different shot geometry used. It has a small displacement at CDP W1010. The TWTT for this reflector is approximately $80 \mathrm{~ms}$.

Reflector-2 (orange) is the top reflector between CDPW200-W920 and CDPE100-E370. It has the highest amplitude and can be traced almost through the entire profile. However, it is not visible for CDPs east of W200. For CDPs west of W920 it is located below the brown reflector but with a better coherence. The orange reflector has a TWTT of about $100 \mathrm{~ms}$ and three major offsets close to CDP E200, CDP W920 and at CDPW1010. The horizon is mostly flat and only shows a slight dip east of CDP E200.

Reflector-3 (green) marks the bottom of the band of high-amplitude reflectivity. It is subparallel to Reflector-2 and can be traced in the same area. However, it is not as continuous and slightly less coherent. An offset in the horizon can be seen at the same CDP location as in the reflector above and additionally a significant offset at CDP W450 is visible. The TWTT for this reflector is approximately $250 \mathrm{~ms}$.

Reflector-4 (light blue) has similar characteristic as the reflectors above but with a smaller amplitude. It has a slightly larger dip east of CDP W920 than the green reflector.

Reflector-5 (dashed purple): Typically greywacke basement reflectors in the SWB are irregular, undulating, low frequency events [Anderton, 1981]. Such a reflector is hard to identify in this seismic section. Its possible position on the profile is marked for CDPs west of W920. Offsets at faults cannot be estimated with confidence. West of CDP W920 the horizon is dipping to the west. It can be traced at the eastern section of the profile with an offset of around 170 ms east of CDP E200.

At least seven faulting structures can be identified and all apart from one can be described as high-angle/vertical faults. Most faults offset the horizons only minor, with the exception of Fault-1 (CDPE250), named Hadfield Fault (pers. com. A. Edwards). This feature offsets the orange horizon by $125 \mathrm{~ms}$ and ruptures all the way to the surface (see figure 3.11). Such a time-offset corresponds 


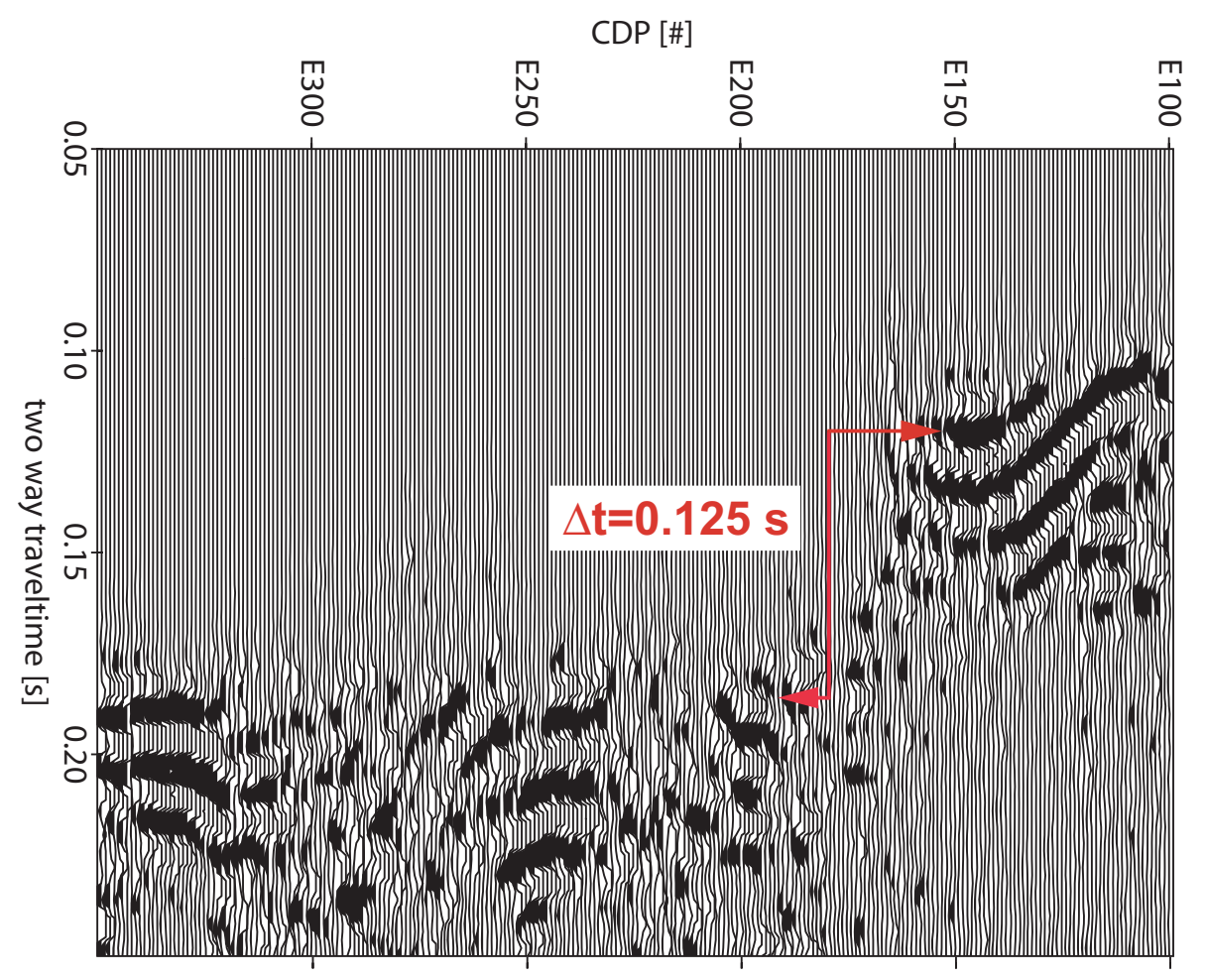

Figure 3.11: Detailed view of the top part of the seismic image of Hadfield Fault (CDP E200). There is an offset of around $125 \mathrm{~ms}$ for the top reflector. This fault is located $\sim 450 \mathrm{~m}$ east of $\mathrm{SH} 1$.

to a $125 \mathrm{~m}$ offset assuming an average P-wave velocity of $2000 \mathrm{~m} / \mathrm{s}$. Fault- 4 under CDP W450 has two different segments to it, shows normal faulting sense and offsets also the shallowest horizon. At CDP W620 (Fault-5) another vertical fault is visible, which does not seem to reach the surface. The proposed fault around CDP 920 (Fault-6) is difficult to analyse because it is the join between the sections Peka-main and Peka-west of the profile line. However, the horizons in both sections are dipping to opposite directions, indicating some kind of movement within this zone. The western most fault (Fault-7) is interpreted as a steep angle reverse fault, which again seems to be a recent feature with displacements of the shallowest horizons.

\subsubsection{Seismic tomography method}

All seismic reflection shots conducted along Peka Peka and Hadfield Road were additionally recorded on a spread which was static for the entire experiment. This spread has a geophone spacing of $50 \mathrm{~m}$ with the first receiver located at CDP W187 on Peka Peka Road (see map in figure 3.9). It consists of 48 receivers and covers a total length of $2400 \mathrm{~m}$. The last geophone is located at the intersection of Peka Peka and Paetawa Road at CDP 1025. Shots fired on the eastern side 


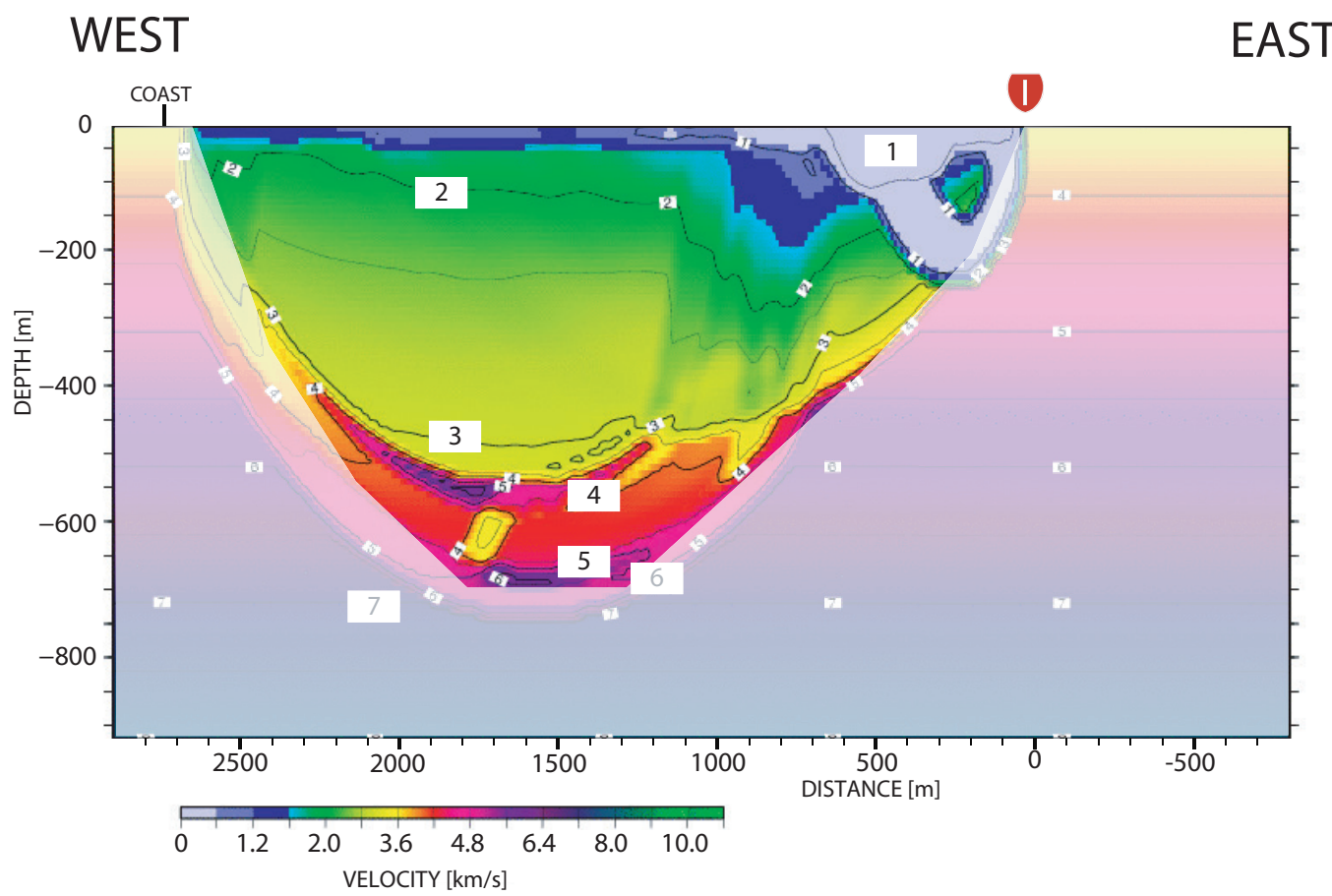

Figure 3.12: Velocity model generated using John Hole's backprojection tomography method [Hole \& Zelt, 1995; Vidale, 1990]. Data are only usable west of SH1 along Peka Peka Road. A distinct low-velocity feature underneath SH1 at the eastern edge of the profile is visible. The curved shape of the model is an artefact of the method (see text). The area which is insufficiently covered by rays is masked out. A strong velocity gradient indicates basement at around $500-600 \mathrm{~m}$ between 1000 and $1700 \mathrm{~m}$ along the profile.

of SH1 show no clear arrivals and so only shots from the western side could be included. There were 113 shots usable and 1900 traces showed clear first breaks which could be picked and further processed.

The data recorded with this 'static line' of receivers are used to create a smooth velocity model of the subsurface. Traveltimes of the first breaks provide the input for the applied John Hole's backprojection tomography approach [Hole \& Zelt, 1995; Vidale, 1990]. This is an inversion method that uses a 3-D finite-difference algorithm to trace the rays from the receiver to the shot and calculate the corresponding traveltimes. Then it compares these with the actual traveltimes and automatically updates the velocity field. Figure 3.12 shows the results from this approach.

The unusual curved shape of the velocity model is an artefact of the method; it represents the raypath of the widest possible rays. The length-to-depth relation of the survey is not ideal for this method. However, a few observations can be made. 

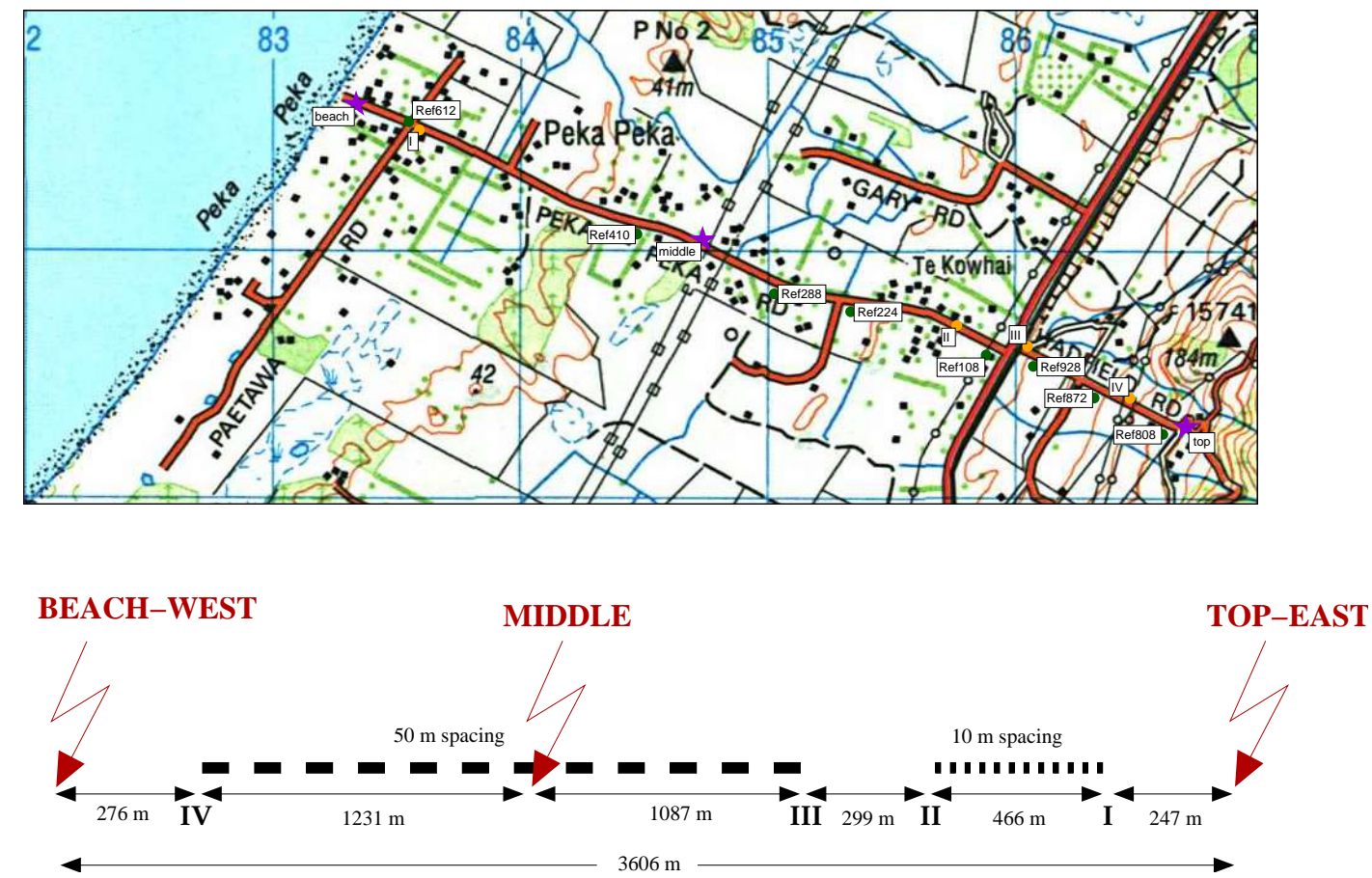

Figure 3.13: (Top) Location map of the east-west survey and (bottom) a sketch of the survey geometry. Purple stars indicate the location of the shots, yellow points represent the start and end point location of the two different recording lines, green points show the location of reflection shots used to create a near-surface velocity model. NOTE: Geometry sketch is not true to scale.

In an area between 1000 and $1700 \mathrm{~m}$ along the profile a high velocity gradient at a depth of around $400 \mathrm{~m}$ indicates the boundary between sediments and basement. Furthermore, there is a distinctive zone of low-velocity $(\sim 1 \mathrm{~km} / \mathrm{s})$ close to the surface (light blue, blue). It has constant thickness of $20-30 \mathrm{~m}$ in the western part of Peka Peka Road and thickens up to $200 \mathrm{~m}$ towards SH1 in the eastern part. Its eastern extent cannot be further established.

\subsubsection{Seismic refraction method: East-west profile}

Three large shots $\left(5 \mathrm{~kg}\right.$ Powergel $\left.{ }^{T M}\right)$ were used as sources for the seismic refraction survey conducted along Peka Peka Road. There were two end-shots, one located at the eastern end of Hadfield Road, the other one at the western end of Peka Peka Road. The third shot was a split-spread shot, located approximately half way between the two end shots (see map figure 3.13). These shots were recorded on two 48-channel recording systems with $50 \mathrm{~m}$ and $10 \mathrm{~m}$ geophone spacing, respectively. For the exact geometry setup and location information see figure 3.13 . 


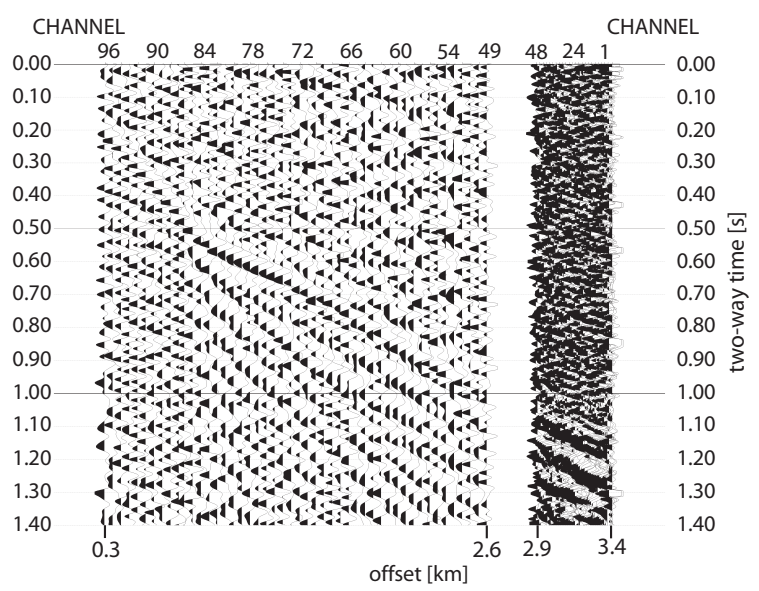

(a) western end-shot

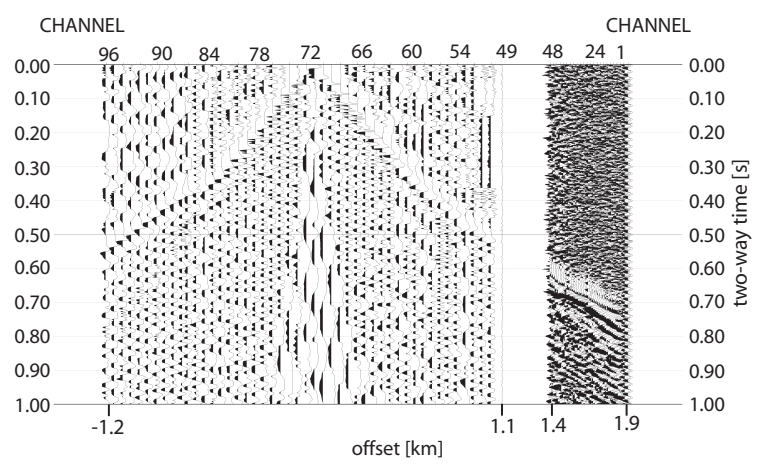

(b) mid-shot

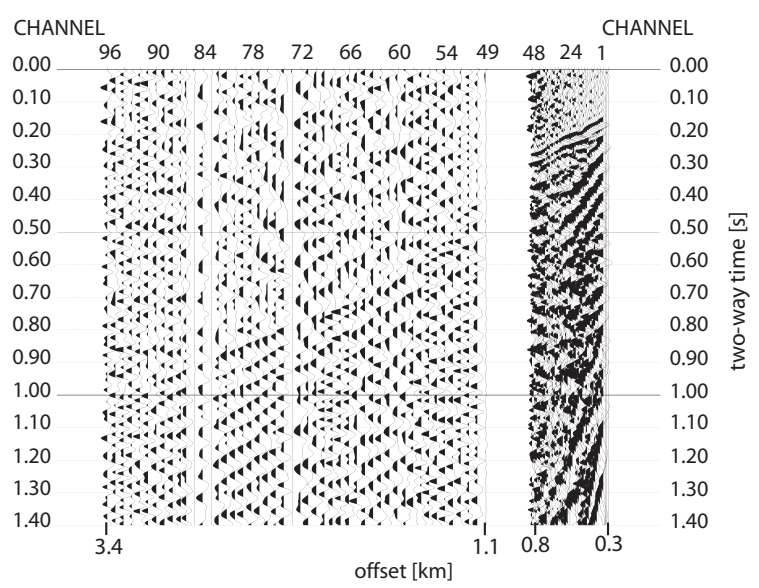

(c) eastern end-shot

Figure 3.14: Raw refraction shotgathers. The offset for channel $1-48$ is $10 \mathrm{~m}$ and $50 \mathrm{~m}$ for channel 49-96. a) Shot at the western end of Peka Peka Road, c) shot at the eastern end of Hadfield Road and b) shot deployed approximately in the middle between the two end shots. For exact survey geometry and shot locations see figure 3.13 
The raw seismic records for the three shots are presented in figure 3.14, with the traces plotted relative to their offset from the shot. All shotgathers show refraction arrivals for almost all channels. The mid-shot (figure 3.14(b)) has the highest signal-to-noise ratio with clear arrivals. For the shot on top of Hadfield Road (figure 3.14(c)) the signal-to-noise ratio is much lower, but first breaks can be identified on $90 \%$ of the channels. In the shotgather from the western end additional to the refraction arrival a clear reflection arrival can be identified (TWT $\sim 400 \mathrm{~ms}$ at channel $88-96$ ). The moveout velocity of this reflection is $\sim 2000 \mathrm{~m} / \mathrm{s}$. The minimum offset for both endshots are similar $(\sim 260 \mathrm{~m})$, but only the beachshot shows a direct wave arrival.

\subsubsection{Intercept-time analysis}

The intercept-time method for the analysis of refraction data is a standard tool to construct a velocity model of the subsurface [e.g. Telford et al., 1990]. However, there are some assumptions to be made when using this method. It assumes isovelocity layers and an increase of velocity with depth. The principles and theory of this method are discussed in more detail in appendix A.2.

Near surface velocity model In the refraction dataset, direct arrivals are identified for the mid-shot and the beach-shot. In order to check and quantify the near surface velocity, a refraction analysis of data recorded on the "moving" small offset seismic reflection spread is undertaken. Seven shotgathers, three located at Hadfield Road and four located along Peka Peka Road, with a high signal-tonoise ratio were chosen to investigate the lateral velocity behaviour of the near surface. Figure 3.15 shows examples of two raw shotgathers. The observed velocities and intercept times as well as the resulting layer thicknesses are summarised in table 3.2. A $30 \mathrm{~m}$ minimum offset was used for most of the reflection shots. Only for three shotgathers (shot position 808, 108, 612) with a smaller minimum offsets, is the direct wave arrival observed. Thus, constant lateral velocity behaviour for the top layer has to be assumed.

The interpretation is divided into two parts; the eastern side of SH1 (Hadfield Road) and the western side along Peka Peka Road. For the western side all shots are fired in one direction and no statement can be made about the dip of the layers. In contrast shot 808 and 872/928 at Hadfield Road are facing in different directions and a dip analysis is possible.

The analysis for the Peka Peka Road profile indicates a thin $(\sim 10 \mathrm{~m})$ top layer with an average velocity of $960 \pm 60 \mathrm{~m} / \mathrm{s}$, which thickens slightly $\left(\operatorname{dip}=1^{\circ}\right)$ to the west. The velocity of the second refractor decreases laterally to the west, which could indicate a change in dip along the line, or a lateral increase in velocity. This cannot be decided with unidirectional shots. At shot location 108 the top layer 


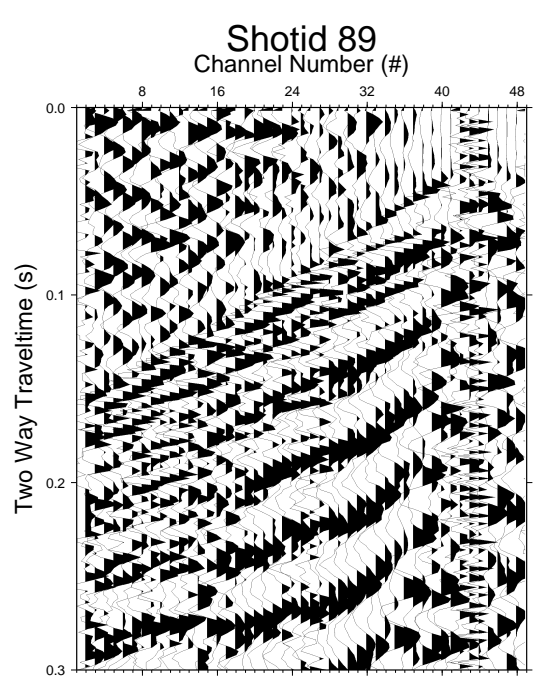

(a) shot location 89

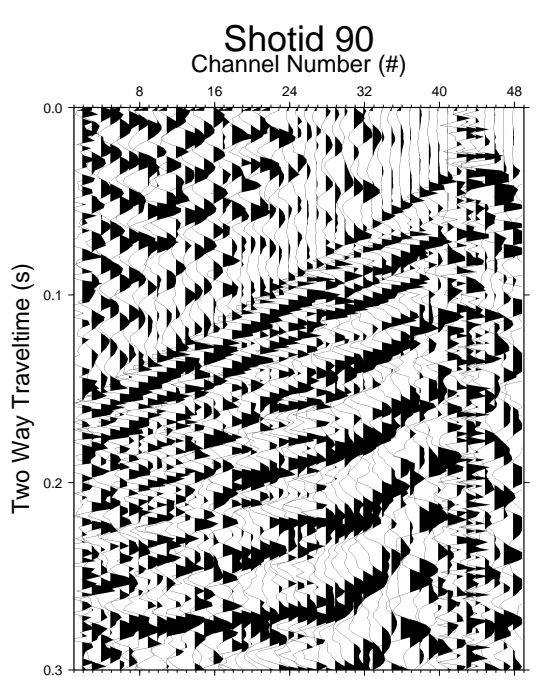

(b) shot location 90

Figure 3.15: Raw shot records from Peka Peka Road seismic reflection survey, located at the intersection of Paetawa Road and Peka Peka Road (see map figure 3.13). Geophone spacing is $5 \mathrm{~m}$, with variable minimum offset.

seems to be thicker and the second layer has significant higher velocity. However, the top low-velocity layer is not as thick as predicted by seismic tomography results (see section 3.2.3).

Along Hadfield Road, dipping layers are inferred due to different refraction velocities in different shot directions. Eastwards directed shots result in a velocity of around $1800 \pm 40 \mathrm{~m} / \mathrm{s}$, whereas westwards shots give an average velocity of $1610 \pm 90 \mathrm{~m} / \mathrm{s}$ for the refractor. This indicates a dip of about $2^{\circ}$ to the east relative to the surface. The thickness of this layer is around $23 \mathrm{~m}$ at the top of Hadfield Road with a velocity of $690 \pm 40 \mathrm{~m} / \mathrm{s}$. The calculated real velocity of the second layer $\left(\mathrm{V}_{2, \text { real }}=2400 \pm 50 \mathrm{~m} / \mathrm{s}\right)$ is significantly higher than the velocity of the second layer along Peka Peka Road.

Refraction data intercept-time analysis Figure 3.14 shows the raw refraction shot data. The first breaks were picked without filtering or any other processing, as this could distort or time-shift the first arrivals [Yilmaz, 1987]. This is possible, because the first breaks were visible on all channels for the west-shot and for the mid-shot. However, for the shot fired at the eastern end, without processing first breaks are only visible on $90 \%$ of the channels but for consistency no processing is applied. 
Chapter 3. Shallow seismic and gravity methods

\begin{tabular}{|c|c|c|c|c|}
\hline \multicolumn{5}{|c|}{ assuming flat top layer along Peka Peka Road } \\
\hline $\begin{array}{c}\text { Shot } \\
\text { position }\end{array}$ & $\begin{array}{c}\text { Direct wave } \\
\text { velocity }(\mathrm{m} / \mathrm{s})\end{array}$ & $\begin{array}{l}\text { first refractor } \\
\text { velocity }(\mathrm{m} / \mathrm{s})\end{array}$ & $\begin{array}{c}\text { first refractor } \\
\text { intercept time (s) }\end{array}$ & $\begin{array}{l}\text { thickness } \\
\text { layer } 1(\mathrm{~m})\end{array}$ \\
\hline 108 & $920 \pm 50$ & $1800 \pm 40$ & $0.018 \pm 0.004$ & $10 \pm 2$ \\
\hline 224 & & $1560 \pm 30$ & $0.011 \pm 0.003$ & $6 \pm 1$ \\
\hline 288 & & $1600 \pm 20$ & $0.016 \pm 0.001$ & $8 \pm 1$ \\
\hline 410 & & $1640 \pm 10$ & $0.024 \pm 0.001$ & $13 \pm 1$ \\
\hline 612 & $1000 \pm 20$ & $1660 \pm 20$ & $0.026 \pm 0.001$ & $16 \pm 1$ \\
\hline \multicolumn{5}{|c|}{ assuming dipping top layer along Hadfield Road } \\
\hline $\begin{array}{c}\text { Shot } \\
\text { position }\end{array}$ & $\begin{array}{c}\text { Direct wave } \\
\text { velocity }(\mathrm{m} / \mathrm{s})\end{array}$ & $\begin{array}{l}\text { first refractor } \\
\text { velocity }(\mathrm{m} / \mathrm{s})\end{array}$ & $\begin{array}{c}\text { first refractor } \\
\text { intercept time (s) }\end{array}$ & $\begin{array}{l}\text { thickness } \\
\text { layer } 1(\mathrm{~m})\end{array}$ \\
\hline 808 & $690 \pm 40$ & $2140 \pm 30$ & $0.026 \pm 0.005$ & $23 \pm 3$ \\
\hline 872 & & $2730 \pm 80$ & $0.045 \pm 0.002$ & \\
\hline 928 & & $2740 \pm 40$ & $0.031 \pm 0.008$ & $40 \pm 7$ \\
\hline
\end{tabular}

Table 3.2: Summary of velocities, intercept times and calculated thicknesses of the first layer (equation A.10), using first break picks from the reflection shots. The direct arrival is only visible for shot position 108 and 612. All other shots only show the refraction arrival from first interface. The calculated thicknesses indicate a small dip of the first layer of less than $1^{\circ}$.

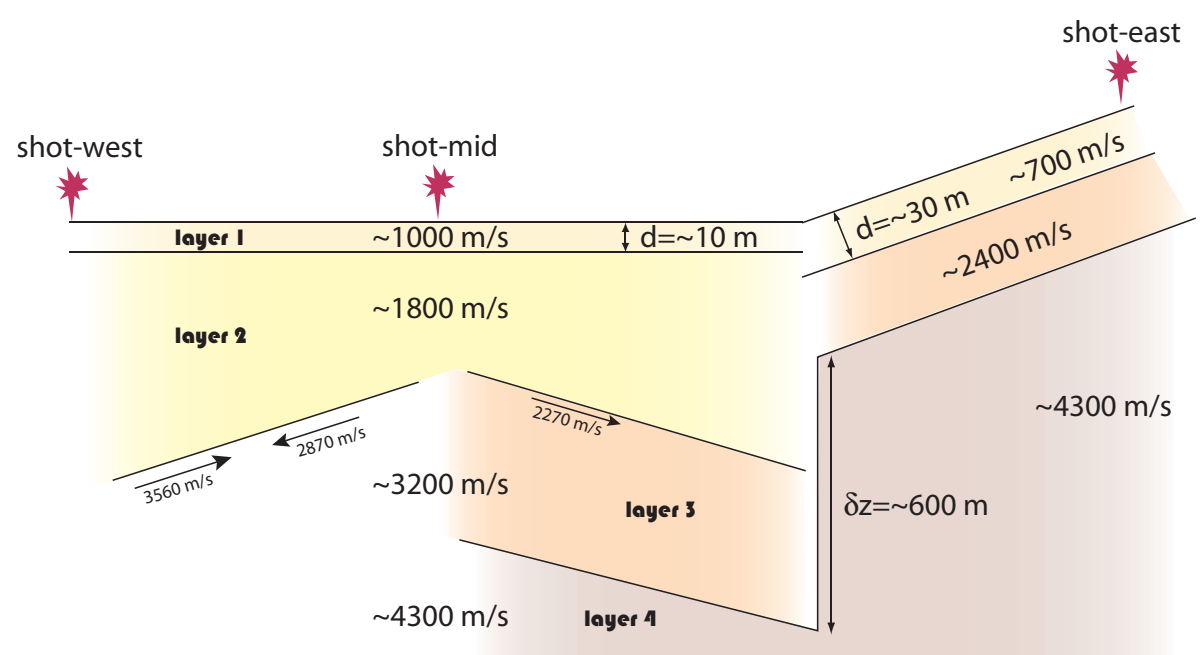

Figure 3.16: Sketch of the velocity model established by applying the intercepttime analysis method to the Peka Peka refraction profile data. Values underneath arrows indicate down and updip velocities from different shot directions, respectively. NOTE: Sketch is not true to scale.

Figure 3.16 gives a summary of all velocities found within the different shotgathers and a sketch of the proposed subsurface model. A detailed discussion of the results follows below. 


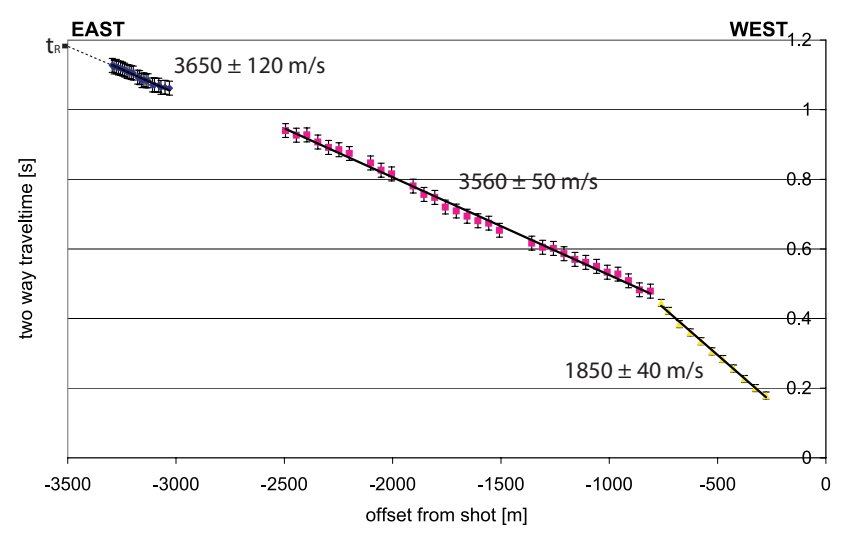

(a) western shot at beach

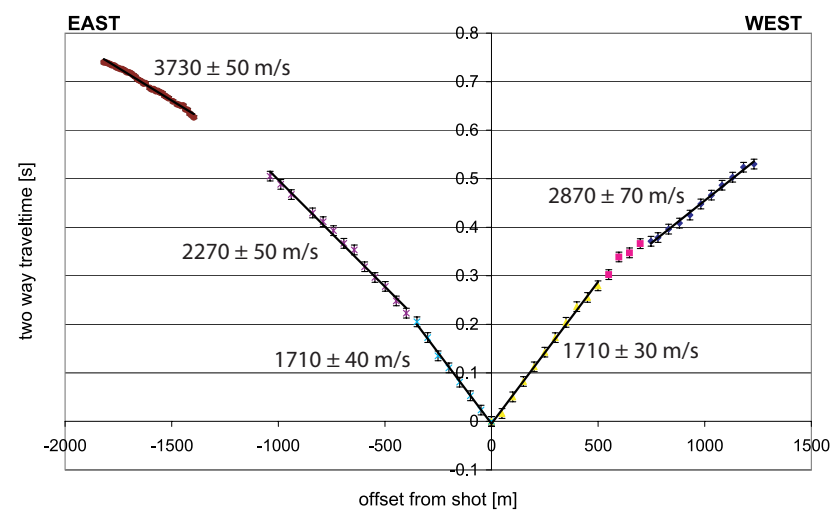

(b) mid-shot

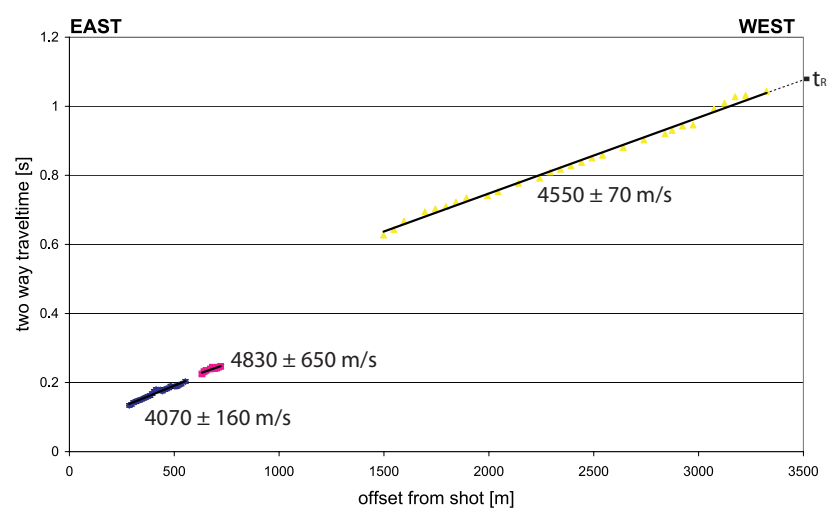

(c) eastern shot at top of Hadfield Road

Figure 3.17: Time-distance plot for the three refraction shots of the Peka Peka survey. Three different slopes are proposed for the eastern-shot (a), three are proposed for the mid-shot in eastern direction and two in western direction (b). The western shot (c) shows two different slopes with a large time offset between them. The shotpoint-to-shotpoint traveltime (reciprocal time, $t_{R}$ ) is almost identical for both endshots. This indicates that the arrival times are picked correctly. All datapoints show error bars. 


\begin{tabular}{|rll|}
\hline top layer velocity & $:$ & $\mathrm{V}_{1}=1710 \pm 30 \mathrm{~m} / \mathrm{s}$ \\
velocity layer 2 WE direction & $:$ & $\mathrm{V}_{2-\text { up }}=3560 \pm 50 \mathrm{~m} / \mathrm{s}$ \\
velocity layer 2 EW direction & $:$ & $\mathrm{V}_{2-\text { down }}=2870 \pm 70 \mathrm{~m} / \mathrm{s}$ \\
intercept time WE direction & $:$ & $\mathrm{t}_{i-\text { up }}=0.244 \pm 0.06 \mathrm{~s}$ \\
intercept time EW direction & $:$ & $\mathrm{t}_{i-\text { down }}=0.106 \pm 0.01 \mathrm{~s}$ \\
& $\Rightarrow$ & \\
real velocity second layer & $:$ & $\mathrm{V}_{2-\text { real }}=3170 \pm 210 \mathrm{~m} / \mathrm{s}$ \\
dipping angle & $:$ & $\alpha=4 \pm 1^{\circ}$ \\
thickness layer 1 under middle shot & $:$ & $\mathrm{d}_{1-\text { middle }}=110 \pm 40 \mathrm{~m}$ \\
thickness layer 1 under western shot & $:$ & $\mathrm{d}_{1-\text { west }}=250 \pm 30 \mathrm{~m}$ \\
\hline
\end{tabular}

Table 3.3: Intercept-time analysis - allowing for dipping layers. Different velocities for the southern and northern shot indicate a dipping top layer. Dip angle is calculated to $\alpha=4 \pm 1^{\circ}$

The time-distance plot for the western shot (figure 3.17(a)) shows two distinct different slopes. One which is interpreted as a direct arrival, with a velocity of $1850 \pm 40 \mathrm{~m} / \mathrm{s}$ (ignoring the low-velocity layer) and one with a velocity of $3600 \pm 120 \mathrm{~m} / \mathrm{s}$, interpreted as the refraction from the top of layer 2 (figure 3.16).

Analysis of the mid-shot shows comparable velocity of the direct arrival with $1710 \pm 40 \mathrm{~m} / \mathrm{s}$, but the refraction velocity on the branch towards the west shows a significant lower velocity $(2870 \pm 70 \mathrm{~m} / \mathrm{s})$ than the observed refraction velocity on the east-shot. This could indicate a west dipping layer. However, the velocity of the branch to the east has an even smaller velocity, indicating a dipping layer to the east. Thus, the top of layer 2 could dip away in both directions underneath the mid-shot or the first breaks originate from a different layer. It appears that the mid-shot is located above a horst structure, which is also in agreement with the gravity data collected along this profile (see section 3.2.1). Consequently, the dip between the mid-shot and the western end is calculated (table 3.3) to be $4^{\circ}$ with a depth under the western end of $248 \mathrm{~m}$. The calculated real velocity $(3170 \pm 210 \mathrm{~m} / \mathrm{s})$ of this layer is too small for a basement refractor.

The time-distance plot for the east-shot (figure 3.17(c)) shows two segments with almost the same slope but significantly different intercept times. This is most likely caused by a step discontinuity along the refractor. To get an approximate idea of the size of the step, flat horizons are assumed, which permits a calculation of the offset by means of equation A.14 (appendix A). Using the calculated real velocity of $2400 \pm 50 \mathrm{~m} / \mathrm{s}$ for the second layer along Hadfield Road and an estimated basement velocity of $4500 \pm 50 \mathrm{~m} / \mathrm{s}$ the step of the basement refractor can be calculated to $\delta \mathrm{z}=600 \pm 200 \mathrm{~m}$. The error bar for this value is large due to the many uncertainties and assumptions underlying the calculation.

The intercept-time analysis method is mainly for planar horizontal or uni- 
formly dipping layers with no lateral velocity inhomogeneities. This assumption is not fulfilled along the whole profile, but it can be used for some parts of the profile and the method provides anchor points for the forward raytracing modelling (section 3.2.4.2).

\subsubsection{Raytracing}

The model developed with the raytracing approach (MacRay ${ }^{T M} 2.0$, see appendix A.2.3) consists of three layers, with a velocity of around $1100 \mathrm{~m} / \mathrm{s}$ for the top layer, $2500 \mathrm{~m} / \mathrm{s}$ for the second layer and $4300 \mathrm{~m} / \mathrm{s}$ for the surrounding basement layer. In the best fitting model (see figure 3.18) the top layer is around $100 \mathrm{~m}$ thick and has a slight dip to the west. The basement interface shows a horst-like structure with the top of the horst ( $200 \mathrm{~m}$ deep) located between kilometre 2 and 2.7 along the profile. The flank on the western side of the basement high is steeper $\left(\sim 36^{\circ}\right)$ than the flank on eastern side $\left(\sim 15^{\circ}\right)$. Both flanks are dipping away from the basement high with a similar offset of around $200-250 \mathrm{~m}$. A vertical feature, $450 \mathrm{~m}$ east of SH1, offsets the basement by around $450 \mathrm{~m}$. This offset is considerable and is close to the location of the large offset fault mapped underneath Hadfield Fault from seismic reflection profiling (section 3.2.2) and gravity modelling (section 3.2.1.1). In the raytracing approach the fault is again modelled as a vertical feature as both a high-angle vertical and a high-angle normal fault could match the data. East of the Hadfield Fault the basement runs parallel to the surface for a distance of $100 \mathrm{~m}$. More about a possible surface break of the high offset structure $(\sim 100 \mathrm{~m})$ and its relation to the mapped strike-slip Hadfield Fault can be found in section 3.2.6.

A comparison with the results from the intercept-time analysis shows a similar basement structure but a different velocity for the second layer. This could be explained by the incomplete coverage of the dipping refractor. Thus, the apparent updip and downdip velocities used in table 3.3 are derived from different segments which could have different slopes or could actually result from different refractors. However, the results from the forward raytracing are in good agreement with the tomography results (section 3.2.3) and with velocities derived from the crossline (section 3.2.5). Therefore, the velocity model in figure 3.18 is accepted as the final velocity model along Peka Peka Road.

\subsubsection{Seismic refraction method: North-south profile}

Additional to the east-west refraction profile (section 3.2.4), a second refraction survey was conducted perpendicular to Peka Peka Road, along Paetawa Road (see map in figure 3.13). Two shots ( $5 \mathrm{~kg}$ of Powergel ${ }^{T M}$ ) were deployed; one at the northern end of the road, the other one $\sim 1400 \mathrm{~m}$ to the south. The recording 


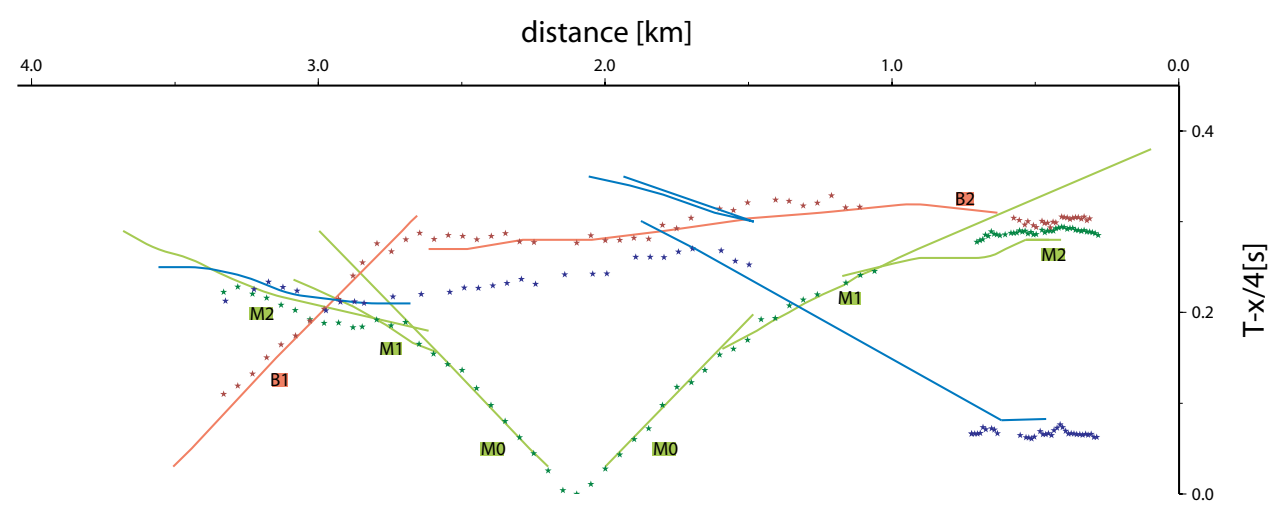

(a)

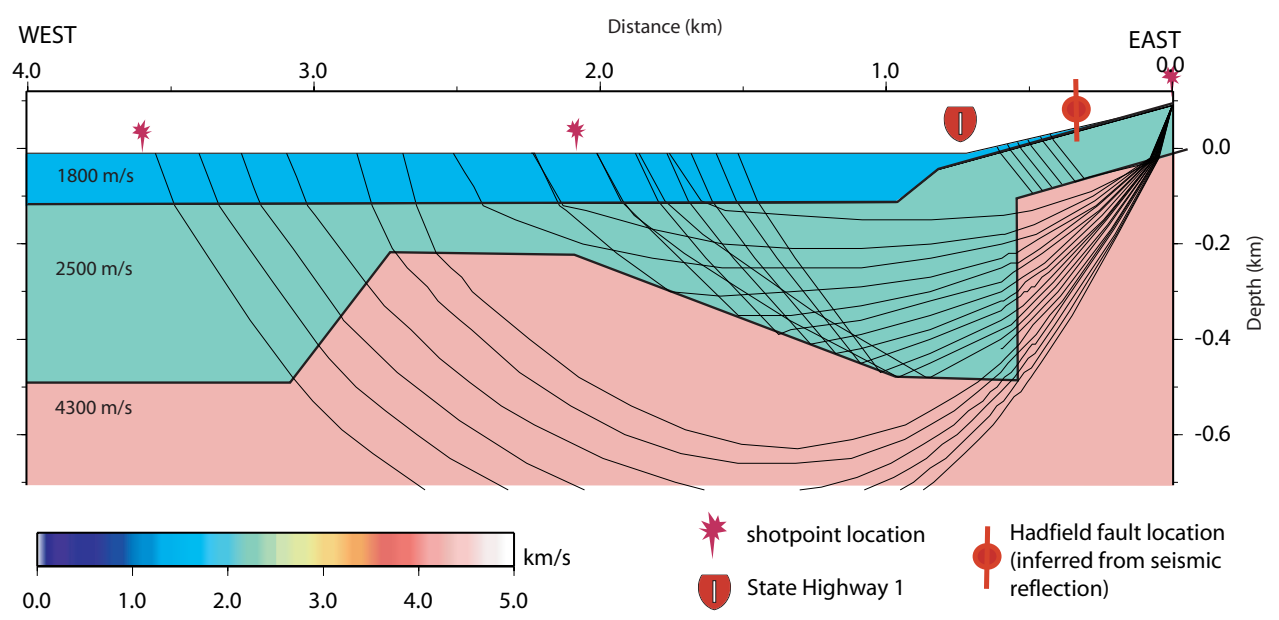

(b)

Figure 3.18: Velocity model generated using forward raytracing software MacRay ${ }^{T M}$. The final velocity model corresponds well to the result of the gravity modelling. It has an upper low-velocity layer $\left(V_{p}=1100 \mathrm{~m} / \mathrm{s}\right.$, sand and loose gravel) underlain by a layer with a considerable higher velocity $\left(V_{p}=2500 \mathrm{~m} / \mathrm{s}\right)$, surrounded by an average basement material velocity $\left(V_{p}=4300 \mathrm{~m} / \mathrm{s}\right)$. The labelling of different segments is done according to shot location and refraction interface, e.g., M2 is the segment of first breaks originating from the mid-shot and refracted at interface 2 . Velocities are similar to the velocity proposed for shallow structures in New Zealand by Sissons \& Dibble [1981].

is done with two 48-channel recording systems with $6.5 \mathrm{~m}$ and $12 \mathrm{~m}$ geophone spacing, respectively. For the exact geometry setup and location information see figure 3.19.

Figure 3.20 shows the seismic raw records for the two shots. The traces are plotted relative to their offset from the shots. A clear first break is visible on all shots for all offsets, but the minimum offsets are too large to record arrival from first direct waves. 

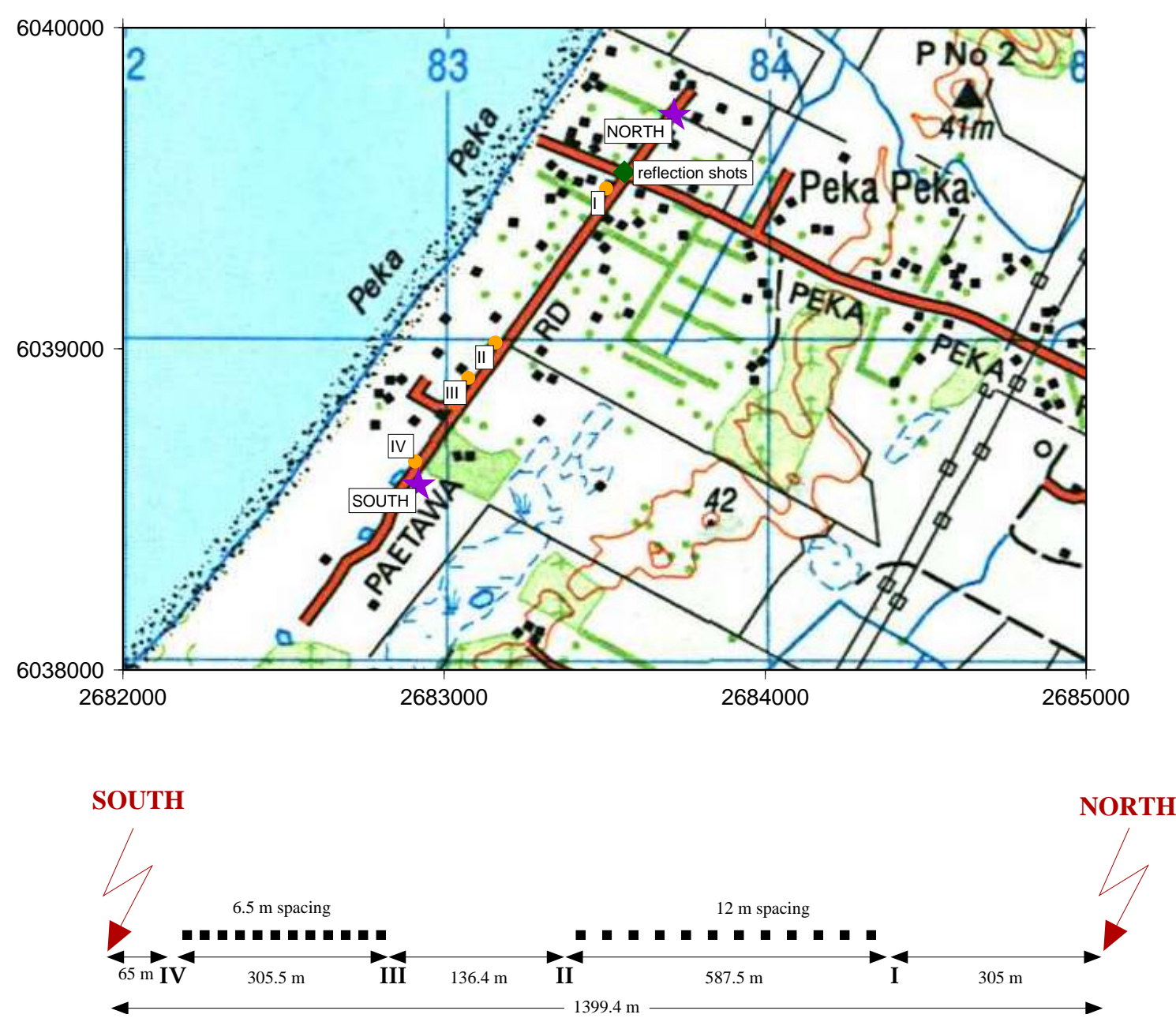

Figure 3.19: (Top) Location map of the north-south survey and (bottom) sketch of the survey geometry. Purple stars indicate the location of the shots, yellow points represent the start point and end point location of the two different recording lines. The green point marks the location of the reflection shots used to estimate the near surface velocity. NOTE: Geometry sketch is not true scale.

\subsubsection{Intercept-time analysis}

Refraction data intercept-time analysis In north-south direction a reflection profile with small offsets, which could be used to establish a near surface velocity model is lacking. However, the north-south profile intersects with the east-west profile and therefore a constant near surface velocity model which is similar to the east-west model can be assumed (see table 3.4 for velocities and thicknesses of the model).

A high signal-to-noise ratio for the raw shotgathers (figure 3.20) makes it possible to pick all first breaks without filtering or any other processing. The timedistance plot for the northern shot (figure 3.21) shows three different slopes with 


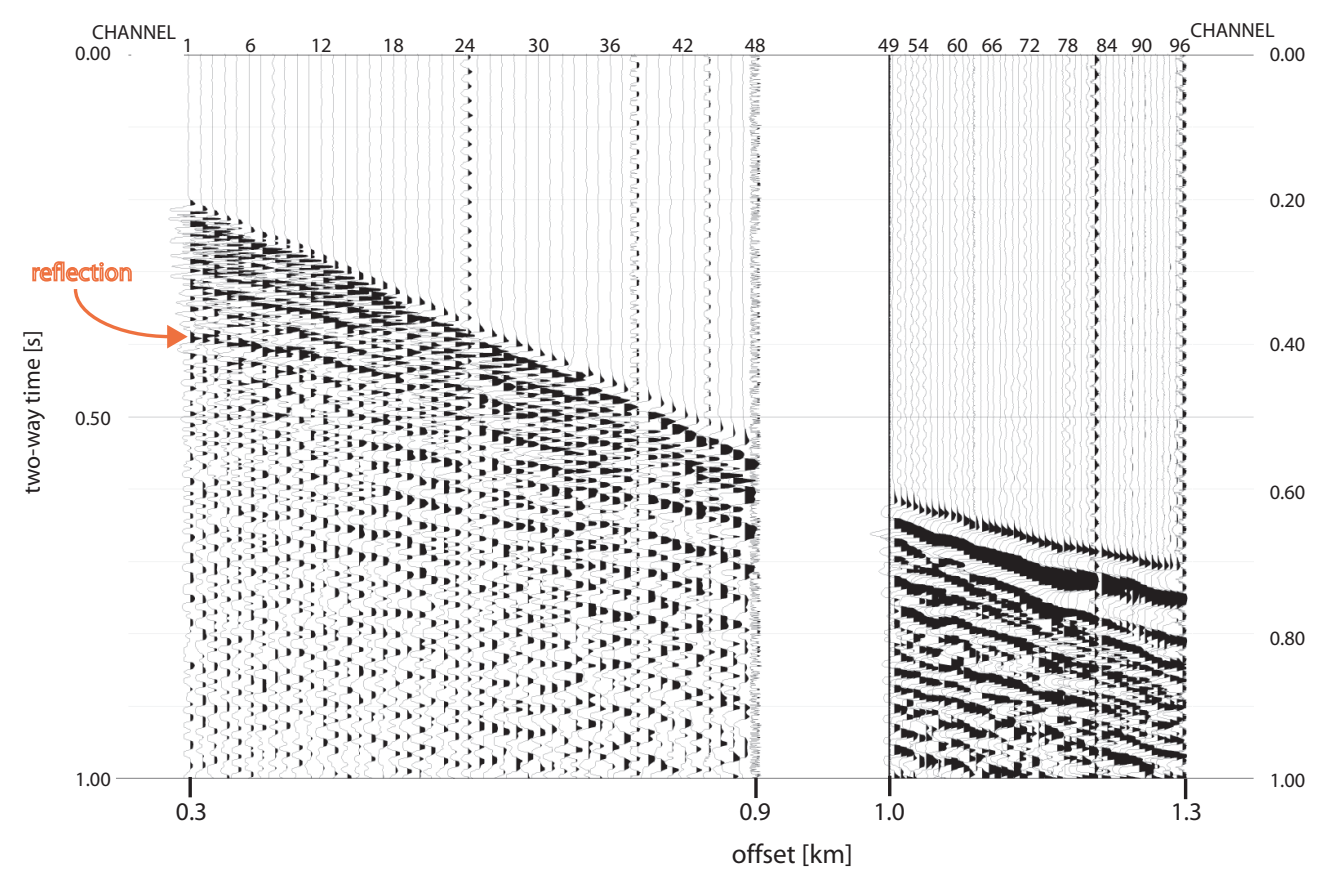

(a) shot north

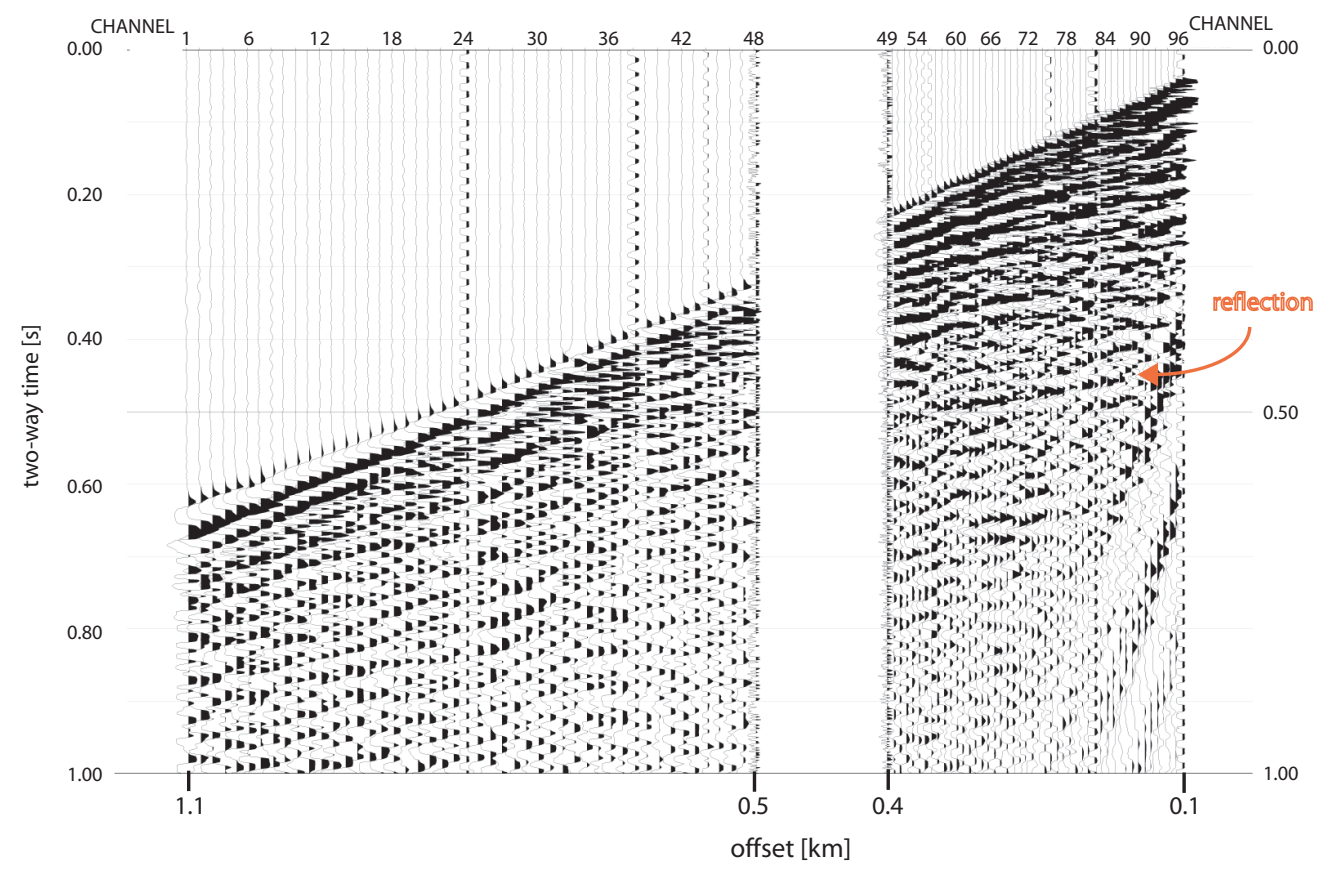

(b) shot south

Figure 3.20: Raw refraction shotgathers. The offset for channels $1-48$ is $12.5 \mathrm{~m}$ and $6.5 \mathrm{~m}$ for channels 49-96. Shotgather for shot at the northern end of Paetawa Road (a) and for shot at the southern end (b).

the following velocities: $1750 \pm 5 \mathrm{~m} / \mathrm{s}$ for the smallest offsets, $2590 \pm 50 \mathrm{~m} / \mathrm{s}$ for the offsets between 1 and $1.2 \mathrm{~km}$ and $4300 \pm 200 \mathrm{~m} / \mathrm{s}$ for offsets larger the $1.2 \mathrm{~km}$. 


\begin{tabular}{|l|c|c|}
\hline & $\begin{array}{c}\text { Velocity } \\
{[\mathrm{m} / \mathrm{s}]}\end{array}$ & $\begin{array}{c}\text { Thickness } \\
{[\mathrm{m}]}\end{array}$ \\
\hline Layer 1 & $1000 \pm 10$ & $20 \pm 2$ \\
\hline Layer 2 & $1640 \pm 20$ & $30 \pm 10$ \\
\hline Layer 3 & $1823 \pm 20$ & \\
\hline
\end{tabular}

Table 3.4: Near surface velocity model for the north-south profile. Velocities and thicknesses are based on the near velocity model established for the east-west profile (section 3.2.4).

For the southern shot, only two different slopes can be identified: a velocity of $1690 \pm 20 \mathrm{~m} / \mathrm{s}$ for offsets smaller than $0.4 \mathrm{~km}$ a velocity of $1910 \pm 10 \mathrm{~m} / \mathrm{s}$ for offsets between $0.6 \mathrm{~km}$ and $1.1 \mathrm{~km}$.

Comparing velocities identified in the two end-shots with the near surface velocity model (see table 3.4) shows that $1690 \pm 20 \mathrm{~m} / \mathrm{s}$ for the southern shot corresponds well to the $1640 \pm 20 \mathrm{~m} / \mathrm{s}$ observed as the velocity of the second layer in the near surface velocity model. However, the $1750 \pm 10 \mathrm{~m} / \mathrm{s}$ from the northern shot and the $1910 \pm 10 \mathrm{~m} / \mathrm{s}$ from the southern shot are not within mutual error margin. This could indicate a dipping layer. The true velocity of the third layer can be calculated with equation A.13 (appendix A) to $1830 \pm 20 \mathrm{~m} / \mathrm{s}$. This velocity, in turn, is within the error margin of the velocity of the third layer found in the near surface velocity model (estimated from west-east shooting) and would indicate that this layer is only dipping in north-south direction but not in east-west direction.

In the northern shotgather, due to the larger offset, refraction arrivals from two deeper layers are observed. The high velocity of the deepest layer $(4300 \pm 200 \mathrm{~m} / \mathrm{s})$ is a strong indicator for a basement interface. Because refractions from layer 4 and 5 are only recorded on one shotgather, a depth calculation is done assuming flat layers. For layer 3 , the true velocity of $1830 \pm 20 \mathrm{~m} / \mathrm{s}$ (assuming a dip $\left.<10^{\circ}\right)$ and a mean intercept time $(0.042 \pm 0.002 \mathrm{~s})$ is used. Thus, the total depth to the basement is calculated to $400 \pm 150 \mathrm{~m}$. All results of this analysis are summarised in table 3.5.

Additionally to the refraction arrivals, strong clear reflection events are visible in both shotgathers (figure 3.20). The latest strong reflection arrival in the northern shotgather (figure 3.20(a)) has a moveout velocity of $1900 \pm 100 \mathrm{~m} / \mathrm{s}$ and a zero-offset two-way traveltime of $355 \pm 10 \mathrm{~ms}$. This corresponds to an event from a depth of $350 \pm 40 \mathrm{~m}$, which is in good agreement with the basement depth, estimated using the refraction arrivals. In the southern shotgather (figure 3.20(b)) a clear reflection arrival can be seen at zero-offset two-way traveltime of $445 \pm 10 \mathrm{~ms}$ with a moveout velocity of $1750 \pm 100 \mathrm{~m} / \mathrm{s}$. This corresponds to an event from a depth of $390 \pm 40 \mathrm{~m}$, which matches well with the depth calculated form the northern shot. The velocity associated with the reflection event is the root mean 


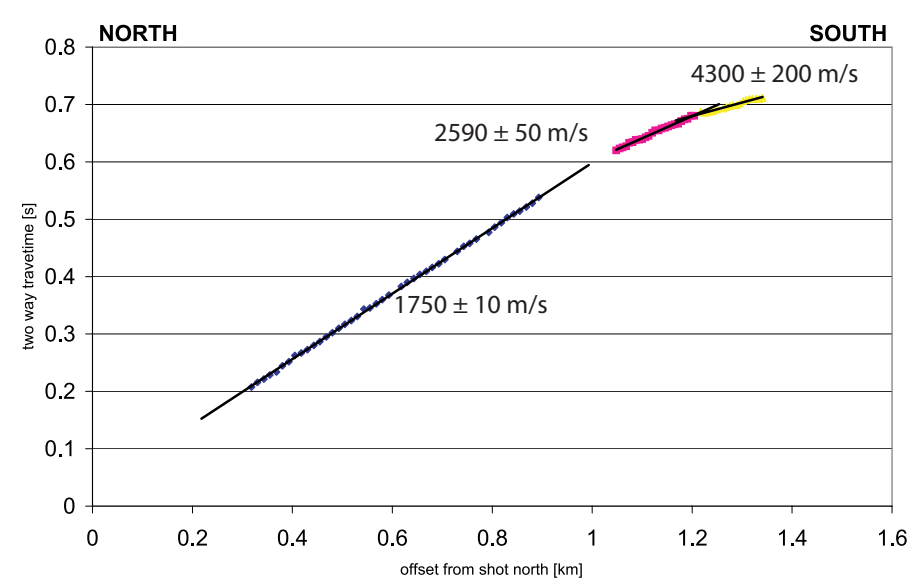

(a) Shot north

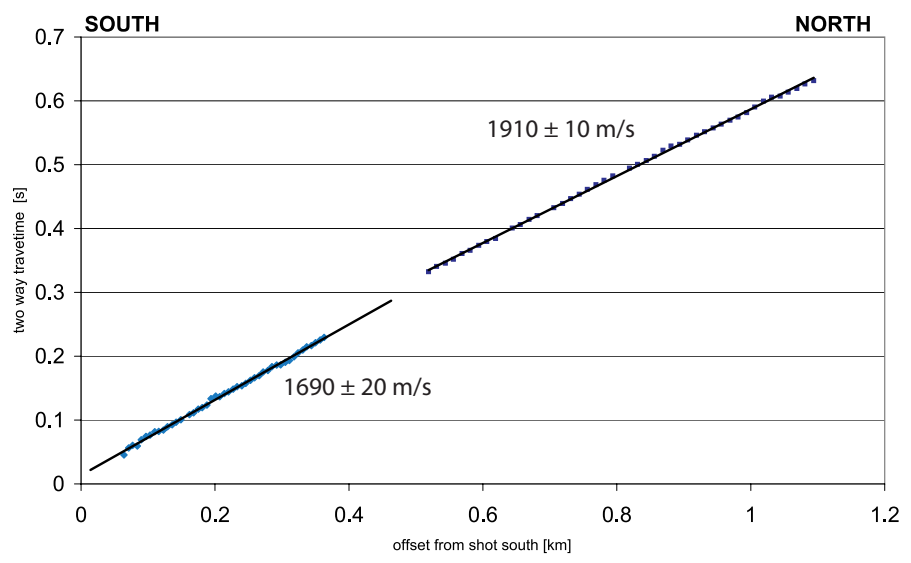

(b) Shot south

Figure 3.21: Time-distance plot for the two refraction shots in the north and in the south of Paetawa Road, respectively. For the northern shot three different slopes are proposed. Two different slopes are proposed for the southern shot. Due to the high signal-to-noise ratio of the data the error bars of the data points are not visible.

square (RMS) velocity of the layers above the reflector. Thus, calculating the RMS-velocity (using equation A.3, appendix A.1.2.8) of the velocity model established based on refraction events (table 3.5 ) should show a similar value. Doing so gives a RMS-velocity of $1840 \mathrm{~m} / \mathrm{s}$ for the refraction model. This value is within the error margin of the normal moveout velocities estimated in the southern and northern shotgather. Therefore, this proves that the main assumption for refraction analysis (no low-velocity layer within the sequence) is valid.

To calculate the dip of the bottom of layer 2, a weighted mean velocity for layer 1 and 2 are to be calculated to reduce this three-layer case to a two-layer case with a dipping interface. Using the velocities and depths from table 3.2 results in a mean velocity of $V_{12}=1390 \pm 10 \mathrm{~m} / \mathrm{s}$ for this new top layer. The other input parameters for the calculation and the results are summarised in table 3.6. 


\begin{tabular}{|c|c|c|c|}
\hline & $\begin{array}{c}\text { Velocity } \\
{[\mathrm{m} / \mathrm{s}]}\end{array}$ & $\begin{array}{c}\text { Intercept time } \\
{[\mathrm{s}]}\end{array}$ & $\begin{array}{c}\text { Thickness } \\
{[\mathrm{m}]}\end{array}$ \\
\hline Layer 1, 2 & $1390 \pm 10$ & & $50 \pm 10$ \\
\hline Layer 3 & $1820 \pm 20$ & $0.042 \pm 0.002$ & $140 \pm 30$ \\
\hline Layer 4 & $2590 \pm 50$ & $0.163 \pm 0.007$ & $210 \pm 100$ \\
\hline Layer 5 & $4300 \pm 190$ & $0.330 \pm 0.013$ & \\
\hline total thickness of sediment layer: $400 \pm 140 \mathrm{~m}$ \\
\hline
\end{tabular}

Table 3.5: Intercept-time analysis - assuming a horizontal model and combining the two top layers to a single layer. Layer 5 which is interpreted as the basement is at a depth of $\sim 400 \mathrm{~m}$.

\begin{tabular}{rrl|}
\hline top layer velocity & $:$ & $\mathrm{V}_{12}=1380 \pm 10 \mathrm{~m} / \mathrm{s}$ \\
velocity layer 2 SN direction & $:$ & $\mathrm{V}_{2-u p}=1910 \pm 10 \mathrm{~m} / \mathrm{s}$ \\
velocity layer 2 NS direction & $:$ & $\mathrm{V}_{2-\text { down }}=1750 \pm 10 \mathrm{~m} / \mathrm{s}$ \\
intercept time SN direction & $:$ & $\mathrm{t}_{\text {i-up }}=0.063 \pm 0.002 \mathrm{~s}$ \\
intercept time NS direction & $:$ & $\mathrm{t}_{\text {i-down }}=0.028 \pm 0.002 \mathrm{~s}$ \\
& $\Rightarrow$ & \\
real velocity second layer & $:$ & $\mathrm{V}_{2-\text { real }}=1830 \pm 60 \mathrm{~m} / \mathrm{s}$ \\
dipping angle & $:$ & $\alpha=3 \pm 0.5^{\circ}$ \\
thickness layer 1 northern end & $:$ & $\mathrm{d}_{1-N}=30 \pm 10 \mathrm{~m}$ \\
thickness layer 1 southern end & $:$ & $\mathrm{d}_{1-S}=70 \pm 10 \mathrm{~m}$ \\
\hline
\end{tabular}

Table 3.6: Intercept-time analysis - allowing for dipping layers. Different velocities for the southern and northern shot indicate a dipping second layer. The problem is reduced to a two-layer case with dipping interface using a combined first and second layer. Thus, the thicknesses of layer 3 and layer 4 cannot be calculated with this method.

The calculated dip of the layer interface is estimated to be smaller than $10^{\circ}$, thus the velocity of the second layer is adapted to $V_{2-r e a l}=1830 \pm 60 \mathrm{~m} / \mathrm{s}$ (see appendix A.2.2).

\subsubsection{Raytracing}

The predicted velocity model from the previous section (section 3.2.5.1) can be reassessed and refined by means of forward raytracing modelling. For details on this method see appendix A.2.

The velocity model from section 3.2.5.1 is used as initial model and than starting from the top, every layer was modified to best fit the observed traveltime picks. Different model parameters were tested, with and without dipping layers. However, the dip of the second layer proposed by the intercept time method (section A.2.2) is too small to be investigated by means of raytracing. Figure 3.22 shows the best fitting model, which consists of five horizontal layers. Veloci- 


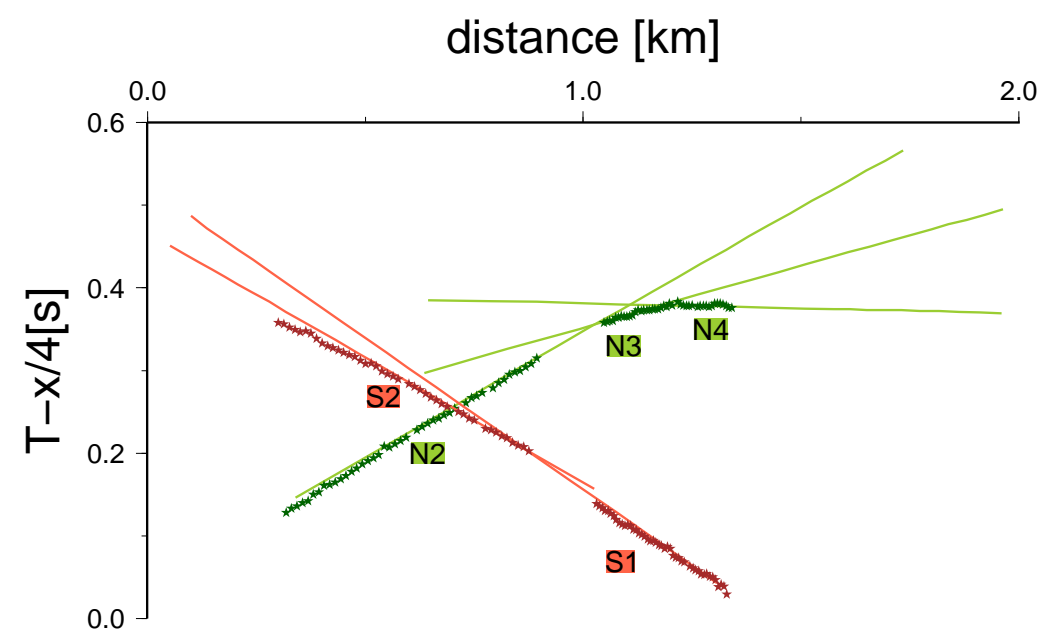

(a)

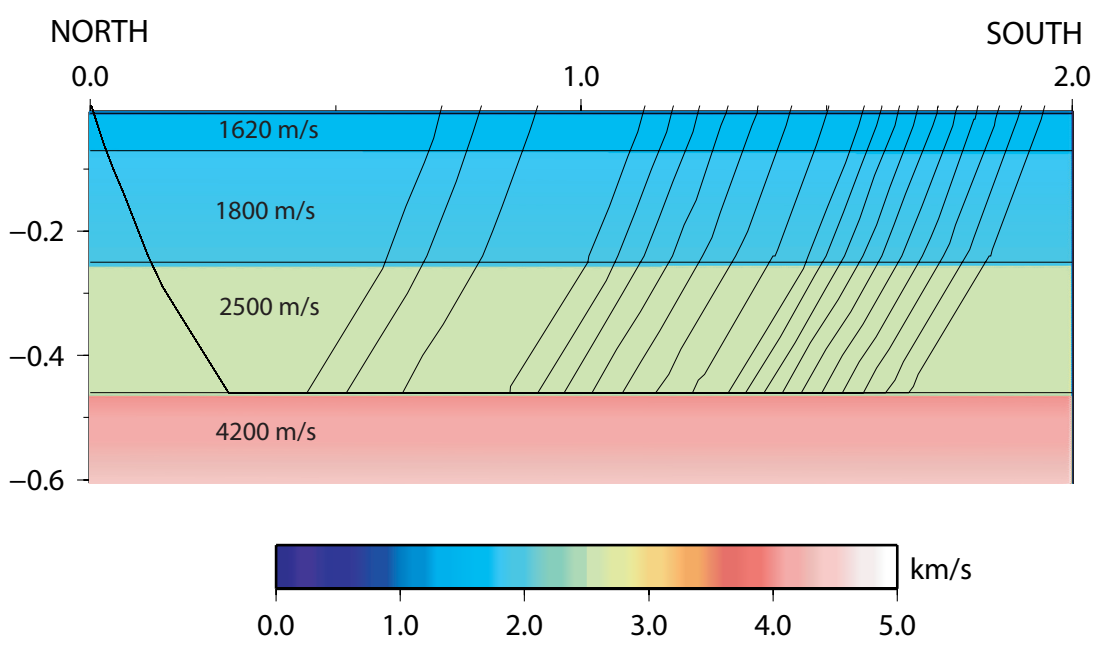

(b)

Figure 3.22: Panel (a) shows the picked first breaks (red and green stars) and the calculated arrival times for the different refractions. Panel (b) shows the velocity model and the raypath for the refraction at the basement interface. The labelling of different segments is done according to shot location and refraction interface; e.g. N3 is the segment of first breaks originating from the northern shot and refracted at interface 3 . Velocities are similar to the velocity proposed for shallow structures in New Zealand by Sissons \& Dibble [1981]. 
ties range from $1050 \mathrm{~m} / \mathrm{s}$ for the $\sim 10 \mathrm{~m}$ thick top layer to $4200 \mathrm{~m} / \mathrm{s}$ for the bottom layer which is interpreted to be basement at a depth of around $470 \mathrm{~m}$. Comparing these results with the results from section 3.2.5.1 shows a $70 \mathrm{~m}$ deeper basement. However, these models are within the error margin of each other.

\subsubsection{Summary of results for the Waikanae survey}

Four different geophysical methods were applied in the Waikanae study area (seismic reflection, seismic refraction, tomography and gravity). Figure 3.23 shows a summary of the discovered features and their locations. Gravity indicates a significant basement drop parallel to the Tararua Ranges. In the south (Moana profile) this step lies to the west of the Waikanae township, whereas in the north (Greenhill and Moana profile) the offset is located just at the front of the ranges underneath SH1. There is also a change in the offset with up to $600 \mathrm{~m}$ in the north (Peka Peka profile) and significant smaller offset to the south ( $\sim 200 \mathrm{~m}$, Greenhill and Moana profile). Gravity modelling cannot distinguish between high-angle normal, high-angle reverse or vertical displacement, because the difference in the gravity anomaly of these features is almost negligible (see appendix B).

Due to a gap in the seismic reflection data beneath $\mathrm{SH} 1$ it is not possible to investigate the basement step in more detail. Nevertheless, in the seismic section to the east, around $400 \mathrm{~m}$ from SH1, an offset of around $120 \mathrm{~m}$ in the shallow horizons is observed. This feature also shows a surface expression. It is marked in the GNS active fault database [GNS Science, 2008] as part of the active, lateral strike-slip Ohariu fault and is called the Hadfield Fault.

The Hadfield Fault cannot be assumed to be part of the large basement offset underneath $\mathrm{SH} 1$ because both faults show an almost vertical displacement. If both features were linked, they should show an approximately $50^{\circ}$ dip.

The two northern gravity lines (Peka Peka (figure 3.5) and Greenhill profile (figure 3.2.1.2)) show a horst-like structure to the west of SH1. This basement high gets narrower and shallower to the south before it seems to merge with the shallow basement underneath Waikanae township (figure 3.23(a)). Seismic refraction and gravity data along Peka Peka Road agree with the position and depth of the basement high (see map in figure 3.23). In the stacked seismic sections a disruption of all horizons above the western flank of the basement high can be seen (Fault-4, figure 3.10). Furthermore, the identified basement high corresponds well to the location of a series of north-south trending sand dunes (see light brown coloured areas in figure 3.23). This is a good indication that these sand dunes are a surface expression of the basement high below and are controlled by the tectonic regime of this area.

The basement along Paetawa Road, parallel to the coastline, is mapped with 
Chapter 3. Shallow seismic and gravity methods

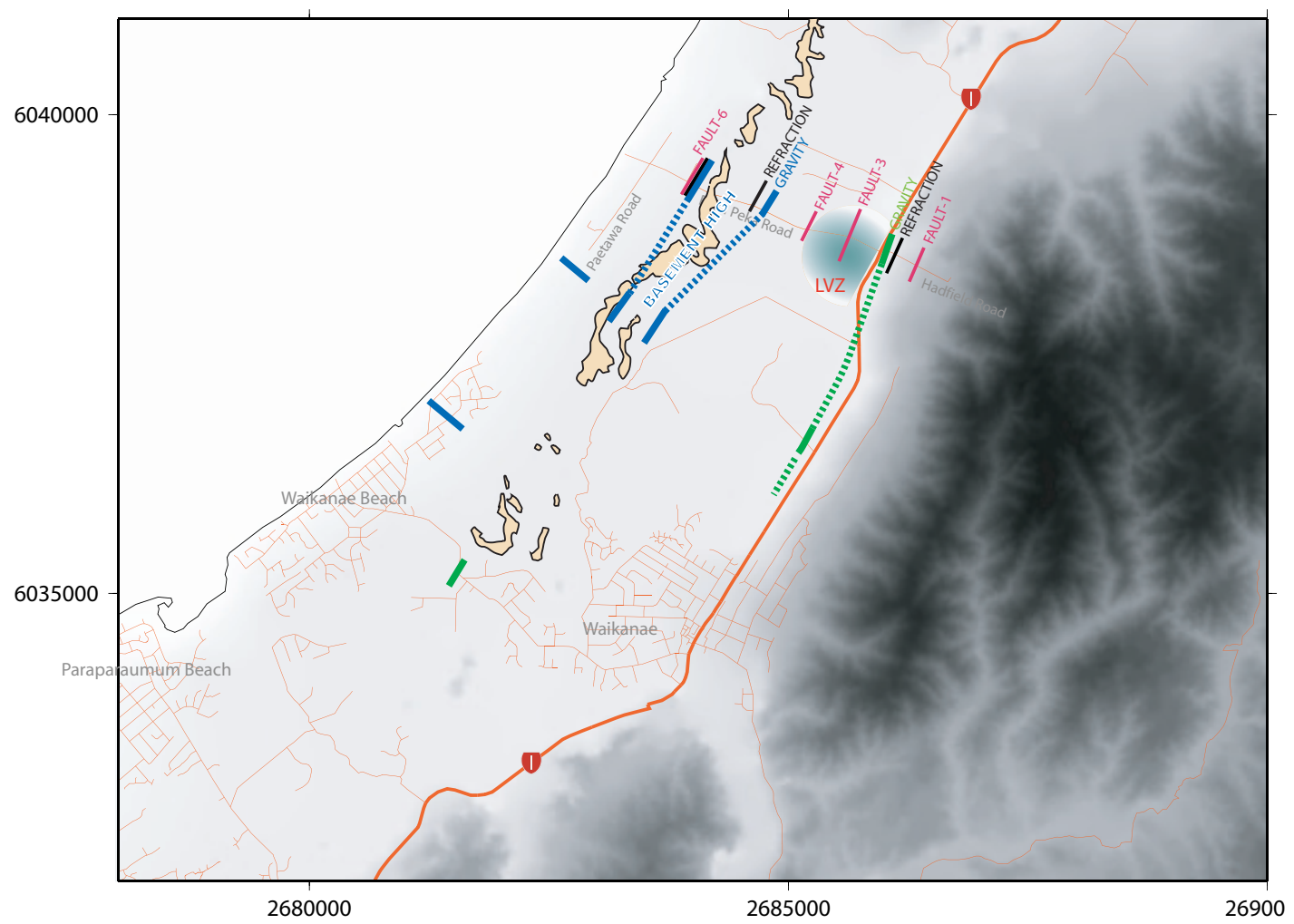

(a)

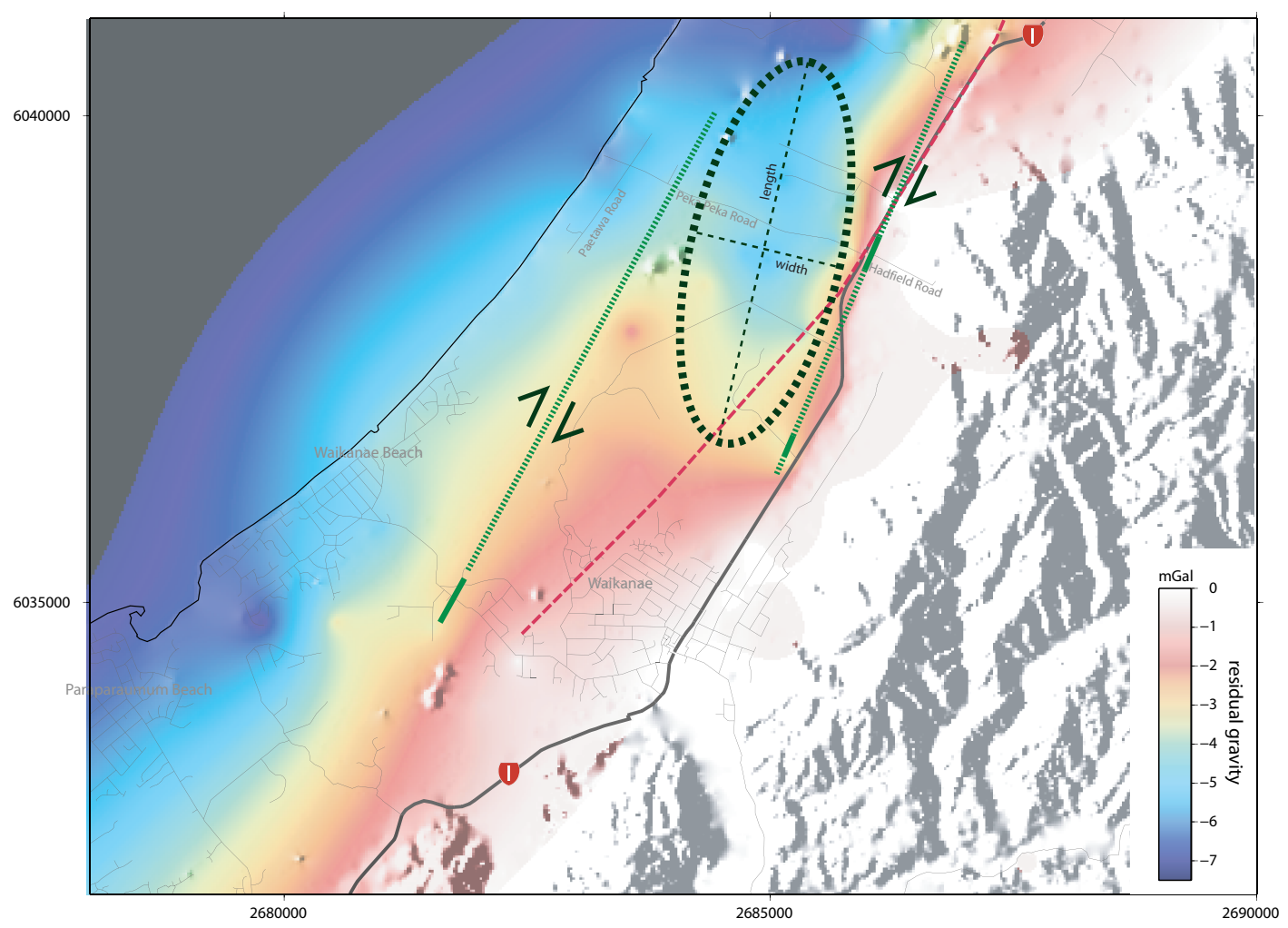

(b)

Figure 3.23: caption next page 
a flat mid-section (depth of around $270 \mathrm{~m}$ ) and is deepening to the south and north, with a vertical $120 \mathrm{~m}$ offset on its northern flank (figure 3.2.1.4). However, this is not constrained by any other data. Thus, the majority of the discovered features trend north-northeast in agreement with the Kapiti-Manawatu Fault System [Lamarche et al., 2005], parallel to the front of the Tararua Ranges and parallel to a zone of right-lateral strike-slip faults [Palmer \& Van Dissen, 2002].

Along Peka Peka Road, a low-velocity $(<1000 \mathrm{~m} / \mathrm{s})$ top layer is proposed by seismic tomography data. This layer thickens towards SH1 and probably even extends along the western part of Hadfield Road, where direct wave velocities of $700 \mathrm{~m} / \mathrm{s}$ are measured. Using shallow groundwater drillhole data, this layer can be interpreted as mainly sand and peat [Clarke, 2003].

The simplest interpretation to connect the mapped large offsets would be to describe all as one single feature, which runs north-south (below SH1) in the north of the study area and bends to the west around Waikanae township. However, this would not be in agreement with the residual gravity map, which proposes a basement high underneath Waikanae with a narrow extension to the north. Therefore, a step-over of a dextral strike-slip fault is proposed, with the basement low underneath Peka Peka Road assumed to be a possible pull-apart basin (figure 3.23(b)).

Such basins normally form on releasing steps or bends in basement strike-slip faults and vary in size from a few metres to tens of kilometres [Aydin \& Nur, 1985; Mann et al., 1983; McClay \& Dooley, 1995]. The stepping strike-slip faults, called master faults, can accommodate large vertical displacements and are normally connected by two oblique-slip extensional faults [Aydin \& Nur, 1985; McClay \& Dooley, 1995]. The shape can vary from rhomboidal to sigmoidal and depending on the difference in extension on the faults, an asymmetrical basin can develop. Some characteristics help to identify pull-apart basins. The geometry of fully

Figure 3.23: Panel (a) shows a summary map of the discovered features and their location: a large basement drop indicated by gravity (blue and green lines) and seismic refraction data (black line); a low-velocity zone (LVZ) proposed by tomography results and faulting of shallow seismic horizons (red lines). Dashed lines indicate proposed interpolation between features. The light brown coloured area shows the location of sand dunes. Note the good match of the location of theses dunes with the proposed basement high. Panel (b) presents interpretation of results: a dextral strike-slip fault with a step-over feature as a pull-apart basin. The lateral extent of the basin to the north is only estimated. The green lines indicate approximate position of proposed strike-slip faults (solid part based on the acquired data, dashed part based on the intra- and extrapolation of the data). The red line shows the location of the 6500 year old shoreline location after Te Punga [1962]. 
developed basins shows characteristic dimension ratios, a length (along strike) to width (perpendicular to strike) ratio of 3:1 and a length-to-depth ratio of 8 or 9:1 [Aydin \& Nur, 1985; Toulmin, 2006]. In stacked seismic data, pull-apart basins are identified by a normal, negative flower structure [McClay \& Dooley, 1995].

In this study the lateral extent of the proposed pull-apart basin is hard to determine, because its northern end is not fully imaged. However, estimating its shape based on the investigated part (see map in figure 3.23(b)) shows a length-to-width ratio of around 3:1 and a length-to-depth ratio of 4:1. The complex internal structure of pull-apart basins [Ioganson, 2005] could explain the observed incoherence of the deeper reflector within the stacked seismic section. Furthermore, Fault-6 and 7 to the west of the section (normal faults dipping east) and Fault- 4 and 3 to the east (normal faults dipping west) could be interpreted as the top part of a negative flower structure.

Due to the oblique subduction in the lower North Island the deformation in the upper plate is partitioned between strike-slip and compression. The strikeslip motion mainly occurs along the North Island dextral fault Belt (NIDFB) (figure 2.2), which is around $450 \mathrm{~km}$ long and contains numerous individual faults [Beanland, 1995]. The compressive deformation produces a well developed accretionary prism [Collot et al., 1996; Lewis \& Pettinga, 1993] east of the North Island and a fore-arc basin in the southeastern North Island [Beanland \& Haines, 1998; Lamarche et al., 1995].

A pull-apart basin fits in the tectonic context of the Kapiti Coast area as part of the northeast trending North Island dextral fault belt (NIDFB) [Beanland, 1995]. This fault system is caused by the oblique subduction in the North Island, where the along strike component is taken up by strike-slip and the compressive component mainly by deformation of the fore-arc region in the southeastern North Island [Beanland \& Haines, 1998; Lamarche et al., 1995]. Main mapped active strike-slip faults in the southern part of this system are the Wellington Fault (6.0$7.6 \mathrm{~mm} / \mathrm{a})$ and the Wairarapa Fault $(6-10 \mathrm{~mm} / \mathrm{a})$. Surface expression of faulting to the west of the Axial Ranges, between the ranges and the coast, is poor because it is masked by an active landscape. Mapped strike-slip faults in this area (Ohariu Fault, Northern Ohariu Fault) show slightly smaller slip rates and trend parallel to the coastline and may be partly offshore at the eastern edge of the SWB. The Ohariu Fault (1-3 mm/a), which is mapped from southwest of Wellington to the Waikanae region and maybe connects with the Northern Ohariu fault (1-3 mm/a) to the north [Heron et al., 1998; Litchfield et al., 2004, 2006], is located 1-2.5 km east of the newly discovered features. Slip-rates on these faults cannot be estimated but significant vertical slip rates can be considered based on seismic and gravity data.

Additionally, the proposed strike-slip system coincides approximately with the location of a $6500 \mathrm{yr}$ old postglacial seacliff (Otaki-Waikanae cliff) [Hawke \& McConchie, 2006; Te Punga, 1962]. This old shoreline can be traced around $13.7 \mathrm{~km}$ 
between the Otaki and the Waikanae rivers in a distance of around $3 \mathrm{~km}$ from the present shoreline (see figure 3.23(b)). The sea cliff runs along SH1 in the northern part and passes just west of the Waikanae township. Thus, the trend of the continuous seacliff is in relatively good agreement with the proposed strike-slip system. At the location where the step in the strike-slip system is proposed, Te Punga [1962] stated a lack of surface expression of the seacliff, which he ascribed to roadworks at this location.

Furthermore, Te Punga [1962] describes this cliff as a marine cut feature, and not as the result of faulting. The large vertical offsets on the basement feature (up to $600 \mathrm{~m}$ ) and the location of the basement high relative to the seacliff provide possible evidence for the tectonic origin of this seacliff. The ancient shoreline runs parallel to the present coastline, the Kapiti-Manawatu faults system and the North Island Dextral Fault Belt.

\subsection{Waikawa Beach survey}

The Waikawa Beach survey was conducted around $20 \mathrm{~km}$ northeast of the Waikanae field area, on the Kapiti Coast (figure 3.1). The exact locations of the gravity and seismic reflection line are shown in figure 3.24. The seismic line has a length of $900 \mathrm{~m}$ (around 10\% of the length of the gravity line) and runs for logistical reasons on a small gravel road $500 \mathrm{~m}$ to the north of Waikawa Beach Road. The field work was carried out in winter 2005 as part of an Honours degree project [Hudson, 2005]. For this study the seismic line is reprocessed and the gravity field observations are newly reduced to both Bouguer and residual gravity anomalies.

\subsubsection{Gravity method}

The gravity dataset contains 15 newly acquired gravity measurements (green squares, figure 3.24) and 14 measurements taken from the GNS Sciences database (white squares). The projected profile line (grey line), with a length of approximately $10 \mathrm{~km}$, starts at Waikawa Beach, crosses SH1 and runs along North Manakau Road into the foothills of the Tararuas.

The raw gravity measurements are first reduced to Bouguer gravity values, followed by the calculation of the regional field, which is then used to reduce the data to residual gravity values. A detailed discussion of the estimation of the regional gravity field as well as other aspects of gravity data analysis can be found in appendix B.

Modelling of the observed residual gravity anomaly is based on a three-layer model. In contrast to the Waikanae gravity study, the second layer is modelled 


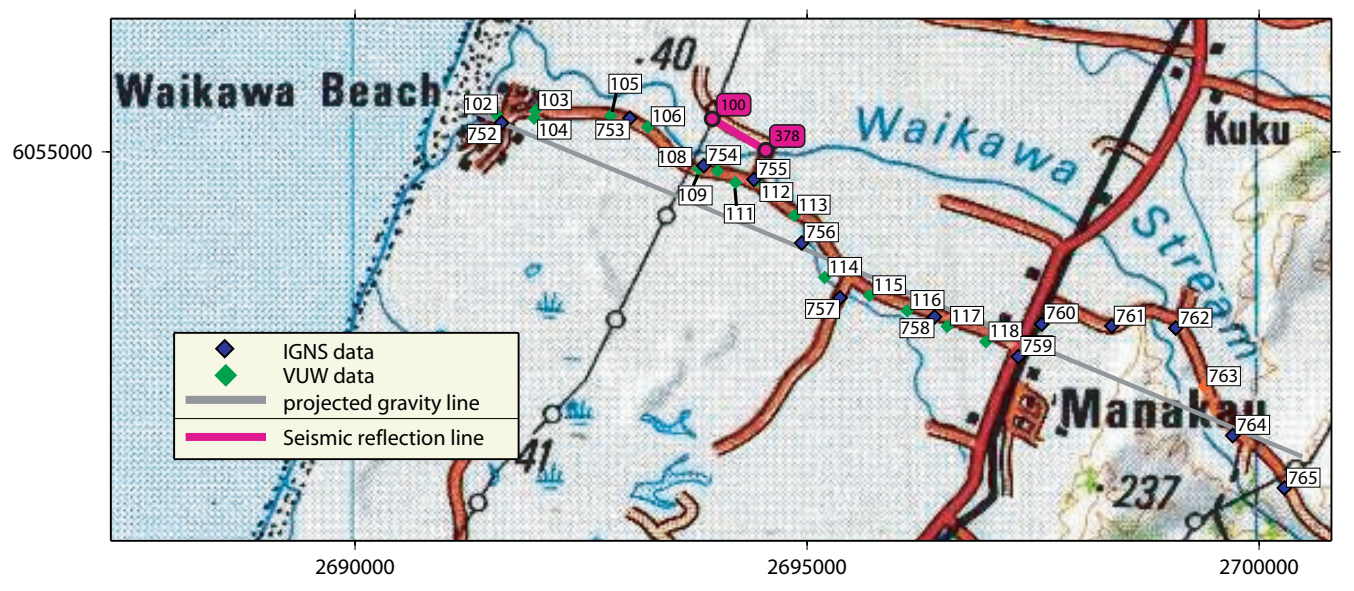

Figure 3.24: Location map of the data points used for the Waikawa gravity/seismic survey. Gravity points comprise of GNS Sciences data (green squares) and VUW data (green squares). All gravity points are projected perpendicular onto the grey profile line. The seismic profile is shown as pink line with CDP-bin numbers of the start and end point.

with a density of $2000 \mathrm{~kg} / \mathrm{m}^{3}$, which is the Pleistocene sediment density proposed for the SWB [Hunt, 1980]. This yields results which are more consistent with the seismic results (see section 3.3.2). Accordingly, layer 1 consists of a thin section with a density contrast of $-770 \mathrm{~kg} / \mathrm{m}^{3}$ representing dune sands and sandy gravels.

The subsurface model based on gravity data (figure 3.25(a)) shows a high-angle fault underneath SH1 with an offset of $180 \mathrm{~m}$. Westwards of this point the basement rises slightly to a peak at $110 \mathrm{~m}$ depth, around $\sim 800 \mathrm{~m}$ along the profile line. Another basement high is located between kilometre 3.8 and 6 along the profile line which has its maximum height ( $170 \mathrm{~m}$ below the surface) at its eastern side. Both flanks of this basement high are modelled again as vertical features because of the non-uniqueness of the method. The displacement at the eastern and western flank is $\sim 130 \mathrm{~m}$ and $\sim 60 \mathrm{~m}$, respectively.

The seismic reflection results from a profile running subparallel to Waikawa Beach Road (section 3.3.2) show a thrust fault (upthrown to the east) at the western end of the section. Assuming a strike of this fault parallel to the coastline, it intersects the gravity line between points 108 and 754 (see map 3.24). This, however, is not in agreement with the gravity data and a different strike has to be assumed. Figure 3.25(b) shows a similar model to figure 3.25(a), but instead of one single upthrown block between 3.8 and $6 \mathrm{~km}$ an additional reverse fault on top of the basement high is included. It is a narrow feature $(400 \mathrm{~m})$, similar to what can be seen in the seismic section. The highest point of this block is around $140 \mathrm{~m}$ deep and has a reverse fault (offset $70 \mathrm{~m}$ ) on its western side. Both models fit the data well. 


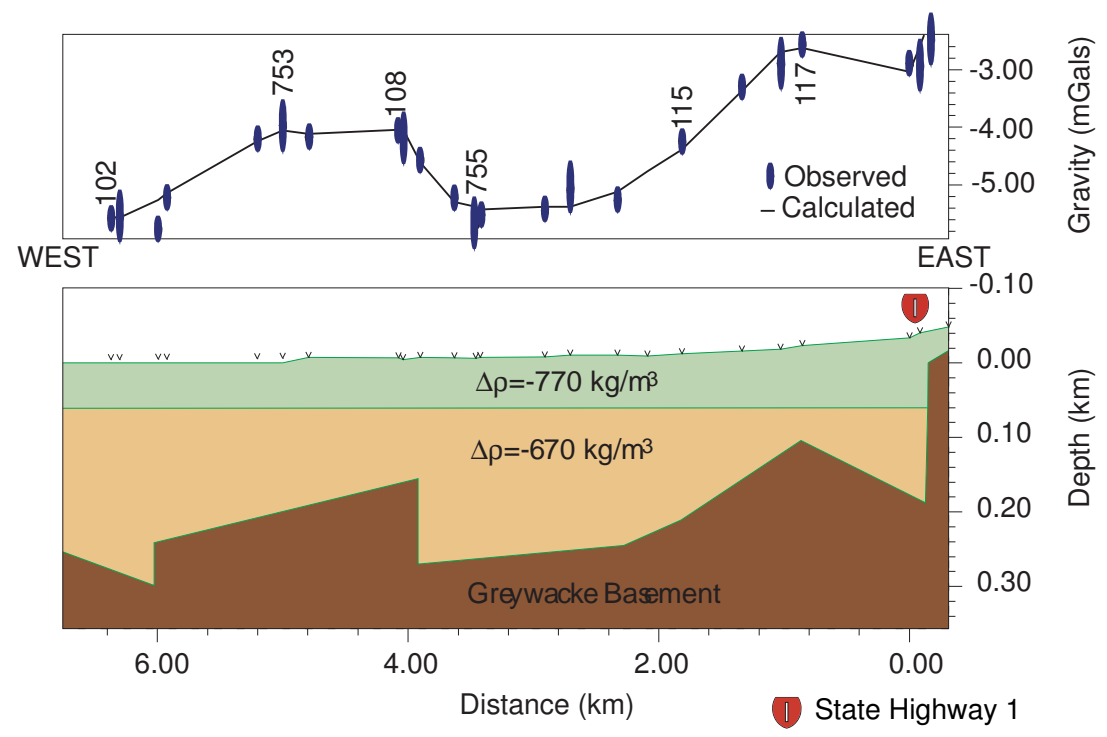

(a)

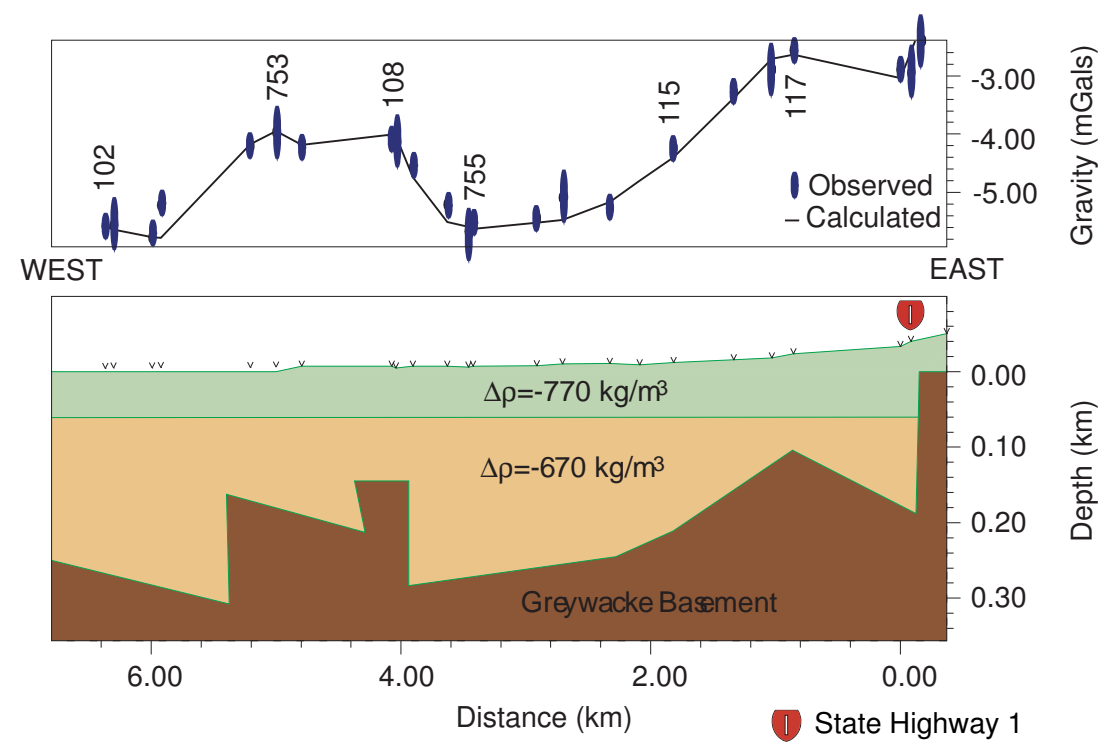

(b)

Figure 3.25: Waikawa residual gravity model: top panels of each figure show the residual gravity measurements (blue dots) and the calculated gravity values (black line). Bottom panels represent the corresponding density model. The surrounding material is assumed to be greywacke (brown layer) with a density of $2670 \mathrm{~kg} / \mathrm{m}^{3}$. Figure (a) shows the final model only based on the gravity measurements. The model in figure (b) includes basement topography constraints from seismic reflection data (for details see text). The zero position on the $x$-axis is equivalent to the location of SH1. The vertical size of the datapoints represent error bars. Depth is relative to sea level and there is a vertical exaggeration of 4 . 


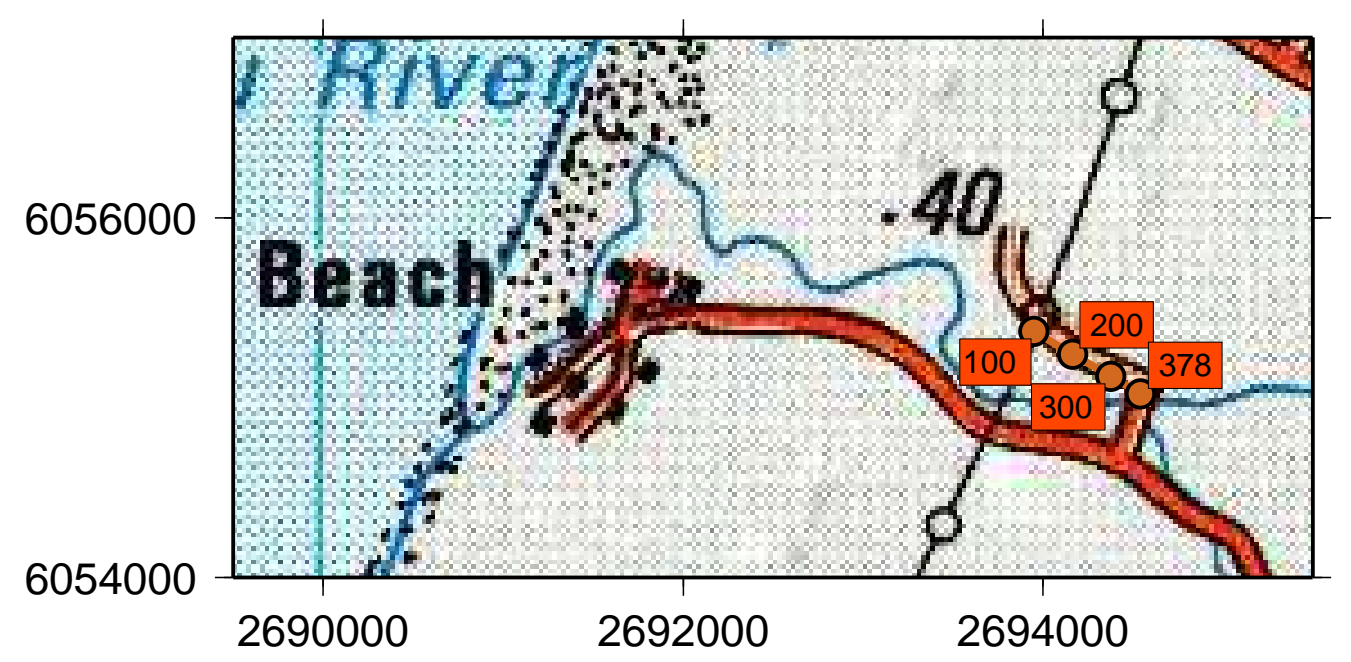

Figure 3.26: Detailed location map for the Waikawa seismic survey. The line runs for $800 \mathrm{~m}$ along a gravel road parallel to Waikawa Beach Road, with a shot spacing of $10 \mathrm{~m}$. The numbers represent the location of the corresponding CDP-bins.

\subsubsection{Seismic reflection method}

This dataset consists of one $800 \mathrm{~m}$ long seismic reflection line which was shot along a road parallel to Waikawa Beach Road (500 $\mathrm{m}$ to the north) in autumn 2005. The seismic source was a hydraulic thumper and 76 shots were fired with a shot spacing of $10 \mathrm{~m}$ (see figure 3.26). This results in a seismic fold of 11, which is approximately half the fold used for the seismic reflection lines in the Peka Peka survey (section 3.2.2). The line was shot using a variable split-spread geometry. An overview of the field parameters can be found in table 3.7.

\subsubsection{Interpretation}

The seismic profile (figure 3.27) is $800 \mathrm{~m}$ long and was conducted with a splitspread geometry. A top layer of dune sands and a low seismic fold is inferred to be the main reasons for a relative low signal-to-noise ratio present in this dataset. However, the data quality along the line is constant and coherent seismic energy is evident down to $\sim 400 \mathrm{~ms}$.

Three main seismic reflectors are picked, correlated and labelled from top to bottom. A description of the different events follows below:

Reflector-1 (orange) is the strongest, continuous top reflector, traceable through all CDPs at a TWTT of approximately $130 \mathrm{~ms}$. The horizon is flat west of CDP 170 
3.3 Waikawa Beach survey

\begin{tabular}{|c|c|}
\hline LINE ID: & Waikawa \\
\hline Source & EG\&G thumper \\
Shot interval & $20 \mathrm{~m}$ \\
Shot depth & $0 \mathrm{~m}$ \\
Geophone spacing & $5 \mathrm{~m}$ \\
Number of geophones & 48 \\
Spread & variable split spread \\
min offset & $0 \mathrm{~m}$ \\
max offset & $235 \mathrm{~m}$ \\
Sampling interval & $1 \mathrm{~ms}$ \\
Recording length & $2048 \mathrm{~ms}$ \\
Fold (maximum) & variable $(11)$ \\
\hline
\end{tabular}

Table 3.7: Field parameters for the seismic line in the Waikawa Beach survey

and east of CDP 280, in between it is curved downwards with it lowest point at CDP 230.

Reflector-2 (light blue) marks the bottom of the band of high-amplitude reflectivity. It can only be traced west of CDP 170, where it is parallel to Reflector-1 and east of CDP 270, where it dips slightly to the east. The amplitude is slightly lower as for Reflector-1 and the horizon is not as continuous.

Reflector-3 (dashed purple) is interpreted as the basement reflector. It can only be traced at the eastern and western end of the section. It misses the typical irregular pattern for greywacke basement (see section 3.2.2.1). However, the visible parts of this reflector are short $(\sim 200 \mathrm{~m})$ and the lack of continuous seismic energy underneath allows to identify it as greywacke basement. The approximate TWTT of this horizon is $\sim 380 \mathrm{~ms}$.

Two distinct faulting structures are identified within this section. One is a vertical fault (Fault-2) at around CDP 280 which offsets the top orange reflector by $\sim 10 \mathrm{~ms}$. The second one is Fault- 1 at around CDP 200, which is interpreted as a shallow thrust fault. This is unusual for the southern onshore part of the SWB as no other thrust fault is identified in any of the seismic sections. The fault offsets the orange reflector by about $50 \mathrm{~ms}$. The two faults uplift an area of sediment between them. Using the average sedimentation rate for this part of the basin of around $7 \mathrm{~mm} / \mathrm{a}$ (section 3.4.2.1) dates the orange reflector to around $140 \mathrm{ka}$ and the light blue to around $300 \mathrm{ka}$.

\subsubsection{Summary of results for Waikawa Beach Road survey}

The basement underneath Waikawa Beach Road reaches a maximum depth of $300 \mathrm{~m}$ and has two distinct features. One is the high-angle fault (offset $180 \mathrm{~m}$ ) just 


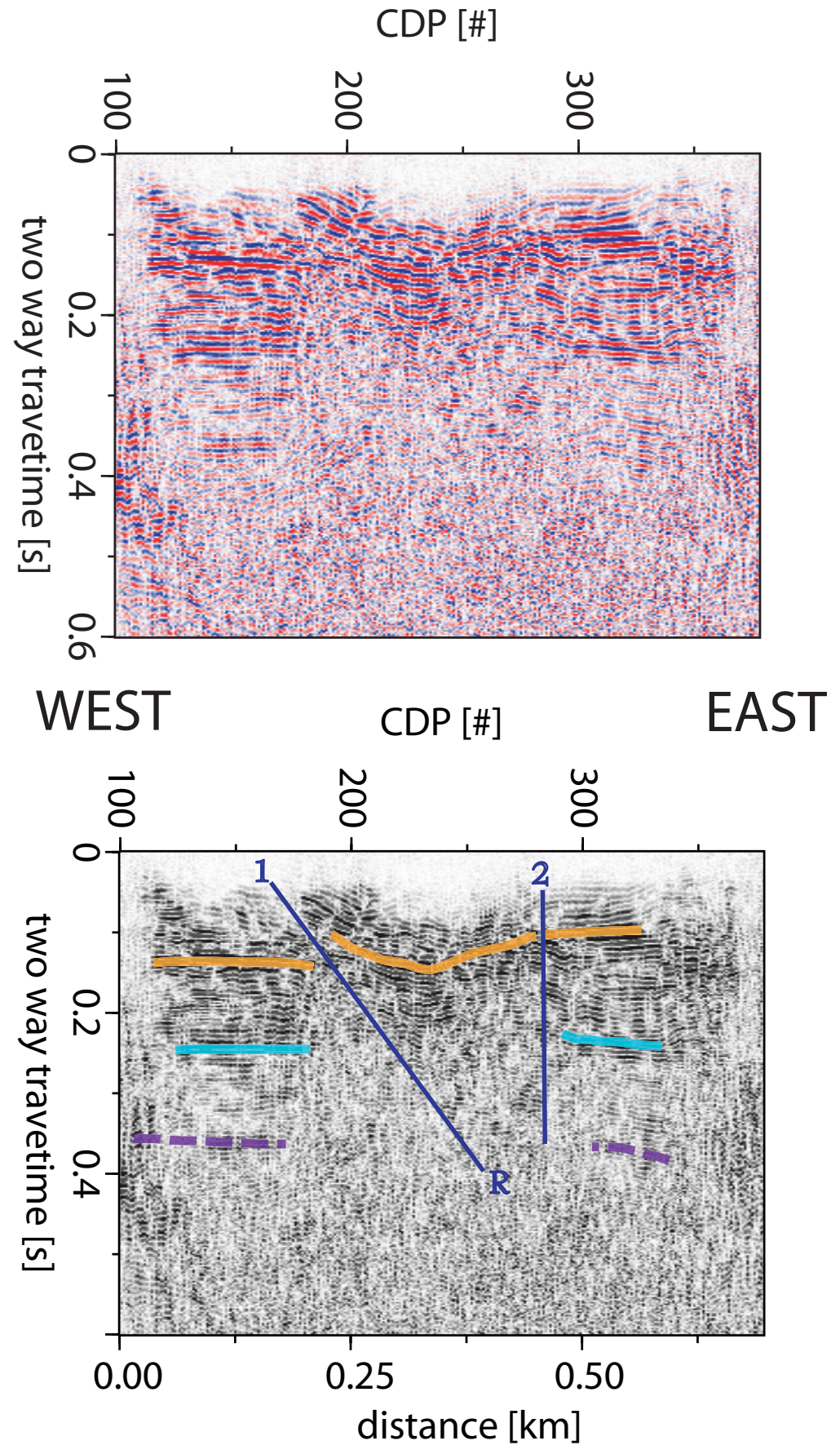

Figure 3.27: Final pre-stack time-migrated stacked section of Waikawa Beach line (top) and the seismic interpretation (bottom). CDP spacing is $2.5 \mathrm{~m}$. A hydraulic thumper was used as seismic source, with a shot spacing of $10 \mathrm{~m}$.

underneath SH1. The other one is a basement high, upthrown by around $120 \mathrm{~m}$ with a thrust fault on top of it. Comparing gravity and seismic results indicates that the strike of the thrust fault is not parallel to the coastline but strikes $55^{\circ}$ to 
north. Most faults in the Kapiti-Manawatu Fault System have a north-northeast trending strike $\left(\sim 30^{\circ}\right.$ to north). However, this strike is almost sub-parallel to the strike of the Northern Ohariu fault ( $\sim 50^{\circ}$ to north).

Hudson [2005], working with the same seismic dataset, interpreted this feature as a blind thrust fault. No surface expression is visible, but a sand dune is located on top of the predicted position of the fault. This location coincides with the extrapolated position of the $6500 \mathrm{yr}$ shoreline [Hawke \& McConchie, 2006]. This was used by Hudson [2005] as an argument for a seacliff controlled by faulting and not eustasy. However, after reprocessing both datasets for this study, the concluded strike of the fault is not in line with the $6500 \mathrm{yr}$ shoreline.

If thrust faults would occur in great numbers in the SWB, they could play a role in the subsidence of the SWB, as denser basement rock would replace sediment close to the surface [Stern \& Holt, 1994]. However, no further evidence of thrust blocks was found in this or in other studies of the SWB [Anderton, 1981; Hunt, 1980; Lamarche et al., 2005].

\subsection{Levin survey}




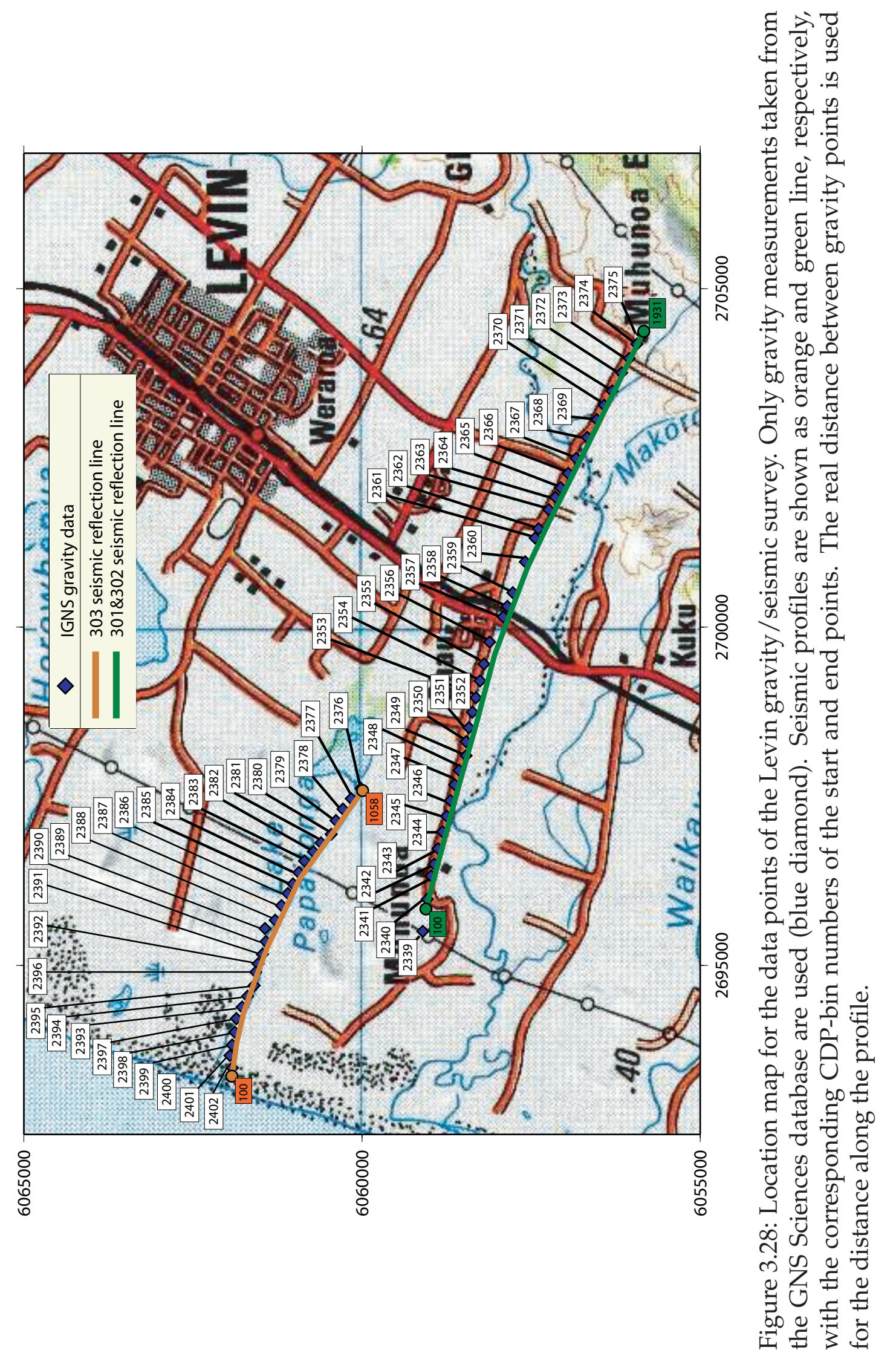


The Levin survey (map figure 3.28) consists of an east-west orientated gravity and a seismic reflection line. The seismic line is subdivided into three $5 \mathrm{~km}$ long legs: 301 and 302 (green line figure 3.28) run along Muhunoa Road from Muhunoa West to Muhunoa East. Line 303 (orange line figure 3.28), $1.7 \mathrm{~km}$ offset to the northeast, was conducted along Waiwiri steam from Lake Papaitonga to the coastline. These datasets were collected and initially interpreted by Aharoni [1991].

Here, both datasets get reassessed, reprocessed and, in case of the gravity dataset, remodelled. A new processed section and interpretation is presented.

\subsubsection{Gravity method}

The gravity dataset consists of 65 datapoints (blue diamonds, figure 3.28), 26 for profile 301 and 39 for profile 301 and 302. All gravity points lie on the same line as the CDP-bins in section 3.4.2, so that no projection onto a straight profile is necessary. Instead the real distance between points is used.

There are two main differences in the processing and modelling of the gravity data between this study and the approach by Aharoni [1991]. Firstly, a different method to calculate the regional field is used. In this thesis it is estimated by a 3D gravity model of the crustal structure and subducting slab (appendix B.3). The approach by Aharoni [1991] is based on calculating a regional field from seismic data collected along the same profile. Secondly, the density values used for the sedimentary infill are slightly different (Aharoni: $\rho=2070 \mathrm{~kg} / \mathrm{m}^{3}$; this study: $\left.\rho=2000 \mathrm{~kg} / \mathrm{m}^{3}\right)$.

The different approaches calculating the regional field resulted in an average $50 \%$ deeper basement depth in the gravity models for this study (figure 3.29). Furthermore, some small scale features modelled by Aharoni [1991] were ignored in this study because the size of the error bars of the data do not allow a reliable modelling of such small features. As for all other gravity models in this chapter, achieving a good fit was attempted with the simplest model possible.

A series of horst and graben structures dominates the Levin 301\&302 lines. In the Levin 303 line the Levin fault at the eastern end of the section and the normal fault at $11.2 \mathrm{~km}$ along the profile line are the main two features. A detailed description of the features along the line can be found in Aharoni [1991].

\subsubsection{Seismic reflection data}

The seismic reflection datasets (figure 3.30) were collected in 1988 and 1989 in cooperation between DSIR and Victoria University Wellington. The geometry of 


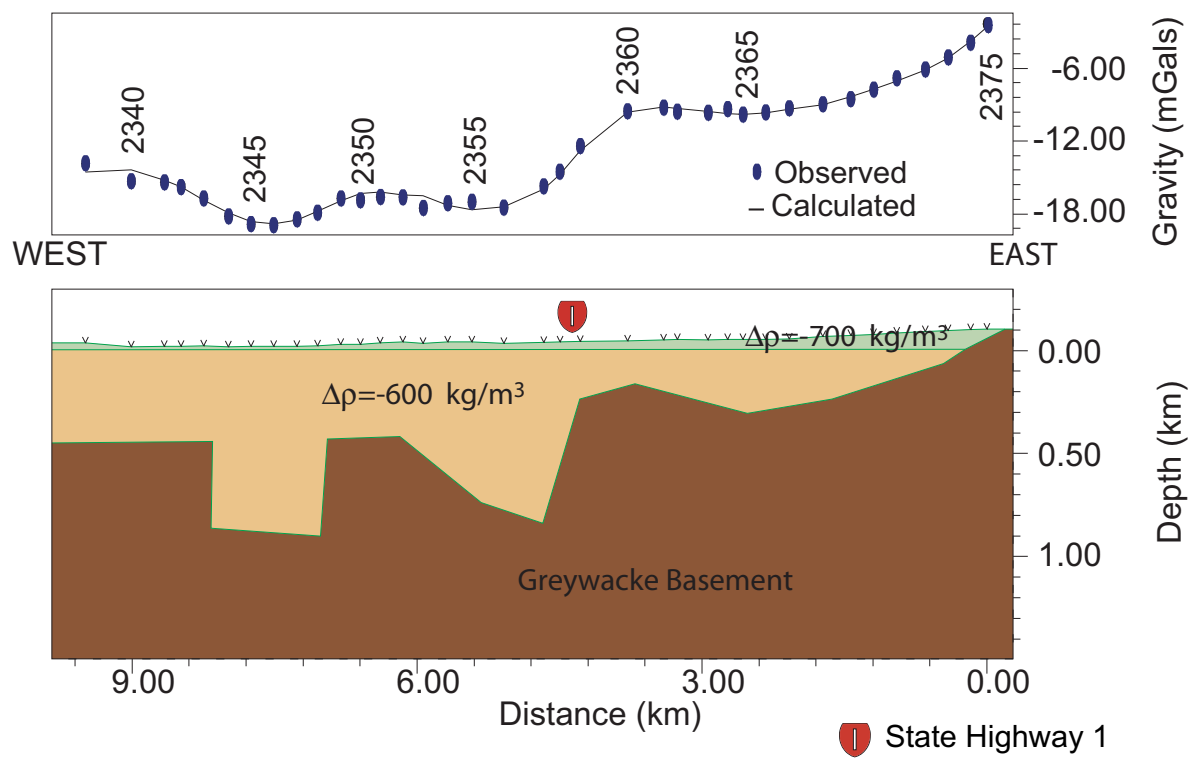

(a) Levin line $301 \& 302$

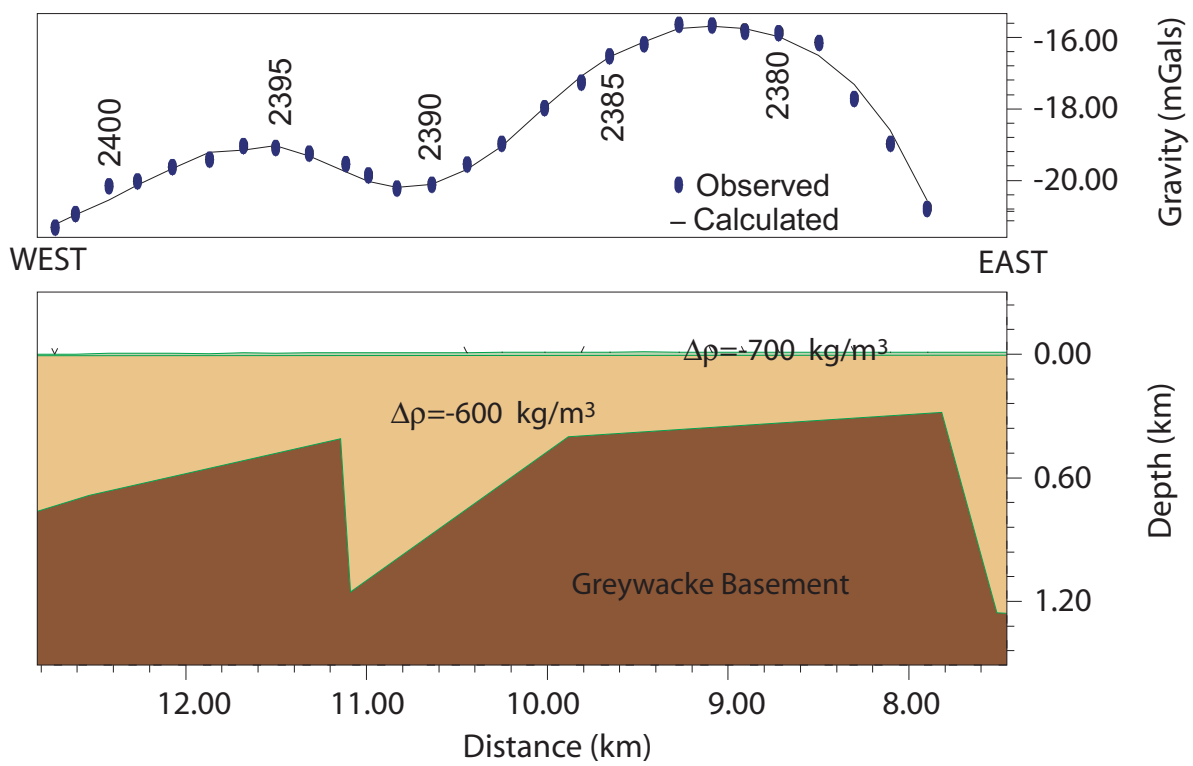

(b) Levin line 303

Figure 3.29: Levin residual gravity profiles: top panels in the figures show the residual gravity measurements (blue dots) and the calculated gravity values (black lines). Bottom panels represent the corresponding density models. The surrounding material (brown layer) is assumed to be greywacke with a density of $2670 \mathrm{~kg} / \mathrm{m}^{3}$. The zero position on the $\mathrm{x}$-axis is equivalent to the location of gravity point 2375. The vertical size of the datapoints represents error bars. Depth is relative to sea level, and there is a vertical exaggeration of 4 .

the three lines (301, 302 and 303) is similar, but the lines 301\&302 only have half 


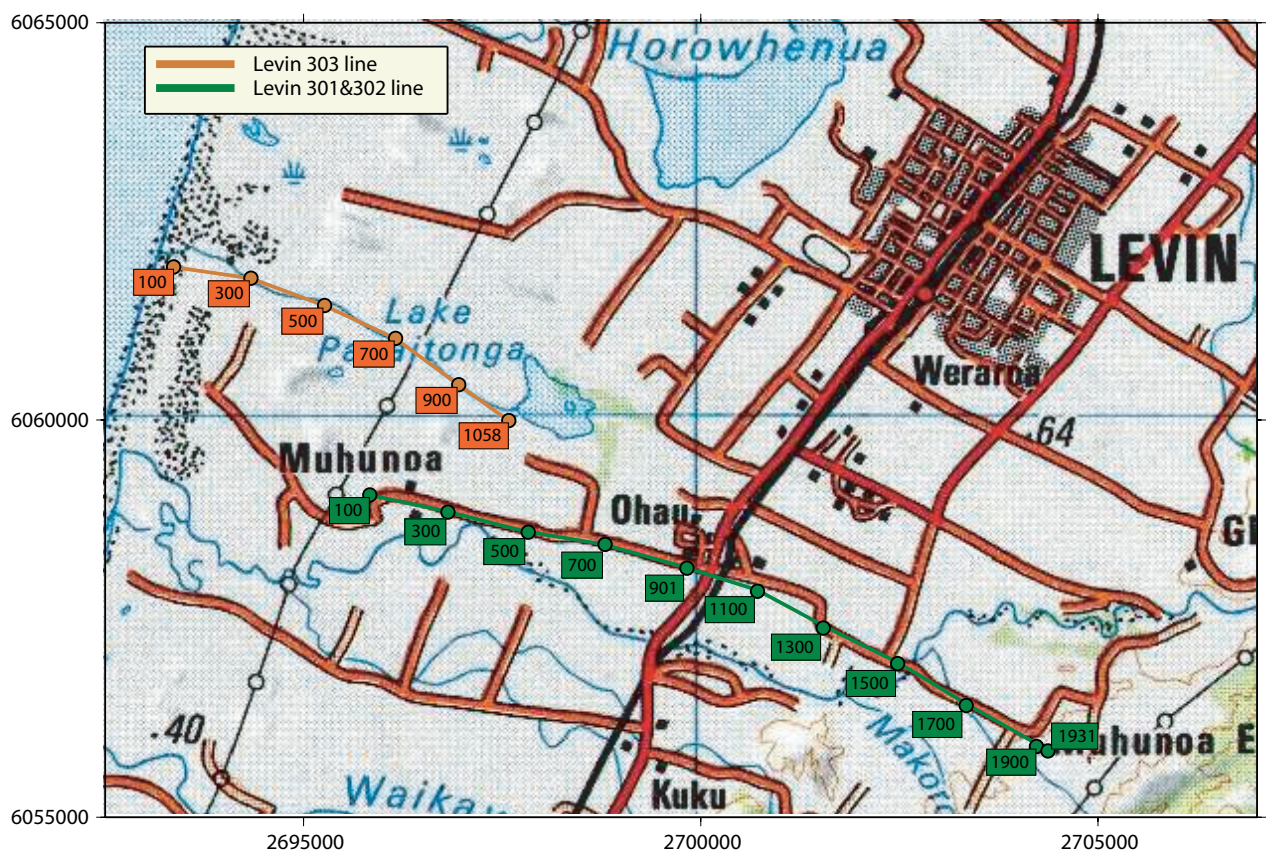

Figure 3.30: Detailed location map for the Levin seismic survey. It consists of three east-west lines. Different seismic sources were used: line 303 (orange line) was shot using explosives; lines 302\&301 (green line) were shot using a MiniSosie signal generator and were shot pre-stack.

\begin{tabular}{|c|c|c|}
\hline LINE ID: & Levin 301\&302 & Levin 303 \\
\hline Source & 3-Mini-Sosie $(65 \mathrm{~kg})$ & Powergel $^{T M} 165-330 \mathrm{~g}$ \\
Shot interval & $10 \mathrm{~m}$ & $20 \mathrm{~m}$ \\
Shot depth & $0 \mathrm{~m}$ & $1 \mathrm{~m}$ \\
Geophone spacing & $5 \mathrm{~m}$ & $5 \mathrm{~m}$ \\
Number of geophones & 48 & 48 \\
Spread & end shots & end shots \\
Min offset & $60 \mathrm{~m}$ & $60 \mathrm{~m} \mathrm{\&} 0 \mathrm{~m}$ \\
Max offset & $530 \mathrm{~m}$ & $420 \mathrm{~m}$ \\
Sampling interval & $1 \mathrm{~ms}$ & $1 \mathrm{~ms}$ \\
Recording length & $3000 \mathrm{~ms}$ & $3000 \mathrm{~ms}$ \\
Fold (maximum) & constant (24) & constant (12) \\
\hline
\end{tabular}

Table 3.8: Field parameters for the seismic lines in the Levin survey

the shot interval (double the seismic fold) of line 303. Furthermore, these two lines were shot with a Mini-Sosie as a seismic source instead of explosives. An overview of the field parameters can be found in table 3.8 . 


\subsubsection{Interpretation}

Interpretation for lines 303 and $301 \& 302$ is done separately, because they have no direct overlap. However, line 303 is only offset by $1.2 \mathrm{~km}$ to the north from lines $301 \& 302$ and therefore some correlation should be attempted. In the summer 2003/2004 a 277 m deep borehole, with good core-logging, was drilled at the southwestern corner of the Levin township, $3 \mathrm{~km}$ north of the line. This allows, in contrast to the interpretations of the other seismic lines in this chapter, a stratigraphic analysis of some of the observed horizons. Hughes [2005] who worked on the stratigraphy and facies analysis of the drillhole, linked his results with the seismic horizons mapped by Aharoni [1991]. Here, their interpretations get reassessed and revised with the new processed dataset. The differences get listed and a summary of the previous results, if still valid, will be given.

Levin 301\&302 Figure 3.31 shows the seismic section of lines $301 \& 302$. This section has a high signal-to-noise ratio and reflectivity can be observed down to 600-700 ms, between CDP 300 and 500, maybe even deeper.

Six main seismic reflectors are picked, correlated and labelled from top to bottom. A description of the different events follows:

Reflector-1 (brown) is a high-amplitude shallow event at approximately $120 \mathrm{~ms}$ TWTT. It can be traced west of CDP 900. At least five faults disrupt this horizon.

Reflector-2 (orange) is also a high-amplitude shallow reflector, but it is of slightly better continuity than Reflector- 1 and it can be almost continuous traced across the section. It defines the top of a high-amplitude zone. This highamplitude zone shows some dip to the west, without much convergence of the reflectors within it.

Reflector-3 (green) is located within the high-amplitude zone just underneath Reflector-2. It is subparallel to Reflector-2 and is also visible in the same areas.

Reflector-4 (yellow) is another distinct, clear, high-amplitude reflector within the high-amplitude zone. It is located at a TWTT of around $250 \mathrm{~ms}$ and is onlaping the basement high at CDP 600.

Reflector-5 (light blue) marks the bottom of the band of high-amplitude reflectivity and can be traced continuously across the whole section. This horizon shows large offsets around CDP $300(150 \mathrm{~ms})$ and around $\sim$ CDP 1200 (80 ms).

Reflector-6 (dashed purple) is an irregular, undulating, low frequency basement reflector. This reflector is hard to pick along the whole section due to its 

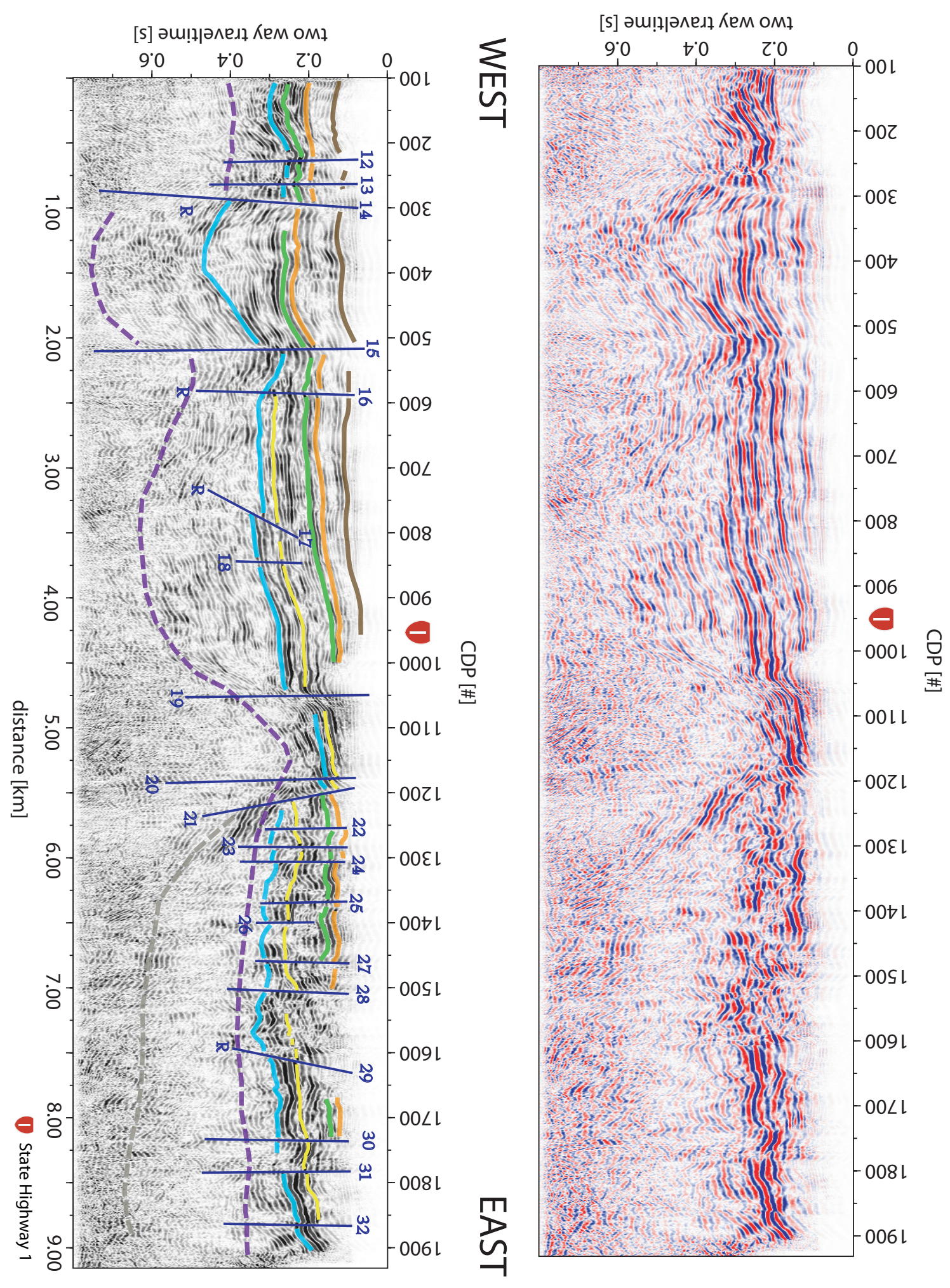

Figure 3.31: Final time-migrated section of the merged Levin 301 \& 302 lines (top) and the interpreted section (bottom). CDP spacing is $2.5 \mathrm{~m}$. Joining point is CDP 1010: west of this point is line 301; east of this point is line 302. 
irregular nature. Thus, often the change in characteristic within the section is used to identify the basement reflector. Three basement highs are visible, one west of CDP 300, one around CDP 550 and one at approximately CDP 1100. They are separated by distinct basement troughs, especially between CDP 300 and 500 with a TWTT of $700 \mathrm{~ms}$ or deeper (end of recording length). Initially, east of CDP 1200, the basement reflector was picked along the dashed grey line which is the lowermost undulating event. However, comparison with the gravity data interpretation along this line (section 3.4.1) suggests a shallow basement. Therefore, the basement horizon (dashed purple line) gets assigned to another undulating, low frequency horizon, just underneath Reflector-5, at a depth which is in better agreement with the gravity model. A detailed discussion about the nature of the grey reflector and its implications can be found in section 3.6.

At least 22 faulting structures can be identified and almost all of them are highangle/vertical faults. There are four faults (Fault-3, Fault-6, Fault-7, Fault-19) which are interpreted as reverse faults and one fault (Fault-11) is interpreted as a normal feature. All faults apart from Fault-7 and Fault- 8 are offsetting the top reflector (yellow).

Levin 303 Figure 3.32 shows the seismic section for line 303. This line has the highest signal-to-noise ratio of all the processed seismic sections in this chapter, with clear seismic horizons.

Six main seismic reflectors are picked, correlated and labelled from top to bottom. A description of the different events follows:

Reflector-1 (brown) is a high-amplitude shallow event at approximately $150 \mathrm{~ms}$ TWTT. It can be traced across all CDPs with a constant dip to the west. This horizon is only offset by Fault- 4 and Fault- 5 and corresponds well with the brown horizon in section 301\&302.

Reflector-2 (orange) can only be traced west of CDP 670 where it onlaps Reflector-5. The amplitude is lower than for Reflector-2 in section 301\&302. It also has a constant dip to the west.

Reflector-3 (green) is subparallel to Reflector-2 and onlaps Reflector-4 at CDP 650. It has a slightly better continuity than the horizon above. The time gap between Reflector- 2 and Reflector-3 is slightly smaller east of CDP 400. This horizon has an average TWTT of $300 \mathrm{~ms}$.

Reflector-4 (yellow) is like in section 301\&302 a distinct, clear, high-amplitude reflector within the high-amplitude zone. Starting in the east, this horizon dips relatively constantly till CDP 700, where its starts to steepen. West of Fault-5 it dips again with a constant rate.

Reflector-5 (light blue) marks the bottom of the band of high-amplitude reflec- 

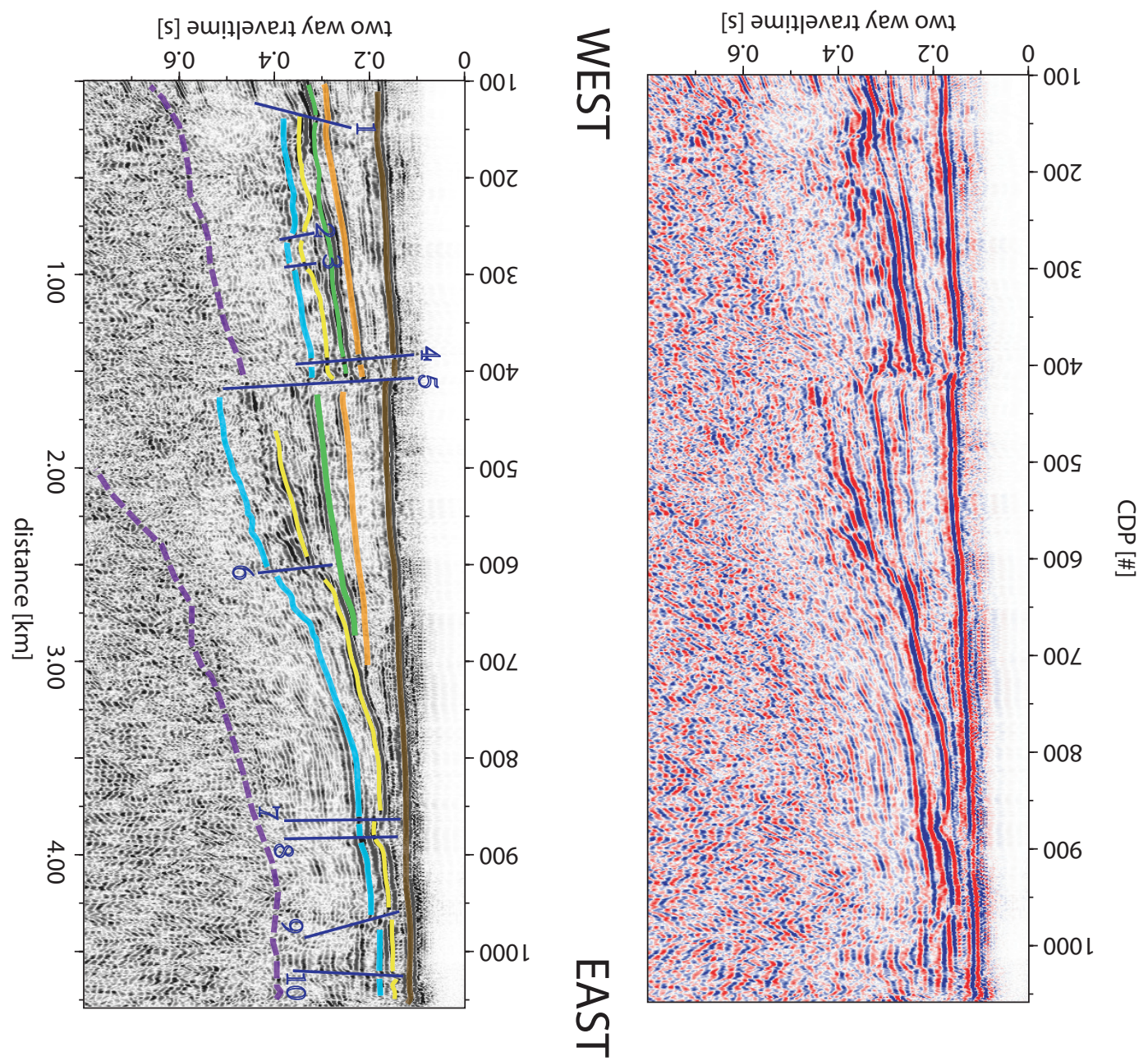

Figure 3.32: Final time-migrated section of the Levin 303 line (top) and the interpreted section (bottom). CDP spacing is $2.5 \mathrm{~m}$.

tivity and is subparallel to Reflector-4. It can be traced across the whole section.

Reflector-6 (dashed purple) is an irregular, undulating, low frequency basement reflector. It is hard to identify just east of CDP 400 and could drop below the actual recording time. Like the layer above it steepens towards Fault- 5 and dips with a constant angle west of it.

Eight faults can be identified, again with a high-angle. However, Fault- 4 shows a good example for a normal fault in the southeastern corner of the SWB. It offsets the top reflector by $20 \mathrm{~ms}$ and the basement reflector by at least $130 \mathrm{~ms}$. Fault-1, Fault-5, Fault-6, Fault-7 and Fault-8 are rupturing every horizon below Reflector1. Fault-2 and Fault-3 are rupturing every horizon underneath Reflector-3.

The chronological interpretation of some of the horizons is done based on deep drillhole data [Hughes, 2005]. In the interpretation by Hughes [2005] the drillhole 
is intersected by three seismic horizons [Aharoni, 1991] at a depth of $\sim 260 \mathrm{~m}$, $\sim 120 \mathrm{~m}$ and $\sim 40 \mathrm{~m}$. At the location of the drillhole the seismic horizons presented here agree well with Aharoni [1991] seismic section. Therefore, the interpretation by Hughes [2005] can be applied to our results:

Reflector-1 (brown): bottom of old flood plain (base of last Glacial strata); depth: $40 \mathrm{~m}$, age: $70 \mathrm{ka} \Rightarrow$ average sedimentation rate $=5.7 \mathrm{~mm} / \mathrm{a}$

Reflector-2 (orange) or Reflector-3 (green): change from coastal to marine strata (approximately base of last interglacial strata); depth: $100 \mathrm{~m}$, age: $120 \mathrm{ka} \Rightarrow$ average sedimentation rate of $8.3 \mathrm{~mm} / \mathrm{a}$

Reflector-5 (light blue): bottom of four sedimentary cycles (deposited during transgression, with a period of $100 \mathrm{ka}$ ); depth: $240 \mathrm{~m}$, age $340 \mathrm{ka} \Rightarrow$ average sedimentation rate $=7.0 \mathrm{~mm} / \mathrm{a}$

An average sedimentation rate of around $7 \mathrm{~mm} / \mathrm{a}$ for the last $340 \mathrm{ka}$ follows from the data above.

There are two main differences in the interpretation of the Levin fault (Fault14) between Aharoni [1991] and the here presented study: Firstly, the offset for Reflector-5 is significantly smaller with only $\sim 160 \mathrm{~m}$ compare to $\sim 240 \mathrm{~m}$ found by Aharoni [1991]. This results in an uplift rate of $\sim 0.5 \mathrm{~mm} / \mathrm{a}$ based on an age of $340 \mathrm{ka}$ for Reflector-5. This is $0.2 \mathrm{~mm} / \mathrm{a}$ less than calculated by Hughes [2005]. Secondly, the here presented interpretation shows a displacement of the shallowest horizons. This makes the Levin fault younger than $70 \mathrm{ka}$.

The locations of the ridges and troughs along the profile line are similar in both studies but with some differences in depth estimation. In this study, the Poroutawhao High (CDP 100-300 in section Levin 301\&302 and CDP 900-1100 in section Levin 303) is located at a depth of around $400 \mathrm{~m}$, compared to $\sim 200 \mathrm{~m}$ as proposed by Aharoni [1991]. Furthermore, the Waiwiri Trough (CDP 400-600 in section Levin 303) is at a greater depth with around $1 \mathrm{~km}(700 \mathrm{~m}$ in Aharoni's interpretation). All other features show similar characteristics and do not need alteration from the interpretation by Aharoni [1991].

\subsubsection{Summary results Levin survey}

The basement along the profile shows a complex, undulating topography (wavelength $\sim 4 \mathrm{~km}$ ), with a depth between a shallow $100 \mathrm{~m}$ and up to $1 \mathrm{~km}$ in some deep troughs. The basement depth interpreted in this study is around $50 \%$ deeper than in Aharoni [1991]. Seismic reflection and gravity data reveal a series of highangle faults, which are interpreted as vertical faults. Five faults located along line 303 can be interpreted as normal. Two faults along lines 301\&302 are interpreted as reverse. Aharoni [1991] interpreted some faults differently, but the separation into two different zones of faulting is still valid; west of the Levin fault a 
more extensional stress regime was active, whereas east of the Levin fault a more compressional regime was active. However, it can be difficult to differentiate between normal and reverse faulting, especially in shallow seismic sections with high-angle faults.

Some of the horizons show evidence for syntectonic sedimentation with a steeper dip for older sediments, because of a longer deforming period. Furthermore, the majority of the observed faults in the east offsets all horizons making them younger than $70 \mathrm{ka}$. However, in the western section only two faults rupture the youngest horizon, which makes the majority of faults in this section older than $70 \mathrm{ka}$. This is in contrast to Aharoni [1991], who interpreted faults to the west of the Levin fault to be younger than the ones to the east. The difference in interpretation is mainly due to an enhanced quality of the newly processed stacked seismic section where the shallow horizons are more clearly imaged and therefore more easily interpreted.

Also in contrast to Aharoni [1991], the Levin fault is interpreted as a reverse fault, but with a similar uplift rate of $\sim 0.5 \mathrm{~mm} / \mathrm{a}$. The interpretation of the basement east of CDP 1200 in lines $301 \& 302$ is chosen to be in agreement with gravity results. It is around $200 \mathrm{~ms}$ shallower than initially interpreted (grey line) based on seismic reflection data. The nature of the lowest reflector is discussed in more detail in section 3.6, as it has possible implications for the Miocene tectonics of this region.

\subsection{Foxton survey}

The Foxton survey consists of two gravity and one seismic reflection line. In figure 3.33 the orange line indicates the initial gravity line using data from the GNS Sciences database. Based on the interpretation of this profile, a seismic reflection (blue line in figure 3.33) and a more detailed gravity survey were conducted (green points in figure 3.33). Due to heavy traffic along the road of the initial gravity profile, the new line was conducted $\sim 1.6 \mathrm{~km}$ southwards along Newth Road.

\subsubsection{Gravity method}

The initial gravity profile (line Foxton, blue line in figure 3.33 ) is around $26 \mathrm{~km}$ long. It starts in the east at Mangahao Power Station, runs through Shannon township along Foxton Shannon Road through Foxton township and ends at Foxton Beach. It consists of 34 datapoints, all taken from the GNS Sciences database. The profile, containing the projected gravity points, consists of one 10 and one $15 \mathrm{~km}$ long leg with an angle of $47^{\circ}$ between them (figure 3.33). 


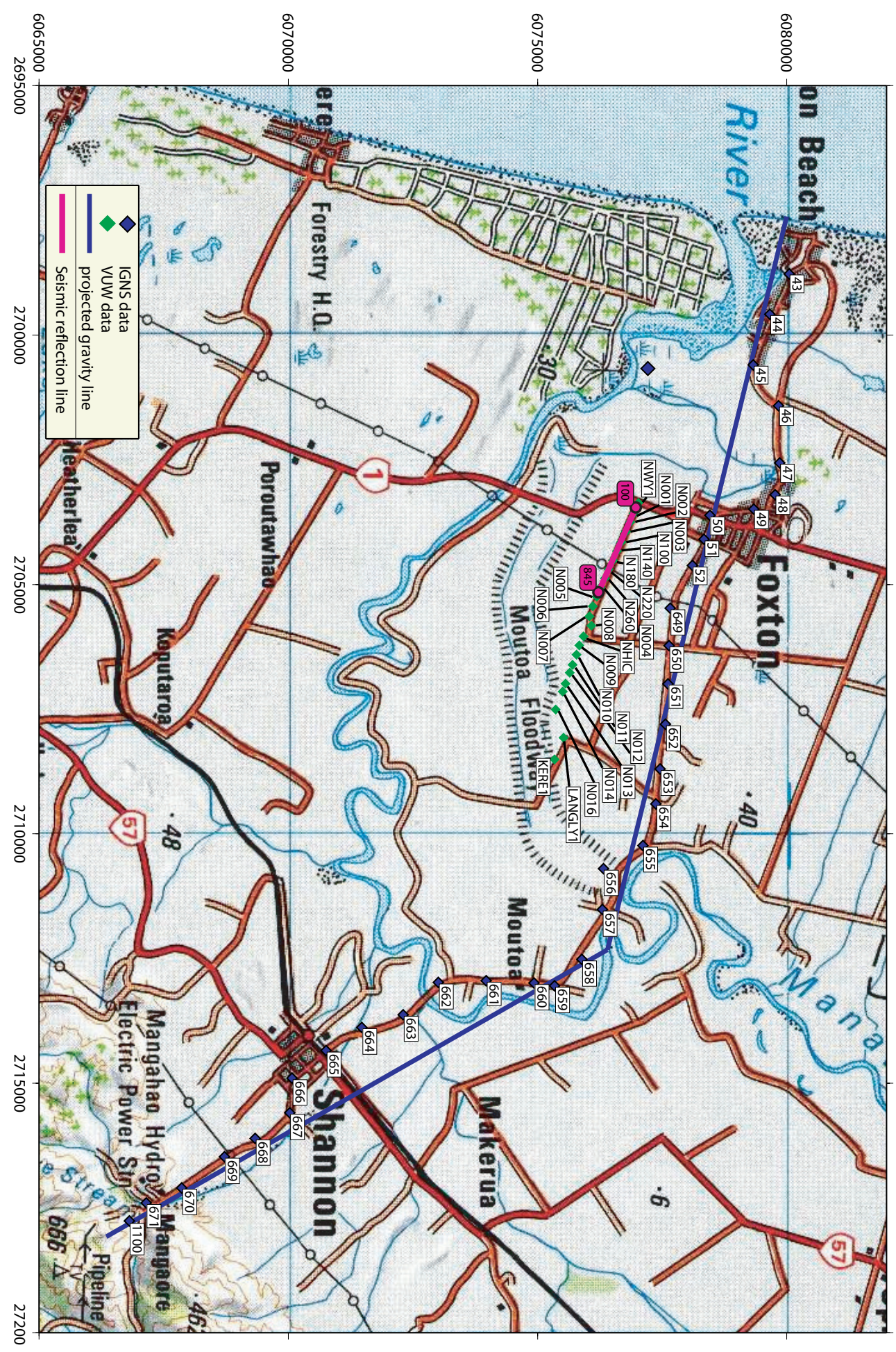

Figure 3.33: Location map of the data points used for the Foxton gravity/seismic survey. Gravity measurements consist of GNS Sciences data (blue squares) and VUW data (green squares). All points are projected onto the corresponding profile line. Seismic profile location is shown as blue line with the corresponding CDP-bin number of start and end point. 
The line along Newth Road (green points in figure 3.33) has 25 datapoints and runs along Newth Road and then along a farm track to the east. It is oriented in the same direction (east-west) as line Foxton but with a smaller station spacing and a length of $\sim 5 \mathrm{~km}$.

The raw gravity measurements are first reduced to Bouguer gravity values, followed by the calculation of the regional field, which is then used to reduce the data to residual gravity values. A detailed discussion of the estimation of the regional gravity field as well as other aspects of gravity data analysis can be found in appendix B.

Residual gravity modelling assumes a three-layer model with densities identical to the ones used in the Waikawa (section 3.3) and Levin survey (section 3.4). Thus, the densities for the layers are: top layer $1900 \mathrm{~kg} / \mathrm{m}^{3}$ [Hunt, 1980], second layer $2000 \mathrm{~kg} / \mathrm{m}^{3}$, surrounding greywacke basement $2670 \mathrm{~kg} / \mathrm{m}^{3}$.

Figure 3.34(a) shows the final model for line Foxton. Starting at the east where the basement outcrops at around $-13 \mathrm{~km}$ along the profile, the basement first drops to $\sim 1.7 \mathrm{~km}$ depth before it is upthrown to a depth of $\sim 600 \mathrm{~m}$ at kilometre 8 along the profile. This basement high itself has slight dip $\left(\sim 5^{\circ}\right)$ to the west and is intersected by a $600 \mathrm{~m}$ deep, $1.4 \mathrm{~km}$ wide basement trough. The flanks of the basement high are modelled as vertical features.

The line along Newth Road was planned to investigate the flanks and the top of the basement high (between kilometre 5.6 and kilometre 8.5) in more detail. The gravity model in figure 3.34(b) shows a basement high along Newth Road, similar to the one observed along the Foxton profile line. Depths to the basement high are identical with $\sim 500 \mathrm{~m}$ in the east and $\sim 600 \mathrm{~m}$ in the west. However, the offsets at the vertical flanks are different with only $\sim 800 \mathrm{~m}$ in the east and over $\sim 1200 \mathrm{~m}$ in the west. The western edge of the Newth Road model is only partly constrained as the gravity datapoints only reach to kilometre 8.6 along the profile. Including a second basement rise, further to the west, would make the trough even deeper, therefore this anomaly is modelled as a single up-thrown block.

\subsubsection{Seismic reflection method}

The seismic reflection dataset (figure 3.35) was collected during two different field experiments in April 2005 and April 2006. Both lines had approximately the same length $(\sim 1200 \mathrm{~m})$, where one was conducted with a $10 \mathrm{~m}$ shot spacing (Foxton05) and one with a $5 \mathrm{~m}$ shot-spacing (Foxton06). However, the higher seismic fold of Foxton06 did not result in a higher signal-to-noise ratio because it was mostly shot with split-spread geometry with small minimum offsets. An overview of the field parameters can be found in table 3.9. 


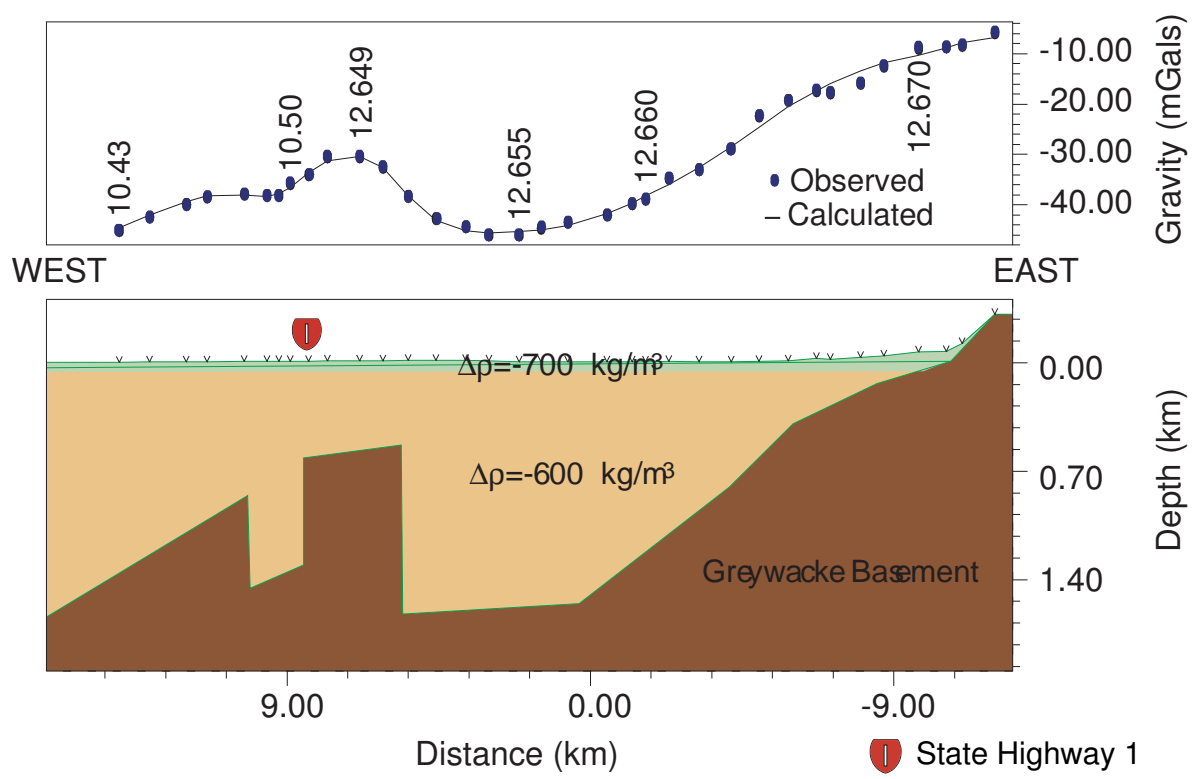

(a) Foxton gravity profile
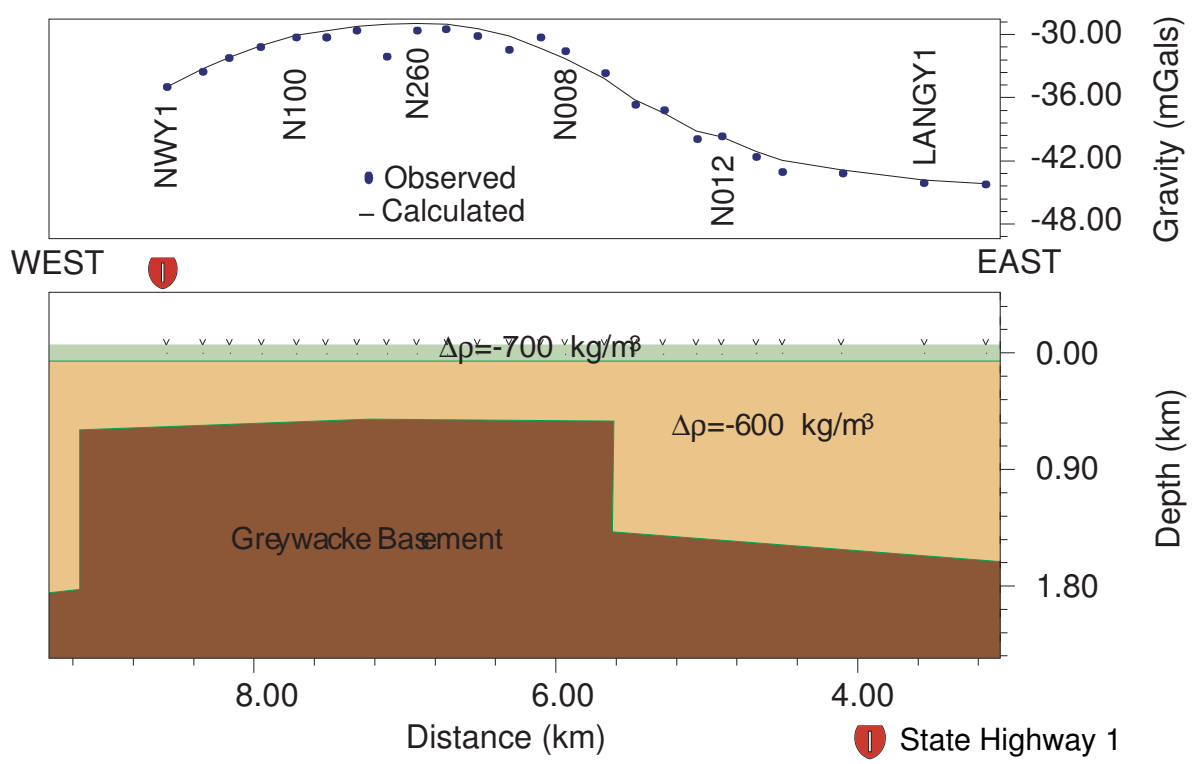

(b) Newth Road gravity profile

Figure 3.34: Foxton/Newth Road residual gravity models: top figures show the residual gravity measurements (blue dots) and the calculated gravity values (black lines). Bottom figures represent the corresponding density models. The surrounding material is assumed to be greywacke with a density of $2670 \mathrm{~kg} / \mathrm{m}^{3}$. The zero position on the x-axis is equivalent to the bend in the projected Foxton profile line. Note the different scales between the profiles. The vertical size of the datapoints represents error bars. Depth is relative to sea level, and there is a vertical exaggeration of 1.2 . 


\begin{tabular}{|c|c|c|}
\hline LINE ID: & Foxton05 & Foxton06 \\
\hline Source & EG\&G thumper & hydraulic thumper \\
Shot interval & $10 \mathrm{~m}$ & $5 \mathrm{~m}$ \\
Shot depth & $0 \mathrm{~m}$ & $0 \mathrm{~m}$ \\
Geophone spacing & $5 \mathrm{~m}$ & $5 \mathrm{~m}$ \\
Number of geophones & 48 & 48 \\
Spread & end shots, roll box & variable split spread \\
Min offset & $60 \mathrm{~m}$ & $60 \mathrm{~m} \& 0 \mathrm{~m}$ \\
Max offset & $530 \mathrm{~m}$ & $420 \mathrm{~m}$ \\
Sampling interval & $1 \mathrm{~ms}$ & $1 \mathrm{~ms}$ \\
Recording length & $3000 \mathrm{~ms}$ & $3000 \mathrm{~ms}$ \\
Fold (maximum) & constant (12) & variable $(24)$ \\
\hline
\end{tabular}

Table 3.9: Field parameters for the seismic lines in the Foxton survey

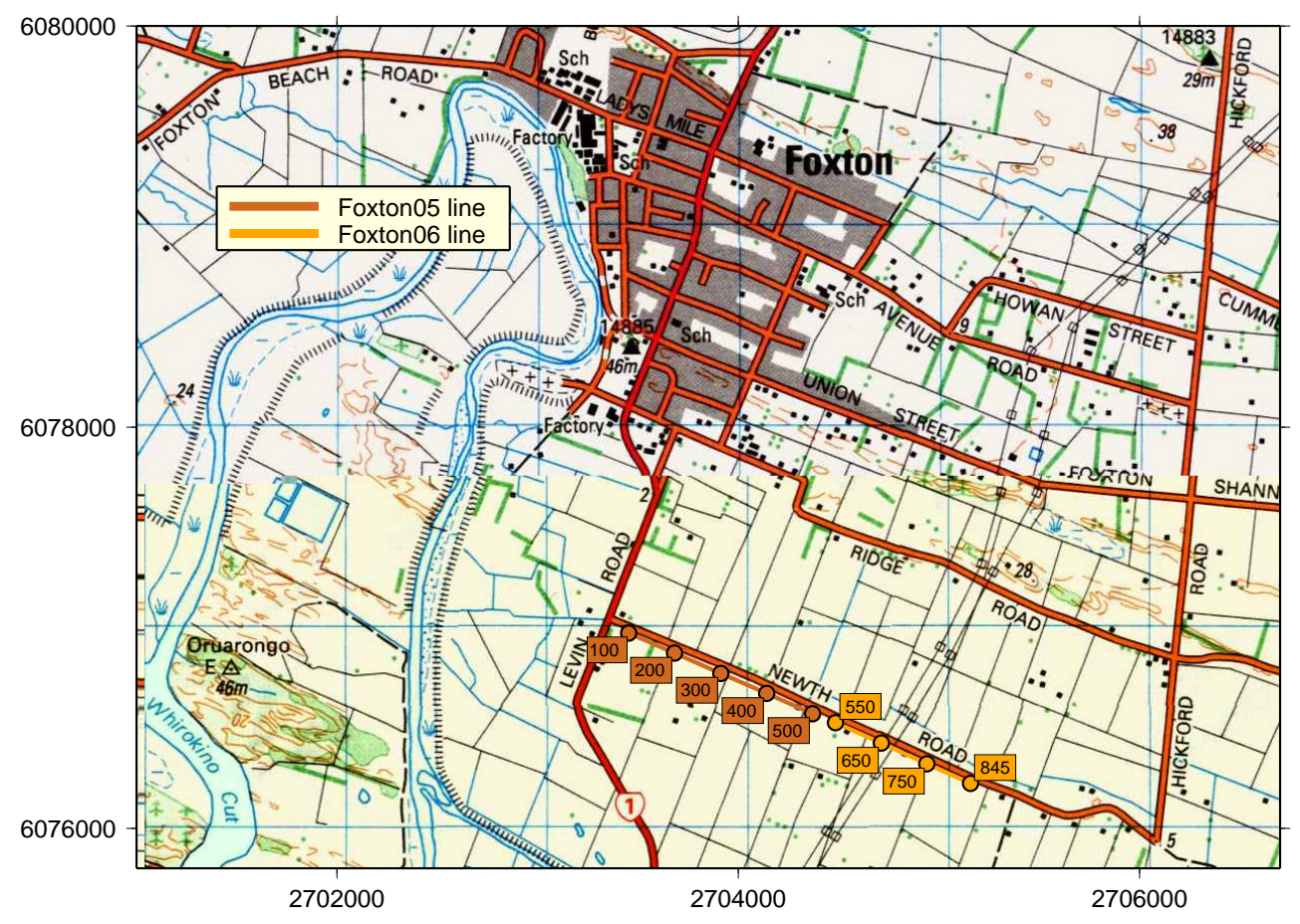

Figure 3.35: Detailed location map for the Foxton seismic survey. The numbers represent the location of the corresponding CDP-bin number.

\subsubsection{Interpretation}

Figure 3.36 shows the final stacked section along Newth Road. It is overall of good quality with the deepest coherent events at around $700 \mathrm{~ms}$ TWTT. The 


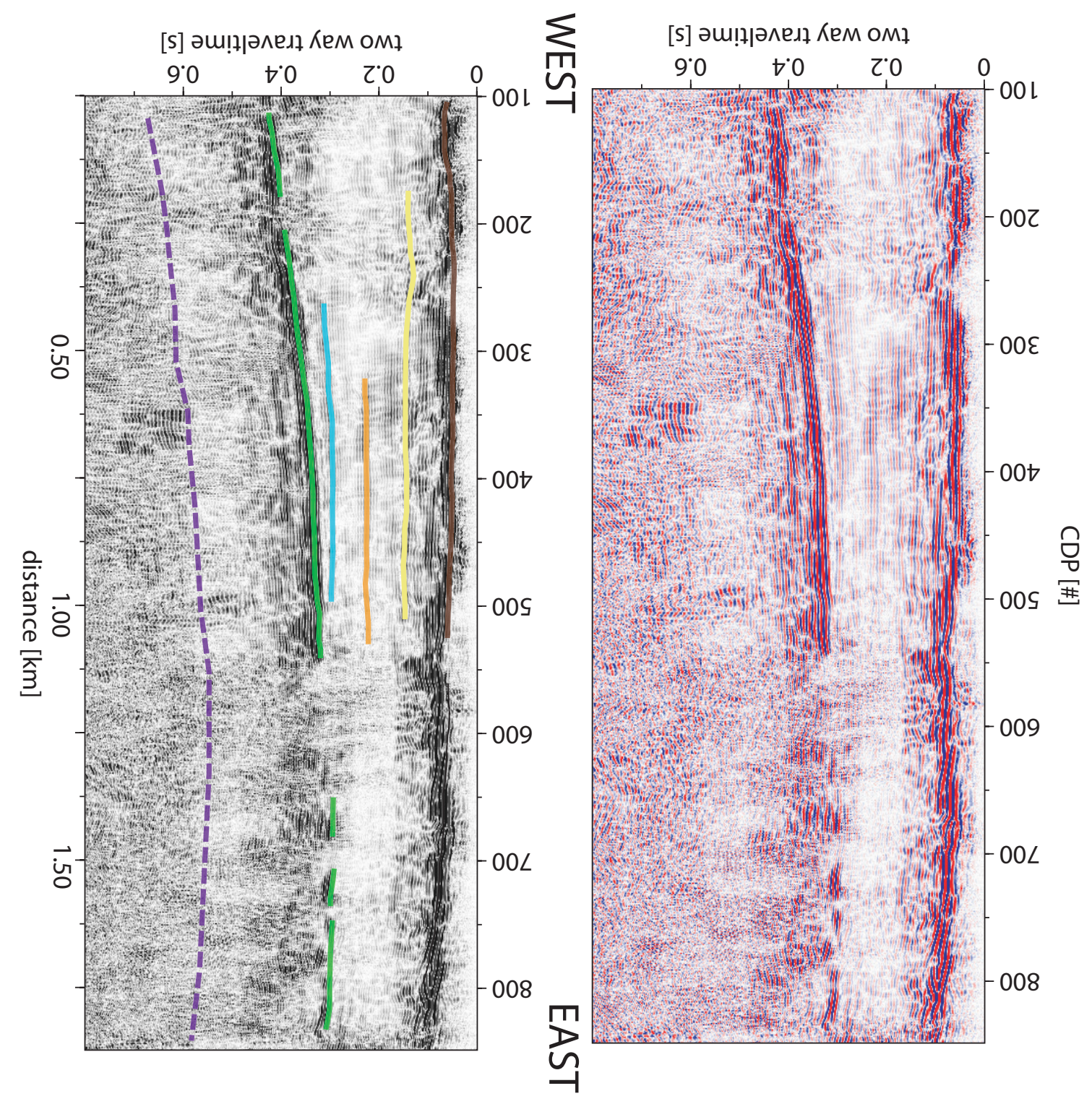

Figure 3.36: Final time-migrated section of the Foxton line (top) and the interpreted section (bottom). CDP spacing is $2.5 \mathrm{~m}$.

joining point of the two different datasets is around CDP 550. To the east of this the quality decreases, but main events are still visible. All the horizons are continuous and not disrupted by faulting structures.

Four main seismic reflectors are picked, correlated and labelled from top to bottom. A description of the different events follows below:

Reflector-1 (brown) is the strong, continuous top reflector, traceable through all CDPs. The TWTT for this flat reflector is $\sim 80 \mathrm{~ms}$.

Reflector-2 (yellow) marks the bottom of the band of high-amplitude reflectiv- 
ity and can be traced in the same area as Reflector-1. It is as continuous and flat but much less coherent.

Reflector-3 (orange) is a low amplitude reflector in the zone between the amplitude bands of reflectivity. It is only traceable west of CDP 500.

Reflector-4 (light blue) similar to Reflector-3. This horizon is located just above the high reflectivity zone (at $400 \mathrm{~ms}$ ) and onlaps (from the west) Reflector-5 at CDP 500.

Reflector-5 (green) is a distinct reflector. It has the highest amplitude and is the most continuous event of the whole section. The TWTT of the horizon is in average $\sim 380 \mathrm{~ms}$ and it is curved with its apex at around CDP 600 .

Reflector-6 (dashed purple) is an irregular, undulating and low frequency basement reflector. It can mainly be traced due to the change in frequency characteristic of the stacked section across it. Located at a TWTT of $\sim 600 \mathrm{~ms}$, it is subparallel to Reflector-3.

The seismic section shows no sign of any faulting. Noteworthy is that Reflector3 and 4 both show a curved shape whereas Reflector- 1 and 2 are flat.

\subsubsection{Discussion and summary of results from the Foxton sur- vey}

The gravity line through Foxton township shows a basement with two distinct upthrown basement blocks at a depth between 500 and $1700 \mathrm{~m}$. The eastern basement block is imaged by a more detailed gravity line $1.5 \mathrm{~km}$ to the south. Both gravity profiles show the flanks of this basement high as vertical features. A seismic reflection profile conducted to investigate this feature could only image the top of the horst. Nevertheless, the data confirm the depth of the basement high and its dome-like structure. The top three horizons do not show any curvature, which indicates that the compression acting on this horst, creating the arc shape of the top, stopped between the sedimentation of horizon 4 and horizon 2 .

The high-amplitude Reflector-5 cannot be correlated to any other seismic sections presented in this chapter or offshore seismic lines in the SWB [Anderton, 1981; Lamarche et al., 2005; Proust et al., 2005]. However, a seismic reflection line $22 \mathrm{~km}$ to the north, in the onshore part of the SWB, shows a series of highly reflective sediments [Melhuish et al., 1996]. The two horizons, which most likely correlate to the observed Reflector-5, are a $0.94 \mathrm{Ma}$ and a $1.2 \mathrm{Ma}$ old horizon within the Castlecliffian sequence. This sequence contains some lignite, which has a lower density than sand and clay. Therefore, a lignite seam should have a negative reflection coefficient within a sediment sequence [Milkereit et al., 1986]. Missing arrivals in the refraction data from a depth of around $400 \mathrm{~m}$ (refraction data not presented in this study) could be one indication for a negative impedance 


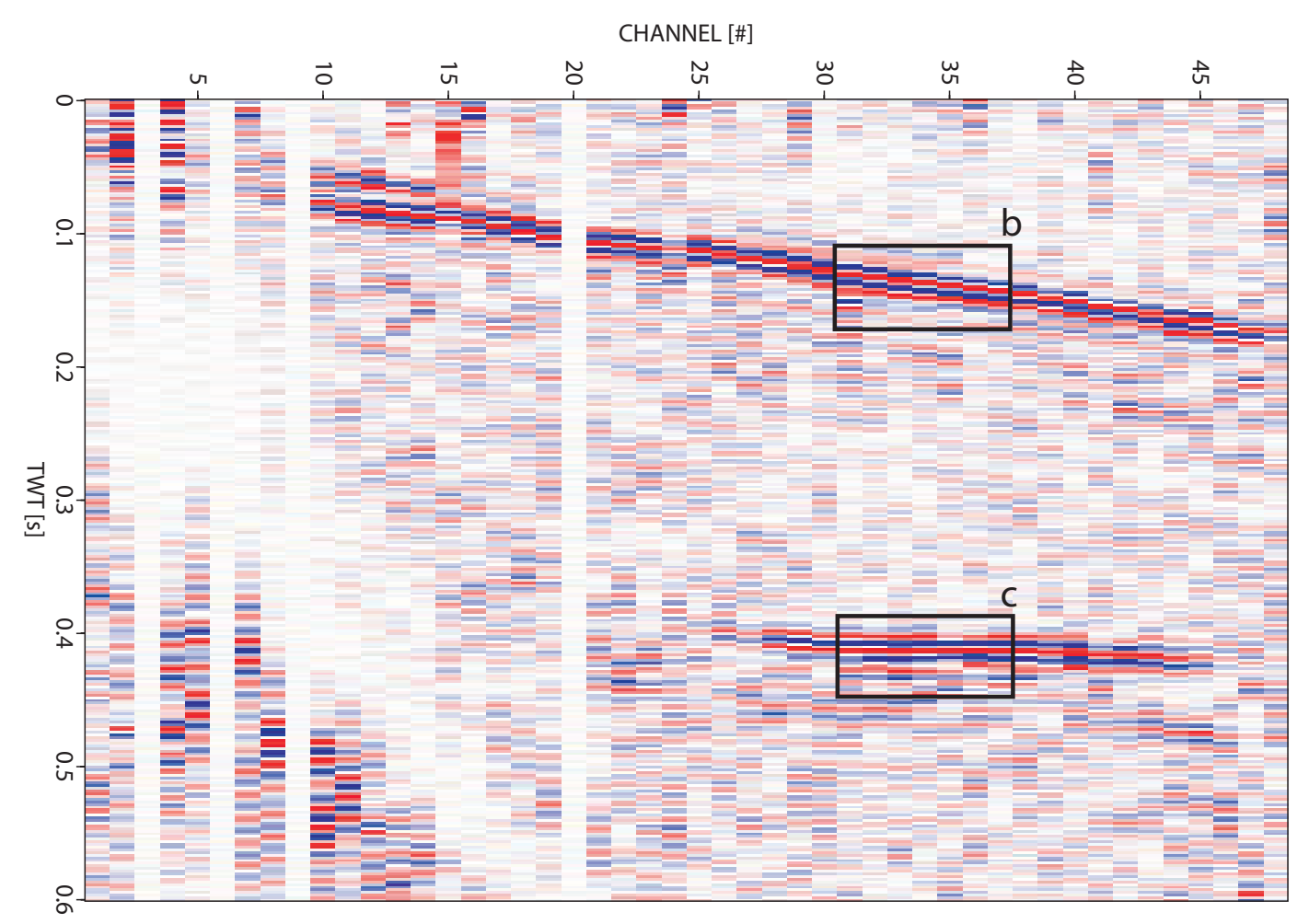

(a) Shotgather \# 24

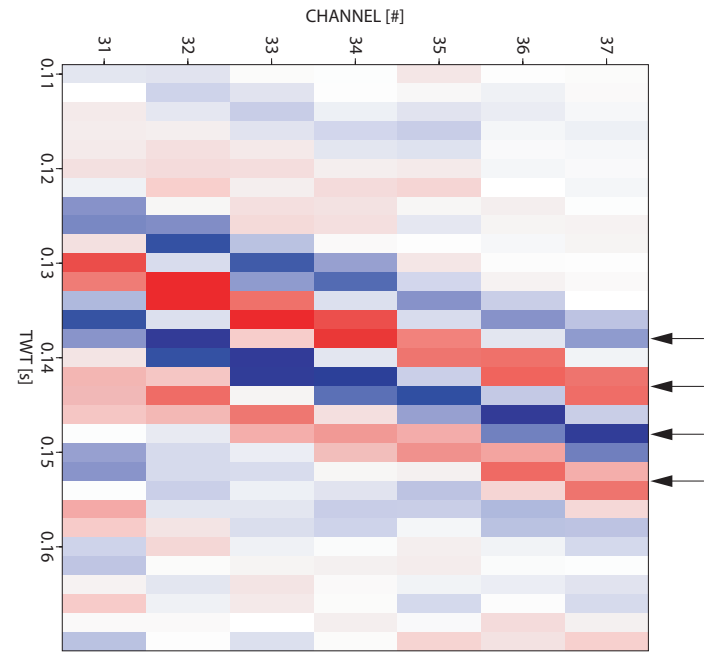

(b)

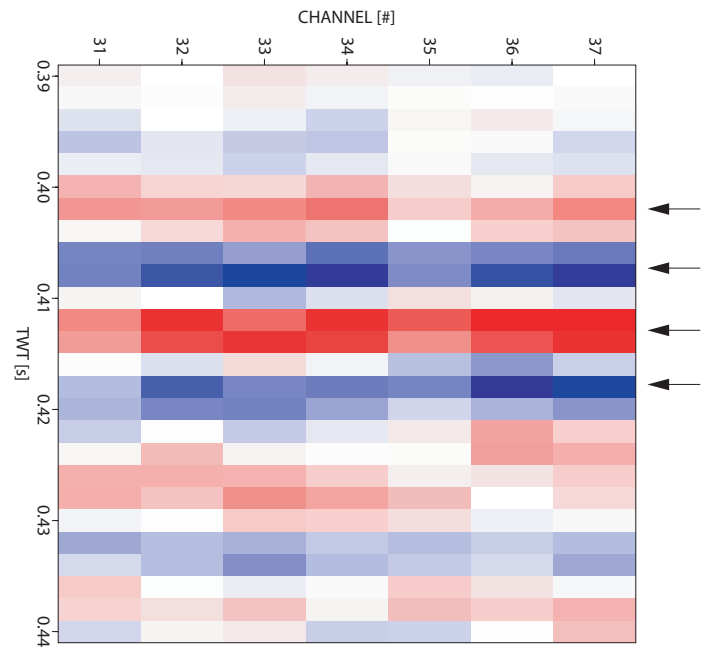

(c)

Figure 3.37: Shotgather (shotid \# 24) after band-pass filtering, fk-filtering and deconvolution (for parameters see section A.1.3.4). Colour represents the amplitude (red-positive, blue-negative). A phaseshift is assumed between the top reflector (around $100 \mathrm{~ms}$ ) and the strong second reflector, which would indicate a negative reflection coefficient.

contrast. A wavelet reflected on such a negative velocity contrast would experience a $180^{\circ}$ phaseshift (figure 3.38). To evaluate such a phaseshift, a zero-phase 

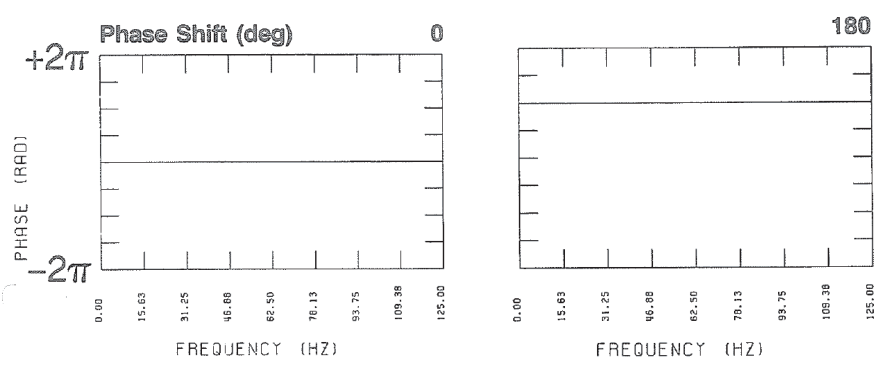

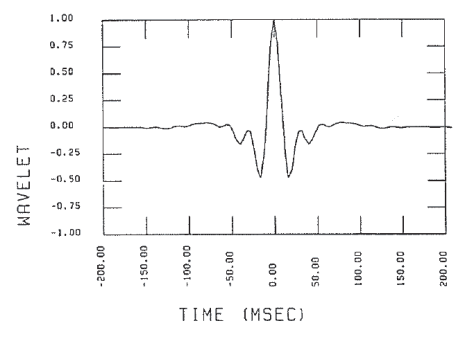

(a)

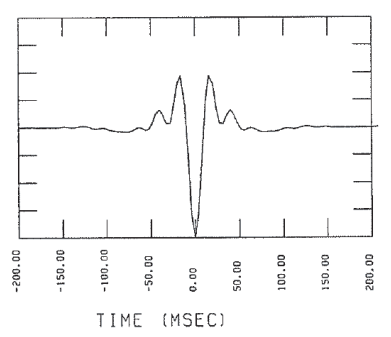

(b)

Figure 3.38: Figure (a) shows a zero-phase wavelet with an $\mathrm{O}^{\circ}$ phaseshift. Panel (b) shows the wavelet after experiencing a $180^{\circ}$ phaseshift. The polarity of the wavelet is reversed after the phaseshift [Yilmaz, 1987].

wavelet has to be present in the data, which is difficult to achieve [Brown, 2001]. Figure 3.37 shows a processed shotgather (shotid \# 24) from the Foxton line, displayed as a variable density plot, with the colours representing different amplitudes (darker colours indicating higher amplitude values). In real data, this allows easier identification of polarity changes. A perfect zero-phase wavelet could not be achieved, because the wavelet consists of two positive and two negative peaks. However, comparing the two enlarged sections (figure 3.37(b) and figure 3.37(c)) shows that the sequence of amplitudes in the wavelet has changed. For the top reflector (figure 3.37(b)) the order is: blue - red - blue - red. For the bottom reflector, proposed to be the reflection from the lignite layer $(\sim 400 \mathrm{~ms})$, the order is the opposite: red - blue - red - blue. However, it has to be mentioned that this is complicated approach and some uncertainties remain.

\subsection{Intra-basement reflections}

The interpretation of seismic lines 301\&302 (section 3.4.2.1) reveals a discrepancy in depth of the initially proposed greywacke reflector and the predicted basement depth by gravity modelling (see section 3.4.2.1). Gravity modelling infers the basement at around 200-300 $\mathrm{m}$ (see figure 3.29), whereas the seismic data (see figure 3.31) show a low frequency undulating reflector at $600 \mathrm{~ms}$, corresponding 


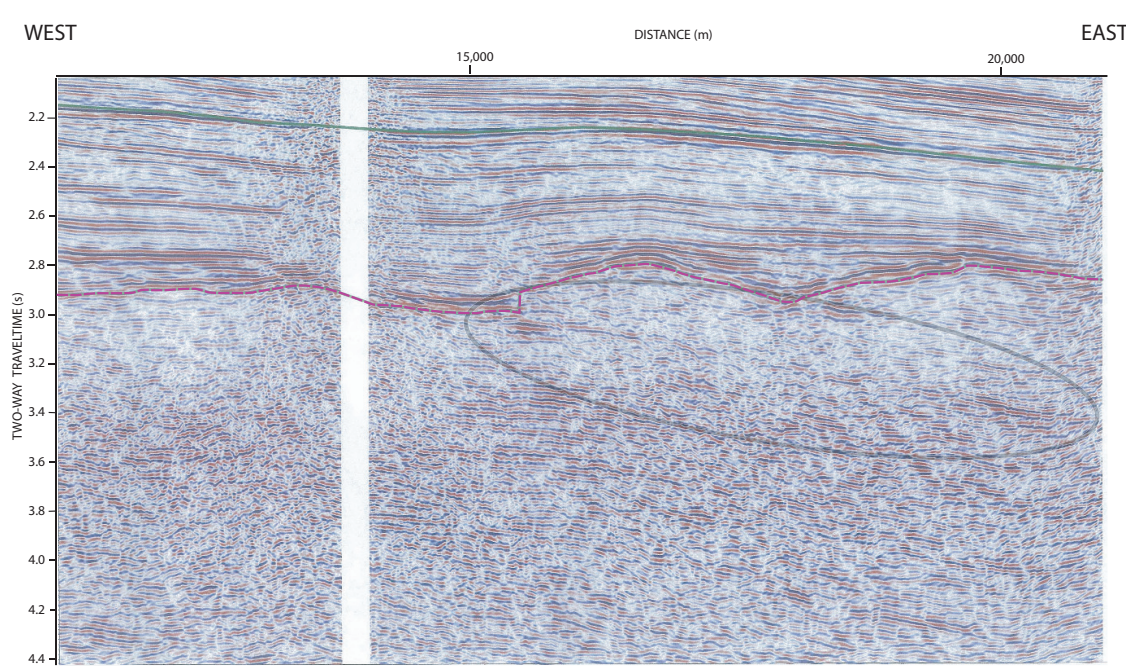

(a)

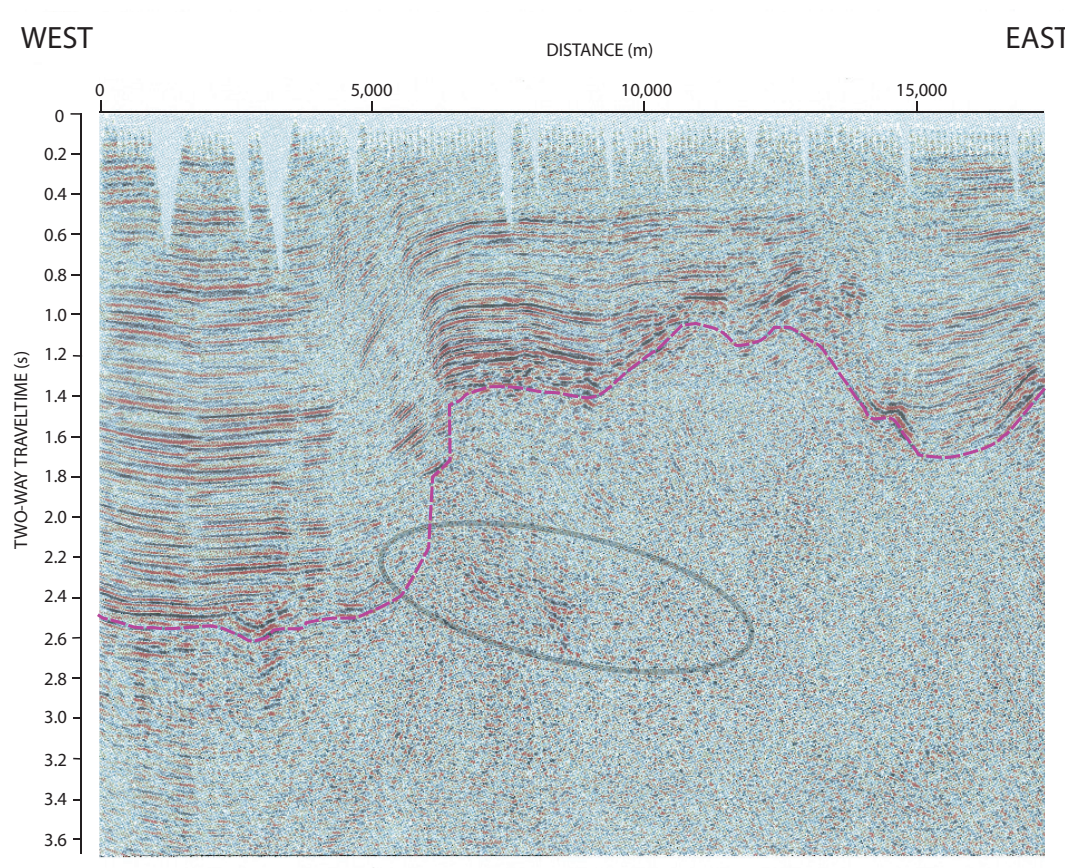

(b)

Figure 3.39: Onshore seismic sections from the SWB. The exact location of lines cannot be given to maintain confidentiality. The final processed seismic section is provided by H. Green Energy Ltd. The basement horizon is marked by a dashed purple line. Light grey ellipse marks the location of the strongest intra-basement reflector. (a) Section running along the Wanganui coastline close to the Wanganui township. There is coherent energy within the basement down to the end of the seismic section. The dip of the intra-basement reflector is $\sim 80 \mathrm{~ms} / \mathrm{km}$. (b) Section running east-west between Foxton and Sanson. The intra-basement reflector is visible between a distance of $5-10 \mathrm{~km}$ and a two-way traveltime of $2.2-2.6 \mathrm{~s}$. The dip of the reflector is $\sim 100 \mathrm{~ms} / \mathrm{km}$. 
approximately to a depth of $600 \mathrm{~m}$ for a shallow section. Therefore, this reflector has to be described as intra-basement reflector. In the east of the section it dips slightly before it steepens underneath CDP 1300 and intersects with the basement reflector at CDP 1200.

Newly acquired and reprocessed on- and offshore seismic datasets from within the SWB present more examples for such intra-basement reflectors with shallow dips (data provided by H. Green Energy Ltd.). Figure 3.39(a) shows an onshore seismic line running along the coastline close to Wanganui township. A coherent intra-basement reflector (marked by grey ellipse) can be identified for a distance of at least $15 \mathrm{~km}$ and at a two-way traveltime between 3 and $3.4 \mathrm{~s}$. The reflector has a shallow dip and intersects with the basement reflector (bottom purple line) at a distance of $\sim 15,000 \mathrm{~m}$. In this seismic section coherent energy within the basement seems to be visible within the entire depth of the section (maximum depth $\sim 6 \mathrm{~km}$ assuming an average seismic velocity of around $3 \mathrm{~km} / \mathrm{s}$ ).

Another example for an intra-basement reflector is shown in figure 3.39(b). This onshore seismic line runs east-west south of Sanson township. The intrabasement reflector (marked in figure by grey ellipse) has a smaller amplitude than the one seen in figure 3.39(a) and is only visible for a distance of $5-10 \mathrm{~km}$. It is located at a similar depth and shows a similar dip as the intra-basement reflector in figure 3.39(a).

The third example for intra-basement reflectors from within the SWB comes from an offshore seismic line which runs in southwest direction away from the Wanganui coastline (figure 3.40). This section shows a pronounced highamplitude, high frequency, apparent intra-basement reflector. It is visible across the entire section between 3-5 s and intersects the basement reflector at the western side of the profile. As in the previous two examples, this reflector shows a low-angle dip. But in contrast to the other seismic lines it is not running across the trend of the faults but almost subparallel to them. Therefore, the intra-basement reflector could be side-swipe from the surrounding faults. This is supported by the unusual high frequency for such a deep reflector. Traveltime calculations for the neighbouring faults, however, produced values which are smaller than expected but side-swipe, e.g. from faults further away, cannot be completely excluded.

Such shallow dipping intra-basement reflectors were previously identified within the Taranaki Fault Zone [Palmer, 1993]. An example is shown in figure 3.41. The reflectors are also situated at a two-way traveltime between $2-5 \mathrm{~s}$ with a similar low-angle dip as seen in the SWB seismic lines. Palmer [1993] interpreted these events within the basement as Mesozoic basement thrusts.

In the early Miocene compression as a response to plate convergence is present in the overriding plate along the entire length of the Hikurangi Margin [Nicol et al., 2007; Rait et al., 1991]. During the 19 Ma duration of the Miocene a total 


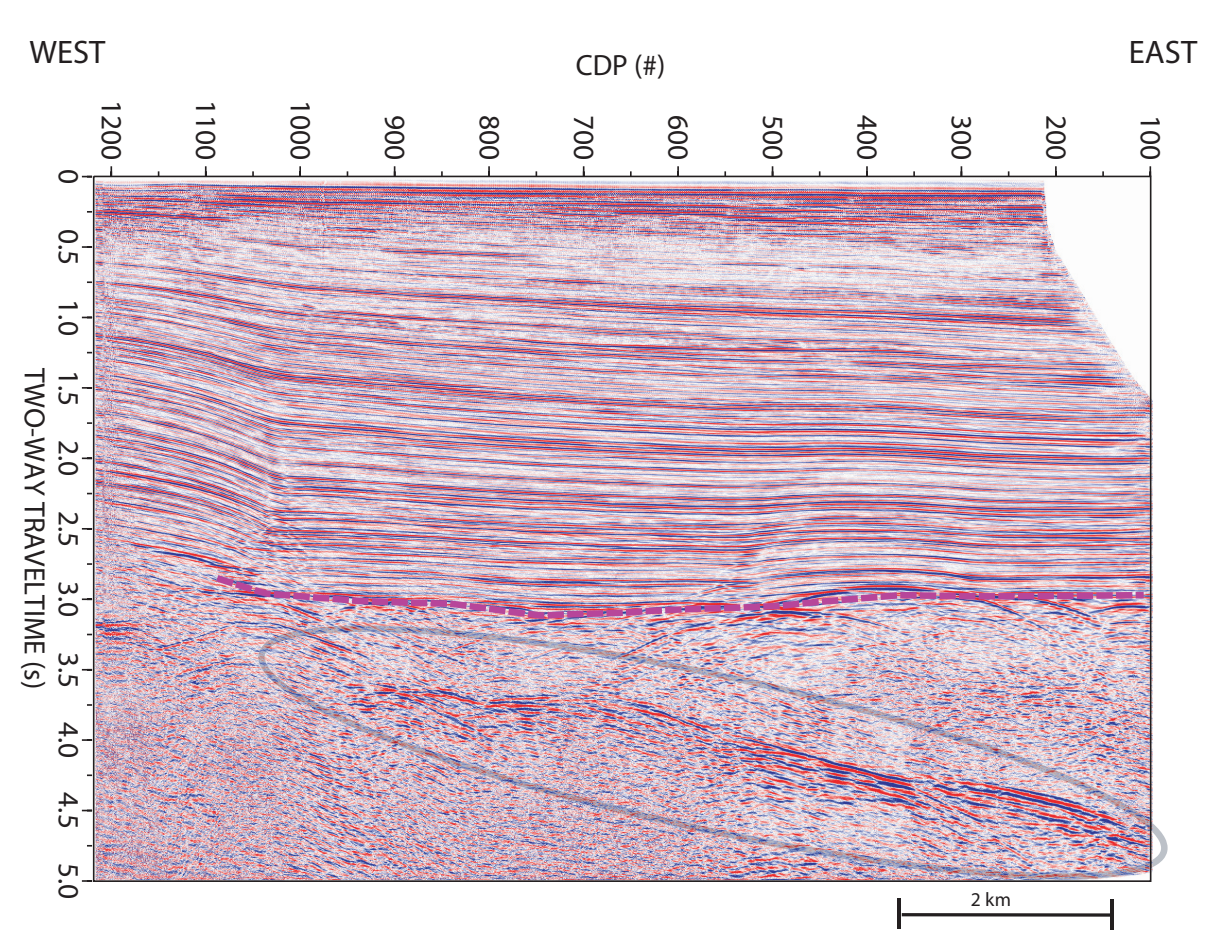

Figure 3.40: Offshore seismic section from the SWB. This section runs southwest perpendicular to the coastline, close to the Santoft township. The exact location cannot be given to maintain confidentiality. The final processed seismic section is provided by H. Green Energy Ltd. The basement horizon is marked by a dashed purple line. The light grey ellipse marks the location of an intra-basement reflector. This reflector shows high amplitudes and is visible across the entire section. The dip of the intra-basement reflector is $\sim 200 \mathrm{~ms} / \mathrm{km}$.

shortening of $75 \pm 35 \mathrm{~km}$ took place across the Taranaki and Wanganui basins (including the Taranaki Fault System, where most of the shortening occurred) [Nicol et al., 2007; Stern et al., 2006]. Thus, in agreement to the Taranaki Basin [Palmer, 1993] the intra-basement reflectors identified within the SWB are interpreted as low-angle thrust faults as a result of the shortening. This is the first discovery of such low-angle thrust faults in the SWB. They could provide a possible hydrocarbon trap, if they overthrust an older sediment sequences.

\subsection{Summary onshore surveys in the South Wan- ganui Basin}

The southeastern corner of the SWB and the transition zone into the Tararua Ranges is marked by a complex basement structure, with many northeast trending troughs and ridges and corresponding faults. Almost all interpreted basement displacements are of high angle, with some showing normal or reverse be- 


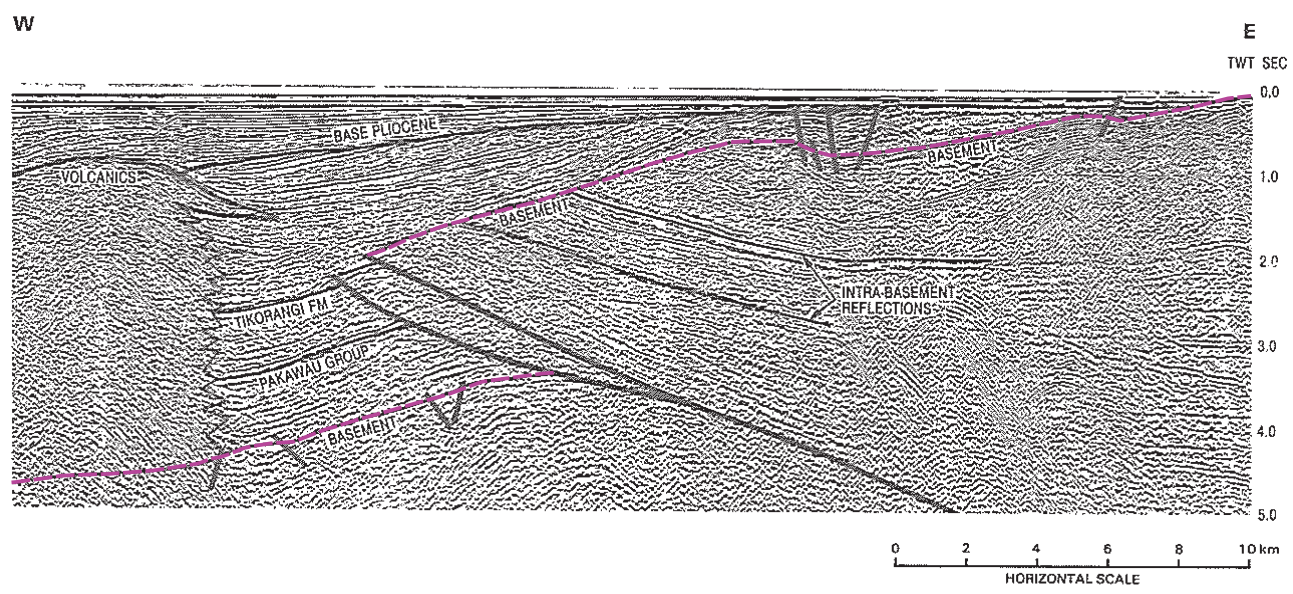

Figure 3.41: Offshore seismic section from the northern Taranaki Basin (figure is modified from Palmer [1993]). The exact location is unknown. The basement horizon is marked by a dashed purple line. Intra-basement reflectors are visible in the eastern part of the line and are interpreted as Mesozoic basement thrusts. The dip of the event is similar to the basement thrusts identified in the SWB seismic sections. The dip of the intra-basement reflector is $\sim 120 \mathrm{~ms} / \mathrm{km}$.

haviour.

In the southern-most study area (Waikanae) there is evidence for a stepped strike-slip fault, with a pull-apart basin centred under the eastern section of Peka Peka Road. Above this basin a low-velocity peat and sand layer is situated with a maximum thickness of around $150 \mathrm{~m}$. The discovered strike-slip faults are in good agreement with the location of the $6500 \mathrm{yr}$ old shoreline, which is therefore possibly fault controlled and not the result of eustasy. Furthermore, evidence was found for a vertical offset on an already mapped active strike-slip fault underneath Hadfield Road [GNS Science, 2008], with an offset of $\sim 120 \mathrm{~m}$ for the shallowest horizons. The southeastern corner of the SWB has a complex stress regime with significant vertical offsets on strike-slip faults. This is a result of the superposition of the stress fields due to oblique subduction, the uplift of the Tararuas and the subsidence of the SWB.

Further to the north, along Waikawa Road, seismic reflection data show a thrust fault sitting on a basement high. The location of the basement high is again in good agreement with the location of the $6500 \mathrm{yr}$ old shoreline, providing further evidence for a fault controlled ancient shoreline.

The preprocessing and new interpretation of the Levin datasets shows an around 50\% deeper overall basement depth than that proposed before [Aharoni, 1991]. A difference in faulting style on either side of the Levin fault could be confirmed, with an extensional stress regime to the west and a compressional regime to the east. An intra-basement reflector is interpreted at the eastern section of the 
line. Similar reflectors could be identified in other lines within the SWB and are interpreted as Miocene basement thrust faults.

A seismic/gravity study through the Foxton area found another basement high and the seismic reflection data show a high-amplitude reflector which got interpreted as an about $1 \mathrm{Ma}$ old layer containing lignite.

Overall it can be concluded that the eastern side of the SWB is mainly driven by recent vertical tectonics with a possible component of strike-slip. This is in contrast to the tectonic regime in the Miocene, where low-angle thrusting dominated. 


\section{Chapter 4}

\section{3-D modelling of the gravity anomaly of the South Wanganui Basin}

\subsection{Introduction}

One of the most striking features of the gravity anomaly map of the North Island [Reilly et al., 1977] is the large negative $(-150 \mathrm{mGal})$ anomaly of the South Wanganui Basin (SWB). This anomaly is located in the southwest of the North Island with its centre near the township of Turakina (figure 4.1). It forms the southern end of a zone of negative anomalies trending southwest-northeast across the island. The anomaly is elliptical in shape, with the main axis extending from the southwest to the northeast. The wavelength of this anomaly is around $300 \mathrm{~km}$. In the west, it is constrained by a positive anomaly, associated with the PateaTongaparutu high, the boundary between the Wanganui and Taranaki Basin [Hunt, 1980]. The shape of the SWB anomaly corresponds well to the sediment isopachs. However, the $4-5 \mathrm{~km}$ of sediment fill of the basin can only account for a third of the anomaly [Hunt, 1980], if a density contrast of $\sim 400 \mathrm{~kg} / \mathrm{m}^{3}$ between sediments and basement is assumed.

Stern et al. [1992] conclude from a first-order, 2-D gravity model that the gravity signature of the SWB is not in agreement with an extensional origin. Their model, instead, explains the anomaly with a flexural downwarp of the entire crust. This is consistent with the interpretation of an abnormally deep Moho $(>40 \mathrm{~km})$ from active seismic studies [Holt \& Stern, 1994]. The maximum vertical deformation of the Moho, however, seems to be larger $(>10 \mathrm{~km})$ than the maximum deformation observed at the top of the crust $(>4 \mathrm{~km})$. This implies a ductile behaviour of the crust or at least parts of the crust (see figure 4.2).

So far, almost all previous studies modelled the gravity anomaly of the SWB with 2-D approaches [Smith et al., 1989; Stern et al., 1992]. The SWB, however, is better described as a 3-D structure. This is most obvious from the relative small 


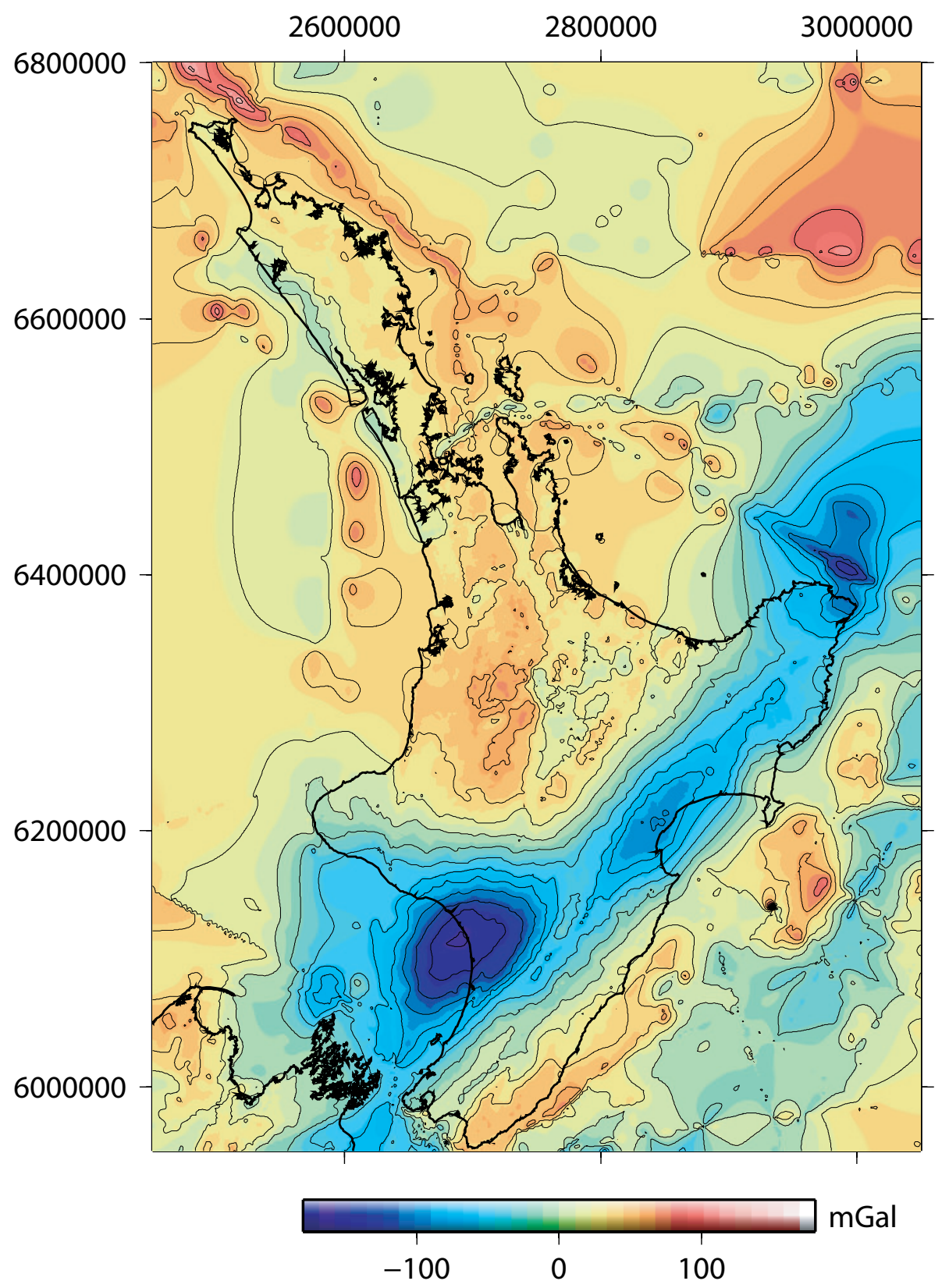

Figure 4.1: Gravity anomaly map of the North Island. The onshore part shows the isostatic anomaly (data taken from the GNS Sciences gravity database); the offshore part shows the free-air anomaly (data taken from U.S. National Geophysical Data Center (http: / / www.ngdc.noaa.gov/mgg/geodas/trackline.html)). One of the most striking features is the strong negative gravity anomaly in the South Wanganui Basin area, which forms the southern end of a zone of negative anomalies trending northeast across the island.

wavelength (200 km; [Stern et al., 1992]) and circular shape of the gravity anomaly. Thus, this chapter presents a detailed 3-D gravity model of the basin additionally 


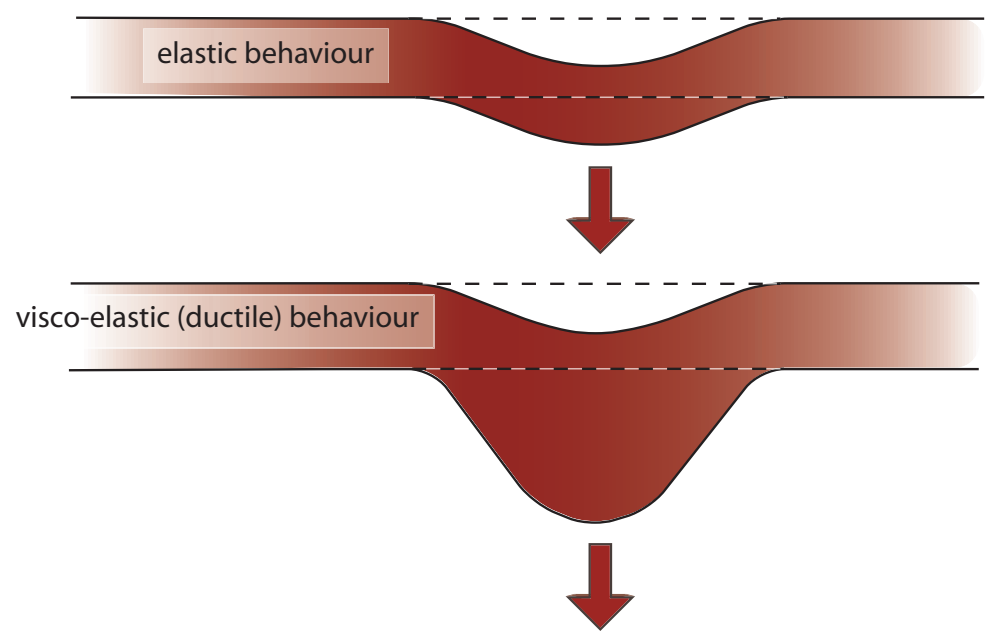

Figure 4.2: Sketch of the deformation of a purely elastic plate versus deformation of a viscoelastic plate. The force downwarping the material acts at the bottom of the plate. For the viscoelastic plate the deformation at the bottom of the plate is larger than at the top. For a purely elastic plate the top and the bottom deform identically.

incorporating the effect of the underlying slab.

\subsection{Model setup}

The gravity anomaly of the SWB is modelled as the combined effect of three different components: 1.) the sediment basin and sediment fill, 2.) the subducting slab and 3.) the crustal thickening underneath the basin. The depth of the Moho and the thickness of the crust of the subducting slab are the unknown parameters in this model which need to be varied to fit the observed gravity anomaly. Other potential variables, such as the density contrasts, are kept fixed.

The gravity anomaly of the subducting Pacific plate is calculated as a $2.5-\mathrm{D}$ model [Cady, 1980], assuming the gravity effect to be constant along strike (section 4.3). The gravity effects of the basin and thickened crust are estimated from a 3-D modelling approach for different vertical Moho deformations (section 4.4). Finally, to create a 3-D model of the subduction system, both models are combined (section 4.5).

Density values used for the gravity modelling are all relative to a standard 


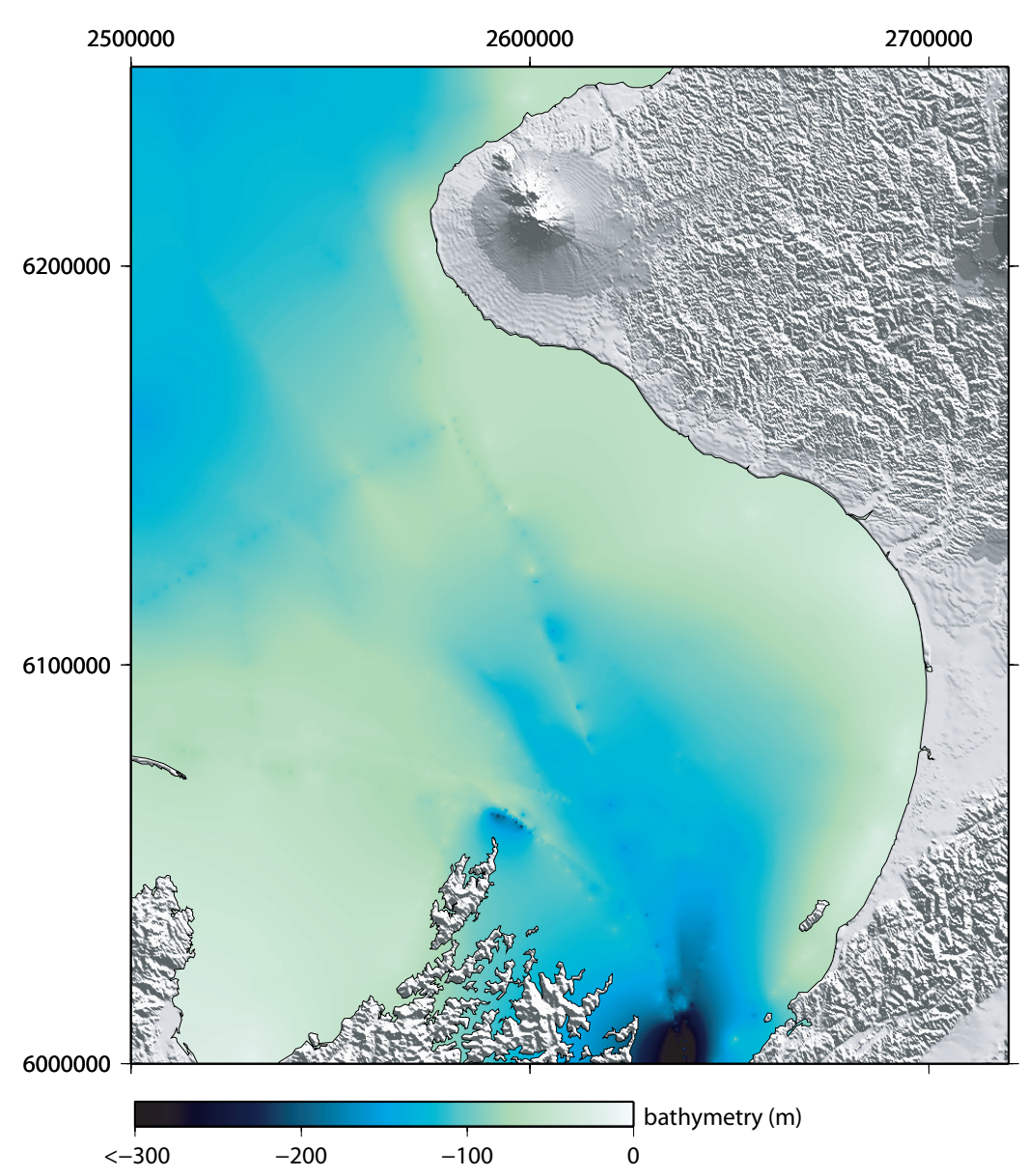

Figure 4.3: Bathymetry map of the southwestern North Island. Data are marine track line data available from the U.S. National Geophysical Data Center (http:/ / www.ngdc.noaa.gov/mgg/geodas/trackline.html). The maximum water depth within the basin does not exceed $150 \mathrm{~m}$.

density model (SDR) of average continental lithosphere (see figure 4.5). This reference model has an intracrustal discontinuity at $15 \mathrm{~km}$ [Christensen \& Mooney, 1995], a Moho at $30 \mathrm{~km}$ [Holt \& Stern, 1994] and a lithosphere-asthenosphere boundary at $100 \mathrm{~km}$ depth [Molnar et al., 1999]. Densities for the crustal layers of the standard density model are: $2750 \mathrm{~kg} / \mathrm{m}^{3}$ for the upper crust and $2900 \mathrm{~kg} / \mathrm{m}^{3}$ for the lower crust. Both values are based on a global compilation of seismic refraction surveys [Christensen \& Mooney, 1995]. The asthenosphere is assumed to have an average density of $3300 \mathrm{~kg} / \mathrm{m}^{3}$ with a $50 \mathrm{~kg} / \mathrm{m}^{3}$ denser mantle lid. The adopted density for the mantle lid is an intermediate estimate between the densities calculated by Zoback \& Mooney [2003] $\left(3304 \mathrm{~kg} / \mathrm{m}^{3}-3367 \mathrm{~kg} / \mathrm{m}^{3}\right)$ and O'Reilly et al. [2001] $\left(3310 \mathrm{~kg} / \mathrm{m}^{3}-3370 \mathrm{~kg} / \mathrm{m}^{3}\right)$. The density distribution used for the subducting slab is described in the following section. Due to the shallow water depth (figure 4.3), the influence of the water on the gravity can be neglected. 


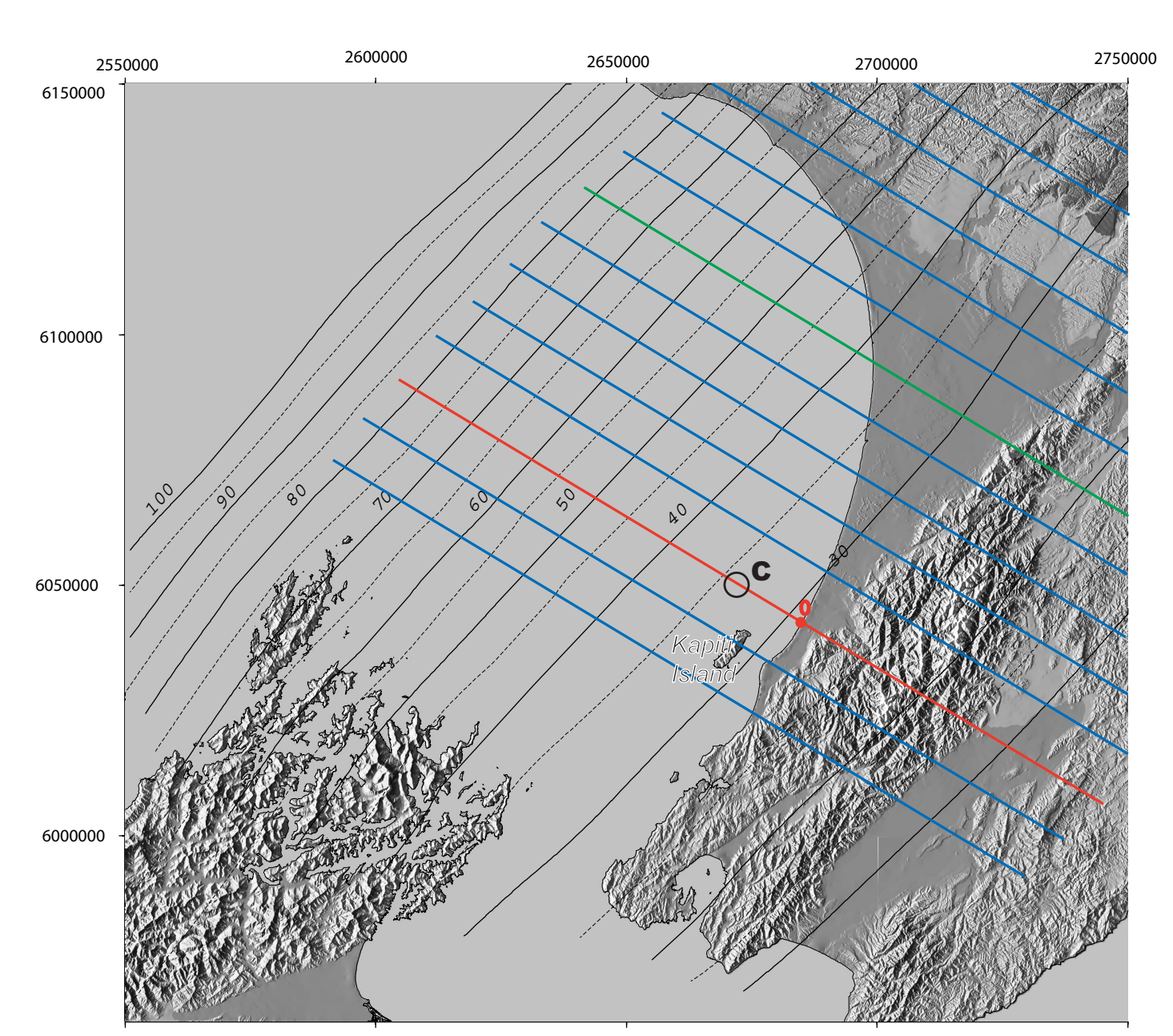

Figure 4.4: Southern part of the SWB. Black lines indicate the depth to the top of the slab in km [Ansell \& Bannister, 1996], which is steepening towards the west. Coloured lines represent profile lines for the individual 2-D gravity modelling of the slab. The red line is the pilot profile and the blue lines are projections parallel to the pilot profile. This allows calculating a 3-D model of the gravity anomaly of the slab (point 0, NZMG E2686705 IS6038222). Point C marks the proposed location for a decrease in crustal thickness of the slab (see text).

\subsection{5-D gravity model of the subducting slab}

The depth and the shape of the top of the subducting slab are determined based on the seismicity associated with the Benioff zone [Ansell \& Bannister, 1996]. The top of the subducted slab is described as a "conical" model with depth isobaths running southwest to northeast. In the study area the isobaths can be approximated to be straight and parallel (figure 4.4). This assumption allows modelling the 3-D gravity effect of the slab by using a 2-D profile, which is perpendicular to the strike of the subducting slab, and extrapolating it as constant along strike. This is here referred to as a 2.5-D model. 
The standard global value for the thickness of subducting oceanic crust is around $7 \mathrm{~km}$ [Moores \& Twiss, 1995]. Studies by Davy \& Wood [1994] and Bourne \& Stuart [2000] show a considerable thicker oceanic crust (up to $15 \mathrm{~km}$ ) to the east of the lower North Island, but it is unclear how much of this thickened crust has already subducted (see also discussion in section 5.3.1). Receiver function studies (see chapter 5 ) indicate around $10 \pm 2 \mathrm{~km}$ of thick oceanic crust underneath the Tararua Ranges. If the oceanic crust is abnormally thick along its entire downdip length, however, the increased buoyancy would have inhibited subduction as is now observed under the southern North Island. Nevertheless, the gravity effect of different crustal thicknesses for the slab and their contribution to the gravity field of the SWB are investigated in this section.

The lithosphere of the subducting Pacific plate is around $30-50 \mathrm{~km}$ thick [Brisbourne \& Stuart, 1998]. This is thin compared to standard values of around $90 \mathrm{~km}$ for oceanic lithosphere older than $100 \mathrm{Ma}$ [Sclater et al., 1981]. Therefore, this study explores the gravity effect due to different lithospheric thicknesses.

Densities assumed for the subducting Pacific plate are $2900 \mathrm{~kg} / \mathrm{m}^{3}$ for the crust of the slab (this assumes the slab is oceanic) and $3350 \mathrm{~kg} / \mathrm{m}^{3}$ for the mantle lithosphere. These values are identical to the values used by Stern et al. [1992] and Holt \& Stern [1994] to model the subducting slab under the lower North Island. The values shown in the model examples (figure 4.5) are relative to the standard density reference model.

At a certain depth the basaltic part of the subducting oceanic crust will transform into denser eclogite $\left(3560 \mathrm{~kg} / \mathrm{m}^{3}\right)$. The location of this transition zone is a significant parameter for the gravity modelling of subduction zones. It depends on the surrounding temperature and pressure conditions as well as the subduction rate. The transition generally starts between 20 to $50 \mathrm{~km}$ [Fukao et al., 1983; Ringwood, 1966] and is not completed until 150-200 km [Hacker et al., 2003a]. During the transition of basalt into eclogite fluids are released [Schmidt \& Poli, 1998]. This hydration process affects and triggers many observed subduction features such as the thermal and rheological evolution of the accretionary prism at shallow depth and partial melting at greater depth [Peacock, 1990]. Below a depth of $200 \mathrm{~km}$, the anhydrous crust is seismically indistinguishable from the surrounding material [Kawakatsu \& Watada, 2007]. There is no evidence that eclogite melts at this depth as it can be stable down to the start of the mantle transition zone at $410 \mathrm{~km}$ [Hacker et al., 2003a,b; Lee \& Chen, 2007].

For New Zealand, the eclogite transition is inferred to start at $50 \mathrm{~km}$ [Bourne \& Stuart, 2000; Gubbins et al., 1994]. The eclogized crust extends downwards to the maximum depth of the slab of around $210 \mathrm{~km}$ (maximum depth of seismicity associated with the plate [Ansell \& Bannister, 1996; Eberhart-Phillips \& Reyners, 1997]).

Figure 4.5 shows gravity anomalies calculated for different earth models. The 


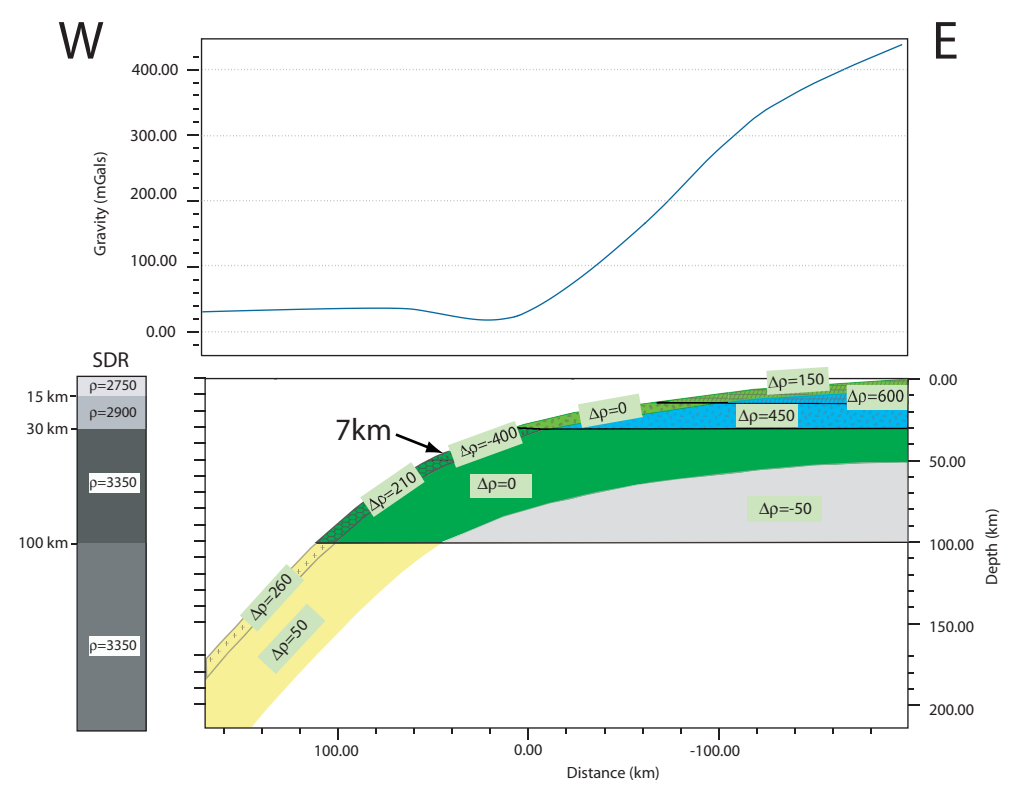

(a) oceanic crust $=7 \mathrm{~km}$; oceanic lithosphere $=50 \mathrm{~km}(\operatorname{model}(\mathrm{A}))$

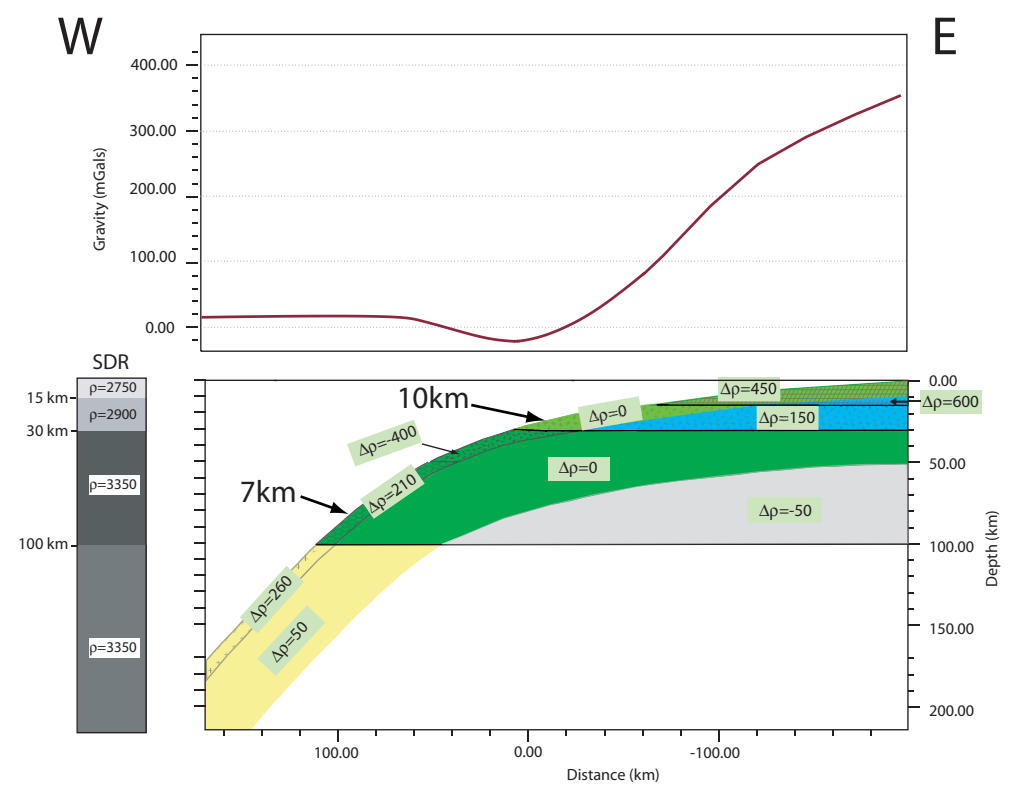

(b) oceanic crust $=7 \mathrm{~km}-10 \mathrm{~km}$; oceanic lithosphere $=50 \mathrm{~km}$ (model (E))

Figure 4.5: 2-D gravity modelling profile of the subducting slab. Bottom figures of (a) and (b) show the earth models. Densities contrasts are relative to the standard density reference model (SDR), shown on the left side in $\mathrm{kg} / \mathrm{m}^{3}$. Corresponding gravity anomalies are shown in the top panel of (a) and (b). Origin of the x-scale is shown as 0 in figure 4.4. The change in crustal thickness in model (b) is located at about the west coast of the North Island. Labelled arrows indicate values of thickness of the oceanic crust. At the eclogite transition boundary $(50 \mathrm{~km})$ the density contrast of the subducting oceanic crust changes from -400 to $210 \mathrm{~kg} / \mathrm{m}^{3}$. 


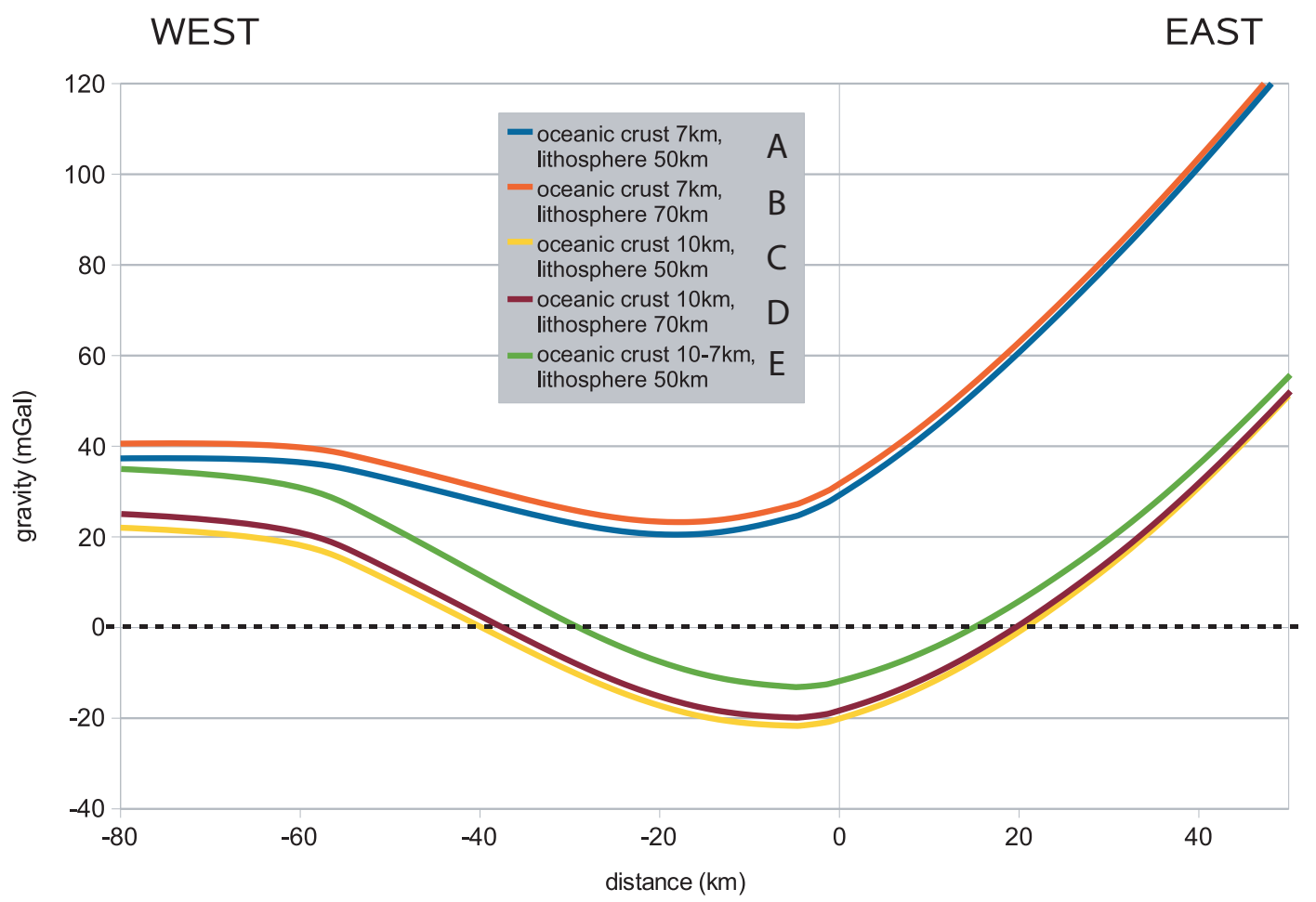

Figure 4.6: Gravity anomalies for different slab thicknesses across the SWB. Density distribution can be seen in figure 4.5. Model geometries for models (A) and (E) are shown in figure 4.5. Other models are not shown but can be inferred from the presented ones. Origin of the $\mathrm{x}$-scale is shown as 0 in figure 4.4.

lithospheric thickness in these models is $50 \mathrm{~km}$. For model A (figure 4.5(a)), the oceanic crustal thickness is fixed to $7 \mathrm{~km}$. Model E (figure 4.5(b)) has a change in crustal thickness from $10 \mathrm{~km}$ in the east to $7 \mathrm{~km}$ in the west, with a smooth changeover point located just west of Kapiti Island (see figure 4.4). The corresponding gravity anomalies (figure 4.5) are similar in shape, but with a difference of around $30 \mathrm{mGal}$ in the centre of the trough of the anomaly $(-10 \mathrm{~km}$ on the profile). Both anomalies are large in the east because oceanic crust is closer to the surface. To the west, they converge to zero because of a progressively deepening slab.

Figure 4.6 gives a compilation of different calculated gravity anomalies. They are displayed between kilometre -80 and 50 along the profile, which is the region of interest for the 3-D gravity modelling of the SWB. The thickness of the crust of the slab has a more significant influence on the anomaly than the thickness of the lithosphere. This is due to the larger depth and smaller density contrasts of the lithosphere. The anomaly of the model with changing crustal thickness (model E) follows the curve of model C (constant crustal thickness of $10 \mathrm{~km}$ ) in the east and then approaches the anomaly of model A (constant crustal thickness of $7 \mathrm{~km}$ ) in the west. 


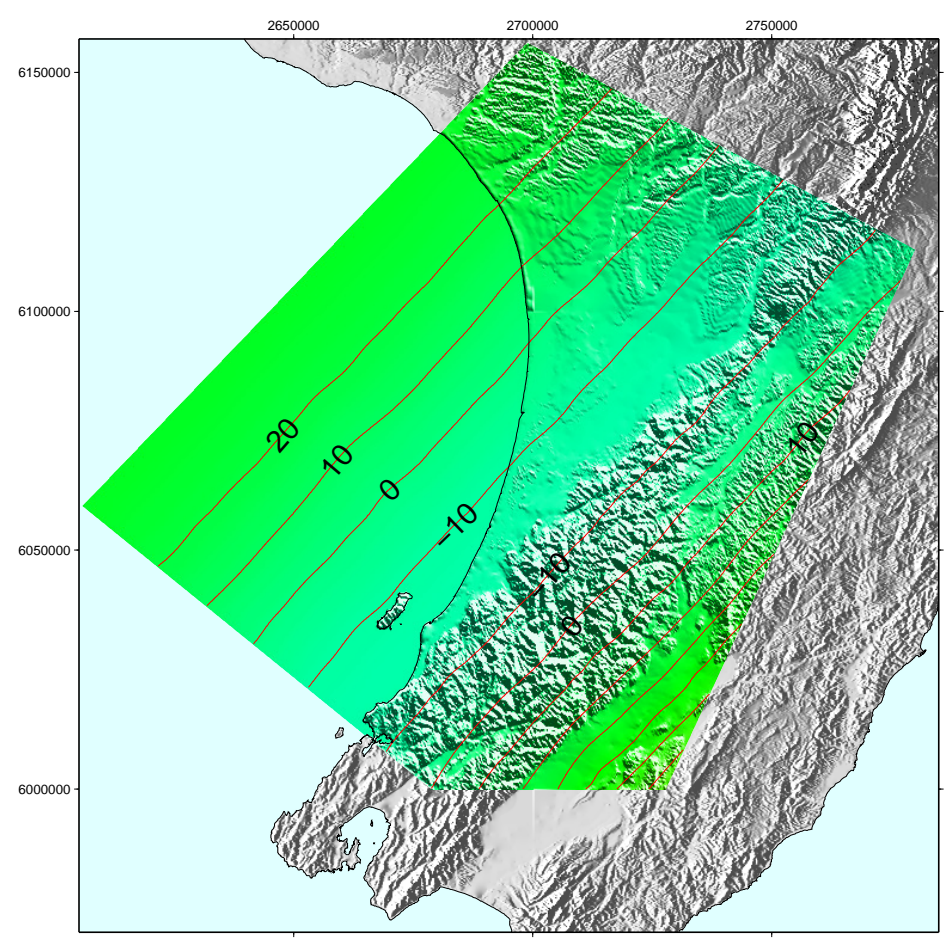

Figure 4.7: The gravity anomaly produced by the subducting slab (model E) with a minimum of slightly under $-15 \mathrm{mGal}$ parallel to the Axial Ranges.

The extrapolation of the 2-D model into the 3-D space uses the gravity values calculated for the pilot profile (red line figure 4.4) on 13 additional lines. The lines are parallel to the pilot profile and have the same distance between the origin and the trench. The slab is modelled as a feature with a limited strike to the south where the slab steepens before the subduction zone dies out [Eberhart-Phillips \& Reyners, 1997]. To the west the modelling region is restricted by the Taranaki Fault Zone (see figure 2.2) which starts to interfere with the gravity anomaly of the SWB. Thrust faults such as the Taranaki Fault normally produce a positive gravity anomaly as denser material replaces less dense material [Stagpoole \& Nicol, 2008].

The 3-D gravity anomaly of the slab (model E) can be seen in plane-view in figure 4.7. Minimum values $(\sim-12 \mathrm{mGal})$ are found parallel and west of the Tararua Ranges. In the centre part of the basin, the gravity field reaches a value of 20 $25 \mathrm{mGal}$. 

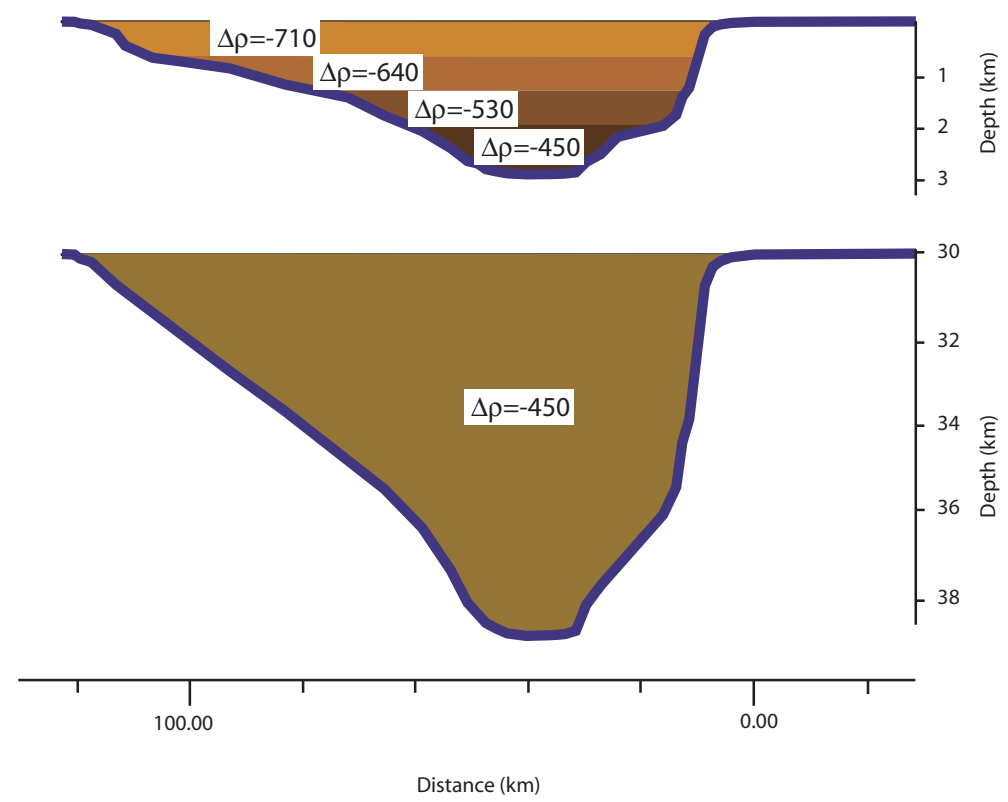

Figure 4.8: Top: A cross-section of the sediment basin and the Moho deformation (along green line figure 4.4). The density contrast $(\Delta \rho)$ relative to surrounding greywacke decreases with depth. Therefore, the model of the basin is subdivided into $1 \mathrm{~km}$ thick layers. Bottom: Example of the Moho underneath the SWB for a model with a scaling factor of 4 (see text). A constant density contrast of $\Delta \rho=$ $-450 \mathrm{~kg} / \mathrm{m}^{3}$ is used.

\subsection{3-D gravity model of the basin and thickened crust}

The South Wanganui Basin is filled with sediments of Pliocene and Pleistocene age with a maximum thickness of about $4 \mathrm{~km}$ [Anderton, 1981]. The depth to the irregular basement of Mesozoic greywacke is well defined from deep and shallow seismic reflection and refraction work [Anderton, 1981; Lamarche et al., 2005].

The modelling approach presented in this section applies and further investigates the proposed theory of a flexural crustal downwarp responsible for the SWB [Stern et al., 1992]. Therefore, the Moho deformation is assumed to have a similar wavelength and shape as the sediment basin but with a scaled amplitude.

Figure 4.8 shows a 2-D section through the deepest part of the basin, perpendicular to the strike of the slab (green line figure 4.4). The top figure shows the basin with the sediment infill, the bottom figure shows the downwarped Moho with a smoothed, scaled version of the sediment basin geometry projected on the standard Moho depth of $30 \mathrm{~km}$. 


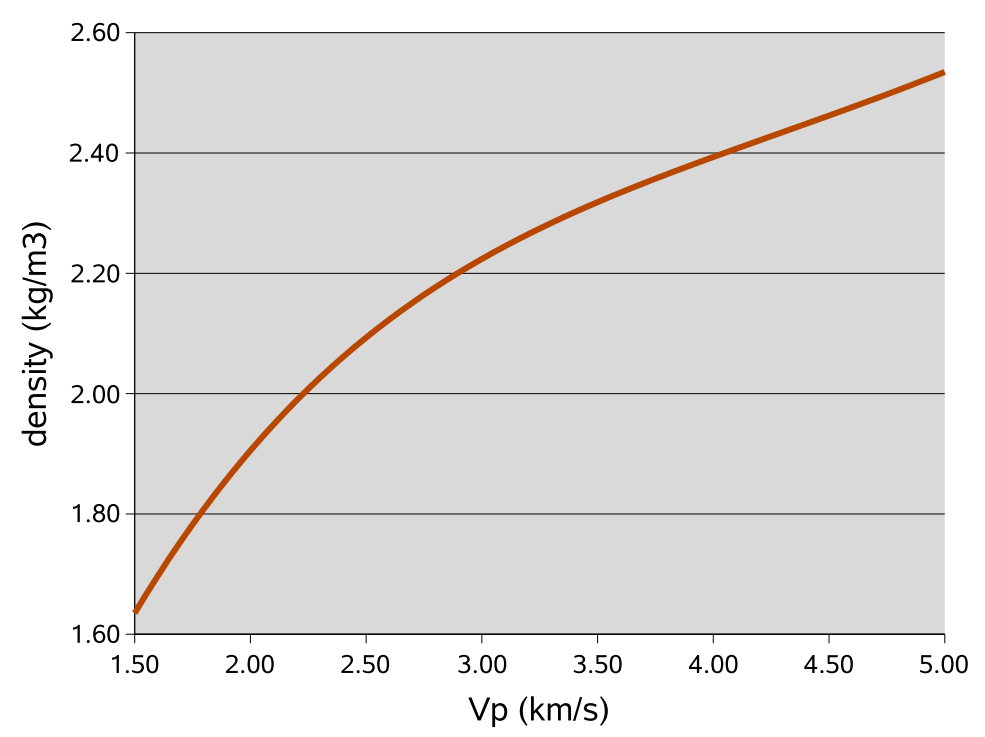

Figure 4.9: Nafe-Drake curve, which gives an empirical relationship between density and seismic P-wave velocities of rocks and sediments [Ludwig et al., 1970].

\subsubsection{Sediment densities}

Also shown in figure 4.8 are the adopted density contrasts. At the bottom of the crust, mantle material is displaced with crustal material. The corresponding constant density contrast is $\Delta \rho=2900-3350 \mathrm{~kg} / \mathrm{m}^{3}=-450 \mathrm{~kg} / \mathrm{m}^{3}$. This value, however, is at the upper limit for proposed crustal root densities [Fischer, 2002].

In the sedimentary basin, the density increases with depth due to compaction of the infill material [Hunt, 1980; Telford et al., 1990]. The density distribution can be derived from seismic interval velocities. An empirical relationship between seismic interval velocities and densities is expressed by the Nafe-Drake curve (figure 4.9) [Ludwig et al., 1970]. This relationship can also be described by a polynomial regression which is valid between 1.5 and $8.5 \mathrm{~km} / \mathrm{s}$ [Brocher, 2005]:

$$
\rho\left(g / \mathrm{cm}^{3}\right)=1.6612 V_{p}-0.4721 V_{p}^{2}+0.0671 V_{p}^{3}-0.0043 V_{p}^{4}+0.000106 V_{p}^{5}
$$

Table 4.1 shows the velocities and corresponding densities for the different $1 \mathrm{~km}$ thick layers. These densities are in good agreement with density values determined by sediment outcrops samples [Hunt, 1980]. Based on the samples, an average Pleistocene sediment density of about $1900 \mathrm{~kg} / \mathrm{m}^{3}$ and Pliocene sediments density of $2200 \mathrm{~kg} / \mathrm{m}^{3}$ is established.

The density contrasts shown in the top of figure 4.8 are relative to surrounding greywacke basement rock with a density of $2670 \mathrm{~kg} / \mathrm{cm}^{3}$ [Hunt, 1980]. 


\begin{tabular}{|l|c|c|}
\hline Depth $(\mathrm{m})$ & $V_{p}(\mathrm{~km} / \mathrm{s})$ & $\rho\left(\mathrm{kg} / \mathrm{m}^{3}\right)$ \\
\hline \hline $0-1000$ & 1.97 & 1890 \\
\hline $1000-2000$ & 2.29 & 2020 \\
\hline $2000-3000$ & 2.75 & 2160 \\
\hline $3000-$ max.depth & 3.0 & 2220 \\
\hline
\end{tabular}

Table 4.1: Basin sediment interval velocities [after Lamarche et al., 2005] and calculated, corresponding densities (with equation 4.1).

\subsubsection{Modelling theory}

The software used for the 3-D gravity forward modelling is based on the approach of Talwani \& Ewing [1960] to calculate the 3-D gravity effect of an arbitrary shaped body. The anomaly body has to be represented by contour lines and each contour gets replaced by a horizontal $n$-sided polygonal lamina. The number of sides needs to be sufficiently large to approximate the true shape of the contour lines. Thus, it is possible to calculate the gravity effect of every single polygon $\left(\Delta g_{\text {lamina }}\right)$ with the intention to get the gravity anomaly of the whole body. To calculate $\Delta g_{\text {lamina }}$, the polygon has to be further subdivided into triangles which have an anomaly per unit thickness $(d h)$ of

$$
\Delta g_{\text {triangle }_{1}}=G \rho\left[\psi_{2}-\psi_{1}-\arcsin \frac{z \cos \theta_{1}}{\left(p_{1}^{2}+z^{2}\right)^{1 / 2}}+\arcsin \frac{z \cos \phi_{1}}{\left(p_{1}^{2}+z^{2}\right)^{1 / 2}}\right] d h
$$

where:

$G$ is the universal gravitational constant,

$\rho$ is the density of the triangle/lamina,

the

$z$ and $\psi$ are the cylindrical coordinates used to define the boundary of

polygon and the angles, and

$\theta$ and $\phi$ are angles used to define the triangle with $p$ being the length

of the one side of the triangle.

Using equation 4.2 and summing over the $n$ sides of the polygon leads to

$$
\begin{aligned}
\Delta g_{\text {lamina }} & =\sum_{i=1}^{n} \Delta g_{\text {triangle }_{i}} \\
& =\underbrace{G \rho\left[\sum_{i=1}^{n}\left[\psi_{i+1}-\psi_{i}-\sin ^{-1} \frac{z \cos \theta_{i}}{\left(p_{i}^{2}+z^{2}\right)^{1 / 2}}+\sin ^{-1} \frac{z \cos \phi_{i}}{\left(p_{i}^{2}+z^{2}\right)^{1 / 2}}\right]\right]}_{V} d h
\end{aligned}
$$


4.43-D gravity model of the basin and thickened crust

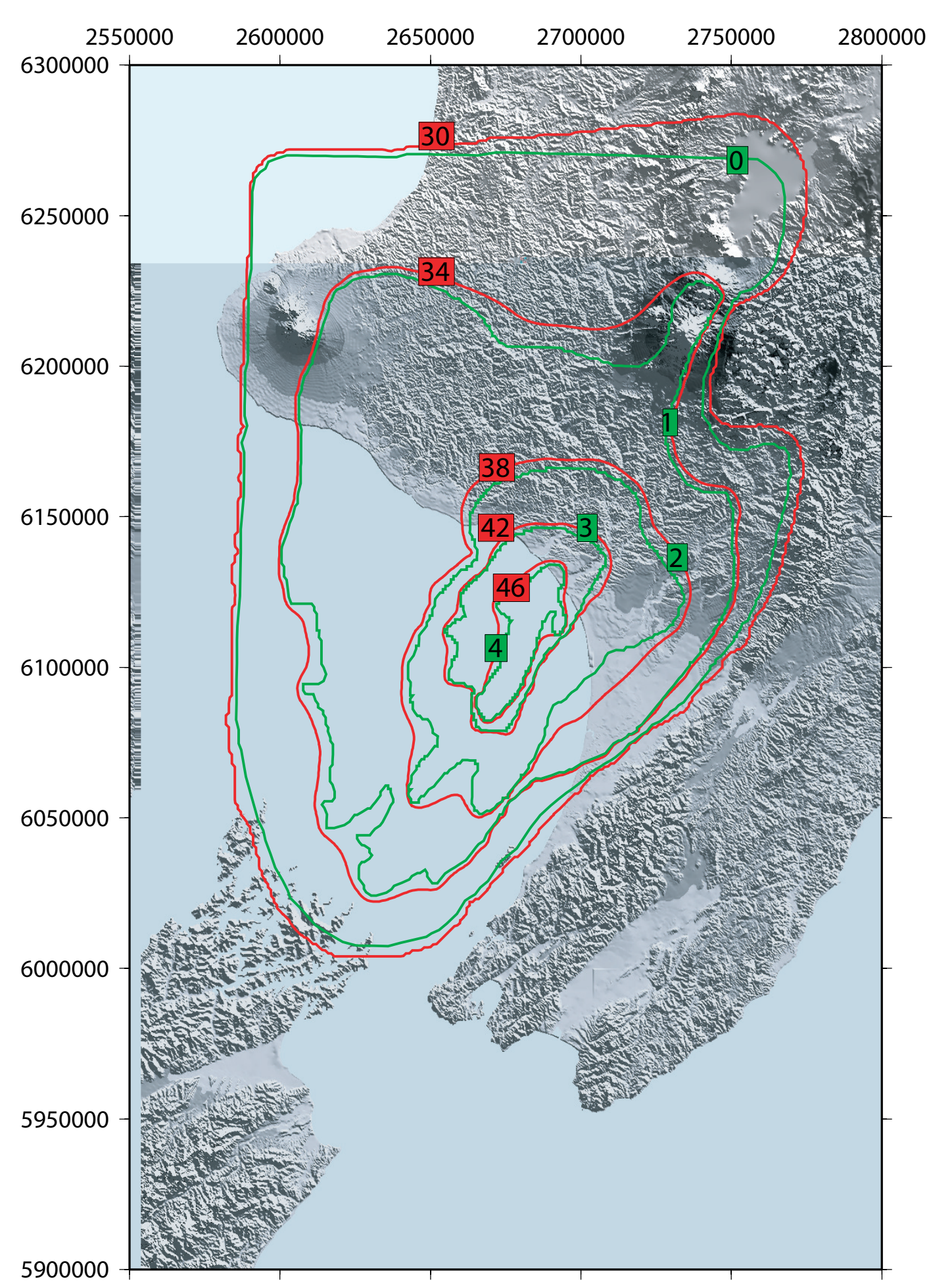

Figure 4.10: Map of the southwestern part of the North Island. The green lines are the contour lines of the depth of the sediment basin. The red lines are an example of the contour line of the Moho depth using a scaling factor of 4 (see text). 
The total anomaly $\Delta g$ caused by the entire body is calculated by numerical integrating between the top $\left(z_{t}\right)$ and the bottom $\left(z_{b}\right)$ of the body [Talwani \& Ewing, 1960]:

$$
\Delta g=\int_{z_{b}}^{z_{t}} V d z .
$$

\subsubsection{Modelling results}

The input parameters provided to model the gravity anomaly of the sediment basin are the $0,1,2,3$ and $4 \mathrm{~km}$ depth contour lines of the basin (green lines in figure 4.10) and the associated density contrasts. For the modelling of the possible larger downwarp of the Moho due to ductile deformation, a smoothed version of the sediment basin contour lines is used and projected onto the appropriate depth. The $0 \mathrm{~km}$ contour line is always projected to a depth of $30 \mathrm{~km}$, the others are situated corresponding to the scaling factor, e.g. with a scaling factor of 4 the contour lines are at 30,34, 38, 42 and $46 \mathrm{~km}$ (red lines in figure 4.10). The density contrast used for the Moho downwarp is constant for every lamina $\left(-450 \mathrm{~kg} / \mathrm{m}^{3}\right)$.

Figures 4.11 and 4.12 show the gravity anomalies individually displayed for sediments and crustal effects as a birdview map (figure 4.11(d)) and east-west cross-section through the basin (figure 4.12). The sediment-filled basin creates a maximum anomaly of $-83 \mathrm{mGal}$ (figure 4.11 (a)) which is located above the deepest part of the basin. The contour lines of the anomaly approximate the shape of the basin well and the $0 \mathrm{mGal}$ line runs parallel to the Axial Ranges. The downwarp of the Moho creates a smoother gravity anomaly (figure 4.11(b)), due to its larger depth. The contour lines are elliptical in shape with the centre of the anomaly also located above the deepest part of the basin. For the example shown (scaling factor of 4), the maximum value of the lower crustal anomaly is $-100 \mathrm{mGal}$. Both features combined can be seen in figure 4.11(c), with a minimum value slightly above $-190 \mathrm{mGal}$.

\subsection{Combined gravity effect}

The gravity effect of the slab, the sediment-filled basin and the downwarp of the Moho can finally be added up for comparison with the observed gravity anomaly of the SWB. A cross-section of the final model setup can be seen in figure 4.13. In this proposed geometry the eastern side of the downwarped Moho sits adjacent to the downgoing slab and the basin sits above a slab depth of $30-90 \mathrm{~km}$. 


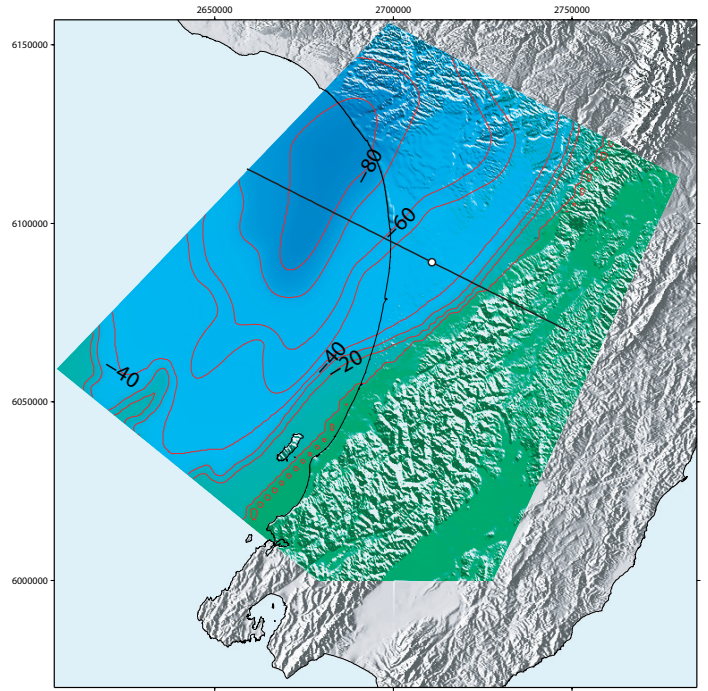

(a) Gravity anomaly due to deformation at the top of the crust and sediment infill

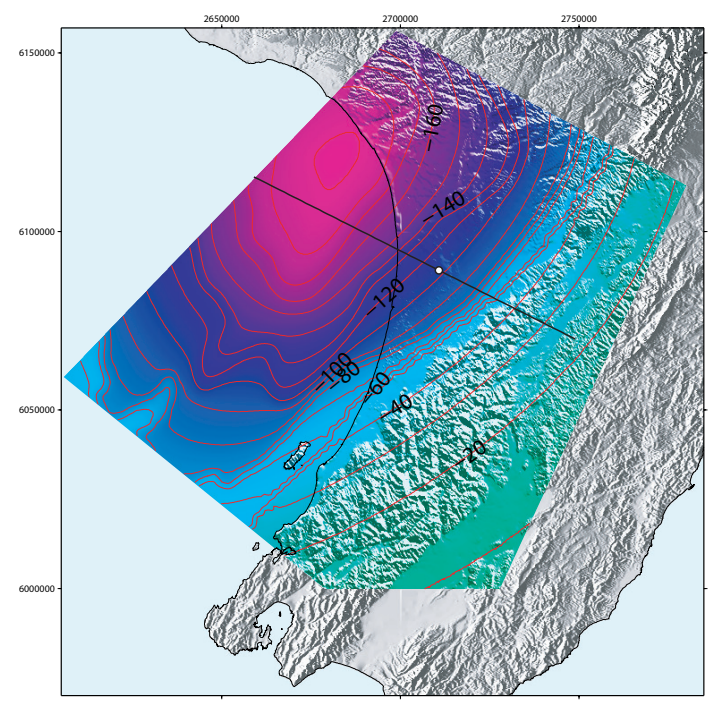

(c) Combination of gravity anomaly from (a) and (b)

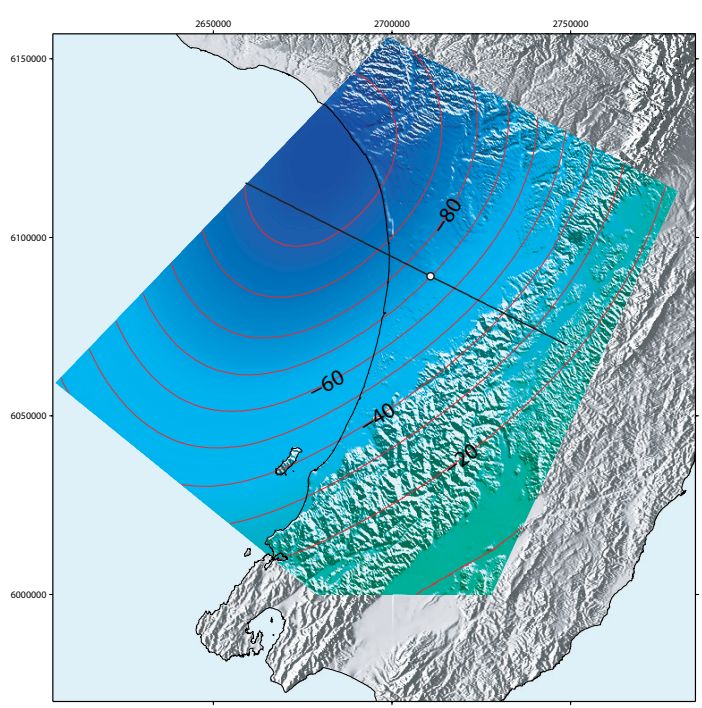

(b) Gravity anomaly due to deformation at the bottom of the crust

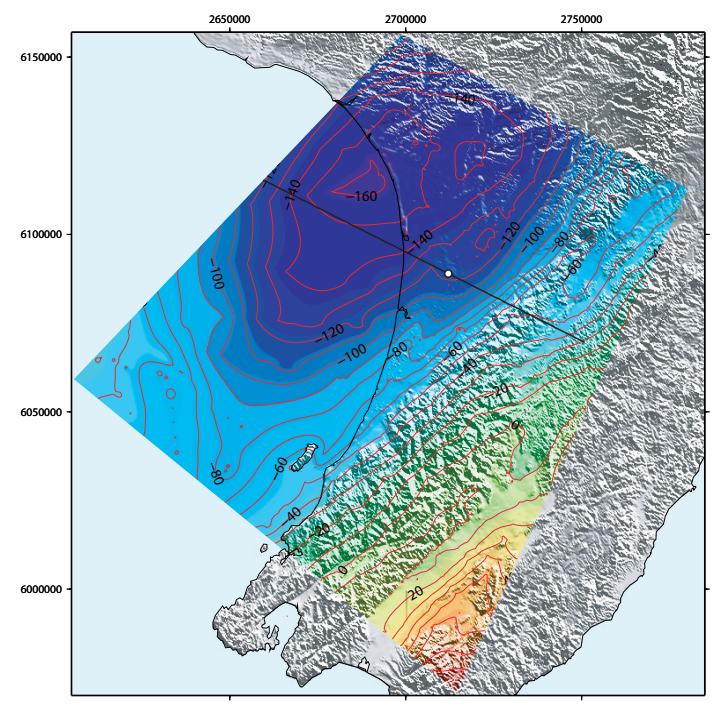

(d) observed

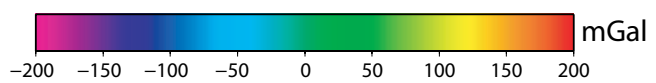

Figure 4.11: The gravity anomaly broken down by their origin: (a) Gravity anomaly due to deformation at the top of the crust and sediment infill (b) Gravity anomaly due to deformation at the bottom of the crust (example with a scaling factor of 4, see text) and (c) the combination of the anomaly from (a) and (b). The black line marks the profile line used for the cross-sections shown in figure 4.12 and the white circle marks the origin of the x-axis.

Figures 4.14(a)-4.14(c) and figure 4.15 show three examples for possible combinations of different slab models and different Moho depth models. For com- 


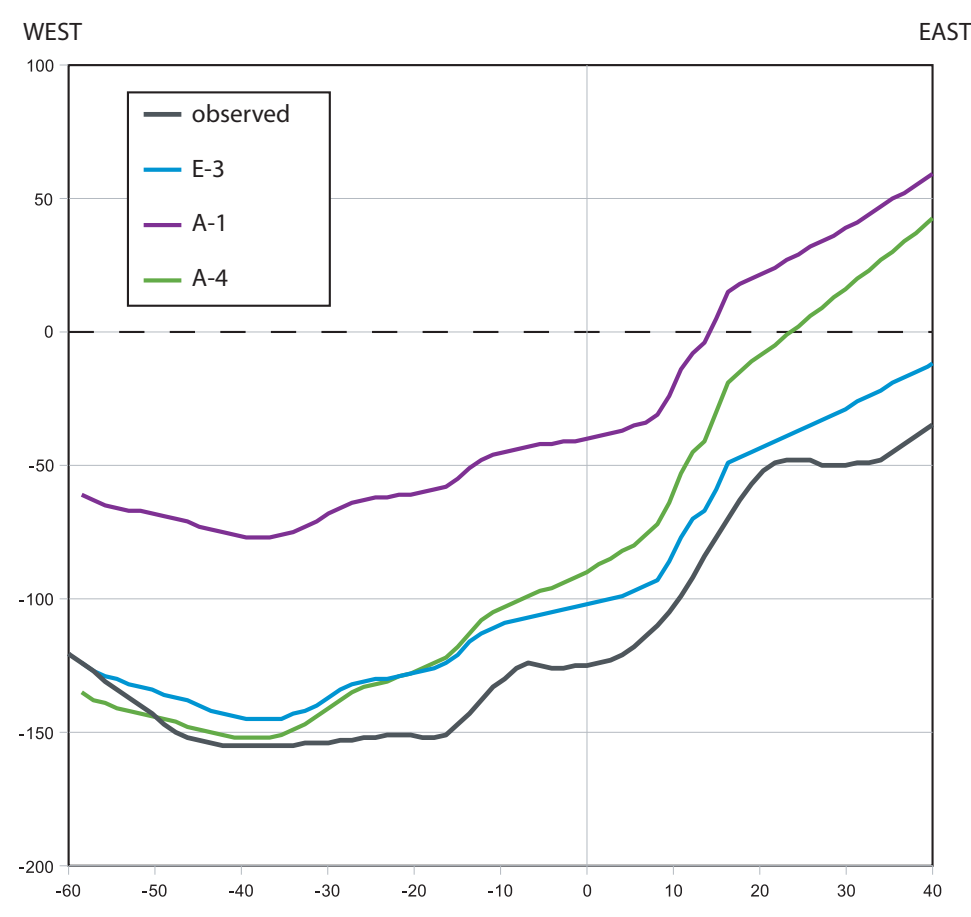

Figure 4.12: Cross-section along the profile (black line) shown in figure 4.11. The observed gravity anomaly can not just be explained by the effect of the sediment infill. Furthermore, a combination of the sediment infill and the thickened crust produces a anomaly which is too large.

parison, figure 4.14(d) shows the observed offshore free-air gravity anomaly and the onshore isostatic anomaly. Identical vertical deformation at the base of the crust and at the sediment-basement interface and using a $7 \mathrm{~km}$ thick oceanic crust (Model A-1) can only achieve a minimum value of $-80 \mathrm{mGal}$. This indicates a ductile behaviour of the crust, where the bottom of the crust is downwarped greater than the top of the crust. Model E-3 (figure 4.14(c), slab model E and Moho model with a scaling factor of 3) and A-4 (figure 4.14(b), slab model A and Moho model with a scaling factor of 4 ) both achieve a minimum value close to the $-155 \mathrm{mGal}$ in comparison to the observed gravity anomaly. However, the model with a changing crustal thickness of the subducting slab (model E-3, figure 4.14(c)) better fits the observed anomaly (figure 4.14(d)) at the eastern corner of the SWB and across the Tararua Ranges. Both the observed anomaly and model E- 3 show the $-40 \mathrm{mGal}$ contour line just at the western side of the Tararua Ranges, where model A-4 (figure 4.14(b)) gives an about $30 \mathrm{mGal}$ higher value.

In summary, the 3-D gravity modelling indicates a crustal root which mimics the extend of the sediment-basement interface, however with a three times larger amplitude. This supports the theory of a ductile deformation of the crust or at least parts of the crust. Thus, crustal thickening with depth can be constrained 


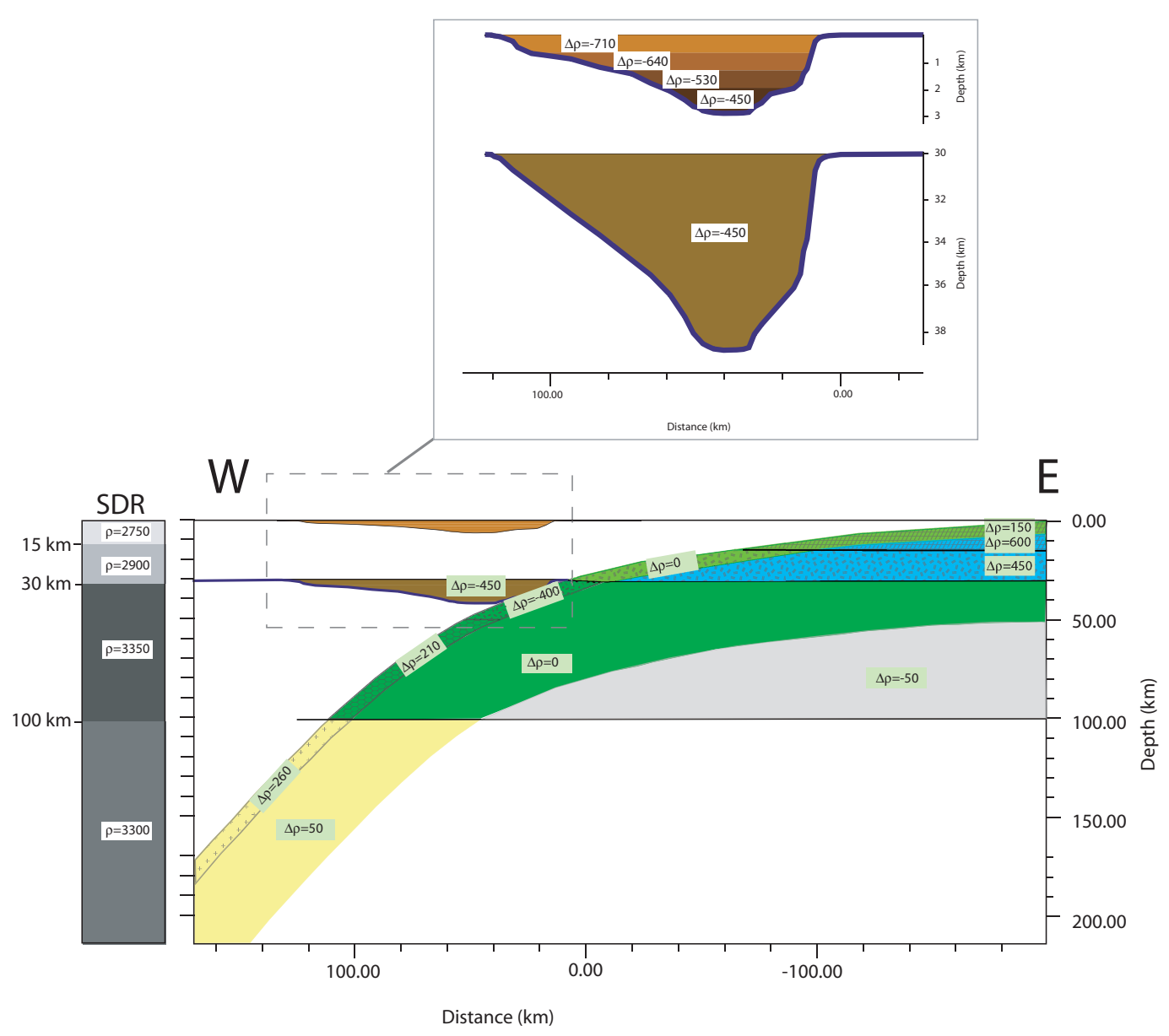

Figure 4.13: A cross-section through the deepest part of the SWB (green line in figure 4.4), showing the location of the sediment basin, the Moho deformation and subducting slab. Density contrasts are all relative to the standard density reference model (SDR) in $\mathrm{kg} / \mathrm{m}^{3}$.

rather well with the gravity data. The exact nature of the subducting slab is uncertain, but the data indicate that the crust of the slab is thicker than standard oceanic crust underneath the lower North Island.

\subsection{Isostasy and mass balance}

In oceanic areas the observed gravity anomaly is normally positive, while across mountainous regions it is normally negative [Fowler, 2001]. Two hypotheses to explain this phenomenon were first proposed by Airy [1855] and Pratt [1859]. Airy [1855] argued that mountain ranges have deep roots and oceans are underlain by a thin crust to compensate for the mass excess or deficit, respectively. Pratt [1859] proposed that the crust extends to a general depth and mass differ- 


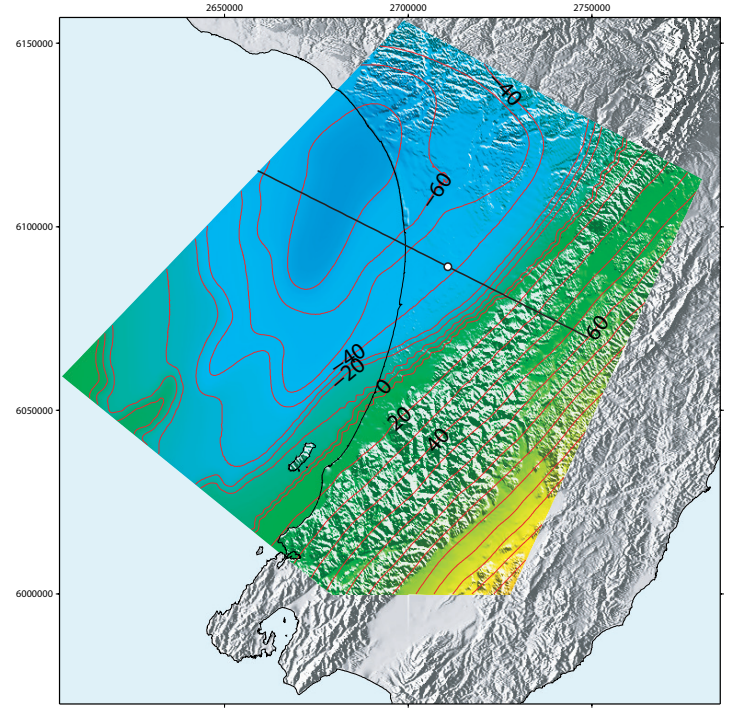

(a) Model A-1

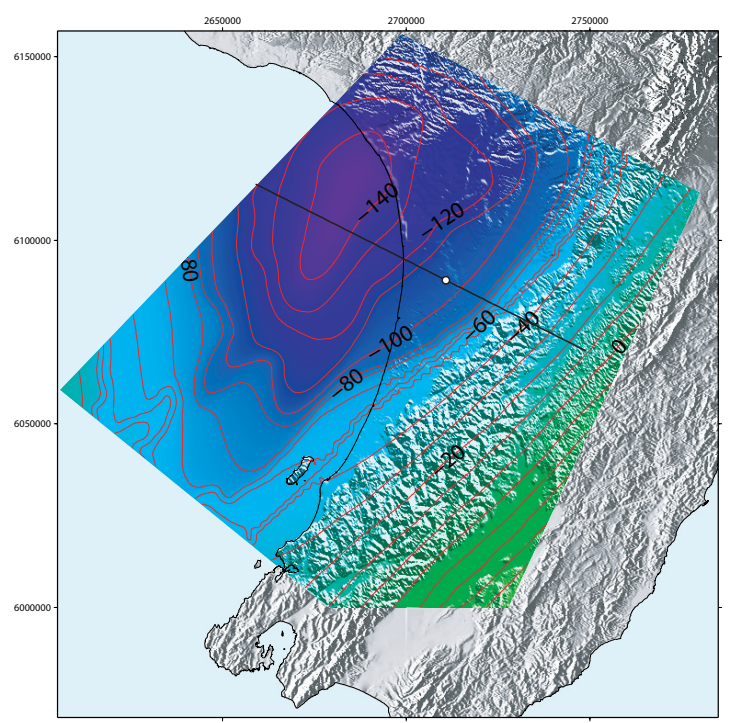

(c) Model E-3

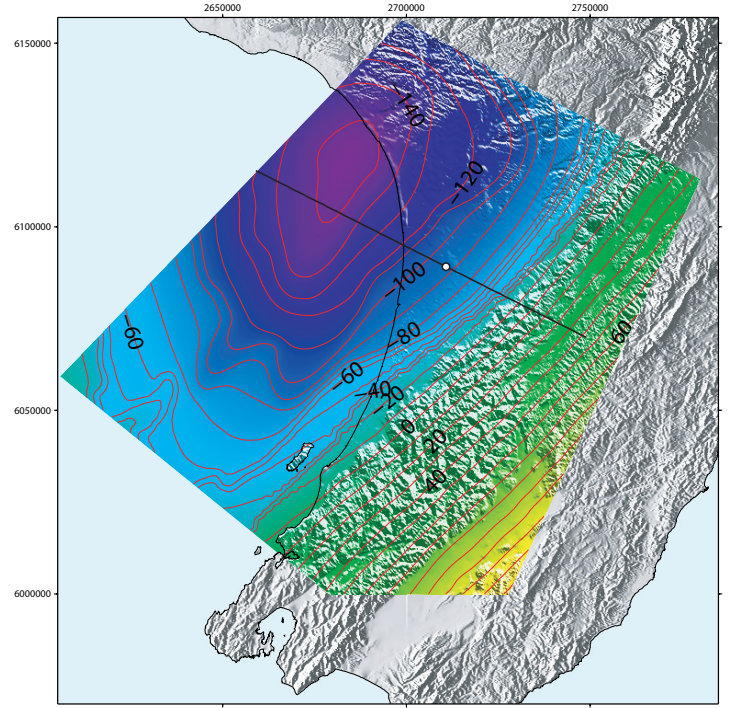

(b) Model A-4

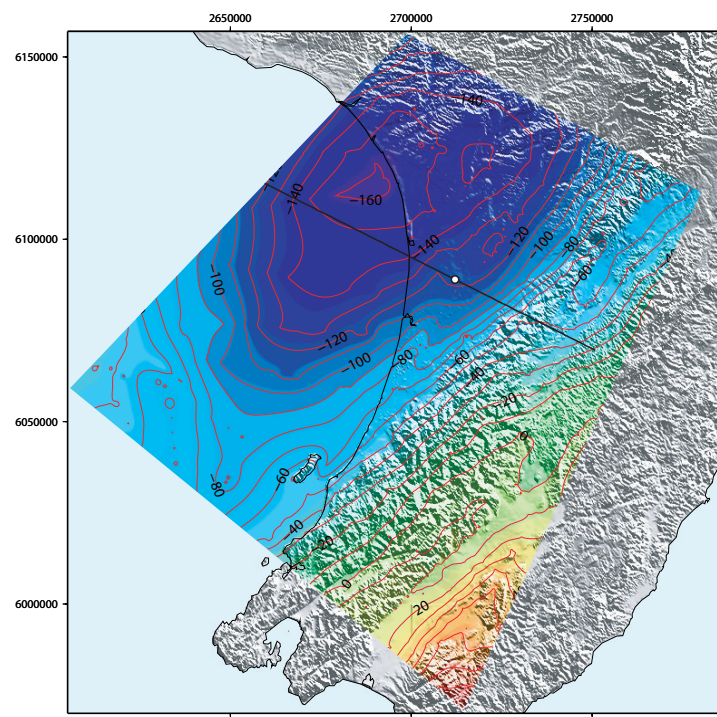

(d) observed (free air (sea) and isostatic (land)

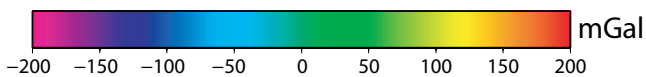

Figure 4.14: Final modelling results with different scaling factors for the vertical deformation at the bottom of the crust and different slab models. Model A-1 (a) which has a scaling factor of 1 can only produce a $-80 \mathrm{mGal}$ anomaly. Models need a scaling factor of 3-4 (panel (b) and (c)) to produce the observed maximum anomaly of around $-150 \mathrm{mGal}(\mathrm{d})$. The black line marks the profile line used for the cross-sections shown in figure 4.15 and the white circle marks the origin of the $x$-axis.

ences are compensated by density variations within the crust. Airy's model is consistent with most seismological and geological studies. For both theories lo- 


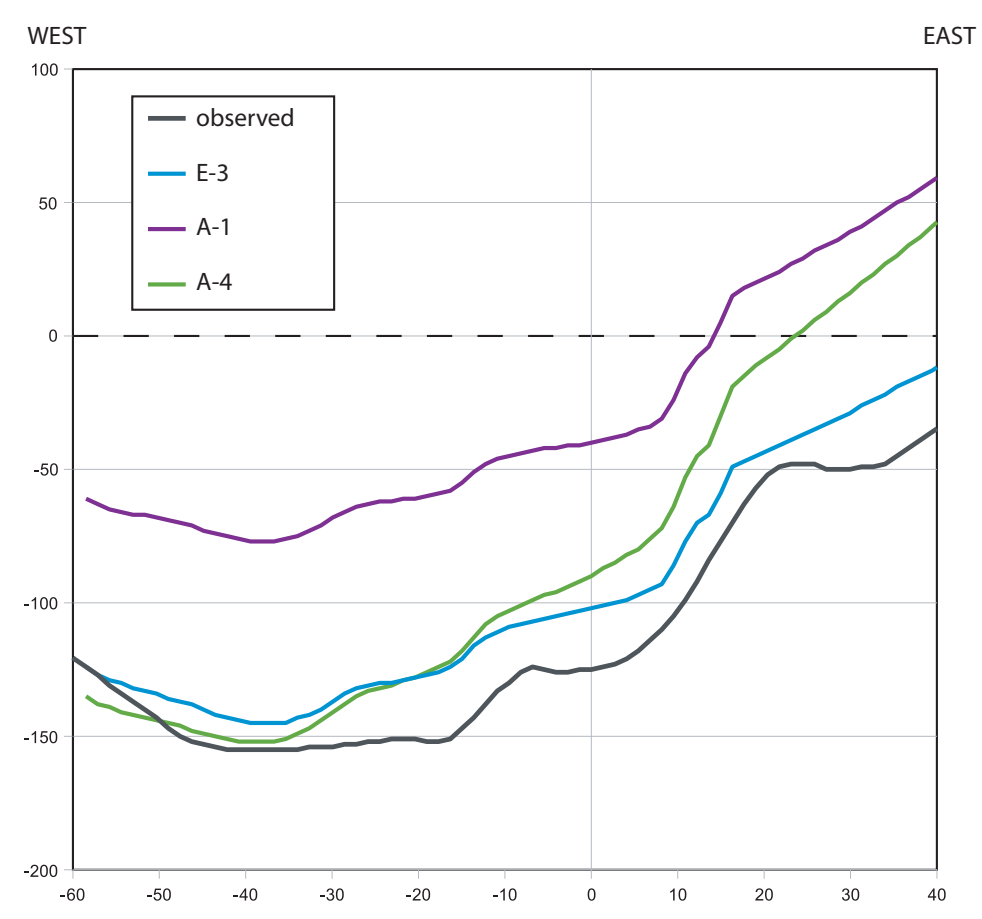

Figure 4.15: Cross-section along the profile (red line) shown in figure 4.14. Graph illustrates the good fit of model A-4 and model E-3 with the observed data, where model E-3 fits better to the east.

cal isostatic equilibrium is reached if at a certain depth (the compensation depth) and beneath this depth, every area unit is under the same pressure regardless of location [Watts, 2001]. In contrast, regional isostasy describes a scenario where the strength of the lithosphere is high enough to distribute the compensation over a wider area [Watts, 2001]. The compensation area depends on the wavelength of the load and the elastic thickness of the supporting lithosphere. For loads with a wavelength less than the elastic thickness there will be a departure from local isostasy as the mass will be supported by stresses within the elastic layer [McNutt, 1980; Watts, 2001].

Oceanic subduction results in a large mass transfer, as heavy lithospheric mantle replaces lighter asthenosphere. This in turn results in a slab pull force (minimum principal stress parallel to the slab) [Moores \& Twiss, 1995], which is proposed to be an important driving mechanism for plate tectonics [Conrad \& Lithgow-Bertelloni, 2002; Harper, 1989]. It is also responsible for the surface subsidence due to isostatic compensation and plays an important role for the observed gravity field [Conrad \& Lithgow-Bertelloni, 2002; Davies, 1981; McKenzie, 1969]. More information on different surface deformation processes above subduction zones can be found in chapter 2.3. Subduction zones are a dynamic setting and can therefore not always be assumed to be in perfect local isostatic 


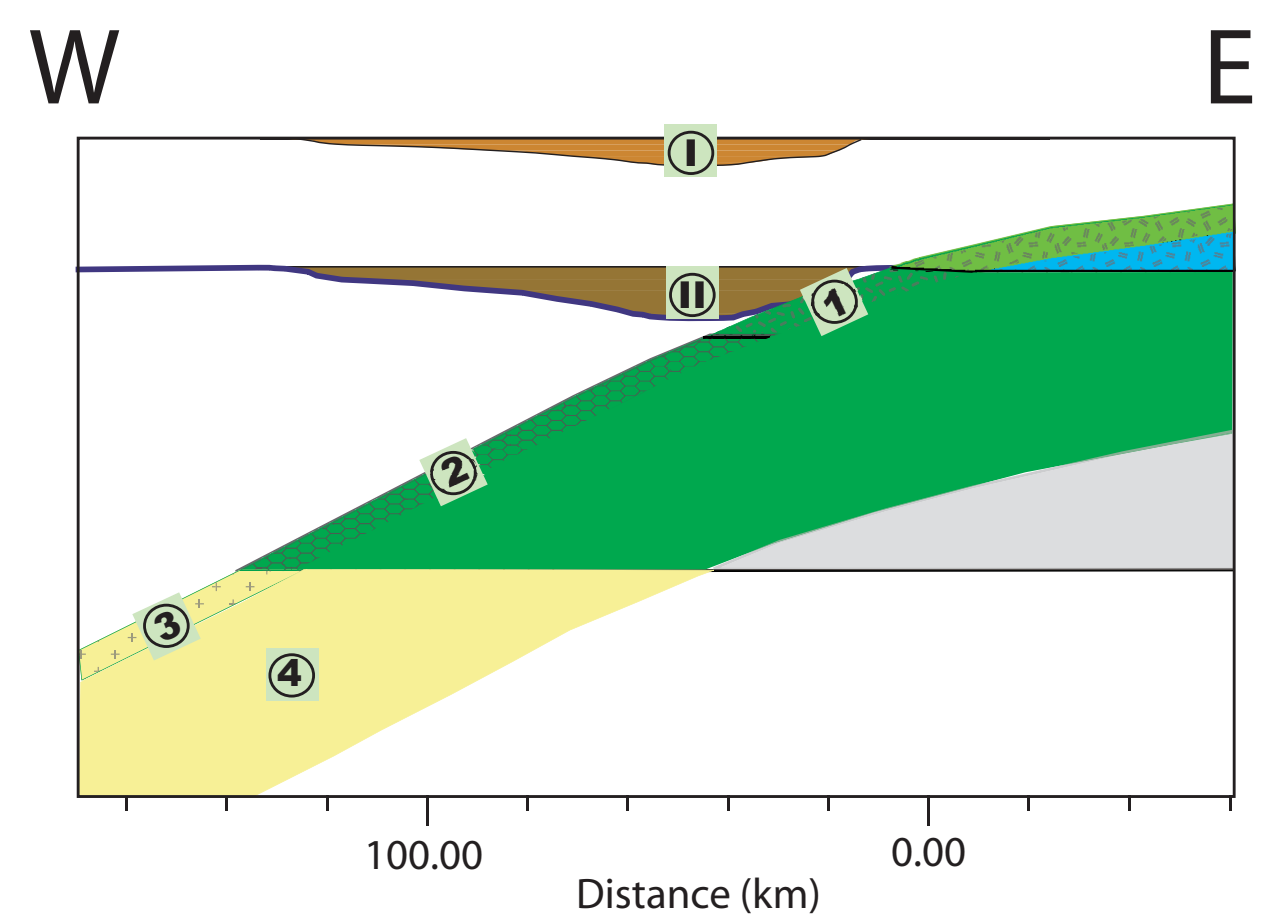

Figure 4.16: Sketch of different density zones of the subducting slab system, labelled for the mass balance calculation. Density contrasts of the zones can be found in figure 4.5 . Table 4.2 shows the corresponding mass anomalies for different thicknesses of crust and lithosphere.

equilibrium.

Following Davies [1983], the mass anomalies are calculated in two dimensions through the deepest part of the basin (green line in figure 4.4). The main contributing factors are the downwarp of the Moho, the sediment basin (figure 4.16), the different parts of the subducting slab and additionally, the flexure bulge (outer rise) of the subducting plate. This bulge arises from the upward elastic flexure of the slab and corresponds to around $10 \%$ of the isostatic surface response [Watts, 2001]. The uncertainties associated with any mass calculation are large because of the high flexural rigidity of the old subducted plates and therefore the wide distribution of mass anomalies across the subduction system. Therefore, the aim of this section is not to determine the model which achieves a perfect mass balance but rather identify models which are more out of isostatic equilibrium than others.

Figure 4.16 shows a cut-out of the subduction zone system underneath the SWB. The figure is only used to illustrate the different section but the actually modelled part of the subduction zone extends further down. The maximum depth for zones (3) and (4) is $210 \mathrm{~km}$. The surfaces of the different parts are calculated describing the slab parts as trapezoids and part (I) and (II) as circle segments. The dip of the slab is taken from Ansell \& Bannister [1996] and Eberhart-Phillips 
\& Reyners [1997]. Assuming isostatic equilibrium in a regional sense, the mass balance associated with the subduction system may be approximated by:

$$
\underbrace{(1)+(\mathrm{I})+\mathrm{III}}_{\text {negative mass anomaly }}=\underbrace{(2)+(3)+(4)+(\mathrm{A})}_{\text {positive mass anomaly }} \text {, }
$$

where

(I) \& III = mass anomaly associated with crustal/surface deformation due to isostatic response,

(1) = mass anomaly associated with subducted oceanic crust within lithosphere,

(2) = mass anomaly associated with subducted eclogized oceanic crust within lithosphere,

(3) = mass anomaly associated with subducted eclogized oceanic crust,

(4) = mass anomaly associated with excess mass of slab,

(A) = mass anomaly associated with the outer rise $(=0.1 *[1+2]$, not shown in figure).

Table 4.2 shows a summary of the calculated mass balance for five different gravity models. The system is approximately in isostatic equilibrium for the two preferred models (Model A-4 and Model E-3), which have a $50 \mathrm{~km}$ thick oceanic lithosphere and a scaling factor of 3-4. For larger crustal and lithospheric thicknesses the system becomes more out of balance. 


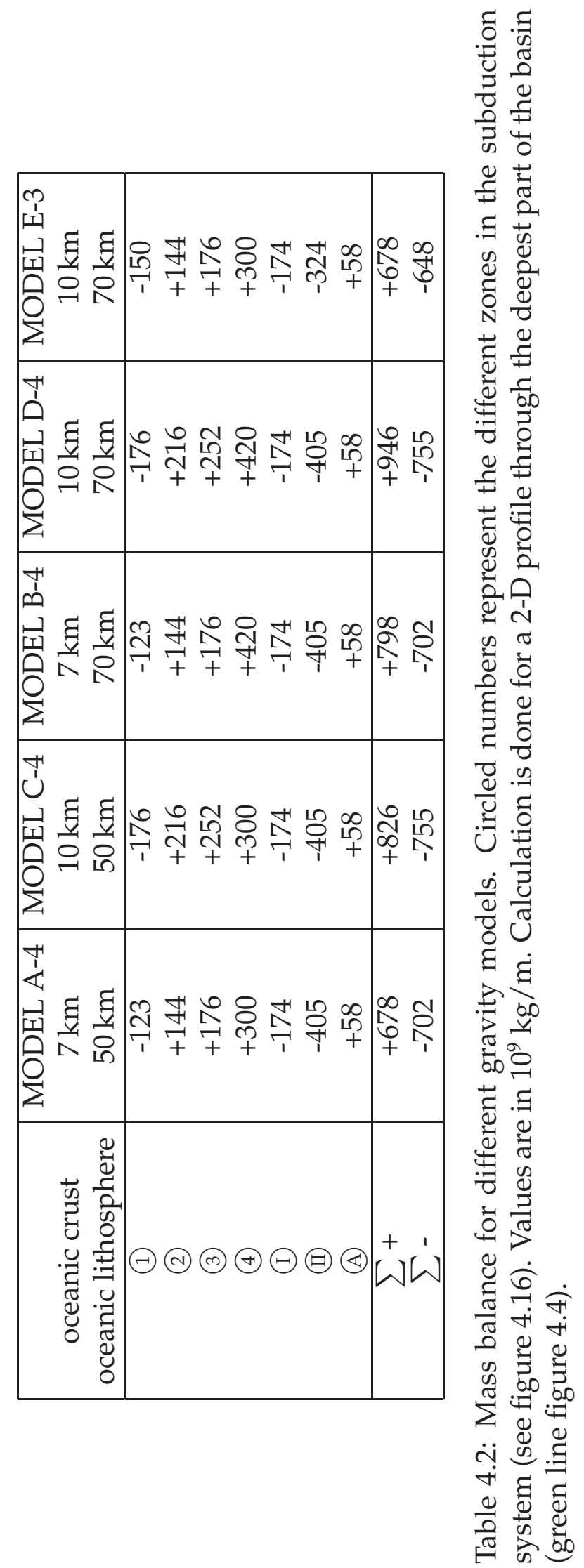


and the red circle marks the origin of the $\mathrm{x}$-axis

\subsection{Summary}

Gravity modelling confirms that crustal thickening beneath the Wanganui Basin is a significant contributor to the observed $-150 \mathrm{mGal}$ gravity anomaly. The sediment basin itself contributes a maximum of $-82 \mathrm{mGal}$ to the overall negative gravity anomaly. It is confirmed that the best-fit gravity model includes a crust that deforms in a ductile manner, with a larger vertical deformation at the bottom of the crust, independent of the chosen slab model parameters. In the preferred final model (Model D-3), the crust has a maximum thickness of $42 \mathrm{~km}$, which corresponds to a three times larger deformation at the crust-mantle interface than at the basement-sediment interface. The slab in this model has an oceanic crustal thickness of $10 \mathrm{~km}$ underneath the southern North Island and a standard oceanic crust of around $7 \mathrm{~km}$ further to the west. This is in good agreement with results from the receiver function study (chapter 5) and other geophysical observations [Bourne \& Stuart, 2000; Moores \& Twiss, 1995; Reading et al., 2001; Savage et al., 2007].

Additionally, it is shown that a thickened oceanic crust for the entire downdip length of the slab creates a higher discrepancy in the mass balance of the system than a standard oceanic crust. The lithospheric thickness of the subducting plate does not play a significant role in the gravity modelling but has to be in the order of $50 \mathrm{~km}$ to create a balanced mass system in the modelling approach presented here. 
Chapter 4.3-D modelling of the gravity anomaly of the South Wanganui Basin 


\section{Chapter 5}

\section{Receiver functions}

\subsection{Dataset and methods used}

Receiver function analysis of teleseismic earthquakes is an established tool for the investigation of crustal and upper mantle structures [Langston, 1979; Owens \& Zandt, 1985]. The method makes use of the fact that an incoming P-wave which encounters a seismic discontinuity will produce transmitted, reflected and converted phases. The transmitted P-phase and the converted Ps-phase will travel to the surface with different velocities. Observed traveltime differences between the two phases are then a direct measure of the depth of the discontinuity, assuming a known velocity model. For more details about the theory and the methods used for processing and analysing receiver functions see appendix $C$.

This study uses teleseismic data from five stations; two stations from the New Zealand national network (GEONET) and three stations from the temporary northern Tararua array [Stuart et al., 1995] (see figure 5.1). These stations form a profile across the southeastern corner of the SWB. The western-most station (DUWZ) is located $31 \mathrm{~km}$ to the south of the profile line and gets projected onto the line. All stations are located on Mesozoic greywacke and are equipped with broadband seismometers with a $100 \mathrm{~Hz}$ sampling rate.

For stations KIW and DUWZ, global earthquakes with a magnitude (M) larger than 6.0 (based on the IRIS data management system (DMC) catalogue) and an epicentral distance $(\Delta)$ between 25 and 110 degrees from the stations are analysed. The four stations from the northern Tararua array (W1, W2, W3, N6) are interpreted for events with $\mathrm{M} \geq 6.3$ and $30^{\circ} \leq \Delta \leq 110^{\circ}$, plus events with $5.4 \leq M \leq 6.3$ for epicentral distances $30^{\circ} \leq \Delta \leq 60^{\circ}$ [see Savage et al., 2007]. This selection is necessary, because for smaller epicentral distances the essential assumption for receiver functions of near vertical incoming P-waves, is violated. For larger distances, the events are within the P-wave shadow zone. Table 5.1 gives a list of the station locations, number of used events and the available time window. As 


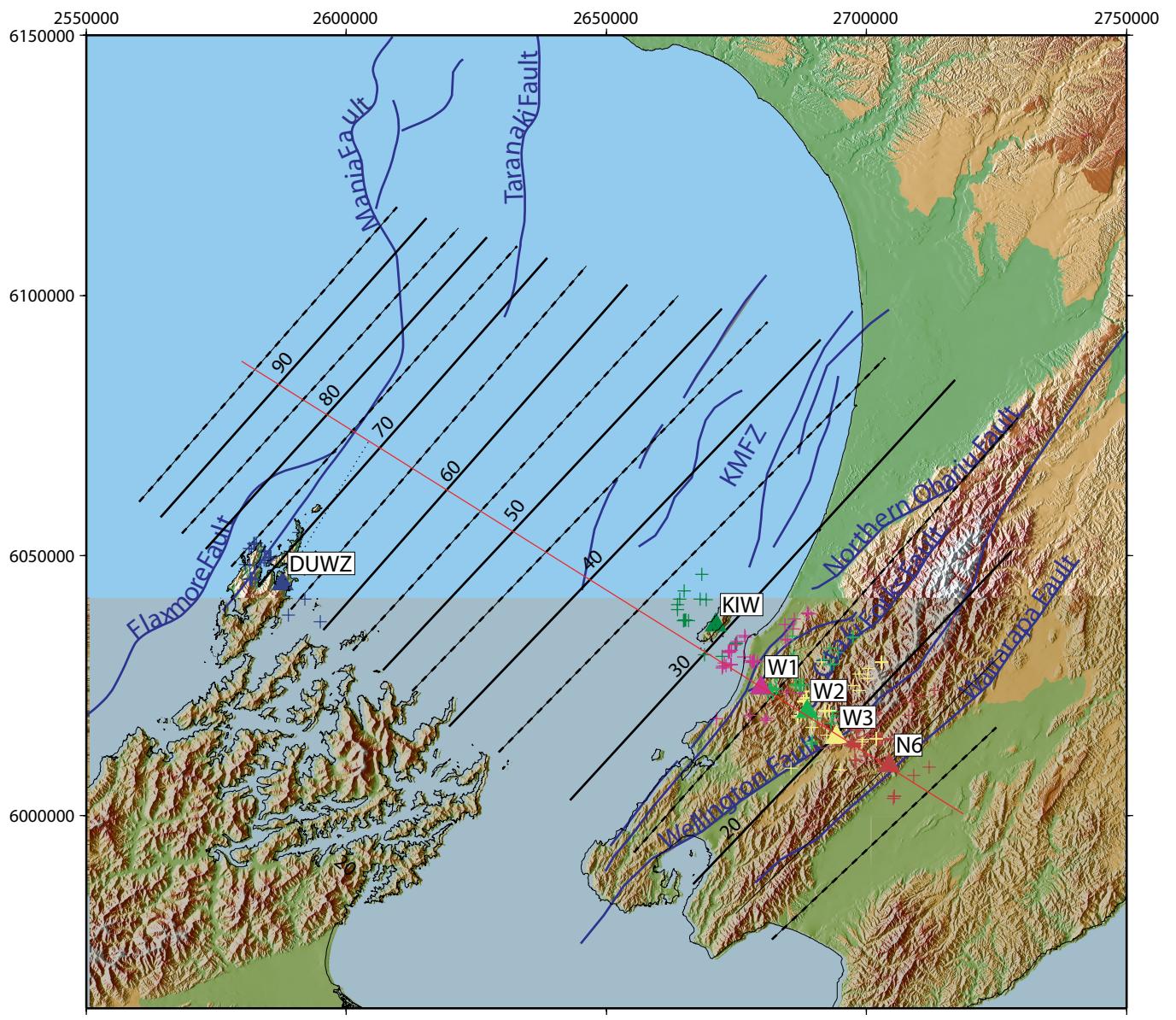

Figure 5.1: Map of the SWB showing the station locations used for the receiver function study (different coloured triangles). Stations W1, W2, W3 and N6 are from the temporary Tararua array [Savage et al., 2007] and KIW and DUWZ are GEONET stations. The coloured crosses show the piercing points corresponding to the same colour station, for a depth of $30 \mathrm{~km}$. The depth to the top of the subducting slab is indicated by solid and dashed black lines [after Ansell \& Bannister, 1996]. All station locations were projected onto the profile line (solid red line). Thin dark blue lines indicate active faults or fault systems.

for most receiver function studies undertaken in New Zealand, the majority of events which fit the criteria originate around the Banda Sea and Papua [Horspool et al., 2006; Salmon, 2008; Savage et al., 2007]. This gives a good coverage of the quadrant with a backazimuth range of $270-360^{\circ}$ and a weak coverage of all other quadrants (see figures 5.2-5.5). In general, events coming from a larger epicentral distance have lower signal-to-noise ratio, especially for higher frequencies, and therefore produce inferior results. 


\begin{tabular}{|c|c|c|c|c|c|}
\hline & EASTING & NORTHING & ELEVATION $(\mathrm{m})$ & $\#$ & TIME \\
\hline \hline DUWZ & 2587756 & 6044565 & 484 & 38 & $03 / 05-02 / 06$ \\
\hline KIW & 2670973 & 6036647 & 381 & 73 & $06 / 04-11 / 05$ \\
\hline W1 & 2679743 & 6024615 & 185 & 41 & $01 / 91-08 / 92$ \\
\hline W2 & 2688548 & 6020039 & 196 & 51 & $01 / 91-08 / 92$ \\
\hline W3 & 2694154 & 6015045 & 196 & 44 & $01 / 91-08 / 92$ \\
\hline N6 & 2728223 & 6040897 & 345 & 49 & $01 / 91-08 / 92$ \\
\hline
\end{tabular}

Table 5.1: Station locations coordinates (in NZMG), number of used events (\#) and time window available at the time of processing.

\subsection{Observed receiver functions}

Preprocessing of the data includes cutting the raw data according to the predicted event arrival times based on the AK135 velocity model [Kennett et al., 1995], with a 120 s time window centred on the direct P-wave arrival. Data were re-sampled to $50 \mathrm{~Hz}$ if necessary. Afterwards the horizontal components were rotated into radial and transverse direction, e.g. the radial component will be aligned along the backazimuth of the event and the transverse orthogonal to it (see appendix C). A further rotation of the system in order to align the vertical component with the P-wave propagation (LQT domain) is possible. This is often applied to data with low-velocity sediment problems. However, tests did not show any significant improvement for the datasets and the LQT rotation is therefore not included. After bandpass filtering $(0.5-2 \mathrm{~Hz})$, the waveforms of every event are examined. Events are only used for further analysis if a clear P-wave arrival on the vertical component is visible.

The actual receiver functions are calculated using the multi-taper correlation method by Park \& Levin [2000]. For more information on this method and the theory behind it see appendix $C$. The processing parameters used for this dataset are the following: The bin size is chosen to be $10^{\circ}$ with a $5^{\circ}$ overlap. Thus, every receiver function belongs to two adjacent bins. The cut off frequency is set to $1 \mathrm{~Hz}$ and the time window is chosen to be $115 \mathrm{~ms}$.

The stations are first analysed individually and a common conversion point (CCP) stack with all stations is produced afterwards (section 5.3.3). The receiver functions for station W1, W2, W3 and N6 were processed and analysed by Savage et al. [2007]. These receiver functions are reprocessed with the same parameters as used for the other stations. The changes in the final results are minor and the interpretation of Savage et al. [2007] can be applied.

The subducted slab has a strike of around $40^{\circ}$ [Reyners et al., 2006]; therefore events with backazimuth of $310^{\circ}$ arrive orthogonal to the strike of the subducting interface. With a window of $30^{\circ}-40^{\circ}$ on both sides the assumption can be 


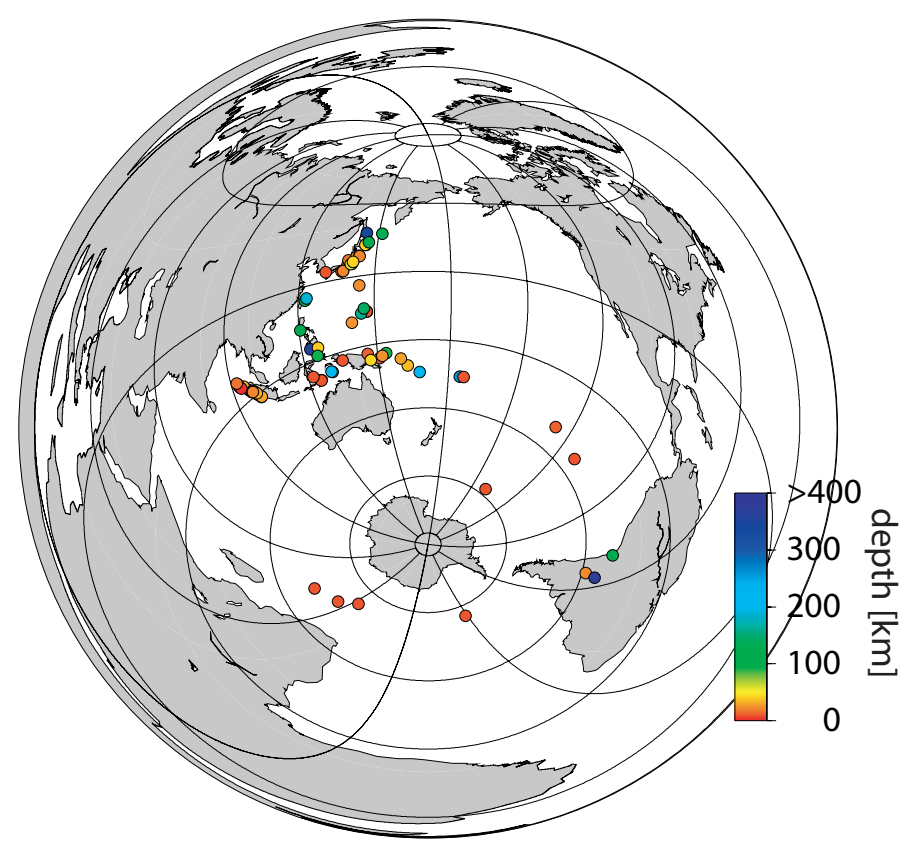

Figure 5.2: Teleseismic events used for receiver function analysis at DUWZ station. Events are colour coded according to their origin depth.

made that all events arrive updip relative to the subducting slab. Furthermore, this backazimuth covers the region with the majority of the usable events $\left(270^{\circ}-\right.$ $340^{\circ}$ ).

All of the stations lie close to major active fault zones (e.g. Wellington Fault, Kapiti-Manuwatu Fault System and Mania Fault; see figure 5.1). Such crustal fault zones as well as coastlines, rugged terrain and sediment basins, all features applicable to the study area, can produce scattering or even Ps conversions, which could contaminate the radial and transverse components [Abers, 1998; Morozov \& Zheng, 2006]. Therefore, data have to be carefully examined for such features. However, their presence in the data can never be fully excluded.

\subsubsection{Station DUWZ}

Station DUWZ is located on d'Urville Island at the northwestern tip of the Marlborough sounds (South Island). It is part of the permanent New Zealand national seismic station network (GEONET) and the western most station of the profile. The top of the subducting Pacific plate is around $65-70 \mathrm{~km}$ below the station [Ansell \& Bannister, 1996]. Data from 11 months were available and 38 events fitted all criteria (see figure 5.2).

The binned radial receiver functions (figure 5.3) show a clear direct $\mathrm{P}$ arrival at Os. Also visible for almost all backazimuths and epicentral distances is a pos- 


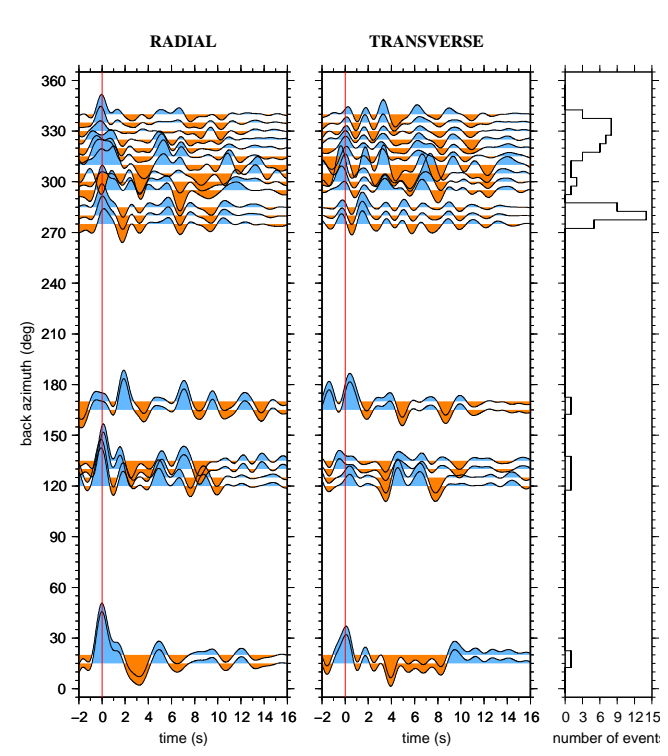

(a) plotted against backazimuth

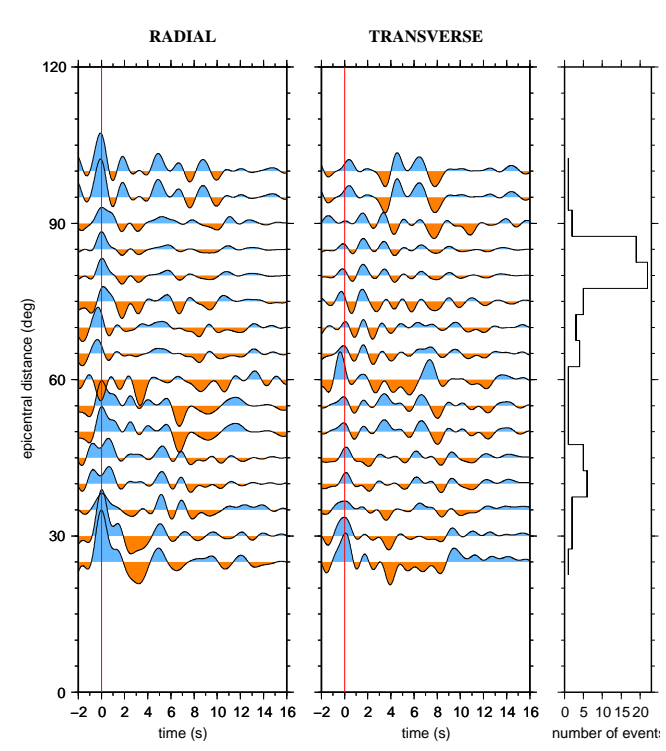

(b) plotted against epicentral distance

Figure 5.3: DUWZ receiver function (binned $\left(5^{\circ}\right)$ and low-pass filtered $(1 \mathrm{~Hz})$ ). Left figure in (a) and (b): radial component; mid figure: transverse component; right figure: number of events stacked in individual bin. Colours represent phase of receiver function: light blue - positive; orange - negative.
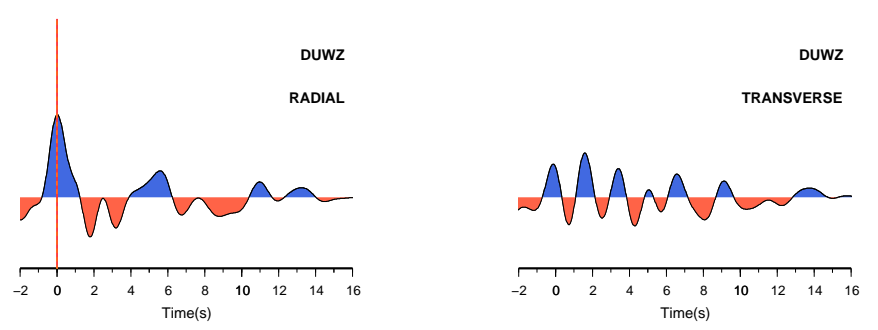

(a) backazimuth $270^{\circ}-340^{\circ}$
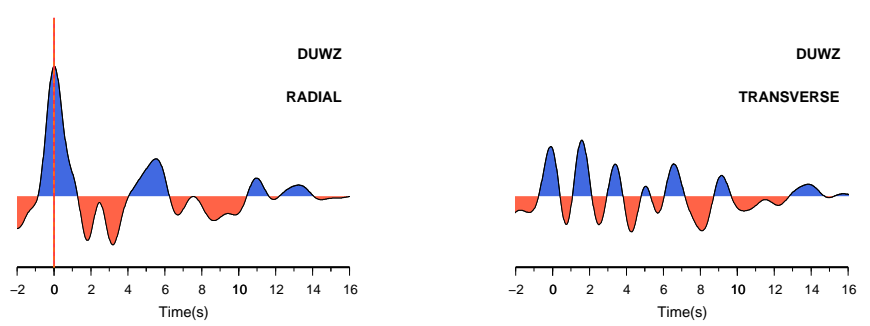

(b) backazimuth $0^{\circ}-360^{\circ}$

Figure 5.4: DUWZ receiver function stacks over different backazimuth ranges. Stacks are similar because the majority of events are located in the backazimuth range of $270^{\circ}-340^{\circ}$.

itive arrival at $\sim 5.8 \mathrm{~s}$. At around $3.2 \mathrm{~s}$ and $1.7 \mathrm{~s}$ there are two negative arrivals 


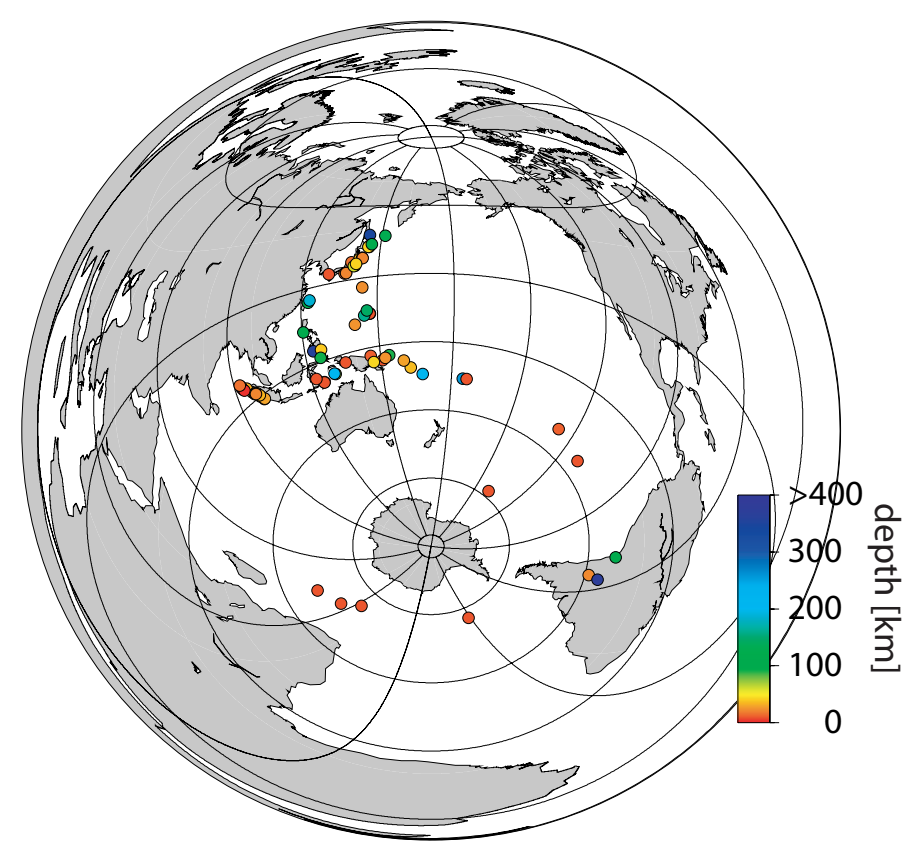

Figure 5.5: Teleseismic events used for receiver function analysis at KIW station. Events are colour coded according to their origin depth.

evident in a backazimuth range of $270^{\circ}-360^{\circ}$. In the epicentral distance plot, the double negative arrival can only be seen between $70^{\circ}$ and $90^{\circ}$. However, backazimuths and epicentral distance range are limited, which makes a discussion of their backazimuthal or epicentral dependency not very meaningful.

The transverse component also shows coherent positive arrivals at around 1, 3 and $6.5 \mathrm{~s}$, with negative arrivals in between. In contrast, there is only one coherent arrival $(\sim 6.5 \mathrm{~s})$ in the epicentral distance stack for the transverse component.

Figure 5.4 shows two receiver function stacks over certain backazimuth ranges. The radial components of both stacks show a clear peak at $5.8 \mathrm{~s}$ delay time with a double negative arrival in front. There is also high energy on the transverse component.

\subsubsection{Station KIW}

The KIW station is located on Kapiti Island, just off the Kapiti coast (North Island). It is a permanent GEONET station and data from around 15 months were analysed, with 73 events fitting the criteria. KIW station is around $75 \mathrm{~km}$ to the east of DUWZ station. Below this station, the top of the subducting plate is expected at a depth of $\sim 30 \mathrm{~km}$ [Ansell \& Bannister, 1996].

There is a small delay (maximum $0.2 \mathrm{~s}$ ) in the direct P-wave arrival for most 


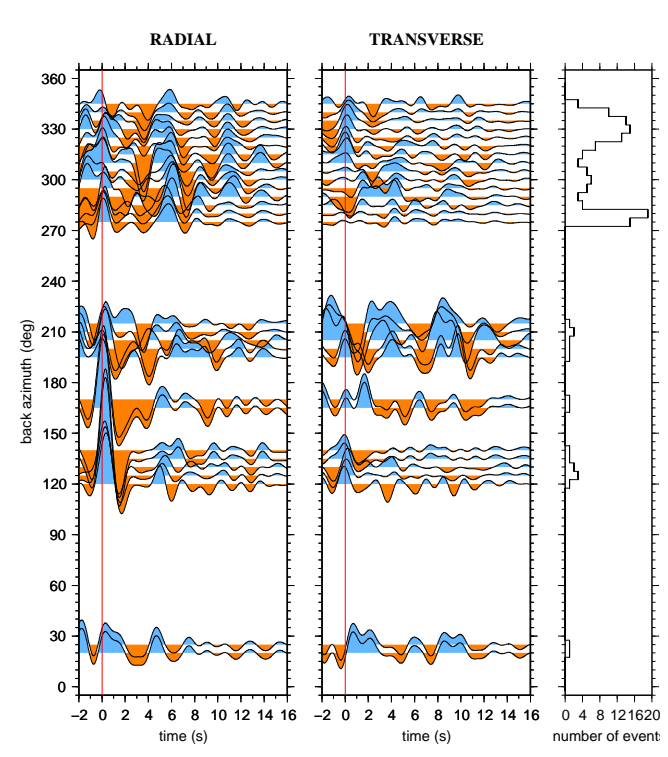

(a) plotted against backazimuth

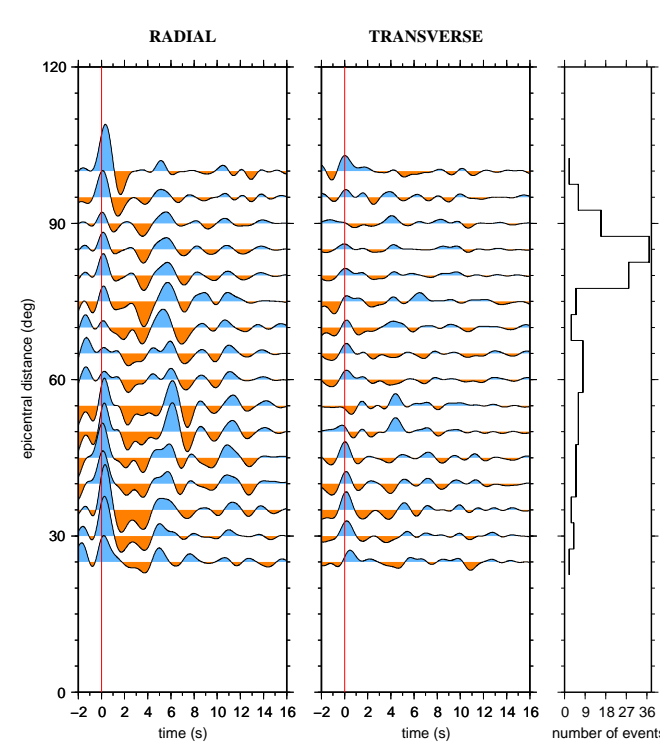

(b) plotted against epicentral distance

Figure 5.6: KIW receiver function (binned $\left(5^{\circ}\right)$, low-pass filtered $(1 \mathrm{~Hz})$ ). Left figure in (a) and (b): radial component; mid figure: transverse component; right figure: number of events stacked in bin. Colours represent phase of receiver function: light blue - positive; orange - negative.
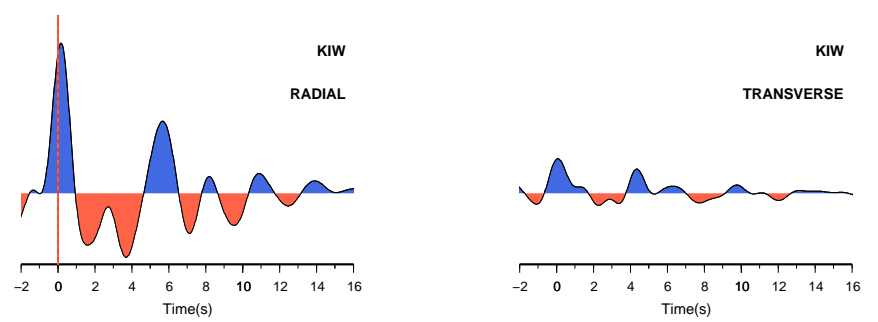

(a) backazimuth $270^{\circ}-340^{\circ}$
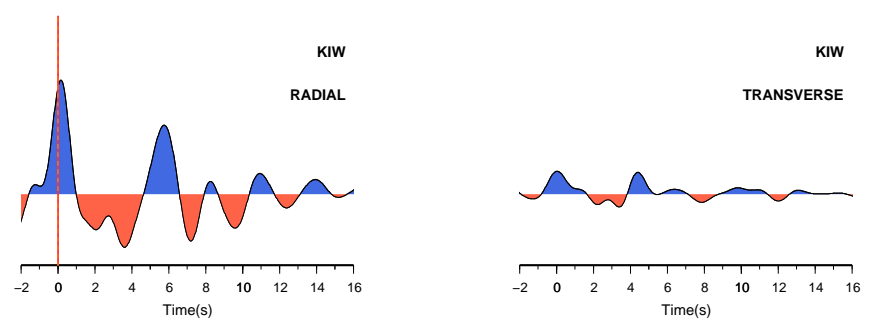

(b) backazimuth $0^{\circ}-360^{\circ}$

Figure 5.7: KIW receiver function bins stacked over different backazimuth ranges.

backazimuth and epicentral distance stacks (figure 5.6). Some backazimuth bins (e.g. $300^{\circ}$ and $305^{\circ}$ ) show a weak direct P-wave arrival. The observed arrivals are similar to the ones in the DUWZ receiver functions. A peak is observed at around 
$5.7 \mathrm{~s}$, preceded by a double negative arrival (1.7 $\mathrm{s}$ and $3.6 \mathrm{~s})$. These troughs are visible for almost all recorded backazimuths and all epicentral distances. Additionally, there are two positive peaks at around $8.5 \mathrm{~s}$ and $10.5 \mathrm{~s}$, especially clear for a backazimuth range of $270^{\circ}-345^{\circ}$. Both of these events have a decreasing delay time with increasing epicentral distance, consistent with a $\mathrm{P}$ to $\mathrm{S}$ conversion from within the mantle. The peak at $5.8 \mathrm{~s}$ is followed by a strong negative arrival at $7.1 \mathrm{~s}$ delay time.

There is considerable energy on the transverse component. However, it is mostly incoherent apart from a peak at $0 \mathrm{~s}$ and a weak positive arrival at around $5 \mathrm{~s}$.

The receiver function stacks over a wider backazimuth (figure 5.7) show substantial more energy on the radial than on the transverse component. In these stacks a strong positive peak at $5.7 \mathrm{~s}$ and the strong double negative arrival are also evident. The backazimuths range of $270^{\circ}-340^{\circ}$ is the most numerous range, so there is almost no difference between the two stacks.

\subsubsection{Tararua deployment}

The Tararua array was a temporary deployment, consisting of nine stations arranged in two arms. One arm is aligned north-south and one arm east-west with one common station [Savage et al., 2007]. In this study, only data from the eastwest arm are used (stations W1, W2, W3, N6; figure 5.1). These stations are located between $25 \mathrm{~km}$ (W1) and $15 \mathrm{~km}$ (N6) above the subducting plate [Bourne \& Stuart, 2000]. The event selection used by Savage et al. [2007] was retained but no $P k P$ phases were used. The station location coordinates and the number of used events can be seen in table 5.1.

Figure 5.8 shows the stacked receiver function for a backazimuth range of $270^{\circ}-$ $340^{\circ}$. This backazimuth range is slightly different from the presented sections in Savage et al. [2007]. They presented two separate stacks, one for a backazimuth of $270^{\circ}-315^{\circ}$ and one for a backazimuth of $315^{\circ}-360^{\circ}$. However, all the major features are visible in all stacked sections and the interpretation by Savage et al. [2007] can be applied.

The delay time of the initial P-phase arrival in the radial component increases slightly to the west, which could be due to the closer proximity of these stations to the sediment-filled basin. A positive arrival (2) is visible for all stations and has a constant delay time of $\sim 2 \mathrm{~s}$. The amplitude of this arrival is decreasing to the west. This peak is followed by a trough (labelled (3)), which can be seen in all stacked receiver functions apart from station W3. Peak (4) has an increasing delay time to the west ( $4 \mathrm{~s}$ for N6 and $5 \mathrm{~s}$ for W1) and a smaller amplitude than peak (2). Additionally, to these features identified by Savage et al. [2007], a second negative arrival is marked at station W1 at around $4.5 \mathrm{~s}$ (labelled (5)). 

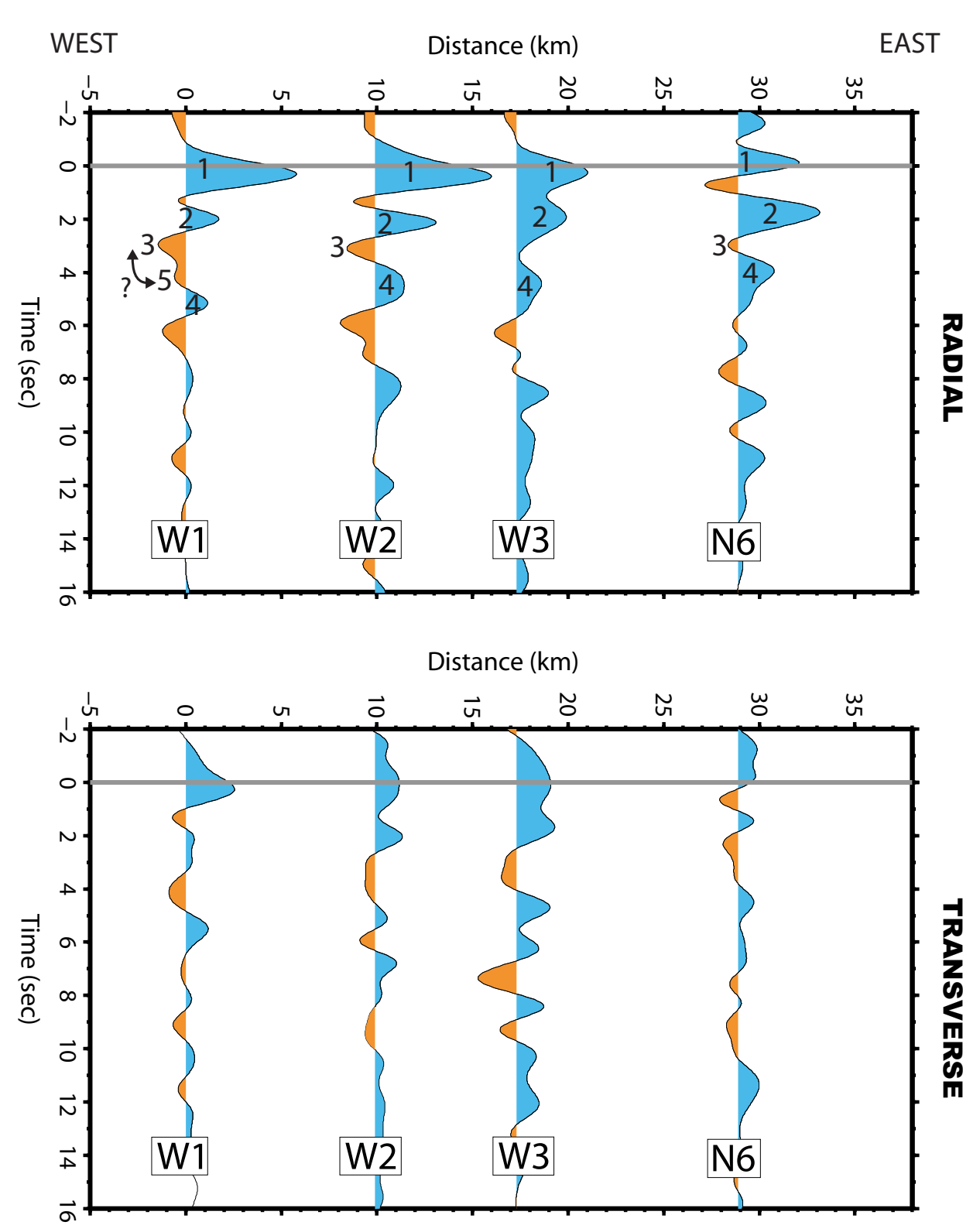

Figure 5.8: Receiver functions stacked over a backazimuth range of $270^{\circ}-340^{\circ}$, at individual stations of the Tararua array. Distance is measured along the profile line (see figure 5.1) with station W1 being the origin.

In the transverse components, the recorded energy is incoherent and the amplitudes of the stacked receiver functions are therefore small. 

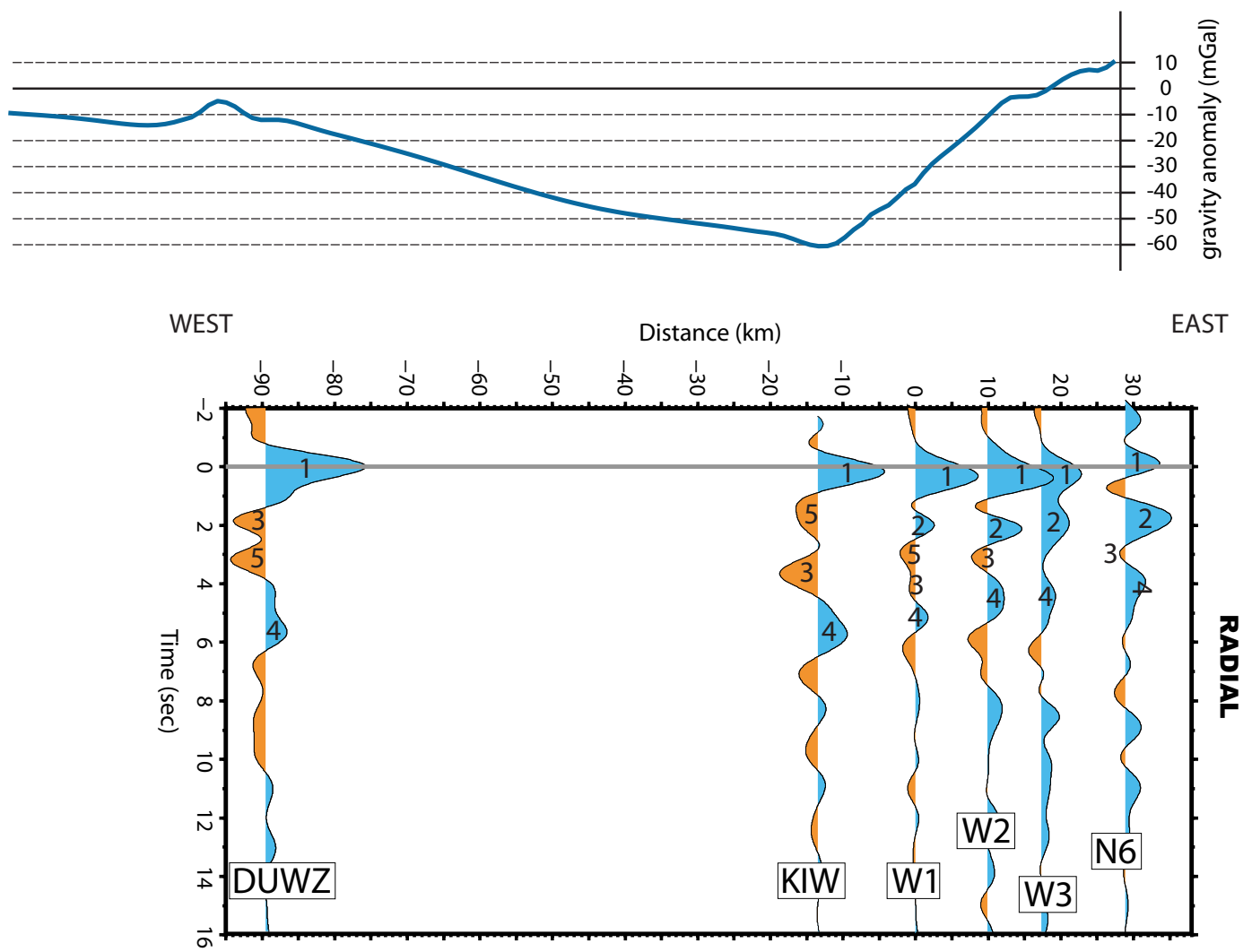

Figure 5.9: BOTTOM: Radial receiver functions stacked over a backazimuth range of $270^{\circ}-340^{\circ}$ for all stations along the profile line (see figure 5.1). TOP: isostatic/free-air gravity anomaly along the same profile. A relative gravity high (between $80-110 \mathrm{~km}$ ) can be seen around station DUWZ, which is close to the Taranaki Fault System. The distance is measured along the profile line with the origin at station W1.

\subsection{Interpretation}

Figure 5.9 shows the radial component of all stations along the profile, stacked for a backazimuth between $270^{\circ}$ and $340^{\circ}$, and the isostatic/free air gravity anomaly (see chapter 4) along the same profile. All receiver functions are now labelled in agreement with section 5.2.3. Peak (4) shows a further increase in delay time to the west relative to the Tararua array stations. At KIW station the double negative trough is much more pronounced and wider. Peak (2) is not clearly visible at KIW, but a small positive peak is identifiable between the negative troughs. At station DUWZ, $75 \mathrm{~km}$ to the west, the receiver function stack also shows a positive peak at around $5.8 \mathrm{~s}$ preceded by a double negative arrival.

Savage et al. [2007] interpreted arrival (2) as a mid-crustal positive Ps conversion, due to a change of the greywacke type or due to a layer of schists. Such a velocity increase in the mid-crust is supported by different studies in this area, e.g. 
seismic refraction data [Garrick, 1968], seismic tomography [Eberhart-Phillips \& Reyners, 1997] and raytracing of converted seismic phases [Reading et al., 2001]. A westward decrease in amplitude of this arrival and the absence underneath station KIW could indicate a reduced velocity contrast to the west. There is no evidence for such a midcrustal conversion in the stacked receiver functions for station DUWZ. However, in the radial receiver function bins (figure 5.3) a positive arrival can be observed at around $2.5 \mathrm{~s}$ delay time for a backazimuth range of $300^{\circ}-330^{\circ}$ and at around $170^{\circ}$.

For the five eastern-most stations arrival (4) is most likely associated with the Moho of the subducting oceanic plate. The delay time increases from east to west as expected for a conversions of a dipping slab. At station DUWZ the situation is different; with the top of the subducting slab over $65 \mathrm{~km}$ deep, the peak at around $5.8 \mathrm{~s}$ is interpreted as a conversion at the Moho of the overriding Australian plate.

The negative arrivals (3) for the stations of the Tararua deployment are explained by a low-velocity layer on top of the subducting slab [Boyd et al., 2007; Savage et al., 2007]. Such a low-velocity layer was also proposed by Bourne \& Stuart [2000] and interpreted as low-velocity sediments on top of the subducting slab. The amplitude of this negative arrival gets larger towards the west, which could indicate a thicker low-velocity layer, a stronger velocity contrast or a combination of both.

Three different analysing techniques were applied to the receiver function data to further investigate subsurface structures and velocity models. Firstly, forward modelling is conducted (section 5.3.1), and then the H- $\kappa$-stacking method is used to get better constraints on the Moho depth (section 5.3.2). Finally, a commonconversion stack is created for the receiver functions data along the profile (section 5.3.3).

\subsubsection{Forward modelling}

To create synthetic receiver functions, a ray-theoretical method is used which includes dipping and anisotropic layers [Frederiksen \& Bostock, 2000]. This approach is also able to model multiples and gives the possibility to include or exclude certain phases. The multiples are modelled sufficiently for a small number of reverberations and simple models [Savage et al., 2007].

The synthetics are generated using the same event and station locations as found in the real data, with a plane P-wave as a source. The processing of the data is done with the multi-taper correlation method (see appendix C.1) as used for the real data with identical parameters. Therefore, real data and synthetic can be directly compared. Receiver function modelling is, however, a non-unique method and trial and error approaches can be impractical because of the large 


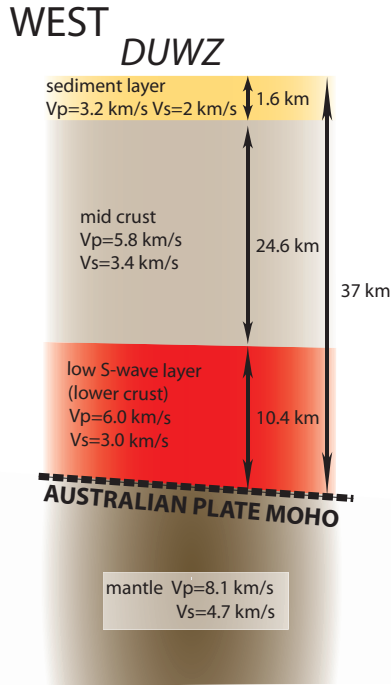

(a)

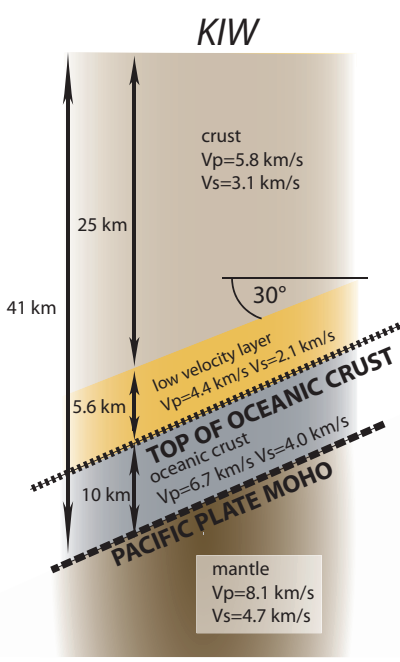

(b)

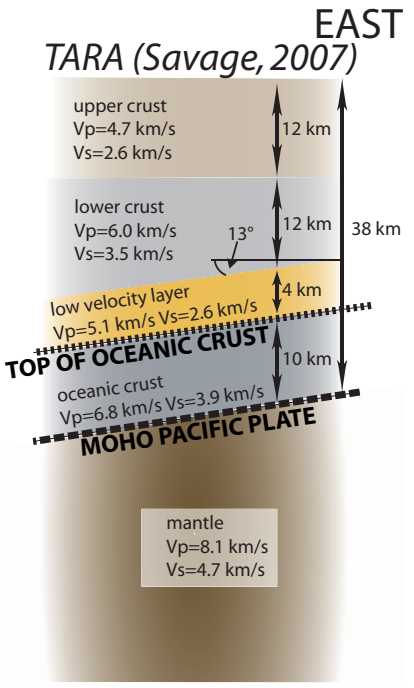

(c)

Figure 5.10: Velocity models for the crustal structure underneath the stations, established using a combination between forward modelling. The velocity model for the Tararua array is taken from Savage et al. [2007]. The DUWZ station model shows a thick crust with a low S-wave velocity layer on top of the Australian plate Moho. Stations in the east show a dipping slab with a $4-6 \mathrm{~km}$ thick low-velocity layer on top.

number of uncertainties. This is especially so for modelling a multi-layer problem.

Forward receiver function modelling for the Tararua array stations was already completed by Savage et al. [2007]. Their preferred velocity model is illustrated on the right hand side in figure 5.10. It shows a five-layer model with a low-velocity layer on top of a $10 \mathrm{~km}$ thick, dipping slab. The strongest amplitude in the receiver functions are explained by a midcrustal boundary (12 km depth). Furthermore, they concluded anisotropy of the lower crust, the sediment layer and the slab of around $4 \%$. This anisotropy estimation is mostly based on receiver function analysis from a permanent station (SNZO), $50 \mathrm{~km}$ to the southwest, where better backazimuth coverage was available [Savage et al., 2007].

The two new stations (DUWZ and KIW) are modelled for the stacked backazimuth range of $270^{\circ}-340^{\circ}$. For the station KIW, the values for the dip of the slab and the low-velocity layer above are fixed to $30^{\circ}$ [after Ansell \& Bannister, 1996]. Additionally, the anisotropy is expected to be similar to estimates for the Tararua array stations [Savage et al., 2007] and the top of the slab is taken to be $30-31 \mathrm{~km}$ deep [Ansell \& Bannister, 1996; Reading et al., 2001]. These values are kept fixed to restrict the number of parameter to solve for. This is necessary due to the lack in backazimuthal range of the data. For the DUWZ station no constraints are available and the modelling is done assuming small dips and no anisotropy. 

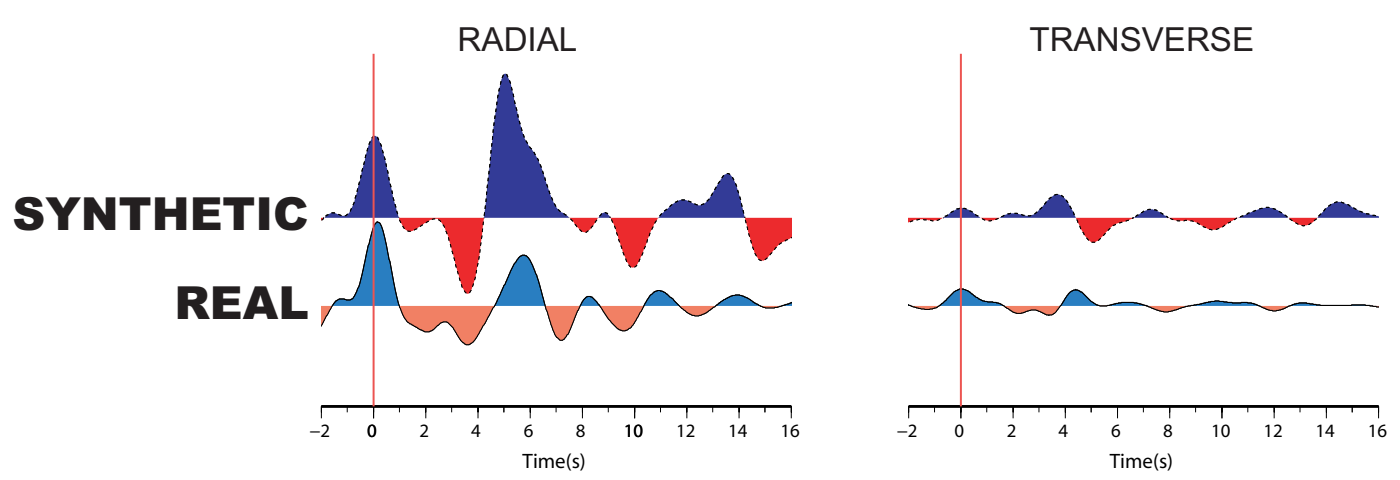

(a) stacked receiver function for final velocity model (see figure 5.10(b))
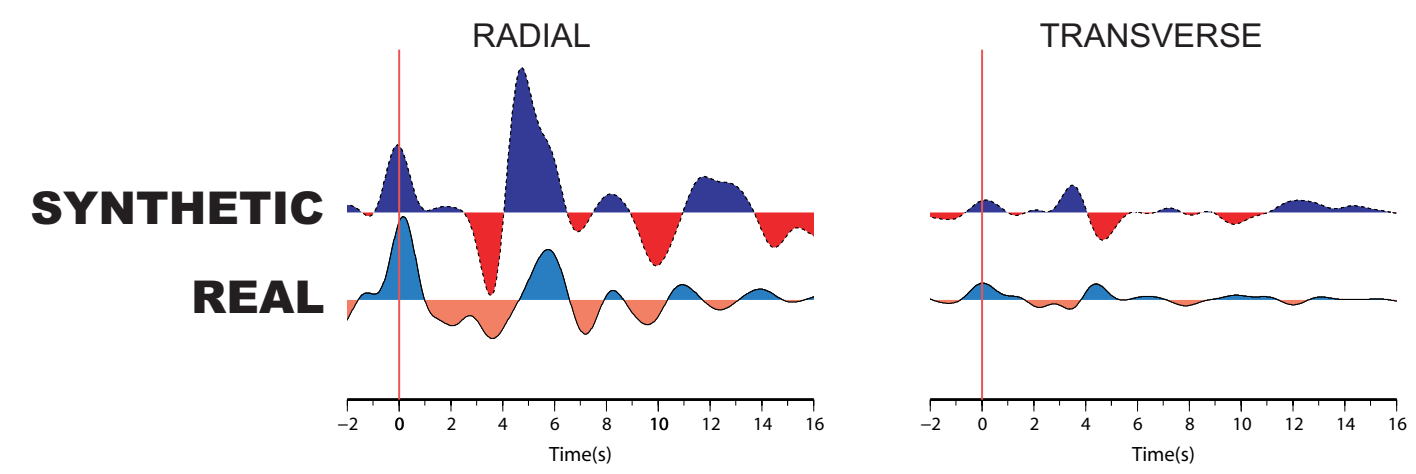

(b) identical velocity model as used in figure (a) but a $4 \mathrm{~km}$ thick low-velocity layer instead of $5.6 \mathrm{~km}$ thick layer
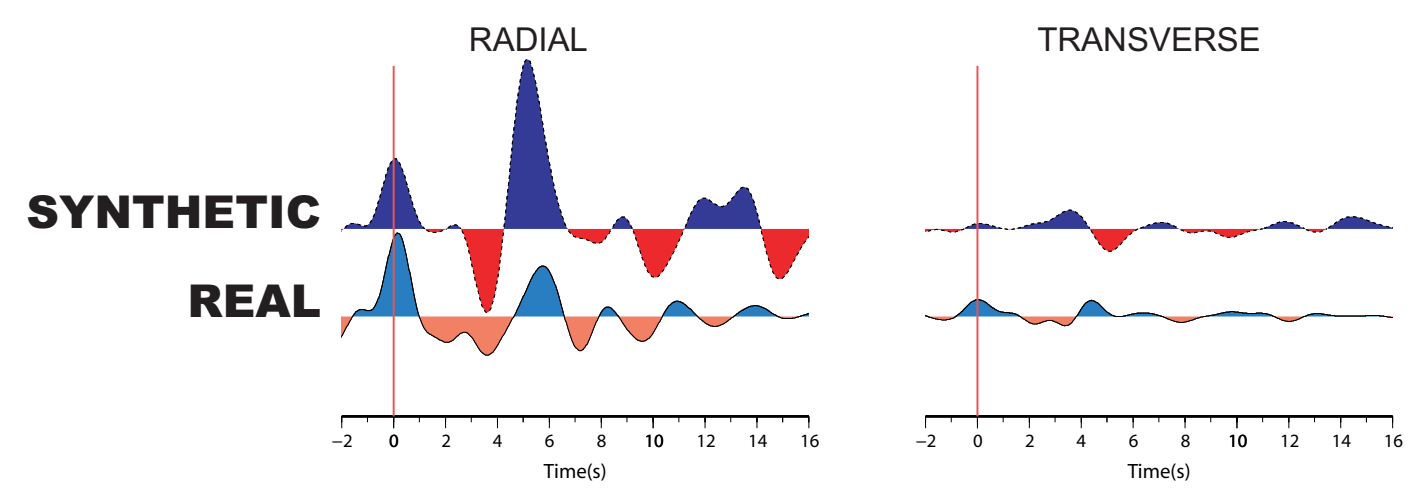

(c) identical velocity model as used in figure (a) but instead of a $10 \mathrm{~km}$ thick oceanic crust only a $7 \mathrm{~km}$ thick crust

Figure 5.11: Synthetic and real receiver functions for a backazimuthal range of $270^{\circ}-340^{\circ}$ for station KIW. The synthetic receiver functions in (a) were calculated with the velocity model from figure 5.10(b). The other two stacked receiver functions are calculated using modification of this velocity model. Note a double negative peak can only be seen in panel (a). 
The forward modelling of the stacked receiver function of station KIW focuses on the arrival times of the strong positive peak at $\sim 5.8 \mathrm{~s}$ and the preceding double negative peak (see figure 5.7). Modelling shows that the positive peak originates from a conversion at the Pacific Moho at a depth of around $40 \mathrm{~km}$. The double negative peak most likely results from a conversion at the negative velocity layer on top of the slab and a corresponding multiple. Such a low-velocity layer is suggested in many studies across the North Island [Ansell \& Bannister, 1996; Chadwick, 1997; Eberhart-Phillips \& Reyners, 1999; Ingham et al., 2001; Reading, 1996; Reading et al., 2001]. However, they vary widely in suggested thickness $(2-5 \mathrm{~km})$ and velocity $\left(V_{p}\right.$ between a low $3 \mathrm{~km} / \mathrm{s}$ and $5.2 \mathrm{~km} / \mathrm{s}$ with a high $V_{p} / V_{s}$ $(>1.8)$ value). This layer most likely represents a crushed zone of crustal material with subducted sediments, volcanic knolls and debris [Ansell \& Bannister, 1996]. It could play an important role in the coupling of the plates, the uplift of the Tararua Ranges and the potential for large subducting thrust earthquakes.

The final velocity model for the station KIW is shown in figure 5.10(b) and the corresponding synthetic stacked receiver functions are shown in figure 5.11(a). This velocity model proposes a thick $(5.6 \mathrm{~km})$ low-velocity layer. A model with a thinner ( $4 \mathrm{~km}$ thick) low-velocity layer cannot produce the double negative peak (see figure 5.11(a)).

The crustal thickness of the slab is modelled to be $10 \mathrm{~km}$, identical to what Savage et al. [2007] found below the Tararua array. This is relatively thick compared to normal oceanic crust of this age (7-8 km, [Moores \& Twiss, 1995]). However, Reading et al. [2001] implied a crustal thickness of $16 \pm 2 \mathrm{~km}$ at the eastern side of the southern North Island based on the distance between the two planes of seismicity (double seismic zone) associated with the subducting slab. Bourne \& Stuart [2000] interpret an 11-15 km thick crust underneath the Tararua Ranges, using $S c S p$ arrivals. The unusual thick crust is explained as part of the subduction of the Hikurangi-Chatham Plateau, which is interpreted to be $10-15 \mathrm{~km}$ thick offshore to the east [Davy \& Wood, 1994]. It is not completely established how much of the plateau has already subducted and how deep downdip this thick crust extends. Rowan \& Roberts [2008] suggests that the subduction of thick Pacific crust started $7 \mathrm{Ma}$ based on a maximum depth of $65 \mathrm{~km}$ for the already subducted thick crust [Reyners et al., 2006]. In contrast, Bourne \& Stuart [2000] predict $100 \mathrm{~km}$ of subducted plateau within at least the last $2.7 \mathrm{Ma}$. Thus, a $10 \mathrm{~km}$ thick crust as modelled for station KIW is thicker than standard oceanic crust of this age but at the lower end for thicknesses proposed for a subducting Hikurangi-Chatham Plateau. Like the subducting sediments, the thickness of the subducting crust can also play an important role in the coupling of the plates and the uplift of the Tararua Ranges. The error bounds on the thickness values of the crust and the low-velocity layer are estimated (assuming a constant velocity for the layers) to be $10 \pm 2 \mathrm{~km}$ and $5.6 \pm 1 \mathrm{~km}$, assuming constant velocities for the layers and a fixed depth to the top of the slab of $30.6 \mathrm{~km}$. 

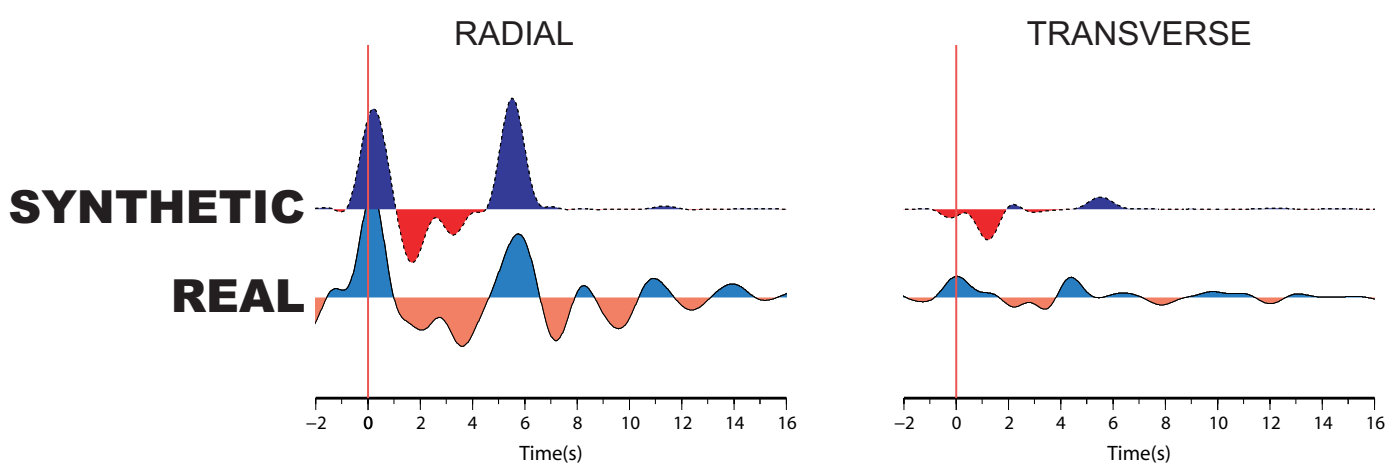

(a) stacked receiver function for final velocity model (see figure 5.10(a))
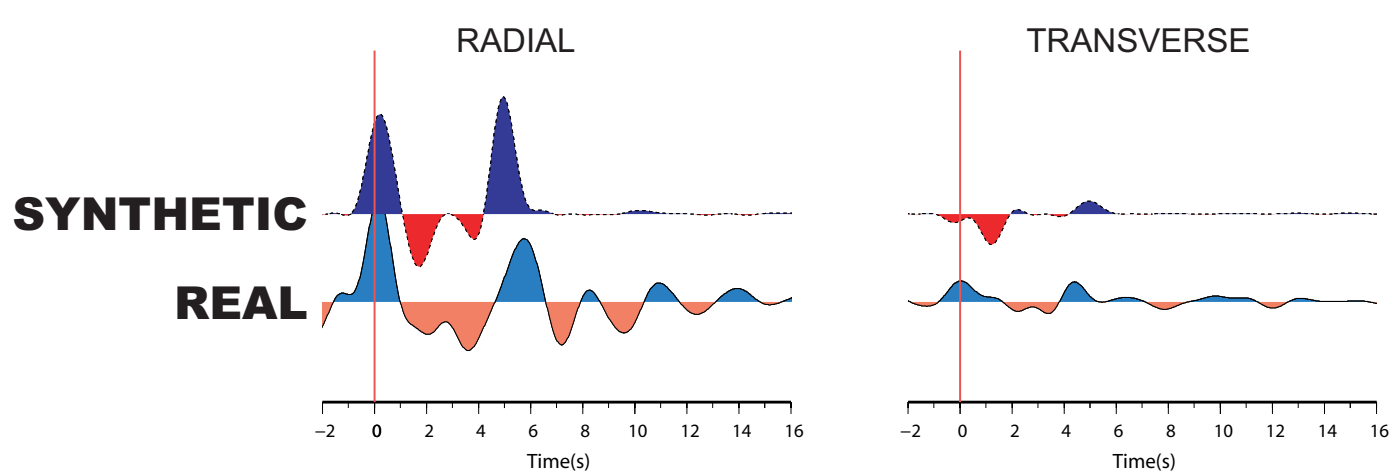

(b) identical velocity model as used in figure (a) but with a low $\mathrm{P}$ - and S-wave velocity layer on top of the Australian Moho $(\mathrm{Vp}=5.1 \mathrm{~km} / \mathrm{s}, \mathrm{Vs}=3 \mathrm{~km} / \mathrm{s})$
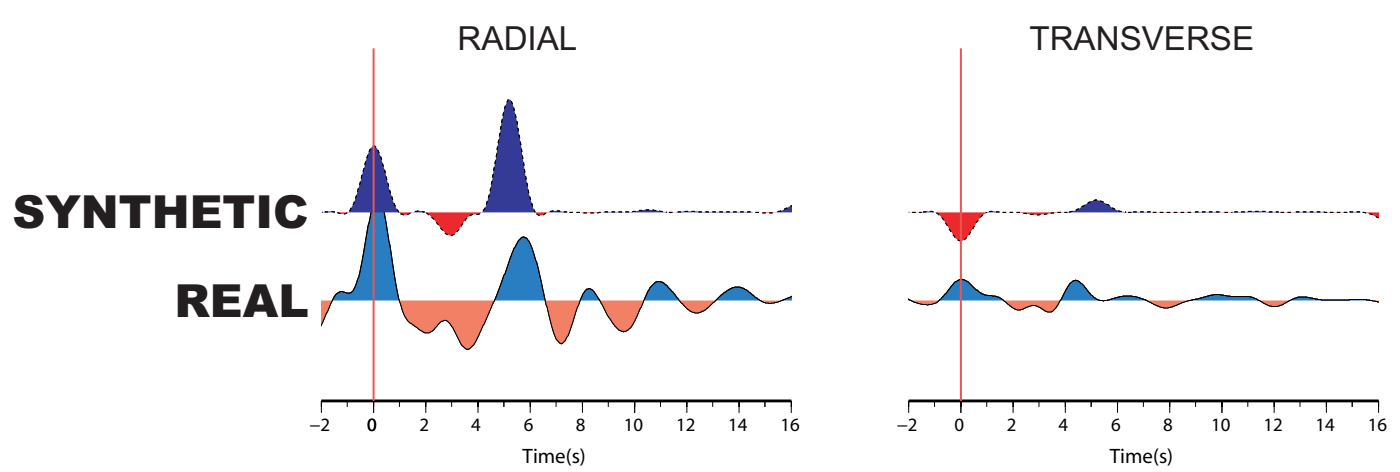

(c) identical velocity model as used in figure (a) but no near surface low-velocity sediment layer

Figure 5.12: Synthetic and real receiver functions for a backazimuthal range of $270^{\circ}-340^{\circ}$ for station KIW. The synthetic receiver functions in (a) were calculated with the velocity model from figure 5.10(a). The other two stacked receiver functions are calculated using modification of this velocity model. 
The situation at station DUWZ is different to the other stations along the profile. It is expected that the slab sits within the mantle, beneath the Moho of the overriding Australian plate. Therefore, the positive arrival at $5.8 \mathrm{~s}$ is assumed to be a Ps conversion from the Australian Moho $(38 \pm 4 \mathrm{~km})$. Additionally to the positive arrival, the real data show a distinct double negative arrival (see figure 5.12). The forward modelling suggests a $12.5 \pm 3 \mathrm{~km}$ thick low S-wave velocity layer $\left(V_{p}=6.2 \mathrm{~km} / \mathrm{s}, V_{s}=3 \mathrm{~km} / \mathrm{s}\right)$ in the lower crust and a shallow sediment layer $(1.6 \pm 0.5 \mathrm{~km})$. In figure 5.12 , additionally to stacked receiver functions for the preferred final model (figure 5.12(a)) there are two more synthetic receiver functions shown for different velocity models. For a model with a low P- and S-wave velocity layer (figure 5.12(b)) instead of just a low S-wave velocity layer the stacked receiver functions also show a double negative peak. But these peaks have different amplitudes and a later second negative arrival than the real data. Figure 5.12(c) shows the corresponding stacked receiver functions for a velocity model with no near surface low-velocity sediment layer. This model only produces the second negative peak but the same strong positive arrival as for the final model (figure 5.12(a)).

The station DUWZ itself is located on greywacke, but the piercing points for the events are to the northeast, on the edge of the Taranaki Basin. A low S-wave velocity layer on top of the Moho of the Australian plate was also proposed for receiver function data from the central North Island [Bannister et al., 2007]. In their study, the low S-wave velocity layer is located above a $40-60 \mathrm{~km}$ deep slab with an S-wave velocity decrease of $\sim 0.5 \mathrm{~km} / \mathrm{s}$, similar to the results found here. However, their layer is less than half the thickness of that proposed here (figure 5.10). Globally, more examples of low S-wave velocity layers above subduction zones can be found. At the Cascadia subduction zone a 5-8 km thick band of high reflectivity in the lower crust was found [Clowes et al., 1987] and explained as a low-velocity layer by receiver function analysis and other geophysical studies [Cassidy \& Ellis, 1991; Nedimovicć et al., 2003; Ramachandran et al., 2006]. Another example is found at the Hellenic subduction zone [Li et al., 2003]. The origin of this low-velocity layer is most likely related to fluids released from the subducting slab which are then stored in the lower crust underneath an impermeable layer [Hyndman, 1988; Stern, 2002]. Hyndman [1988] proposes that this boundary is a result of upwards migrating fluids, which reach an area in the crust with a temperature $\left(350-400^{\circ} \mathrm{C}\right)$ allowing for mineral precipitation. Thus, the depth of the impermeable layer depends on the temperature gradient, which could explain the much thicker low-velocity layer under the DUWZ station due to a much deeper Moho. 


\subsubsection{H- $\kappa$ stacking}

The H- $\kappa$ stacking procedure of Zhu \& Kanamori [2000] produces estimates for the depth of the major Ps conversion and the average $V_{p} / V_{s}(\kappa)$ value for the layers above, under the assumption of a known average $V_{p}$ velocity. It uses the delay time of multiples and the primary Ps conversion to produce a stack, where a maximum is reached if the direct and reverberated converted phases stack coherently. For more details about the method see appendix C.2.

The average crustal P-wave velocity used for the analysis is based on the velocity models developed with forward modelling (figure 5.10). A summary of previous published velocity models of the North Island is shown in table 5.2. The Tararua array velocity model developed by Savage et al. [2007] shows a lowvelocity for the upper $12 \mathrm{~km}$ (upper crust) and an average to low-velocity for the lower crust, plus an additional low-velocity layer on top of the slab. The calculated average velocity for the entire crust is $V_{p}=5.3 \mathrm{~km} / \mathrm{s}$. In the here proposed velocity model for station KIW the crust consists of two layers, a $25 \mathrm{~km}$ thick crustal layer $\left(V_{p}=5.8 \mathrm{~km} / \mathrm{s}\right)$ and a low-velocity layer below. The average P-wave velocity for this crustal model is around $5.6 \mathrm{~km} / \mathrm{s}$, which is also relatively low. As an input for the $\mathrm{H}-\kappa$ stack, a $V_{p}$ of $5.7 \mathrm{~km} / \mathrm{s}$ was therefore used for stations KIW, $\mathrm{W} 1, \mathrm{~W} 2, \mathrm{~W} 3$, and N6 (figure 5.14). For station DUWZ, a higher $V_{p}$ value is assumed $(5.8 \mathrm{~km} / \mathrm{s})$, because there is no low P-wave velocity layer. However, the stacking procedure highly depends on the $V_{p} / V_{s}$ value and is not very sensitive to the absolute velocity model [Zhu \& Kanamori, 2000]. An error of $0.1 \mathrm{~km} / \mathrm{s}$ in the assumed P-wave velocity leads to an error of $\sim 0.5 \mathrm{~km}$ in the calculated depth, where an error in $\kappa$ of 0.1 leads to an around $4 \mathrm{~km}$ error in depth.

One of the basic assumptions of the $\mathrm{H}-\kappa$ stacking method is horizontal interfaces (see appendix C.2). Lombardi et al. [2008] investigate the error induced by applying the classic H- $\kappa$ approach [Zhu \& Kanamori, 2000] on dipping interfaces. They conclude that using only events arriving from the updip direction results in a small overestimation of the Moho depth and an underestimation of the $V_{p} / V_{s}$ value. For events arriving from the downdip direction the opposite effect is found, but it is stronger [Lombardi et al., 2008]. To check the uncertainties on the results of $\mathrm{H}-\kappa$ stack due to the assumed dip under KIW, the synthetic receiver functions produced by the forward modelling are tested as an input for the H- $\kappa$ stack. The depth of the Moho in the model is $40.6 \mathrm{~km}$. However, the maximum stacking amplitude in the $\mathrm{H}-\kappa$ stack gives a conversion at a depth of $42.1 \mathrm{~km}$ ((figure 5.13). Thus, in this study where most events come from a backazimuth range of $270^{\circ}$ and $340^{\circ}$, which is approximately in the downdip direction of the slab, an overestimation of the Moho depth in the order of $1-2 \mathrm{~km}$ can be expected due to ignoring a dip of the interface in the $\mathrm{H}-\kappa$ approach.

In the receiver function stacks of the Tararua array (figure 5.9), the two distinct positive arrivals are identified as a mid crustal $\left(P_{m} s\right)$ and a Moho conver- 


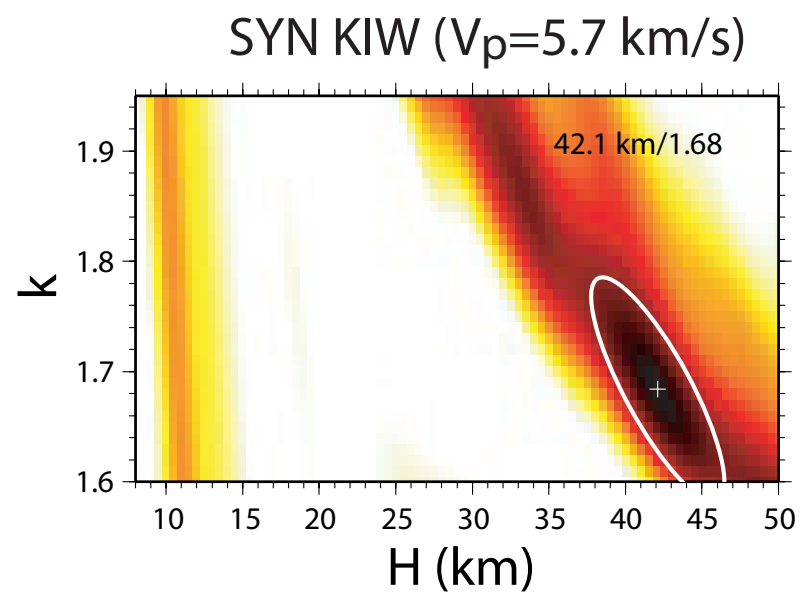

Figure 5.13: H- $\kappa$ stack for synthetic data for station KIW. These data are based on the velocity model in figure 5.10(b). The average crustal $V_{p}$ for the stack is $5.7 \mathrm{~km} / \mathrm{s}$. Colour indicates stacking amplitudes, with darker red representing higher values. The white cross indicates the peak amplitude and the white ellipse encompasses the $95 \%$ confidence region. For $V_{p}=5.7 \mathrm{~km} / \mathrm{s}$, the peak amplitude occurs at $H=42.1 \pm 4 \mathrm{~km}, V_{p} / V_{s}=1.68 \pm 0.1$.

sion $\left(P_{M} s\right)$. Both of these arrivals can be observed as positive stacking amplitude lines in the $\mathrm{H}-\kappa$ stack (figure 5.14(b)-5.14(d)). The multiples from the midcrust are strong on all Tararua array stations in the $\mathrm{H}-\kappa$ stack. In contrast, the multiple from the Moho is not showing up clearly or is not present. For all of the Tararua array stations, the highest stacking amplitude is located between 8 and $9 \mathrm{~km}$ depth with a high $V_{p} / V_{s}(>2 \pm 0.5)$.

At station KIW, the maximum stacking amplitude represent the oceanic Moho conversion with a depth of $39 \pm 4 \mathrm{~km}$ and a $V_{p} / V_{s}$ of $1.78 \pm 0.08$. Assuming the same $V_{p} / V_{s}$ for the Tararua stations, the Moho depth can be roughly estimated by intersecting the positive stack line from the Moho conversion with the assumed $V_{p} / V_{s}$ value (see figure 5.14(a)). So, a depth of around $34 \mathrm{~km}$ for the western-most side of the Tararua array can be estimated. For the two eastern most stations a constant value $(\sim 30 \mathrm{~km})$ is estimated.

Station DUWZ has a maximum stacking amplitude at a depth of $41 \pm 4 \mathrm{~km}$ and a $V_{p} / V_{s}$ value of $1.75 \pm 0.11$ (figure 5.15). This is interpreted as a result from a conversion at the Moho of the Australian plate. A similar depth was proposed by the forward modelling of the receiver functions (section 5.3.1), but this depth is larger than suggested by gravity modelling (see chapter 4 ). The explanation for the modelled thick crust underneath DUWZ could be the proximity to the Mania fault (see figure 5.1). This fault is part of the Taranaki Fault System, which is a subduction back thrust fault and possibly extends to the base of the crust [Stagpoole \& Nicol, 2008]. Such a thrust is often associated with a relative gravity high due to upthrusting of denser material closer to the surface [Holt \& Stern, 

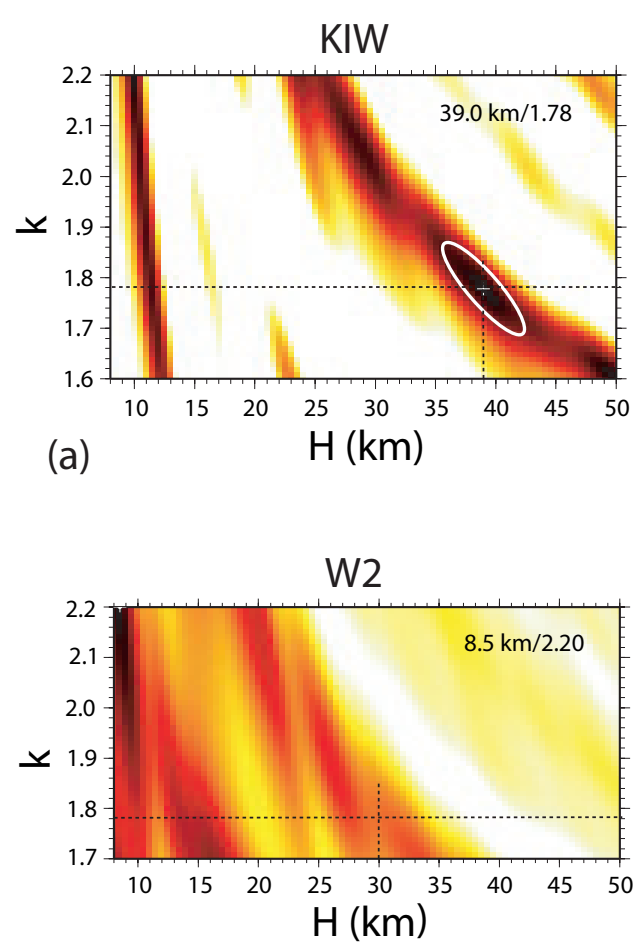

(c)
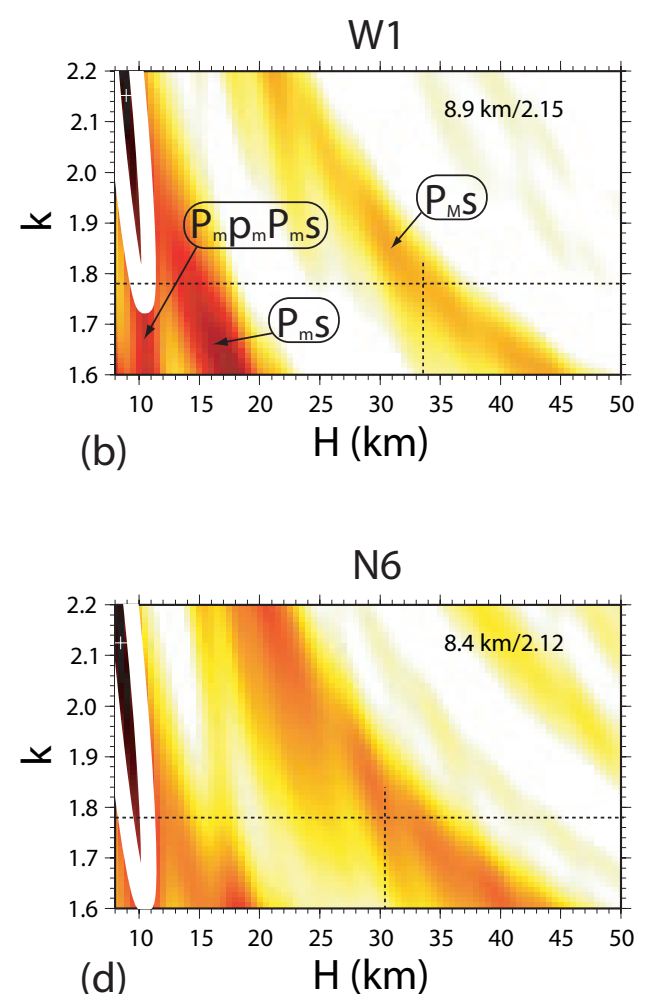

Figure 5.14: H- $\kappa$ stack (full backazimuth range) for stations KIW (a), W1 (b), W2 (c) and N6 (d). Assumed average crustal $V_{p}$ for all stacks is $5.5 \mathrm{~km} / \mathrm{s}$. Different phases contributing to the stack are labelled in (b) as an example. Indices with a small ' $\mathrm{m}$ ' represent conversion or multiples from the midcrustal discontinuity. Indices with a capital ' $\mathrm{M}$ ' represent conversion or multiples from the Pacific plate Moho. Horizontal dashed black lines indicate a $V_{p} / V_{s}$ of 1.78. Vertical dashed black lines indicate the cross point of the Ps conversion and the $V_{p} / V_{s}$ of 1.78. Colour represents stacking amplitudes, with darker red representing higher values. The white cross indicates the peak amplitude and the white ellipse encompasses the $95 \%$ confidence region.

1994]. Such a relative gravity high can also be seen close to station DUWZ in the gravity anomaly along the profile (figure 5.9). However, it cannot be completely ruled out that the receiver function data are contaminated by side-scattering of the crustal Taranaki Fault System.

To summarise, with the H- $\kappa$ stacking method the Moho depth suggested by the forward modelling (section 5.3.1) could be confirmed for stations KIW and DUWZ. For the Tararua array, the suggested Moho is around $5 \mathrm{~km}$ shallower than proposed by Savage et al. [2007]. The midcrustal boundary shows up strongly in the stack, but slightly shallower than in Savage et al. [2007]. This could be due to the used $V_{p}$ value for the $\mathrm{H}-\kappa$ stack, which is a constant crustal average and therefore in general slightly higher than the velocity for just the upper crust. The estimated $V_{p} / V_{s}$ value for the upper crust is high $(>2)$ but includes a large error 


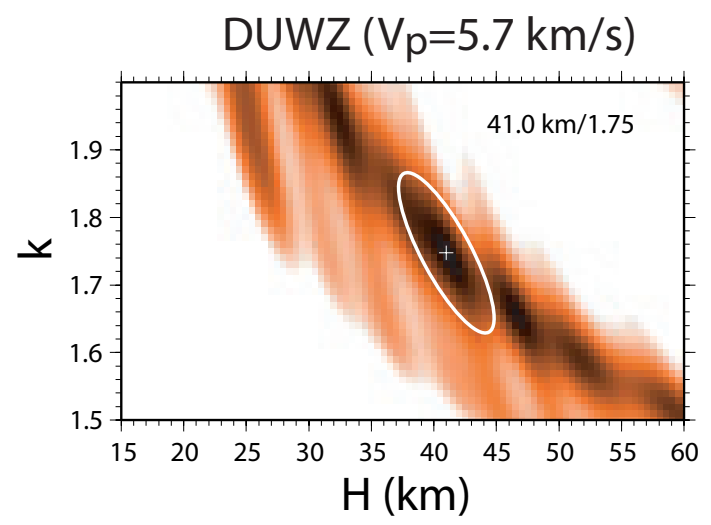

Figure 5.15: H- $\kappa$ stack for station DUWZ. Average crustal $V_{p}$ for stack is $5.7 \mathrm{~km} / \mathrm{s}$. Colour indicates stacking amplitudes, with darker red representing higher values. The white cross indicates the peak amplitude and the white ellipse encompasses the $95 \%$ confidence region. For $V_{p}=5.7 \mathrm{~km} / \mathrm{s}$, the peak amplitude occurs at $H=41 \mathrm{~km}, V_{p} / V_{s}=1.75$.

margin.

For future work it is suggested to use an advanced $\mathrm{H}-\kappa$ stacking method which is also able to solve for the dip of the interface [e.g. Hayes \& Furlong, 2007; Lombardi et al., 2008].

\subsubsection{Common conversion point (CCP) stacking}

The common conversion point stack (CCP) is a method, similar to the common midpoint stacking in seismic reflection processing, to improve the signal-to-noise ratio of receiver functions in a dense station arrangement [Dueker \& Sheehan, 1998]. In this approach, the receiver functions are first binned accordingly to their piercing points at depth, then moveout corrected with a 1-D velocity model and finally stacked. For more details about this method see appendix C.3.

The 1-D velocity model used (model TARA) for the moveout correction is based on results from the previous two sections (section 5.3.1-5.3.2) and the study of Savage et al. [2007]. Table 5.2 shows a summary of velocity models proposed for different areas of the North Island. The model for the Wellington region is spatially the closest. This model shows significant larger velocities for the lower crust than the velocity models established by forward modelling of the receiver functions.

The possible vertical and horizontal resolution achievable with this method depends on the Fresnel zone and the main frequency. The Fresnel zone changes with depth (see section C.3) and is around $10 \mathrm{~km}$ for a depth of $30 \mathrm{~km}$, with a standard New Zealand velocity model and $1 \mathrm{~Hz}$ frequency. The chosen horizontal bin 


\begin{tabular}{|c|c|c|c|}
\hline Model & layer depth $(\mathrm{km})$ & $V_{p}(\mathrm{~km} / \mathrm{s})$ & $V_{s}(\mathrm{~km} / \mathrm{s})$ \\
\hline \hline New Zealand & $0.0-12.0$ & 5.50 & 3.30 \\
Standard & $12.0-33.0$ & 6.50 & 3.70 \\
Maunder [2002] & $>33.0$ & 8.10 & 4.60 \\
\hline Wellington & $0.0-0.4$ & 4.40 & 2.54 \\
Maunder [2002] & $0.4-5.0$ & 5.63 & 3.16 \\
& $5.0-15.0$ & 5.77 & 3.46 \\
& $15.0-25.0$ & 6.39 & 3.50 \\
& $25.0-35.0$ & 6.79 & 3.92 \\
& $35.0-45.0$ & 8.07 & 4.80 \\
& $>45.0$ & 8.77 & 4.86 \\
Western North Island & $0.0-2$. & 4.00 & \\
& $2.0-7.0$ & 5.50 & \\
& $7.0-15.0$ & 6.00 & \\
& $15.0-25.0$ & 6.20 & \\
& $>25.0$ & 7.80 & \\
\hline TARA & $0.0-2.0$ & 4.00 & 2.40 \\
& $2.0-25.0$ & 5.70 & 3.00 \\
& $25.0-30.0$ & 4.40 & 2.10 \\
& $30.0-45.0$ & 6.70 & 4.00 \\
& $>45.0$ & 8.10 & 4.70 \\
\hline
\end{tabular}

Table 5.2: New Zealand velocity models for different regions. The Tararua velocity model is based mainly on results from the forward receiver function modelling (section 5.3.1).

\begin{tabular}{|l|l|}
\hline bandpass filter & $0.5-1.5 \mathrm{~Hz}$ \\
\hline depth increment & $1 \mathrm{~km}$ \\
\hline bin width & $8 \mathrm{~km}$ \\
\hline backazimuth & $40-360^{\circ}$ \\
\hline
\end{tabular}

Table 5.3: Parameters used for CCP stack in figure 5.16

width is slightly smaller $(8 \mathrm{~km})$ to achieve some overlap between the traces. The vertical resolution is approximately $1 / 4$ of the minimum wavelength, therefore the vertical bin size is chosen to be $1 \mathrm{~km}$. Bins are only plotted if they are covered by more than 10 rays. Chosen parameters are summarised in table 5.3.

Figure 5.16 shows the final CCP stack and the interpreted section. In this depthdistance domain plot red colour indicates positive amplitudes (increasing velocity with depth) and blue colour indicates negative amplitudes (decreasing velocity with depth). Station DUWZ is too far to the west from the other stations to achieve any advantage due to the stacking method. The same is true above for depth above $\sim 15 \mathrm{~km}$ for all stations. At this depth, the Fresnel zones of neigh- 
bouring stations do not necessarily overlap and results are identical with a single station stack. The strongest event in the section comes from what is interpreted as a midcrustal discontinuity. It is located at a depth of around $10 \mathrm{~km}$ and slightly dips to the west. Under station KIW this event seems to either step down to $20 \mathrm{~km}$, where the strongest amplitude is located, or to stay at around $10 \mathrm{~km}$. Both interpretations are possible. The second strongest positive amplitude band, interpreted as the Pacific Moho conversion, can be found at around $25 \mathrm{~km}$ below the eastern-most station (N6). It dips slightly to the west, similar to the mid-crustal discontinuity and shows a significant step between stations W1 and KIW. Under station KIW the Moho reaches a depth of $\sim 40 \mathrm{~km}$. Another band of positive amplitudes is identified $10 \mathrm{~km}$ above the Moho conversion, also dipping westwards. This is interpreted as the top of the subducting slab, only producing a visible positive amplitude because it is overlain by a low-velocity layer which results in a strong decreasing velocity contrast. The dotted line (figure 5.16(b)) is the predicted top of the subducting slab from Ansell \& Bannister [1996]. It agrees well with the positive amplitude band and the plotted seismicity (magnitude larger than 2, events after 1990 [GeoNet, 2008]) along the profile line. The dashed line is the proposed trend of the Pacific Moho. Between the midcrustal discontinuity and the top of the slab, a negative velocity contrast is seen, which is most likely linked to the low-velocity layer.

Based on previous results (section 5.3.1 and section 5.3.2) the Australian plate Moho is around $39 \mathrm{~km}$ deep in the west, underneath station DUWZ. At this depth, a positive amplitude band is identified in the CCP stack. It is not clear if the subducting slab can be seen within the mantle underneath DUWZ. Within the mantle, the crust of the slab normally represents a low-velocity layer. Thus, the top of the crust is often identified by a negative conversion, whereas the bottom shows up as a strong positive conversion [Bannister et al., 2007]. However, such a feature cannot be clearly identified in the CCP stack.

Additionally to the study of Savage et al. [2007] the data from the Tararua array are also used in a second receiver function study [Boyd et al., 2007]. In this study receiver function data from stations of the lower North Island and upper South Island are projected onto a profile across Cook strait, with a significant northeastsouthwest distance between the two station sets. A CCP stack and a Kirchhoff migrated version of the stack are produced. In agreement with the here presented study, their results also identify the Moho of the slab as a positive conversion. The dip of the slab is steepening to the west and a relatively weak Australian Moho conversion is identified at a depth of $35 \mathrm{~km}$ in the west of the profile. For the eastern side of the profile a low-velocity layer on top of the slab is implied, which reaches to a depth of $60 \mathrm{~km}$. Furthermore, in agreement with this study Boyd et al. [2007] show that a low average crustal velocity has to be assumed to match the top of the slab conversion with the seismicity linked to the Benioff zone.

Similar to the CMP method in reflection seismic, the CCP stack also assumes a 


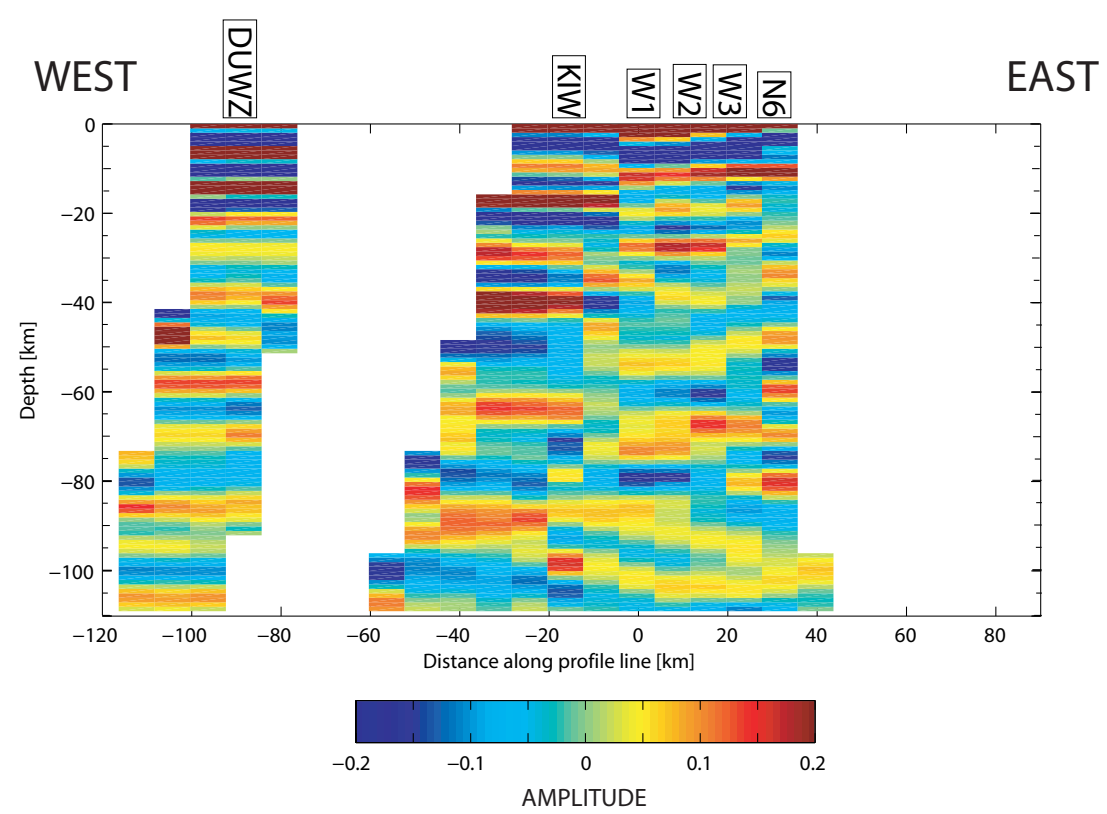

(a) CCP stack

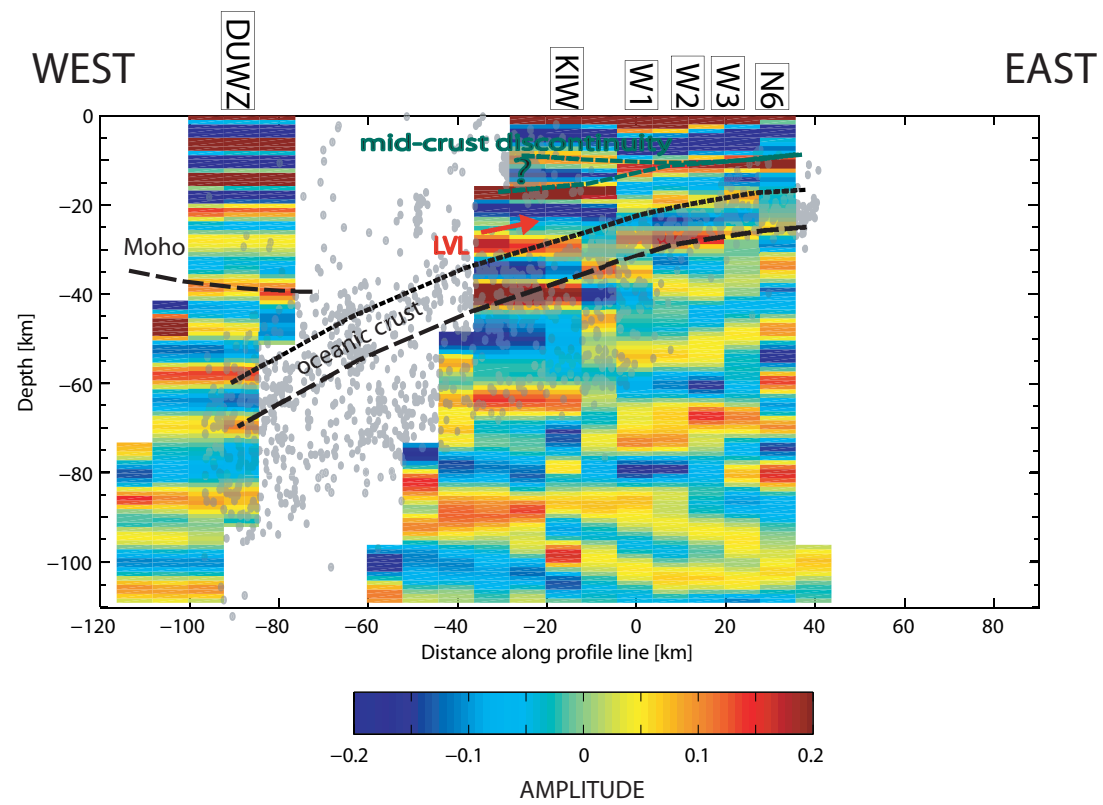

(b) CCPstack+interpretation+seismicity

Figure 5.16: CCP stack for stations along the profile using velocity model TARA (table 5.2). The x-axes of the stack runs along the profile (see figure 5.1) and station $\mathrm{W} 1$ is chosen as the origin. Red colour indicates positive phases, blue colours indicates negative phases. (a) Original stack for a backazimuth range of 40-360 ${ }^{\circ}$ (b) Stack overlaid by interpretation and seismicity. Grey dots represent earthquakes after 1990 with an amplitude larger than 2 [GeoNet, 2008]. Dashed black line indicates position of Moho. Dotted black line indicates top of subducting oceanic crust. Green line shows the position of the midcrustal discontinuity. The blue amplitude band, between midcrust and top of Moho, is interpreted as the low-velocity layer. 
horizontal constant velocity field. If significant lateral heterogeneities are present, diffraction and scattering can contaminate the stack [Chen et al., 2005; Sheehan et al., 2000]. Under the lower North Island the dip along the slab is up to $30^{\circ}$ and the velocity structure is assumed to change significantly, especially between the Tararua array stations and DUWZ station. Thus, the error margins on these results have to be estimated as relatively high. For future work, a post-stack migration of receiver function data is suggested [Boyd et al., 2007], e.g. with a post-stack wave equation migration for CCP stacked data [Chen et al., 2005].

\subsection{Summary}

This receiver function study across the southeastern corner of the SWB reveals a thick crust $(\sim 39.5 \pm 3 \mathrm{~km})$ underneath the northwestern tip of the Marlborough Sounds bordering the Taranaki Basin. The data at station DUWZ also show a thick $(12.5 \pm 3 \mathrm{~km})$ low S-wave velocity layer in the lower crust, which is most likely related to fluids released from the subducting slab and stored in the lower crust underneath an impermeable layer. This could also be the explanation for the swarm-like earthquake activity seen in the lower crust in the SWB (see chapter 2).

To the east, below the Tararua Ranges and the Kapiti Coast, a thick (minimum $10 \pm 2 \mathrm{~km}$ ) crust is subducting underneath the overriding Australian plate. On top of this slab, a low-velocity layer is proposed which seems to thicken below station KIW. It is interpreted as a crushed zone of crustal material together with subducted sediments, with the increase in thickness due to accumulation of the sediments [Walcott, 1987]. A positive amplitude band in the CCP stack coincides with the top of the subducting slab defined by the seismicity along the profile line. Another feature is a strong midcrustal velocity discontinuity at a depth of around $10 \mathrm{~km}$, interpreted as a change in greywacke types. This feature seems to disappear towards the west. 


\section{Chapter 6}

\section{3-D finite element modelling of deformation in the North Island}

The mid and lower North Island topography can broadly be characterised by three different physiographic provinces: the long spinal uplift of the Tararua and Ruahine mountains, the dome shaped uplift of the central North Island and the focused subsidence of the Wanganui Basin (figure 2.2). The proposed driving forces behind these vertical motions can be broadly summarised by three components: 1.) Replacement of mantle lithosphere is most likely the reason for the uplift of the central North Island [Pulford \& Stern, 2004; Salmon et al., 2005], given the time (5 Ma) and space scale ( $400 \mathrm{~km}$ wavelength) over which the uplift occurred 2.) An isostatic flexural response due to the mass excess of the subducting slab and the high friction between the two plates possibly causing the subsidence of the Wanganui Basin and 3.) The Axial Ranges as a result of tilting of basement blocks due to ramping of the Australian plate up over the unlocked portion of the Pacific Plate [Neef, 1999; Nicol \& Beavan, 2003; Wells, 1989]. Additionally, sediment loading and erosion play a significant role in augmenting the vertical deformation observed. This chapter further investigates the driving forces behind the deformation in 3-D using finite-element modelling (FEM) and makes a quantitative statement about the necessary load distribution and amplitudes as well as the rheology underneath the SWB. In this chapter the term uplift is used in the sense of "rock-uplift" (exhumation + surface uplift) [England \& Molnar, 1990], unless otherwise stated.

\subsection{Model Setup}

Stern et al. [1992] and Pulford [2002] modelled the flexural deformation of the SWB and the central North Island, respectively, with a finite-difference overrelaxation technique. The main restriction of this modelling approach is that it 
is based on an equation which describes the behaviour of the lithosphere as a single thin elastic plate overlying an inviscid asthenosphere. This corresponds to the definition of the elastic thickness $\left(T_{e}\right)$ of the lithosphere, which is only a simplified approximation to the gross strength of the continental lithosphere. It is mainly used as a basis for comparison of different continental regions [Watts, 2001]. However, the continental crust can be separated into at least two different layers with different geophysical, geochemical and petrological properties [e.g. Rudnick \& Fountain, 1995] and thus, each of these layers will deform differently and will have an influence of the observed vertical motion at the surface.

A further restriction of the approach used by Stern et al. [1992] and Pulford [2002] is the restriction of the vertical driving forces to the top of the plate. This restriction is valid in the case of a purely elastic plate, but in the viscoelastic case the location of the application point of the force becomes of significant importance. In the here presented modelling approach the driving force for the subsidence of the SWB is placed on the bottom of the crust. For all the uplift processes of the North Island, which are only included as the boundary condition for the basin, it is assumed that the driving forces act on the top of the plate.

The finite-element modelling method presented in this chapter can be used to overcome the above mentioned limitations. In this method, the number of layers is not restricted, the load can be applied at every point within the model and the material parameters can easily be changed. This makes it possible to simulate a more realistic image of the crust and underlying mantle compared to a single elastic plate. However, the model does not simulate the subduction zone as such, it only looks at deformation occurring on a "block" of crust/mantle material above the subduction zone.

The model development will be discussed for the commercially available finiteelement software ABAQUS ${ }^{T M}$ (Abaqus Inc.). It is a robust finite-element modelling program and allows simple creation and alteration of model geometries and parameters using the program ABAQUS ${ }^{T M}$ CAE $^{T M}$ (Complete ABAQUS ${ }^{T M}$ Environment) [Karlsson \& Sorensen, 2007].

The configuration of the model is relatively simple (see figure 6.1). It consists of 4 flat, $1200 \mathrm{~km}$ (north-south extension) by $600 \mathrm{~km}$ (east-west extension) plates of variable thickness and material parameters. The plates are 'stacked' on top of each other and 'tied' (welded) together, which means that no relative motion between the plates is allowed. From top to bottom the four layers represent the upper crust, the lower crust, the mantle lithosphere and the top of the mantle asthenosphere. 


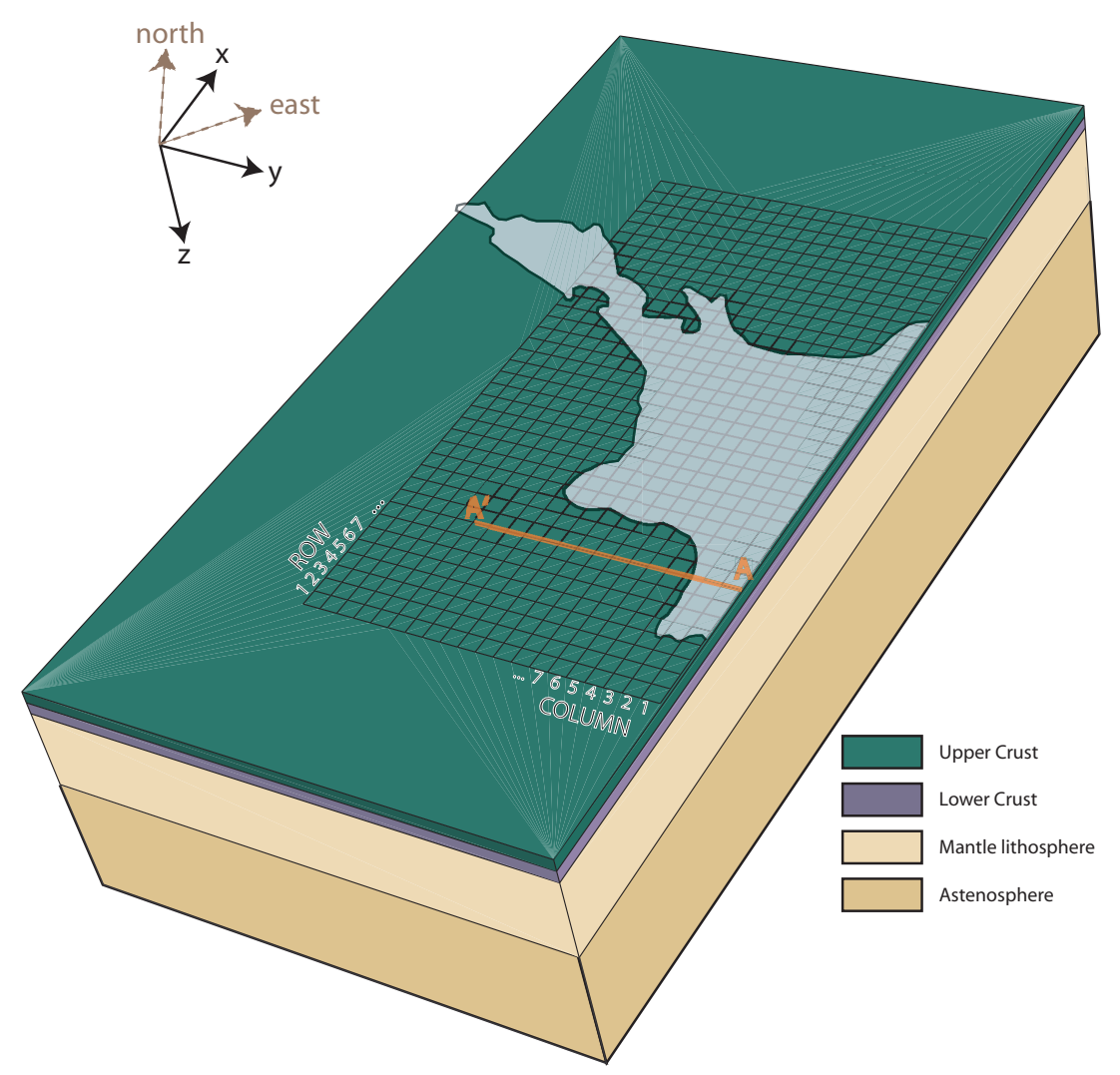

Figure 6.1: Basic model setup: four flat layers with a surface of 1200 by $600 \mathrm{~km}$, with different material properties and thicknesses 'tied' (welded) together. The white shaded area is the western part of the North Island rotated anticlockwise by $33^{\circ}$, in the xy-plane. The orange line is the profile line for the presented crosssections. The raster on the surface illustrates the grid used and shows the labelling of the grid with the cell in row 1 and column 1 (R1|C1) being in the southeast corner of the grid.

\subsubsection{Why a viscoelastic layer?}

The reason for using a viscoelastic modelling attempt is based on different geophysical observations, which suggest a ductile crustal thickening within the SWB [Stern \& Davey, 1985, 1990] and beneath the Taranaki fault [Holt \& Stern, 1994]. In particular, the 3-D modelling of the gravity basin anomaly is consistent with a downwarp and differential thickening of the entire crust (chapter 4). To fit the observed gravity, the downwarp of the Moho has to be three to four times greater than the downwarp of the sediment-basement interface. It is therefore proposed that ductile thickening of the crust increases with depth. 


\subsubsection{Boundary conditions and grid definition}

Boundary conditions of the model are a fixed bottom for displacements on the lowest plate in all three dimensions and fixed vertical sides on all four layers for horizontal displacement. This is necessary because the eastern side is described as a free edge (see below) but is still part of the larger plate. Therefore, vertical movement of the sides should be possible but without the tilting of side surfaces of the model.

At the top and bottom of every plate a spatially restricted two-dimensional grid with 740 cells and a cell-size of $20 \times 20 \mathrm{~km}$ (see figure 6.1) is defined. Every cell of the grid has a number, relative to its location, starting with row 1 and column 1 (R1|C1) in the southeast corner of the grid. The coordinate system of the model is rotated anticlockwise by an angle of $33^{\circ}$ relative to the geographical coordinate system. The origin of rotation is NZMG 2484500E|6076250S which corresponds to the common point of cell R10|C11, R10|C10, R9|C11 and R9|C10 in the model domain. Thus, an individual load can be placed on every cell of the grid and every cell can be assigned with a different buoyancy force. The rotation is done to line up the eastern boundary of the model parallel to the southern part of Hikurangi trench and to place the eastern edge of the model exactly at the centre of the Axial Ranges of the North Island. This makes it possible to simulate a free edge which is assumed to be due to the presence of the Waiararapa Fault, lying immediately east of the southern section of the ranges [Darby \& Beanland, 1992]. Figure 6.1 also shows the coastline of the North Island of New Zealand.

\subsubsection{Forces, gravity and buoyancy}

Different load patterns can be simulated by applying individual loads to cells on the grid, whereby they can act as 'pull' or a 'push' depending on their sign and the location of the cell. A negative load (tensional force) applied to a cell at the top of a plate results in an upward 'pull', whereas a positive load (compressional force) applied to a cell at the bottom results in an upward 'push' and vice versa.

Buoyant restoring forces within the model have to be adjusted to include the effect of erosion and sedimentation. This is done by using Winkler foundations, which are elastic forces proportional to the displacement, similar to a spring [Watts, 2001]. This force can then be individually adjusted for every cell at the bottom of the crust. In ABAQUS ${ }^{T M}$, the amplitudes of the Winkler forces are defined by the gravitational accelerations $(g)$ multiplied by the density contrast $(\Delta \rho)$ (Abaqus, 2006). In the case of tectonic uplift (no erosion), the density contrast has to be calculated between air and mantle $\left(\Delta \rho=3300 \mathrm{~kg} / \mathrm{m}^{3}\right)$. This value is used for the Tararua Ranges, characterised by high uplift rates and erosion resistant rock [Walcott, 1987]. For efficient erosion in the sediment covered regions there is an amplified rock uplift due to the isostatic rebound and the density contrast 
will be between mantle and sediment, $\Delta \rho=3300-2200 \mathrm{~kg} / \mathrm{m}^{3}=1100 \mathrm{~kg} / \mathrm{m}^{3}$. Pulford [2002] used a density contrast of $2200 \mathrm{~kg} / \mathrm{m}^{3}$ for the central North Island which is halfway between tectonic and rock uplift. Within the basin the restoring forces are calculated by means of a density contrast between sediment fill and underlying mantle material. Using an average Plio-Pleistocene sediment density of $2200 \mathrm{~kg} / \mathrm{m}^{3}$ [Hunt, 1980], this results in a $\Delta \rho$ of $1100 \mathrm{~kg} / \mathrm{m}^{3}$.

One of the most common ways to simulate gravity in FEM is to apply Winkler restoring forces along the surface [e.g. Cohen, 1994]. But this only allows an accurate calculation of the vertical displacement at the surface. The background stress due to gravity is incorporated by pre-stressing the model. Therefore, the pre-stress values are estimated in an initial run of the model by applying only gravity forces. The resulting internal stress then defines the background stress field in the actual model. This approach ensures that the model does not deform under gravity forces.

\subsubsection{Definition of material properties}

Different materials deform differently under the same state of stress. Therefore, the modelling materials of the different layers need to be described by the density, the elastic parameters (Young's modulus E (Pa) and Poisson's ratio $\nu$ ) and for materials which behave viscoelastic also by the viscosity $(\eta(\mathrm{Pa} \cdot \mathrm{s}))$. A linear elastic solid describes the deformation of a material proportional to the applied stress. The material fully recovers as soon as the stress is released. A mechanical analogue to the elastic behaviour is a spring. For small stresses and cold temperatures, rock can be described by only elastic parameters [Twiss \& Moores, 1992]. However, for higher loads, higher temperatures and long loading times rock starts to flow. The simplest way to describe this behaviour is by linear viscosity, where the strain rate is proportional to the applied stress with an instantaneous response. This deformation is not recoverable. If a certain stress amplitude (yield stress) is necessary to start the viscous deformation of the material, it is called plastic. Additionally, for high homologous temperature (defined as the ratio between actual temperature and melting temperature of the material), the material can flow below the yield stress which is called creep [Twiss \& Moores, 1992].

For most problems the earth can be described by an elastic or a linear viscoelastic material [e.g. Peltier, 1998; Wang et al., 1994; Wolf, 1984]. The mechanical analogue for the viscoelastic case is a spring and dashpot in series (Maxwell model, figure 6.2). With a high viscosity, this system behaves likes an elastic material for loads of short duration but like a viscous material for long-term loads. This is useful in modelling the response of the earth's crust, which undergoes short term elastic deformation for rapid loading and gradually flows for loads with long periods [Twiss \& Moores, 1992]. The time separation (Maxwell time $\tau$ ) of 

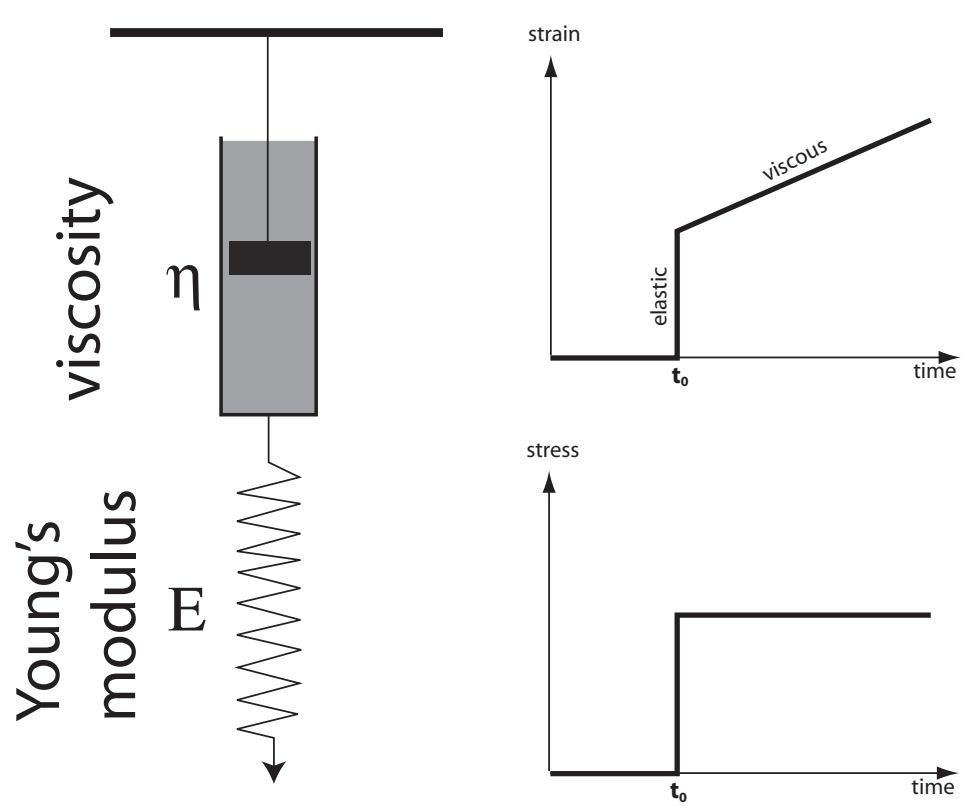

Figure 6.2: Left: Maxwell model for a viscoelastic material, consisting of a dashpot (viscosity $\eta$ ) in series with a spring (Young's Modulus E). Right: Idealised stress and corresponding strain plotted over time for a viscoelastic Maxwell material

this system is defined as

$$
\tau=\frac{\eta}{E} .
$$

For times $t \ll \tau$, the response is dominated by the elastic component and for $t \gg \tau$, the viscous component dominates.

In ABAQUS ${ }^{T M}$, there are two different ways to describe the linear viscous component of a material; 1.) with a Prony series, which in its basic form describes a standard linear solid model. This is a single Maxwell element parallel with a spring. The system has a single relaxation time but does not allow unrestricted flow. 2.) with the use of the power-law creep function (equation 6.2). If the $e^{(-Q / R T)}$ term and the stress exponent are set to one, $C=1 / \eta$ [Ranalli, 1995].

$$
\dot{\epsilon}=C(\sigma)^{n} e^{(-Q / R T)}
$$

where:

$\dot{\epsilon}$ is the strain rate,

$\sigma$ is the stress,

$C$ is a constant,

$n$ is the stress exponent, which describes the stress strain rate relation,

$Q$ is the activation energy per mole for the creep process,

$R$ is the Boltzmann constant per mole,

$T$ is the temperature in Kelvin. 


\begin{tabular}{|l|c|c|c|c|}
\hline LAYER & $\begin{array}{c}\text { Density } \\
\left(\mathrm{kg} / \mathrm{m}^{3}\right)\end{array}$ & $\begin{array}{c}\text { Young's modulus } \\
{[\mathrm{GPa}]}\end{array}$ & Poisson's ratio & $\begin{array}{c}\text { Viscosity } \\
(\text { Pa s })\end{array}$ \\
\hline \hline Upper crust & 2750 & 80 & 0.256 & - \\
\hline Lower crust & 2900 & 70 & 0.33 & $10^{21}$ \\
\hline Mantle lithosphere & 3350 & 150 & 0.27 & $10^{21}$ \\
\hline Asthenosphere & 3300 & 150 & 0.25 & $10^{21}$ \\
\hline
\end{tabular}

Table 6.1: Material parameters for Model 100. This model acts as a reference model and all other models presented are variations of this model.

For geological timescales, the upper crust can be considered elastic due to its low temperature. In general, the lower crust and mantle have viscosities between $10^{18}$ and $10^{22} \mathrm{~Pa} \cdot \mathrm{s}$ [Lowrie, 1997; Peltier, 1998; Yamasaki \& Seno, 2005].

The densities $(\rho)$ used for the different layers are identical to the densities proposed in the standard density model (SDR) for the gravity modelling in chapter 4; with $2750 \mathrm{~kg} / \mathrm{m}^{3}$ for the upper crust, $2900 \mathrm{~kg} / \mathrm{m}^{3}$ for the lower crust, $3350 \mathrm{~kg} / \mathrm{m}^{3}$ for the mantle lid and an upper asthenosphere density of $3300 \mathrm{~kg} / \mathrm{m}^{3}$. The Young's modulus and Poisson's ratio are calculated by means of the above densities and the seismic P- and S-wave velocities established by the receiver function study (chapter 5), with the following equations:

$$
\begin{aligned}
\nu & =\frac{1}{2} \frac{V_{p}^{2}-2 V_{s}^{2}}{V_{p}^{2}-V_{s}^{2}} \\
E & =V_{s}^{2}[2(1+\nu) \rho]
\end{aligned}
$$

A low S-wave velocity $\left(V_{s}=3.1 \mathrm{~km} / \mathrm{s}\right)$ layer with a high $V_{p}-V_{s}$ ratio $\left(V_{p} / V_{s}=2\right)$ is used for the lower crust. The upper crust has standard values of $V_{p}=5.8 \mathrm{~km} / \mathrm{s}$ and $\mathrm{V}_{s}=3.4 \mathrm{~km} / \mathrm{s}$. For the entire mantle a standard seismic velocity of $\mathrm{V}_{p}=8.1 \mathrm{~km} / \mathrm{s}$ and $\mathrm{V}_{s}=4.7 \mathrm{~km} / \mathrm{s}$ are used. A summary of the parameters used for the reference model (model 100) is given in table 6.1. The Young's modulus and the viscosity values are further investigated within the modelling.

\subsubsection{Meshing of the model}

The principle of finite-element modelling is the breaking up, or discretizing, of a physical domain into a discrete number of smaller parts to perform an analysis on these elements with the aim to get a solution for the global problem. The discretizing, or meshing, is an important step during the set up of the finite-element model. While surfaces normally get subdivided into triangle or quadrilateral shapes, volumes will mainly be divided into tetrahedral or hexahedral shapes. For this model, it turned out that a hexahedral dominated mesh is the most practical, mainly for two reasons. Firstly, the overall shape of the model is hexahedral by nature. Secondly, the use of a hexahedral shape vastly reduces the number of elements compared to a tetrahedral mesh. 


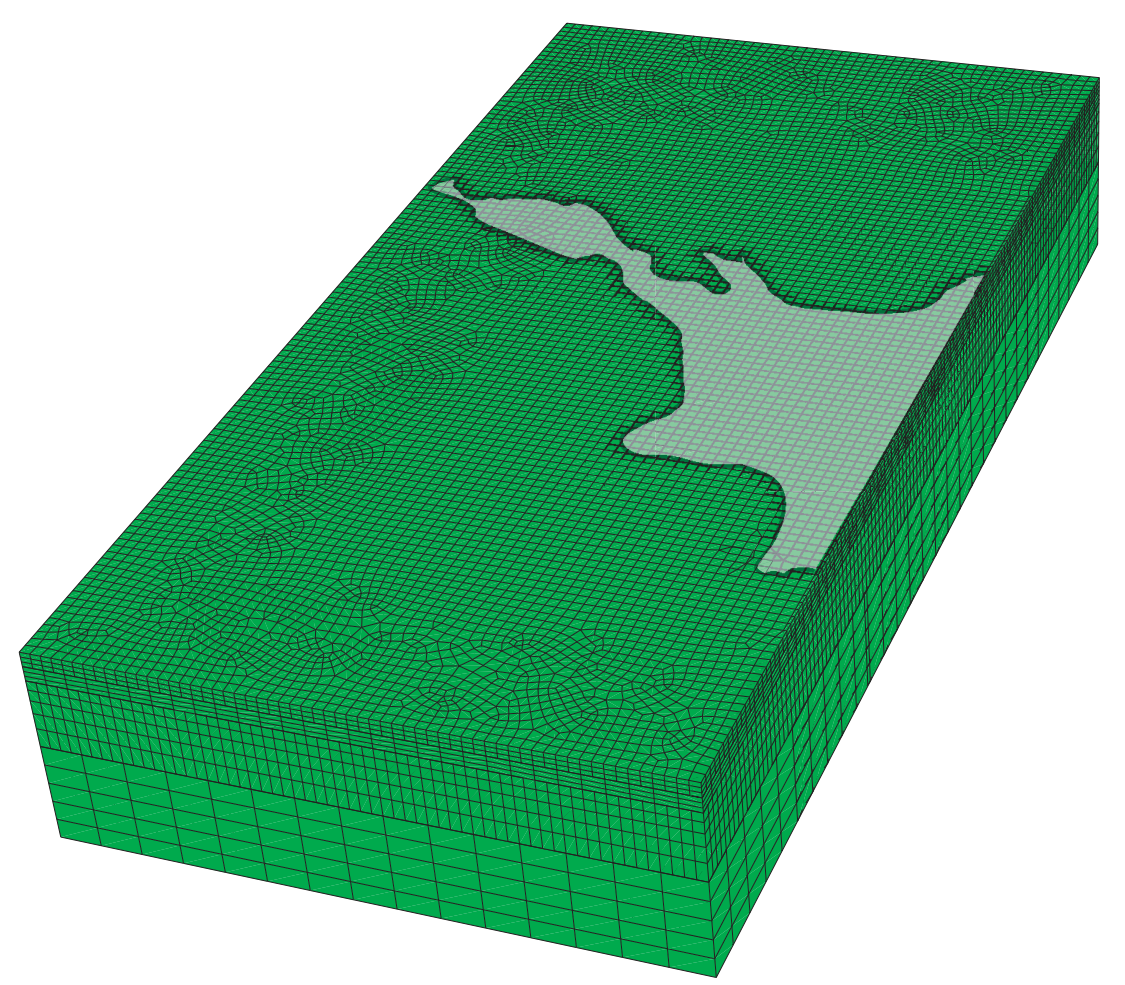

Figure 6.3: Illustration of the mesh with a dominant hexahedral shape for the elements. The upper and lower crust has a slightly finer mesh in vertical direction. This mesh consists of around 83,000 elements and 16,000 nodes.

However, choosing the size of the elements is a compromise between an accurate, detailed solution and the necessary computing time for the analysis. The mesh here used consists of around 83,000 elements and 16,000 nodes. The elements are $5 \mathrm{~km}$ thick for the upper and lower crust and $10 \mathrm{~km}$ thick for the mantle lithosphere and asthenosphere, with a variable surface width (see figure 6.3).

\subsection{Modelling}

The aim of this study is not to model the exact rheology of the overriding Australian plate, but to give a qualitative statement about viscosity contrasts, load distributions and load amplitudes necessary to create the observed deformation of the crust underneath the SWB. The joint thickness of the upper and lower crust is kept constant at $30 \mathrm{~km}$, which is the depth of the reflection Moho west of the Wanganui Basin [Holt \& Stern, 1994]. The mantle lithosphere thickness is initially set to $70 \mathrm{~km}$. Together with the crust this gives a total thickness of the lithosphere of $100 \mathrm{~km}$ [Moores \& Twiss, 1995; Watts, 2001]. This is underlain by a $100 \mathrm{~km}$ thick block representing the top of the asthenosphere, which is included into the model 


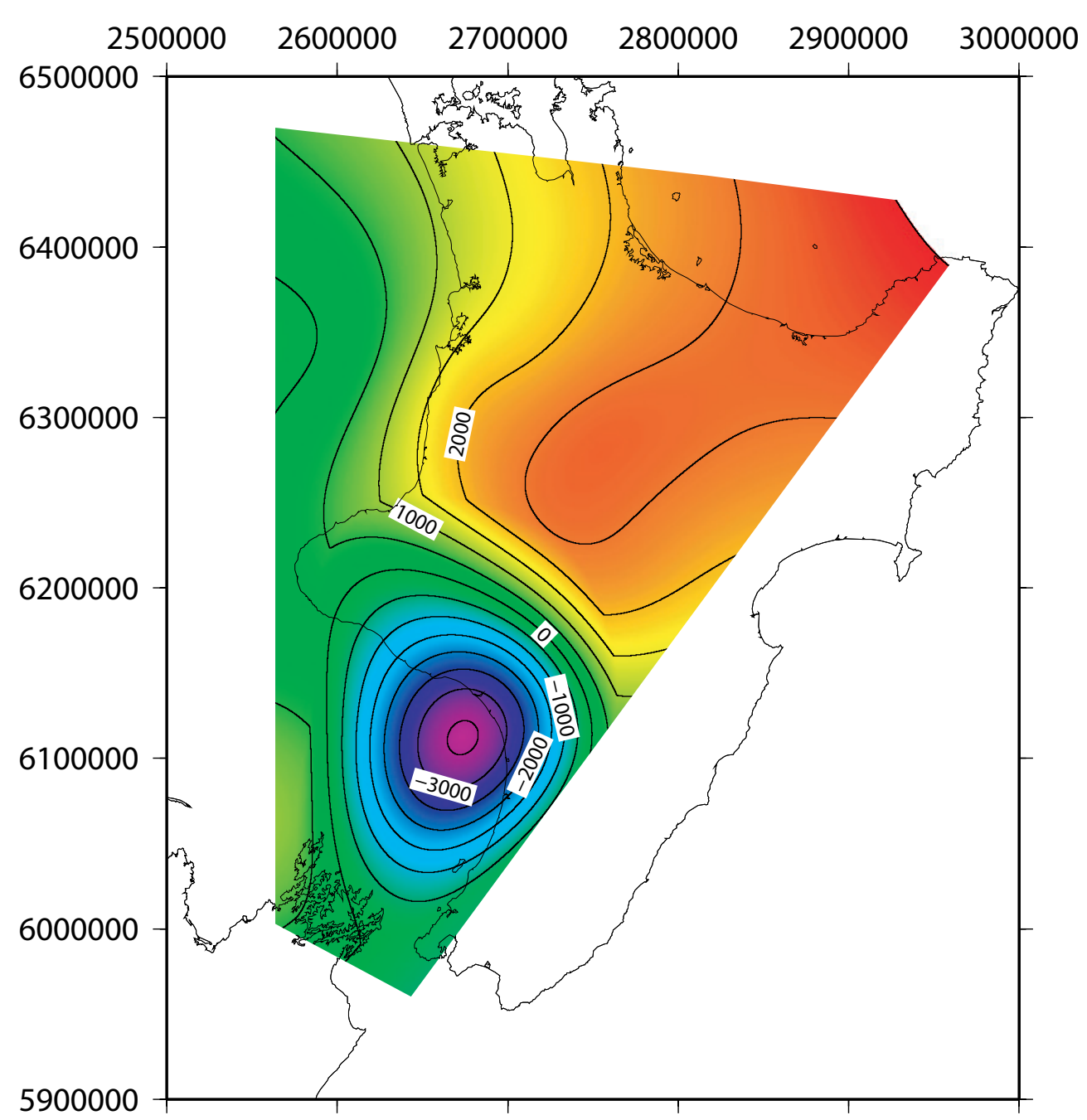

Figure 6.4: Rock uplift and subsidence of the North Island since the Miocene. The contours displayed here result from combining the rock uplift (exhumation + smoothed topography) [see Pulford, 2002] and the subsidence of the Wanganui basin (smoothed sediment depth contour lines) [Anderton, 1981; Hunt, 1980].

to eliminate possible boundary effects.

To satisfy the boundary conditions around the basin, it is also necessary to include the uplift of the central North Island and the Tararua Ranges. The rock uplift is calculated by adding the exhumation, which is calculated from mudstone porosities, and the surface uplift (a low-pass filtered version of the topography as shallow marine sediments are now exposed around the edges of the central North Island) [Pulford, 2002]. A maximum value of around $2.8 \mathrm{~km}$ is computed. The depth of the sediments basin (maximum of around $4 \mathrm{~km}$ ) is known from extensive seismic surveying [Anderton, 1981; Hunt, 1980]. Figure 6.4 shows a vertical deformation map, which combines the rock uplift of the central North Island and the low-pass filtered subsidence contours of the SWB. 
Two different seismic experiments within the North Island suggest crustal thickening of over $10 \mathrm{~km}$ underneath the SWB. A seismic-reflection profile through the South Taranaki and South Wanganui Basin [Stern \& Davey, 1990] shows a Moho deepening to $\sim 40 \mathrm{~km}$ coming from the west into the basin, but it is not visible directly below the basin. In a study from Stern \& Davey [1985], using active seismic refraction shots, "a $3.5^{\circ}$ dip on the Moho and a depth to the Moho of some $40 \mathrm{~km}$ beneath Wanganui" is estimated. This is supported by the 3 -D gravity modelling in chapter 4 , which predicts an around three times larger vertical subsidence at the base of the crust than at the surface. This implies a maximum crustal thickness of around $42 \mathrm{~km}$ ( 3 times maximum thickness of sediments of $4 \mathrm{~km}+30 \mathrm{~km}$ of standard Moho depth $=42 \mathrm{~km})$. To simplify matters, the vertical deformation ratio between upper $\left(d_{t}\right)$ and lower crust $\left(d_{b}\right)$ is from now on called $\Delta \epsilon$.

In contrast to purely elastic models, for viscoelastic materials the loading time becomes important. Therefore, all the models shown here run for $4 \mathrm{Ma}$ which is approximately the age of the Wanganui Basin [Anderton, 1981]. ABAQUS ${ }^{T M}$ allows the user to write out intermediate results after defined time steps.

The uplifts of the central North Island and the Tararua Ranges are simulated with negative loads (tensional forces) acting on the surface. Figure 6.5 gives an overview of the acting forces and their application; green arrows represent uplifting negative loads, red arrows describing the positive loads and orange arrows show the direction of possible horizontal forces due to shear at the subduction interface. Figure 6.6 shows the amplitudes of load distribution (for models 100$126)$; with red coloured numbers ( $\mathrm{MPa})$ corresponding to downward directed forces from figure 6.5 and green numbers describing the magnitudes of the upward directed forces $(\mathrm{MPa})$.

Previous finite modelling studies of subduction zones show that the surface deformation observed above subduction zones mainly depends on the density contrast of the subducting slab and the friction coefficient of the subduction interface [Bott, 1991; Hassani et al., 1997; Shemenda, 1993; Whittaker et al., 1992]. The difference between a locked and unlocked interface lies mainly in the horizontal stress regime in the interior of the overlying plate. The isostatic compensation of the mass excess due to the slab is partitioned between a "trench" and a "wedge"-flexural depression created by vertical forces transmitted through the upper mantle [Davies, 1981]. The modelling results by Whittaker et al. [1992] show that the vertical component of the shear stress at a dipping subduction interface creates vertical flexure and the horizontal component creates horizontal stress within the overriding plate (for more details see chapter 1). Therefore, in the model presented below, the shear stress cannot be simulated as a horizontal and vertical force at the base of the crust but as a vertical force at the base with in-plane compression of the crust. The effect of the additional in-plane stress is investigated in section 6.2.4. 


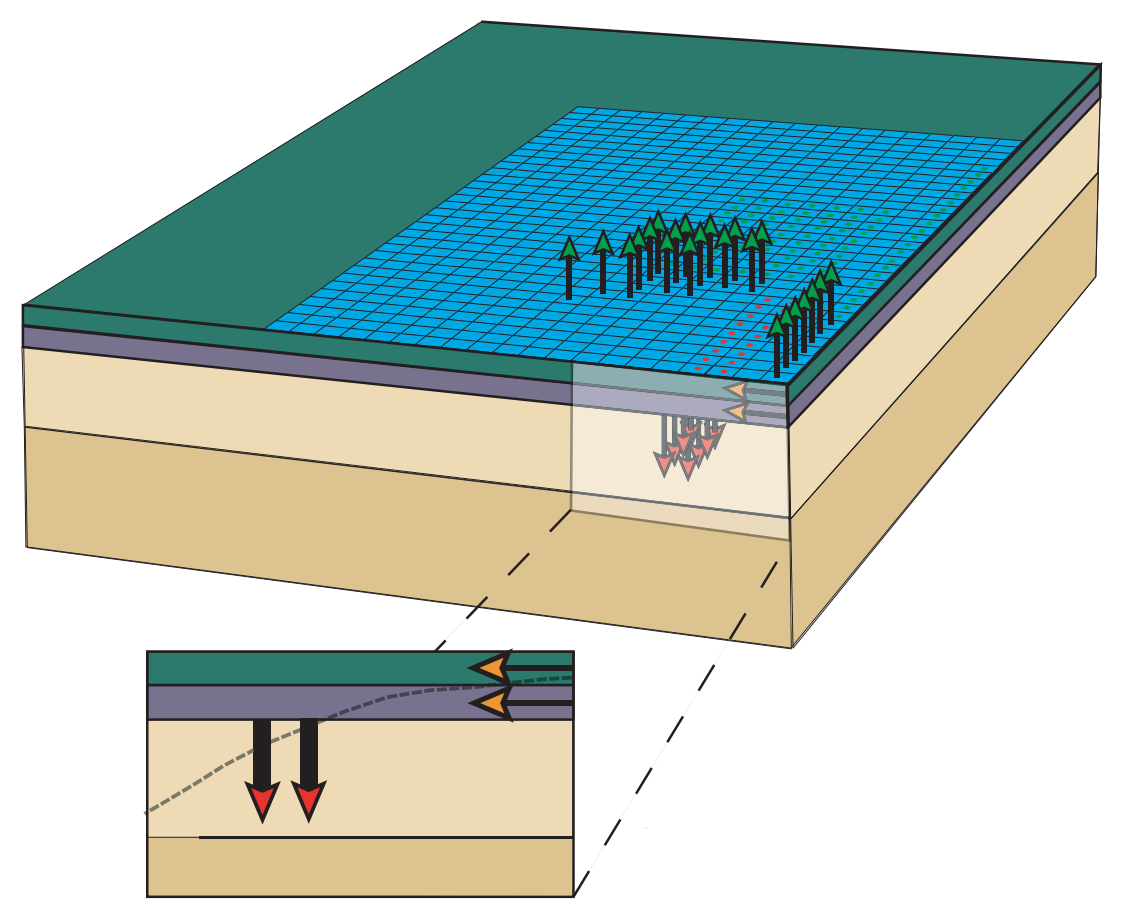

Figure 6.5: A sketch illustrating the basic setup of the model. Arrows represent loads which were applied to the defined grid (at the top or bottom of a $30 \mathrm{~km}$ thick double layer). Load pattern and amplitude are varied to fit the observed deformation (see section 6.2.4). Red arrows represent the loads which simulate the downwarp of the SWB and green arrows represent forces responsible for uplift. Orange arrows show a possible in-plane component of force, acting at entire length of the eastern side of the crust. The approximate position of the slab is indicated by fine dashed line in cross-section sketch.

In sections 6.2.1-6.2.2 that follow, only the rheological parameters of the models are varied and the load distribution is fixed (load distribution for these models shown in figure 6.6). Only vertical forces are applied. This initial load setup is largely taken from flexural modelling studies by Stern et al. [1992] and Pulford [2002] for the SWB and central North Island, respectively. In the final section (6.2.4), the rheology is fixed and different load amplitudes and distributions are tested, including horizontally acting forces. The effect of the different parameter values are explored by comparing them to the reference model (model 100).

Figure 6.7 (vertical exaggeration factor of 10) shows the chronology of deformation for one of the models (model 100, loads see figure 6.6), with an elastic upper and viscoelastic lower crust. After around 200 years, a time smaller than the Maxwell relaxation time ( $\sim 400$ years) for upper crust and mantle lithosphere, the deformation of the upper and lower crust are equal, which corresponds with a purely elastic behaviour of the material. At 13,400 years the deformation at the Moho starts to get larger than the deformation at the surface. After this time the vertical deformation at the top of the plate stays almost constant, but the defor- 


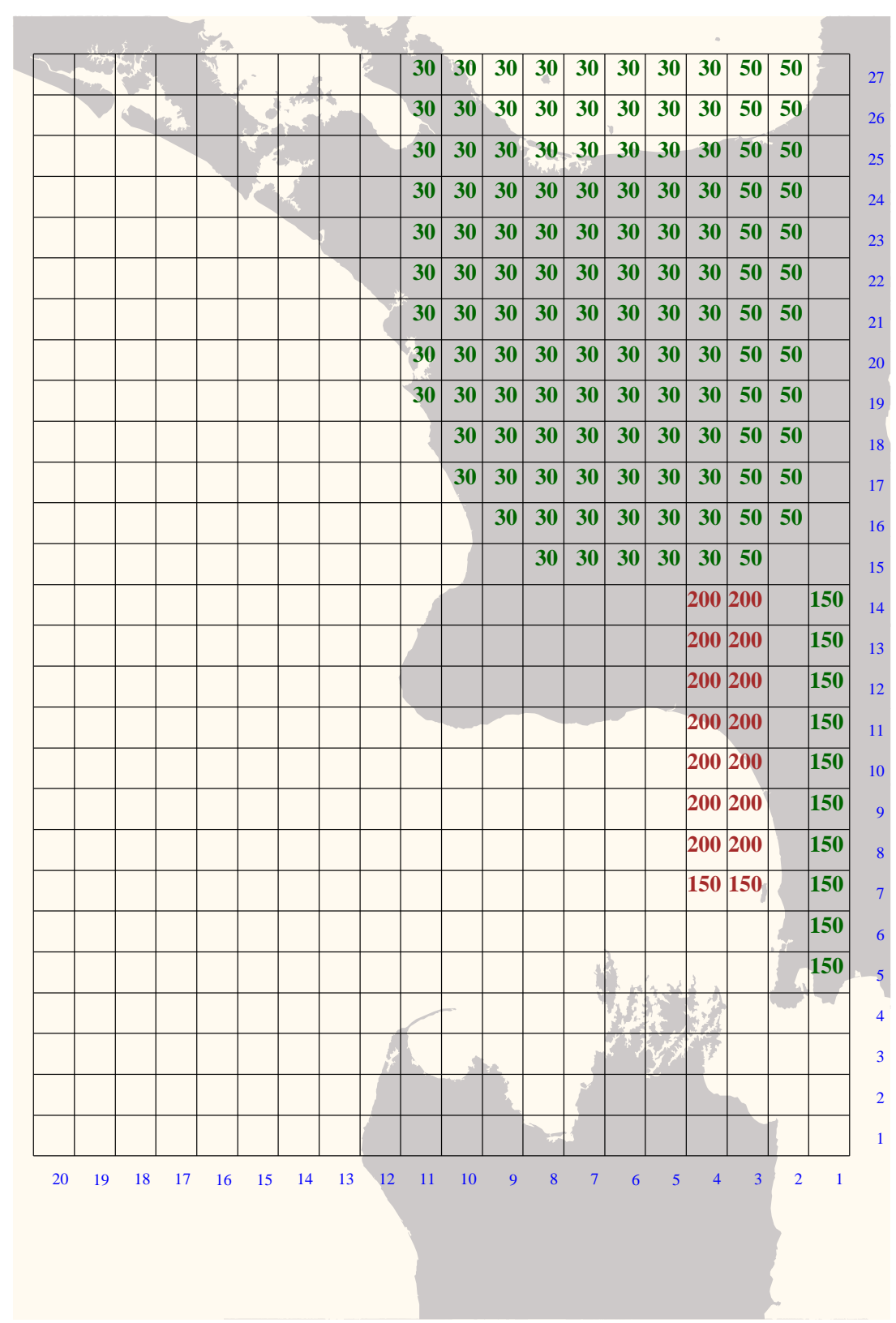

Figure 6.6: Load distribution used for model100, model104, model 105, model 106, model 109, model110, model 111, model112, model 113, model 125 and model 126. Green numbers represent upwards directed loads which are acting at the top of the crust, and red numbers represent downwards directed loads acting at the bottom of the crust. All values are in $\mathrm{MPa}$. 
6.2 Modelling
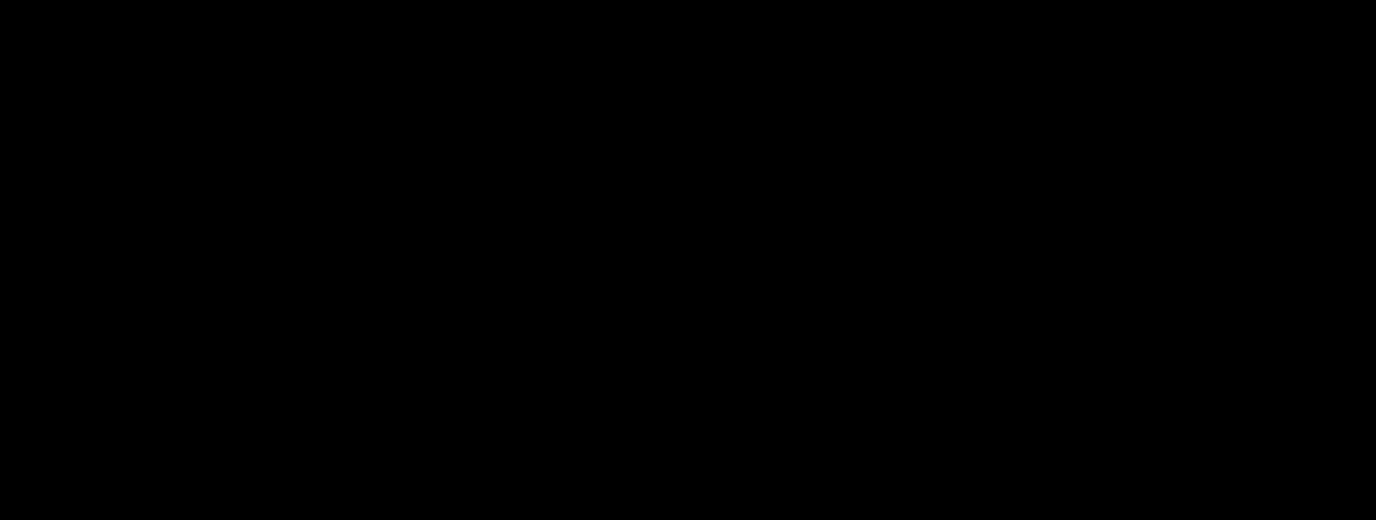

(a) 200 years 
mation at the bottom of the crust continues to grow. The last figure (figure 6.7(f)) shows the model after $4 \mathrm{Ma}$. All forces in this model are applied starting in the Pliocene which is approximately the time the SWB started to subside [Anderton, 1981]. This fits well with the timing of the uplift of the central North Island [Pulford \& Stern, 2004], however, the uplift of the Tararua Ranges started most likely in the Pleistocene (<2 Ma) [Lamb \& Vella, 1987; Wells, 1989] and the application of this force for the entire runtime has to be mentioned as an uncertainty of the model.

\subsubsection{Different viscosities}

This first modelling step investigates the different viscosities of the layers necessary to simulate a discrepancy in vertical deformation between the surface and the base of the crust. Therefore, all values for density, Young's modulus and Poisson's ratio are kept constant (as model 100, table 6.1) and only the upper crust viscosities are altered.

The most practical way to investigate the deformation difference between the top and the base of the crust is by comparing cross-sections running through approximately the deepest point of the basin. The chosen line $\left(A-A^{\prime}\right)$ has its origin at the eastern edge of the model and runs between grid line 8 and 9 for $200 \mathrm{~km}$ to the left (see figure 6.1).

Figure 6.8 shows the vertical deformation for the reference model along the profile line for the top (solid lines) and the base of the crust (dashed lines) after $4 \mathrm{Ma}$ for the reference model (model 100). This model has a purely elastic upper crust. The maximum deformation amplitude at the base of the crust is $\sim 8 \mathrm{~km}$ and the maximum vertical offset at the surface is $\sim 3 \mathrm{~km}$. The wavelength of the surface deformation is around $200 \mathrm{~km}$, located between 50 and $250 \mathrm{~km}$ along the profile. At the eastern side of the model, a surface uplift of around $2 \mathrm{~km}$ is observed. This is a good simulation of the rock uplift of the Tararua Ranges. Furthermore, the flank on the eastern side of the basin has a steeper dip than that on the western side, similar to what is observed in the SWB (see figure 4.8 in chapter 4 ). The wavelength $(100 \mathrm{~km})$ of the Moho deformation is only half that observed at the top of the crust.

For a viscosity ratio between upper $\left(\eta_{u}\right)$ and lower crust $\left(\eta_{l}\right)$ of $\eta_{u} / \eta_{l}=10^{2}$ (model109, red lines in figure 6.9), the deformation between the top and the base of the crust is almost identical $(\Delta \epsilon=0.9)$ with an unrealistic high uplift at the eastern edge of the model. Nevertheless, the vertical deformation for both parts of the crust has increased compared to the reference model. A raise of the viscosity ratio to $10^{3}$ (model 110, green lines figure 6.9) results in an overall smaller deformation but an observable deformation difference of $\Delta \epsilon=1.3$. A further increase of the viscosity for the upper crust $\left(\eta_{u} / \eta_{l}=10^{4}\right.$; model 111, blue line figure 6.9) pro- 


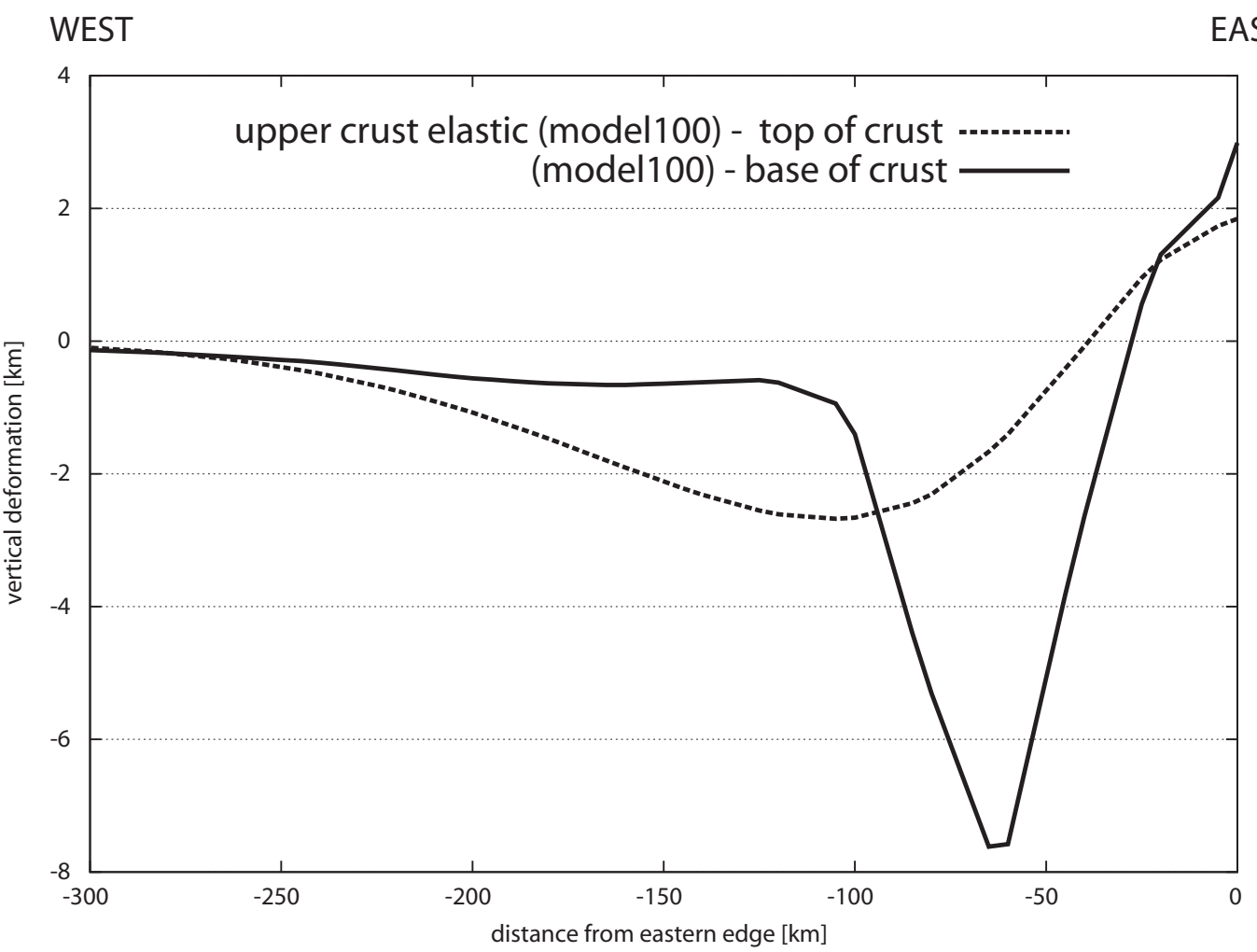

Figure 6.8: Cross section between $\mathrm{A}$ and $\mathrm{A}^{\prime}$ (figure 6.1) showing the vertical deformation at the top (dashed line) and bottom (solid line) of the crust for model 100.

duces a deformation pattern similar to the case of a purely elastic upper crust. With a viscosity of $10^{25} \mathrm{~Pa} \cdot \mathrm{s}$ the Maxwell relaxation time for the upper crust is so high (5.4 Ma) that the properties of the upper crust for a 4 Ma loading period can be described as purely elastic. The maximum $\Delta \epsilon$ achievable with this model setup is slightly below 3 . A summary of the viscosities used and observed deformation along the profile can be found in table 6.2.

In the next step the viscosity of the lower crust is varied and the upper crust is assumed to be purely elastic. Figure 6.10 shows the deformation observed along the profile and table 6.3 summarises the results. A higher viscosity (model 104, green lines) compared to the reference model produces a smaller vertical displacement at Moho depth and a similar deformation amplitude at the surface. The depocenter of the basin has moved to the east, mainly due to the decreased uplift on the eastern side of the model from around $2 \mathrm{~km}$ in the reference model to around $1 \mathrm{~km}$ in model 104.

Decreasing the viscosity of the lower crustal layer by a factor of 10 (model 105, 


\begin{tabular}{|c|c|c|c|c|}
\hline \multicolumn{5}{|c|}{ PARAMETERS } \\
\hline LAYER & $\begin{array}{c}\text { model } 100 \\
\eta(\mathrm{Pa} \cdot \mathrm{s})\end{array}$ & $\begin{array}{c}\text { model } 109 \\
\eta(\mathrm{Pa} \cdot \mathrm{s})\end{array}$ & $\begin{array}{c}\text { model } 110 \\
\eta(\mathrm{Pa} \cdot \mathrm{s})\end{array}$ & $\begin{array}{c}\text { model } 111 \\
\eta[\mathrm{Pa} \cdot \mathrm{s}]\end{array}$ \\
\hline upper crust & - & $1 \cdot 10^{23}$ & $1 \cdot 10^{24}$ & $1 \cdot 10^{25}$ \\
\hline lower crust & $1 \cdot 10^{21}$ & $1 \cdot 10^{21}$ & $1 \cdot 10^{21}$ & $1 \cdot 10^{21}$ \\
\hline \multicolumn{5}{|c|}{ RESULTS } \\
\hline & model 100 & model 109 & model 110 & model 111 \\
\hline$d_{t}(\mathrm{~km})$ & 2.7 & 11.7 & 7.0 & 3.5 \\
\hline$d_{b}(\mathrm{~km})$ & 7.6 & 11.5 & 9.3 & 8.0 \\
\hline$\Delta \epsilon$ & 2.8 & 0.9 & 1.3 & 2.3 \\
\hline
\end{tabular}

Table 6.2: Top: Viscosities $(\eta)$ of the upper and lower crust for the different models, with a fixed lower crustal $\eta$. Bottom: Maximum deformation along the profile line (in $\mathrm{km}$ ) and the deformation ratio between top and bottom of the crust. $d_{t}$ and $d_{b}$ are the maximum deformations at the surface or base of the crust, respectively. $\Delta \epsilon$ is the ratio between $d_{b}$ and $d_{t}$.

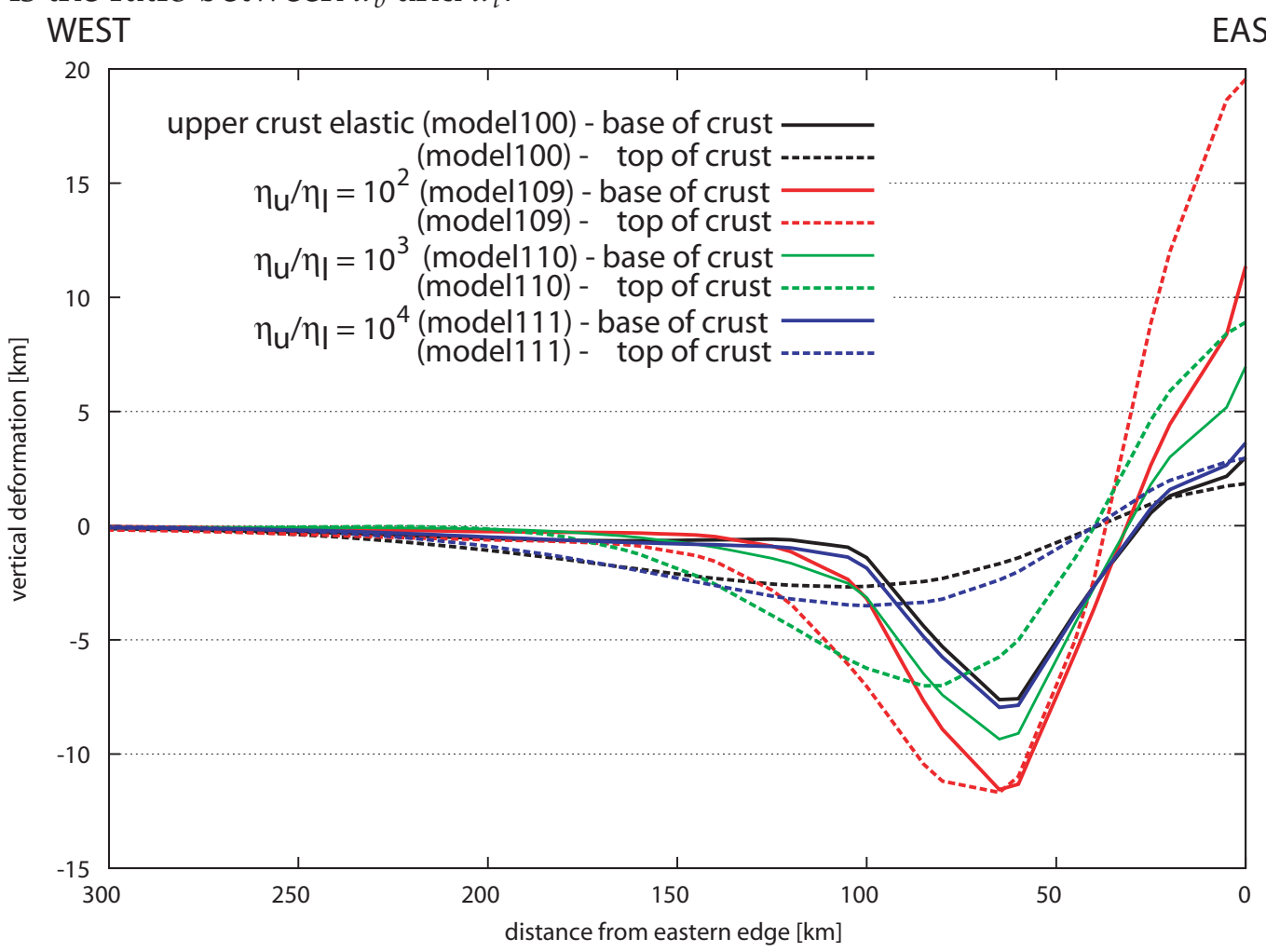

Figure 6.9: Cross section between $\mathrm{A}$ and $\mathrm{A}^{\prime}$ (figure 6.1) showing the vertical deformation at the top (dashed line) and bottom (solid line) of the crust for models with variable viscosity ratios $\left(\eta_{u} / \eta_{l}\right)$ between upper and lower crust. For parameters see table 6.2. 


\begin{tabular}{|c|c|c|c|}
\hline \multicolumn{4}{|c|}{ PARAMETERS } \\
\hline LAYER & $\begin{array}{c}\text { model } 100 \\
\eta[P a \cdot s]\end{array}$ & $\begin{array}{c}\text { model } 104 \\
\eta[P a \cdot s]\end{array}$ & $\begin{array}{c}\text { model } 105 \\
\eta[P a \cdot s]\end{array}$ \\
\hline upper crust & - & - & - \\
\hline lower crust & $1 \cdot 10^{21}$ & $1 \cdot 10^{22}$ & $1 \cdot 10^{20}$ \\
\hline \multicolumn{4}{|c|}{ RESULTS } \\
\hline & model 100 & model 104 & model 105 \\
\hline$d_{t}(\mathrm{~km})$ & 2.7 & 2.8 & 2.4 \\
\hline$d_{b}(\mathrm{~km})$ & 7.6 & 6.2 & 7.8 \\
\hline$\Delta \epsilon$ & 2.8 & 2.2 & 3.3 \\
\hline
\end{tabular}

Table 6.3: Top: Viscosities $(\eta)$ of the lower crust for the different models. The upper crust is assumed to behave purely elastic. Bottom: Maximum deformation along the profile line (in $\mathrm{km}$ ) and the deformation ratio between top and bottom of the crust. $d_{t}$ and $d_{b}$ are the maximum deformations at the surface or base of the crust, respectively. $\Delta \epsilon$ is the ratio between $d_{b}$ and $d_{t}$.

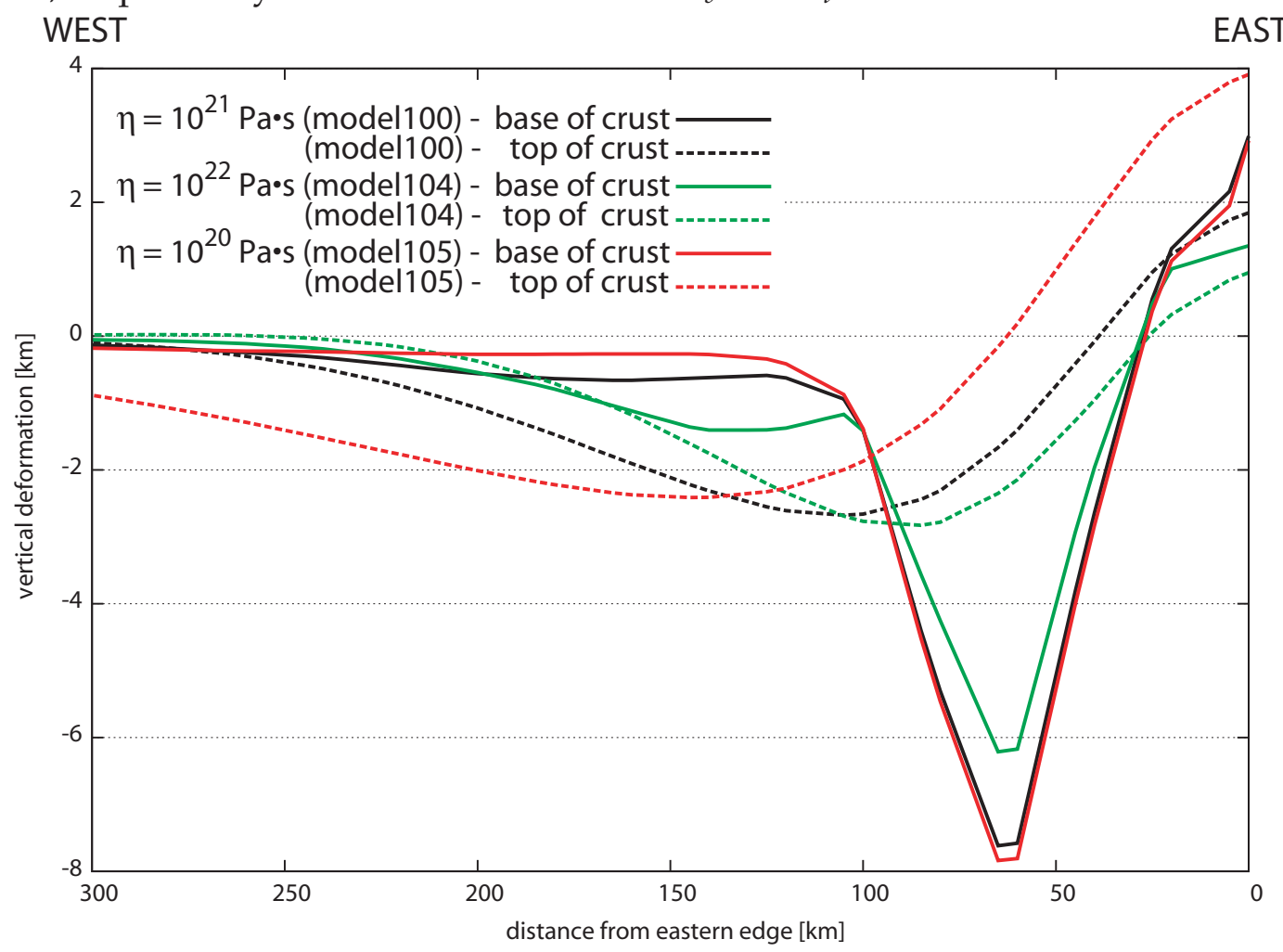

Figure 6.10: Cross section between $A$ and $A^{\prime}$ (figure 6.1) showing the vertical deformation at the top (dashed line) and bottom (solid line) of the crust for models with changing viscosity of the lower crust. For parameters see table 6.3. 
red lines) only yields a 3\% increase in deformation at the base of the crust. The basin depth (dashed line, figure 6.10) is similar to the other two models and the depocenter has moved to the west. Thus, the horizontal offset between the vertical deformation of the surface and Moho gets larger.

In summary, the modelling shows that a significant discrepancy in deformation between the top and the base of the crust can only be achieved if the upper part of the crust behaves elastically and a lower part behaves viscoelastically and has a Maxwell time less than $4 \mathrm{Ma}$, which is the time the SWB needed to develop. With the chosen material parameters and load patterns, a viscosity value of $\eta=$ $10^{21} \mathrm{~Pa} \cdot \mathrm{s}$ for the lower crust achieves an around three times larger downwarp for the Moho than at the surface. The maximum amplitudes are slightly smaller than observed and predicted from gravity modelling for the SWB (chapter 4).

\subsubsection{Different thicknesses}

The second model describes the influence of different layer thicknesses on the deformation amplitudes and $\Delta \epsilon$. All material parameters were kept constant (identical to reference model 100) and only the thicknesses of the individual layers within the crust were varied, with a constant total thickness for the entire crust.

A thicker lower crust (model 112, blue line figure 6.11) results in $60 \%$ increase in deformation at the surface compared to the reference model (model 100, black line). The deformation at the Moho only increases slightly to a maximum value of $9 \mathrm{~km}$, which leads to a decrease in $\Delta \epsilon$. In contrast, assuming a thicker upper crust (model 113, red line) produces a higher $\Delta \epsilon$ with an overall smaller vertical deformation (see table 6.4). The uplift modelled at the eastern end of the profile is close to zero for a thicker upper crust and up to $5.5 \mathrm{~km}$ for a thicker lower crust.

The total crustal thickness is kept constant for the entire model. However, a significant lateral change of the different layer thicknesses and the crustal thickness itself can be assumed across North Island or even between the SWB and the Tararua Ranges. Nevertheless, it can be seen that a thinner viscoelastic lower crust produces smaller overall deformation but with a larger deformation ratio.

\subsubsection{Different Young's moduli}

Another parameter further investigated is the stiffness (Young's modulus) of the lower crust and mantle. Again, all other material parameters are kept constant 


\begin{tabular}{|l||c|c|c|}
\hline \multicolumn{4}{|c|}{ PARAMETERS } \\
\hline LAYER & model 100 & model 112 & model 113 \\
\hline \hline upper crust $[\mathrm{km}]$ & 15 & 10 & 20 \\
lower crust $[\mathrm{km}]$ & 15 & 20 & 10 \\
mantle lithosphere $[\mathrm{km}]$ & 60 & 60 & 60 \\
\hline \hline \multicolumn{4}{|c|}{ RESULTS } \\
\hline$d_{t}[\mathrm{~km}]$ & 2.7 & 4.4 & 1.8 \\
$d_{b}[\mathrm{~km}]$ & 7.6 & 9.0 & 5.8 \\
$\Delta \epsilon$ & 2.8 & 2.0 & 3.2 \\
\hline
\end{tabular}

Table 6.4: Top: Thicknesses for the upper crust, lower crust and mantle lithosphere (all in $\mathrm{km}$ ). Bottom: Maximum deformation along the profile line (in $\mathrm{km}$ ) and the deformation ratio between top and bottom of the crust. $d_{t}$ and $d_{b}$ are the maximum deformations at the surface or base of the crust, respectively. $\Delta \epsilon$ is the ratio between $d_{b}$ and $d_{t}$.

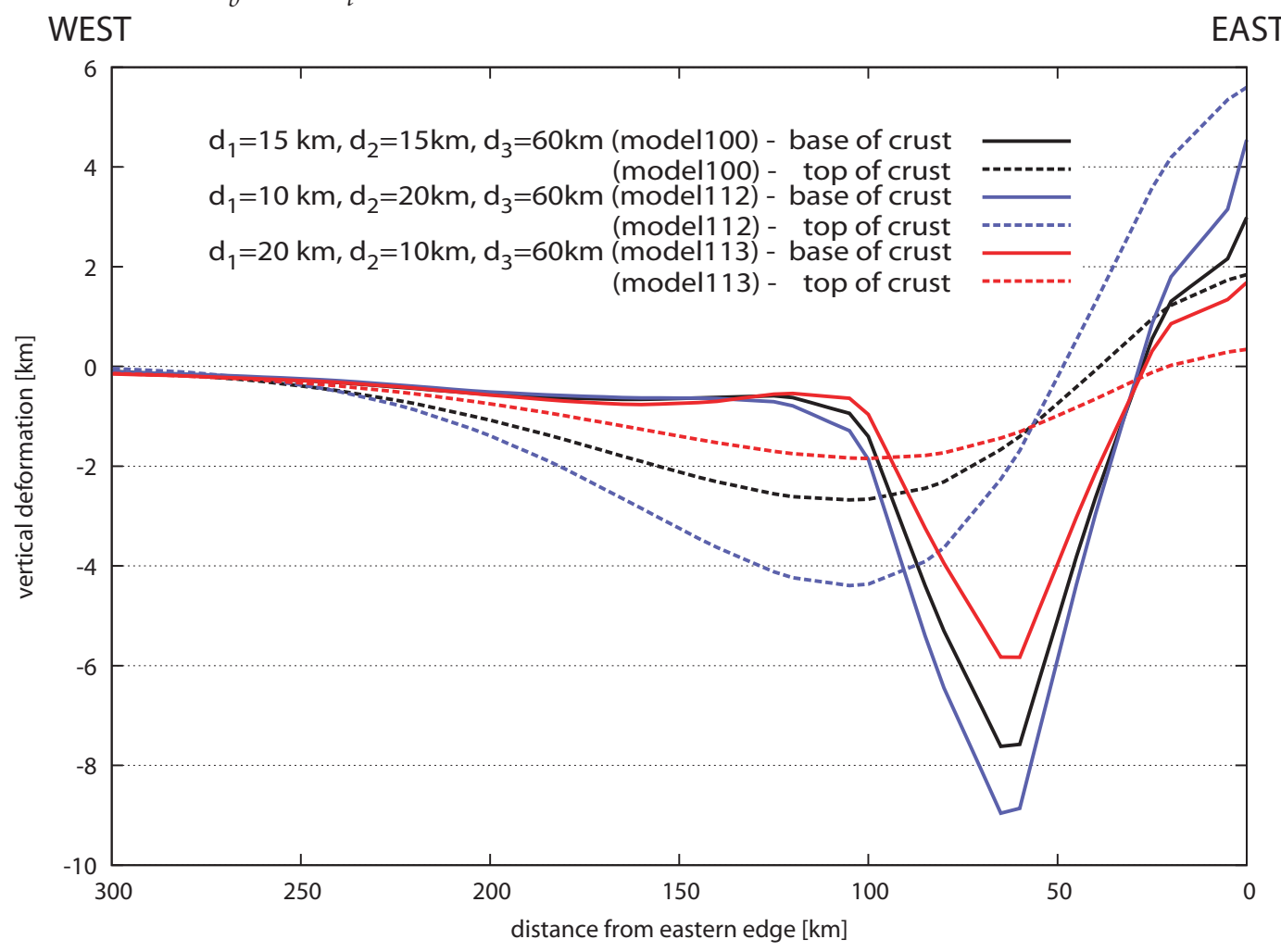

Figure 6.11: Cross section between $A$ and $A^{\prime}$ (figure 6.1) showing the vertical deformation at the top (dashed line) and bottom (solid line) of the crust for models with changing layer thicknesses. For parameters see table 6.4. 
(identical to reference model 100) and only the Young's modulus for the lower crust and mantle are varied.

Figure 6.12 shows three different examples. The black lines represent the reference model (model 100), which has a Young's modulus of $6 \cdot 10^{10} \mathrm{~Pa}$ for the lower crust and a value of $10 \cdot 10^{10} \mathrm{~Pa}$ for the upper mantle layer underneath. The yellow lines in the graph represent a model with a Young's modulus half the value of the reference model. The vertical deformation of the Moho is around 10\% larger than the reference model, with an equal surface deformation. An additional reduction of the rigidity of the mantle (model 116, blue lines) enhances the deformation amplitude of the Moho by a further $20 \%$. This leads to a deformation ratio of $\Delta \epsilon=3.8$, the highest value achieved with any of the presented models (see table 6.5).

These Young's moduli are, however, smaller than the ones calculated based on receiver function velocities (see section 6.1.4) or values found by Cohen \& Darby [2003] (crust $10-15 \cdot 10^{10} \mathrm{~Pa}$, mantle $20 \cdot 10^{10} \mathrm{~Pa}$ ), based on velocity estimation for the crust [Eberhart-Phillips et al., 2005; Reading et al., 2001] and mantle [Haines, 1979]. To halve the Young's modulus, as done in this modelling step, corresponds to an around 30\% decrease in S-wave velocity. This is a high value for velocity changes and it can therefore be concluded that the model is insensible to realistic changes in Young's modulus.

\subsubsection{Load distributions}

The last model investigates the loading amplitudes and loading patterns necessary to produce the observed subsidence of the SWB as well as the rock uplift of the central North Island and the Tararua Ranges. Furthermore, results are presented from a model incorporating an in-plane compressive force of $200 \mathrm{MPa}$ for the crust.

The yellow line in figure 6.13 shows the vertical deformation profile for a model which is identical to the reference model (model 100) apart from an additional in-plane compressive force. The force is applied on the eastern side of the upper crust. The boundary conditions had to be changed to allow for a horizontal movement of this layer. This, however, also results in a tilt of the eastern side of the model, which is undesired. Nevertheless, the results show a 30\% higher maximum vertical deformation of the upper crust due to in-plane stresses but with the same deformation pattern for the subsidence part. The uplift of the eastern edge is significantly amplified for both parts of the crust, which is mostly a boundary effect due to the tilting. The shear stress model which corresponds with the horizontal and vertical component on a $45^{\circ}$ dipping interface is impossible high with $\sim 280 \mathrm{MPa}$.

The final models which compare the overall deformation of the entire North Island and the SWB in particular, are calculated only for vertical loads. For this 


\begin{tabular}{|l||c|c|c|}
\hline \multicolumn{4}{|c|}{ PARAMETERS } \\
\hline LAYER & $\begin{array}{c}\text { model 100 } \\
\text { E (Pa) }\end{array}$ & $\begin{array}{c}\text { model 125 } \\
\text { E (Pa) }\end{array}$ & $\begin{array}{c}\text { model 126 } \\
\text { E (Pa) }\end{array}$ \\
\hline \hline upper crust & $8 \mathrm{e}+10$ & $8 \mathrm{e}+1$ & $7.9 \mathrm{e}+1$ \\
lower crust & $7 \mathrm{e}+10$ & $3.5 \mathrm{e}+10$ & $3.5 \mathrm{e}+10$ \\
mantle lithosphere & $15 \mathrm{e}+10$ & $15 \mathrm{e}+10$ & $7.5 \mathrm{e}+10$ \\
asthenosphere & $15 \mathrm{e}+10$ & $15 \mathrm{e}+10$ & $15 \mathrm{e}+10$ \\
\hline \hline \multicolumn{4}{|c|}{ RESULTS } \\
\hline$d_{t}[\mathrm{~km}]$ & 2.7 & 2.7 & 2.7 \\
$d_{b}[\mathrm{~km}]$ & 7.6 & 8.4 & 10.1 \\
$\Delta \epsilon$ & 2.8 & 3.1 & 3.8 \\
\hline
\end{tabular}

Table 6.5: Top: Young's moduli for different models. Bottom: Maximum deformation along the profile line (in $\mathrm{km}$ ) and the deformation ratio between top and bottom of the crust. $d_{t}$ and $d_{b}$ are the maximum deformations at the surface or base of the crust, respectively. $\Delta \epsilon$ is the ratio between $d_{b}$ and $d_{t}$.

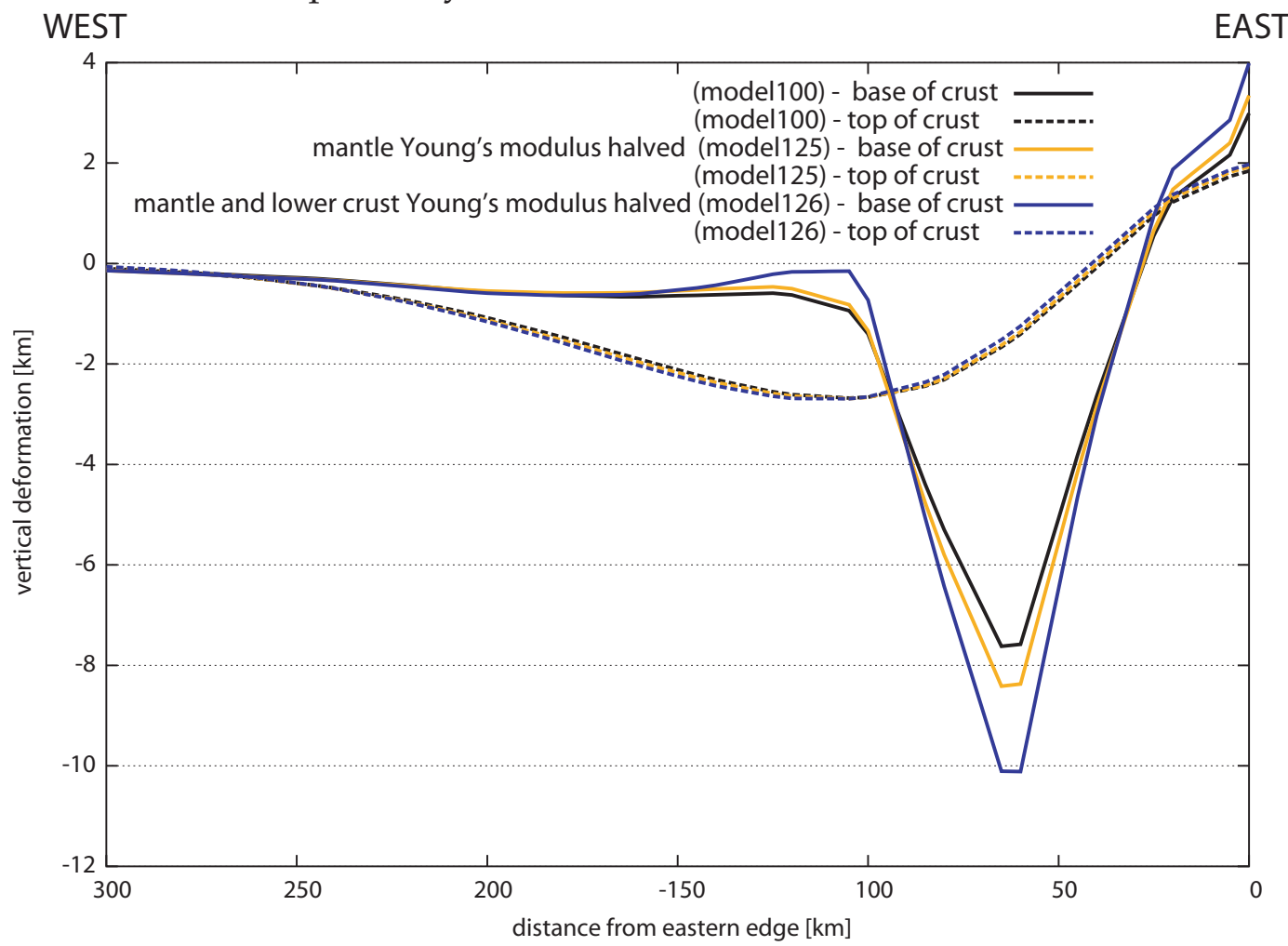

Figure 6.12: Cross section between $\mathrm{A}$ and $\mathrm{A}^{\prime}$ (figure 6.1) showing the vertical deformation at the top (dashed line) and bottom (solid line) of the crust for models with different Young's moduli. 


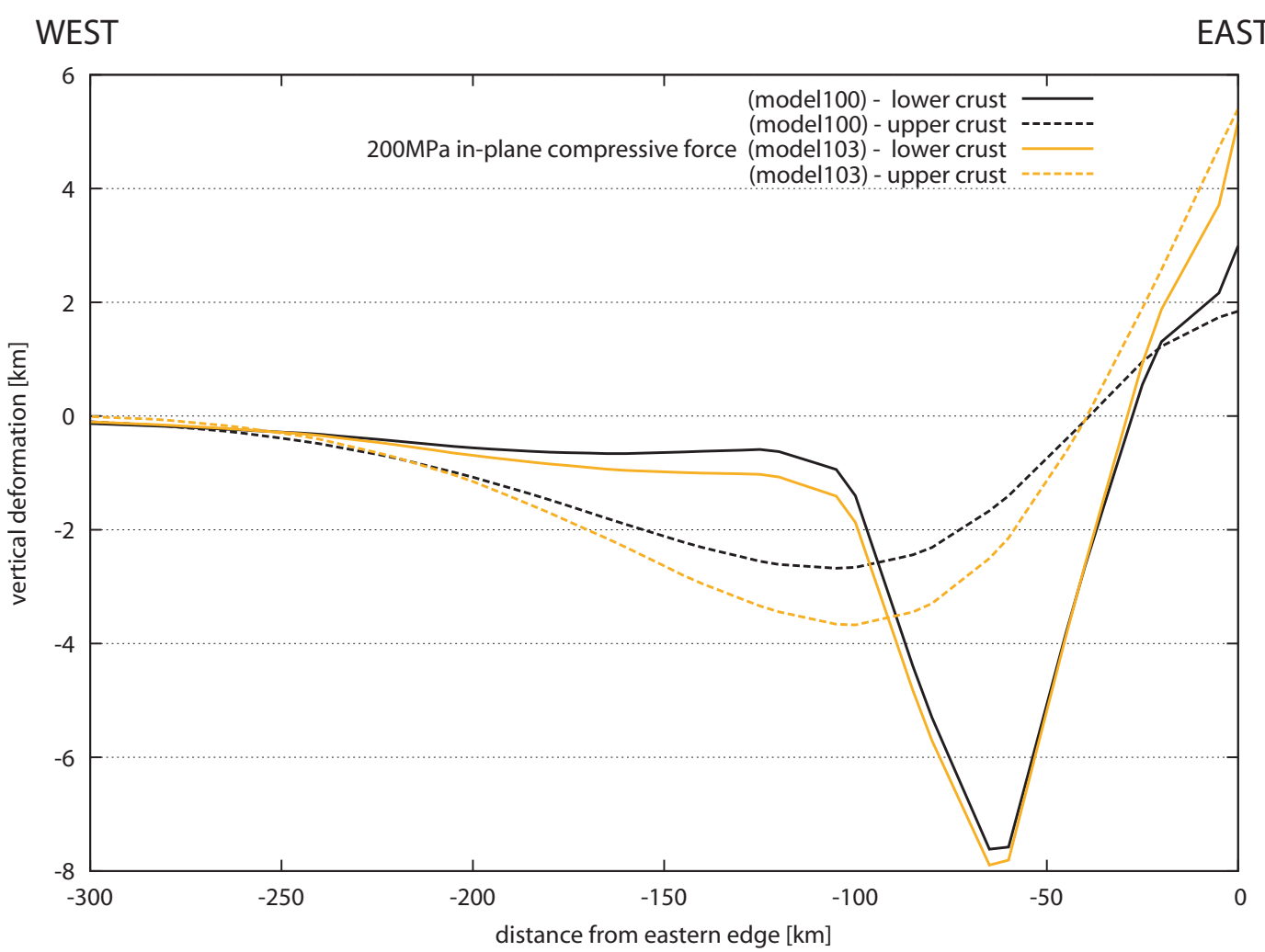

Figure 6.13: Cross section between $A$ and $A^{\prime}$ (figure 6.1) showing the vertical deformation at the top (dashed line) and bottom (solid line) of the crust. Model 100 (black lines) has only vertical loads applied. Model 103 has an additional horizontal $200 \mathrm{MPa}$ force applied at the subsidence patch (details see text).

modelling step, the results are presented as vertical deformation contour maps (top figure 6.14-6.16). The load distributions can be seen at the bottom of figure 6.14-6.16 and the material parameters are identical to model 100 (table6.1), with exception of model FINAL6, which is calculated with a smaller Young's modulus for crust and mantle.

Figure 6.14 presents the surface deformation (panel (a)), the relative downwarp of the Moho (panel (b)) and the load distribution for model 100 (panel (c)). As mentioned earlier, the load distribution and load magnitude used for this model are mainly based on results from flexural modelling by Stern et al. [1992] and Pulford [2002]. The loading pattern consists of a 20x200 km north-south trending upwards directed (positive) loading 'patch' (150 MPa) to simulate the uplift of the Tararuas, a 40x160 km negative loading 'patch' to simulate the downwarp of the SWB ( 200 MPa) and a 200x240 km 'patch' for the central North Island (30$50 \mathrm{MPa}$ ). The resulting surface deformation shows a $1.5 \mathrm{~km}$ uplift at the southeastern edge of the model, a wide flat plateau of uplift in central North Island and an around $3 \mathrm{~km}$ deep surface basin in the SWB region. Apart from the uplift of the central North Island, where the gradient of uplift on the flanks is too strong, 


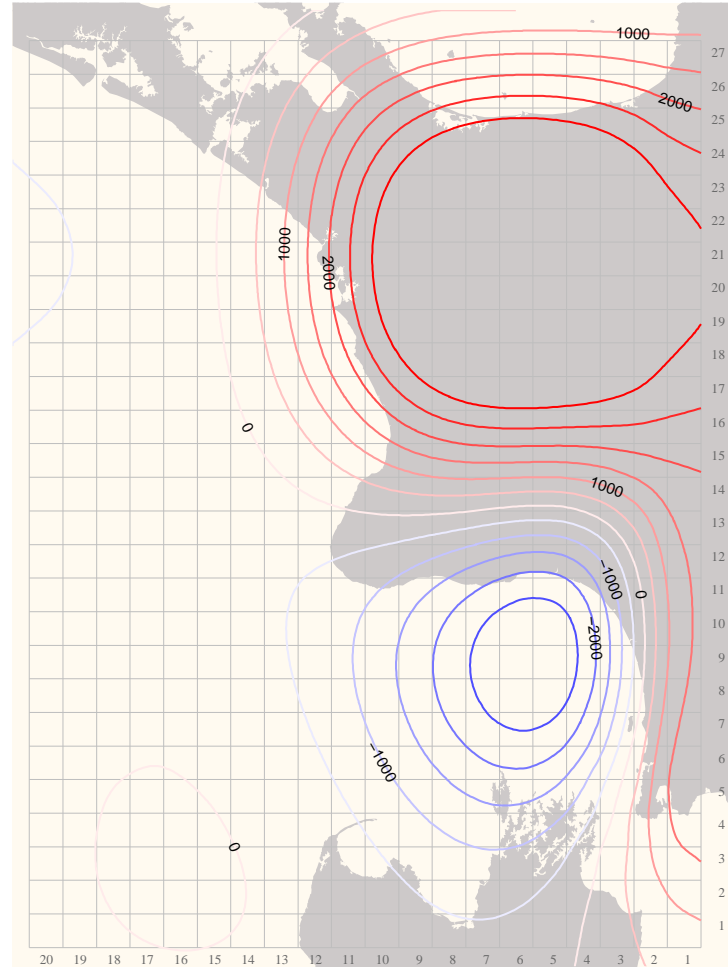

(a) Vertical surface deformation

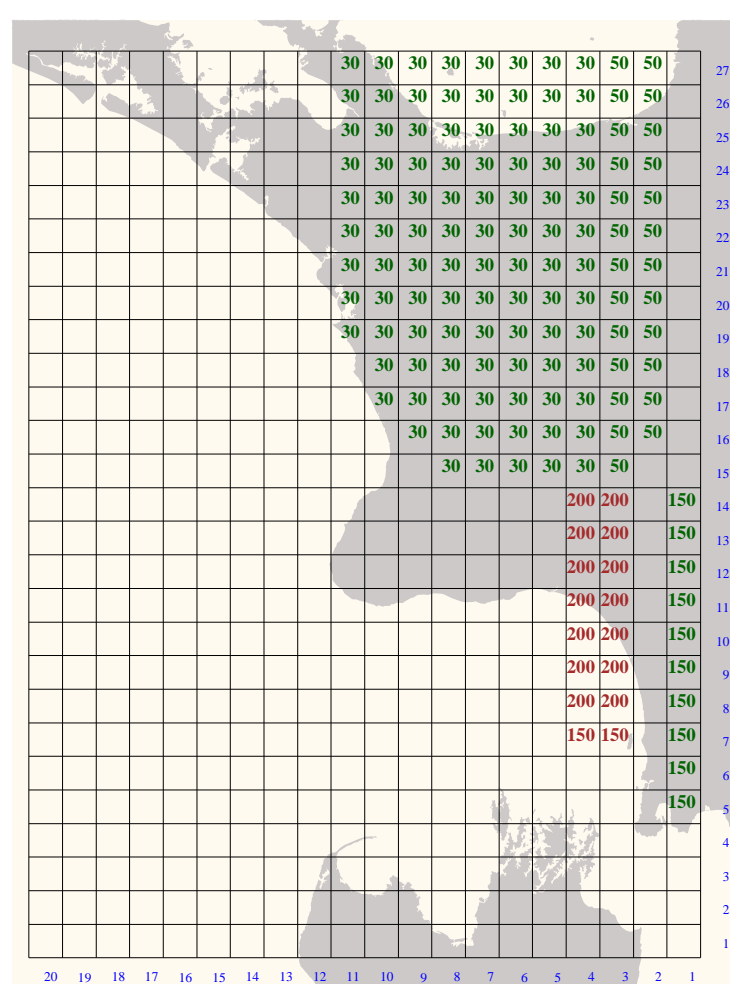

(c) Load distribution

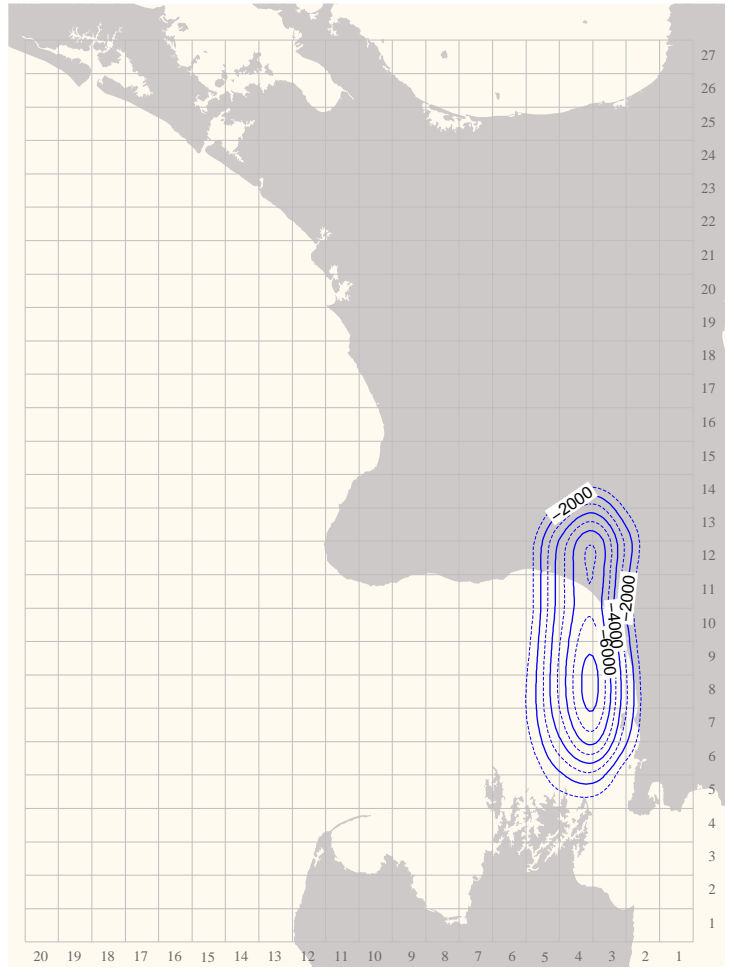

(b) Vertical deformation at depth of $30 \mathrm{~km}$

Figure 6.14: Model 100: Vertical surface deformation (a) and deformation at a depth of $30 \mathrm{~km}$ with the input loads for the FEM modelling shown in panel (c). Loading pressures are shown in $\mathrm{MPa}$ with different colours representing different loading directions. Red are negative loads (directed downwards); green are positive load (directed upwards). 


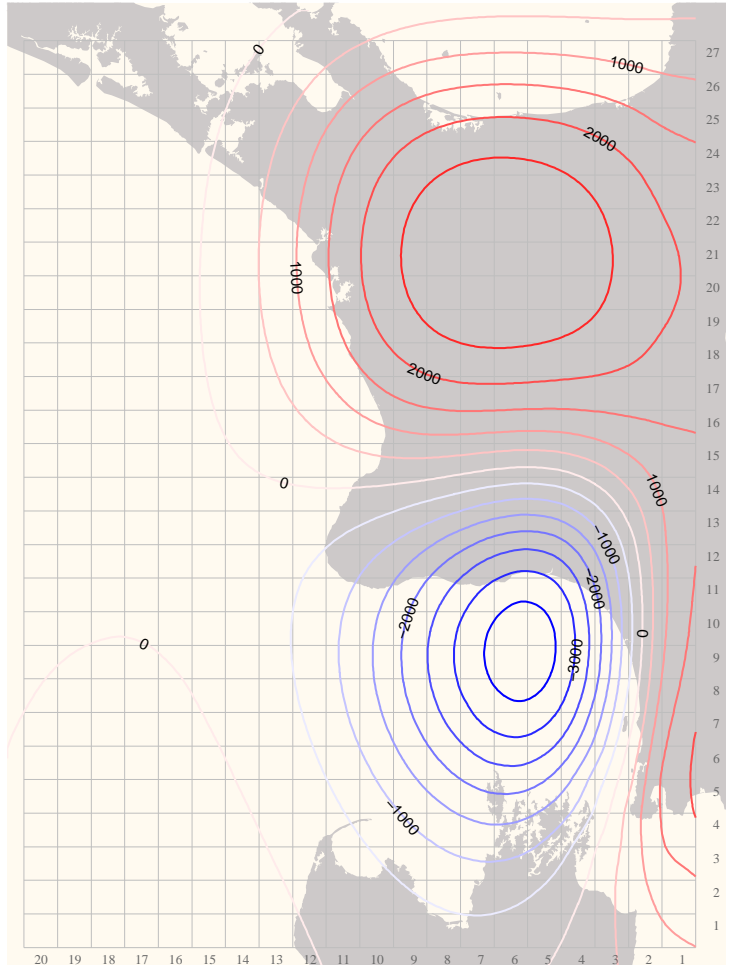

(a) Vertical surface deformation

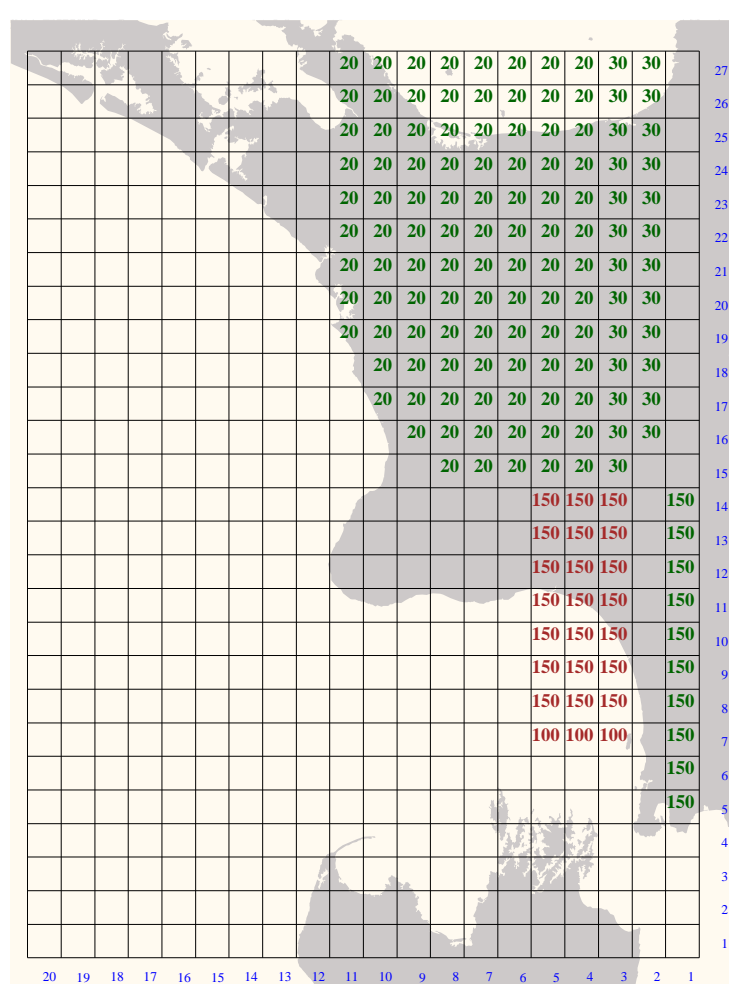

(c) Load distribution

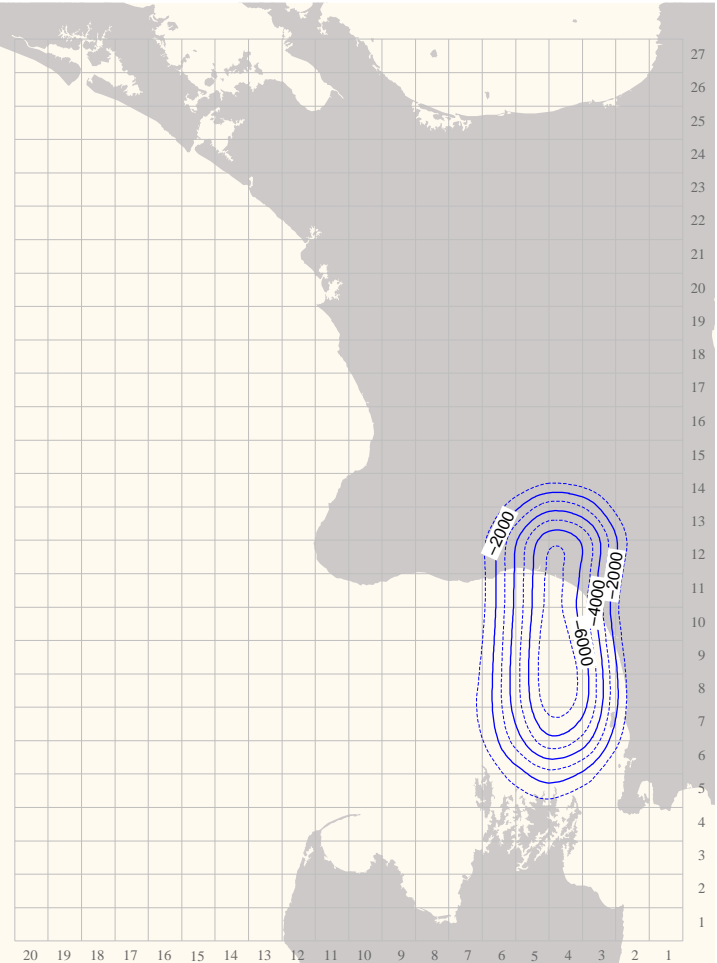

(b) Vertical deformation at depth of $30 \mathrm{~km}$

Figure 6.15: Model FINAL3: Vertical surface deformation (a) and deformation at a depth of $30 \mathrm{~km}$ with the input loads for the FEM modelling shown in panel (c). Loading pressures are shown in $\mathrm{MPa}$ with different colours representing different loading directions. Red are negative loads (directed downwards); green are positive load (directed upwards). 


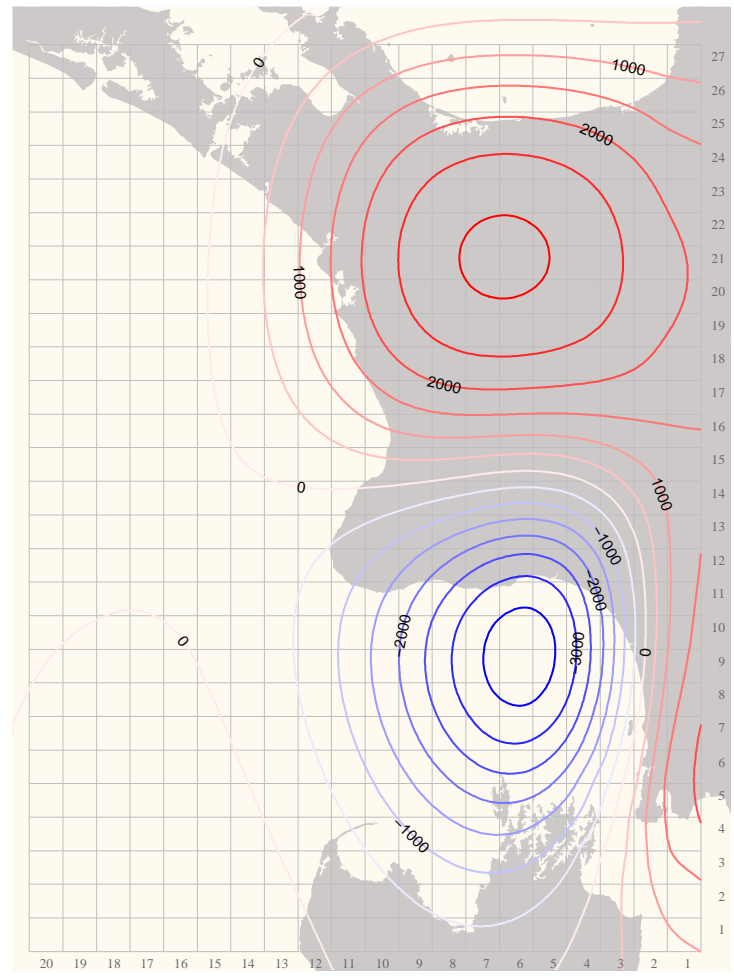

(a) Vertical surface deformation

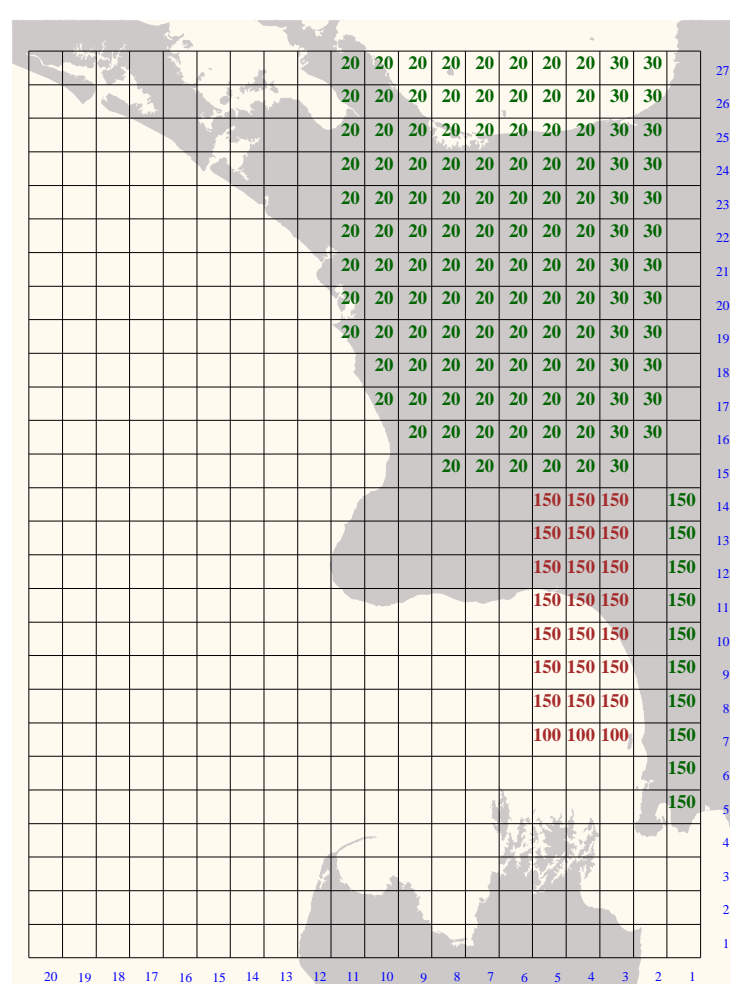

(c) Load distribution

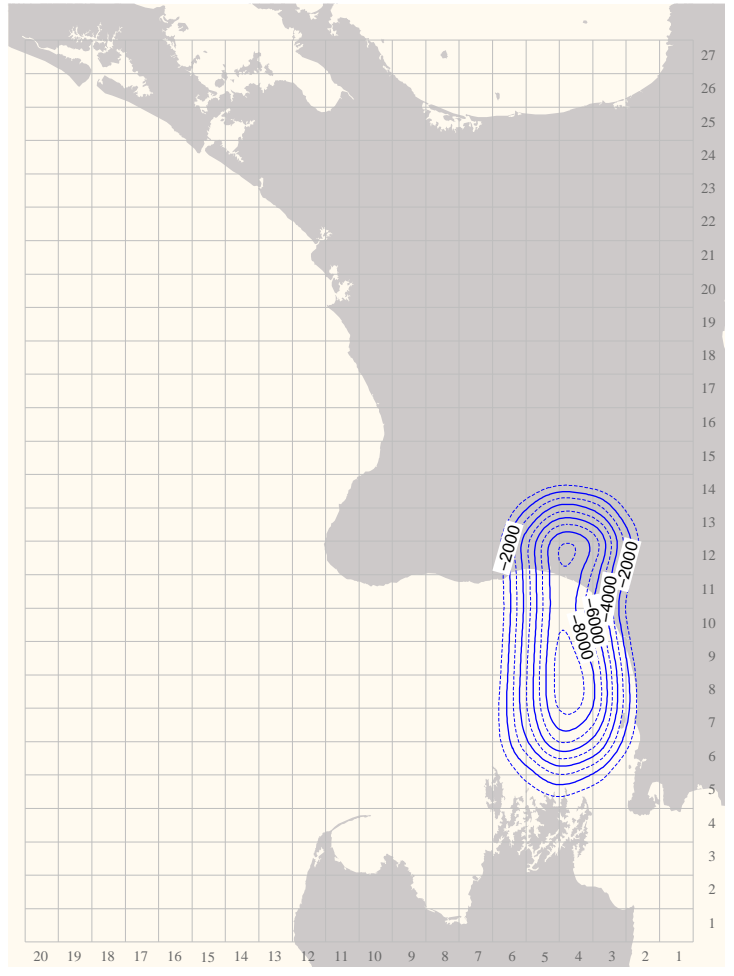

(b) Vertical deformation at depth of $30 \mathrm{~km}$

Figure 6.16: Model FINAL6: Vertical surface deformation (a) and deformation at a depth of $30 \mathrm{~km}$ with the input loads for the FEM modelling shown in panel (c). Loading pressures are shown in $\mathrm{MPa}$ with different colours representing different loading directions. Red are negative loads (directed downwards); green are positive load (directed upwards). 
these modelling results fit well with the surface deformation map presented in the beginning of this chapter (figure 6.4). The modelled Moho downwarp (figure 6.14(b)) has a similar wavelength in north-south direction as the surface deformation, but in east-west direction it is narrower and has approximately half the extent predicted by 3-D gravity modelling (chapter 4 ).

In another model (model FINAL3, figure 6.2.4) the width of the negative load patch responsible for the downwarp is slightly increased to $60 \mathrm{~km}$, with decreased load amplitudes. Furthermore, the positive loads for the central North Island are reduced to 20 and $30 \mathrm{MPa}$ to produce a smaller uplift in this area. The modelled surface deformation fits well with the surface deformation map (see figure 6.4) and the east-west wavelength of the Moho deformation is increased by around $30 \%$, where the basin wavelength is unchanged. However, the amplitude of the Moho deformation is still smaller than that predicted from gravity modelling $(\sim 12 \mathrm{~km})$, and the applied loads are already relatively high compared to loads used by Stern et al. [1992]'s flexural modelling of the SWB. A model is, therefore, produced where the values of the Young's modulus of the lower crust and upper mantle are halved (model FINAL6, figure 6.16). This produces an almost unchanged surface deformation but a 10\% larger Moho deformation, which correspond to a maximum crustal thickness of $41 \mathrm{~km}$. However, such a change in Young's modulus corresponds to a large 30\% drop in $\mathrm{V}_{s}$ velocity (see section 6.1.4).

A side by side comparison of the observed and predicted (model FINAL3) vertical uplift is shown in figure 6.17. The overall pattern of deformation is matched well with model FINAL3. It successfully predicts the approximately $500 \mathrm{~m}$ of NE directed tilting in the Marlborough sounds as well as the elliptical shape of the subsidence basin and the uplift to the north. The uplift of the Tararuas is not included in the observed deformation map (figure 6.4). Furthermore, the Taranaki Basin and the Taranaki Fault Zone are not included in the modelling approach which explains the discrepancy between the observed and predicted deformation at the western side of the basin.

\subsection{Predicted faulting styles}

Onshore seismic reflection lines (chapter 3) at the eastern corner of the SWB at the transition zone between the basin and Tararua Ranges show steep reverse faulting and normal faulting in close proximity. Furthermore, steep reverse faulting is observed on the eastern edge of the basin (Rangitikei Faults and Kapiti Manawatu faults system; see figure 6.19) and normal faulting is observed on the western edge of the basin. These different faulting styles associated with the basin are puzzling aspect of the SWB. Their origin is further investigated in this section using the principal stress at the surface, which is a co-product of the FEM. 


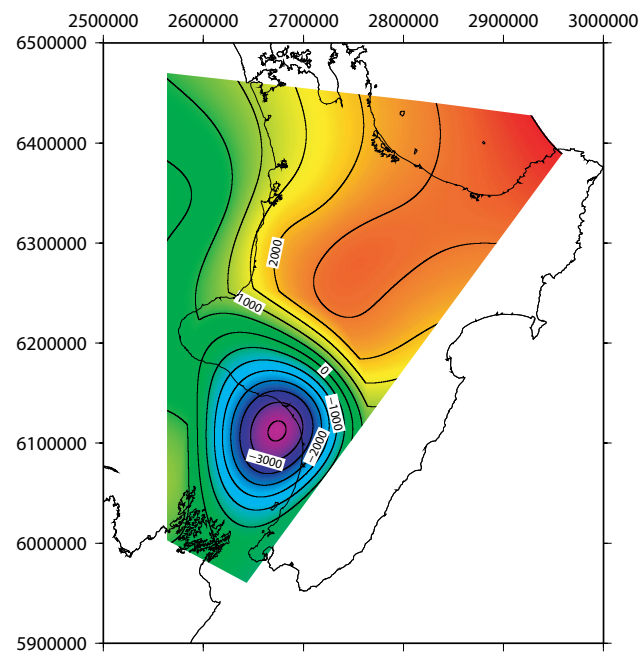

(a) 'real' rock uplift + subsidence

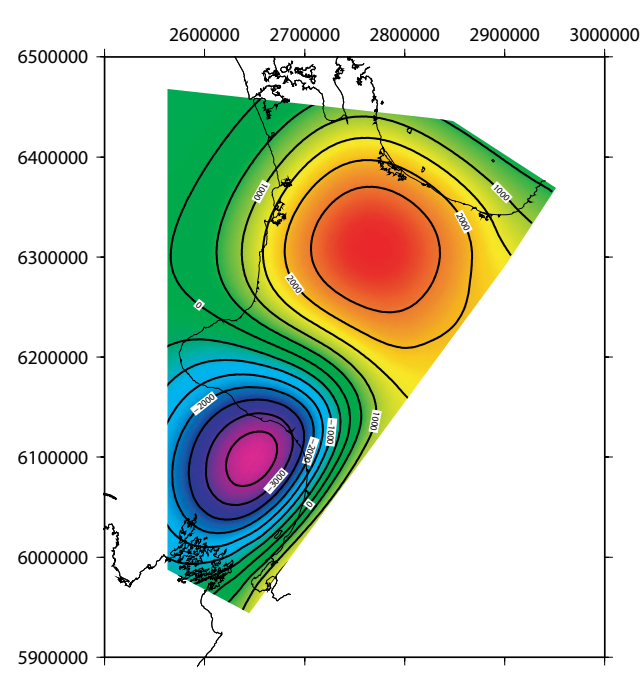

(b) modelled vertical surface deformation

Figure 6.17: (a) Observed uplift and subsidence for North Island (figure 6.4 rotated by $33^{\circ}$ ). (b) Calculated vertical deformation at the top surface with model FINAL3. Both figures are coloured using the same colour scheme

In the simplest analysis of faulting, the relative magnitude of the principal vertical stress determines the favoured faulting regime [Twiss \& Moores, 1992]. If the principal vertical stress is the least compressive, intermediate or the most compressive it will favour reverse, strike-slip or normal faulting, respectively.

Nevertheless, this theory has some limitations; it does not include pre-existing zones of weakness and it cannot incorporate mixtures between the different faulting style (e.g. transtensional faulting). Furthermore, the model does not consider other processes occurring in the lower North Island such as the oblique subduction.

The predicted faulting for model FINAL3 is shown in figure 6.18. The grey colour indicates the area where the stress field favours reverse faulting, blue shows the region of possible strike-slip faulting and in the red area normal faulting is most likely. The results are calculated for a $10 \times 10 \mathrm{~km}$ grid. The predicted faulting map (figure 6.18) shows preferred normal faulting at the eastern side of the model along the Tararua Ranges, at the eastern corner of the basin and to the north. Within the basin, the dominant faulting style is reverse, with strike-slip faulting to the west and south. There is a small strip of predicted strike-slip faulting which separates the normal faulting in the east and the reverse faulting in the centre. It starts at Kapiti Island and runs northeast. These faulting patterns do not vary with in-plane stresses.

The predicted faulting regions with the here presented approach are similar to those found by Stern et al. [1992] for the SWB. They calculated the bend- 


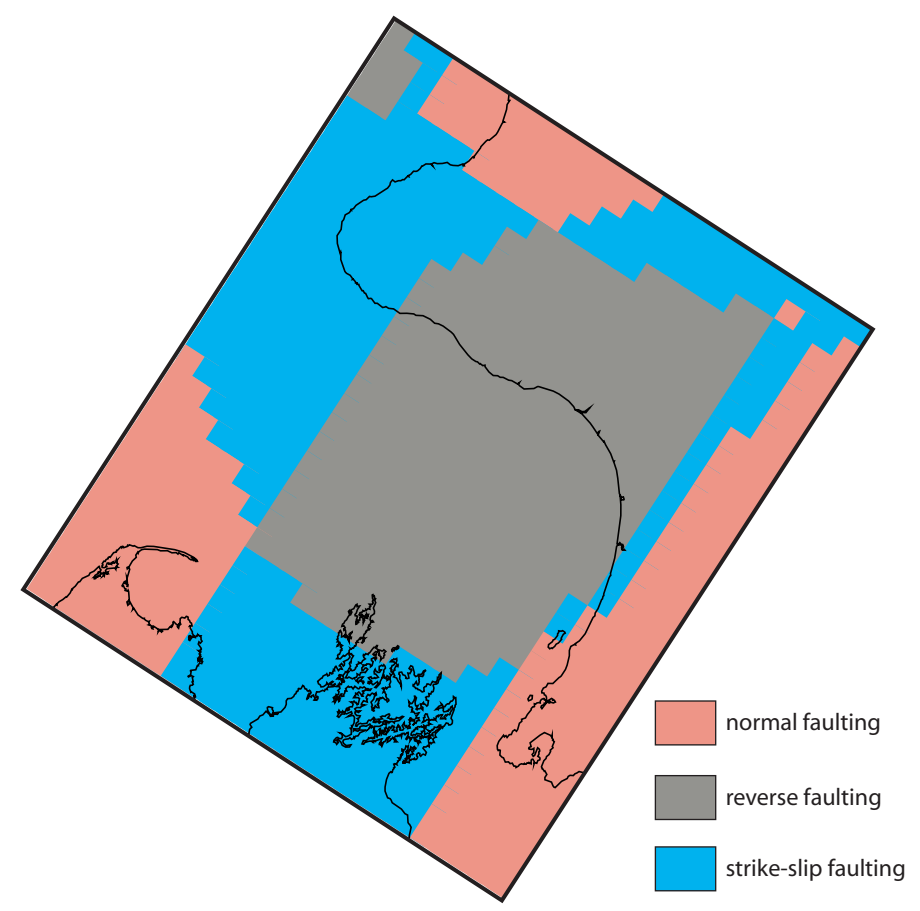

Figure 6.18: Predicted favoured faulting sense based on the principal stresses observed by finite-element modelling (model FINAL3, figure 6.2.4). This model cannot allow for existing weaknesses or mixed faulting styles and only describes second order effects due to bending. The model includes the uplift of the Tararuas and central North Island as well as the subsidence of the SWB.

ing stresses in a thin elastic plate and used a similar approach to determine the favoured faulting style. However, their zone of predicted normal faulting in the north stretches across the Taranaki Peninsula and covers the mostly normal Waverly fault zone (figure 2.2), where the here presented model predicts reverse faulting for this area. The difference could be due to the wider negative loading zone $(60 \mathrm{~km})$ underneath the basin used for the here presented model, resulting in a wider zone of favoured reverse faulting.

A comparison of the predicted faulting and the faults observed in the southeastern corner of the SWB is shown in figure 6.19. Within the basin the observed reverse faulting is in good agreement with the prediction. At the eastern corner, between the basin and the ranges, no clear pattern can be established in the observed faulting. A mix between steep normal and steep reverse faulting dominates the onshore region (see chapter 3). A small band of normal faulting characterises the eastern offshore region in the SWB, just of the Kapiti coast [Lamarche et al., 2005]. In this area, the predicted faulting map implies a transition from normal faulting in the east to reverse faulting in the west, with some strike-slip in between.

The strike-slip faults mapped within the Tararua Ranges are interpreted as a re- 


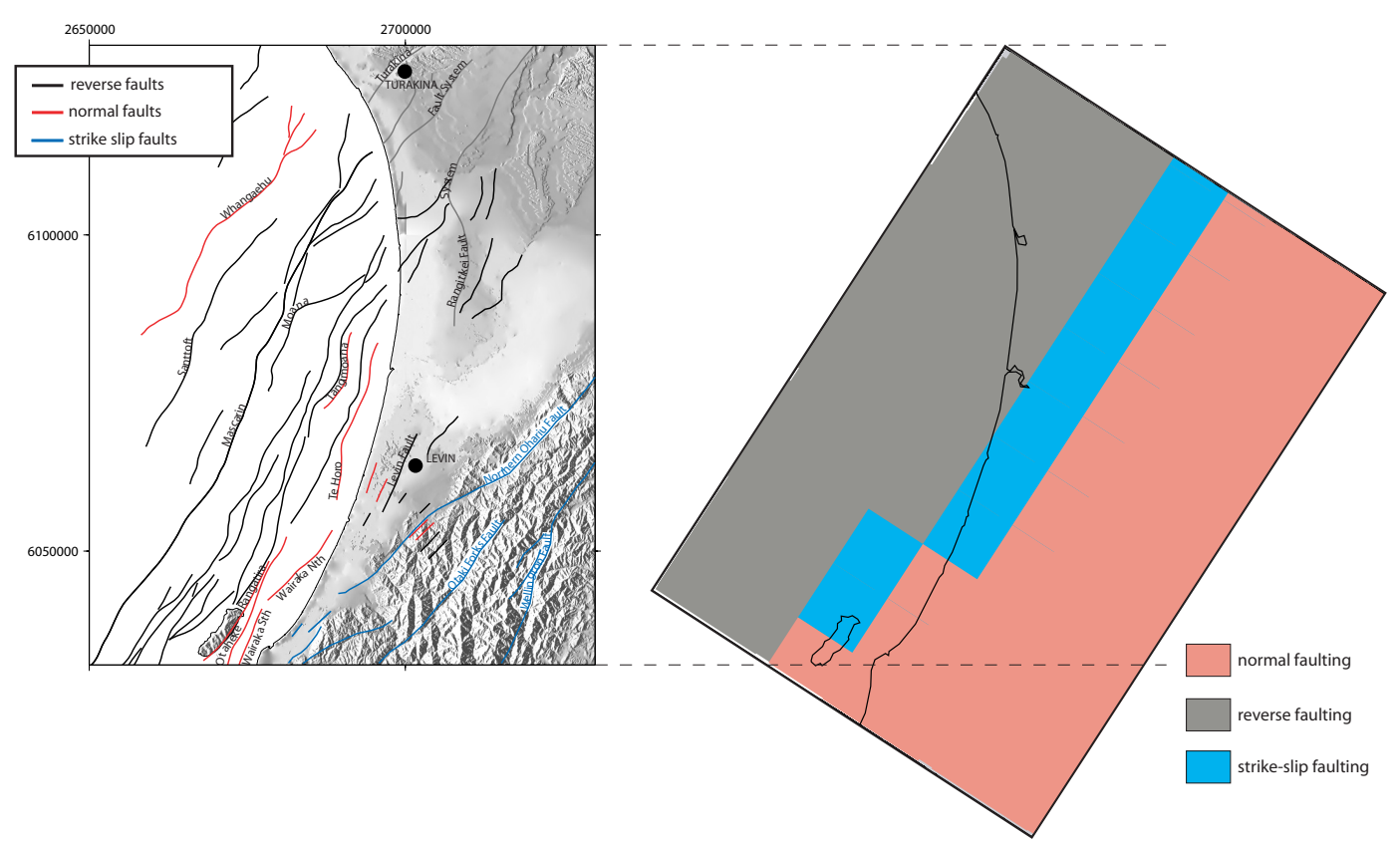

Figure 6.19: Comparison of predicted favoured faulting (right panel) and observed faulting in the southeastern corner of the SWB (left panel) [Lamarche et al., 2005]. Within the basin the observations fit well with the predicted pattern of reverse faulting. At the eastern corner of the SWB, a mix of high-angle normal and reverse faulting faults is found. The prediction shows a transition from normal to reverse faulting.

sult of the oblique subduction occurring in the southern North Island [Beanland \& Haines, 1998], which is not included in the modelling. A component of strikeslip in the mapped normal and reverse faults cannot, therefore, be excluded. Nevertheless, these results verify the changing faulting style at the eastern corner of the SWB as a second-order effect due to bending stresses and support the theory of a deformation of the upper crust due to predominant vertical loading.

\subsection{Discussion}

Rheology parameters The FEM modelling of the downwarp of the SWB requires a viscosity contrast of more than $10^{4} \mathrm{~Pa} \cdot \mathrm{s}$ between the upper and lower crust to produce a crustal thickening with depths consistent with the 3-D gravity modelling (see chapter 4) and crustal seismic data [Stern \& Davey, 1990]. The best result is achieved with a completely elastic upper crust and a viscoelastic lower crust. This model is in agreement with other observations of continental deformation, where the brittle deformation of the upper crust is often decoupled from the deformation of the lower crust [Gans, 1987; McKenzie et al., 2000]. The occurrence of flow in the lower crust mainly de- 
pends on the temperature conditions [Stocker \& Ashby, 1973]. McKenzie et al. [2000] predicts that for a $30 \mathrm{~km}$ thick crust and a temperature gradient of $20^{\circ} \mathrm{C} / \mathrm{km}$ the bottom $5-10 \mathrm{~km}$ will be able to flow. However, the heat flow underneath the SWB is low [Funnell et al., 1996] and is not sufficient to reach the required temperatures $(70 \%$ of the solidus temperature [Stocker \& Ashby, 1973]). Nevertheless, the presence of fluids decreases the viscosity and can therefore provide a locus for flow in the lower crust [Cooper \& Kohlstedt, 1986; Iio et al., 2002]. Swarm-like earthquake activity observed in the SWB and the low S-wave velocity layer discovered in the receiver function study (chapter 5) are indications of fluids released from the subducting slab hydrating the bottom part of the crust.

The thickness of the viscoelastic lower crust is chosen to be $15 \mathrm{~km}$ for the final models, which provides the best compromise for the different requirements of the model. However, a thinner $(10 \mathrm{~km})$ lower crust would be in better agreement with the thickness of the low S-wave velocity layer proposed by the receiver function study (chapter 5) and would create a higher deformation ratio between surface and base of the crust. Nevertheless, such a model needs loads with even higher amplitudes to create the deformation amplitudes observed.

The preferred viscosity for the lower crust is $10^{21} \mathrm{~Pa} \cdot \mathrm{s}$. This is in the upper region for viscosities proposed for the continental lower crust [Lowrie, 1997; Peltier, 1998; Yamasaki \& Seno, 2005]. Higher values do not create the desired deformation ratios between surface and base of the crust. Lower values do not produce significantly higher deformation amplitudes. The other rheology parameters are taken to be in agreement with other geophysical studies (see table 6.1).

Stress analysis The FEM demonstrates that a high vertical load (up to $200 \mathrm{MPa}$ ) is necessary to create the observed vertical deformation in the SWB. These loads are slightly higher than what was proposed by Stern et al. [1992], using flexural modelling of a thin elastic plate. One of the main reasons for this discrepancy is that the here presented model also includes the uplift of the central North Island, which works against the subsidence of the SWB. In the following, the question is addressed of how such a high load can be achieved in the subduction zone system of the lower North Island.

Calculation and modelling of shear stresses at subduction zone interfaces and thrust faults show values between 1-150 MPa, with the mean shear stresses being around $15 \mathrm{MPa}$ [Hyndman \& Wang, 1993; Lamb, 2006; Molnar \& England, 1990; Peacock, 1996]. The maximum shear stress which could be sustained by the lithosphere is estimated to be around $200 \mathrm{MPa}$ [McNutt, 1980; Stephenson \& Cloetingh, 1991; Watts \& Burov, 2003]. The shear stress at the subduction interface is determined by the available slab pull (chapter 2.3), the rheological parameters (pressure and temperature) 
and the friction coefficient [Lamb, 2006]. The theoretical calculation of the slab pull force due to the negative buoyancy of the subducting slab requires knowledge of numerous terms (e.g. the gravitational force of the denser mantle lithosphere and subduction resistance force acting on the subducting slab) and is therefore relatively uncertain. For typical lithospheric structures the slab pull is estimated to be between $4 \cdot 10^{12}-10 \cdot 10^{12} \mathrm{~N} / \mathrm{m}^{-1}$ [Lee et al., 2002; Whittaker et al., 1992]. For the SWB, Stern \& Davey [1989] calculated the gross slab pull force per metre of trench based on an estimation equation [Crough \& Jurdy, 1980] to be $5.7 \cdot 10^{12} \mathrm{~N} / \mathrm{m}$. The corresponding loads for such forces, using the upper limit for what is predicted for the slab pull force $\left(10 \cdot 10^{12} \mathrm{~N} / \mathrm{m}\right)$ and assuming a $45^{\circ}$ dipping subduction interface, have values of $176 \mathrm{MPa}$ and $120 \mathrm{MPa}$ for a 40 or $60 \mathrm{~km}$ wide subduction thrust, respectively. Thus, even for the case of a theoretical friction coefficient of 1 (completely locked interface), the slab pull forces alone would be too small to be responsible for the observed surface deformation. Therefore, in agreement with the flexural modelling by Stern et al. [1992], the model presented here suggests that the negative buoyancy force due to the subducting slab alone cannot be responsible for the observed deformation.

An additional mechanism proposed to drive topography above subduction zones is mantle convection [Davies, 1981; Harper, 1986; Zhong \& Gurnis, 1994]. The origin and nature of mantle convection is variable, but it is primarily driven by viscous slab-wedge coupling [Conrad \& LithgowBertelloni, 2002]. However, the induced depression in the overriding plate due to flow in the mantle has a much larger wavelength than what is observed in the SWB [Billen \& Gurnis, 2001; Stern \& Holt, 1994; Zhong \& Gurnis, 1992]. Such a long wavelength mantle flow can therefore be excluded as an additional force to create the basin.

For the central North Island, Stern et al. [2006] proposed the removal of overthickened mantle lithosphere as a driving mechanism for the dome shaped uplift of the area. Lithospheric thickening occurred east of and adjacent to the Taranaki thrust fault during compression in the Miocene [Holt \& Stern, 1994; King, 2000]. For the central North Island, as mentioned before, this thickened mantle is supposed to have been rapidly removed at $5 \mathrm{Ma}$ [Stern et al., 2006], but it is most likely to still exist underneath the southern North Island. A thickened mantle lid represents a body of positive density contrast within the mantle, which results in a buoyancy force similar to the slab. Thus, the buoyancy force of the slab and overthickened mantle lithosphere can reinforce each other and together they can provide the high load values needed in the modelling (see figure 6.20).

The volume of the thickened mantle can be estimated based on its history of shortening. Across the Taranaki Basin and SWB, the amount of shortening which occurred during the Miocene $(75 \pm 35 \mathrm{~km})$ [Nicol et al., 2007; 


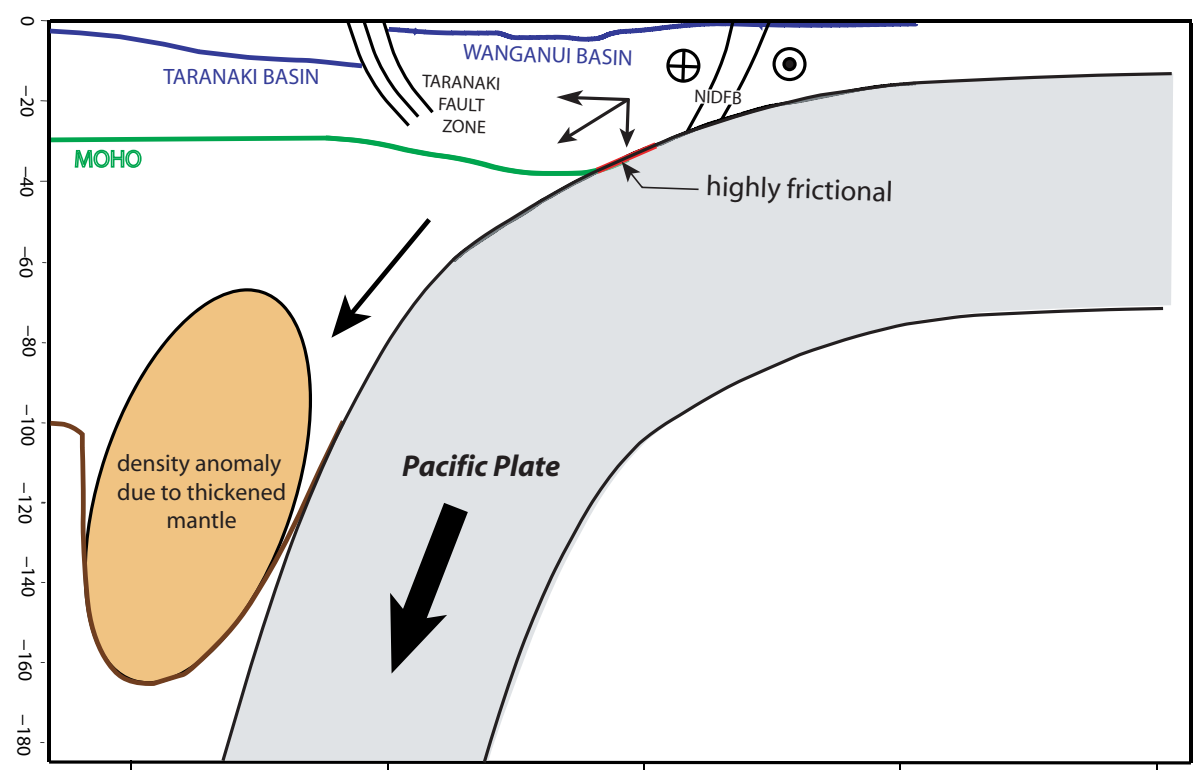

Figure 6.20: Cross-section cartoon of the southern part of the SWB qualitatively illustrating proposed driving forces of the basin. The shear force at the highly coupled interface creates a vertical pull as well as in-plane stress in the overriding plate. An additional possible driving force is presented by an overthickened mantle lithosphere, which creates a density anomaly within the mantle. The blue line shows the depth of the sediment basin. The green line shows the proposed Moho of the thickened Australian plate. Also shown are the approximate location of the Taranaki Fault Zone in the west and of the North Island dextral fault belt (NIDFB) in the east.

Stern et al., 2006] is similar to what is observed in the South Island for the last $7 \mathrm{Ma}(\sim 100 \mathrm{~km})$ [Stern et al., 2000]. Their gravity modelling implies an anomalous mantle body of $90 \mathrm{~km}$ width, $100 \mathrm{~km}$ and a density contrast of $30 \mathrm{~kg} / \mathrm{m}^{3}$. This model is adopted here to estimate the order of the buoyancy force due to a thickened mantle lithosphere. Such a body produces a pull force per metre trench of around $3 \cdot 10^{12} \mathrm{~N} / \mathrm{m}$. The corresponding load depends on the width over which the force acts. For a width of $90 \mathrm{~km}$ or $60 \mathrm{~km}$ the corresponding loads are $\sim 30 \mathrm{MPa}$ or $\sim 50 \mathrm{MPa}$, respectively. Thus, an overthickened mantle lithosphere creates loads which can significantly contribute to the driving of the basin. However, this idea is speculative and many questions and uncertainties remain, such as, what is the exact shape of the anomaly, how is the buoyancy force transmitted to the lower crust, and over what area would the buoyancy force act (if only underneath the $\mathrm{SWB}$, how is it guided)? To date, no geophysical data are available to provide evidence for a thickened mantle in southern North Island in the same manner as has been presented in the central South Island. For further research, a traveltime residual analysis combining teleseismic events and local events associated with the slab, recorded at seismograph stations within 
the offshore part of SWB and the Taranaki Basin is suggested to further investigate the possible existence of a density anomaly within the mantle.

Another speculative idea for an additional mechanism to drive the subsidence of the basin involves the rollback of the slab (pers. com. S. Lamb). When the slab retreats from the trench, the created open space ontop of the slab has to be filled with mantle material. In the central North Island, where new hot low viscous mantle exists due to the viscous removal of the mantle lithosphere, this space can immediately be filled from material around. In the lower North Island, where a thickened old mantle lithosphere is still likely to exist, the filling of a gap possibly happens by low viscous material from below. This material would then have to flow up in a channel opened due to the slab roll back, creating a suction force pulling down the crust. Details on this idea are not further discussed in this thesis and the qualitative calculations of the corresponding forces remain an incentive for further research. Furthermore, to avoid boundary effects in future modelling, it is suggested to apply the in-plane stress as a pre-stress, similar as it is done for the gravity forces.

Load distribution An issue arising from the modelling work is the width and the location of the proposed zone of high coupling along the subduction thrust and its corresponding zone of negative loading in the model. Based on the location of the seismic zones, Reyners [1998] argues that in the Wellington/Wairarapa region the plates are strongly coupled over a $70 \mathrm{~km}$ downdip width in a maximum depth range of $22-25 \mathrm{~km}$. Further to the south, the interface is assumed to be permanently locked; further to the north the coupling gets weaker. A GPS study of the surface deformation in the lower North Island is interpreted to show a similar pattern but with a wider and deeper zone of strong coupling, extending across the west coast of the lower North Island (figure 6.21(a)) [Wallace \& Beavan, 2006].

The negative loading zone proposed in the modelling (figure $6.14-6.16$ ) has a width $(40-60 \mathrm{~km})$ similar to the zone of strong coupling but the location of the loading is further to the northwest. However, the here proposed loading zone (figure 6.15(c)) fits well with an area of identified slow slip earthquakes on the subduction interface (figure 6.21(b)), and a slip deficit map (figure 6.21(a) shows a local maxima close to the present depocenter of the basin.

The presented models by [Wallace \& Beavan, 2006] are based on GPS data from the last 10 years and can therefore only give a snapshot of the present situation. Furthermore, their modelling region is mainly restricted to the onshore part of the North Island. Therefore, a strong interaction between the Pacific and Australian plates for the lower North Island can be concluded, possible extending further to the west as previous proposed. The finite element modelling shows that the loading zone to create the subsidence 


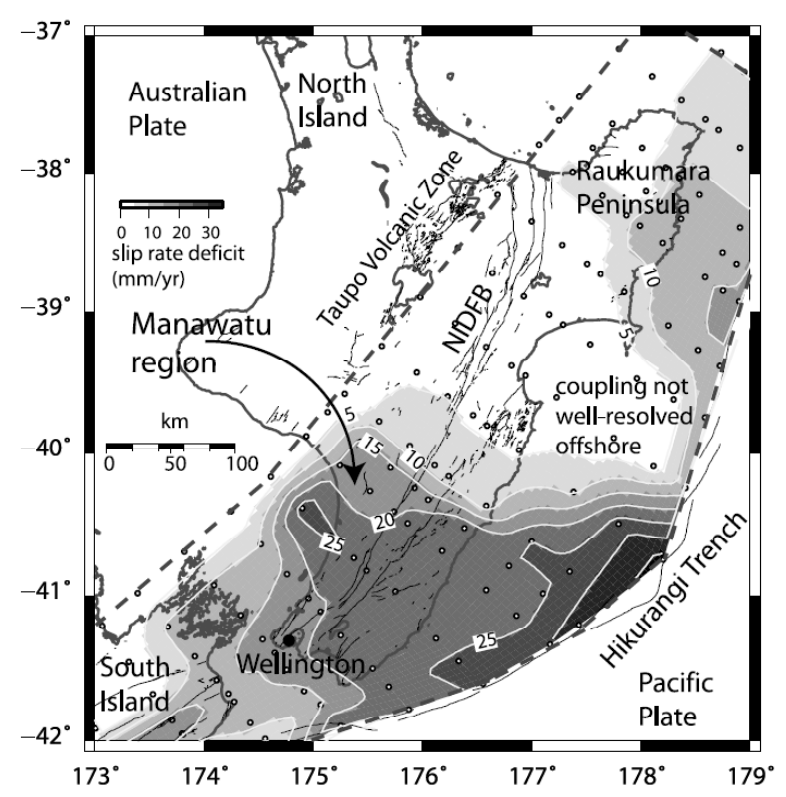

(a)

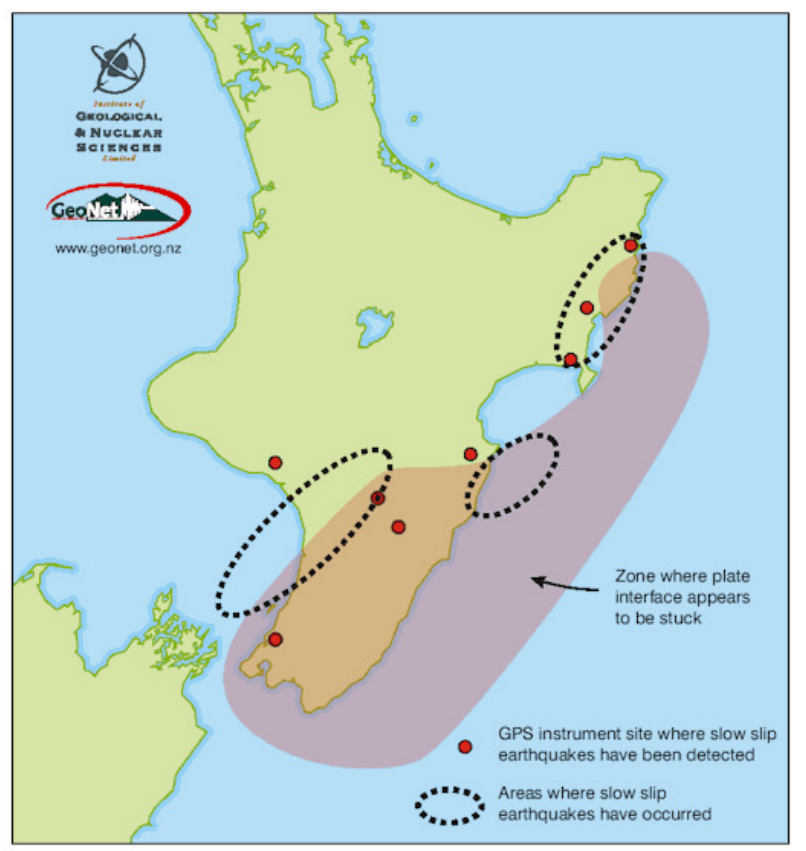

(b)

Figure 6.21: (a) Distribution of subduction interface interseismic slip rate deficit (shaded and contoured in $5 \mathrm{~mm} / \mathrm{a}$ ) based on GPS measurements [Wallace \& Beavan, 2006]. (b) Sketch of locations of detected slow slip earthquakes on the subduction interface (dashed lines). The purple shaded area marks the zone of strong "interaction" between the subducting and overriding plate. Figure taken from http:/ / www.gns.cri.nz/news/release/slow.html. 
of the basin cannot act across the entire area of high coupling identified by GPS measurements but has to be spatially restricted underneath the basin.

Future work The model presented here is an expansion of the model by Stern et al. [1992]. It does not include a slab within the model, it only investigates the deformation of the overriding plate due to forces of the subducting slab. This is a constrain of the the presented model. A future study could aim to include the influence of the slab. This requires a much more complex modelling approach and model setup. However, the direct influence of the underlying slab on the deformation of the overriding plate can not be fully investigated otherwise.

\subsection{Summary}

- To achieve a vertical deformation ratio of 3-4 between the base of the crust and the surface, the crust underneath the SWB is modelled as a two-layer model, with a purely elastic top layer and a viscoelastic bottom layer.

- The predicted viscosity of the lower crust is on the order of $10^{21} \mathrm{~Pa} \cdot \mathrm{s}$.

- The thickness of the viscoelastic lower crust is between 10-15 km, assuming an initial total crustal thickness of $30 \mathrm{~km}$.

- The wavelength of deformation at the base of the crust is smaller than the wavelength of deformation at the surface. This is in contrast to what is predicted by 3-D gravity modelling, but the contrast decreases with the width of the loading zone. The preferred width of the loading zone is $60 \mathrm{~km}$.

- High vertical loads of up to $200 \mathrm{MPa}$ are necessary to simulate the downwarp of the basin. These loads cannot originate from the negative buoyancy of the slab alone. An additional mechanism is proposed with an overthickened mantle lithosphere creating a possible second force supporting the growth of the basin.

- A free edge on the eastern side of the model and a load of $150 \mathrm{MPa}$ simulate the observed rock uplift of the Tararuas.

- Loads to simulate the doming in the central North Island are around 30$50 \mathrm{MPa}$.

- Analysing the stress field of the model shows mainly reverse faulting within the basin and a combination of normal and reverse faulting in its vicinity. This is in good agreement with the observe faulting within and around the basin and supports the theory of a bending deformation of the upper crust due to predominantly vertical loading. 
Chapter 6. 3-D finite element modelling of deformation in the North Island 


\section{Chapter 7}

\section{Summary and conclusions}

The conclusions of this thesis are presented in two parts. The first part concentrates on the shallow structure in the southeastern offshore corner of the SWB. In the second part, implications about the broader structure of the basin, its driving mechanism and its tectonic setting in the context of the North Island of New Zealand are summarised.

\subsection{Shallow structures in the southeastern offshore corner of the SWB}

The seismic and the gravity study of the southeastern corner of the SWB (chapter 3) identify mostly high-angle faulting features. The basement structure of this region is complex, combining normal, reverse and strike-slip faulting mechanisms, and no clear regional patterns can be established. However, the additional inclusion of offshore data into the analysis reveals a clearer picture, with prevailing normal faulting on the eastern edge of the basin along the Kapiti Coast and reverse faulting further to the west in the middle of the basin. These shallow structures are in good agreement with the faulting pattern derived as a result of vertical driving force models for the basin (chapter 6).

At the southern end of the study region, in the Waikanae area close to the Tararua Ranges, evidence is found for a stepped strike-slip fault, with a pullapart basin (400 $\mathrm{m}$ deep) separating the two segments. The strike-slip faults are assumed to be part of the northeast trending North Island dextral fault belt. The location of this newly discovered strike-slip fault is in good agreement with the suggested location of the 6500 year shoreline. This shows that the location of this shoreline is most likely controlled by faulting and not eustasy.

Interpretation of gravity and seismic data close to the township of Levin identi- 
fied an intra-basement low-angle $\left(\sim 30^{\circ}\right)$ reflector under the eastern section of the profile line. Similar reflectors could be identified for other on- and offshore lines within the SWB. The characteristic of the events resembles other events found within the Taranaki Basin, which are interpreted as low-angle basement thrust faults due to Miocene shortening across the basins.

Further new shallow features discovered in this study are a $\sim 200 \mathrm{~m}$ vertical offset on an active strike-slip fault (Hadfield fault), which is located at the eastern side of SH1 close to Waikanae, and a high-amplitude reflector at a depth of around $400 \mathrm{~m}$ in the Foxton area. This horizon corresponds to the top of a $\sim 1 \mathrm{Ma}$ old sediment layer containing lignite.

The style, the strike and the location of the faulting in the SWB changes with age. In the Miocene mainly low-angle thrust faulting occurred on the north-south trending ( $5^{\circ}$ to north) Taranaki Fault Zone at the eastern side of the basin. During the late Pliocene and Pleistocene vertical deformation dominated along the southwest-northeast trending ( $30^{\circ}$ to north) Kapiti-Manawatu Fault System at the eastern side of the basin. In contrast, the most recent faulting occurs at the eastern corner of the basin and is mainly strike slip with a vertical component of movement (strike is $50^{\circ}$ to north). Thus, the strike of the faults appears to rotate clockwise with time and the faulting style varies from low-angle thrusts in the west over mostly vertical faulting east of the basin centre to strike slip faulting at the eastern boundary of the basin.

\subsection{Deeper structures of the SWB}

Modelling the gravity anomaly of the SWB in three dimensions verified the hypothesis of a ductile thickened crust underneath the SWB. Depending on the thickness of the crust of the subducting Pacific plate, the vertical deformation of the Moho is proposed to be three to four times larger than the deformation of the sediment-basement interface. The best model to describe the gravity anomaly implies that the subduction of thick oceanic crust $(10 \mathrm{~km})$ reaches to the west coast of the lower North Island with a maximum Moho depth of $42 \mathrm{~km}$. Such a high thickness of the subducting crust is an indicator for the subduction of the Hikurangi Plateau under the lower North Island.

In order to produce a ductile downwarp of the crust in the subsequent finite element modelling, the crust has to consist of at least two distinct different layers (chapter 6). The model requires the top $15-20 \mathrm{~km}$ of the crust (total crustal thickness $30 \mathrm{~km}$ ) to behave purely elastic and the lower part to be viscoelastic with a proposed viscosity of $10^{21} \mathrm{~Pa} \cdot \mathrm{s}$. Such a ductile lower continental crust can be caused by temperatures close to the solidus temperature [Stocker \& Ashby, 1973]. In the low heat flow environment of the SWB, a "wet" lower crust is proposed which decreases the solidus temperature. Evidence for fluids in the lower 
crust are provided by an around $10 \mathrm{~km}$ thick low S-wave velocity in the lower crust found by the receiver function study (chapter 5) and from the swarm-like earthquake activity in the area [Garrick \& Gibowicz, 1983].

To create the observed deformation of the basin in the model, it is necessary to apply high vertical loads (up to $200 \mathrm{MPa}$ ) to the base of the crust. It is shown that these load amplitudes can hardly be explained by slab pull forces transmitted by the strongly coupled subduction interface alone. The maximum force estimated due to this mechanism is around $180 \mathrm{MPa}$ for a completely locked interface. This is a high value in comparison to literature values, where values range between 1-150 MPa, with the mean shear stresses being around $15 \mathrm{MPa}$.

The downdip width of the strong coupling zone at the subduction interface has a strong influence on the east-west wavelength of the Moho deformation. It is shown that a coupling/loading zone of around $60 \mathrm{~km}$ creates similar deformation wavelengths for the top and the base of the crust. This width is in good agreement with the locking zone width predicted from GPS measurements in the lower North Island [Wallace \& Beavan, 2006].

A thickened mantle lithosphere is proposed as an additional driving force for the basin. The thickening of the mantle resulted from shortening in the North Island during the Miocene. In the central and western North Island this possibly developed into an instability which finally dropped off. In the lower North Island such thickened mantle is most likely to still exist, creating a density contrast and corresponding buoyancy force which could help to drive the basin. The maximum buoyancy force generated by this mantle density anomaly is estimated to be in the order of $50 \mathrm{MPa}$. In agreement with Stern et al. [1992], it is concluded that the main driving force of the basin is the high frictional coupling of the subducting Pacific and the overriding Australian Plate in the southern North Island. The basin is therefore described as a flexural basin where ductile thickening increases with depth.

The thickness of the crust of the subducting Pacific plate underneath the mainland in the lower North Island is investigated by receiver function analysis. The station on Kapiti Island and the stations to the east within the Tararua Ranges reveal a crustal thickness of around $10 \pm 2 \mathrm{~km}$. Such a thick crust underneath the lower North Island fits well with the 3-D gravity modelling results from chapter 4 .

A further feature discovered by the receiver function analysis is an up to $5.6 \pm 1 \mathrm{~km}$ thick low-velocity layer located on top of the slab. This layer is interpreted as a crushed zone of crustal material together with subducted sediments. The layer thickens towards the west due to an accumulation of the sediments during the subduction process. Underneath the station on d'Urville Island (DUWZ) in the Marlborough Sounds the crust is predicted to be thicker $(39.5 \pm 1.5 \mathrm{~km})$ than predicted by the $3-\mathrm{D}$ gravity modelling for this area. This 
discrepancy is explained by its location within the Taranaki Fault Zone. Finally, a distinct signal from a midcrustal discontinuity is interpreted as a change in greywacke types.

In summary, the SWB cannot be described by classic models for orogenic belts but has to be ascribed to a downwarp of the entire crust with a ductile deformation of the lower crust. The driving mechanism of the basin is still not fully resolved, but it is shown that the high friction between the two overriding plates cannot be the sole cause of the basin. Different additional driving mechanisms, such as a thickened mantle lithosphere or channel flow along a void which opens due to slab-roll back, are proposed but need further research to evaluate their role in the SWB. Furthermore, gravity and receiver function analysis state the presence of a thicker than standard $(10 \pm 2 \mathrm{~km})$ oceanic crust under the mainland of the lower North Island. 


\section{Appendix A}

\section{Seismic Method}

\section{A.1 Seismic reflection method}

Reflection seismic serves as a method to construct images of the subsurface, whereby different kinds of sources (such as explosion, airgun, sledgehammer, etc.) send elastic or acoustic waves into the subsurface to investigate the area of interest. The incoming waves are reflected and transmitted at impedance contrasts (rapid changes in medium velocity and/or density) and partly propagate back to the surface, where a series of receivers is positioned to record the signal. In case of 2-D data acquisition, the source and receivers are usually arranged along a straight line on the surface, in boreholes or as hydrophones just below the water surface. The traveltime of the waves are affected by the properties of the reflectors (depth, dip, curvature) and by the subsurface media (velocity, density) above the reflector and can therefore be used to acquire information about the subsurface structure. Seismic reflection surveying is the most common applied geophysical technique and it can be used to explore a depth of tens of meters to kilometres. This appendix gives a brief overview about setup geometries, equipment, as well as an introduction about common processing techniques for seismic reflection data.

\section{A.1.1 Seismic reflection data acquisition}

\section{A.1.1.1 Spread geometry}

The quality of the recording and consequently of the final seismic images are strongly dependent upon the geometry of the spread used to shoot and record the seismic data. The minimum and maximum source receiver offset has to be designed according to the target of the investigation and to minimise the amount of noise recorded. A rule of thumb for the maximum offset says that it should be 
equal (or 0.7 to 1.5 times) to the depth of the target reflector [Knapp \& Steeples, 1986]. The minimum offset has to be chosen so that the target reflection arrives before the 'ground roll' (optimum offset) [Sharma, 1997]. Ground roll is a low frequency, high amplitude Rayleigh wave [Yilmaz, 1987], which travels with a speed slightly slower than the S-wave velocity of the top layer [Lowrie, 1997].

For most of the seismic reflection profiling done for this study, a minimum offset of $30 \mathrm{~m}$ and a maximum offset of $265 \mathrm{~m}$, with 48 geophones, was used. Sometimes, due to logistical problems, a constant minimum offset could not be maintained. For the exact survey geometry used, see the tables in chapter 3.

\section{A.1.1.2 Seismic Sources}

Choosing the right source for a shallow seismic reflection survey, depends on many factors, like the depth of the target reflector, desired resolution, accessibility, budget, environmental damage and safety requirements. The seismic reflection profiles, which were shot for this study, used mainly two different sources; explosives and an EG\&G hydraulic thumper.

The hydraulic thumper is a drop weight, based on a trailer, with an additional acceleration due to engine generated vacuum (see figure A.1) [Gordon, 2003]. The main advantages of the hydraulic thumper are the easy repeatability of the source, the low cost and almost no safety or environmental issues. Tests with this source showed a main frequency of around $70 \mathrm{~Hz}$ and a maximum penetration depth of 1 second TWTT.

For the Peka Peka seismic reflection line (see chapter 3.2.2), 500 gm charges of Powergel $^{T M}$ Pyromexl $^{T M}$ were fired at a depth of $3 \mathrm{~m}$. The frequency content of explosives is normally relative high, but along Peka Peka road it is similar to the characteristic of the EG\&G hydraulic thumper. This can be explained due to the high attenuation properties of the material in the near surface within the study area.

The reprocessed datasets in the Levin area (see chapter 3.4.2) were shot by GNS Sciences [Aharoni, 1991] using explosives (330 gm Powergel $^{T M}$ ) and a MiniSosie, which is a modified pneumatic hammer which vibrates in a random sequence.

\section{A.1.1.3 Receivers}

All used geophones had a frequency response of $10 \mathrm{~Hz}$ and were connected to four cables with twelve takeouts (6 meter distance). Seismic data were recorded digitally, with a Geometrics ${ }^{T M}$ Strataview ${ }^{T M} \mathrm{R} 48$. This device can record a maximum of 48 channels. 


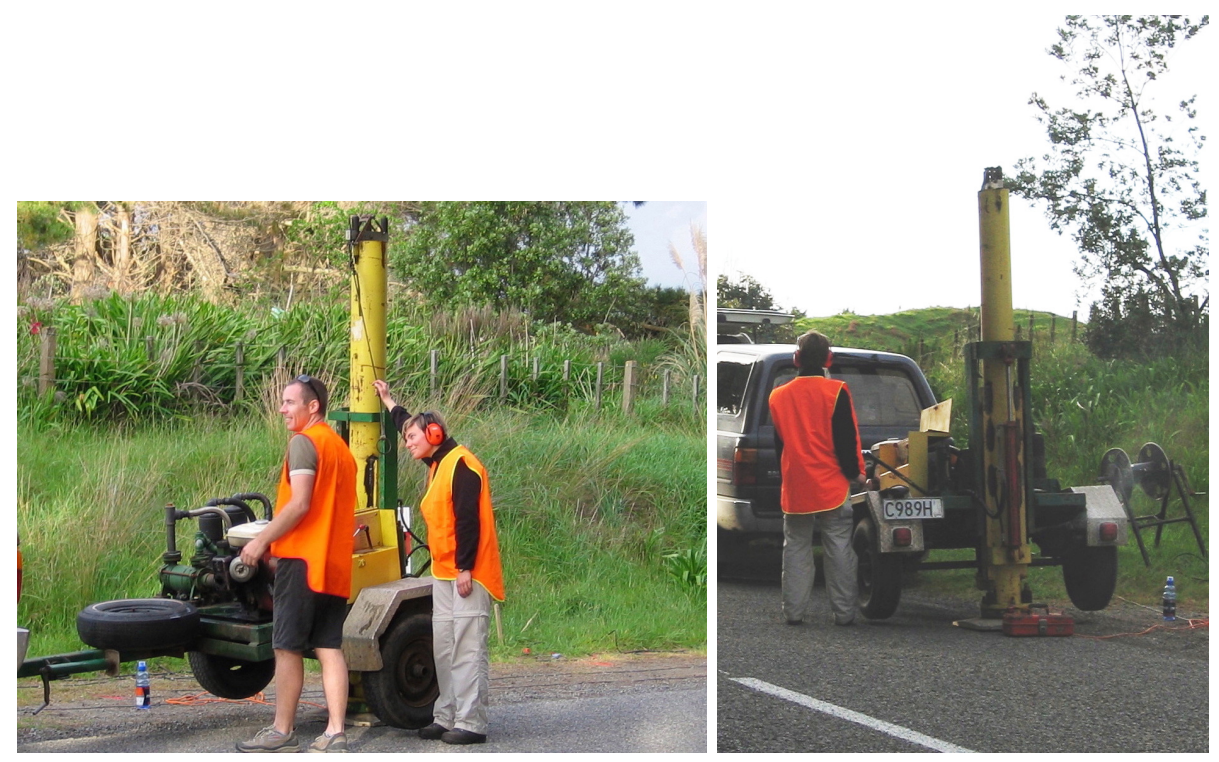

Figure A.1: Picture of the hydraulic EG\&G thumper used as a source for some of the seismic surveys. The drop-weight runs within the yellow vertical tube. An engine is mounted on the trailer to lift the weight inside the tube and to generate an additional vacuum to accelerate the drop of the weight.

\section{A.1.2 Seismic reflection processing}

To create an image of the subsurface, the recorded seismic reflection data needed to be checked, filtered, deconvolved, migrated and finally stacked. The success of the processing steps not just depends on the chosen parameters, it also depends on the effectiveness of the processing steps already completed [Yilmaz, 1987]. Figure A.2 gives an overview over the standard processing sequence used in this study.

\section{A.1.2.1 Debiasing}

Due to recording artefacts or geological factors it is possible that the mean of the trace amplitudes depart from the expected value zero. DEBIAS (Claritas ${ }^{T M}$ module) removes this DC bias by subtracting the mean value of all samples from every sample within a defined window.

\section{A.1.2.2 Header information}

- Every shot has to be checked for the right shot-ID number, right channel numbering and information in other header fields. This is done with the Claritas $^{T M}$ module RENUMBERING and the SEGY_ANALYSER tool. 


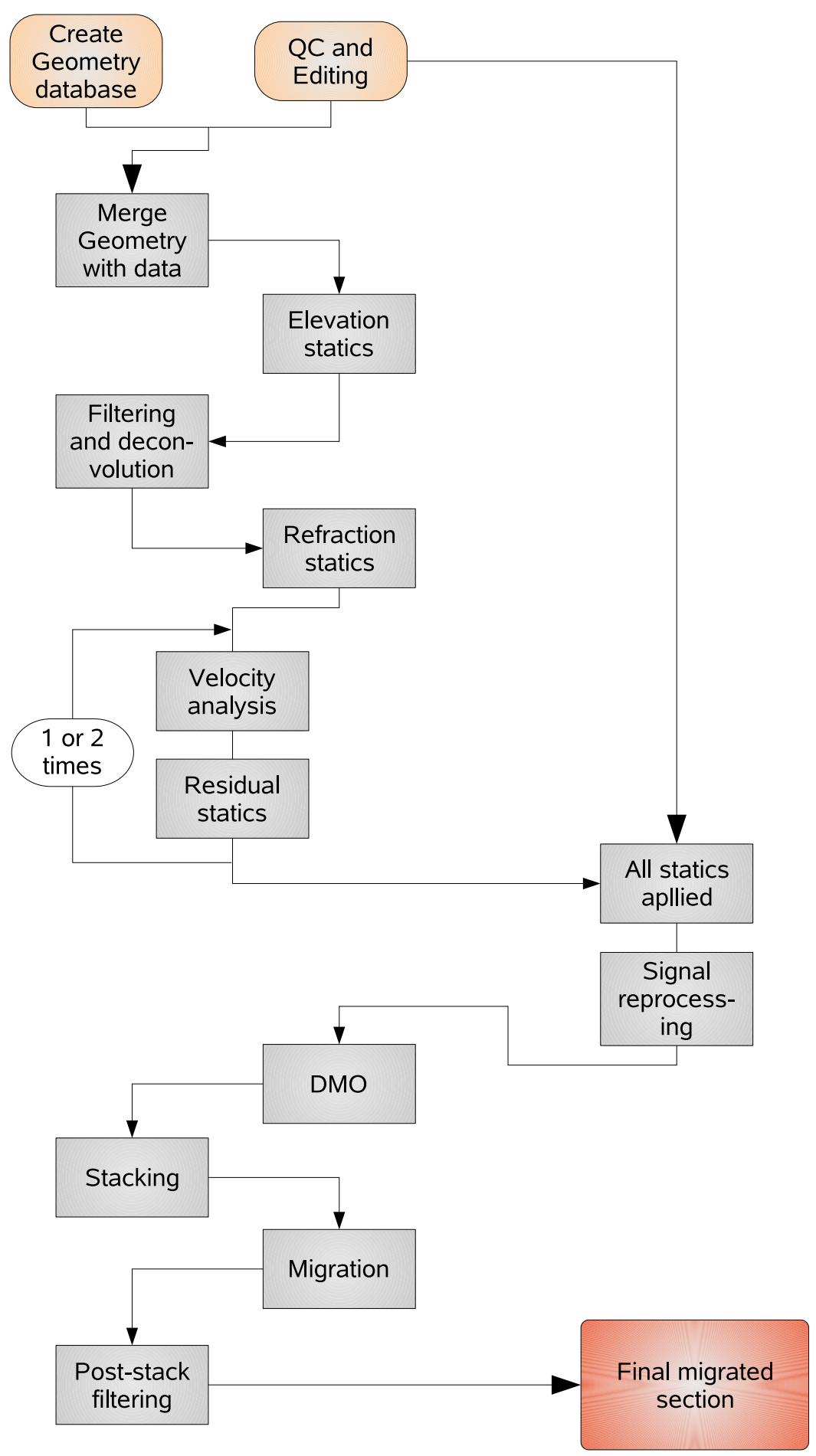

Figure A.2: Flowchart with the seismic processing sequence. It shows the main modules, for some lines additional steps were necessary. 
- For further processing and sorting, it is important to know where every shot was fired, which channels were active and where the recording receivers were located. All this information needs to be stored in the seismic data header. Therefore, a survey file containing all peg locations, and an observer $\log$ file, containing peg number of the shots and active receiver, needs to be created. These files are then merged, using the GEOMETRY application, to one geometry file, which also contains the locations of the Common Depth Points (CDP) and the CDP bin size. For all processed lines a linear CDP gathering could be used. The actual storing into the seismic header fields is done with the ADDGEOM processing module.

\section{A.1.2.3 Quality control}

\section{FRONTMUTE}

- The first break (onset of energy) of every channel in a seismic recording normally originates from a seismic refraction, which has usually strong amplitudes. During the processing of the data these events would interfere with the later incoming seismic reflections and contaminate the final seismic image. Therefore, in every shotgather, an upper limit is defined above which all amplitudes are set to zero. This, so called front mute process, is applied with the SMUTE module within the processing sequence. Choosing the limit is often a compromise between keeping seismic reflections and removing seismic refractions. This is, because especially for larger offsets, the shallow reflection events overlap or merge with the refraction arrivals.

- Sometimes traces within the shotgathers are contaminated by strong random noise, or did not record any coherent signal. This could be caused by a localised noise source, a badly or not connected geophone, or a badly placed geophone. The only solution is often to mute such channels. Identification of theses traces is done by eye or with the AREAL tool, which outputs the mean amplitude for every channel recorded. The discovered 'bad' or 'dead' traces are then removed with the TREDIT module.

- For some processed datasets the groundroll was so strong that attempts to remove it with filtering and other processing sequences (see section A.1.2.4) did not succeed. Thus, it was necessary to apply a surgical mute to remove the groundroll, which also removes some desired signal within it. For every shotgather a polygon was designed, which masked all of the groundroll, and then applied using the POLYMUTE processing module. 


\section{A.1.2.4 Filtering}

- Frequency filtering: A seismic energy source, as well as most coherent noise sources, consists of energy with a certain frequency characteristic. This can be used to filter noise from the signal in the frequency domain (fd). If the frequency bands do not overlap, a complete removal of the noise without interference with signal can be achieved. However, if they overlap filtering of the noise also eliminates some energy of the seismic signal. An fd-filter can be designed as a low-pass (cuts out high frequencies), high-pass (cuts out low frequencies) or band-pass (cuts out high and low frequencies) filter. The designed filters have to be tapered to minimise the effect of the Gibbs phenomena, which is a 'ringing' in the time-domain data, after an inverse Fourier transform from the frequency domain [Mamdouh, 2004]. Thus, a band-pass filter (mostly used in this study) has to be described by four values: the upper and lower frequency and the width of the two linear tapers. A rule of thumb for the taper says that its width should be at least 25-30\% of the cut-off frequency. This filter is realized within the Claritas ${ }^{T M}$ FDFILT module [Yilmaz, 1987].

Butterworth is another Claritas ${ }^{T M}$ module which also represents a filter in the frequency domain, but the taper is a bell-shaped sine-square function and not just a linear function like in the FDFILT module [Mamdouh, 2004].

- Frequency-wavenumber (f-k) filtering: This approach allows to remove certain types of unwanted energy, especially ground roll, guided waves and side scattered energy. Normally, these types of noise are located in different segments of the fk-domain than the reflection energy and can therefore be eliminated. The transition from the time-offset (tx)-domain into the fk-domain is done by a 2-D Fourier transform [Yilmaz, 1987]. Within Claritas $^{T M}$, the transformation as well as the filtering is realized by the $F K-$ FILT processing module.

\section{A.1.2.5 Compensation for attenuation}

- SPHDIV (Claritas ${ }^{T M}$ module): The amplitude of a seismic wave decays with the distance from the point of origin, called geometrical spreading. Additionally the energy attenuates due to dissipation when travelling through different layers. These effects can be corrected for within Claritas ${ }^{T M}$ by a semi-empirical process, which multiplies each sample of the trace by a scalar. This scalar is described by the following equation:

$$
G(t)=V(t)^{V_{\text {power }}} \cdot t^{T_{\text {power }}} \cdot e^{(V(t) t \alpha)} \cdot x^{X_{\text {power }}}
$$

The power parameters $\left(V_{\text {power }}, T_{\text {power }}, \alpha, X_{\text {power }}\right)$ are chosen by empirical tests, where parameters are varied to find the ones which recover the seismic am- 
plitudes most sufficiently. $V(t)$ is the normal moveout velocity (NMO). The default values, used for almost all datasets in this study, are a $V_{\text {power }}$ of 2 and a $T_{\text {power }}$ of 1 . Both other parameters are normally set to zero, which eliminates the exponential term and source receiver offset $(x)$ dependency of the equation.

- BALANCE (Claritas ${ }^{T M}$ module) is a processing module which scales traces so that the average amplitude of the output traces is constant for all traces within the gather. In a gather which is not corrected for spherical divergence, the near offset traces have normally a higher amplitude and would dominate in the stacked section. Therefore, trace balancing is necessary before stacking the data and often assists the SPHDIV module.

- Automatic gain control (AGC, Claritas ${ }^{T M}$ module) multiplies each sample with a scalar. This scalar is determined so that the average amplitude within a chosen time window, centred on the sample, is constant down the entire trace. This process is non-linear and destroys all relative amplitude information. Like the BALANCE module, it can also assist the SPHDIV module and is often used for interim on-screen assessment of shotgathers.

\section{A.1.2.6 Deconvolution}

In theory, a noise free seismogram can be described as the convolution of the seismic source wavelet and the impulse response of the rock sequence [Buttkus, 2000]. Thus, with deconvolution it is possible to extract the impulse response under the assumption of knowing the source wavelet. Predictive deconvolution is a more complex process. It attempts to remove the predictable part of a real seismogram which is the seismic wavelet, as well as the multiples and reverberations, but not the random sequence of signal arrivals. Within Claritas ${ }^{T M}$, a one-sided Wiener predictive deconvolution algorithm is used, which can optionally be gapped (DECONW, Claritas ${ }^{T M}$ module). In this module, a design window has to be chosen, which should contain a strong reflection and all reverberations of it. The prediction lag (or operator gap) is the time in the future where the seismogram is predicted. Practically, this value influences the spectrum of the output and with an increasing gap length the output spectrum gets narrower. As a rule of thumb, the operator gap should be approximately the length of the second zero crossing of the autocorrelation of the data. The window over which the filter is applied is chosen with the 'application gate' parameter in the DECONW module.

The optimum values are established by try and error with the aim to achieve the clearest, sharpest reflection event and the best removal of multiples. 


\section{A.1.2.7 Static correction}

For most seismic onshore acquisitions it is necessary to correct the traveltimes for the effect of irregular topography and the weathering layer. The weathering layer is a low-velocity zone (between $500 \mathrm{~m} / \mathrm{s}$ and $800 \mathrm{~m} / \mathrm{s}$ ), which can vary rapidly in the lateral and vertical direction [Cox, 1999]. It can be between a few centimetres and $\sim 50 \mathrm{~m}$ thick. The aim of static correction is to adjust the traveltimes as they would be observed from shot and receivers deployed on a flat datum underneath the weathering layer. This is done in different steps:

- Floating datum and horizontal reference datum: The elevation static correction, the moving of shot and receiver onto the horizontal datum, has to be split. In the first step, they get placed on a so called floating datum, which is a smoothed version of the topography. In the second step, after the normal moveout correction (see section A.1.2.8) and before the stack, they move further onto the horizontal reference datum. This is necessary because a too large datum correction would result in a deviation of the reflection traveltimes from a hyperbolic relationship [Profeta \& Koremblit, 1995].

- Refraction statics: For the actual shift onto a horizontal datum plane, the knowledge of the near surface velocity model is required. This is because the assumption of a single near surface layer with a constant velocity is often insufficient. The estimation of this model can be done using refraction arrivals. Claritas ${ }^{T M}$ provides an interactive tool (refstat), which, after picking the first breaks in the shotgathers, calculates iteratively the best fitting 2-D shallow velocity model and the corresponding static corrections.

- Residual statics: The datum static correction is done under many assumptions and mainly considers long wavelength irregularities. Small errors, neglected or introduced by the datum correction, have to be removed by the residual static correction process. A correction term for every shot and receiver location has to be calculated.

Therefore, a pilot-trace (stacked CDP gather, see section A.1.2.11) is produced and cross-correlated with every trace within the normal moveout corrected receiver and shotgathers, respectively. All traces are then adjusted with the corresponding shot and receiver residual values. Afterwards, a new velocity analysis is performed, a new pilot-trace is calculated and the crosscorrelation can be redone. This iterative process is done till the residual values fall below a certain threshold or a certain number of iteration is completed. The residual static values are estimated within Claritas ${ }^{T M}$ using the SPSTAT tool. It is usually done just before the CDP-sorting, the NMOcorrection and the stack of the CDP-gathers (see section A.1.2.11)

All static timeshifts calculated are added to the data and written into the headers using the STATIC processing module. 


\section{A.1.2.8 Velocity analysis}

The traveltime for a ray with an offset between source and receiver is larger than the traveltime for a zero-offset ray which is reflected at the same point in depth. This is because the wave has to travel a horizontal distance to the point at depth, additional to the way down and up. Thus, the traveltime of a flat reflector in the tx-domain can be described as a polynomial, which depends on the distance (offset-x) between source and receiver, the two-way zero offset traveltime $\left(t_{0}\right)$ and the velocity above the reflector $(V)$. The difference between the two-way traveltime, at any given geophone location, and the zero-offset traveltime is called normal moveout $(\delta t)$

$$
\delta t \approx \frac{x^{2}}{2 V^{2} t_{0}}
$$

This equation forms the basis of the velocity analysis. The velocity above the reflector can be determined with known offset and known zero-offset two-way traveltime. In practice, the correction is tested with different velocities. The one which corrects best for the normal moveout represents the so called stacking velocity. In a horizontal, multi-layered case, the stacking velocity will be equal to the root-mean-square (RMS) velocity of the layer sequence above

$$
V_{R M S}=\left[\sum\left(V_{i n t . i}^{2} t_{i n t . i}\right) / \sum_{i} t_{i n t . i}\right]^{1 / 2}
$$

where $V_{\text {int. } i}$ is the corresponding seismic interval velocity to every layer and $t_{\text {int.i }}$ the zero-offset two-way traveltime within it. This leads to the so called Dix equation, which calculates the interval velocity based on stacking velocity established during velocity analysis

$$
V_{\text {int.n }}=\left[\frac{V_{R M S . n}^{2} t_{n}-V_{R M S . n-1}^{2} t_{n-1}}{t_{n}-t_{n-1}}\right]^{1 / 2},
$$

where $V_{\text {int.n }}$ is the interval velocity over the $n$th interval and $V_{R M S . n}, V_{R M S . n-1}, t_{n}$ and $t_{n-1}$ are the RMS velocities and zero offset traveltimes to the $n$th and $n-1$ th reflector, respectively.

Claritas $^{T M}$ stand alone application for the velocity analysis, called CVA, includes different methods to perform a velocity analysis:

- CVS performs a real-time stacking velocity analysis. The user chooses a range of velocities and the application calculates the corresponding constant velocities stacks. A manual assessment decides which velocity results in the clearest, highest amplitude event for the investigated target. 
- CVG performs a velocity analysis on CDP gathers (see section A.1.2.11). The user chooses the velocity which creates the 'flattest' seismic events within the gather.

- SEMBLANCE performs an automatic or semi-automatic velocity analysis, using a semblance calculation, within CDP-gathers.

The main part of the velocity analysis for the datasets in this thesis, is done using the CVS tool. However, all velocities are checked using the other two tools. Knowledge of the velocity field is necessary for many processing steps (e.g. correction for spherical divergence, residual static correction) within the processing sequence. Therefore, the velocity model has to be analysed at different stages of the processing and eventually updated for the earlier steps. For most datasets up to four velocity analyses were performed.

\section{A.1.2.9 Dip moveout (DMO) correction}

The description of the NMO term in section A.1.2.8 is only valid for flat reflectors. In case of a dipping reflector the two-way traveltime also depends on the dip of the reflector $(\alpha)$. Dipping reflectors can create the so called conflicting dip problem in the time-domain, where a flat event intersects with a dipping event. Without dip moveout (DMO) correction both events cannot be preserved. The $\mathrm{DMO}$ correction is performed on a NMO corrected shotgathers, using flat event horizons. The theory of the DMO correction is complex and is not discussed here in more detail. In Claritas ${ }^{T M}$, an initial dip independent moveout correction is applied as a first step, followed by the dip moveout correction in the tx-domain using the DMO_TX module (default parameters are used). Finally, the initial NMO correction is removed and a new velocity analysis is performed.

\section{A.1.2.10 Migration}

Migration is a process which moves dipping reflector to their true position in the time-domain and collapses diffraction hyperbola to their origin. It is aimed to create a stacked section which is similar to a geological cross-section and in which a direct statement can be made about the dip and structure of layers. Migration is preferred to be done in the time-depth-domain, mainly for two reasons: (1) the general inaccuracy in the velocity models needed for a depth migration; (2) to be able to compare the migrated section with the unmigrated section. However, time migration can only be used if lateral velocity inhomogeneities are not to strong. There are a number of different migration approaches. Within this study two prestack time migration methods were applied or tested for the data presented:

- FDMIG-Claritas ${ }^{T M}$ module: Is a finite difference time migration routine. It is developed for dip angles not much larger than $45^{\circ}$. Velocities can vary 
laterally and with depth and no NMO correction needs to be applied before the migration.

- STOLT -Claritas ${ }^{T M}$ module: Is a generalised Stolt migration in the fkdomain. It allows, in comparison to the 'classic' Stolt migration, a velocity variation with depth.

For this migration, the data from the time-domain are transformed into the fk-domain. Then, the frequency is translated to vertical wavenumber before a scaling factor is applied (Gadallah \& Fisher [2004]). Finally, an inverse Fourier transform back into the time-domain is conducted.

This method is one of the fastest methods, but does not allow lateral velocity changes. As an input, a velocity function as a function of time has to be given and the traces need to be NMO corrected before the migration can be applied. However, it is significant faster than the FDMIG routine.

\section{A.1.2.11 Stacking}

The aim of seismic reflection processing is to create a so-called stacked section, which is similar to a zero-offset section but with a higher signal-to-noise ratio. Therefore, all recorded traces have to be first sorted into so-called common mid point (CMP) or, in case of dipping reflectors, into common depth point (CDP) gathers, which contain all traces reflected from the same point at depth. The number of traces within a gather is called 'seismic fold'. After sorting, the gathers are normal moveout corrected and finally, all traces within a CDP or CMP gather are summed (stacked) to a single trace, which shows the same traveltime for the reflection as a zero-offset trace would.

The sorting of the traces in Claritas ${ }^{T M}$ is done using the CDPSORT module. It needs the geometry file as input, which contains all location information created with the geometry application (see section A.1.2.2). The stacking is done with the STACK module, which does not need any additional input and is used with the default values.

\section{A.1.2.12 Post-stack enhancement}

These are processes which are applied after stacking to remove remaining noise or introduced noise due to processing artefacts. Furthermore, some processes can enhance the amplitude and coherency of seismic event. The applied or tested modules are

- BUTTERFILT (Claritas ${ }^{T M}$ module): A Butterworth filter in the time-domain, identical to the module used pre-stack (see section A.1.2.4) 
- QFKPS: A filter in the fk-domain similar to the module used pre-stack (see section A.1.2.4)

- FXDECON: A deconvolution in the frequency-domain, which uses a complex Wiener deconvolution algorithm. It is mainly used to remove random noise.

\section{A.1.3 Processing parameters}

This section presents the seismic processing parameters used for the datasets presented in chapter 3 . The standard processing sequence is shown in figure A.2. If special processing techniques are necessary they will be mentioned for the particular datasets.

\section{A.1.3.1 Waikanae survey}

All three sub-datasets of the Waikanae survey (chapter 3.2) are processed separately and dataset Peka-main and Peka-west are merged post-stack. A pre-stack merge was not possible due to the different source characteristics of the used seismic signal sources. Theoretically, it is possible to phase match different datasets [Pritchett, 1990], but that could not be achieved with this dataset because the wavelets could not be estimated accurately enough. For the post-stack merge the amplitudes of both stacked datasets are matched by using the amplitude decay curve. To get a smooth transition from one dataset to another, the amplitudes of the overlapping part are scaled so that the central section of the overlapping part in the final stack consists of $50 \%$ of each dataset, increasing from the middle to the sides.

Peka-main The main dataset was processed with the standard processing sequence (figure A.2). The dataset (see example shotgather in figure A.3) contains a strong $\sim 50 \mathrm{~Hz}$ noise signal, which is most likely to be induced by electric fences and power lines in the vicinity. Therefore, a second bandpass filter (for details see below) is necessary. The post-stack processing for line Peka-main and Peka-west is done after the merge, to get a better transition between the two datasets.

The following list summarises all processing parameters for this dataset.

$\longrightarrow$ pre-stack processing

- resample: from $1 \mathrm{~ms}$ to $2 \mathrm{~ms}$ sampling interval

- elevation static correction: with a datum height of $40 \mathrm{~m}$ and a replacement velocity of $1600 \mathrm{~m} / \mathrm{s}$ to floating datum 


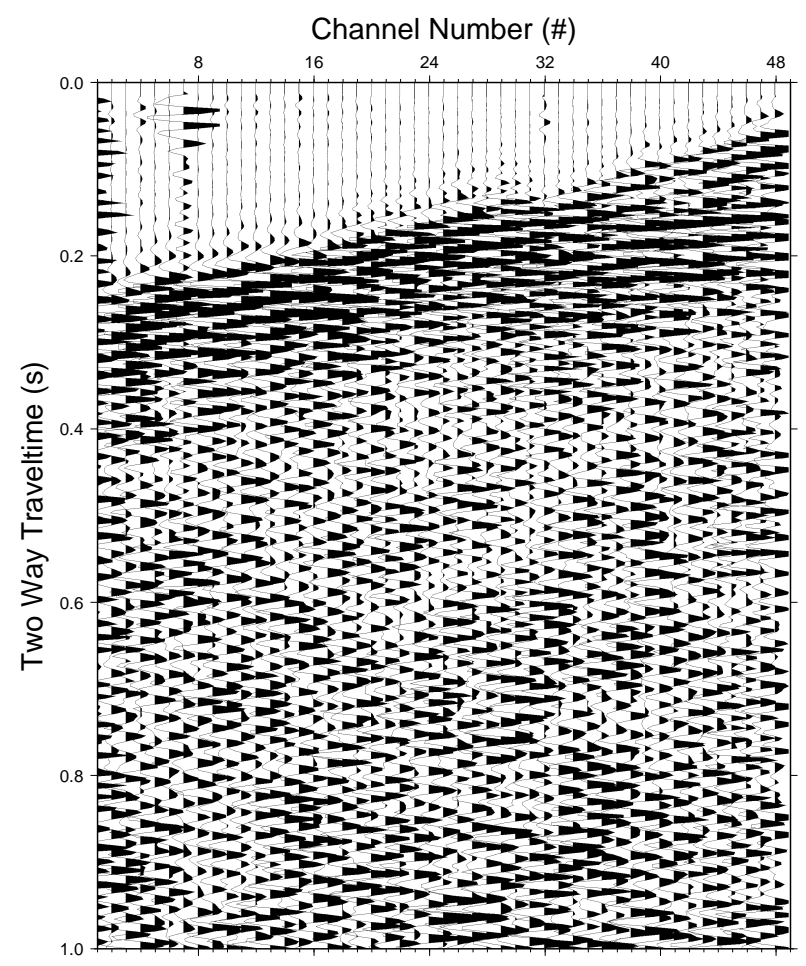

Figure A.3: Raw shotgather (shotid 75) from the Peka-main profile. This shotgather shows a clear first arrival and reflections between a two-way traveltime between 150 and 300 ms. Later reflections can not be identified on the raw shotgather.

- bandpass frequency-filtering: BS (40-45-55-60 Hz) and zero-phase Butterworth filter (20-30-90-110)

- spherical divergence compensation: $V^{2} * T^{1}$

- fk-filtering: cut-off dip $=20$, taper $=0.75$

- bad trace and spike edit

- Wiener predictive deconvolution: operator length $=110$, gap $=24$

- automatic gain control: time gate $=200 \mathrm{~ms}$

- trace balance

- residual static corrections: 2 iterations

- common midpoint sort: nominal CDP fold $=10$

- normal moveout correction

- dip moveout correction

- time migration 
- final elevation statics

- common midpoint stack

$\longrightarrow$ post-stack processing of line Peka-main and Peka-west done after merge

- post-stack bandpass frequency-filtering: BS (20-30-100-150)

- post-stack fk-filtering: cut-off dip $=16$

- post-stack fx-deconvolution: filterlength in traces $=19$, time window length $=100$, window-overlap $=20$

Peka-west For the used shot geometry, with a small minimum offset (see table 3.1), high-amplitude groundroll cuts through the crucial time window of the shotgathers (see example shotgather in figure A.4). Therefore, a surgical mute had to be applied to the raw shotgather. This improves the signal-to-noise ratio of the final stack. Tests with other processing methods to eliminate the ground roll from the desired signal information (e.g. additional fk-filtering) did not lead to satisfactory results. Because the frequency band of the hydraulic thumper is not as wide as for the explosives, an additional filter to eliminate the electrical noise is not necessary.

The following list summarises all processing parameters for this dataset.

$\longrightarrow$ pre-stack processing:

- resample: from $1 \mathrm{~ms}$ to $2 \mathrm{~ms}$ sampling interval

- elevation static correction: with a datum height of $40 \mathrm{~m}$ and a replacement velocity of $1600 \mathrm{~m} / \mathrm{s}$ to floating datum

- airwave removal: for a velocity of $200 \mathrm{~m} / \mathrm{s}$

- muting of groundroll

- bandpass frequency-filtering: zero-phase Butterworth filter (50-70-120140)

- spherical divergence compensation: scalar scaling $=0$ at $0 \mathrm{~ms}, 200$ at $1000 \mathrm{~ms}$

- fk-filtering: cut-off inside defined polygon

- bad trace and spike edit

- Wiener predictive deconvolution: operator length $=100$, gap $=16$

- automatic gain control: time gate $=498 \mathrm{~ms}$

- trace balance

- residual static corrections: 2 iterations 


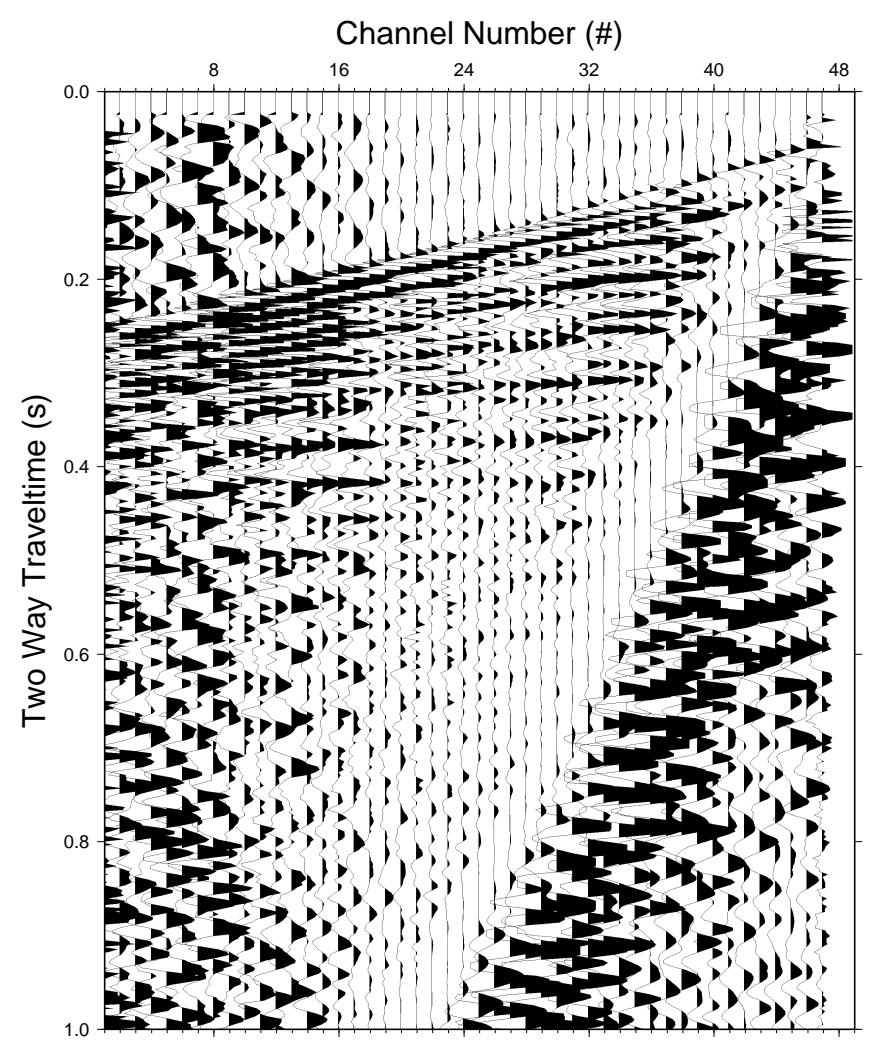

Figure A.4: Raw shotgather (shotid 69) from the Peka-west profile. This shotgather also shows a clear first arrival and clear reflections down to a two-way traveltime of $450 \mathrm{~ms}$. Strong ground roll can be observed for channels 24-48.

- common midpoint sort: nominal CDP fold $=22$

- normal moveout correction

- dip moveout correction

- time migration

- final elevation statics

- common midpoint stack

$\longrightarrow$ post-stack processing of line Peka-main and Peka-west done after merge

- post-stack bandpass frequency-filtering: BS (20-30-100-150)

- post-stack fk-filtering: cut-off dip $=16$

- post-stack fx-deconvolution: filterlength in traces $=19$, time window length $=100$, window-overlap $=20$ 


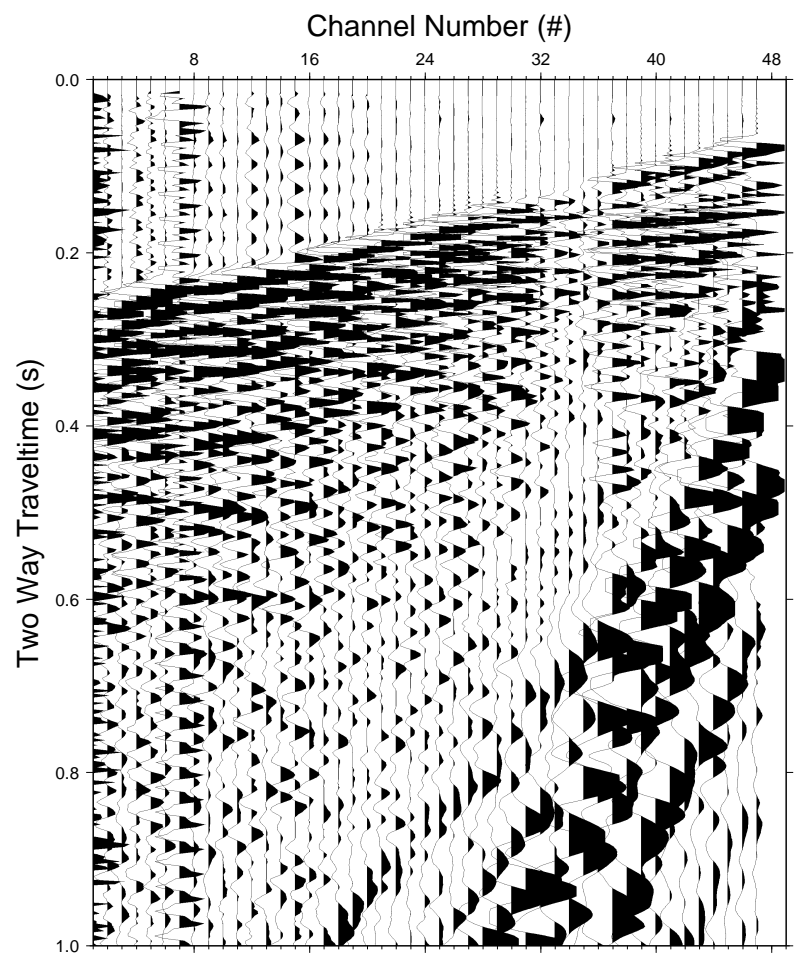

Figure A.5: Raw shotgather (shotid 19) from the Peka-east profile. This shotgather also shows a clear first arrival and reflections down to a two-way traveltime of $380 \mathrm{~ms}$. Ground roll can be observed for channels 24-48.

Peka-east The processing for the Peka-east dataset is similar to the Peka-main sequence due to the same seismic signal source and the similar subsurface conditions (see example shotgather in figure A.5). However, the datum height for the elevation static correction has to be raised due to higher topography along the profile and the replacement velocity is increased based on seismic refraction results (see section 3.2.4).

The following list summarises all processing parameters for this dataset.

$\longrightarrow$ pre-stack processing:

- resample: from $1 \mathrm{~ms}$ to $2 \mathrm{~ms}$ sampling interval

- elevation static correction: with a datum height of $150 \mathrm{~m}$ and a replacement velocity of $1800 \mathrm{~m} / \mathrm{s}$ to floating datum

- bandpass frequency-filtering: BS (10-30-90-120), BS (40-45-55-70)

- spherical divergence compensation: $V^{2} * T^{1}$

- fk-filtering: cut-off dip $=20$, taper $=0.75$

- bad trace and spike edit 
- Wiener predictive deconvolution: operator length $=110$, gap $=24$

- automatic gain control: time gate $=498 \mathrm{~ms}$

- trace balance

- residual static corrections: 2 iterations

- common midpoint sort: nominal CDP fold $=6$

- normal moveout correction

- dip moveout correction

- time migration

- final elevation statics

- common midpoint stack

$\longrightarrow$ post-stack processing:

- post-stack bandpass frequency-filtering: BS (20-30-100-150)

- post-stack fk-filtering: cut-off dip $=16$

- post-stack fx-deconvolution: filterlength in traces $=19$, time window length $=100$, window-overlap $=20$

\section{A.1.3.2 Waikawa survey}

Seismic reflection processing of the Waikawa reflection survey was performed with the standard processing sequence (figure A.2). An example for an raw shotgather is shown in figure A.6.

The following list summarises the processing parameters.

$\longrightarrow$ pre-stack processing

- resample: from $1 \mathrm{~ms}$ to $2 \mathrm{~ms}$ sampling interval

- elevation static correction: with a datum height of $20 \mathrm{~m}$ and a replacement velocity of $1500 \mathrm{~m} / \mathrm{s}$ to floating datum

- bandpass frequency-filtering: zero-phase Butterworth filter (45-65-140170)

- spherical divergence compensation: $V^{2} * T^{1}$

- fk-filtering: cut-off dip $=10$, taper $=0.75$

- bad trace and spike edit

- Wiener predictive deconvolution: operator length $=180$, gap $=24$ 


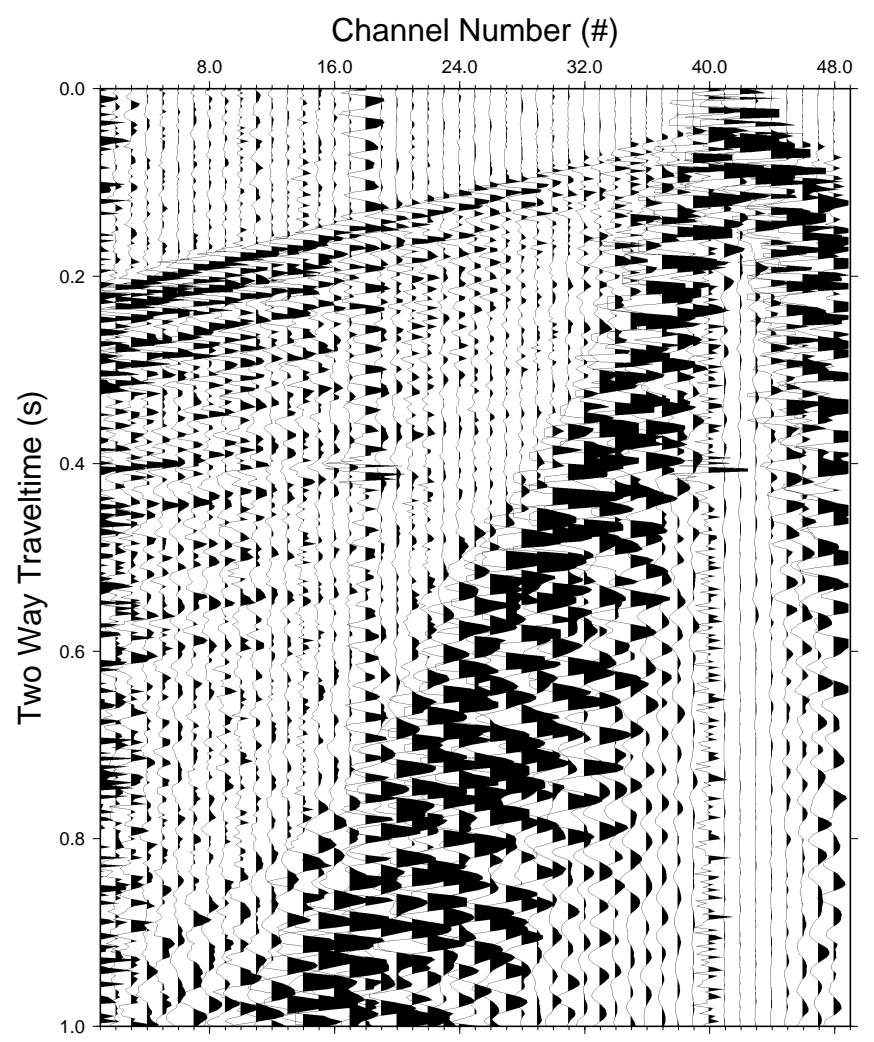

Figure A.6: Raw shotgather (shotid 52) from the Waikawa profile. This shotgather also shows a clear first arrival. Shallow reflection events are not as numerous as for the Waikanae reflection surveys. However, a clear deeper reflection can be observed at a two-way traveltime of $450 \mathrm{~ms}$. The shotgather has split-spread geometry and contains a strong ground roll signal.

- automatic gain control: time gate $=498 \mathrm{~ms}$

- trace balance

- residual static corrections: 2 iterations

- common midpoint sort: nominal CDP fold = 11

- normal moveout correction

- dip moveout correction

- time migration

- final elevation statics

- common midpoint stack

$\longrightarrow$ post-stack processing 


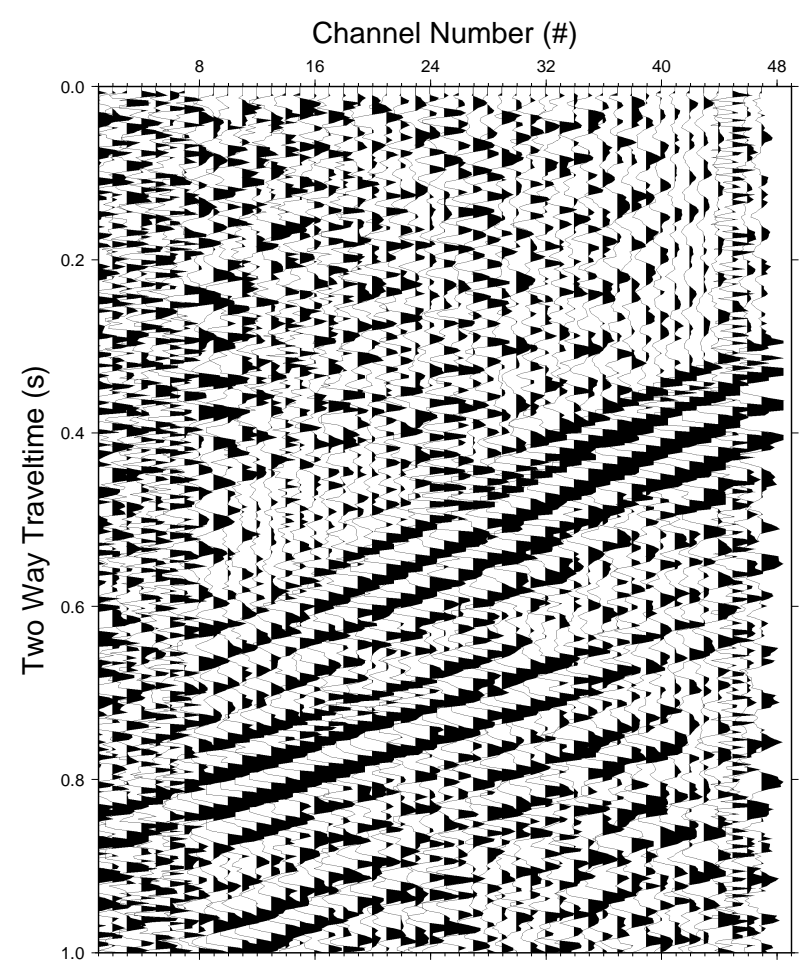

Figure A.7: Raw shotgather (shotid 3) from the Levin 301 profile. This shotgather shows no clear first arrival. However, it shows two strong reflection arrival bands at a two-way traveltime of 350-700 ms and 700-900 ms, respectively.

- post-stack bandpass frequency-filtering: BS (20-30-100-150)

- post-stack fk-filtering: cut-off dip $=16$

- post-stack fx-deconvolution: filterlength in traces $=19$, time window length $=100$, window-overlap $=20$

\section{A.1.3.3 Levin survey}

The sub datasets 301 and 302 of the Levin seismic reflection survey got merged pre-stack and then processed as one line. This was possible because of the same seismic source with the same amplitude and frequency characteristic. Line 303 got processed separately.

Levin 301\&302 Processing of the main dataset was done with the standard processing sequence (figure A.2). The datasets contain no problems which would require special processing treatment (see example shotgather in figure A.7). As mentioned earlier, the merge of the two datasets was done pre-stack. 
The following list summarises the processing parameters.

$\longrightarrow$ pre-stack processing

- resample: from $1 \mathrm{~ms}$ to $2 \mathrm{~ms}$ sampling interval

- elevation static correction: with a datum height of $40 \mathrm{~m}$ and a replacement velocity of $1600 \mathrm{~m} / \mathrm{s}$ to floating datum

- bandpass frequency-filtering: zero-phase Butterworth filter (15-18-100120) (Levin 301)

- bandpass frequency-filtering: zero-phase Butterworth filter (10-30-80-100) (Levin 302)

- spherical divergence compensation: $V^{2} * T^{1}$

- fk-filtering: cut-off dip $=10$, taper $=0.75$ (Levin 301)

- fk-filtering: cut-off dip =7, taper $=0.75$ (Levin 302)

- bad trace and spike edit

- Wiener predictive deconvolution: operator length $=100$, gap $=16$

- automatic gain control: time gate $=498 \mathrm{~ms}$

- trace balance

- residual static corrections: 2 iterations

- merge of the two dataset by adjusting the geometry input file

- common midpoint sort: nominal CDP fold $=24$

- normal moveout correction

- dip moveout correction

- time migration

- final elevation statics

- common midpoint stack

$\longrightarrow$ post-stack processing

- post-stack bandpass frequency-filtering: BS (20-30-100-150)

- post-stack fk-filtering: cut-off dip $=16$

- post-stack fx-deconvolution: filterlength in traces $=19$, time window length $=100$, window-overlap $=20$ 


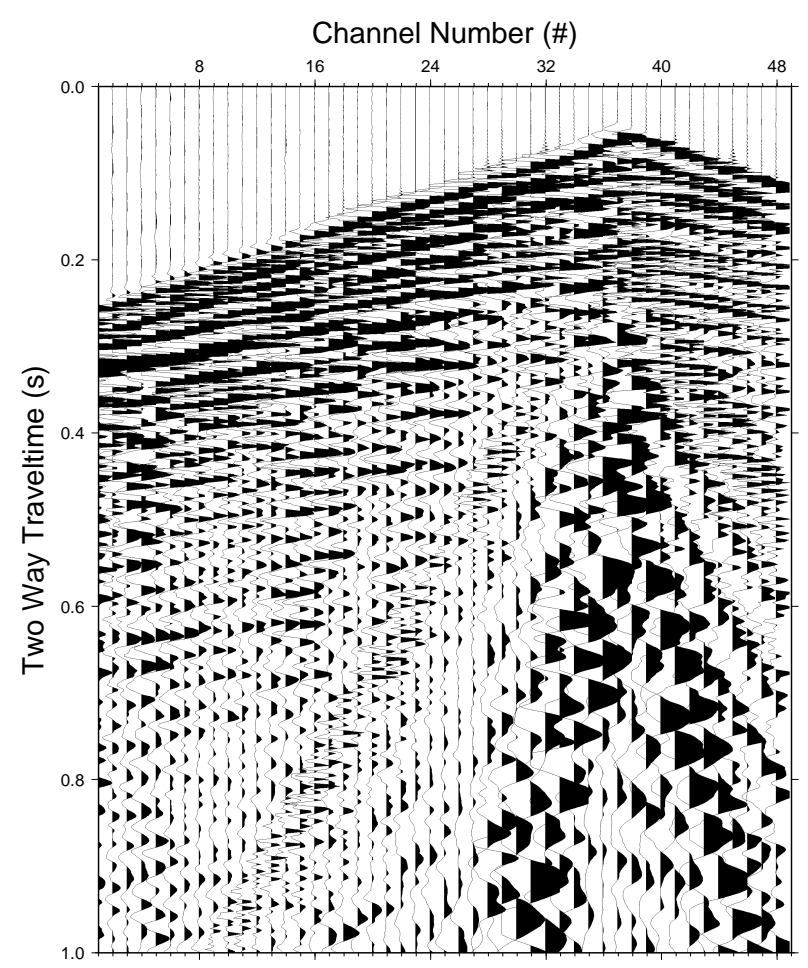

Figure A.8: Raw shotgather (shotid 113) from the Levin 303 profile. This shotgather also shows a clear first arrival and very clear reflection events down to a two-way traveltime of $700 \mathrm{~ms}$. The geometry for this shotgather was spilt-spread and ground roll can be observed for channels 24-48. This shotgather has the best signal to noise ratio of all shotgather presented in this chapter.

Levin 303 For line 303 the same standard processing sequence is used as for line 301\&302. However, the seismic source signal is of different characteristic than for the other two datasets and therefore different processing parameters needed to be applied (see example shotgather in figure A.8).

The following list summarises them.

$\longrightarrow$ pre-stack processing

- resample: from $1 \mathrm{~ms}$ to $2 \mathrm{~ms}$ sampling interval

- elevation static correction: with a datum height of $40 \mathrm{~m}$ and a replacement velocity of $1600 \mathrm{~m} / \mathrm{s}$ to floating datum

- bandpass frequency-filtering: zero-phase Butterworth filter (10-20-90-120)

- spherical divergence compensation: $V^{2} * T^{1}$

- fk-filtering: cut-off dip $=10$, taper $=0.75$

- bad trace and spike edit 
- Wiener predictive deconvolution: operator length $=170$, gap $=16$

- automatic gain control: time gate $=498 \mathrm{~ms}$

- trace balance

- residual static corrections: 2 iterations

- common midpoint sort: nominal CDP fold $=10$

- normal moveout correction

- dip moveout correction

- time migration

- final elevation statics

- common midpoint stack

$\longrightarrow$ post-stack processing

- post-stack bandpass frequency-filtering: BS (20-30-100-150)

- post-stack fk-filtering: cut-off dip $=16$

- post-stack fx-deconvolution: filterlength in traces $=19$, time window length $=100$, window-overlap $=20$

\section{A.1.3.4 Foxton survey}

The main difference in the processing of the two sub datasets of Foxton seismic reflection survey is a surgical polymute which is applied to dataset Foxton06 in order to remove the strong ground roll. However, this also eliminates the desired signal energy within the ground-roll, but tests with different $\mathrm{fk}$ and fd filtering techniques showed that this "harsh" approach produces the best signal-to-noise ratio for the final stack section. Both datasets contain a strong $50 \mathrm{~Hz}$ noise signal (see example shotgather in figure A.9). Only one standard bandpass filter was necessary because the main frequency contents of the hydraulic thumper lies above $50 \mathrm{~Hz}$. Furthermore, the datasets were merged pre-stack, because they have the same seismic source, with the same amplitude and frequency characteristic.

The following list summarises the processing parameters.

$\longrightarrow$ pre-stack processing

- resample: from $1 \mathrm{~ms}$ to $2 \mathrm{~ms}$ sampling interval

- elevation static correction: with a datum height of $50 \mathrm{~m}$ and a replacement velocity of $1700 \mathrm{~m} / \mathrm{s}$ to floating datum 


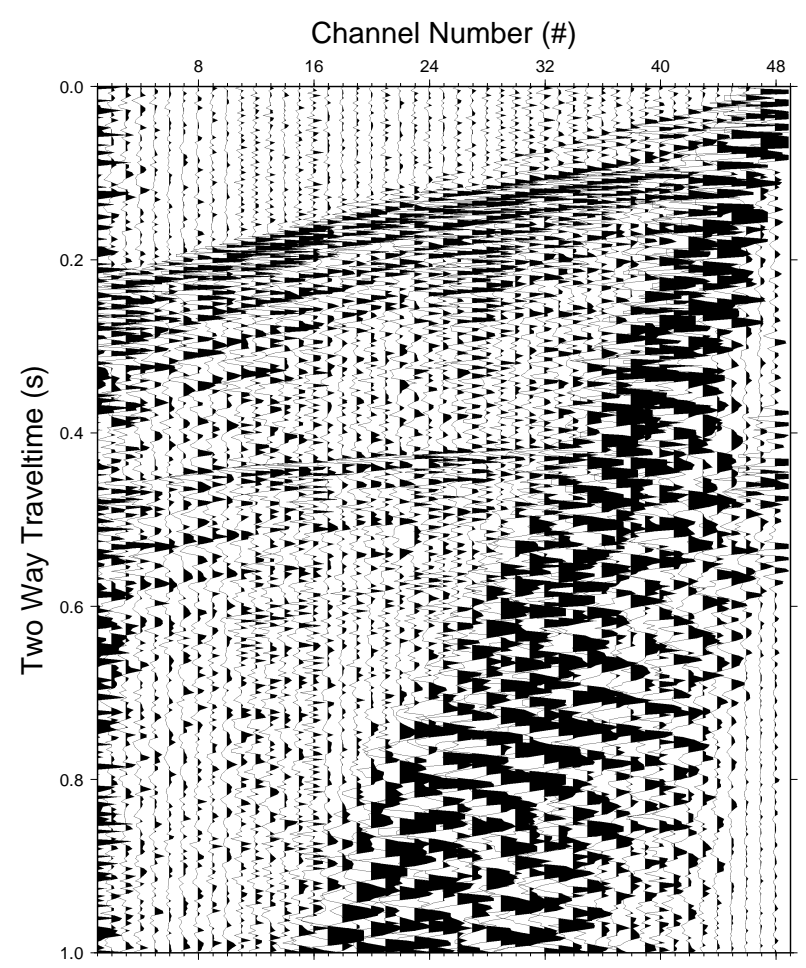

Figure A.9: Raw shotgather (shotid 173) from the Foxton profile. This shotgather shows a clear first arrival and strong band of shallow reflections (two-way traveltime between 100-300 ms. Furthermore, a strong reflection event is visible at a two-way traveltime of $450 \mathrm{~ms}$. Strong ground roll can be observed for channels $16-48$.

- bandpass frequency-filtering: zero-phase Butterworth filter (52-70-120140)

- spherical divergence compensation: $V^{2} * T^{1}$

- fk-filtering: cut-off dip $=10$, taper $=0.75$ (

- surgical poly-mute individual for every shotgather (Foxton06)

- bad trace and spike edit

- Wiener predictive deconvolution: operator length $=100$, gap $=16$

- automatic gain control: time gate $=498 \mathrm{~ms}$

- trace balance

- residual static corrections: 2 iterations

- merge of the two dataset by adjusting the geometry input file

- common midpoint sort: nominal CDP fold $=12$ 
- normal moveout correction

- dip moveout correction

- time migration

- final elevation statics

- common midpoint stack

$\longrightarrow$ post-stack processing

- post-stack bandpass frequency-filtering: BS (20-30-100-150)

- post-stack fk-filtering: cut-off dip $=16$

- post-stack fx-deconvolution: filterlength in traces $=19$, time window length $=100$, window-overlap $=20$

\section{A.2 Seismic refraction method}

\section{A.2.1 Theory}

A seismic ray which encounters a boundary between two layers with different elastic properties splits into different parts. Some of the energy of the ray is reflected and stays in the same layer. The other energy gets refracted into the adjoining medium according to Snell's law (see Figure A.10)

$$
\frac{\sin \theta_{1}}{\sin \theta_{2}}=\frac{V_{1}}{V_{2}}
$$

where the ratio of incident angle $\theta_{1}$ to the refracted angle $\theta_{2}$ is equal to the ratio of the velocities of the two media $V_{1}$ and $V_{2}$. As long as $V_{2}$ is greater than $V_{1}$, which means applied to a geological setting, as long as the velocity increases with depth, the ray is refracted away from the interface normal. For a certain incident angle, called critical angel $\left(\theta_{c}\right)$, the refracted angle becomes $90^{\circ}$. From equation A.5 follows

$$
\sin \theta_{c}=\frac{V_{1}}{V_{2}}
$$

An under the critical angle incoming wave will propagate along the boundary between the two layers with the velocity of the lower medium. At every point along its travelpath it will emit a seismic wave under the critical angle. 


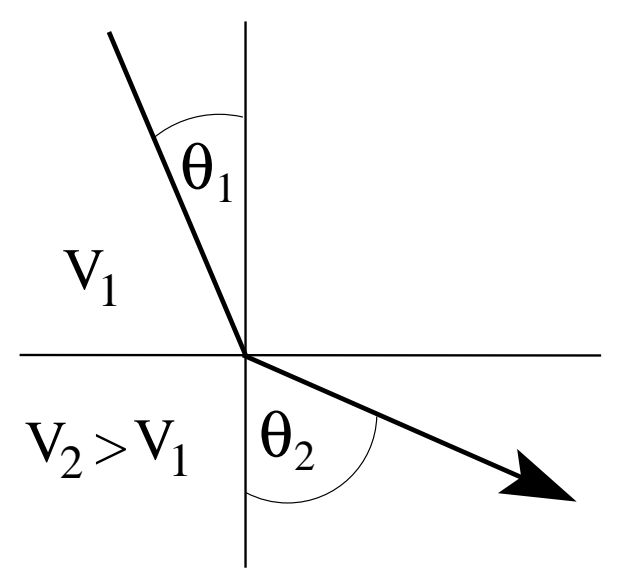

Figure A.10: Parameters of a seismic ray refracted into a medium with a higher velocity. The ratio between the sinus of the incident angle $\theta_{1}$ and refracted angle $\theta_{2}$ is equal to the ratio of the velocities of the two layers ( $V_{1}$ and $V_{2}$ ) (Snell's law).

\section{A.2.2 Intercept time analysis}

The most convenient way to represent refraction data is to plot the first-arrival time $t_{x}$ against the source-receiver distance $x$ (see figure A.11). In this plot, the refraction from a horizontal interface is represented by straight line, which has a slope of $1 / V_{2}$ and which intersects the $t_{x}$ axis $(x=0)$ at the so-called intercept time

$$
t_{1}=\frac{2 z_{1} \sqrt{V_{2}^{2}-V_{1}^{2}}}{V_{1} V_{2}} .
$$

The direct wave (which travels along the top of the upper layer) has a slope of $1 / V_{1}$ and an intercept time of zero. After the crossover distance (distance where the critically refracted waves precede the direct waves), the refracted arrivals will be the earliest events in the plot (first breaks).

Following from equation A.7, the thickness of the first layer $z_{1}$ can be calculated in terms of $t_{1}$ and the velocities $V_{1}$ and $V_{2}$

$$
z_{1}=\frac{t_{1}}{2} \frac{V_{1} V_{2}}{\sqrt{V_{2}^{2}-V_{1}^{2}}} .
$$

In case of a three layer situation (see figure A.12), after a certain distance, another refracted first arrival will be visible, with a slope of $1 / V_{3}$. The thickness of the second layer can be calculated as

$$
z_{2}=\frac{t_{2}}{2} \frac{V_{2} V_{3}}{\sqrt{V_{3}^{2}-V_{2}^{2}}}-z_{0} V_{2} \frac{\sqrt{V_{3}^{2}-V_{1}^{2}}}{\sqrt{V_{3}^{2}-V_{2}^{2}}},
$$




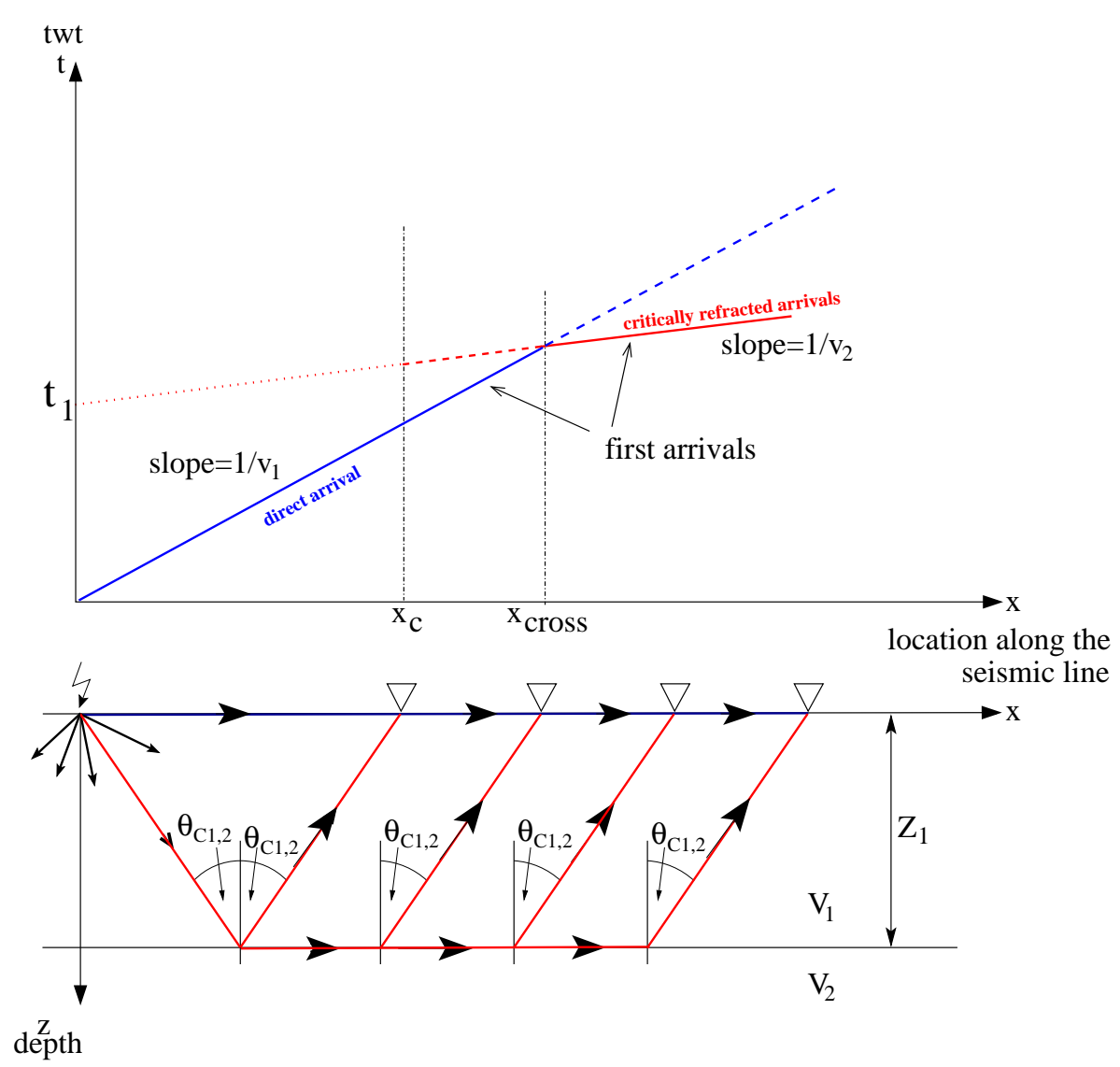

Figure A.11: Top: $t_{x}$ against $x$ plot of the traveltime curves of the refracted and the direct wave. Bottom: Refracted and direct rays in the corresponding twolayer model with a horizontal interface.

with $t_{2}$ being the intercept time for the second refractor.

When the refractor in the two-layer case has an angle of dip (see figure A.13), the geometry described so far gets more complex and in order to solve the problem a second shot is needed to be fired from the other direction into the same geophone array (reverse shot). The velocities found in the $t_{x}$ against $x$ plots are apparent velocities and will be higher when the receiver array is 'updip' relative to the shot and smaller when it is 'downdip' from the shot.

The dip of the refracting layer can be calculated using equation

$$
\gamma_{1}=\frac{1}{2}\left[\sin ^{-1}\left(\frac{V_{1}}{V_{2 d}}\right)-\sin ^{-1}\left(\frac{V_{1}}{V_{2 u}}\right)\right]
$$

where $\gamma_{1}$ is the dip of the layer, $V_{2 d}$ the apparent velocity shooting downdip and $V_{2 u}$ the updip velocity. 


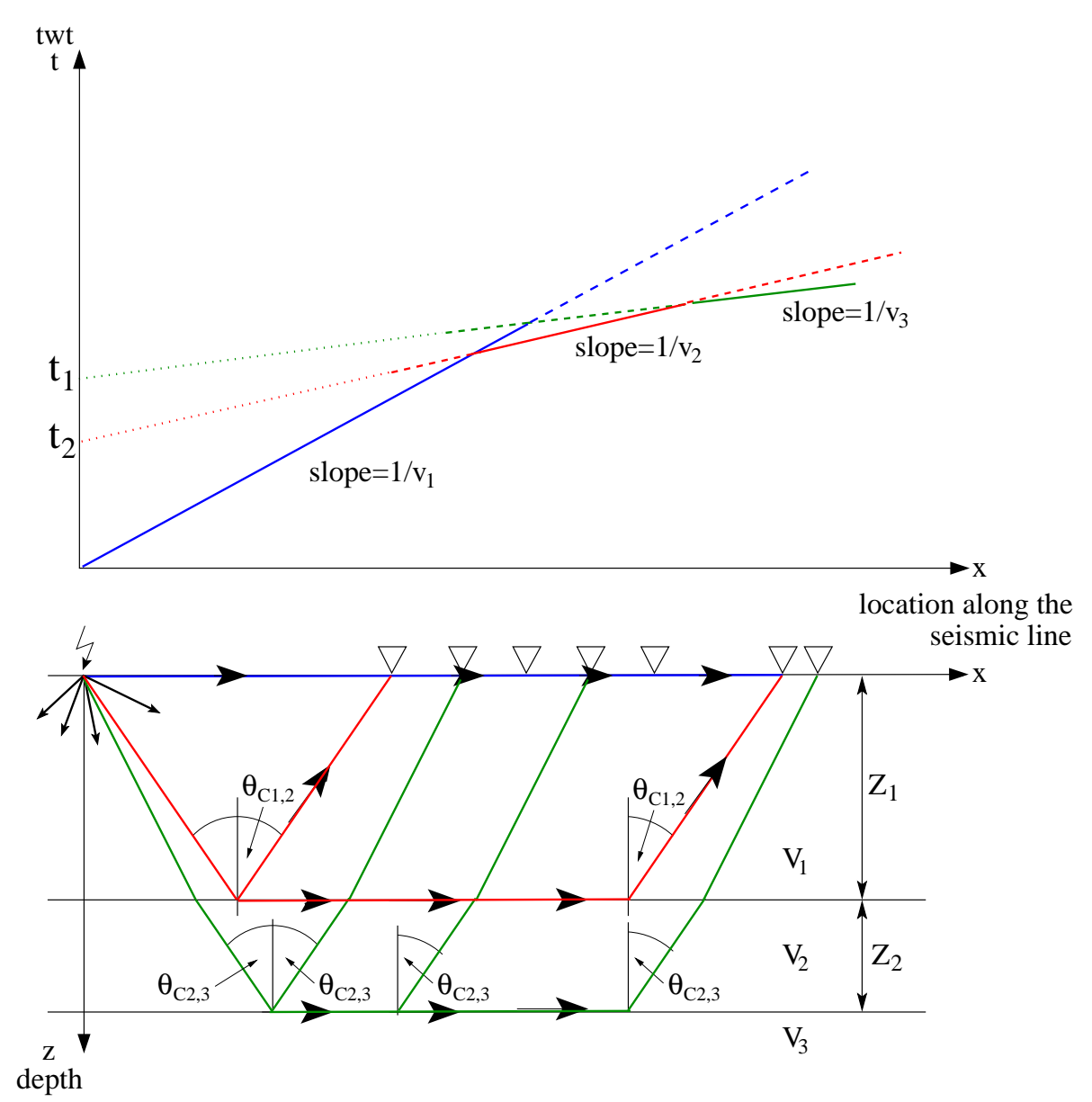

Figure A.12: Top: $t_{x}$ against $x$ plot of the traveltime curves of the two refracted waves and the one direct wave. Bottom: Refracted and direct rays in the corresponding three-layer model with horizontal interfaces.

The distances from the shotpoints down to the refractor are

$$
\begin{aligned}
& z_{A}=\frac{1}{2} t_{A} V_{1} \cos ^{-1}\left(\theta_{C 1,2}\right) \\
& z_{B}=\frac{1}{2} t_{B} V_{1} \cos ^{-1}\left(\theta_{C 1,2}\right)
\end{aligned}
$$

For shallow dip angles $\left(<10^{\circ}\right)$ the true velocity can be approximated to

$$
V_{2}=\frac{1}{2}\left(V_{d}+V_{u}\right)
$$

The last model discussed is the one of a step discontinuity along the refractor. Figure A.14 illustrates the problem and the different parameters. Assumed is a planar layer with a small discontinuity compared to the depth of the refractor. The height of the step $(\delta z)$ can be calculated to 


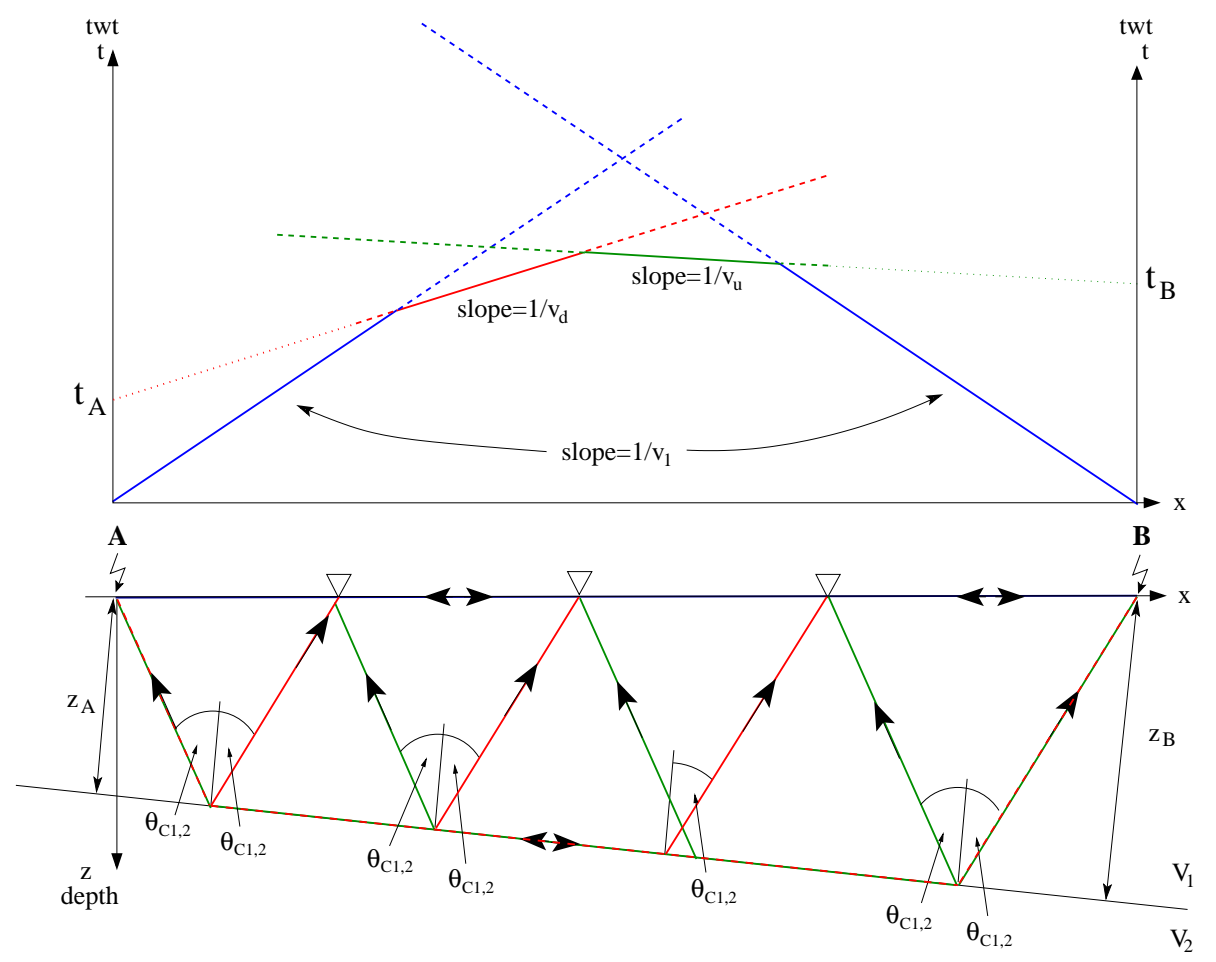

Figure A.13: Top: $t_{x}$ against $x$ plot of the traveltime curves of the refracted and the direct wave for both shots. Bottom: refracted and direct rays in the corresponding two-layer model with a dipping interface.

$$
\delta z=\delta t \frac{V_{1} V_{2}}{\sqrt{V_{2}^{2}-V_{1}^{2}}}
$$

with $\delta t$ being the observed difference in intercept time between the two straight lines with the same slope.

The methods presented in this section assume iso-velocity layers and an increase of velocity with depth. If the last assumption is not fulfilled, a so-called hidden layer problem appears; because a negative velocity contrast (higher velocity overlying smaller velocity) does not create a critical refraction. A reflection on a negative velocity contrast can be identified by a $180^{\circ}$ phaseshift of the wavelet reflected on this horizon.

However, a hidden layer problem can also be caused by two other situations [Reynolds, 2000]: (1) no velocity contrast between two different layers; (2) a layer thinner than one wavelength of the incident wave (e.g. a P-wave velocity of $2000 \mathrm{~m} / \mathrm{s}$ with a frequency of $70 \mathrm{~Hz}$ could not create a visible refraction from a layer thinner than $28 \mathrm{~m}$ ). 


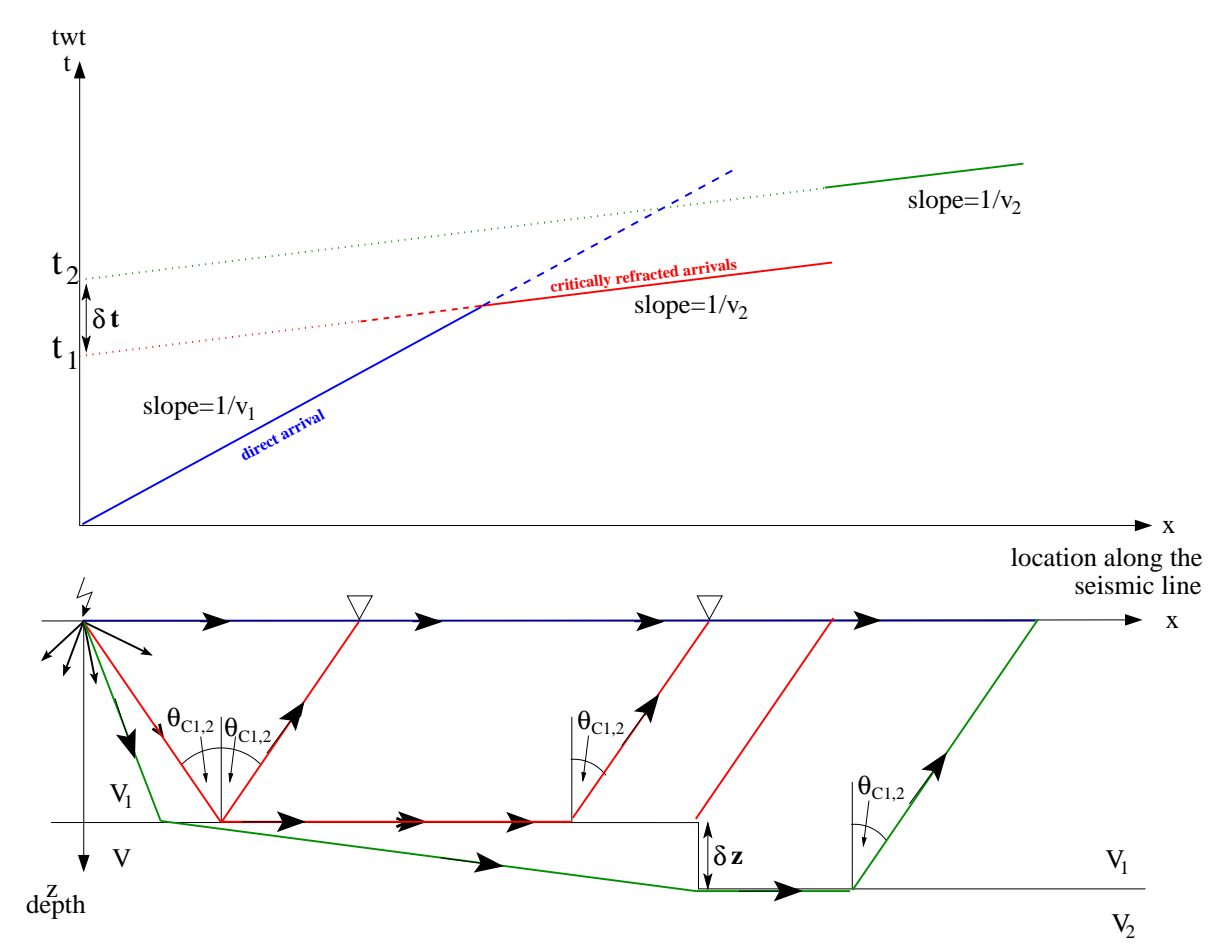

Figure A.14: Top: $t_{x}$ against $x$ plot of the traveltime curves of the refracted and the direct wave. Bottom: refracted and direct rays in the corresponding two-layer model with a horizontal interface and a step discontinuity along the refractor.

\section{A.2.3 Raytracing}

Forward modelling (raytracing) computer programs provide the possibility to calculate the ray path using Snell's law through different and arbitrary complex velocity structures. In this study, MacRay ${ }^{T M} 2.0$ raytracing software [Luetgert, 1992] is used. It allows a user to calculate traveltime curves for complex twodimensional velocity models. They are no constrains on the velocity behaviour with depth or on lateral velocity variations. The software can take topography into account and calculates traveltimes of various phases. Any raytracing software, however, produces non-unique models.

Manipulations on the velocity model can be done interactively by the user and resulting traveltimes can be compared. A velocity value at the top and bottom of the layer defines the velocity within the layer, which can be inhomogeneous. The propagation of the rays within a layer is calculated using an algorithm which is based on the stepwise integration of the system of first-order differential equations [Luetgert, 1992]. 
Chapter A. Seismic Method 


\section{Appendix B}

\section{Gravity Methods}

The gravity method is used to observe differences in the gravitational field of the earth, caused by local masses with a different density to the surrounding material. The term 'gravity' mainly used in conjunction with this method is a short form for 'variation of the acceleration due to gravity of the earth'. Gravity exploration can be used for all different aspects of geological problems, e.g. hydrocarbon exploration, isostatic compensation determination, determination of glacier thickness and regional geological studies [Reynolds, 2000].

Many factors influence the gravitational field of the earth. The main ones are: the mass of the earth itself, latitude and elevation of the point of observation, location of the sun and moon relative to the earth and local factors like the nearby terrain and density variations in the subsurface [Kearey et al., 2002].

\section{B.1 Theory}

The theory of gravity is mainly based on two different principles derived by Sir Isaac Newton in 1687: (1) the universal law of gravitation, (2) the second law of motion. Combining both and applying it to the case of the earth defines the acceleration of gravity of the earth $(\mathrm{g})$ as

$$
g=\left(G M_{e} / R_{e}^{2}\right)
$$

with $M_{e}$ being the mass of the earth, $R_{e}$ the radius of the earth and $G$ being the gravitational constant $\left(G=6.67 \cdot 10^{-11} \mathrm{~m}^{3} \mathrm{~kg}^{-1} \mathrm{~s}^{-2}\right)$.

However, gravity is not constant over the earth because the earth is not perfectly round but has the shape of an ellipse of rotation, bulging at the equator and flattened at the poles [Reynolds, 2000]. The International Union of Geodesy 
and Geophysics proposed in 1930 an equation (IGF30) to approximate the gravity for the earth

$$
g_{(\phi)}=978049\left(1+0.052884 \sin ^{2} \phi-00000059 \sin ^{2} 2 \phi\right),
$$

where $\phi$ is the geodetic latitude of the observation.

The unit of gravity is called Gal, in honour of Galileo, with $1 \mathrm{Gal}=1 \mathrm{~cm} / \mathrm{s}^{2}$. The average value on the earth surface is around $980 \mathrm{Gal}$ [Telford et al., 1990] and anomalies observed on the surface are usually expressed in mGal.

\section{B.2 Gravity data processing and reduction}

As mentioned earlier, the observed gravity values depend on many factors. Thus, the gravity measurement has to be reduced to an equipotential surface to free them from most of these influences. This happens in five steps; (1) drift correction (2) latitude correction (3) free-air correction (4) terrain correction and (5) Bouguer correction. The end product of this correction process is the Bouguer anomaly $\left(g_{B}\right)$, which can be expressed as

$$
\begin{aligned}
\Delta g_{B} & =\underbrace{g_{\phi}-\delta g_{F}+\delta g_{B}-\delta g_{T C}}_{g_{\text {pred }}}-g_{o b s} \\
\Delta g_{B} & =g_{\text {pred }}-g_{\text {obs }},
\end{aligned}
$$

where $g_{\phi}$ is the gravity predicted by IGF30, $\delta g_{F}$ the free air correction term, $\delta g_{B}$ the Bouguer correction, $\delta g_{T C}$ the terrain correction and $g_{o b s}$ the drift corrected observed gravity. The first four terms of equation B.4 can be summarised as the predicted gravity $\left(g_{\text {pred }}\right)$, the theoretical value expected at the location.

The gravity instrument used (Lacoste \& Romberg model G gravitymeter) is a relative gravity instruments. It has to be tied to a known absolute gravity point in order to get absolute values. In New Zealand, there are 437 absolute gravity stations, established by Robertson \& Reilly [1960]. The integration into this system is done by looping (repeat measurements to correct for instrument drift, see appendix B.2.1) to one of these known absolute values. Furthermore, the reading taken with the Lacoste \& Romberg instruments is only in scale units, and has to be converted to $\mathrm{mGal}$ by referring to a conversion table provided with the instrument.

\section{B.2.1 Drift correction}

A gravitymeter can change its null readings over time. This happens mainly due to two reasons: the tidal effects or creep of the springs within the instruments. 
Both effects can be removed with repeated measurement (looping) at a station during the survey. Therefore, the same station or any station can be reoccupied within a time interval of 3-4 hr [Telford et al., 1990]. A linear drift between measurements is assumed and a correction of the stations only occupied once can be done.

Another approach, not used in this thesis, is to calculate the actual tidal effect and remove it before the drift correction. Thus, the drift correction applied here only accounts for the drift of the gravitymeter itself. However, in most cases the drift correction for both effects is sufficient and within the error margins of the measurements. A higher accuracy of the drift correction can be achieved with a smaller time interval between measurements.

\section{B.2.2 Latitude correction}

The latitude correction is the calculation of the difference between the theoretical gravity value, calculated by the IGF30 equation (equation B.2, $g_{\phi}$ ) minus the observed value $\left(g_{o b s}\right)$. They are updated versions of equation B.2 to calculate the theoretical value [Nabighian et al., 2005; Wollard, 1979]. However, all existing gravity values of the GNS Sciences database used within this thesis are processed with equation B.2. Thus, for consistency and to be able to use existing data it was necessary to process newly collected data also with the slightly less accurate IGF30 equation.

\section{B.2.3 Free-air correction}

Gravity decreases with the square of the distance. Therefore, it is necessary to correct for elevation changes and reduce the observed measurement to a datum surface $\left(\delta g_{F}\right)$. Such a correction, however, only accounts for the difference in height, but not for the volume of material between the station and the datum surface. The corresponding equation can be derived from equation B.1 as

$$
\delta g_{F}=0.3086[\mathrm{mGal} / \mathrm{m}] \cdot h[\mathrm{~m}],
$$

with $h$ being the height above sea level in metres.

\section{B.2.4 Terrain correction}

The terrain correction $\left(\delta g_{T C}\right)$ allows for variations in the topography from a flat plane around the station. Thereby hills and valleys have the same effect on the gravity measurements, one is a lack of material below, the other one is an excess of material above. Both have to be added to the station reading. 
There are different methods to correct for the terrain around the station; the one used for this study is the Hammer method [Hammer, 1939]. The area around the station is divided into 13 concentric circles and each annulus (zones A-M) is further divided into a certain number of equal sized compartments. The circles have different radii and extend out to $22 \mathrm{~km}$. In each compartment, the difference between average elevation and the elevation at the station has to be estimated. This can be done for zone E-M (170 m-22 km) by placing a transparent chart on a topographic map. However, the inner zones (B-D, 2-170 m) have to be assessed in the field by the field crew and the most inner zone $(\mathrm{A}<2 \mathrm{~m})$ should be chosen to be flat. The actual gravity effect of every compartment can be determined by a conversion table [Woodward \& Ferry, 1973] and they are added up for the total value of the terrain correction.

For this study the terrain correction for zone E-M $(170 \mathrm{~m}-22 \mathrm{~km})$ is calculated by the software tool demtools using the Victoria University of Wellington owned Digital Elevation Model (DEM, $25 \mathrm{~m}$ resolution) of the mainland of New Zealand.

\section{B.2.5 Bouguer correction}

The Bouguer correction accounts for the volume of material between the station and the datum plane, not included in the Free-air correction. This is done by assuming the station is located on an infinite slab of material with a uniform thickness and density. Thus, the gravity effect of this 'Bouguer slab' can be calculated to

$$
\delta g_{B}=2 \pi \rho G h
$$

where $\rho$ is the density of the slab in $m g / \mathrm{m}^{3}, G$ is the universal gravity constant and $h$ is the height above sea level in metres. In this study, the slab is assumed to consist out of greywacke rock with a density of $2670 \mathrm{mg} / \mathrm{m}^{3}$ [Hunt, 1980].

\section{B.3 Regional gravity field and residual gravity val- ues}

The Bouguer anomaly can be considered to be a combination of a long and short wavelength anomaly, with the short wavelength anomalies resulting from shallower, localised geological features. Thus, if interested in such features, it is often necessary to separate them from the overprinting long wavelength anomaly (regional gravity field). After the separation, the short wavelength anomaly is called residual gravity anomaly and can be used for further analysis. 


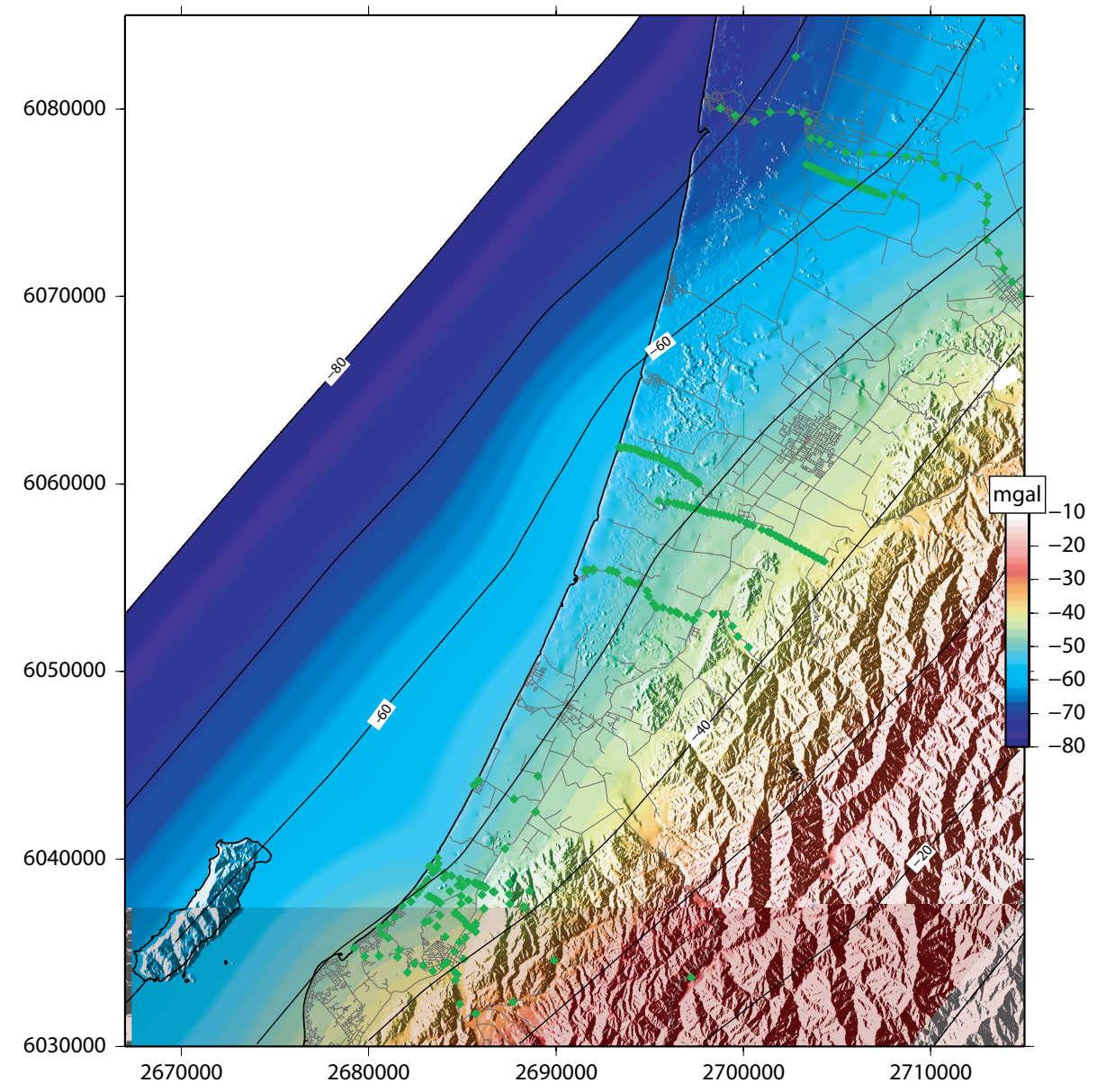

Figure B.1: Regional gravity anomaly in the Kapiti-Horowhenua region, based on a 3-D gravity model of the crustal structure and subducting slab (modelE3 without deformation at the top of the crust; chapter 4), adjusted with known stations on greywacke. Green diamonds indicate locations of gravity stations occupied in this study.

There are different ways to remove the regional field from the data; for example fitting a low-order polynomial to the Bouguer anomaly and subtracting those values from the observed Bouguer anomaly [Reynolds, 2000]. If the gravity anomaly over a sediment basin is investigated (like in this study) a common approach is to estimate the regional field based on three different datasets, which can be used separately or as a combination [Hunt, 1980]: (1) gravity data from basement rocks at the side of the basin or basement outcrops within the basin; (2) using seismic reflection profiling or (3) drillhole data to subtract the effect of sediment thicknesses from Bouguer gravity data. Contouring and eventually smoothing of these data produces the regional gravity field.

For this study, however, a different approach is required, mainly because of the lack of any of the data described above. Thus, the regional gravity field is 
assumed to be composed of the effect of crustal thickening as well as the influence of the subducted slab underneath the southern North Island. This anomaly can be evaluated by means of the 3-D gravity model developed for the SWB in chapter 4. However, the calculation of the 3-D gravity model has a relatively high inaccuracy in the absolute value and has to be slightly adjusted (static shift $7 \mathrm{mGal}$ ) with gravity station known to be located on greywacke. A difference in the used geoid height between the different models is the most likely explanation for this discrepancy. The final regional field is shown in figure B.1.

\section{B.4 Uncertainties in gravity measurements}

There are four main error sources within the taken gravity measurements; the uncertainties introduced by the reader of the instrument, the uncertainties due to drift or drift correction, the error in the position of the datapoint and the inaccuracies in the terrain correction.

A standard field procedure is to repeat the instrument reading at every point three to five times, check the instrument levelling between every reading and get measurements within 0.05 reading units of each other. This is a procedure to minimise the reading error which so can be considered to $\pm 0.05 \mathrm{mGal}$ for all readings. Some data within the VUW database have a larger reading error $( \pm 0.2 \mathrm{mGal})$, because they were taken from first time readers during field projects.

Removing the drift of the instrument introduces an error mainly due to the uncertainty within interpolation of the drift curve. Here, a linear interpolation between measurements is assumed and the repeat interval was kept relatively small with approximate $2 \mathrm{hr}$. However, the estimated error for the drift correction is $\pm 0.1 \mathrm{mGal}$. Another source of error could be a so-called thermal or mechanical tare, which is a significant drift/jump of the instrument readings, produced by knock of an unlocked instrument or a drop in temperature within the instrument. These errors can normally be identified in the field and corresponding datapoint can be removed.

The terrain correction consists of two parts: the inner terrain correction, based on the height estimation of the field crew, and the outer correction, based on a digital elevation model (DEM). Field tests with student groups showed that the error in estimating the heights for the inner terrain correction is between 10 and $20 \%$, depending of the experience level of the person. So, assuming a maximum $20 \%$ error in height estimation and an inner terrain correction not higher than $0.1 \mathrm{mGal}$ yields an error of $\pm 0.02 \mathrm{mGal}$. The inaccuracy due to the outer terrain correction is negligible.

The position of all gravity stations within the VUW database is determined by the differential Global Positioning System (GPS) technique. This method has an 


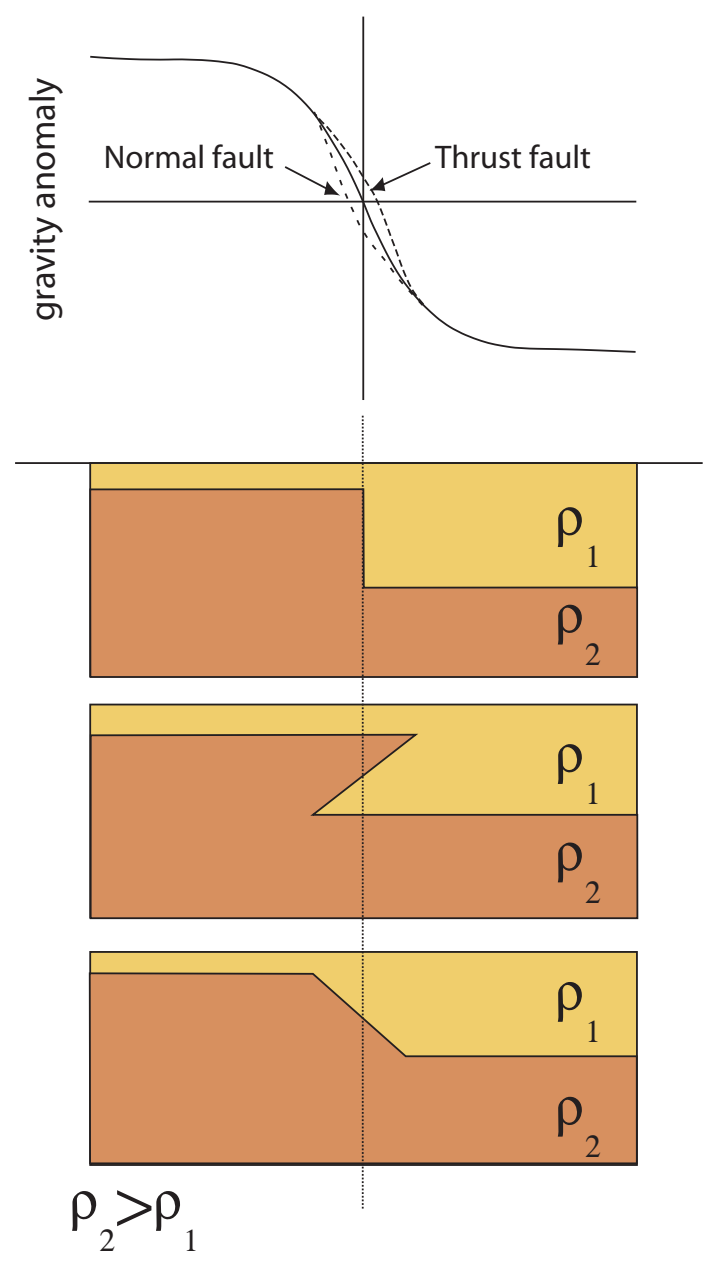

Figure B.2: A sketch illustrating the similarity between vertical (top), high-angle reverse (middle) and high-angle normal (bottom) faulting of a dense basement overlain by less dense sediments. A small gravity station spacing should resolve the type of basement offset, but often either type will fit the observation within uncertainties [Twiss \& Moores, 1992].

uncertainty of around $20 \mathrm{~cm}$ in height and less than $10 \mathrm{~cm}$ in latitude and longitude. The error due to height uncertainties in the Bouguer anomaly can be calculated to $0.08 \mathrm{mGal}$. Analysis for the error due to latitude and longitude uncertainties shows that they are negligible $(<0.0001)$ [Toulmin, 2006].

Calculating the final maximum uncertainty in the Bouguer anomalies shows error values between 0.2 and $1 \mathrm{mGal}$ (student field crew).

Bouguer gravity values used from GNS Sciences database have an uncertainty of $1.5 \mathrm{mGal}$ in flat areas, and up to $5-10 \mathrm{mGal}$ in mountainous terrain [Reilly, 1972]. This higher uncertainty can mainly be ascribed to the higher errors in heights, which were estimated by barometric levelling. However, some GNS Sciences database points were reoccupied and the difference was smaller than 
$1 \mathrm{mGal}$ for all stations. Therefore, a maximum uncertainty of the GNS Sciences data of $1.5 \mathrm{mGal}$ is used and gravity variations much smaller than $1-1.5 \mathrm{mGal}$ between gravity points are not modelled. Datapoints which show large variation of the overall trend were reoccupied/rechecked in later field surveys or eliminated from the dataset.

The error in the regional field for the Kapiti-Horowhenua area is hard to estimate because it is based on many assumption and uncertainties. However, a comparison with the local regional field in the Waikanae area, established with stations on greywacke, shows a discrepancy smaller than $1 \mathrm{mGal}$. Therefore, the maximum error of the regional field is set to be $\pm 1 \mathrm{mGal}$.

Gravity interpretation is non-unique, which means that there are an infinite number of models that satisfactorily describe the observations. For example, high-angle reverse, vertical and high-angle normal faults offsetting dense basement overlain by less dense sediments produce similar gravity anomalies (figure B.2) [Twiss \& Moores, 1992]. For this reason it is important to constrain the model with all available geological information and to decrease the station spacing across significant subsurface features.

\section{B.5 Gravity data}

Table B.1: Waikanae gravity data

\begin{tabular}{|c|c|c|c|c|c|c|}
\hline \multicolumn{1}{|c|}{$\begin{array}{c}\text { GNS stations } \\
\text { ID }\end{array}$} & $\begin{array}{c}\text { Easting } \\
(\mathbf{m})\end{array}$ & $\begin{array}{c}\text { Northing } \\
(\mathbf{m})\end{array}$ & $\begin{array}{c}\text { Elevation } \\
(\mathbf{m})\end{array}$ & $\begin{array}{c}\text { Observed } \\
\text { gravity } \\
(\mathbf{m G a l})\end{array}$ & $\begin{array}{c}\text { Bouguer } \\
\text { anomaly } \\
(\mathbf{m G a l})\end{array}$ & $\begin{array}{c}\text { Residual } \\
\text { anomaly } \\
(\mathbf{m G a l})\end{array}$ \\
\hline 12.879 & 2684855 & 6032264 & 70.2 & - & -35.22 & 0.36 \\
\hline 12.880 & 2684626 & 6033533 & 48.7 & - & -37.8 & 0.63 \\
\hline 12.881 & 2684521 & 6034030 & 41.1 & - & -39.58 & 0.02 \\
\hline 12.882 & 2683981 & 6034338 & 31.2 & - & -40.47 & 0.44 \\
\hline 12.883 & 2682910 & 6034305 & 13.1 & - & -42.91 & -0.81 \\
\hline 12.884 & 2682428 & 6034410 & 13.6 & - & -43.03 & -0.18 \\
\hline 12.885 & 2681626 & 6035146 & 4.3 & - & -48.21 & -2.97 \\
\hline 12.886 & 2681049 & 6035775 & 2.6 & - & -51.85 & -4.74 \\
\hline 12.887 & 2680608 & 6036337 & 3 & - & -53.79 & -5.12 \\
\hline 12.888 & 2685986 & 6038589 & 13.6 & - & -48.79 & -1.16 \\
\hline 12.1130 & 2687268 & 6040538 & 103.6 & - & -52.61 & -2.47 \\
\hline 12.1131 & 2683686 & 6040045 & 65.5 & - & -58.71 & -5.19 \\
\hline
\end{tabular}

continued on next page 
B.5 Gravity data

Table B.1: continued

\begin{tabular}{|c|c|c|c|c|c|c|}
\hline 12.1132 & 2682994 & 6036625 & 68.6 & - & -49.48 & -2.53 \\
\hline 12.1134 & 2689911 & 6034599 & 73.2 & - & -21.17 & 12.3 \\
\hline 12.1136 & 2687711 & 6032361 & 70.1 & - & -32.7 & -0.66 \\
\hline \multicolumn{7}{|c|}{ VUW stations } \\
\hline $\begin{array}{l}\text { Station } \\
\text { ID }\end{array}$ & $\begin{array}{c}\text { Easting } \\
\text { (m) }\end{array}$ & $\begin{array}{l}\text { Northing } \\
\text { (m) }\end{array}$ & $\begin{array}{l}\text { Elevation } \\
\text { (m) }\end{array}$ & $\begin{array}{c}\text { Observed } \\
\text { gravity } \\
\text { (mGal) }\end{array}$ & $\begin{array}{c}\text { Bouguer } \\
\text { anomaly } \\
\text { (mGal) }\end{array}$ & $\begin{array}{l}\text { Residual } \\
\text { anomaly } \\
\text { (mGal) }\end{array}$ \\
\hline$\overline{\text { HE001 }}$ & 2687506 & 6038098 & 458.08 & 976868.96 & -44.04 & 0.43 \\
\hline HE002 & 2687523 & 6037598 & 541.68 & 976952.56 & -44.02 & -0.68 \\
\hline HE003 & 2687481 & 6038695 & 322.66 & 976733.54 & -44.98 & 0.84 \\
\hline HE004 & 2686705 & 6038222 & 123.72 & 976534.60 & -45.50 & 0.36 \\
\hline HA002 & 2686648 & 6038244 & 113.62 & 976524.50 & -45.33 & 0.65 \\
\hline HA001 & 2686252 & 6038483 & 38.58 & 976449.46 & -46.89 & 0.15 \\
\hline PP001 & 2685922 & 6038596 & 10.79 & 976421.67 & -49.44 & -1.71 \\
\hline PP002 & 2685288 & 6038774 & 7.45 & 976418.33 & -53.65 & -4.72 \\
\hline PP003 & 2684890 & 6038920 & 6.75 & 976417.63 & -54.10 & -4.36 \\
\hline PP004 & 2684424 & 6039104 & 8.64 & 976419.52 & -54.58 & -3.89 \\
\hline PP005 & 2684030 & 6039253 & 7.19 & 976418.07 & -55.68 & -4.22 \\
\hline PP006 & 2683642 & 6039451 & 3.37 & 976414.25 & -57.69 & -5.38 \\
\hline PP007 & 2683371 & 6039557 & 4.08 & 976414.96 & -59.02 & -6.2 \\
\hline PP008 & 2683232 & 6039599 & 0 & 976410.88 & -59.33 & -6.27 \\
\hline BA001 & 2688313 & 6037429 & 508.67 & 976919.55 & -40.98 & 0.86 \\
\hline BA002 & 2688596 & 6038285 & 350.18 & 976761.06 & -42.81 & 0.50 \\
\hline SHF01 & 2697208 & 6033679 & 120.96 & 976531.84 & -21.98 & 0.19 \\
\hline PNEW1 & 2685779 & 6038667 & 5.610 & 980200.80 & -51.84 & -3.77 \\
\hline PNEW2 & 2685819 & 6038645 & 5.742 & 980201.09 & -51.48 & -3.51 \\
\hline PNEW3 & 2685874 & 6038606 & 5.768 & 980201.45 & -51.02 & -3.21 \\
\hline PNEW4 & 2685922 & 6038597 & 6.289 & 980201.85 & -50.42 & -2.69 \\
\hline PNEW5 & 2685668 & 6038716 & 5.782 & 980199.85 & -52.9 & -4.58 \\
\hline HNEW1 & 2686183 & 6038513 & 26.111 & 980199.81 & -47.96 & -0.76 \\
\hline HNEW2 & 2686107 & 6038547 & 18.270 & 980200.93 & -48.53 & -1.15 \\
\hline HNEW3 & 2685991 & 6038587 & 6.984 & 980202.41 & -49.57 & -1.95 \\
\hline AWA1 & 2683716 & 6039727 & 2.683 & 980194.94 & -58.56 & -5.74 \\
\hline AWA2 & 2683417 & 6039269 & 0.000 & 980196.49 & -57.88 & -5.71 \\
\hline AWA3 & 2683143 & 6038880 & 1.477 & 980197.85 & -56.53 & -4.9 \\
\hline AWA4 & 2682920 & 6038576 & 2.228 & 980199.14 & -55.37 & -4.16 \\
\hline AWA5 & 2682699 & 6038328 & 0.661 & 980199.55 & -55.3 & -4.39 \\
\hline AWA6 & 2682266 & 6037720 & 1.415 & 980200.89 & -54.35 & -4.29 \\
\hline RE1 & 2684987 & 6038522 & 4.07 & 980255.54 & -53.95 & -5.2 \\
\hline RE2 & 2684780 & 6038588 & 6.89 & 980255.49 & -54.17 & -5.02 \\
\hline
\end{tabular}

continued on next page 
Chapter B. Gravity Methods

Table B.1: continued

\begin{tabular}{|c|c|c|c|c|c|c|}
\hline RE3 & 2684929 & 6037610 & 3.67 & 980256.28 & -50.55 & -3.72 \\
\hline RE4 & 2684615 & 6037087 & 8.69 & 980256.7 & -49.66 & -3.59 \\
\hline RE5 & 2684080 & 6035840 & 11.63 & 980257.71 & -45.99 & -1.98 \\
\hline RE8 & 2683310 & 6037977 & 5.57 & 980256.01 & -52.92 & -3.4 \\
\hline RE9 & 2683610 & 6037813 & 7.05 & 980256.14 & -50.75 & -2.5 \\
\hline RE10 & 2683813 & 6037641 & 2.02 & 980256.27 & -50.95 & -2.72 \\
\hline RE11 & 2683645 & 6036389 & 3.61 & 980257.28 & -47.59 & -1.88 \\
\hline RE12 & 2683239 & 6036711 & 5.20 & 980257.03 & -49.23 & -2.36 \\
\hline ODMN & 2684019 & 6038965 & 3.50 & 980255.2 & -54.94 & -4.08 \\
\hline REAW1 & 2682552 & 6038120 & 0.00 & 980255.91 & -55.14 & -4.52 \\
\hline FARM & 2684340 & 6038268 & 2.02 & 980255.76 & -52.22 & -3.24 \\
\hline FARM2 & 2684921 & 6038020 & 3.61 & 980255.95 & -52.14 & -4.4 \\
\hline FARM3 & 2685337 & 6037804 & 5.20 & 980256.11 & -50.82 & -4.08 \\
\hline \multicolumn{7}{|c|}{ VUW stations (Geol368 2003) } \\
\hline $\begin{array}{c}\text { Station } \\
\text { ID }\end{array}$ & $\begin{array}{c}\text { Easting } \\
(\mathrm{m})\end{array}$ & $\begin{array}{l}\text { Northing } \\
\text { (m) }\end{array}$ & $\begin{array}{c}\text { Elevation } \\
\text { (m) }\end{array}$ & $\begin{array}{c}\text { Observed } \\
\text { gravity } \\
\text { (mGal) }\end{array}$ & $\begin{array}{l}\text { Bouguer } \\
\text { anomaly } \\
\text { (mGal) }\end{array}$ & $\begin{array}{c}\text { Residual } \\
\text { anomaly } \\
\text { (mGal) }\end{array}$ \\
\hline W0001 & 2680697 & 6035981 & $\overline{15.1}$ & 980204.21 & -52.85 & -4.99 \\
\hline W0002 & 2684185 & 6034481 & 44.1 & 980210.58 & -40.87 & 0.1 \\
\hline W0003 & 2685078 & 6034659 & 108 & 980195.95 & -40.99 & -0.76 \\
\hline W0004 & 2685721 & 6031730 & 87.8 & 980211.84 & -32.79 & 0.65 \\
\hline W0005 & 2679232 & 6035255 & 14.6 & 980203.61 & -54.18 & -6.63 \\
\hline W0006 & 2680577 & 6034814 & 17.6 & 980208.69 & -48.77 & -3.22 \\
\hline W0007 & 2682066 & 6033957 & 21.6 & 980213.95 & -43.11 & -0.81 \\
\hline W0008 & 2683423 & 6034010 & 34.1 & 980212.91 & -41.1 & -0.21 \\
\hline W0009 & 2681542 & 6034755 & 19.1 & 980209.36 & -47.88 & -3.37 \\
\hline W0010 & 2679792 & 6034802 & 18.1 & 980203.68 & -53.6 & -7.4 \\
\hline \multicolumn{7}{|c|}{ Kapiti Island stations } \\
\hline W0013 & - & - & 15.7 & 980202.21 & -51.5 & -1.5 \\
\hline W0014 & - & - & 531.5 & 980083.00 & -51.85 & 0 \\
\hline \multicolumn{7}{|c|}{ VUW stations (Geol368 2005) } \\
\hline $\begin{array}{c}\text { Station } \\
\text { ID }\end{array}$ & $\begin{array}{c}\text { Easting } \\
\text { (m) }\end{array}$ & $\begin{array}{l}\text { Northing } \\
\text { (m) }\end{array}$ & $\begin{array}{l}\text { Elevation } \\
\text { (m) }\end{array}$ & $\begin{array}{c}\text { Observed } \\
\text { gravity } \\
\text { (mGal) }\end{array}$ & $\begin{array}{c}\text { Bouguer } \\
\text { anomaly } \\
\text { (mGal) }\end{array}$ & $\begin{array}{c}\text { Residual } \\
\text { anomaly } \\
\text { (mGal) }\end{array}$ \\
\hline 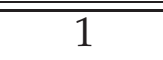 & 2682245 & 6037714 & 2.37 & 980200.90 & $\overline{-54.25}$ & -4.19 \\
\hline 2 & 2681406 & 6036886 & 6.37 & 980201.89 & -53.07 & -3.96 \\
\hline 3 & 2680987 & 6036535 & 5.71 & 980202.65 & -52.77 & -4.01 \\
\hline 12 & 2685214 & 6036479 & 8.22 & 980205.73 & -47.28 & -3.29 \\
\hline 13 & 2686149 & 6037350 & 64.9 & 980194.42 & -45.21 & -0.52 \\
\hline 15 & 2685714 & 6036548 & 11.6 & 980197.19 & -44.39 & -0.89 \\
\hline
\end{tabular}


Table B.1: continued

\begin{tabular}{|c|c|c|c|c|c|c|}
\hline 16 & 2985513 & 6036198 & 53.45 & 980198.91 & -44.14 & -1.15 \\
\hline 17 & 2685158 & 6035796 & 47.54 & 980202.01 & -43.34 & -0.77 \\
\hline 18 & 2684851 & 6035536 & 7.64 & 980205.59 & -42.02 & 0.38 \\
\hline 19 & 2684596 & 6035060 & 8.65 & 980205.92 & -41.56 & 0.13 \\
\hline 24 & 2685426 & 6036321 & 6.75 & 980202.51 & -44.48 & -1.11 \\
\hline 25 & 2685715 & 6036115 & 94.37 & 980191.89 & -42.02 & 0.53 \\
\hline \multicolumn{7}{|c|}{ VUW stations (Geol368 2008) } \\
\hline $\begin{array}{c}\text { Station } \\
\text { ID }\end{array}$ & $\begin{array}{c}\text { Easting } \\
(\mathbf{m})\end{array}$ & $\begin{array}{c}\text { Northing } \\
\text { (m) }\end{array}$ & $\begin{array}{c}\text { Elevation } \\
\text { (m) }\end{array}$ & $\begin{array}{c}\text { Observed } \\
\text { gravity } \\
\text { (mGal) }\end{array}$ & $\begin{array}{c}\text { Bouguer } \\
\text { anomaly } \\
\text { (mGal) }\end{array}$ & $\begin{array}{c}\text { Residual } \\
\text { anomaly } \\
\text { (mGal) }\end{array}$ \\
\hline \hline T1 & 2686250 & 6039155 & 3.88 & 980202.42 & -49.73 & 0.63 \\
\hline T2 & 2685850 & 6039160 & 6.12 & 980198.78 & -53.63 & -4.26 \\
\hline T3 & 2685160 & 6039358 & 8.07 & 980196.71 & -55.68 & -5.46 \\
\hline T4 & 2686880 & 6040175 & 14.26 & 980199.42 & -50.5 & -1.50 \\
\hline T5 & 2686475 & 6040825 & 7.74 & 980193.38 & -57.85 & -3.91 \\
\hline T6 & 2685780 & 6040825 & 18.49 & 980189.37 & -59.92 & -7.20 \\
\hline
\end{tabular}

Table B.2: Waikawa gravity profile data

\begin{tabular}{|c|c|c|c|c|c|c|}
\hline \multicolumn{7}{|c|}{ GNS stations } \\
\hline $\begin{array}{c}\text { Station } \\
\text { ID }\end{array}$ & $\begin{array}{c}\text { Easting } \\
\text { (m) }\end{array}$ & $\begin{array}{c}\text { Northing } \\
\text { (m) }\end{array}$ & $\begin{array}{c}\text { Elevation } \\
\text { (m) }\end{array}$ & $\begin{array}{c}\text { Observed } \\
\text { gravity } \\
\text { (mGal) }\end{array}$ & $\begin{array}{c}\text { Bouguer } \\
\text { anomaly } \\
\text { (mGal) }\end{array}$ & $\begin{array}{c}\text { Residual } \\
\text { anomaly } \\
\text { (mGal) }\end{array}$ \\
\hline 12.752 & 2691622 & 6055323 & 4.6 & - & -72.75 & -5.06 \\
\hline 12.753 & 2693041 & 6055374 & 6.1 & - & -69.6 & -3.48 \\
\hline 12.754 & 2693858 & 6054848 & 4.6 & - & -67.98 & -3.68 \\
\hline 12.755 & 2694412 & 6054695 & 6.1 & - & -68.56 & -5.18 \\
\hline 12.756 & 2694941 & 6053994 & 10.6 & - & -66.2 & -4.59 \\
\hline 12.757 & 2695363 & 6053387 & 9.1 & - & -65.31 & -5.19 \\
\hline 12.758 & 2696409 & 6053174 & 18.3 & - & -60.93 & -2.39 \\
\hline 12.759 & 2697338 & 6052736 & 33.5 & - & -59.11 & -2.4 \\
\hline 12.760 & 2697595 & 6053095 & 40.2 & - & -59.51 & -2.46 \\
\hline 12.761 & 2698372 & 6053072 & 65.5 & - & -54.08 & 2.03 \\
\hline 12.762 & 2699076 & 6053052 & 68.6 & - & -54.22 & 0.97 \\
\hline 12.763 & 2699396 & 6052403 & 85.2 & - & -51.31 & 2.19 \\
\hline 12.764 & 2699710 & 6051864 & 96 & - & -51.58 & 0.44 \\
\hline 12.765 & 2700278 & 6051281 & 135.6 & - & -50.1 & 0 \\
\hline \multicolumn{7}{|c|}{ VUW stations } \\
\hline $\begin{array}{l}\text { Station } \\
\text { ID }\end{array}$ & $\begin{array}{c}\text { Easting } \\
\text { (m) }\end{array}$ & $\begin{array}{l}\text { Northing } \\
\text { (m) }\end{array}$ & $\begin{array}{c}\text { Elevation } \\
\text { (m) }\end{array}$ & $\begin{array}{c}\text { Observed } \\
\text { gravity }\end{array}$ & $\begin{array}{l}\text { Bouguer } \\
\text { anomaly }\end{array}$ & $\begin{array}{l}\text { Residual } \\
\text { anomaly }\end{array}$ \\
\hline
\end{tabular}

continued on next page 
Chapter B. Gravity Methods

Table B.2: continued

\begin{tabular}{|c|c|c|c|c|c|c|}
\hline & & & & (mGal) & (mGal) & (mGal) \\
\hline \hline 102 & 2691570 & 6055408 & 4.08 & 980167.19 & -72.96 & -5.08 \\
\hline 103 & 2691994 & 6055456 & 4.71 & 980167.23 & -72.76 & -5.28 \\
\hline 104 & 2691981 & 6055373 & 5.07 & 980167.9 & -72.08 & -4.72 \\
\hline 105 & 2692829 & 6055397 & 5.56 & 980169.73 & -70.12 & -3.71 \\
\hline 106 & 2693239 & 6055277 & 7.37 & 980170.1 & -69.41 & -3.67 \\
\hline 108 & 2693801 & 6054815 & 6.85 & 980172.05 & -67.85 & -3.54 \\
\hline 109 & 2694009 & 6054789 & 7.11 & 980171.78 & -68.09 & -4.07 \\
\hline 111 & 2694210 & 6054662 & 6.93 & 980171.73 & -68.29 & -4.71 \\
\hline 112 & 2694442 & 6054678 & 7.01 & 980171.62 & -68.34 & -5.02 \\
\hline 113 & 2694859 & 6054298 & 7.85 & 980172.88 & -67.15 & -4.95 \\
\hline 114 & 2695196 & 6053612 & 10.52 & 980174.51 & -65.45 & -4.77 \\
\hline 115 & 2695692 & 6053411 & 12.22 & 980176.19 & -63.51 & -3.75 \\
\hline 116 & 2696109 & 6053245 & 15.88 & 980177.25 & -61.79 & -2.79 \\
\hline 117 & 2696549 & 6053070 & 23.33 & 980177.36 & -60.26 & -2.06 \\
\hline 118 & 2696976 & 6052899 & 44.82 & 980176.72 & -59.65 & -2.23 \\
\hline
\end{tabular}

Table B.3: Levin gravity profile data

\begin{tabular}{|c|c|c|c|c|c|c|}
\hline $\begin{array}{c}\text { Station } \\
\text { ID }\end{array}$ & $\begin{array}{c}\text { Easting } \\
(\mathbf{m})\end{array}$ & $\begin{array}{c}\text { Northing } \\
\mathbf{( m )}\end{array}$ & $\begin{array}{c}\text { Elevation } \\
\mathbf{( m )}\end{array}$ & $\begin{array}{c}\text { Observed } \\
\text { gravity } \\
\text { (mGal) }\end{array}$ & $\begin{array}{c}\text { Bouguer } \\
\text { anomaly } \\
\text { (mGal) }\end{array}$ & $\begin{array}{c}\text { Residual } \\
\text { anomaly } \\
(\mathbf{m G a l})\end{array}$ \\
\hline 12.2339 & 2695499 & 6059100 & 38 & - & -64.3 & -13.89 \\
\hline 12.2340 & 2695974 & 6059034 & 17.1 & - & -65.33 & -15.35 \\
\hline 12.2341 & 2696319 & 6058977 & 19.5 & - & -65.04 & -15.38 \\
\hline 12.2342 & 2696492 & 6058933 & 19.4 & - & -65.23 & -15.75 \\
\hline 12.2343 & 2696723 & 6058873 & 21.7 & - & -65.96 & -16.72 \\
\hline 12.2344 & 2696971 & 6058809 & 18.2 & - & -67.18 & -18.2 \\
\hline 12.2345 & 2697203 & 6058749 & 19.4 & - & -67.62 & -18.88 \\
\hline 12.2346 & 2697435 & 6058689 & 20.2 & - & -67.46 & -18.96 \\
\hline 12.2347 & 2697668 & 6058628 & 20.8 & - & -66.78 & -18.52 \\
\hline 12.2348 & 2697880 & 6058562 & 22.1 & - & -65.95 & -17.92 \\
\hline 12.2349 & 2698098 & 6058460 & 28.8 & - & -64.49 & -16.73 \\
\hline 12.2350 & 2698305 & 6058461 & 30.8 & - & -64.48 & -16.88 \\
\hline 12.2351 & 2698509 & 6058420 & 37.3 & - & -64.06 & -16.65 \\
\hline 12.2352 & 2698741 & 6058365 & 42.5 & - & -63.8 & -16.63 \\
\hline 12.2353 & 2698952 & 6058315 & 34.7 & - & -64.49 & -17.53 \\
\hline 12.2354 & 2699203 & 6058254 & 42.4 & - & -63.87 & -17.16 \\
\hline 12.2355 & 2699451 & 6058196 & 43.1 & - & -63.53 & -17.07 \\
\hline
\end{tabular}


B.5 Gravity data

Table B.3: continued

\begin{tabular}{|c|c|c|c|c|c|c|}
\hline 12.2356 & 2699777 & 6058113 & 35.1 & - & -63.61 & -17.48 \\
\hline 12.2357 & 2700146 & 6057908 & 39.3 & - & -61.35 & -15.71 \\
\hline 12.2358 & 2700303 & 6057851 & 41.8 & - & -60.02 & -14.55 \\
\hline 12.2359 & 2700504 & 6057770 & 43.2 & - & -57.64 & -12.41 \\
\hline 12.2360 & 2700963 & 6057584 & 47.5 & - & -54.26 & -9.56 \\
\hline 12.2361 & 2701314 & 6057442 & 51 & - & -53.55 & -9.25 \\
\hline 12.2362 & 2701451 & 6057387 & 52.8 & - & -53.79 & -9.65 \\
\hline 12.2363 & 2701732 & 6057238 & 52.4 & - & -53.46 & -9.68 \\
\hline 12.2364 & 2701917 & 6057139 & 54.3 & - & -52.9 & -9.36 \\
\hline 12.2365 & 2702060 & 6057063 & 54.2 & - & -53.14 & -9.78 \\
\hline 12.2366 & 2702270 & 6056950 & 54.9 & - & -52.76 & -9.67 \\
\hline 12.2367 & 2702491 & 6056833 & 56.7 & - & -52.1 & -9.29 \\
\hline 12.2368 & 2702799 & 6056669 & 67.1 & - & $\begin{array}{l}-51.39 \\
\end{array}$ & -8.96 \\
\hline 12.2369 & 2703064 & 6056529 & 72.5 & - & -50.59 & -8.5 \\
\hline 12.2370 & 2703275 & 6056417 & 76.8 & - & -49.64 & -7.81 \\
\hline 12.2371 & 2703490 & 6056303 & 84.7 & - & -48.4 & -6.84 \\
\hline 12.2372 & 2703755 & 6056162 & 91.4 & - & -47.33 & -6.1 \\
\hline 12.2373 & 2703966 & 6056049 & 97.2 & - & -46.09 & -5.12 \\
\hline 12.2374 & 2704177 & 6055937 & 101.6 & - & -44.55 & -3.84 \\
\hline 12.2375 & 2704327 & 6055856 & 104.9 & - & -42.88 & -2.35 \\
\hline 12.2376 & 2697613 & 6060018 & 10.3 & - & -70.63 & -20.78 \\
\hline 12.2377 & 2697464 & 6060159 & 8.9 & - & -69.1 & -18.98 \\
\hline 12.2378 & 2697307 & 6060280 & 8.7 & - & -68.09 & $\begin{array}{l}-17.72 \\
\end{array}$ \\
\hline 12.2379 & 2697139 & 6060385 & 9.1 & - & -66.77 & -16.15 \\
\hline 12.2380 & 2696934 & 6060456 & 9.5 & - & -66.72 & -15.87 \\
\hline 12.2381 & 2696809 & 6060604 & 9.4 & - & -66.91 & -15.79 \\
\hline 12.2382 & 2696676 & 6060720 & 9.4 & - & -67.02 & -15.67 \\
\hline 12.2383 & 2696542 & 6060848 & 8.7 & - & -67.24 & -15.64 \\
\hline 12.2384 & 2696371 & 6060934 & 11.9 & - & -68.04 & -16.21 \\
\hline 12.2385 & 2696200 & 6061019 & 10.6 & - & -68.57 & -16.52 \\
\hline 12.2386 & 2696062 & 6061096 & 10.1 & - & -69.5 & -17.25 \\
\hline 12.2387 & 2695881 & 6061188 & 9.2 & - & -70.45 & -17.96 \\
\hline 12.2388 & 2695666 & 6061285 & 9.6 & - & -71.75 & -18.98 \\
\hline 12.2389 & 2695544 & 6061434 & 6.9 & - & -72.57 & -19.54 \\
\hline 12.2390 & 2695351 & 6061419 & 6.4 & - & -73.28 & -20.12 \\
\hline 12.2391 & 2695163 & 6061470 & 6.9 & - & -73.6 & -20.23 \\
\hline 12.2392 & 2695022 & 6061535 & 8.3 & - & -73.42 & -19.87 \\
\hline 12.2393 & 2694900 & 6061570 & 8.2 & - & -73.22 & -19.54 \\
\hline 12.2394 & 2694702 & 6061595 & 7.6 & - & -73.11 & -19.25 \\
\hline 12.2395 & 2694541 & 6061692 & 5.5 & - & -73.19 & -19.09 \\
\hline
\end{tabular}

continued on next page 
Chapter B. Gravity Methods

Table B.3: continued

\begin{tabular}{|l|l|l|l|l|l|l|}
\hline 12.2396 & 2694382 & 6061770 & 8 & - & -73.35 & -19.04 \\
\hline 12.2397 & 2694214 & 6061857 & 3.6 & - & -73.97 & -19.43 \\
\hline 12.2398 & 2694009 & 6061882 & 4.9 & - & -74.36 & -19.64 \\
\hline 12.2399 & 2693822 & 6061920 & 4.8 & - & -74.94 & -20.03 \\
\hline 12.2400 & 2693666 & 6061949 & 4.6 & - & -75.21 & -20.15 \\
\hline 12.2401 & 2693482 & 6061916 & 1.1 & - & -76.1 & -20.94 \\
\hline 12.2402 & 2693372 & 6061931 & 0 & - & -76.59 & -21.33 \\
\hline
\end{tabular}

Table B.4: Foxton gravity profile data

\begin{tabular}{|c|c|c|c|c|c|c|}
\hline \multicolumn{1}{|c|}{$\begin{array}{c}\text { GNS stations } \\
\text { ID }\end{array}$} & $\begin{array}{c}\text { Easting } \\
(\mathbf{m})\end{array}$ & $\begin{array}{c}\text { Northing } \\
(\mathbf{m})\end{array}$ & $\begin{array}{c}\text { Elevation } \\
\mathbf{( m )}\end{array}$ & $\begin{array}{c}\text { Observed } \\
\text { gravity } \\
\text { (mGal) }\end{array}$ & $\begin{array}{c}\text { Bouguer } \\
\text { anomaly } \\
\text { (mGal) }\end{array}$ & $\begin{array}{c}\text { Residual } \\
\text { anomaly } \\
\text { (mGal) }\end{array}$ \\
\hline 10.43 & 2698774 & 6080044 & 3 & - & -117.06 & -45.08 \\
\hline 10.44 & 2699586 & 6079655 & 4.6 & - & -113.35 & -42.48 \\
\hline 10.45 & 2700601 & 6079324 & 4.6 & - & -109.53 & -39.91 \\
\hline 10.46 & 2701420 & 6079832 & 6.1 & - & -107.93 & -38.48 \\
\hline 10.47 & 2702564 & 6079854 & 9.1 & - & -106.34 & -37.91 \\
\hline 10.48 & 2703202 & 6079762 & 9.1 & - & -105.98 & -38.24 \\
\hline 10.49 & 2703492 & 6079334 & 9.1 & - & -105.19 & -38.19 \\
\hline 10.50 & 2703613 & 6078452 & 9.1 & - & -101.73 & -35.82 \\
\hline 10.51 & 2704095 & 6078337 & 9.1 & - & -99.38 & -34.04 \\
\hline 10.52 & 2704618 & 6078103 & 12.1 & - & -95.13 & -30.53 \\
\hline 12.649 & 2705475 & 6077658 & 12.1 & - & -93.85 & -30.54 \\
\hline 12.650 & 2706224 & 6077636 & 13.6 & - & -95.17 & -32.58 \\
\hline 12.651 & 2706992 & 6077615 & 15.1 & - & -100.15 & -38.3 \\
\hline 12.652 & 2707804 & 6077564 & 16.8 & - & -103.83 & -42.8 \\
\hline 12.653 & 2708698 & 6077456 & 16.8 & - & -104.45 & -44.38 \\
\hline 12.654 & 2709400 & 6077372 & 13.6 & - & -105.29 & -45.97 \\
\hline 12.655 & 2710234 & 6077111 & 6.1 & - & -104.32 & -46.07 \\
\hline 12.656 & 2710696 & 6076320 & 7.6 & - & -101.62 & -44.67 \\
\hline 12.657 & 2711518 & 6076297 & 7.6 & - & -99.69 & -43.54 \\
\hline 12.658 & 2712513 & 6075884 & 7.6 & - & -96.74 & -41.98 \\
\hline 12.659 & 2713046 & 6075339 & 7.6 & - & -93.51 & -39.83 \\
\hline 12.660 & 2712989 & 6074929 & 4.6 & - & -92.28 & -38.98 \\
\hline 12.661 & 2712943 & 6073970 & 9.1 & - & -87.19 & -34.87 \\
\hline 12.662 & 2712980 & 6073009 & 7.6 & - & -84.23 & -32.97 \\
\hline 12.663 & 2713628 & 6072304 & 7.6 & - & -78.83 & -28.9 \\
\hline 12.664 & 2713878 & 6071474 & 9.1 & - & -71.32 & -22.48 \\
\hline
\end{tabular}


B.5 Gravity data

Table B.4: continued

\begin{tabular}{|c|c|c|c|c|c|c|}
\hline 12.665 & 2714343 & 6070756 & 13.6 & - & -67.01 & -19.33 \\
\hline 12.6660 & 2714899 & 6070073 & 27.2 & - & -63.95 & -17.46 \\
\hline 12.667 & 2715593 & 6070026 & 22.8 & - & -63.67 & -17.83 \\
\hline 12.668 & 2716104 & 6069334 & 33.5 & - & -60.69 & -15.98 \\
\hline 12.669 & 2716471 & 6068720 & 44.2 & - & -56.34 & -12.55 \\
\hline 12.670 & 2717096 & 6067861 & 68.6 & - & -51.35 & -8.91 \\
\hline 12.671 & 2717396 & 6067148 & 74.7 & - & -50.14 & -8.62 \\
\hline 12.1100 & 2717761 & 6066808 & 124.7 & - & -49.3 & -8.39 \\
\hline 12.1102 & 2721186 & 6064378 & 353.2 & - & -33.08 & 3.07 \\
\hline \multicolumn{7}{|c|}{ VUW stations } \\
\hline $\begin{array}{l}\text { Station } \\
\text { ID }\end{array}$ & $\begin{array}{c}\text { Easting } \\
\text { (m) }\end{array}$ & $\begin{array}{c}\text { Northing } \\
\text { (m) }\end{array}$ & $\begin{array}{l}\text { Elevation } \\
\text { (m) }\end{array}$ & $\begin{array}{c}\text { Observed } \\
\text { gravity } \\
\text { (mGal) }\end{array}$ & $\begin{array}{c}\text { Bouguer } \\
\text { anomaly } \\
\text { (mGal) }\end{array}$ & $\begin{array}{c}\text { Residual } \\
\text { anomaly } \\
\text { (mGal) }\end{array}$ \\
\hline NWY1 & 2703363 & 6077018 & 2.89 & 980123.93 & -99.48 & $\begin{array}{l}-15.18 \\
\end{array}$ \\
\hline N001 & 2703577 & 6076927 & 2.92 & 980125.77 & -97.77 & -13.78 \\
\hline N002 & 2703750 & 6076858 & 4.02 & 980127.07 & -96.31 & -12.58 \\
\hline N003 & 2703940 & 6076770 & 5.44 & 980128.23 & -94.98 & -11.54 \\
\hline N100 & 2704148 & 6076676 & 6.59 & 980129.41 & -93.67 & -10.54 \\
\hline N140 & 2704330 & 6076593 & 5.27 & 980129.93 & -93.46 & -10.62 \\
\hline N180 & 2704514 & 6076515 & 5.99 & 980130.82 & -92.48 & -9.92 \\
\hline N220 & 2704695 & 6076425 & 6.52 & 980130.82 & -94.97 & $\begin{array}{l}-12.71 \\
\end{array}$ \\
\hline N260 & 2704877 & 6076347 & 7.94 & 980130.91 & -92.09 & -10.12 \\
\hline N004 & 2705060 & 6076261 & 10.11 & 980130.88 & -91.71 & $\begin{array}{l}-10.04 \\
\end{array}$ \\
\hline N005 & 2705242 & 6076186 & 9.69 & 980130.78 & -92.04 & -10.65 \\
\hline N006 & 2705437 & 6076108 & 10.06 & 980129.76 & -92.97 & -11.89 \\
\hline NHIC & 2706041 & 6075922 & 10.31 & 980128.52 & -94.39 & -14.22 \\
\hline N007 & 2705640 & 6076040 & 8.42 & 980131.45 & -91.65 & -10.88 \\
\hline N008 & 2705827 & 6076078 & 9.01 & 980130.15 & -92.77 & -12.16 \\
\hline N009 & 2706219 & 6075833 & 5.25 & 980126.88 & -97.09 & $\begin{array}{l}-17.24 \\
\end{array}$ \\
\hline N010 & 2706404 & 6075780 & 9.28 & 980125.61 & -97.60 & -18.03 \\
\hline N011 & 2706610 & 6075702 & 4.93 & 980124.14 & -99.99 & -20.76 \\
\hline N012 & 2706770 & 6075642 & 11.03 & 980123.52 & -99.45 & -20.49 \\
\hline N013 & 2706990 & 6075559 & 4.46 & 980123.07 & -101.26 & -22.66 \\
\hline N014 & 2707145 & 6075502 & 1.47 & 980122.59 & -102.37 & -24.03 \\
\hline N016 & 2707509 & 6075362 & 3.31 & 980122.46 & -102.16 & -24.45 \\
\hline KER1 & 2708506 & 6075340 & 2.31 & 980123.43 & -102.15 & -25.70 \\
\hline LAN1 & 2708070 & 6075519 & 2 & 980122.55 & -102.83 & -25.60 \\
\hline WYL1 & 2702783 & 6082786 & 11.43 & 980101.66 & -115.54 & -24.52 \\
\hline
\end{tabular}


Chapter B. Gravity Methods 


\section{Appendix C}

\section{Receiver function theory}

Receiver functions are computed from nearly vertical travelling body waves recorded at three-component seismic stations. The different polarisation of Pand S-waves allows a separation of the different phases. Under the assumption that the waveforms contain only the source-time function $(s(t))$, the instrument response $(i(t))$, propagation effects from the mantle and effects from local structure underneath the recording site, it is possible to determine the impulse response of the medium underneath the station $(h(t)$, receiver function).

First, the recorded seismograms need to be rotated into the vertical-radialtransverse (Z-R-T) coordinate system. In this system, the radial (R) component is aligned along the backazimuth (angle to north between station and event) and the transverse (T)-component is aligned orthogonally to $\mathrm{R}$. The radial, transverse and vertical particle motion $\left(u_{R}(t), u_{T}(t)\right.$, and $\left.u_{Z}(t)\right)$ can then be written as

$$
\begin{gathered}
u_{R}(t)=i(t) * h_{P, R} * s_{p}(t) \\
u_{T}(t)=i(t) * h_{P, T} * s_{p}(t) \\
u_{Z}(t)=i(t) * h_{P, Z} * s_{p}(t) .
\end{gathered}
$$

Under the assumption that for vertical incoming P-waves $h_{P, R}$ is equal to $\delta(t)$, equation C.3 can be reduced to

$$
\begin{aligned}
& u_{R}(t)=h_{P, T} * u_{R}(t) \\
& u_{T}(t)=h_{P, Z} * u_{R}(t)
\end{aligned}
$$

The receiver functions can then be calculated by deconvolving the horizontal components with the vertical component.

The amplitude and polarity of the phases depend on the elastic properties across the discontinuity and the incident angle of the arriving wave. Assuming an incident planar wave, the delay time between the initial P phase and the 


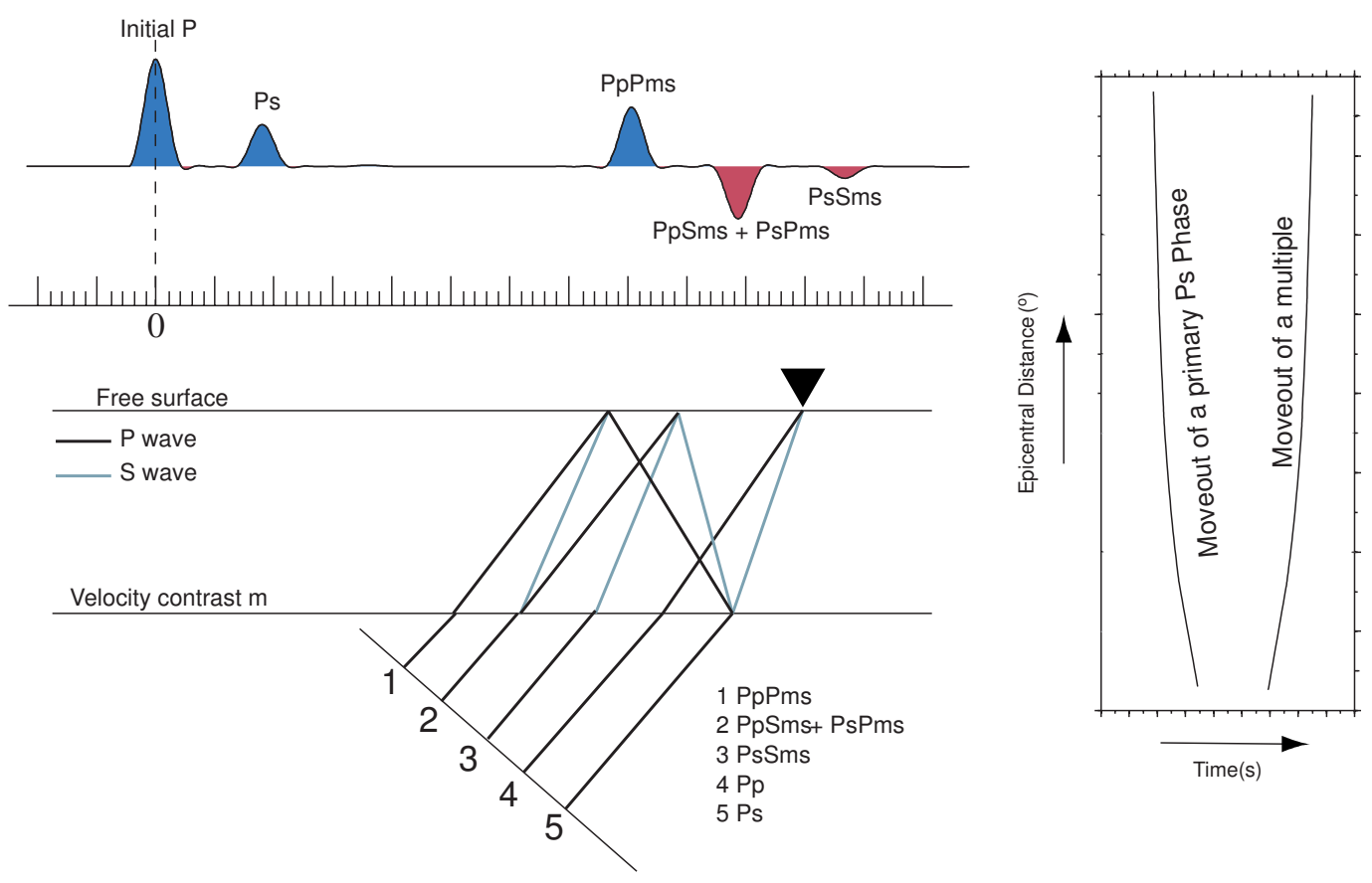

Figure C.1: Schematic illustration of receiver functions principles. Bottom left shows the raypaths for 5 different phases (Pp, Ps, PpPs, PsPs and PpSs). Except for the first letter, lower case letters denote up-going travel paths and upper case letters denote down-going travel paths. The top left side shows the idealised receiver function for theses phases. The right hand side shows idealised receiver functions for the Ps phase and multiples of it, plotted against epicentral distance. Note that the moveout of this phases is different, where for Ps conversion the traveltime decreases with epicentral distance, the traveltime of the multiples increases with epicentral distance.

Ps phase can be calculated depending on the velocity of the S-wave $\left(V_{s}\right)$ between discontinuity and surface, the corresponding P-wave velocity $\left(V_{p}\right)$, and the horizontal slowness $p$ or ray parameter $(p=d T / D \Delta$, with $T$ being the traveltime and $\Delta$ being the angular distance for a station event pair). The delay time can be expressed as:

$$
t_{P s}=H\left(\sqrt{\frac{1}{V_{s}^{2}}-p^{2}}-\sqrt{\frac{1}{V_{p}^{2}}-p^{2}}\right)
$$

Additionally to the two primary phases, there are multiples which have at least two reflections along their travelpath. They were reflected on the free surface or within a layer underneath the station and are partly assumed to be noise, because they can overlap with later arrivals. However, they can also be used to get a better constraint on the velocity model developed (see section C.2). 


\section{C.1 Analysing receiver functions}

In practise, the computation of receiver functions is a complex process and different methods exist. The simplest way is a time domain deconvolution [Abers et al., 1995], but this approach is dominated by higher frequencies and can therefore often only be used on bandpass filtered $(<0.5 \mathrm{~Hz})$ data. Another method is the spectral division [Ammon et al., 1990], which calculates the ratio of Fourier transforms of the different components: $H_{R}(f)=Y_{R}(f) / Y_{Z}(f)$ and $H_{T}(f)=Y_{T}(f) / Y_{Z}(f)$, where $Y_{R}(f), Y_{T}(f)$ and $Y_{Z}(f)$ are the Fourier spectra of the radial, transverse and vertical component, respectively. An inverse Fourier transform of the spectral functions $\left(H_{R}(f)\right.$ and $\left.H_{T}(f)\right)$ into time domain then provides a prediction filter. However, this creates an unstable result due to zeros in the $Y_{Z}(f)$ function and a waterlevel has to be introduced to avoid this. This, in turn, obscures low amplitude spectral components.

The multiple-taper correlation method [Park \& Levin, 2000] used in this study has several advantages compared to the two methods presented before. It can handle higher frequency data, accounts for noise and provides uncertainties in the frequency domain which can be used for weighting the individual receiver functions before stacking. The method works in the frequency domain, where multi-taper spectral estimation is used. For this, the data are multiplied by several leakage resistant tapers and a single spectrum is estimated out of their Fourier-transforms. This minimises spectral leakage, so low-amplitude portions can contribute usefully to the receiver functions estimation, which increases the useable bandwidth. Including a damping factor, estimated from pre-event data, allows to account for noise. Furthermore, the method allows creating a weighted linear combination from different seismic records by calculating an uncertainty for the horizontal component.

The following section describes the theoretical background and the algorithm used [Park \& Levin, 2000]. Starting with three finite time series $\left[u_{R}(n \tau), u_{T}(n \tau)\right.$ and $\left.u_{Z}(n \tau)\right]$, which describe the radial, transverse and vertical particle motion, with $n$ being the sample number and $\tau$ the sample interval, the discrete spectrum can be estimated to

$$
Y_{\gamma}^{(k)}(f)=\sum_{n=0}^{N-1} u_{n}^{\gamma} w_{n}^{(k)} e^{i 2 \pi f n \tau}
$$

where $\gamma$ denotes either $\mathrm{R}, \mathrm{T}$ or $\mathrm{Z}$ components, $\mathrm{N}$ is the number of samples and $w_{n}^{(k)}$ is the Kth taper for a user-chosen time-bandwidth product $p$. Choosing the parameters $p$ and $K$ presents a trade-off between the resolution and the variance of spectral estimates. The usage of three tapers $(\mathrm{K}=3)$ and a $p$ value of 2.5 is ideal for the investigation of Ps conversions from depth not larger than $100 \mathrm{~km}$ [Park \& Levin, 2000]. 
The frequency domain radial and transverse receiver functions $\left(H_{R}(f)\right.$ and $\left.H_{T}(f)\right)$ can be calculated using the damped spectral correlation estimators

$$
\begin{aligned}
& H_{R}(f)=\frac{\sum_{k=0}^{K-1}\left(Y_{Z}^{(k)}(f)\right)^{*} Y_{R}^{(k)}(f)}{\left(\left(\sum_{k=0}^{K-1}\left(Y_{Z}^{(k)}\right)^{*} Y_{Z}^{(k)}\right)+S_{o}(f)\right)} \\
& H_{T}(f)=\frac{\sum_{k=0}^{K-1}\left(Y_{Z}^{(k)}(f)\right)^{*} Y_{T}^{(k)}(f)}{\left(\left(\sum_{k=0}^{K-1}\left(Y_{Z}^{(k)}\right)^{*} Y_{Z}^{(k)}\right)+S_{o}(f)\right)},
\end{aligned}
$$

where the damping factor $S_{o}(f)$ is a spectrum estimate of the pre-event data (noise) on the vertical component.

The coherence estimates, $C_{R}(f), C_{T}(f)$, between vertical and horizontal components in the frequency domain are calculated as

$$
\begin{aligned}
& C_{R}(f)=\frac{\sum_{k=0}^{K-1}\left(Y_{Z}^{(k)}(f)\right)^{*} Y_{R}^{(k)}(f)}{\sqrt{\left(\sum_{k=0}^{K-1}\left(Y_{R}^{(k)}(f)\right)^{*} Y_{R}^{(k)}(f)\right)\left(\sum_{k=0}^{K-1}\left(Y_{Z}^{(k)}(f)\right)^{*} Y_{Z}^{(k)}(f)\right)}} \\
& C_{T}(f)=\frac{\sum_{k=0}^{K-1}\left(Y_{Z}^{(k)}(f)\right)^{*} Y_{T}^{(k)}(f)}{\sqrt{\left(\sum_{k=0}^{K-1}\left(Y_{T}^{(k)}(f)\right)^{*} Y_{T}^{(k)}(f)\right)\left(\sum_{k=0}^{K-1}\left(Y_{Z}^{(k)}(f)\right)^{*} Y_{Z}^{(k)}(f)\right)}},
\end{aligned}
$$

where a coherence value of 1 represents a perfect correlation between the components and a value of zero represents no correlation. With the coherence estimates (equations C.9) the uncertainties of the receiver functions can be calculated under the assumption that the residual variance on the horizontal components can be used to estimate the total noise level,

$$
\begin{aligned}
& \operatorname{var}\left(H_{R}(f)\right)=\left(\frac{1-\left(C_{R}(f)\right)^{2}}{(K-1)\left(C_{R}(f)\right)^{2}}\right)\left|H_{R}(f)\right|^{2} \\
& \operatorname{var}\left(H_{T}(f)\right)=\left(\frac{1-\left(C_{T}(f)\right)^{2}}{(K-1)\left(C_{T}(f)\right)^{2}}\right)\left|H_{T}(f)\right|^{2} .
\end{aligned}
$$

The inverse of this variance is then used for weighting the individual receiver functions, where functions with a good correlation between horizontal and vertical component will influence the final receiver function more than a less correlated pair.

After the individual receiver functions are correlated and weighted, they are stacked into bins. Finally, every bin gets low-pass filtered with a cosine-squared filter $\left(\cos ^{2}\left(\frac{\pi f}{2 f_{c}}\right)\right)$ to prevent the Gibbs-effect (ringing).

Receiver functions in the time domain are calculated by an inverse Fourier 
transform and are normalised with the factor $2 f_{N} / f_{c}$, where $f_{N}=1 /(2 \tau)$, which preserves the amplitude of the converted phases. Formal uncertainties are nonexistent for time domain receiver functions.

\section{C.2 H- $\kappa$ stacking technique}

The H- $\kappa$ stacking technique is a straightforward method to obtain the Moho depth and the $V_{p} / V_{s}$ ratio. It transforms the time domain receiver functions into a depth $-V_{p} / V_{s}$ domain, under the assumption of a known $V_{p}$ value. Therefore, the amplitudes of individual receiver functions are stacked at predicted arrival times for different pairs of crustal thickness $(H)$ and $V_{p} / V_{s}$ ratio $(\kappa)$ [Zhu \& Kanamori, 2000]

$$
s(H, \kappa)=\sum_{n=1}^{N}\left[w_{1} A_{n}\left(t_{P s}\right)+w_{2} A_{n}\left(t_{P p P_{s}}\right)-w_{3} A_{i}\left(t_{P p P_{s}+P_{s} P_{s}}\right)\right],
$$

where $s$ is the stacked amplitude in the $\mathrm{H}-V_{p} / V_{s}$ domain, $w_{1}, w_{2}, w_{3}$ are the weights associated with amplitude $A$ of the $P s, P p P s$ and $P p P s+P s P s$ phases, respectively and $\mathrm{N}$ is the number of receiver functions stacked. $s(H, \kappa)$ reaches a maximum where the direct and reverberated converted phases stack coherently. The relationship between the delay times $t_{P_{s}}, t_{P p P_{s}}$ and $t_{P p P_{s}+P_{s} P_{s}}$ and the crustal thickness, P-wave velocity and the rayparameters $(p)$ are as follows:

$$
\begin{aligned}
& H=\frac{t_{P s}}{\sqrt{\frac{1}{V_{s}^{2}}-p^{2}}-\sqrt{\frac{1}{V_{p}^{2}}-p^{2}}} \\
& H=\frac{t_{P p P_{s}}}{\sqrt{\frac{1}{V_{s}^{2}}-p^{2}}+\sqrt{\frac{1}{V_{p}^{2}}-p^{2}}} \\
& H=\frac{t_{P p S s+P_{s} P_{s}}}{2 \sqrt{\frac{1}{V_{s}^{2}}-p^{2}}}
\end{aligned}
$$

The $P s, P p P s$ have positive amplitudes. The latest arrival, the $P p P s+P_{s} P_{S}$ phase, has a negative polarity. Identifying the different phases in the receiver function stacks can be hard and none of the data presented here (figures 5.6 and 5.3) show a PpPs $+P s P s$ arrival. Therefore, the weighting factor for this phase is set to zero, where the other two phases are weighted equally with $w_{1}=0.5$ and $w_{2}=0.5$.

Uncertainties are calculated using a bootstrap method for 200 randomly selected sample populations from each station dataset to obtain the $95 \%$ confidence interval [Salmon, 2008]. An uncertainty in the assumed $V_{p}$ velocity will have only little influence on the $V_{p} / V_{s}$ ratio, but more on the depth of the Moho. The er- 
ror for the depth estimation can be assumed to be $\pm 1.5 \mathrm{~km}$ [Mohsen et al., 2005]. This is based on a Moho depth of $35 \mathrm{~km}$ and on an uncertainty of $0.2 \mathrm{~km} / \mathrm{s}$ in the average crustal velocity $V_{p}$. Another uncertainty factor is the limited bandwidth of the teleseismic data. Phase readings on common teleseismic data have an accuracy of around $0.2-0.3 \mathrm{~s}$, which limits the resolution to about $\pm 2 \mathrm{~km}$ on the Moho depth [Lombardi et al., 2008]. Thus, the uncertainty in the results of the $\mathrm{H}-\kappa$ stacking technique is the summed uncertainty from bootstrapping, the $V_{p}$ uncertainty and the finite bandwidth considerations.

The presence of structural complications, like anisotropy, strong velocity contrasts (apart from the Moho) and dipping layers make the analysing of receiver functions rather complex. A dipping Moho results in a change of arrival times for the different phases from different backazimuths, which results in an incoherent stack.

\section{C.3 Common conversion point (CCP) stacking}

A better method to study lateral changes in the subsurface feature is the common conversion point (CCP) stack. This method is similar to common midpoint stacking of reflected data, which is a standard tool in the reflection seismic exploration [Dueker \& Sheehan, 1997]. This method works basically in three steps [Chen et al., 2005]; (1) receiver functions get moveout corrected based on a one dimensional velocity model, (2) they get binned according to their sampling points and (3) finally stacked. For the moveout correction, the traveltime of the receiver function are corrected as they would be observed from a zero receiver-event distance (horizontal slowness $\mathrm{p}=0$ ). The correction term can be calculated as the time difference between the predicted traveltime of the Ps conversion at a conversion depth $d\left(T_{P_{d} s}(p)\right)$, based on an assumed $1 \mathrm{D}$ velocity model, and the traveltime of the hypothetical zero distance $\mathrm{P}$ to $\mathrm{S}$ conversion at a conversion depth $d\left(T_{P_{d} S}(0)\right)$ :

$$
\Delta T_{P_{d} S}(p)=T_{P_{d} S}(p)-T_{P_{d} S}(0) .
$$

Assuming a flat layered velocity model and a planar incident wave, $T_{P_{d} s}(p)$ can be calculated as:

$$
T_{P_{d} S}(p)=\int_{-d}^{0}\left[\sqrt{\frac{1}{V_{s}(z)^{2}}-p^{2}}-\sqrt{\frac{1}{V_{p}(z)^{2}}-p^{2}}\right] d z,
$$

with $V_{s}$ and $V_{p}$ being the vertical varying velocities. After the moveout correction, the individual receiver functions are sorted into conversion point bins according to their piercing point at a certain depth. These piercing points are found by tracing the converted S-wave raypath using the same 1-D velocity model as 
used for the moveout correction. Finally, the receiver functions are stacked within their respective bins.

The final stacked section is then similar to what is expected for a perpendicular incoming P-wave. An additional advantage of this method is that signal generated coherent noise, such as sediment reverberations, becomes incoherent in the multistation stack [Dueker \& Sheehan, 1997]. 


\section{Appendix D}

\section{Finite element modelling (FEM) theory}

Finite element methods and techniques are in use in many different areas for engineers and scientists. Finite element modelling (FEM) provides an approach to solve problems which would otherwise be difficult to achieve. The basic idea of FEM is to solve a physical or mathematical problem by breaking up the whole into a discrete number of smaller, finite, parts called elements. Then, an analysis is performed on these "local" elements. Afterwards, reassembling achieves a solution for the original "global" problem.

The theory will be introduced using a simple, illustrative example, a three member truss. First, one has to divide the example into elements, which will be a single truss member (see figure D.1). It is assumed that this part can only support axial loads, where further splitting would not increase accuracy of the final result. Furthermore, with the assumption of a linear relationship between forces and displacement for such a truss member, the equation system D.2 - D.4 can be set up.

The notation for this example is as follows: the nodes are labelled with Roman numbers $(I-I I I)$ and the different elements are labelled with Latin numbers (1) - (3). Lower case letters are used for local (element) quantities, whereas upper case letters are used for global (entire truss) quantities.

$$
\begin{gathered}
f_{1 x}=k_{11} u_{1 x}+k_{12} u_{1 y}+k_{13} u_{2 x}+k_{14} u_{2 y} \\
f_{1 y}=k_{21} u_{1 x}+k_{22} u_{1 y}+k_{23} u_{2 x}+k_{24} u_{2 y} \\
f_{2 x}=k_{31} u_{1 x}+k_{32} u_{1 y}+k_{33} u_{2 x}+k_{34} u_{2 y} \\
f_{2 y}=k_{41} u_{1 x}+k_{42} u_{1 y}+k_{43} u_{2 x}+k_{44} u_{2 y}
\end{gathered}
$$

where $f_{i}$ is the force in direction $i, u_{j}$ is the displacement in direction $j$ and $k_{i j}$ the 


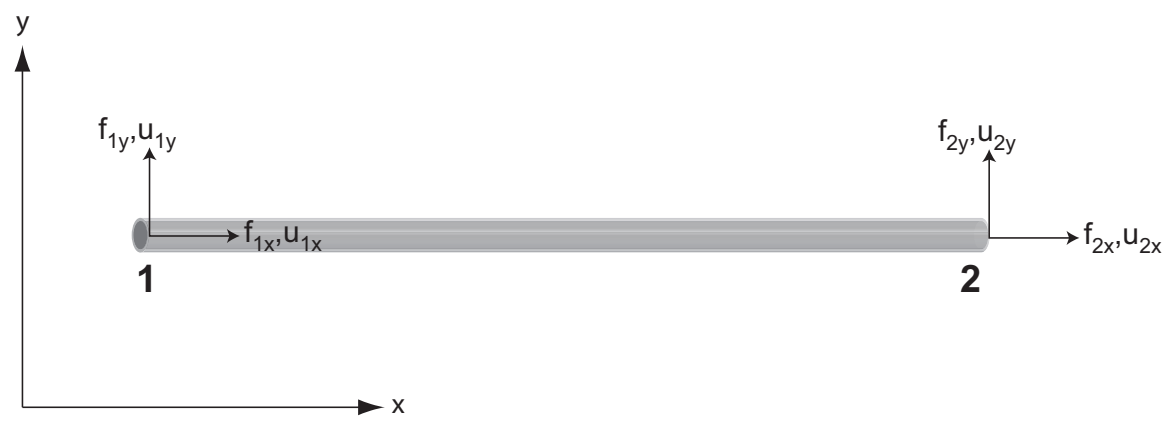

Figure D.1: Single truss member and it forces and displacements at the end of the truss

"stiffness coefficient". Using a matrix notation:

$$
\left(\begin{array}{l}
f_{1 x} \\
f_{1 y} \\
f_{2 x} \\
f_{2 y}
\end{array}\right)=\left|\begin{array}{llll}
k_{11} & k_{12} & k_{13} & k_{14} \\
k_{21} & k_{22} & k_{23} & k_{24} \\
k_{31} & k_{32} & k_{33} & k_{34} \\
k_{41} & k_{42} & k_{43} & k_{44}
\end{array}\right|\left(\begin{array}{l}
u_{1} \\
u_{2} \\
u_{3} \\
u_{4}
\end{array}\right) .
$$

The square matrix $|k|$ is called the "stiffness matrix". This matrix defines the material properties of the truss or element, respectively. The elements of the "stiffness matrix" need to be determined. This can be done by the following procedure. First, the magnitudes of $f_{1 y}$ and $f_{2 y}$ (the second and fourth row) are set to zero. Also the second and forth columns can be set to zero because of the fundamental relationship that the displacement in $y$ direction should not affect the magnitude of the force in $x$ direction. Therefore, equation D. 5 becomes:

$$
\left(\begin{array}{l}
f_{1 x} \\
f_{1 y} \\
f_{2 x} \\
f_{2 y}
\end{array}\right)=\left|\begin{array}{cccc}
k_{11} & 0 & k_{13} & 0 \\
0 & 0 & 0 & 0 \\
k_{31} & 0 & k_{33} & 0 \\
0 & 0 & 0 & 0
\end{array}\right|\left(\begin{array}{l}
u_{1} \\
u_{2} \\
u_{3} \\
u_{4}
\end{array}\right) .
$$

Finally, a displacement in positive $x$ direction at node 2 will result in forces just opposite to those at node 1 in positive $x$ direction, so $k_{i 3}=-k_{i 1}$ :

$$
\left(\begin{array}{l}
f_{1 x} \\
f_{1 y} \\
f_{2 x} \\
f_{2 y}
\end{array}\right)=k\left|\begin{array}{cccc}
1 & 0 & -1 & 0 \\
0 & 0 & 0 & 0 \\
-1 & 0 & 1 & 0 \\
0 & 0 & 0 & 0
\end{array}\right|\left(\begin{array}{l}
u_{1} \\
u_{2} \\
u_{3} \\
u_{4}
\end{array}\right)
$$

This is the stiffness matrix for the special case of a truss with no incline to the horizontal. So, a similar derivation as shown above can be used to create the 


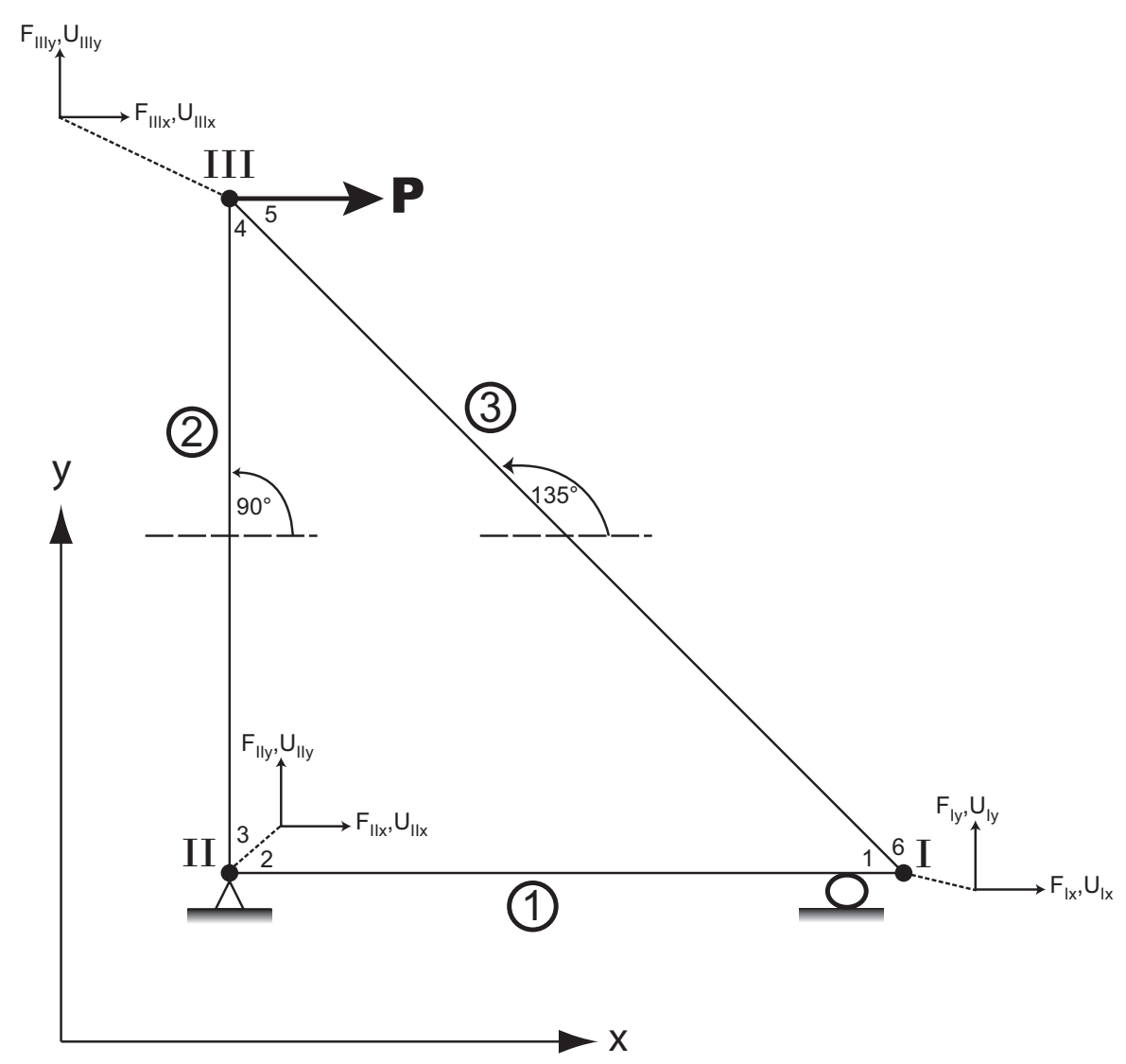

Figure D.2: Entire truss, consisting out of three single parts. Furthermore, the external force $P$ acting in $x$-direction at node $I I$ is shown.

general stiffness matrix:

$$
\left(\begin{array}{l}
f_{1 x} \\
f_{1 y} \\
f_{2 x} \\
f_{2 y}
\end{array}\right)=k\left|\begin{array}{cccc}
c^{2} & s c & -c^{2} & -s c \\
s c & s^{2} & -s c & -s^{2} \\
-c^{2} & -s c & c^{2} & s c \\
-s c & -s^{2} & s c & s^{2}
\end{array}\right|\left(\begin{array}{l}
u_{1} \\
u_{2} \\
u_{3} \\
u_{4}
\end{array}\right),
$$

where $s$ and $c$ are abbreviations for $\sin \theta$ and $\cos \theta$, respectively, and $\theta$ is the angle against the horizontal.

The main objective is not only to know the stiffness matrix for a single truss but also to get the joint displacement and the element force for any given problem matrix for any problem. The proceeding is explained for such a case by means of a three element truss with a given force $P$, shown in figure D.2. First, the solution for every single truss is determined, before everything is assembled, to get a displacement at each node.

The stiffness matrix for the elements is: 
element (1) with $\theta=0^{\circ}$

$$
\left(\begin{array}{l}
f_{2 x} \\
f_{2 y} \\
f_{1 x} \\
f_{1 y}
\end{array}\right)=k\left|\begin{array}{cccc}
1 & 0 & -1 & 0 \\
0 & 0 & 0 & 0 \\
-1 & 0 & 1 & 0 \\
0 & 0 & 0 & 0
\end{array}\right|\left(\begin{array}{l}
u_{2 x} \\
u_{2 y} \\
u_{1 x} \\
u_{1 y}
\end{array}\right)
$$

element (2) with $\theta=90^{\circ}$

$$
\left(\begin{array}{l}
f_{3 x} \\
f_{3 y} \\
f_{4 x} \\
f_{4 y}
\end{array}\right)=k\left|\begin{array}{cccc}
0 & 0 & 0 & 0 \\
0 & 1 & 0 & -1 \\
0 & 0 & 0 & 0 \\
0 & -1 & 0 & 1
\end{array}\right|\left(\begin{array}{l}
u_{3 x} \\
u_{3 y} \\
u_{4 x} \\
u_{4 y}
\end{array}\right)
$$

element (3) with $\theta=135^{\circ}$

$$
\left(\begin{array}{l}
f_{6 x} \\
f_{6 y} \\
f_{5 x} \\
f_{5 y}
\end{array}\right)=k\left|\begin{array}{cccc}
\frac{1}{2} & -\frac{1}{2} & -\frac{1}{2} & \frac{1}{2} \\
-\frac{1}{2} & \frac{1}{2} & \frac{1}{2} & -\frac{1}{2} \\
-\frac{1}{2} & \frac{1}{2} & \frac{1}{2} & -\frac{1}{2} \\
\frac{1}{2} & -\frac{1}{2} & -\frac{1}{2} & \frac{1}{2}
\end{array}\right|\left(\begin{array}{l}
u_{6 x} \\
u_{6 y} \\
u_{5 x} \\
u_{5 y}
\end{array}\right)
$$

Now, it is necessary to set relationships between global and local forces. For node $I$, they are defined as:

$$
\begin{aligned}
& x-\text { direction }: F_{I x}-f_{1 x}-f_{6 x}=0 \\
& y-\text { direction: } F_{I y}-f_{1 y}-f_{6 y}=0
\end{aligned}
$$

Considering that the single trusses are connected with each other and thus the local forces and displacements at the end for two connected trusses are the same, one can substitute $u_{1}, u_{2}, u_{3}, u_{4}, u_{5}, u_{6}$ :

$$
\begin{gathered}
u_{1}=u_{6}=U_{I} \\
u_{2}=u_{3}=U_{I I} \\
u_{4}=u_{5}=U_{I I I}
\end{gathered}
$$

Solving for $F_{I x}$ and $F_{I y}$ and substituting $f_{1 x}, f_{6 x}, f_{1 y}, f_{6 y}$ leads to:

$$
\begin{aligned}
& F_{I x}=k\left(\frac{3}{2} U_{I x}-\frac{1}{2} U_{I y}-U_{I I x}-\frac{1}{2} U_{I I I x}+\frac{1}{2} U_{I I I y}\right) \\
& F_{I y}=k\left(-\frac{1}{2} U_{I x}+\frac{1}{2} U_{I y}+\frac{1}{2} U_{I I I x}-\frac{1}{2} U_{I I I x}\right) .
\end{aligned}
$$


Accordingly, for node $I I$ and $I I I$ :

$$
\begin{aligned}
F_{I I x} & =k\left(-U_{I x}+U_{I I x}\right) \\
F_{I I y} & =k\left(-U_{I y}+U_{I I y}\right) \\
F_{I I I x} & =k\left(-\frac{1}{2} U_{I x}+\frac{1}{2} U_{I y}+\frac{1}{2} U_{I I I x}-\frac{1}{2} U_{I I I y}\right) \\
F_{I I I y} & =k\left(\frac{1}{2} U_{I x}-\frac{1}{2} U_{I y}-U_{I I y}-\frac{1}{2} U_{I I I x}+\frac{3}{2} U_{I I I y}\right) .
\end{aligned}
$$

The global force-displacement equation in matrix notation is

$$
\left(\begin{array}{l}
F_{I x} \\
F_{I y} \\
F_{I I x} \\
F_{I I y} \\
F_{I I x} \\
F_{I I I y}
\end{array}\right)=k\left|\begin{array}{cccccc}
\frac{3}{2} & -\frac{1}{2} & -1 & 0 & -\frac{1}{2} & \frac{1}{2} \\
-\frac{1}{2} & \frac{1}{2} & 0 & 0 & \frac{1}{2} & -\frac{1}{2} \\
-1 & 0 & 1 & 0 & 0 & 0 \\
0 & -1 & 0 & 1 & 0 & 0 \\
-\frac{1}{2} & \frac{1}{2} & 0 & 0 & \frac{1}{2} & -\frac{1}{2} \\
\frac{1}{2} & -\frac{1}{2} & 0 & -1 & -\frac{1}{2} & \frac{3}{2}
\end{array}\right|\left(\begin{array}{c}
U_{I x} \\
U_{I y} \\
U_{I I x} \\
U_{I I y} \\
U_{I I I x} \\
U_{I I I y}
\end{array}\right) .
$$

In the next step, $R_{I I I x}$ is set to the external force $P$. With the "boundary conditions" that node II is pinned and node I is able to move in $x$-direction but not in $y$-direction, equation D.23 can be written as:

$$
\left(\begin{array}{c}
0 \\
F_{I y} \\
F_{I I x} \\
F_{I I y} \\
P \\
0
\end{array}\right)=k\left|\begin{array}{cccccc}
\frac{3}{2} & \frac{1}{2} & -1 & 0 & -\frac{1}{2} & \frac{1}{2} \\
-\frac{1}{2} & \frac{1}{2} & 0 & 0 & \frac{1}{2} & -\frac{1}{2} \\
-1 & 0 & 1 & 0 & 0 & 0 \\
0 & -1 & 0 & -1 & 0 & 0 \\
-\frac{1}{2} & \frac{1}{2} & 0 & 0 & \frac{1}{2} & \frac{1}{2} \\
\frac{1}{2} & -\frac{1}{2} & 0 & -1 & -\frac{1}{2} & \frac{3}{2}
\end{array}\right|\left(\begin{array}{c}
U_{I x} \\
0 \\
0 \\
0 \\
U_{I I I x} \\
U_{I I I y}
\end{array}\right)
$$

Thus, the matrix can be reduced to solve for unknown displacement or unknown forces. An example for the displacement is:

$$
\left(\begin{array}{l}
0 \\
P \\
0
\end{array}\right)=k\left|\begin{array}{ccc}
\frac{3}{2} & -\frac{1}{2} & \frac{1}{2} \\
-\frac{1}{2} & \frac{1}{2} & -\frac{1}{2} \\
\frac{1}{2} & -\frac{1}{2} & \frac{3}{2}
\end{array}\right|\left(\begin{array}{c}
U_{I x} \\
U_{I I I x} \\
U_{I I I y}
\end{array}\right)
$$

This leads to

$$
\begin{aligned}
U_{I x} & =\frac{P}{k} \\
U_{I I I x} & =4 \frac{P}{k} \\
U_{I I I y} & =\frac{P}{k}
\end{aligned}
$$


This shows the result for the global displacement at the three different nodes in either $x$ - or $y$-direction. As mentioned before, the unknown global forces can be calculated in the same way. Most of the problems FEM is used for are much more complex and involve large numbers of elements and nodes to get an accurate solution. This can be very time consuming even on modern computers. However, the above example illustrates the basic idea behind FEM and helps to understand the necessary steps which have to be taken to set up a model for FEM. 


\section{Appendix E}

\section{Three-component refraction data from the northwestern edge of the SWB}

\section{E.1 Introduction}

Oil and gas exploration companies collect many multi channel seismic surveys in potential hydrocarbon basins. In the Wanganui Basin alone there are several hundreds of kilometres of multi channel seismic (MCS) data collected over the last 20 years. In New Zealand this data stays confidential for 5 years, before it becomes available for other companies and research institutes. The seismic data are normally recorded with single vertical geophones. In this chapter an experiment is described where over 650 on- and offshore shots were recorded with five three-component short period seismometers. The aim of this study was to test if this method records higher quality data and consequently be able to record larger offsets than standard industry equipment. In addition, the recording of two additional horizontal components should provide better S-wave arrivals and thus increases the likelihood to acquire some information about Poisson's ratio.

\section{E.2 Dataset}

In June 2006 Austral-Pacific Ltd. conducted a seismic experiment across the southern coast of the Taranaki Peninsula (figure E.1). Their experiment covered two different lines. One line (Line A) was shot perpendicular to the coastline and consisted of 659 shots of which 445 were offshore shots. The second line (Line B) runs parallel to the coastline, thus normal to LINE A, and consisted of 208 offshore shots. The shot interval for both lines was $25 \mathrm{~m}$. For the detailed listing of 


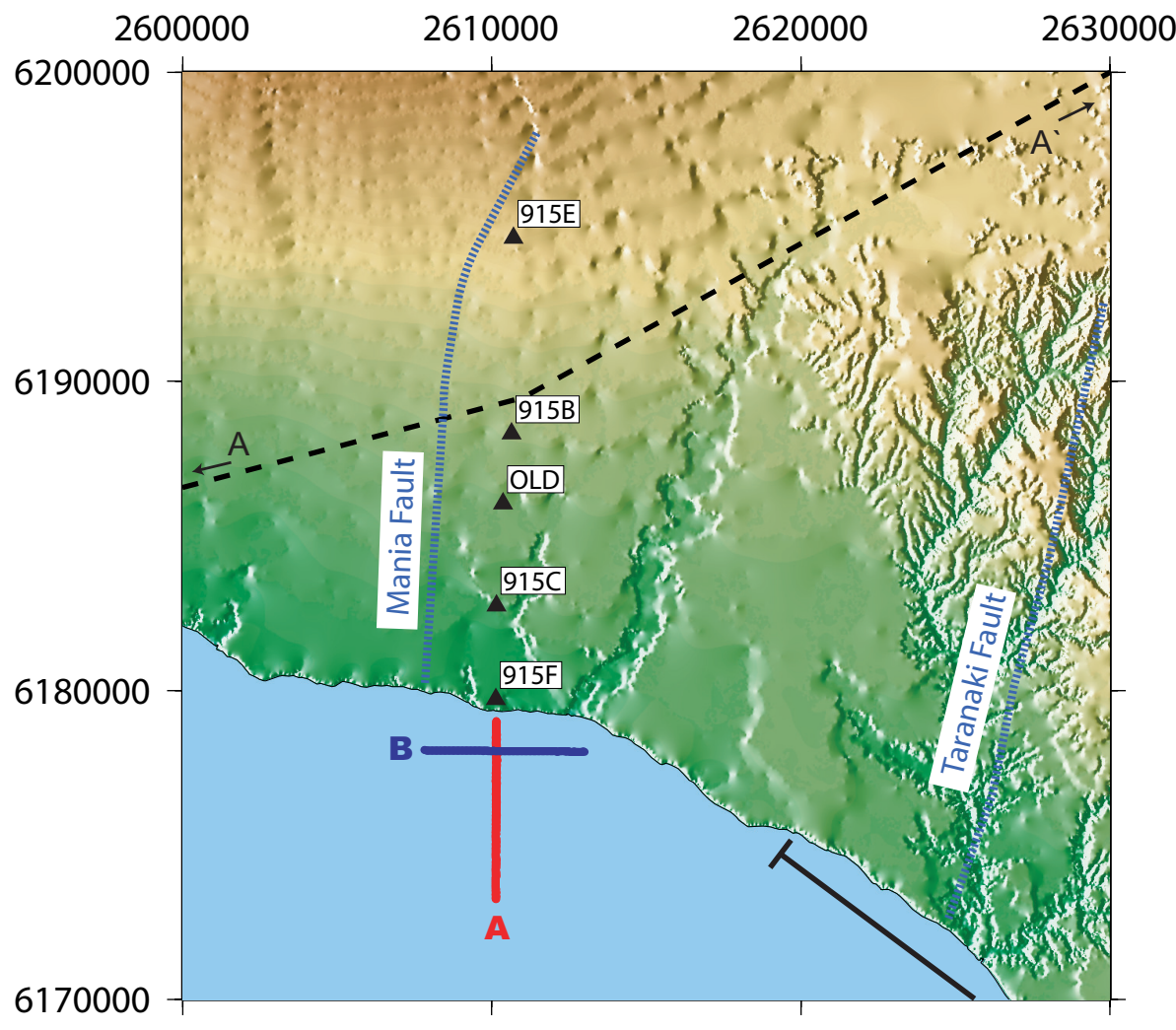

Figure E.1: Overview map of the deployment. Black triangles indicate receiver locations for three-component seismographs. Red and blue dots indicate the locations of the shots from line $A$ and line $B$, respectively (shotspacing of $25 \mathrm{~m}$ to small to identify individual points). The blue dashed lines represent the two major faults in the study area, which are both part of the Taranaki Fault Zone. The black dashed line shows the profile of the schematic geological cross-section shown in figure E.10. Black solid line indicates the location of the seismic reflection profile shown in figure E.8.

the field parameters see table E.1.

The data were recorded by Australian Pacific with a continuous on-offshore line, with hydrophones offshore and geophones onshore. This data could be used during processing of our three-component data as a resource for defining the timebase (see section E.3), but is not shown in this thesis because of confidentially reasons.

Within the context of this experiment five three-component onshore short period seismometer could be deployed along a line, perpendicular to the coast, in line with shotline LINE A (see map in figure E.1). The seismometers were deployed a day before the experiment took place and were setup for continuous recording with a sample rate of 200 samples per second. The company conducting the experiment provided the GPS timing for the offshore shots of Line A. 
E.3 Processing

\begin{tabular}{|c|c|}
\hline shot info & \\
\hline $\begin{array}{c}\text { offshore source } \\
\text { shot spacing } \\
\text { min offset } \\
\text { max offset } \\
\text { length shot spread }\end{array}$ & $\begin{array}{c}\text { Sodera Gi GUNS with } 600 \text { cu.in. gun Volume } \\
25 \mathrm{~m} \\
1185 \mathrm{~m} \text { (LINE A) } \\
21721 \mathrm{~m} \text { (LINE A) } \\
5825 \mathrm{~m} \text { LINE (A) } \\
5124 \mathrm{~m} \text { LINE (B) }\end{array}$ \\
\hline \multicolumn{2}{|l|}{ "receiver data } \\
\hline hardware & $\begin{array}{l}\text { recording device: } 4 \text { Reftek } 130 \text { and } 1 \text { Reftek } 87 \\
\text { sensors: } 5 \text { Mark product L4-C } 1 \mathrm{~Hz} \text { seismometer }\end{array}$ \\
\hline \multicolumn{2}{|l|}{ receiver location } \\
\hline $\begin{array}{l}\text { Rec No 915B } \\
\text { min offset }\end{array}$ & $\begin{array}{c}2610633 \mathrm{E} \quad 6188303 \mathrm{~N} \\
9798 \mathrm{~m}\end{array}$ \\
\hline $\begin{array}{l}\text { Rec No 915C } \\
\text { min offset }\end{array}$ & $\begin{array}{c}2610151 \mathrm{E} \quad 6182749 \mathrm{~N} \\
4231 \mathrm{~m}\end{array}$ \\
\hline $\begin{array}{l}\text { Rec No 915E } \\
\text { min offset }\end{array}$ & $\begin{array}{c}2610686 \mathrm{E} \quad 6194635 \mathrm{~N} \\
16127 \mathrm{~m}\end{array}$ \\
\hline $\begin{array}{l}\text { Rec No } 915 \mathrm{~F} \\
\text { min offset } \\
\text { OLD } \\
\text { min offset }\end{array}$ & $\begin{array}{c}2610117 \mathrm{E} \quad 6179703 \mathrm{~N} \\
1185 \mathrm{~m} \\
2610358 \mathrm{E} \quad 6186034 \mathrm{~N} \\
6838 \mathrm{~m}\end{array}$ \\
\hline
\end{tabular}

Table E.1: Field parameters for the experiment. Line B did not get processed due to lack of shot time information.

\section{E.3 Processing}

The first processing step was the conversion of the rawdata from the recording devices into the SEGY file format. As mentioned before, all the recording units recorded continuously from the time of their deployment. Thus, these data needed to be cut, starting at the time of the shot and sorted into so called receivergathers. These gathers contain all information recorded by a single receiver starting at the shot times for a certain time-window. The position of receiver and shots are interchangeable, because the raypath is reversible. This means there is no difference if several shots are recorded by a single receiver or if a single shot is recorded by an array of receivers. Thus, receiver gathers are equivalent to shotgathers, which are used in shallow active seismic experiments.

First visual examination of the recorded data showed clear arrivals only for the two closest receivers (915F and 915C). The other three receivers did not show any sign of coherent energy. The length of the time-windows for the cutting was chosen to $5 \mathrm{~s}$ so that all the recognisable events are within the window. Figure E. 2 shows an example of the three-component data for the receiver located closest to the shots $(915 \mathrm{~F})$. 
The recording units are all equipped with a global positioning (GPS) antenna, which delivers an absolute timing and the exact location coordinates. The receiver gathers were produced by means of software tool called "segygather" which is part of the PASCAL ${ }^{T M}$ processing software package and cuts and sorts continuous SEGY files into common receiver-gathers, using a provided shot time file. The output can directly be read by Claritas ${ }^{T M}$ processing software for further processing and interpretation.

In receiver gathers the first arrivals are supposed to line up, with increasing traveltime for larger offsets. However, cutting the gathers with the provided shot times produces gathers where the first arrivals in the gathers do not line up as expected and have a time offset of up to $\pm 300 \mathrm{~ms}$ (see E.3(a)). A miss function in the recording units can be excluded because all the gathers for all recording units show the same behaviour. The most likely explanation is an inaccurate shot time which was confirmed by the operating company.

To create a new timebase for the receiver-gathers the following approach is used: The traveltimes picked from one of the one-component geophones, which was located at the same position as the three-component seismometer 915F, can be used to calculated the absolute shot time by subtracting these traveltimes from the absolute time of the first arrival picked on the three-component data. These new shot times where then used to create new receiver-gathers. Figure E.3(b) shows the same section of the data as figure E.3(a) but created with a new timebase. The first arrivals are much better aligned but there are still offsets between two neighbouring channels. This residual timeshift can be explained by the shot order sequence: On the way away from the coast the shots were fired with a $50 \mathrm{~m}$ shotspacing. On the way back, they were also fired with a $50 \mathrm{~m}$ spacing but exactly between the previous shots to get an overall shotspacing of $25 \mathrm{~m}$. Thus, the neighbouring traces in figures E.3(a) and E.3(b) are shot with a large time gap between them (up to 3 hours). The bigger the time gap between shots, the bigger the time offset between to adjoining traces in an offset sorted gather. This indicates a timedrift in the timebase. A constant time drift correction of $1.57 \mathrm{~ms} / \mathrm{min}$ for gather $915 \mathrm{~F}$ eliminates the time offset in this gather. This is shown in figure E.3(c). After the time drift correction, all the first arrivals line up, with increasing traveltimes for increasing offset. The most likely explanation for the observed time drift is a problem with the internal clocks within the recording units. The different drift correction necessary for the alignment of the first arrivals for unit 915C $(2.08 \mathrm{~ms} / \mathrm{min})$ and $915 \mathrm{~F}$ support this explanation.

For the timing of the recording units an internal clock gets updated with external GPS time every $20 \mathrm{~min}$ and runs self-sufficient in the meantime. The log files, which record all activities within the units, show timing issues during the recording for both units. Even though this cannot satisfactorily explain this time drift problem, the consultation with the manufacturer of the recording units did not provide another solution. Thus, this problem was corrected for as a constant 


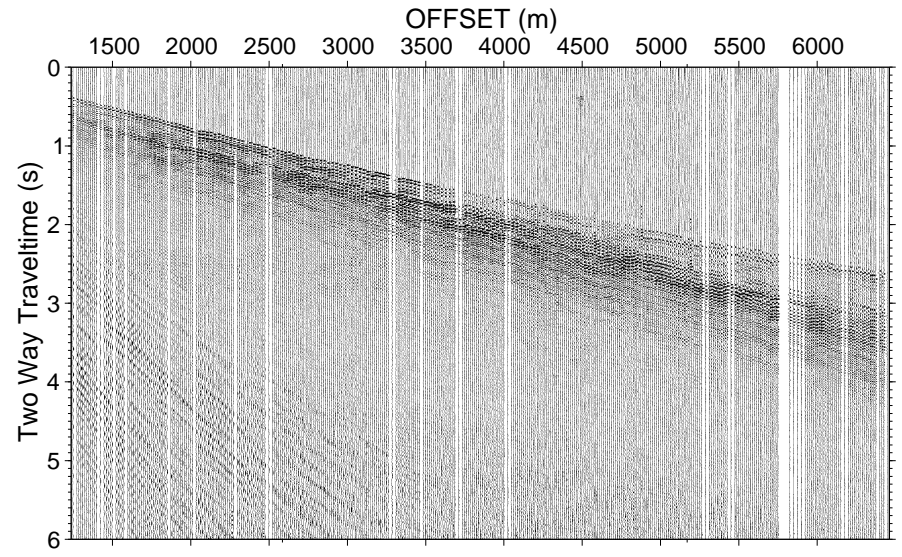

(a) Z-Component

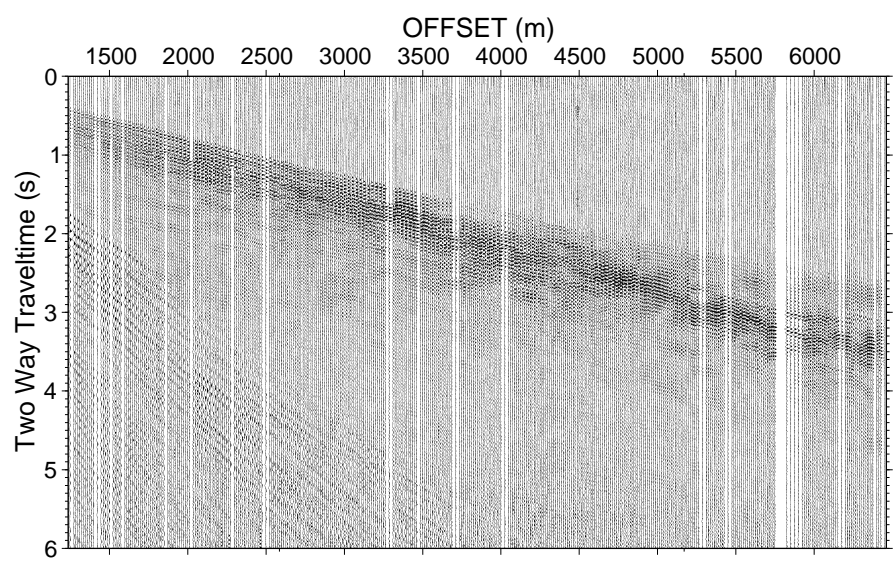

(b) NS-Component

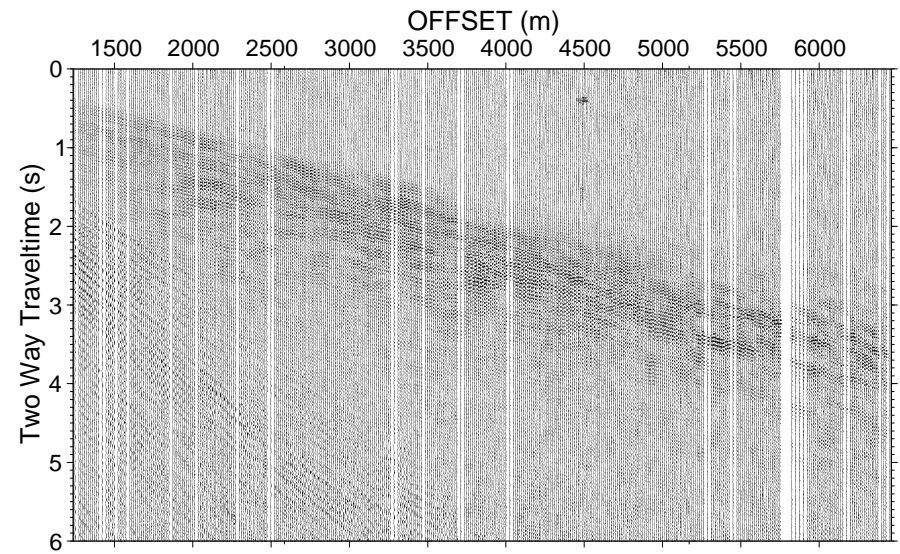

(c) EW-Component

Figure E.2: Final receiver-gathers for receiver 915F (min offset $1198 \mathrm{~m}$ ) 


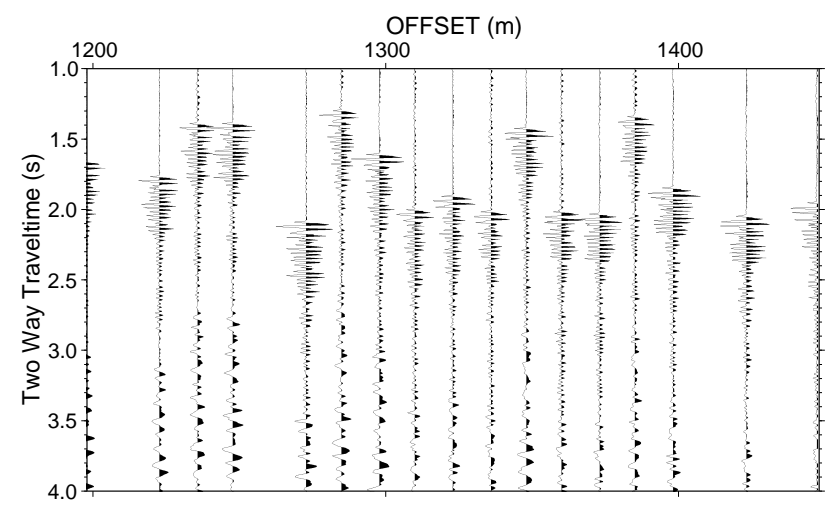

(a) original timebase

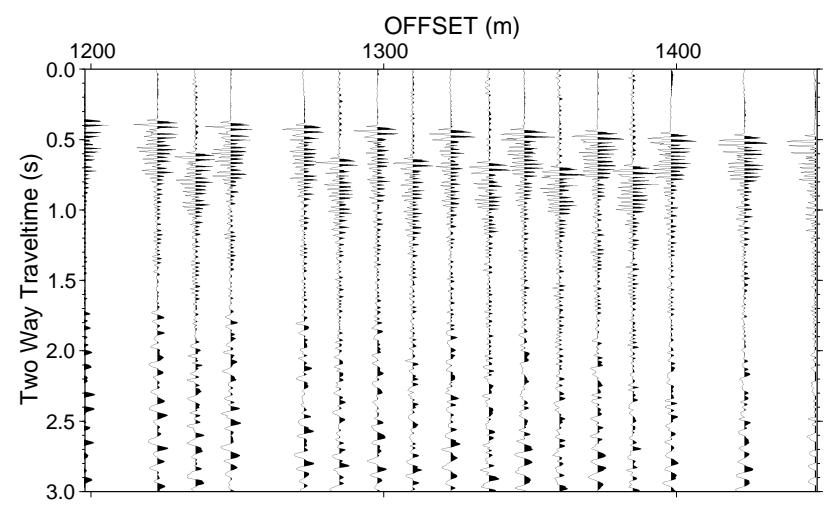

(b) corrected timebase

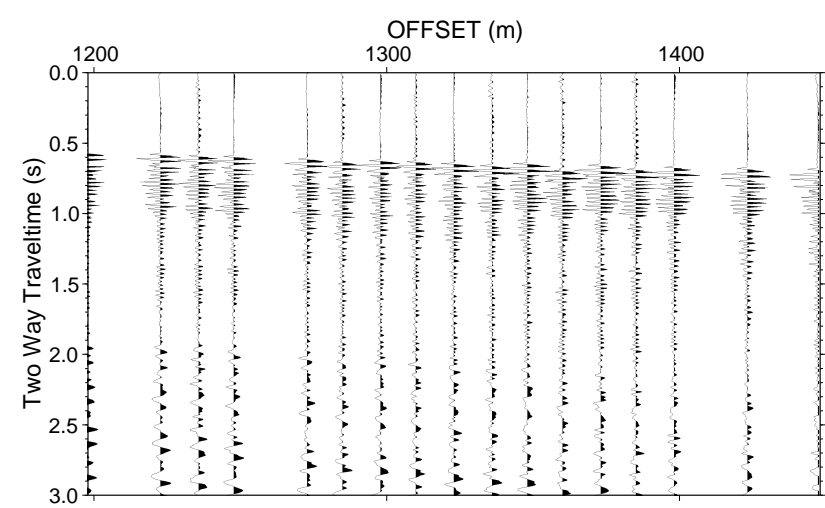

(c) corrected timebase + timedrift correction

Figure E.3: Subsection of receiver-gather 915F to illustrate the original timebase the traces have a random timeshifts (a). After creating the new timebase by means of first break picking the random timeshifts are eliminated (b) but the drift in the timebase is obvious. Figure c shows the traces after performing a correction for the drift of the timebase 


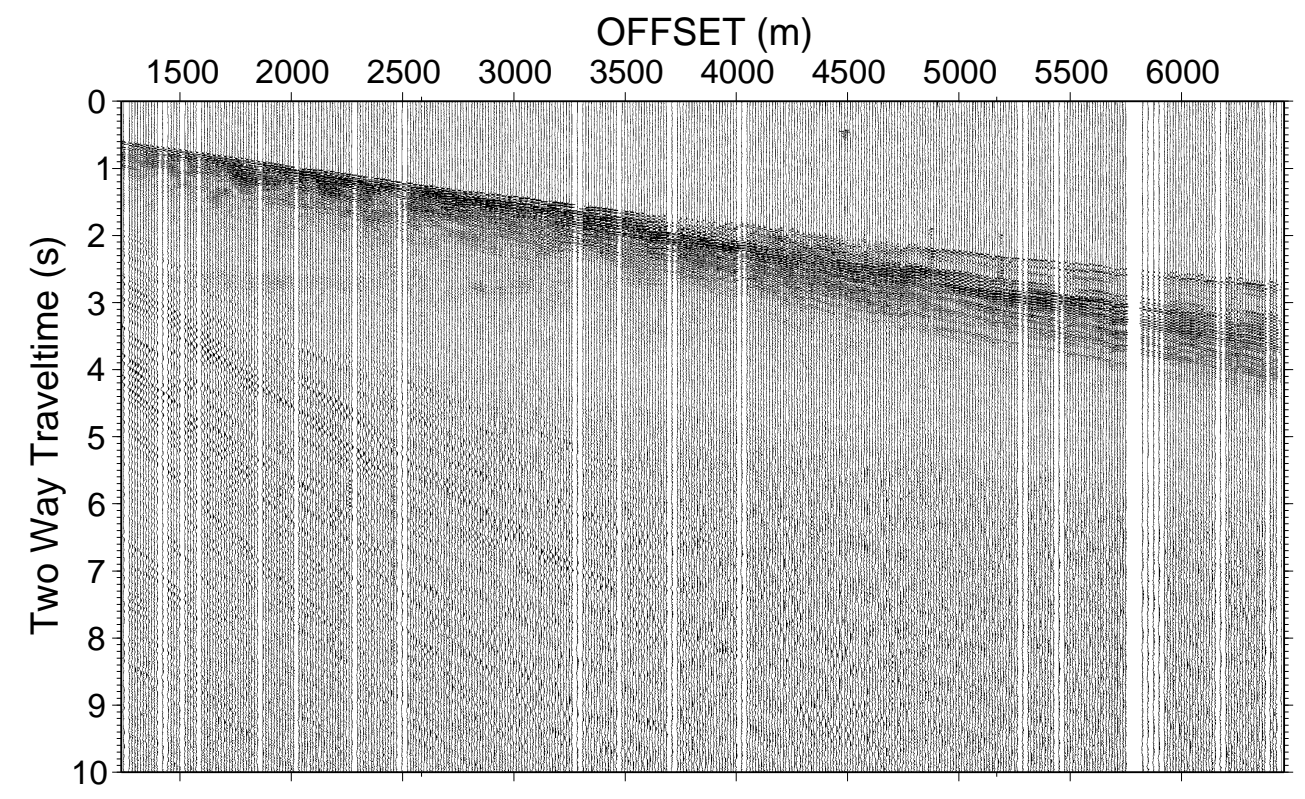

(a) Receiver-gather 915F, min-offset $1198 \mathrm{~m}$

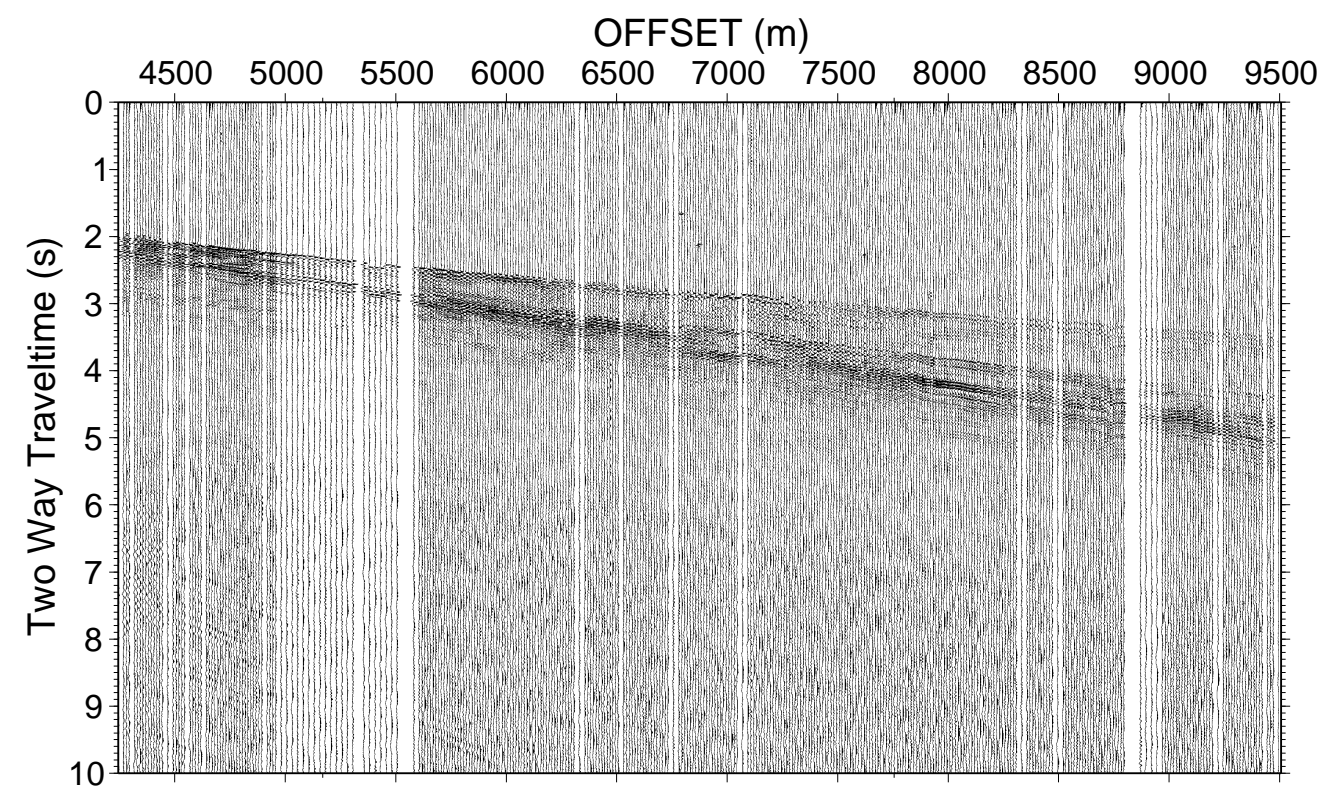

(b) Receiver-gather 915C, min-offset $4244 \mathrm{~m}$

Figure E.4: Z-Component receiver-gathers for the two receivers closest to the shot line. Clear first arrivals are visible across the section for both gathers. 
time drift.

Figures E.4 shows the final offset sorted receiver-gathers after time corrections for the two receivers closest to the shot line. First arrivals are clearly visible. In comparison receiver gathers $915 \mathrm{~B}$ and $915 \mathrm{E}$ (figure E.5) do not show any clear arrivals. They are plotted without any time correction.

\section{E.4 Interpretation}

The recorded receiver gathers are especially suitable for seismic refraction analysis because they have large offset and clear first arrivals. The method of seismic refraction analysis is based on the fact that after the critical distance the first energy which arrives at a geophone is normally a refracted P-wave [Telford et al., 1990]. The major strength of the refraction method is to resolve lateral changes in depth to the top of a refractor and the seismic velocity within it. For more details about refraction theory see appendix A.2. The arrival times of the picked first breaks are evaluated in two different ways; with the traveltime calculation method (see section E.4.1) and the raytracing method (see E.4.2). As mentioned earlier, there are only two receivers gathers (gather 915F and 915C) with clear arrivals that are usable for further interpretation.

\section{E.4.1 Intercept time method for vertical component data}

The most basic way to interpret refraction data is to plot the first break arrivaltimes versus the offset from the shot. In the case of a horizontal refractor, the slope of the resulting straight traveltime line corresponds with the reciprocal of the velocity. Furthermore, the intercept time (time at which the back-extrapolated refracted arrival line cuts the time axis) is a direct measurement of the depth of the refractor [Telford et al., 1990]. In case of a dipping refractor it is necessary to undertake shots at both ends of the lines or in this experiment place receivers at both ends, in order to determine all the parameters required to solve the refractor geometry. In our dataset, with all receivers north of the shotline, no statement can be made about the dip of the refractor and flat layering within the model has to be assumed.

Figure E.6(a) shows the Z-component of the receiver-gather 915F and the interpretation of the first arrivals. Three different slopes for the first breaks are proposed and they are shown by different coloured lines. The intercept time for the first slope is zero and thus it indicates that these events result from the direct wave with a velocity of $\mathrm{V}_{1 F}=1900 \pm 50 \mathrm{~m} / \mathrm{s}$. The velocities of the second and third part are $V_{2 F}=2500 \pm 150 \mathrm{~m} / \mathrm{s}$ and $V_{3 F}=3100 \pm 200 \mathrm{~m} / \mathrm{s}$, respectively. Receivergather 915C, which has larger offsets than gather 915F, shows only two distinct 


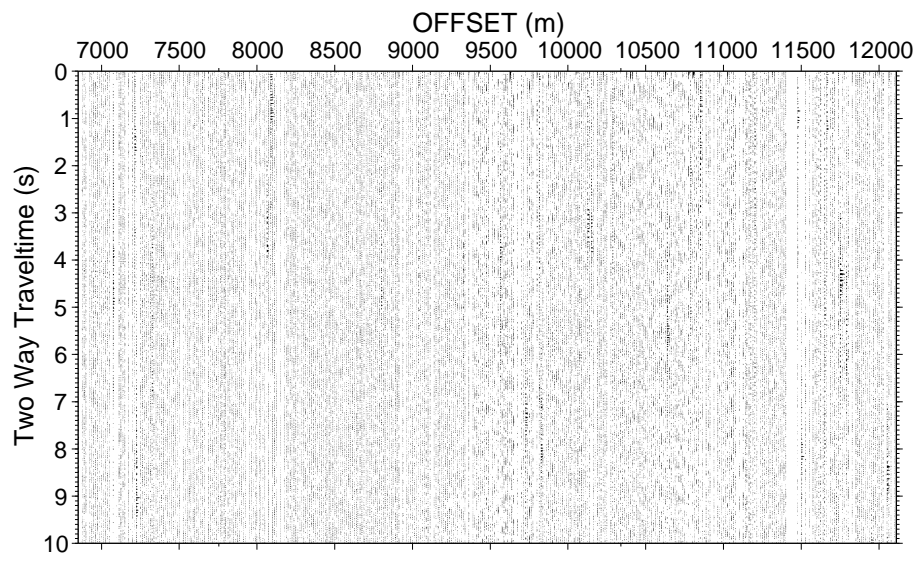

(a) Receiver-gather OLD, min-offset $6850 \mathrm{~m}$

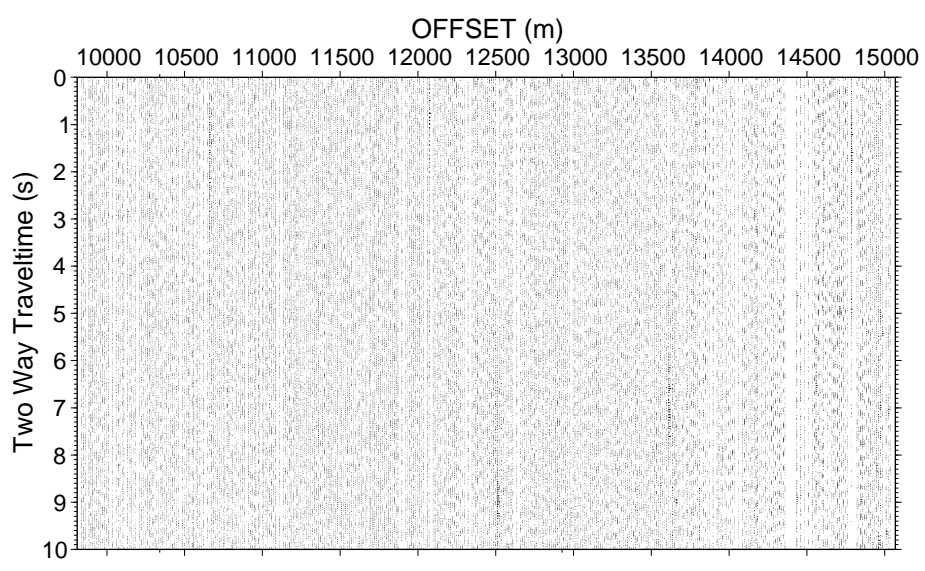

(b) Receiver-gather 915B, min-offset $9809 \mathrm{~m}$

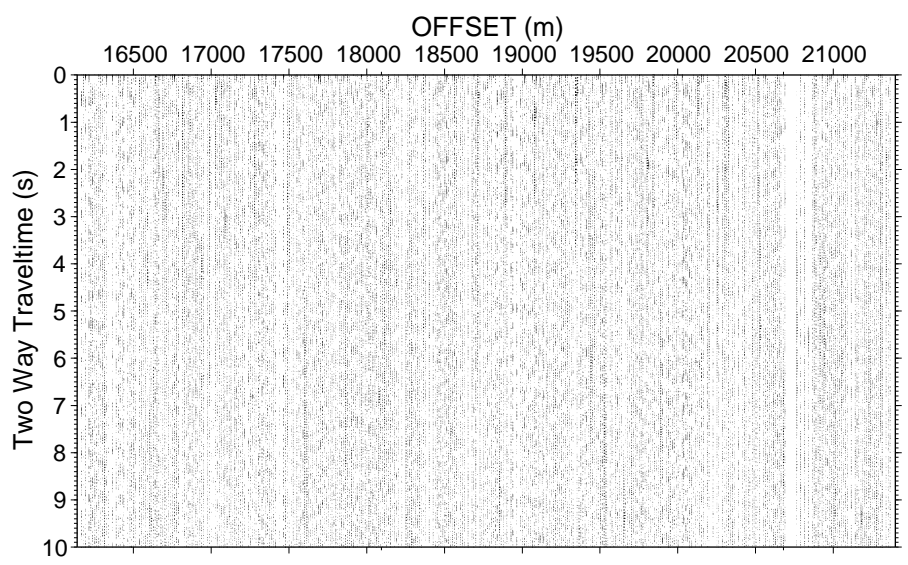

(c) Receiver-gather 915E, min-offset $16138 \mathrm{~m}$

Figure E.5: Z-Component receiver-gathers with increasing min-offset. No first arrivals are visible. 
Chapter E. Three-component refraction data

\begin{tabular}{|c|c|c|c|}
\hline & intercept time [ms] & velocity [m/s] & depth $[\mathrm{m}]$ \\
\hline \hline direct wave & & $1900 \pm 50$ & \\
\hline refractor 1 & $250 \pm 5$ & $2500 \pm 150$ & $360 \pm 20$ \\
\hline refractor 2 & $640 \pm 25$ & $3150 \pm 250$ & $1100 \pm 200$ \\
\hline refractor 3 & $1270 \pm 20$ & $4200 \pm 300$ & $2500 \pm 400$ \\
\hline
\end{tabular}

Table E.2: Parameter summary for final velocity/depth model from forward calculation. Intercept time and velocities for refractor 2 are average values from picks for gather 915F and gather 915C. Depths are measured from the surface to the top of the layer and are calculated with equations E.1-E.3.

different slopes in the first arrival times. The slope of the first part has a similar velocity $\left(V_{3 C}=3200 \pm 150 \mathrm{~m} / \mathrm{s}\right.$ ) as $V_{3 F}$ from gather $915 \mathrm{~F}$ and also a similar intercept time. For the largest offsets, a velocity of $V_{4 C}=4200 \pm 200 \mathrm{~m} / \mathrm{s}$ is estimated (for summary of velocities and intercept times see table E.4.1). The fact that the same velocity for both receiver-gathers is found at the same offset range makes it possible to deal with the problem as a flat three-layer case where the depth of the refractor can be calculated with the following equations (based on Snell's law, see also appendix A.2) [Telford et al., 1990]:

$$
\begin{gathered}
z_{1}=\frac{t_{2} V_{1} V_{2}}{2 \sqrt{V_{2}^{2}-V_{1}^{2}}} \\
z_{2}=\frac{t_{3} V_{2} V_{3}}{2 \sqrt{V_{3}^{2}-V_{2}^{2}}}-\frac{z_{1} V_{2} \sqrt{V_{3}^{2}-V_{1}^{2}}}{V_{1}\left(\sqrt{V_{3}^{2}-V_{2}^{2}}\right.} \\
z_{3}=\frac{t_{4} V_{3} V_{4}}{2 \sqrt{V_{4}^{2}-V_{3}^{2}}}-\frac{z_{1} V_{3} \sqrt{V_{4}^{2}-V_{1}^{2}}}{V_{1}\left(\sqrt{V_{4}^{2}-V_{3}^{2}}\right.}-\frac{z_{2} V_{3} \sqrt{V_{4}^{2}-V_{2}^{2}}}{V_{2}\left(\sqrt{V_{4}^{2}-V_{3}^{2}}\right.}
\end{gathered}
$$

where $V_{1}, V_{2}, V_{3}$ and $V_{4}$ are the velocities of the three different layers and $t_{2}, t_{3}$ and $t_{4}$ are the corresponding intercept times. The resulting thicknesses are: $\mathrm{z} 1=360 \pm 20 \mathrm{~m}, \mathrm{z} 2=1100 \pm 200 \mathrm{~m}$ and $\mathrm{z} 3=2100 \pm 200 \mathrm{~m}$. A summary of the velocities, intercept times and the calculated thicknesses of the layers is shown in table E.4.1.

A reflection event is visible in gather 915F. It has a zero-offset two-way traveltime of $t_{0}=2500 \pm 50 \mathrm{~ms}$ and a RMS velocity (see appendix A.1.2.8) of $\mathrm{V}_{R M S}=2400 \pm 400 \mathrm{~m} / \mathrm{s}$ (figure E.8). This corresponds to an event from a depth $3000 \pm 600 \mathrm{~m} / \mathrm{s}$. This depth is within the error margins of the depth of layer 4 from the refraction modelling. Calculating the RMS-velocity (using equation A.3, appendix A.1.2.8) of the velocity model established based on refraction events (table E.4.1) yields a value of $2600 \pm 300 \mathrm{~m} / \mathrm{s}$. This value is also within the error margin of the RMS velocity of reflection event and therefore this reflector can be assigned to the top of layer 4 . Furthermore, it proves that the main assumption for refraction analysis (no low-velocity layer within the sequence) is valid. 


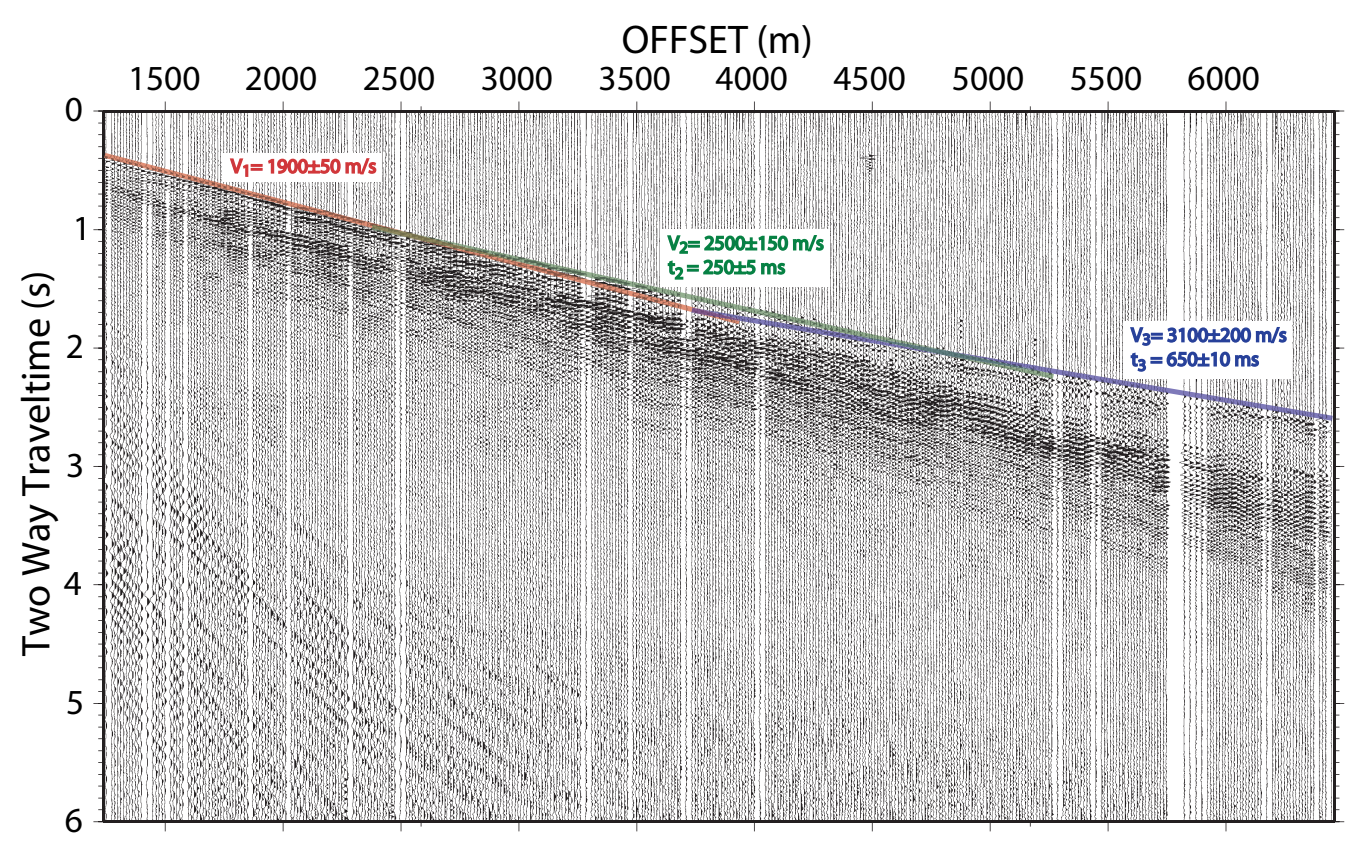

(a) gather $915 \mathrm{~F}$

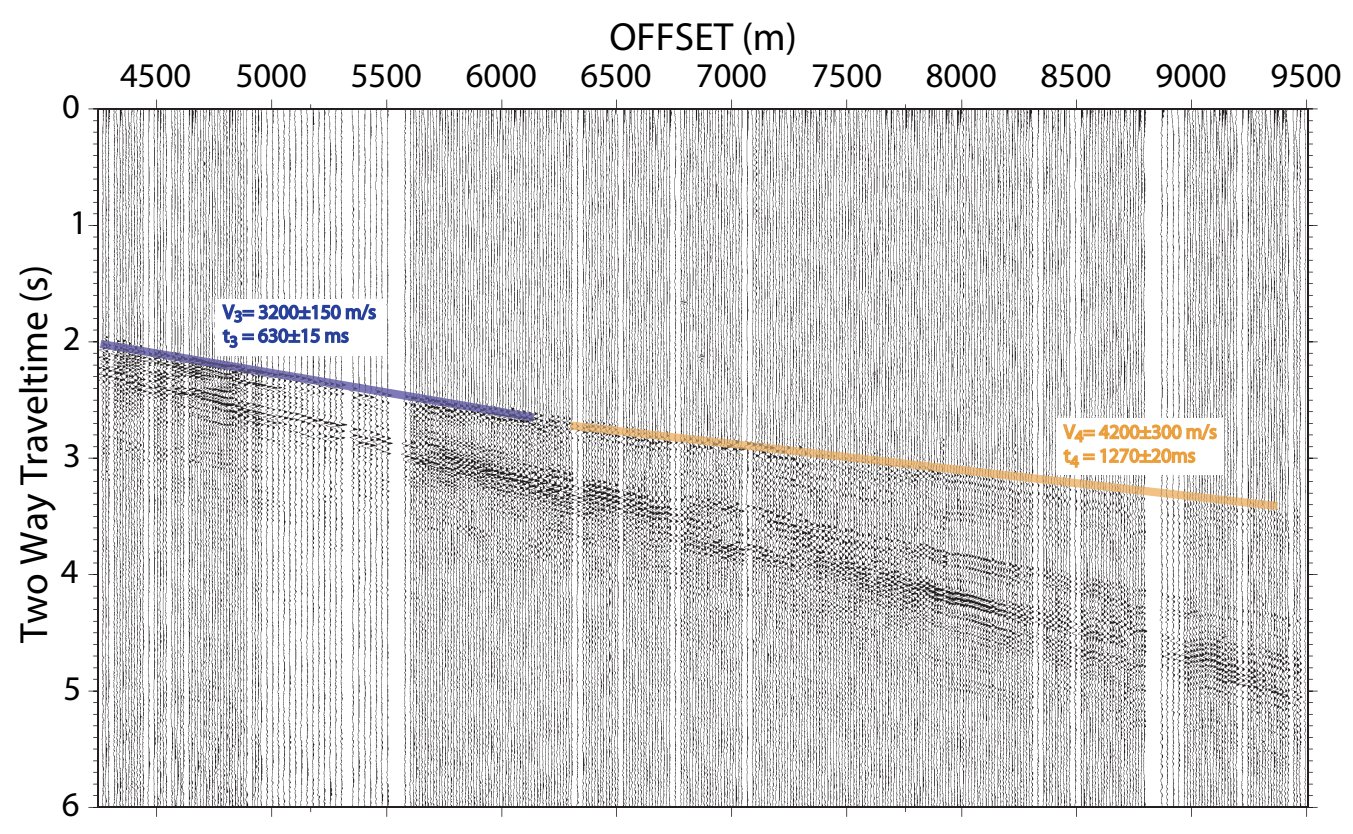

(b) gather 915C

Figure E.6: Refraction analysis of gather 915F (a) and 915C (b). First arrivals are marked with coloured lines. For gather $915 \mathrm{~F}$ three different slopes are identified. For gather 915C, which has the larger offsets, only two different slopes are proposed. Note that the blue line in gather $915 \mathrm{~F}$ has a similar slope as the purple line in gather $915 \mathrm{C}$. 


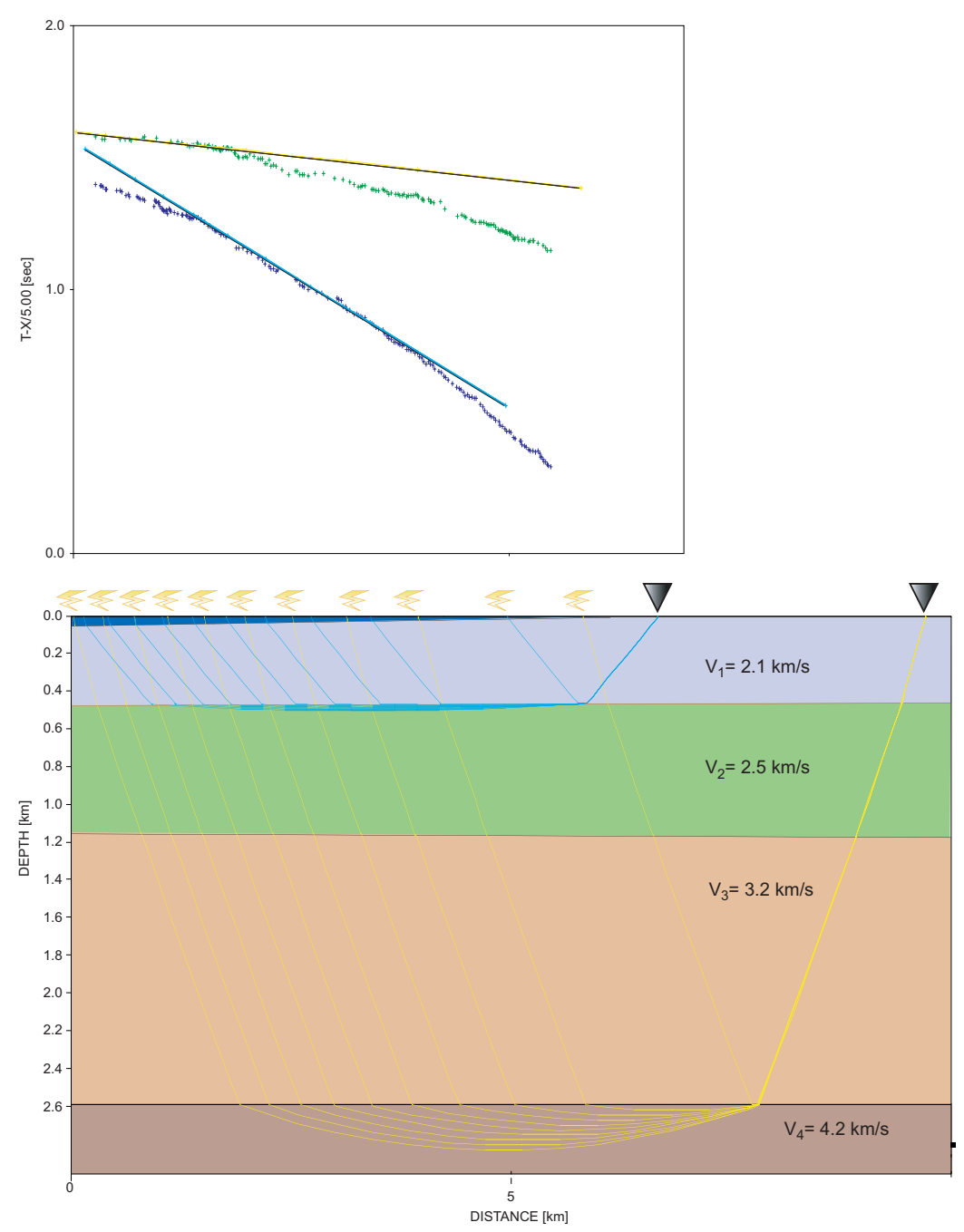

Figure E.7: BOTTOM: the final model used for forward raytracing. Yellow and blue lines indicate raypath for refraction at first and third layer recorded at receiver 915C and 915F. Velocities are shown within the layers. TOP: picked first arrival times are indicated as stars and corresponding calculated traveltimes as solid lines

\section{E.4.2 Raytracing of vertical component data}

The second method applied to the data was forward raytracing. MacRay ${ }^{T M} 2.0$ raytracing software is used, which allows a user to calculate traveltimes of various phases propagating through the model. With this software one can set up complex models and topography can be taken into account.

Our initial starting model is based on the results from section E.4.1, a flat fourlayer model, where a thin wedge shaped water layer on the south side of our profile is included. The water depth information was acquired from a bathymetry map (figure 4.3). Only minor adjustments are necessary to fit the data. The ve- 


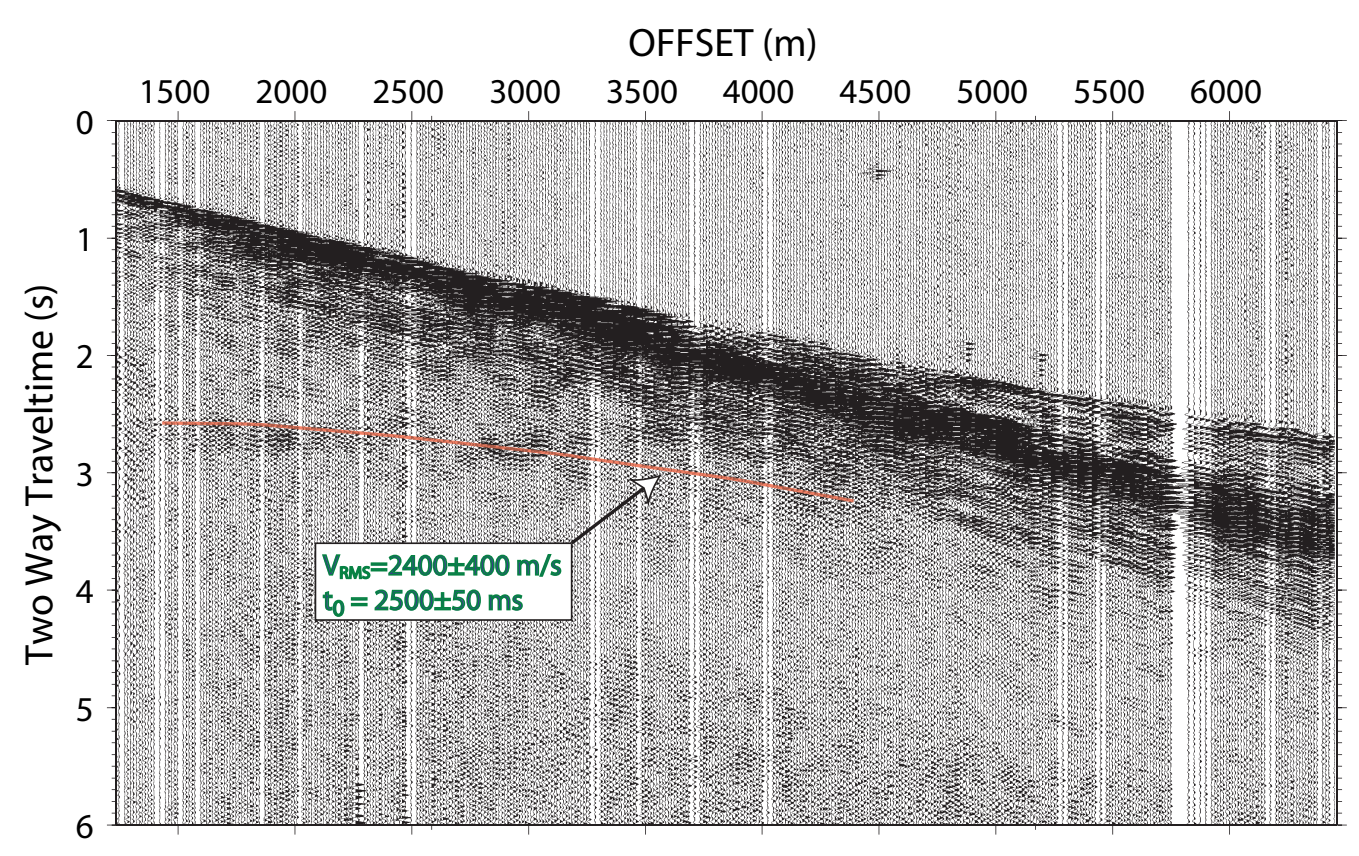

Figure E.8: Filtered (bandpass-filter $15-30 \mathrm{~Hz}$ ) vertical component of receiver gather915F. The filtering is applied to enhance the reflection event, which is marked by the red line. No further reflection events can be identified.

locity and thickness of layer 1 was increased to $V_{1}=2.1 \mathrm{~km} / \mathrm{s}$ and $z_{1}=480 \mathrm{~m}$, respectively, all other layer boundaries remained at the same depth. The final model and resulting traveltimes can be seen in figure E.7.

\section{E.4.3 Three-component nature of the data}

One of the main foci of this experiment was to take advantage of the threecomponent nature of our dataset. In contrast to P-waves which are normally the main focus of shallow refraction and reflection surveys, S-waves produce more energy on the horizontal components than on the vertical components. Thus, they should be easier to identify on the horizontal N-S and E-W component. By means of the S-wave arrival times it is possible to get information about the Poison ratio within the layers and get a second constraint on the depth of the layers. S-wave arrivals are characterised by a later arrival time, lower velocity and a lower frequency contents than P-waves.

Figure E.9 shows a subset of the three-component receiver-gather $915 \mathrm{~F}$ after applying a low-pass filter $(<15 \mathrm{HZ})$ to the data to emphasise possible S-wave arrivals. Events are easy to identify in the N-S component of the data (figure E.9(b)). Clear arrivals are visible for the smallest offsets at around $1800 \mathrm{~ms}$ with a kink in the slope at an offset of around $1800 \mathrm{~m}$. For an offset larger than $3400 \mathrm{~m}$, these Swave arrivals disappear. Using the visible arrivals, the arrivals can be interpreted 


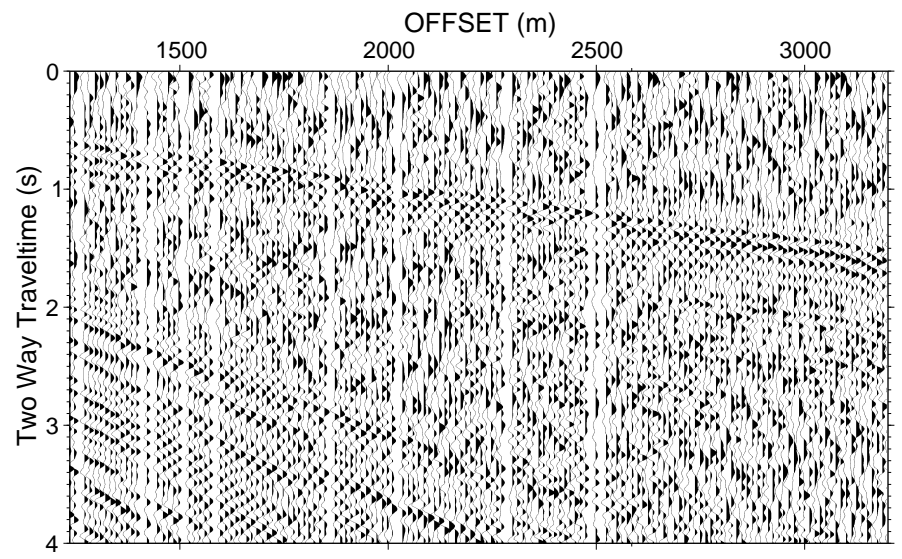

(a) Z-Component

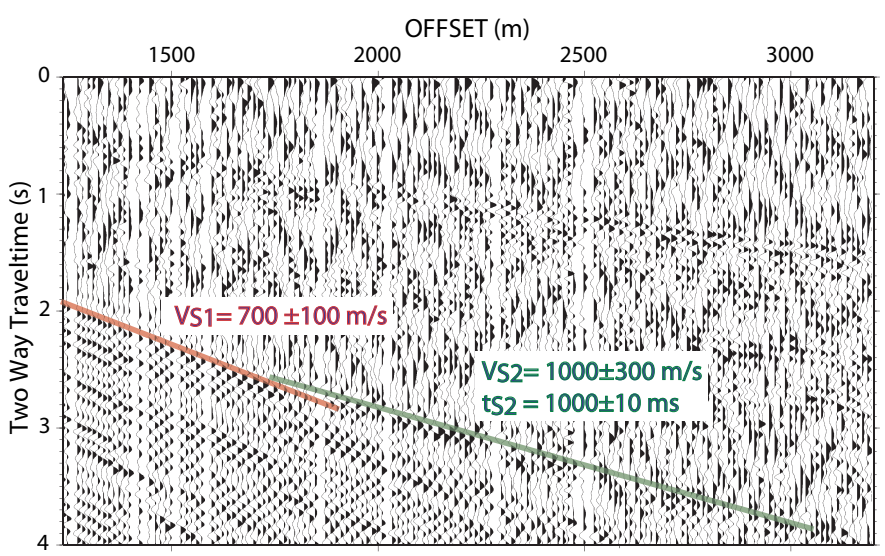

(b) NS-Component

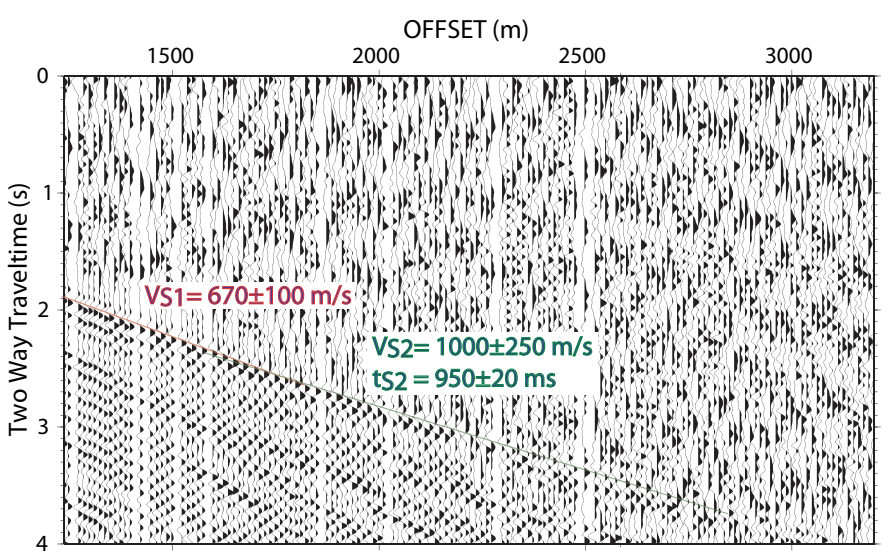

(c) EW-Component

Figure E.9: Cut outs of receiver-gather 915F. Red line highlights the direct wave arrivals, green line the refraction arrivals from a layer of a depth of around $740 \mathrm{~m}$. 


\begin{tabular}{|c|c|c|c|}
\hline \multicolumn{4}{|c|}{ N-S component } \\
\hline & intercept time [ms] & velocity [m/s] & depth [m] \\
\hline \hline layer 1 & $(\sim 40)$ & $700 \pm, 100$ & \\
\hline layer 2 & $1000 \pm 10$ & $1000 \pm 300$ & $450 \pm 50$ \\
\hline \hline \multicolumn{4}{|c|}{ E-W component } \\
\hline & intercept time [ms] & velocity [m/s] & depth [m] \\
\hline \hline layer 1 & $(\sim-10)$ & $670 \pm 100$ & \\
\hline layer 2 & $780 \pm 10$ & $1000 \pm 250$ & $460 \pm 50$ \\
\hline
\end{tabular}

Table E.3: Parameter summary for final velocity/depth model for S-wave forward calculation. Depths are measured from the surface to the top of the layer and are calculated with equations E.1-E.3.

as a two-layer model, with an average velocity in the first layer of $684 \mathrm{~m} / \mathrm{s}$ and an average velocity of $999 \mathrm{~m} / \mathrm{s}$ for the second layer. For the calculation of the depth of the boundary between the two layers equation E. 1 is used, with S-wave velocities instead of P-wave velocities. The resulting thickness of the first layer is $451 \mathrm{~m}$ using the N-S component and $458 \mathrm{~m}$ using the E-W component (a summary of the model parameters can be found in table E.3). In comparison, the results from Pwave arrival calculations (see section E.4) show a slightly larger thickness for the first layer (around $90 \mathrm{~m}$ ). The calculation of the $V_{p} / V_{s}$ ratio using the averaged S-wave velocities from table E. $3\left(\mathrm{~V}_{S_{1}} \oslash=685 \pm 120 \mathrm{~m} / \mathrm{s}\right.$ and $\mathrm{V}_{S_{2}} \oslash=100 \pm 300 \mathrm{~m} / \mathrm{s}$ ) and the P-wave velocities from table E.4.1 result in high $V_{p} / V_{s}$ ratios $(\sigma)$ for both layers with $V_{P 1} / V_{S 1}=2.75 \pm 0.3$ for the first layer and $V_{P 2} / V_{S 2}=2.50 \pm 0.5$ for the second layer.

Furthermore, it is important to mention that in the case of offshore shots, there is no initial generation of S-waves at the source location. Thus, the arrivals interpreted as S-wave arrivals have to originate from a wave which started as a $\mathrm{P}$-wave and got converted to an S-wave at an interface. This situation does not affect the identified S-wave velocities or the $V_{p} / V_{s}$ ratio but the intercept time and depth. The water depth in our study area is very shallow with an average value of less than $50 \mathrm{~m}$. Thus, if is assumed that the conversion from a P to S-wave took place at the ocean floor, the traveltime error introduced through this phase conversion would be around $40 \mathrm{~ms}$. Which means in the ideal case the intercept time for first branch off arrivals should be $-40 \mathrm{~ms}$, because the wave travels with a faster velocity for the first $50 \mathrm{~m}$. The estimated intercept times for the direct arrival for our N-S and E-W component are within the error margin.

\section{E.4.4 Conclusions}

The profile line of the experiment is located within the Taranaki Fault Zone, between the Taranaki and Mania Fault. This area is part of the Taranaki Basin, on the 


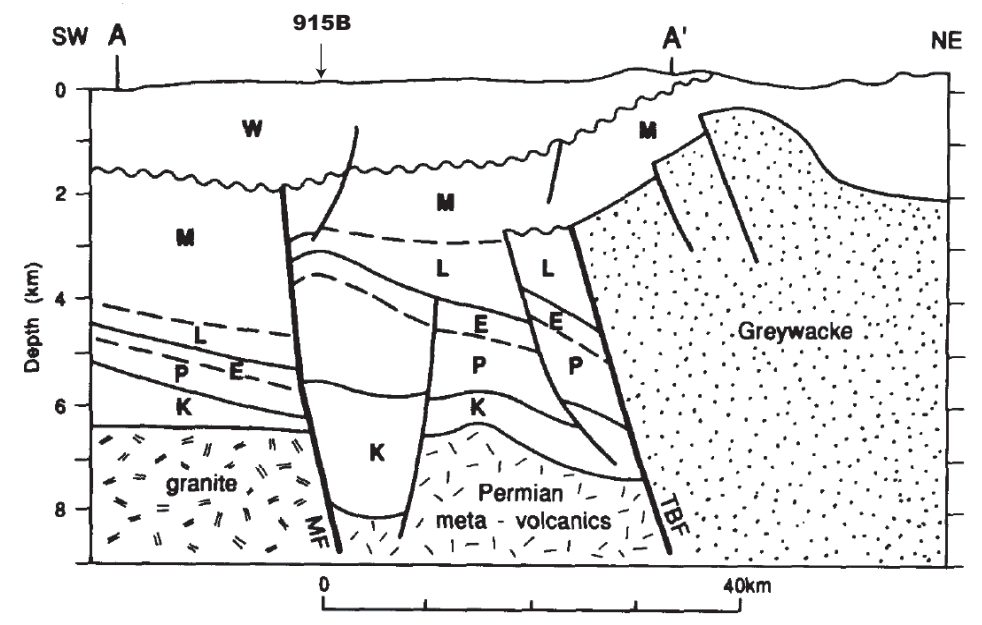

Figure E.10: Schematic geological cross-section running southwest-northeast intersecting the profile line of the experiment just north of receiver 915B (see figure E.1 for location). The location of the receiver along the section is marked at the top. W-Pliocene-Pleistocene; M-Miocene; L-Oligocene; E-Eocene; P-Paleocene; K-Cretaceous. MF-Manaia Fault; TBF-Taranaki Fault. Figure modified from Ravens et al. [1993].

boundary to the northwestern edge of the SWB. Figure E.10 shows a schematic cross-section of the study area. This section runs southwest-northeast and intersects the seismic profile just north of receiver 915B (see figure E.1). It shows a sediment thickness of $6-8 \mathrm{~km}$ between the Taranaki and Manaia Fault. The deepest sequence consists of Cretaceous sediments. The top 1-1.5 km are of PlioPleistocene age.

The velocities inferred from the refraction analysis in the Taranaki Basin can be matched with an empirical relation for seismic velocities for sediments of any single age related to the depth of burial Z(M) [Stagpoole, 1997]. The empirical relationships for the Pliocene, the late Miocene, the mid Miocene and the Oligocene are as follows:

$$
\begin{aligned}
\text { Pliocene }: & =104 Z^{0.37}+1045 \pm 190 \mathrm{~m} / \mathrm{s} \\
\text { Late Miocene }: V & =104 Z^{0.37}+1500 \pm 280 \mathrm{~m} / \mathrm{s} \\
\text { Middle Miocene }: V & =104 Z^{0.37}+1805 \pm 295 \mathrm{~m} / \mathrm{s} \\
\text { Oligocene }: V & =104 Z^{0.37}+2175 \pm 550 \mathrm{~m} / \mathrm{s}
\end{aligned}
$$

Thus, the bottom layer in the refraction velocity model, at a depth of $\sim 2500 \mathrm{~m}$ (figure E.7), should have a velocity of $\sim 4100 \mathrm{~m} / \mathrm{s}$ if it was the top of an Oligocene layer. As part of a Miocene sequence, it would have a velocity of $\sim 3700 \mathrm{~m} / \mathrm{s}$. The refraction data show a velocity of $4200 \pm 300 \mathrm{~m} / \mathrm{s}$. Therefore, based on the velocity of layer 4 (figure E.7), it is interpreted as an Oligocene layer. The velocity of layer 


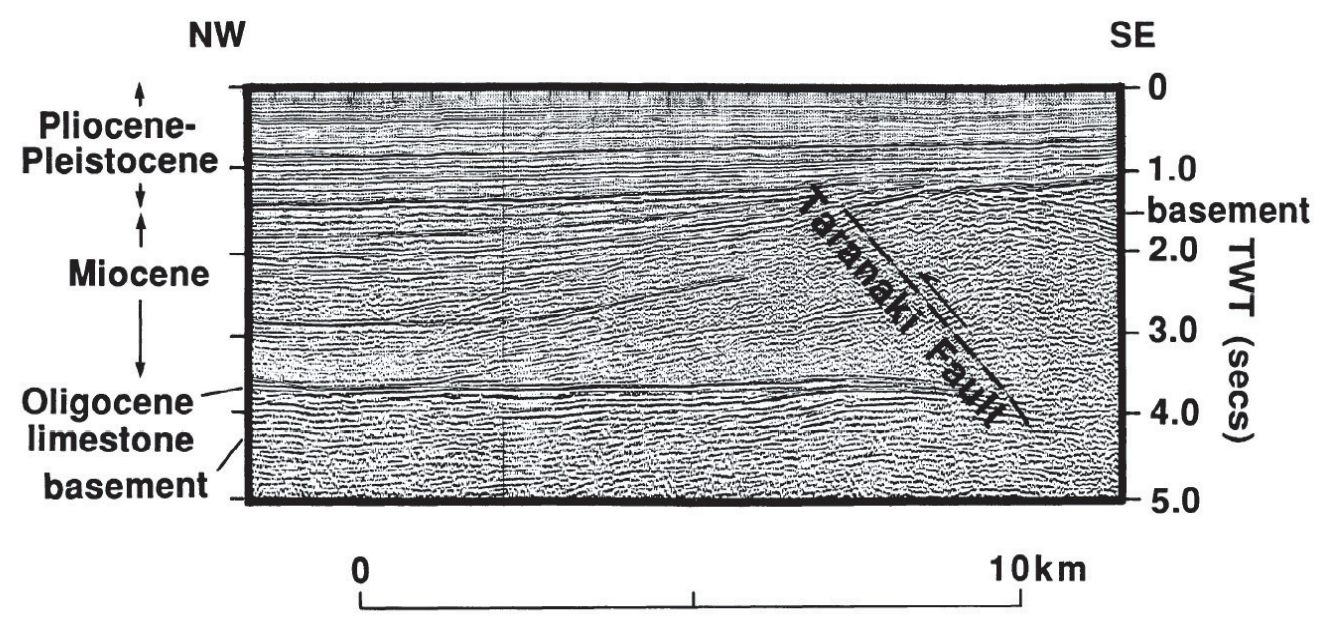

Figure E.11: Seismic reflection image across the Taranaki Fault Zone. Its locality is shown in figure E.1. The strongest reflector at $\sim 3 \mathrm{~s}$ originates from an Oligocene limestone layer. This correspond to the boundary to layer 4 in the predicted velocity model for the here presented profile (figure E.7). Figure taken from Holt \& Stern [1994].

$3(3150 \pm 250 \mathrm{~m} / \mathrm{s})$, which starts at a depth of $1100 \mathrm{~m}$, fits well with the predicted velocity for a Mid-Miocene sediment layer $(\sim 3200 \mathrm{~m} / \mathrm{s})$. With this method, layer 3 can be interpreted as a late Miocene layer and layer 1 as a Pliocene layer.

In the geological cross-section to the north (figure E.10) the Oligocene layer starts at around $3 \mathrm{~km}$ and the Miocene layer at $1.5 \mathrm{~km}$. Thus, the depth of the Oligocene layer in the refraction velocity model is in agreement with the crosssection, but the boundary to the Miocene is around $1 \mathrm{~km}$ shallower. However, there are no constraints on the dip of the layers in north-south direction. Further evidence for layer 4 being an Oligocene layer can be taken from a seismic reflection section to the southeast (figure E.11, for line location see figure E.1). In this section, the strongest reflector (two-way traveltime of around $3.5 \mathrm{~s}$ ) corresponds to an Oligocene limestone reflector. This agrees with the fact that the strong reflector found in gather 915F (figure E.8) is interpreted as the top of the Oligocene sediment sequence.

For crustal rocks the $V_{p} / V_{s}$ ratio is assumed to be smaller than 2 and is generally in the order of 1.75 [Christensen, 1996]. For sediments, however, a global compilations of marine sedimentary rocks shows that the $V_{p} / V_{s}$ can be much higher with up to 13 in the near surface region [Hamilton, 1979; Shillington et al., 2008]. The $V_{p} / V_{s}$ ratio increases with increasing porosity. Therefore, the $V_{p} / V_{s}$ decreases with depth due to burial compaction. Hamilton [1979] predicts a $V_{p} / V_{s}$ ratio of 2.6 at a depth of $1000 \mathrm{~m}$ which is similar to the values found for layer 1 and $2\left(\mathrm{~V}_{P 1} / \mathrm{V}_{S 1}=2.75 \pm 0.3 ; \mathrm{V}_{P 2} / \mathrm{V}_{S 2}=2.50 \pm 0.5\right)$, at a depth between $0-1200 \mathrm{~m}$. The $V_{p} / V_{s}$ ratio gives information about the porosity and the porosity contents 
of a material. For example, the presence of hydrocarbons, particularly gas, in the pore space instead of water tends to cause a decrease of as much as $10-20 \%$ in $V_{p} / V_{s}$ [Gregory, 1976]. Thus, the here presented approach could help to identify such targets.

This experiment demonstrated that the recording of standard industry reflection seismic shots with three-component instruments can help to acquire more information about the subsurface, especially about the $V_{p} / V_{s}$ ratio. However, the energy source used for this experiment was slightly too small to reach all deployed instruments. To acquire information about deeper layers (older sediments), a larger offset is necessary. Thus, to make such experiments a success, larger energy sources would be necessary.

Furthermore, it has to be noted that due to the problems in the timebase and several correction procedures the uncertainties in the results are relatively high. This demonstrates the need for accurate shot time information for such experiments. 


\section{Appendix F}

\section{Geometry information about the conducted surveys}

The geometry information about the reflection surveys can be found on the supplementary CD, which is attached at the back cover of the thesis. This CD contains the shot and receiver information as a pdf file as well as the original observer and survey log files in the Claritas ${ }^{T M}$ format. 
Appendix G

Enlarged seismic sections from chapter 3 



\section{References}

ABERS, G. 1998. Array measurements of phases used in receiver-function calculations: importance of scattering. Bulletin of the Seismological Society of America, 88(1), 313-318.

ABERS, G., HU, X., AND SYKES, L. 1995. Source scaling of earthquakes in the Shumagin region, Alaska: time- domain inversions of regional waveforms. Geophysical Journal International, 123(1), 41-58.

AHARONI, E. 1991. Seismic reflection study across the Horowhenua coastal plain, North Island, New Zealand. M.Phil. thesis, Victoria University of Wellington, New Zealand.

AIRY, G. B. 1855. On the Computation of the Effect of the Attraction of MountainMasses, as Disturbing the Apparent Astronomical Latitude of Stations in Geodetic Surveys. Philosophical Transactions of the Royal Society of London, 145, 101-104.

AMMON, C., RANDAlL, G., AND ZANDT, G. 1990. On the nonuniqueness of receiver function inversions. Journal of Geophysical Research, 95(B10), 1530315318.

Anderton, P. 1981. Structure and evolution of the South Wanganui Basin, New Zealand. New Zealand Journal of Geology and Geophysics, 24, 39-63.

ANSELl, J., AND BANNISTER, S. 1996. Shallow morphology of the subducted Pacific plate along the Hikurangi margin, New Zealand. Physics of the Earth and Planetary Interiors, 93, 3-20.

AYDIN, A., AND NUR, A. 1985. The types and role of stepovers in strike-slip tectonics. Pages 35-44 of: Strike-slip deformation, basin formation, and sedimentation. SEPM Special Publications.

Bannister, S., Reyners, M., Stuart, G., And SAVAge, M. 2007. Imaging the Hikurangi subduction zone, New Zealand, using teleseismic receiver functions: Crustal fluids above the forearc mantle wedge. Geophysical Journal International, 169(2), 602-616.

BEANLAND, S. 1995. The North Island dextral fault belt, Hikurangi subduction margin, New Zealand. Ph.D. thesis, Victoria University of Wellington, New Zealand. 
BEANLAND, S., AND HAINES, J. 1998. The kinematics of active deformation in the North Island, New Zealand, determined from geological strain rates. New Zealand Journal of Geology and Geophysics, 41(4), 311-323.

BEKESI, G. 1989. Geopysical studies over the north Horowhenua sedimentary basin. M.Phil. thesis, Victoria University of Wellington, New Zealand.

Bibby, H., CAldwell, T., DAVEy, F., AND WEBB, T. 1995. Geophysical evidence on the structure of the Taupo Volcanic Zone and its hydrothermal circulation. Journal of Volcanology and Geothermal Research, 68(1-3), 29-58.

BILlEN, M., AND GURNIS, M. 2001. A low viscosity wedge in subduction zones. Earth and Planetary Science Letters, 193(1-2), 227-236.

BotT, M. 1991. Sublithospheric loading and plate-boundary forces. Philosophical Transactions - Royal Society of London, 337(1645), 83-93.

BotT, M. 1993. Modelling the plate-driving mechanism. Journal of the Geological Society (London), 150(5), 941-951.

Bott, M., Waghorn, G., AND Whittaker, A. 1989. Plate boundary forces at subduction zones and trench-arc compression. Tectonophysics, 170(1-2), 1-15.

Bourne, M., AND StuART, G. 2000. ScSp observed on North Island, New Zealand: Implications for subducting plate structure. Geophysical Journal International, 142(3), 925-932.

Boyd, O., SAVAge, M., Sheehan, A., AND Jones, C. 2007. Illuminating the plate interface structure beneath Cook Strait, New Zealand, with receiver functions. Journal of Geophysical Research B: Solid Earth, 112(6), doi:10.1029/2006JB004552.

BRISBOURNE, A., AND STUART, G. 1998. Shear-wave velocity structure beneath North Island, New Zealand, from Rayleigh-wave interstation phase velocities. Geophysical Journal International, 133(1), 175-184.

BROCHER, T. 2005. Empirical relations between elastic wavespeeds and density in the Earth's crust. Bulletin of the Seismological Society of America, 95(6), 20812092.

BROWN, A. R. 2001. Data polarity for the interpreter. The Leading Edge, 549.

BUTTKUS, B. 2000. Spectral analysis and filter theory in applied geophysics. SpringerVerlag, Berlin.

CADY, J. 1980. Calculation of gravity and magnetic anomalies of finite-length right polygonal prisms. Geophysics, 45(10), 1507-1512.

CANZ (Charting AROUnd New Zealand). 1997. New Zealand region bathymetry, 1:4 000 000. National Instititue of Water and Atmospheric Research Chart, Series 73. 
Carmichael, R. S. 1989. Practical Handbook of Physical Properties of Rocks and Minerals. CRC Press, Inc.

CASSIDY, J., AND ELLIS, R. 1991. Shear wave constraints on a deep crustal reflective zone beneath Vancouver Island. Journal of Geophysical Research, 96(B12), 19843-19851.

CHADWICK, M. 1997. Hikurangi margin seismic experiment. Ph.D. thesis, Victoria University of Wellington, New Zealand.

CHEN, L., WeN, L., AND ZHENG, T. 2005. A wave equation migration method for receiver function imaging: 1. Theory. Journal of Geophysical Research B: Solid Earth, 110(11), 1-15.

CHen, W.-P., AND MOlnaR, P. 1983. Focal depths of intracontinental and intraplate earthquakes and their implications for the thermal and mechanical properties of the lithosphere. Journal of Geophysical Research, 88(B5), 4183-4214.

Christensen, N. 1996. Poisson's ratio and crustal seismology. Journal of Geophysical Research B: Solid Earth, 101(2), 3139-3156.

Christensen, N., AND MOONEY, W. 1995. Seismic velocity structure and composition of the continental crust: a global view. Journal of Geophysical Research, 100(B6), 9761-9788.

Clarke, S. 2003. Waikanae/Otaihanga Borefield Drilling Strategy. Tech. rept. Kapiti Coast District Council.

Clowes, R., Brandon, M., Green, A., Yorath, C., Sutherland Brown, A., KanASEWICH, E., AND SPENCER, C. 1987. LITHOPROBE-southern Vancouver Island: Cainozoic subduction complex image by deep seismic reflections. Canadian Journal of Earth Sciences, 24(1), 31-51.

COHEN, S. 1994. Evaluation of the importance of model features for cyclic deformation due to dip-slip faulting. Geophysical Journal International, 119(3), 831-841.

COHEN, S., AND DARBY, D. 2003. Tectonic plate coupling and elastic thickness derived from the inversion of a steady state viscoelastic model using geodetic data: Application to southern North Island, New Zealand. Journal of Geophysical Research B: Solid Earth, 108(3), doi:10.1029/2001JB001687.

COLE, J. 1990. Structural control and origin of volcanism in the Taupo volcanic zone, New Zealand. Bulletin of Volcanology, 52(6), 445-459.

Cole, J., DARby, D., And Stern, T. 1995. Taupo Volcanic Zone and Central Volcanic Region: Backarc structures of North Island New Zealand. Pages 1-28 of: TAYLOR, B. (ed), Backarc Basins. New York: Plenun Press. 
Collot, J.-Y., Delteil, J., Lewis, K., DaVy, B., LAmarche, G., Audru, J.-C., Barnes, P., Chanier, F., Chaumillon, E., LAllemand, S., De LePinay, B., Orpin, A., Pelletier, B., Sosson, M., Toussaint, B., And Uruski, C. 1996. From oblique subduction to intra-continental transpression: Structures of the southern Kermadec-Hikurangi margin from multibeam bathymetry, sidescan sonar and seismic reflection. Marine Geophysical Researches, 18(2-4), 357381.

Conrad, C., And Lithgow-Bertelloni, C. 2002. How mantle slabs drive plate tectonics. Science, 298(5591), 207-209.

COOPER, R., AND KOHLSTEDT, D. 1986. Rheology and structure of olivine-basalt partial melts. Journal Geophysical Research, 91, 9315-9323.

Cope, R. N. 1967. The Cretaceous paleogeology of the Taranaki - Cook Strait area. Australian Institute of Mining and Metallurgy, Proceedings, 222, 63 - 72.

Cox, M. 1999. Static Correction for Seismic Reflection Surveys. Society of Exploration Geophysicists.

CROUGH, S., AND JuRdy, D. 1980. Subducted lithosphere, hot spots and the geoid. Earth and Planetary Science Letters, 48, 15-22.

DARBY, D., AND BEANLAND, S. 1992. Possible source models for the 1855 Wairarapa earthquake, New Zealand. Journal of Geophysical Research, 97(B9), 12375-12389.

DAVEY, F., AND STERN, T. 1990. Crustal seismic observations across the convergent plate boundary, North Island, New Zealand. Tectonophysics, 173(1-4), 283-296.

DAVIES, G. 1981. Regional compensation of subducted lithosphere: effects on geoid, gravity and topography from a preliminary model. Earth and Planetary Science Letters, 54(3), 431-441.

DAVIES, G. 1983. Subduction zone stresses: constraints from mechanics and from topographic and geoid anomalies. Tectonophysics, 99(2-4), 85-98.

DAVY, B., AND WOOD, R. 1994. Gravity and magnetic modelling of the Hikurangi Plateau. Marine Geology, 118(1-2), 139-151.

DeMets, C., Gordon, R., Argus, D., And Stein, S. 1990. Current plate motions. Geophysical Journal International, 101, 425-478.

DUEKER, K., AND SHEEHAN, A. 1997. Mantle discontinuity structure from midpoint stacks of converted $P$ to $S$ waves across the Yellowstone hotspot track. Journal of Geophysical Research B: Solid Earth, 102(B4), 8313-8327. 
DUEKER, K., AND SHEEHAN, A. 1998. Mantle discontinuity structure beneath the Colorado Rocky Mountains and High Plains. Journal of Geophysical Research B: Solid Earth, 103(4), 7153-7169.

EBerhart-Phillips, D., AND REYNERS, M. 1997. Continental subduction and three-dimensional crustal structure: The northern South Island, New Zealand. Journal of Geophysical Research B: Solid Earth, 102(6), 11843-11861.

Eberhart-Phillips, D., AND REYNERS, M. 1999. Plate interface properties in the northeast Hikurangi subduction zone, New Zealand, from converted seismic waves. Geophysical Research Letters, 26(16), 2565-2568.

Eberhart-Phillips, D., ReYNers, M., CHADWICK, M., AND CHIU, J.-M. 2005. Crustal heterogeneity and subduction processes: 3-D Vp, Vp/Vs and $\mathrm{Q}$ in the southern North Island, New Zealand. Geophysical Journal International, 162(1), 270-288.

EIBY, G. A. 1968. A descriptive catalogue of New Zealand earthquakes. New Zealand Journal of Geology and Geophysics, 11, 16-40.

ENGlAnd, P., AND MOLnAR, P. 1990. Surface uplift, uplift of rocks, and exhumation of rocks. Geology, 18(12), 1173-1177.

FISCHER, K. M. 2002. Waning buoyancy in the crustal roots of old mountains. Nature, 417(6892), 933-936.

FLeming, C. A. 1975. The geological history of New Zealand and its biota. In: Kuschel, G. (ed), Biogeography and ecology in New Zealand. The Hague.

Fowler, C. M. R. 2001. The Solid Earth: An Introduction to Global Geophysics. Cambridge University Press.

FrederiKsen, A., AND BostocK, M. 2000. Modelling teleseismic waves in dipping anisotropic structures. Geophysical Journal International, 141(2), 401-412.

FUKAO, Y., HORI, S., AND UKAWA, M. 1983. A seismological constraint on the depth of basalt-eclogite transition in a subducting oceanic crust. Nature, 303(5916), 413-415.

Funnell, R., Chapman, D., Allis, R., And Armstrong, P. 1996. Thermal state of the Taranaki Basin, New Zealand. Journal of Geophysical Research B: Solid Earth, 101(B11), 25197-25215.

Gadallah, M. R., And Fisher, R. L. 2004. Applied Seismology: A Comprehensive Guide to Seismic Theory and Application. PennWell Books.

GANS, P. 1987. An open-system, two-layer crustal stretching model for the eastern Great Basin (USA). Tectonics, 6(1), 1-12. 
GARRICK, R. A., AND GIBOWICZ, S. J. 1983. Continuous swarm-like seismicity: the Wanganui, New Zealand, earthquakes. Geophysical Journal International, 75(2), 493-512.

GARRICK, R. 1968. A reinterpretation of the Wellington crustal refraction profile. New Zealand Journal of Geology and Geophysics, 11, 1280-1294.

GeONet. 2008. The GeoNet Project - Monitoring geological hazards in New Zealand. Website: http://www.geonet.org.nz.

GHANI, M. A. 1978. Late Cenozoic vertical crustal movements in the Southern North Island, New Zealand. New Zealand Journal of Geology and Geophysics, 22, 117-126.

GNS SCIENCE. 2008. New Zealand Active Faults Database. Website: http://data.gns.cri.nz/af/.

GORDON, H. 2003. EGEG seismic Sound source Trial, Wawiri-1 Well Site, Taranaki, New Zealand. Tech. rept. Austral Pacific Energy Ltd.

GREGORY, A. 1976. Fluid saturation effects on dynamic elastic properties of sedimentary rocks. Geophysics, 41(5), 895-921.

GubBins, D., BARNiCOAT, A., AND CANN, J. 1994. Seismological constraints on the gabbro-eclogite transition in subducted oceanic crust. Earth and Planetary Science Letters, 122(1-2), 89-101.

HACKer, B., Abers, G., AND PeAcock, S. 2003a. Subduction factory: 1. Theoretical mineralogy, densities, seismic wave speeds and $\mathrm{H}_{2} \mathrm{O}$ contents. Journal of Geophysical Research, 108(B1), doi:10.1029/2001JB001127.

Hacker, B., Peacock, S., Abers, G., And Holloway, S. 2003b. Subduction factory: 2. Are intermediate-depth earthquakes in subducting slabs linked to metamorphic dehydration reactions? Journal of Geophysical Research, 108(B1), 2030-2046.

HAINES, A. 1979. Seismic wave velocities in the uppermost mantle beneath New Zealand. New Zealand Journal of Geology and Geophysics, 22, 245 - 257.

HAMilton, E. 1979. Vp/Vs and Poisson's ratios in marine sediments and rocks. Journal of the Acoustical Society of America, 66, 1093-1101.

Hammer, S. 1939. Terrain corrections for gravity stations. Geophysics, 4(3), 184195.

HanNAH, J. 1984. Map Projections: their development and use in New Zealand. Tech. rept. NZ Institute of Surveyors: Auckland.

HARPER, F. 1989. Force driving plate tectonics: the use of simple dynamical models. Aquatic Science, 1, 31-336. 
HARPER, J. 1986. Mantle flow and plate motions. Geophysical Journal - Royal Astronomical Society, 87(1), 155-171.

HASSANI, R., JONGMANS, D., AND CHEÉRY, J. 1997. Study of plate deformation and stress in subduction processes using two-dimensional numerical models. Journal of Geophysical Research B: Solid Earth, 102(B8), 17951-17965.

HAWKe, R., AND MCCONCHIE, J. 2006. Dune phases in the Otaki-Te Horo area (New Zealand): A geomorphic history. Earth Surface Processes and Landforms, 31(6), 633-645.

Hayes, G., AND FurlONG, K. 2007. Abrupt changes in crustal structure beneath the Coast Ranges of northern California - developing new techniques in receiver function analysis. Geophysical Journal International, 170(1), 313-336.

Heron, D., VAn Dissen, R., AND SAWA, M. 1998. Late Quaternary movement on the Ohariu Fault, Tongue Point to MacKays Crossing, North Island, New Zealand. New Zealand Journal of Geology and Geophysics, 41(4), 419-439.

Hole, J., AND ZELT, B. 1995. 3-D finite-difference reflection traveltimes. Geophysical Journal International, 121(2), 427-434.

HOLT, W., AND STERN, T. 1994. Subduction, platform subsidence, and foreland thrust loading: the late Tertiary development of Taranaki Basin, New Zealand. Tectonics, 13(5), 1068-1092.

Horspool, N., SAVAGe, M., AND BAnNister, S. 2006. Implications for intraplate volcanism and back-arc deformation in northwestern New Zealand, from joint inversion of receiver functions and surface waves. Geophysical Journal International, 166(3), 1466-1483.

Houseman, G., AND MolnaR, P. 1997. Gravitational (Rayleigh-Taylor) instability of a layer with non-linear viscosity and convective thinning of continental lithosphere. Geophysical Journal International, 128(1), 125-150.

HudSON, K. 2005. Thrust faulting and subsidence along the southeastern boundary of the South Wanganui Basin: An investigation using gravity and seismic modelling, Honour's Thesis, Victoria University of Wellington.

HuGHES, G. R. 2005. Evolution of the north Horowhenua coastal depositional system in response to late pleistocene sea level changes. M.Phil. thesis, Victoria University of Wellington, New Zealand.

HUNT, T. 1980. Basement structure of the Wanganui Basin, interpreted from gravity data. New Zealand Journal of Geology and Geophysics, 23(1), 1-16.

HYNDMAN, R. 1988. Dipping seismic reflectors, electrically conductive zones, and trapped water in the crust over a subducting plate. Journal of Geophysical Research, 93(B11), 13391-13405. 
HYNDMAN, R., AND WANG, K. 1993. Thermal constraints on the zone of major thrust earthquake failure: the Cascadia Subduction Zone. Journal of Geophysical Research, 98(B2), 2039-2060.

IIO, Y., SAgIYA, T., KOBAYASHI, Y., AND SHIOZAKI, I. 2002. Water-weakened lower crust and its role in the concentrated deformation in the Japanese Islands. Earth and Planetary Science Letters, 203(1), 245-253.

Ingham, M., Whaler, K., AND MCKNight, D. 2001. Magnetotelluric sounding of the Hikurangi Margin, New Zealand. Geophysical Journal International, 144(2), 343-355.

IOGANSON, L. 2005. Pull-apart basins: A review. Geotectonics, 39(2), 156-168.

KAMP, P. 1999. Tracking crustal processes by FT thermochronology in a forearc high (Hikurangi margin, New Zealand) involving Cretaceous subduction termination and mid-Cenozoic subduction initiation. Tectonophysics, 307, 313-343.

KAMP, P. J. J. 1986. The mid-Cenozoic Challenger rift system of western New Zealand and its implications for the age of Alpine Fault inception. Geological Society of America Bulletin, 97(3), 255-281.

KARIG, D. 1970. Kermadec arc - NZ tectonic confluence. New Zealand Journal of Geology and Geophysics, 13, 21-29.

KARLSSON, H., AND SORENSEN. 2007. ABAQUS analysis user's manual, 6.7. Inc. Hibbitt.

KATZ, H., AND LEASK, B. 1990. The South Wanganui Basin - A neglected hydrocarbon prospect Petroleum exploration in New Zealand. Petroleum Exploration New Zealand News, 19-25.

KAWAKATSU, H., AND WATADA, S. 2007. Seismic evidence for deep-water transportation in the mantle. Science, 316(5830), 1468-1471.

KeARey, P., BroOKS, M., AND Hill, I. 2002. An Introduction to Geophysical Exploration. Blackwell Publishing.

KennetT, B., EngDahl, E., And Buland, R. 1995. Constraints on seismic velocities in the Earth from traveltimes. Geophysical Journal International, 122(1), 108-124.

KING, P. 2000. Tectonic reconstructions of New Zealand: 40 Ma to the present. New Zealand Journal of Geology and Geophysics, 43, 611-638.

KInG, P., AND Thrasher, G. P. 1996. Cretaceous - Cenozoic geology and petroleum systems of the Taranaki Basin, New Zealand. Institute of Geological and Nuclear Sciences, Monograph, 13. 
KNAPP, R., AND STEEPLES, D. 1986. High-resolution common-depth-point seismic reflection profiling: field acquisition parameter design. Geophysics, 51(2), 283-294.

Kokusho, T., HARA, T., AND HiRAOKA, R. 2004. Undrained shear strength of granular soils with different particle gradations. Journal of Geotechnical and Geoenvironmental Engineering, 130(6), 621-629.

LAmarche, G., BeAnland, S., And Ravens, J. 1995. Deformation style and history of the Eketahuna region, Hikurangi forearc, New Zealand, from shallow seismic reflection data. New Zealand Journal of Geology and Geophysics, 38(1), 105-115.

Lamarche, G., Proust, J., AND Nodder, S. 2005. Long-term slip rates and fault interactions under low contractional strain, Wanganui Basin, New Zealand. Tectonics, 24(4), 1-30.

LAMB, S., AND VELLA, P. 1987. Last million years of deformation in part of the New Zealand plate-boundary zone. Journal of Structural Geology, 9(7), 877-891.

LAMB, S. 2006. Shear stresses on megathrusts: Implications for mountain building behind subduction zones. Journal of Geophysical Research, 111, doi:10.1029/2005JB003916.

LANGSTON, C. 1979. Structure under Mount Rainier, Washington, inferred from teleseismic body waves. Journal of Geophysical Research, 84(B9), 4749-4762.

LEE, C.-T. A., AND CHEN, W.-P. 2007. Possible density segregation of subducted oceanic lithosphere along a weak serpentinite layer and implications for compositional stratification of the Earth's mantle. Earth and Planetary Science Letters, 255(3-4), 357-366.

Lee, W. H., Kanamori, H., Jennings, P., And Kisslinge, C. (eds). 2002. International Handbook of Earthquake and Engineering Seismology. Academic Press.

LEWIS, K. B., AND PETTINGA, J. R. 1993. The emerging, imbricate frontal wedge of the Hikurangi margin, in Sedimentary Basins of the World. Vol. 2. Elsevier, New York.

Li, X., Bock, G., Vafidis, A., Kind, R., Harjes, H.-P., Hanka, W., WYleGALlA, K., VAN DER MEIJDE, M., AND YUAN, X. 2003. Receiver function study of the Hellenic subduction zone: Imaging crustal thickness variations and the oceanic Moho of the descending African lithosphere. Geophysical Journal International, 155(2), 733-748.

Litchfield, N., VAn Dissen, R., LAngridge, R., Heron, D., And PrenTICE, C. 2004. Timing of the most recent surface rupture event on the Ohariu Fault near Paraparaumu, New Zealand. New Zealand Journal of Geology and Geophysics, 47(1), 123-127. 
Litchfield, N., VAn Dissen, R., Heron, D., And RhoAdes, D. 2006. Constraints on the timing of the three most recent surface rupture events and recurrence interval for the Ohariu Fault: Trenching results from MacKays Crossing, Wellington, New Zealand. New Zealand Journal of Geology and Geophysics, 49(1), 57-61.

LitTle, A., AND JONES, A. 1998. Seven million years of strike-slip and related off-fault deformation, northeastern Marlborough fault system, South Island, New Zealand. Tectonics, 17(2), 285-302.

Lombardi, D., Braunmiller, J., Kissling, E., And Giardini, D. 2008. Moho depth and Poisson's ratio in the Western-Central Alps from receiver functions. Geophysical Journal International, 173(1), 249-264.

LOWRIE, W. 1997. Fundamentals of Geophysics. Cambridge University Press.

Ludwig, J., NAfe, J., AND DraKe, C. 1970. Seismic refraction. Pages 53 - 84 of: MAXWELL, A. (ed), The Sea. Wiley, New York.

LUETGERT, J. H. 1992. MacRay Interactive two-dimensional seismic raytracing for the Macintosh ${ }^{T M}$ (Open-file No. 92-356). Tech. rept. U.S. Geological Survey.

MagGi, A., JACKSON, J., MCKenZie, D., AND PRIESTley, K. 2000. Earthquake focal depths, effective elastic thickness, and the strength of the continental lithosphere. Geology, 28(6), 495-498.

Mamdouh, R. G. 2004. Applied Seismology: A comprehensive guide to seismic theory and application. PennWell Books.

Mann, P., Hempton, M., Bradley, D., And Burke, K. 1983. Development of pull-apart basins. Journal of Geology, 91(5), 529-554.

MAUndeR, D. E. 2002. New Zealand seismological report 2000: Seismological observatory bulletin e-183. Tech. rept. Institute of Geological and Nuclear Sciences.

MCClay, K., AND DOOleY, T. 1995. Analogue models of pull-apart basins. Geology, 23(8), 711-714.

McKenzie, D., Nimmo, F., Jackson, J., Gans, P., And Miller, E. 2000. Characteristics and consequences of flow in the lower crust. Journal of Geophysical Research B: Solid Earth, 105(B5), 11029-11046.

MCKenZIE, D. P. 1969. Speculation on the consequencesw and causes of plate motions. Geophysical Journal - Royal Astronomical Society, 18, 1-32.

MCNUTT, M. 1980. Implications of regional gravity for state of stress in the earth's crust and upper mantle. Journal of Geophysical Research, 85(B11), 63776396. 
Melhuish, A., VAn Dissen, R., And Berryman, K. 1996. Mount StewartHalcombe Anticline: A look inside a growing fold in the Manawatu region, New Zealand. New Zealand Journal of Geology and Geophysics, 39(1), 123-133.

Milkereit, B., Stumpel, H., AND RabBel, W. 1986. Shear-wave reflection profiling for near-surface lignite exploration. Geophysical Prospecting, 34(6), 845855.

Mohsen, A., Hofstetter, R., Bock, G., Kind, R., Weber, M., Wylegalla, K., AND RÜMPKER, G. 2005. A receiver function study across the Dead Sea Transform. Geophysical Journal International, 160(3), 948-960.

MOlnAR, P., AND ENGLAND, P. 1990. Temperatures, heat flux, and frictional stress near major thrust faults. Journal Geophysical Research, 95, 4833-4856.

Molnar, P., Anderson, H. J., Audoine, E., Eberhart-Phillips, D., GledHill, K. R., Klosko, E. R., McEvilly, T. V., OKayA, D., SAvage, M. K., STERN, T., AND WU, F. 1999. Continuous Deformation Versus Faulting Through the Continental Lithosphere of New Zealand. Science, 286(5439), 516519.

MoOneY, H. 1970. Upper mantle inhomogeneity beneath New Zealand: seismic evidence. Journal of Geophysical Research, 75, 285 - 309.

Moores, E. M., AND Twiss, R. J. 1995. Tectonics. W. H. Freeman and Company.

Morozov, I. B., AND ZHENG, H. 2006. Effects of trench-zone scattering on receiver functions over a subduction zone: A 3-D finite-difference modelling study. Tectonophysics, 420(1-2), 317-332.

Nabighian, M., Ander, M., Grauch, V., Hansen, R., LaFehr, T., Li, Y., Pearson, W., Peirce, J., Phillips, J., And Ruder, M. 2005. Historical development of the gravity method in exploration. Geophysics, 70(6), doi:10.1190/1.2133785.

Nedimovicć, M., Hyndman, R., Ramachandran, K., And Spence, G. 2003. Reflection signature of seismic and aseismic slip on the northern Cascadia subduction interface. Nature, 424(6947), 416-420.

NEEF, G. 1999. Neogene development of the onland part of the forearc in northern Wairarapa, North Island, New Zealand: A synthesis. New Zealand Journal of Geology and Geophysics, 42(1), 113-135.

Nicol, A., AND BEAVAN, J. 2003. Shortening of an overriding plate and its implications for slip on a subduction thrust, central Hikurangi Margin, New Zealand. Tectonics, 22(6), 9-1.

Nicol, A., Mazengarb, C., Chanier, F., Rait, G., Uruski, C., AND WalLACE, L. 2007. Tectonic evolution of the active Hikurangi subduction margin, New Zealand, since the Oligocene. Tectonics, 26(4), doi:10.1029/2006TC002090. 
Nodder, S., Lamarche, G., Proust, J.-N., And Stirling, M. 2007. Characterizing earthquake recurrence parameters for offshore faults in the low-strain, compressional Kapiti-Manawatu Fault System, New Zealand. Journal of Geophysical Research B: Solid Earth, 112(12), doi:10.1029/2007JB005019.

O’Reilly, S. Y., Griffin, W. L., Poudjom Djomani, Y. H., And Morgan, P. 2001. Are Lithospheres Forever? Tracking Changes in Subcontinental Lithospheric Mantle Through Time. GSA Today, 11(4), 4-10.

OWENS, T., AND ZANDT, G. 1985. The response of the continental crust- mantle boundary observed on broadband teleseismic receiver functions ( $\mathrm{N}$ America). Geophysical Research Letters, 12(10), 705-708.

PALMER, A., AND VAN Dissen, R. 2002. Northern Ohariu Fault: Earthquake hazard assessment of a newly discovered active strike-slip fault in Horowhenua. Tech. rept. New Zealand Earthquake Commission Research Report 97/263.

Palmer, J. A. P. B. 1993. Cretaceous-Tertiary Sedimentation and Implied Tectonic Controls on the Structural Evolution of Taranaki Basin, New Zealand. Pages 309-328 of: BAllancE, P. F. (ed), Sedimentary Basins of the World. Elsevier, New York.

PARK, J., AND LEVIN, V. 2000. Receiver functions from multiple-taper spectral correlation Estimates. Bulletin of the Seismological Society of America, 90(6), 15071520 .

PEACOCK, S. M. 1996. Thermal and petrologic structure of subduction zones. Pages 119-133 of: BeBout, G. E. (ed), Top to Bottom, Geophs. Monogr. Ser., vol. 96. AGU, Washington, D. C. Press.

PeAcOcK, S. A. 1990. Fluid Processes in Subduction Zones. Science, 248(4953), 329-337.

Peltier, W. 1998. Postglacial variations in the level of the sea: Implications for climate dynamics and solid-earth geophysics. Reviews of Geophysics, 36(4), 603689.

PRATT, J. H. 1859. On the Deflection of the Plumb-Line in India, Caused by the Attraction of the Himmalaya Mountains and of the Elevated Regions Beyond; and Its Modification by the Compensating Effect of a Deficiency of Matter below the Mountain Mass. Philosophical Transactions of the Royal Society of London, $149,745-778$.

PritchetT, W. 1990. Acquiring Better Seismic Data. Springer.

ProfetaM.and Moscoso, J., And Koremblit, M. 1995. Minimum field static corrections. The Leading Edge, 14, 684-687. 
Proust, J.-N., LAmarche, G., Nodder, S., AND Kamp, P. 2005. Sedimentary architecture of a Plio-Pleistocene proto-back-arc basin: Wanganui Basin, New Zealand. Sedimentary Geology, 181(3-4), 107-145.

Pulford, A., AND Stern, T. 2004. Pliocene exhumation and landscape evolution of central North Island: The role of the upper mantle. Journal of Geophysical Research, 109.

PulforD, A. K. 2002. Crustal structure and lithospheric doming: aspects of deformation along an obliquely convergent plate margin, New Zealand. Ph.D. thesis, Victoria University of Wellington, New Zealand.

RAIT, G., CHANIER, F., AND WATERS, D. 1991. Landward and seaward-directed thrusting accompanying the onset of subduction beneath New Zealand. Geology, 19, 230-233.

RAMACHANDRAN, K., HYNDMAN, R., AND BROCHER, T. 2006. Regional P wave velocity structure of the Northern Cascadia Subduction Zone. Journal of Geophysical Research B: Solid Earth, 111(12), doi:10.1029/2005JB004108.

RanalLi, G. 1995. Rheology of the earth. Chapman and Hall.

RAvens, J., O'CONNOR, R., ZHU, H., AND Anderson, H. 1993. Deep seismic reflection profiling in east Taranaki using standard oil-industry acquisition parameters. New Zealand Journal of Geology and Geophysics, 36(1), 69-75.

READING, A. 1996. Deep Lithospheric Structure from Multi-phase Tomography: The Subduction Zone Beneath Southern North Island, New Zealand. Ph.D. thesis, University of Leeds, United Kingdom.

Reading, A., Gubbins, D., And MAO, W. 2001. A multiphase seismic investigation of the shallow subduction zone, southern North Island, New Zealand. Geophysical Journal International, 147(1), 215-226.

ReIlly, W. I. 1972. New Zealand Gravity Map Series. New Zealand Journal of Geology and Geophysics, 15, 3-15.

Reilly, W. I., Whiteford, C. M., AND Doone, A. 1977. North Island. Gravity Map of New Zealand, 1:1 000 000, Bouguer Anomalies. Department of Scientific and Industrial Research, Wellington, New Zealand.

REYNERS, M. 1998. Plate coupling and the hazard of large subduction thrust earthquakes at the Hikurangi subduction zone, New Zealand. New Zealand Journal of Geology and Geophysics, 41(4), 343-354.

Reyners, M., Eberhart-Phillips, D., Stuart, G., AND Nishimura, Y. 2006. Imaging subduction from the trench to $300 \mathrm{~km}$ depth beneath the central North Island, New Zealand, with Vp and Vp/Vs. Geophysical Journal International, 165(2), 565-583. 
ReYNOLDS, J. M. 2000. An Introduction to Applied and Environmental Geophysics. John Wiley \& Sons.

RINGWOOD, A. E. 1966. The chemical composition and origin of the Earth. In: Hurley, P. (ed), Advances in Earth Sciences. Advances in Earth Sciences, MIT Press, Cambridge.

Robertson, E. I., AND REILly, W. I. 1960. New Zealand primary gravity network. New Zealand Journal of Geology and Geophysics, 3(1), 41-68.

ROWAN, C. J., AND ROBERTS, A. P. 2008. Widespread remagnetizations and a new view of Neogene tectonic rotations within the Australia-Pacific plate boundary zone, New Zealand. Journal of Geophysical Research, 113, doi:10.1029/2006JB004594.

RUdNiCK, R., AND Fountain, D. 1995. Nature and composition of the continental crust: A lower crustal perspective. Reviews of Geophysics, 33(3), 267-309.

SALMON, M. 2008. Crust and upper mantle inhomogeneities beneath western North Island, New Zealand: Evidence from seismological and electromagnetic data. Ph.D. thesis, Victoria University of Wellington, New Zealand.

Salmon, M., SAVAGe, M., AND T., S. 2005. Seismic Attenuation, Temperature, $\mathrm{H}_{2} \mathrm{O}$, Mantle Melting and Rock Uplift, Central North Island New Zealand. Pages Abstract T13B-0478 of: Fall Meet. Suppl. Eos Trans. AGU, vol. 86, no. 52.

SATAKE, K., AND HASHIDA, T. 1989. Three-dimensional attenuation structure beneath the North Island, New Zealand. Tectonophysics, 159, $181-194$.

SAVAGE, M., PARK, J., AND TODD, H. 2007. Velocity and anisotropy structure at the Hikurangi subduction margin, New Zealand from receiver functions. Geophysical Journal International, 168(3), 1034-1050.

SCHMIDT, M., AND POLI, S. 1998. Experimentally based water budgets for dehydrating slabs and consequences for arc magma generation. Earth and Planetary Science Letters, 163(1-4), 361-379.

Sclater, J., PARsons, B., AND JAupart, C. 1981. Oceans and continents: similarities and differences in the mechanisms of heat loss. Journal of Geophysical Research, 86(B12), 11535-11552.

Sharma, P. V. 1997. Environmental and Engineering Geophysics. Cambridge University Press.

Sheehan, A., Shearer, P., Gilbert, H., And Dueker, K. 2000. Seismic migration processing of P-SV converted phases for mantle discontinuity structure beneath the Snake River Plain, western United States. Journal of Geophysical Research B: Solid Earth, 105(B8), 19055-19065. 
SHEMENDA, A. 1993. Subduction of the lithosphere and back arc dynamics: insights from physical modeling. Journal of Geophysical Research, 98(B9), 167-185.

SHEPHERD, M. J. 1987. Holocene alluviation and transgressive dune activity in the lower Manawatu Valley, New Zealand. New Zealand Journal of Geology and Geophysics, 30, 175-187.

Shillington, D., Minshull, T., Peirce, C., And O'Sullivan, J. 2008. P-and S-wave velocities of consolidated sediments from a seafloor seismic survey in the North Celtic Sea Basin, offshore Ireland. Geophysical Prospecting, 56(2), 197211.

Sissons, B. A., AND DibBle, R. R. 1981. A seismic refraction experiment southeast of Ruapehu volcano. New Zealand Journal of Geology and Geophysics, 24, 31-38.

SMITH, E., STERN, T., AND REYNERS, M. 1989. Subduction and back-arc activity at the Hikurangi convergent margin, New Zealand. Pure and Applied Geophysics, 129(1-2), 203-231.

Stagroole, V. 1997. A geophysical study of the northern Taranaki Basin, New Zealand. Ph.D. thesis, Victoria University of Wellington, New Zealand.

StAGPOOlE, V., AND NicOl, A. 2008. Regional structure and kinematic history of a large subduction back thrust: Taranaki Fault. Journal of Geophysical Research, 113.

Stephenson, R., AND ClOetingh, S. 1991. Some examples and mechanical aspects of continental lithospheric folding. Tectonophysics, 188(1-2), 27-37.

STERN, R. 2002. Subduction zones. Reviews of Geophysics, 40(4), 3-1.

Stern, T., Molnar, P., OKayA, D., And Eberhart-Phillips, D. 2000. Teleseismic $P$ wave delays and modes of shortening the mantle lithosphere beneath South Island, New Zealand. Journal of Geophysical Research B: Solid Earth, 105(B9), 21615-21631.

STERN, T. A. 1982. Seismic and gravity investigations of the Central Volcanic Region North Island New Zealand. Ph.D. thesis, Victoria University of Wellington, New Zealand.

Stern, T. A., AND DAVEY, F. J. 1985. Crustal structure studies within the central North Island: The Central Volcanic Region. Tech. rept. 207. Geophysical Division, Department of Scientific and Industrial Research, New Zealand.

Stern, T. A., Stratford, W. R., AND SAlmon, M. L. 2006. Subduction evolution and mantle dynamics at a continental margin: Central North Island, New Zealand. Reviews of Geophysics, 44(4), 171-207. 
STERN, T. 1979. Regional and residual gravity fields, central North Island, New Zealand. New Zealand Journal of Geology and Geophysics, 22(4), 479-485.

STERN, T. 1987. Asymmetric back-arc spreading, heat flux and structure associated with the Central Volcanic Region of New Zealand. Earth and Planetary Science Letters, 85, 265-276.

Stern, T., AND DaVey, F. 1989. Crustal structure and origin of basins formed behind the Hikurangi subduction zone, New Zealand. Origin and Evolution of Sedimentary Basins and Their Energy and Mineral Resources, 48, 73-85.

STERN, T., AND DAVEY, F. 1990. Deep seismic expression of a foreland basin: Taranaki Basin, New Zealand. Geology, 18(10), 979-982.

STERN, T., AND HOLT, W. 1994. Platform subsidence behind an active subduction zone. Nature, 368(6468), 233-236.

Stern, T., Quinlan, G., AND Holt, W. 1992. Basin formation behind an active subduction zone: Three-dimensional flexural modelling of Wanganui Basin, New Zealand. Basin Research, 4, 197-214.

StOCKer, R. L., AND ASHBY, M. F. 1973. On the rheology of the upper mantle. Reviews of Geophysics, 11, 391-426.

STRATFORD, W. R., AND STERN, T. A. 2004. Strong seismic reflections and melts in the mantle of a continental back-arc basin. Geophysical Research Letters, 31, doi:10.1029/2003GL019232.

STRATFORD, W. R., AND STERN, T. A. 2006. Crust and upper mantle structure of a continental backarc: central North Island, New Zealand. Geophysical Journal International, 166(1), 469-484.

StuArt, G., Francis, D., Gubbins, D., And SMith, G. 1995. Tararua broadband array, North Island, New Zealand. Bulletin - Seismological Society of America, 85(1), 325-333.

Sutherland, R. 1995. The Australia-Pacific boundary and Cenozoic plate motions in the SW Pacific: Some constraints from Geosat data. Tectonics, 14(4), 819-831.

TALWANI, M., AND EWING, M. 1960. Rapid computation of gravitational attraction of three-dimensional bodies of arbitrary shape. Geophysics, 25, 203 - 225.

TE PungA, M. 1962. Some geological features of the Otaki-Waikanae district. New Zealand Journal of Geology and Geophysics, 5, 517-530.

Te PungA, M. T. 1957. Live anticlines in western Wellington. New Zealand Journal of Science and Technology, 38(5), 433-446.

Telford, W. M., Geldart, L. P., And Sheriff, R. E. 1990. Applied Geophysics. Cambridge University Press. 
Toulmin, J. S. 2006. Galatea Basin: The geophysical exploration of a transtensional basin in the southern Bay of Plenty, New Zealand. M.Phil. thesis, Victoria University of Wellington, New Zealand.

Twiss, R. J., AND MoOres, E. M. 1992. Structural geology. W. H. Freeman and Company, New York.

UyEDA, S. 1981. Subduction zones and back arc basins - A review. Geologische Rundschau, 70(2), 552-569.

UYEDA, S., AND KANAMORI, H. 1979. Back-arc opening and the mode of subduction. Journal Geophysical Research, 84, 1049-1061.

Van Dissen, R., Heron, D., And Palmer, A. 1999. Ohariu and Northern Ohariu faults: field guide to Late Quaternary active faulting. Pages 29-69 of: Geological Society of New Zealand Inc 1999 Annual Conference, 29 November - 1 December, Massey University, Palmerston North : field trip guidesGeological Society of New Zealand miscellaneous publication 107B, for Geological Society of New Zealand.

VIDALE, J. E. 1990. Finite-difference calculation of traveltimes in three dimensions. Geophysics, 55(5), 521-526.

VILlAMOR, P., AND BERRYMAN, K. 2001. A late Quaternary extension rate in the Taupo Volcanic Zone, New Zealand, derived from fault slip data. New Zealand Journal of Geology and Geophysics, 44, 243-269.

WALCOTT, R. 1984. The kinematics of the plate boundary zone through New Zealand : a comparison ofshort and long term deformation. Geophysical Journal - Royal Astronomical Society, 79, 613-633.

WALCOTT, R. 1987. Geodetic strain and the deformational history of the North Island of New Zealand during the late Cainozoic. Philosophical Transactions of the Royal Society of London, 321(1557), 162-181.

WAlCOTT, R. 1998. Modes of oblique compression: late Cenozoic tectonics of the South Island of New Zealand. Reviews of Geophysics, 36(1), 1-26.

WALlACE, L., AND BEAVAN, J. 2006. A large slow slip event on the central Hikurangi subduction interface beneath the Manawatu region, North Island, New Zealand. Geophysical Research Letters, 33(11), doi:10.1029/2006GL026009.

Wallace, L., Beavan, J., McCAffrey, R., And Darby, D. 2004. Subduction zone coupling and tectonic block rotations in the North Island, New Zealand. Journal of Geophysical Research B: Solid Earth, 109(12), 1-21.

WANG, K., DragerT, H., AND Melosh, H. 1994. Finite element study of uplift and strain across Vancouver Island. Canadian Journal of Earth Sciences, 31(10), 1510-1522. 
WATts, A. B. 2001. Isostasy and Flexure of the Lithosphere. Cambridge University Press.

WATTS, A., AND BUROV, E. 2003. Lithospheric strength and its relationship to the elastic and seismogenic layer thickness. Earth and Planetary Science Letters, 213(1-2), 113-131.

WATts, A., Bodine, J., AND RiBE, N. 1980. Observations of flexure and the geological evolution of the Pacific Ocean basin. Nature, 283(5747), 532-537.

WELLS, P. 1989. Burial history of late Neogene sedimentary basins on part of the New Zealand convergent plate margin. Basin Research, 2(3), 145-160.

Whiteford, C. 1974. Gravity Map of New Zealand, 1:250 000, Bouguer Anomalies. Sheet 12, Wellington. Department of Scientific and Industrial Research, Wellington, New Zealand.

WhitTAKer, A., Bott, M., AND WAGHORN, G. 1992. Stresses and plate boundary forces associated with subduction plate margins. Journal of Geophysical Research, 97(B8), 11933-11944.

Wilson, G., AND MCGuiRE, D. 1995. Distributed deformation due to coupling across a subduction thrust: mechanism of young tectonic rotation within the south Wanganui Basin, New Zealand. Geology, 23(7), 645-648.

WOLF, D. 1984. The relaxation of spherical and flat Maxwell Earth models and effects due to the presence of the lithosphere. Journal of Geophysics - Zeitschrift für Geophysik, 56(1), 24-33.

WOllaRD, G. P. 1979. New gravity system - Changes in international gravity base values and anomaly values. Geophysics, 44(8), 1352-1366.

WOODWARD, D., AND FERRY, L. 1973. Gravity terrain correction tables. Technical Note 66. Geophysics Division, Department of Scientific and Industrial Research, Wellington, New Zealand.

YAMASAKI, T., AND SENO, T. 2005. High strain rate zone in central Honshu resulting from the viscosity heterogeneities in the crust and mantle. Earth and Planetary Science Letters, 232(1-2), 13-27.

YILMAZ. 1987. Seismic data analysis. Society of Exploration Geophysics.

ZHONG, S., AND GURNIS, M. 1992. Viscous flow model of a subduction zone with a faulted lithosphere: long and short wavelength topography, gravity and geoid. Geophysical Research Letters, 19(18), 1891-1894.

ZHONG, S., AND GURNIS, M. 1994. Controls on trench topography from dynamic models of subducted slabs. Journal of Geophysical Research, 99(B8), 15683-15695. 
ZHU, L., AND KANAMORI, H. 2000. Moho depth variation in southern California from teleseismic receiver functions. Journal of Geophysical Research B: Solid Earth, 105(B2), 2969-2980.

ZoBACK, M., AND MOONEY, W. 2003. Lithospheric buoyancy and continental intraplate stresses. International Geology Review, 45(2), 95-118. 
